\title{
"Prácticas y representaciones sobre desnutrición infantil de causa primaria en familias pobres urbanas del Gran La Plata"
}

Tesista: María Susana Ortale

Directora: Amalia Cristina Eguía

Co-directora: Marta Maffia

Tesis para optar al título de Doctor en Ciencias Naturales

Orientación Antropología

Facultad de Ciencias Naturales y Museo

Universidad Nacional de La Plata

La Plata, agosto de 2002 


\section{N D I CE G E N R A L}

RESUMEN

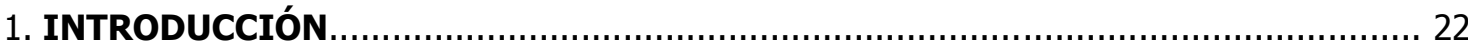

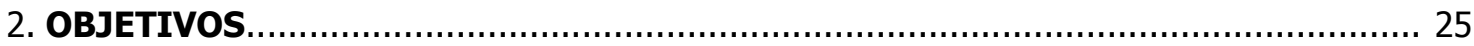

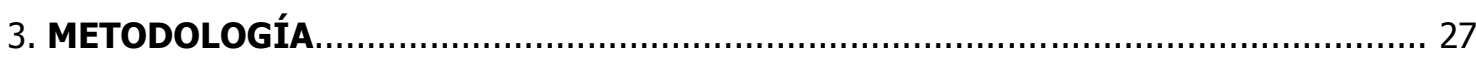

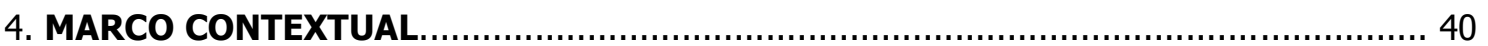

4.1. El contexto socioeconómico

4.1.1. A propósito de la desigualdad social en nuestro país

4.1.2. El contexto local: trabajo, educación y vivienda en el Gran La Plata

4.2. La mirada de la oferta y los estudios de mercado

4.3. Globalización, pauperización y hábitos alimentarios

4.4. La situación nutricional en la Argentina

4.4.1. La desnutrición en la Pcia. de Bs. As. y en la localidad de La Plata

4.4.2. Normativas y propuestas sanitarias vigentes

4.4.3. Salud pública y desnutrición: problemas de diagnóstico y tratamiento

5. ANTROPOLOGÍA Y ALIMENTACIÓN

5.1. Breve descripción de los estudios sobre alimentación en Ciencias Sociales

5.2. Estudios en nuestro país

6. LAS NARRATIVAS DEL CONSUMO ALIMENTARIO

Y LOS MODELOS DE HOMBRE

6.1. Discursos actuales sobre la problemática alimentaria

6.2. Por qué el dilema? Conceptualización médica y antropológica del hombre

6.2.1. La medicina y la reducción orgánica del hombre

6.2.2. La antropología y la naturaleza variable del hombre

6.2.3. A modo de reflexión

\section{LA CENTRALIDAD DE LAS PRÁCTICAS Y REPRESENTACIONES}

EN LOS PROCESOS DE REPRODUCCIÓN SOCIAL

7.1. Nuevos términos para viejos problemas: el concepto de reproducción social Niveles de análisis (macro/micro) y dimensiones de la realidad (material/simbólica)

7.2. Las representaciones sociales

8. ESTRATEGIAS FAMILIARES Y CONSUMO ALIMENTARIO

8.1. Introducción al concepto de estrategias familiares

8.2. Estrategias familiares, necesidades y consumo alimentario

9. REPRODUCCIÓN SOCIAL Y SALUD

9.1. La desnutrición como proceso social

9.2. La construcción de los conceptos de enfermedad y enfermo

10. MODELO MÉDICO HEGEMÓNICO Y DESNUTRICIÓN INFANTIL 
10.1. Modelo Médico Hegemónico

10.2. Proceso de medicalización

11. SABER MÉDICO.

11.1. Proceso de atención y saber médico

11.2. Saber médico y desnutrición infantil

\section{COMPONENTES ESTRUCTURALES Y ESTRATEGIAS ALIMENTARIAS}

EN LAS FAMILIAS ESTUDIADAS.

12.1. Condiciones de salud de los niños de 0 a 5 años según su estado nutricional

12.2. Características demográficas

12.3. Características educacionales

12.4. Características de la vivienda

12.5. Situación ocupacional

12.6. Nivel de ingreso familiar

12.7. Estrategias alimentarias

12.7.1. Caracterización de los programas alimentarios de la Pcia. de Buenos Aires

12.7.2. Utilización y evaluación de las estrategias alimentarias en las familias estudiadas

12.8. Síntesis y comentarios del análisis comparativo

\section{ORGANIZACIÓN DOMÉSTICA Y ALIMENTACIÓN FAMILIAR:}

PRÁCTICAS Y REPRESENTACIONES SOBRE LA COMIDA HABITUAL

13.1. La alimentación de las familias con niños eutróficos

13.1.1. Trabajo, situación familiar y organización de la alimentación

13.1.2. Estrategias alimentarias

13.1.3. Conocimientos y valoraciones alimentarias

13.1.4. La comida habitual

13.2. La alimentación de las familias con niños desnutridos

13.2.1. Trabajo, situación familiar y organización de la alimentación

13.2.2. Estrategias alimentarias

13.2.3. Conocimientos y valoraciones alimentarias

13.2.4. La comida habitual

13.3. Síntesis comparativa de las representaciones y prácticas alimentarias

\section{REPRESENTACIONES Y PRÁCTICAS MATERNAS SOBRE}

DESNUTRICIÓN INFANTIL.

14.1. Diferenciación y estigmatización en el discurso de las madres con hijos eutróficos

14.2. Identificación, diferenciación, manipulación y negación en el discurso de las madres con hijos desnutridos

14.3. A modo de síntesis: comparación de las representaciones y prácticas maternas sobre desnutrición infantil

\section{REPRESENTACIONES Y PRÁCTICAS MÉDICAS SOBRE}

DESNUTRICIÓN INFANTIL

15.1. La perspectiva y experiencia de los pediatras de hospitales públicos

15.2. La perspectiva y experiencia de los pediatras de unidades de atención primaria

15.3. Resultados de la encuesta provincial sobre recomendaciones alimentarias

15.4. Síntesis comparativa de las prácticas y representaciones de los pediatras de hospitales públicos y de Unidades Sanitarias.

Estudios recientes sobre alimentación familiar (1999-2001) 


\section{RESUMEN}

En nuestro país, los procesos de contracción económica, la caída del empleo asalariado industrial, la creciente segmentación del mercado, el aumento de la terciarización y precarización en las relaciones de trabajo, el aumento del desempleo y subempleo, el aumento de las actividades de escasa productividad, la disminución de los ingresos y la mayor inequidad en su distribución así como en la distribución de bienes y servicios, han producido un fuerte deterioro en las condiciones de vida de importantes sectores de la población.

El efecto más global consiste en un fuerte aumento de los hogares pobres: los pobres estructurales o población con necesidades básicas insatisfechas que llevan consigo una historia de pobreza profundizan sus carencias, los sectores medios en su mayoría se empobrecen y un pequeño grupo ocupa una posición aún más privilegiada.

A este panorama se agrega la crisis del sector público, la disminución de los servicios sociales y la caída en la calidad de los mismos.

La persistente recesión económica y la creciente pobreza para amplias capas de la población, han afectado con especial dureza a la infancia, socavando sus condiciones de salud, nutrición y educación.

Los estudios de mercado muestran cómo la recesión cambió los hábitos de consumo de los argentinos. Tanto medido por precio como por cantidad, el consumo viene cayendo, pese al aumento del gasto familiar en ese rubro, a tasas crecientemente empinadas, modificando hábitos de compra y rituales familiares. Asimismo, otros indicadores reflejan cambio de hábitos alimentarios derivados de los procesos de globalización y pauperización. La ampliación de la brecha entre ricos y pobres hizo que la clase baja y media empobrecida restringiera no sólo cuánto se come sino la calidad de lo que come. De este modo, la problemática alimentaria en la Argentina actual compromete la salud de vastos sectores; la misma aparece reflejada en la mayor participación de los alimentos en el gasto total de los hogares; la disminución de la demanda efectiva de alimentos en la progresiva segmentación del consumo; el aumento de la desnutrición crónica en sectores de extrema pobreza; la concurrencia creciente de la hipoalimentación en los índices de morbimortalidad. En condiciones de pobreza crecer menos constituye un estereotipo de adaptación afectando diversas esferas del desarrollo biopsicosocial; la inadecuada nutrición en la infancia tiene repercusiones sobre el crecimiento, desarrollo y salud general de los niños. 
Este estudio plantea que la desnutrición infantil de causa primaria constituye un indicador sensible y temprano de inadecuadas condiciones de reproducción social y por ello compara dentro de dos grupos de familias pobres urbanas del Gran La Plata, las condiciones de vida diferenciales asociadas a la presencia de tal problemática. Utilizando los conceptos "componentes estructurales" y "estrategias alimentarias" se analiza la articulación de factores sociodemográficos, ocupacionales, niveles de ingreso, vivienda, acceso y utilización de programas alimentarios públicos y/o no gubernamentales y los recursos alimentarios autogenerados incluyendo las redes de intercambio y ayuda en la comunidad.

En tanto el alimento constituye un consumo relativamente inelástico y representa dentro del presupuesto familiar de los sectores pobres- el gasto relativo más importante, se analiza cómo intervienen los problemas de escasez y elección de alimentos, tomando como referentes dos poblaciones: una con hijos desnutridos y otra sin presencia de hijos desnutridos en todo el desarrollo de su ciclo vital.

Para el estudio del conjunto de los condicionantes y de las estrategias desplegadas por las familias para su alimentación, se incorpora el universo de representaciones y prácticas de las informantes sobre el consumo alimentario familiar y sobre la desnutrición infantil.

Se sostiene que ellas se encuentran sujetas a procesos de medicalización y expresan aquellas constituidas como hegemónicas que son vehiculizadas por los servicios de salud y por eso se indaga su contenido en un grupo de médicos pediatras que trabajan en instituciones públicas.

La alimentación es un aspecto central de la reproducción individual y social y un indicador elocuente de las condiciones de vida de las familias.

La satisfacción colectiva de la alimentación recrea patrones de heterogeneidad en la accesibilidad al alimento con manifestaciones concretas en la condición nutricional del grupo. La alimentación/nutrición ligada estrechamente a la salud/enfermedad ofrece una imagen de desigualdad y polarización, pues la satisfacción de dicha necesidad aún no está resuelta para muchos.

Las restricciones impuestas a los comportamientos alimentarios de las unidades domésticas se dan por lo menos a tres niveles (Hintze, 1989):

a- El referido a aquellos aspectos que son determinantes en el consumo de los alimentos

(situación ocupacional, ingresos, precio de los alimentos).

Frente a una situación de crisis estructural como la que atraviesa nuestro país, es predecible que la reproducción vía ingreso directo se vea afectada tanto por la retracción del mercado de trabajo como por la capacidad adquisitiva del ingreso. 
b- El acceso y/o uso de consumos no mercantilizados provistos por programas sociales estatales, de organizaciones no gubernamentales o recursos alimentarios autogenerados por las familias.

c- Los condicionantes culturales e ideológicos que afectan los patrones de consumo.

La desnutrición remite, tanto en términos de causalidad estructural como de prevención, no sólo a factores político-económicos sino también culturales.

En ese sentido se retoman los planteos críticos referidos tanto a la concepción naturalista de las necesidades como a su correlato: la concepción instrumental de los bienes.

La antropología reconoce que la alimentación ocupa un lugar determinado dentro del simbolismo general de una sociedad, hecho que la convierte en objeto de análisis de prácticas, discursos e imaginarios sociales. No hay cultura alguna desprovista de un aparato de categorías y reglas alimentarias: la variabilidad observada en la especie humana obedece no a su presencia sino a su contenido

El concepto de representación, en tanto conocimiento socialmente elaborado y compartido conformado a partir de experiencias, de informaciones, conocimientos, y modelos de pensamiento que recibimos y transmitimos a través de la tradición, la educación y la comunicación social, alude al conjunto de significados que funcionan como sistemas de referencia e interpretación de las circunstancias, los fenómenos y las interacciones sociales que dan sentido a la vida cotidiana constituyendo modalidades de pensamiento práctico orientadas hacia la comunicación, la comprensión y el dominio del entorno social, material e ideal.

Pertenecer a un grupo o a una comunidad supone compartir al menos parcialmente, el complejo simbólico, es decir, el núcleo de representaciones sociales que los caracteriza y define.

Las representaciones sociales sirven como marcos de percepción y de interpretación de la realidad y como guías de los comportamientos y prácticas de los agentes sociales.

Con base en ellas y definido como "lo social incorporado", "interiorización de la exterioridad", el habitus constituye un principio de generación y estructuración de las prácticas sociales y de percepción y apreciación de la realidad. El concepto de habitus refiere a aquellas disposiciones a actuar, a percibir, a pensar y a sentir de una cierta manera más que de otra, ligadas a definiciones referidas a lo posible y lo no posible, lo pensable y lo no pensable, lo que es para nosotros y lo que no es para nosotros. Se trata de las disposiciones que han sido interiorizadas por el individuo -en el curso de su historia y dentro de los límites y posibilidades brindadas por las condiciones objetivas de vida- que actúan como principio de estructuración de prácticas. 
Así, por ejemplo, las diversas clasificaciones de lo comestible están ligadas en mayor - menor medida a otras categorías sean médicas, estéticas, religiosas. La preocupación por la salud y el valor terapéutico de los alimentos ha estado en mayor o menor grado siempre presente en la construcción de las pautas alimentarias y muchos estudios antropológicos sobre salud/enfermedad se sostienen en la información sobre alimentación recogida en las diversas culturas.

En la actualidad, la alimentación y la medicina mantienen una relación particular e e indisociable. La alimentación es un medio de ejercer control sobre el cuerpo, es decir, un instrumento privilegiado de intervención médica; de allí que la medicina reivindique un derecho de control sobre la alimentación, propiciando un modelo corporal basado en patrones científicos que enfatizan la importancia de la alimentación para el mantenimiento de la salud.

El enfoque se aproxima de este modo, a los estudios desarrollados en el campo de la Antropología y Salud, especialidad temática que se ocupa de los procesos de salud/enfermedad/atención que refieren a contextos económico-políticos-culturales específicos y los expresan. Se reconoce que los determinantes de la salud/enfermedad de la población son componentes propios de los procesos de producción y reproducción social, los que conforman condiciones diferenciales de vida y procesos diferenciales de morbimortalidad. En este sentido, la desnutrición infantil es paradigmática.

La pertenencia a determinados niveles socioeconómicos establecen los límites y las condiciones dentro de las cuales el proceso salud/enfermedad/atención adquiere características diferenciales tanto en términos de morbimortalidad como de los saberes referidos a la misma. Todo conjunto social produce y reproduce representaciones y prácticas respecto de los padecimientos, dolores, angustias, malestares, etc. que lo afectan.

Se considera entonces que los procesos de salud/enfermedad no sólo son emergentes de las condiciones de vida sino también y fundamentalmente, objeto de construcción de representaciones y prácticas por parte de los conjuntos sociales.

Por lo tanto, la detección de conocimientos, saberes y prácticas respecto de la salud, la enfermedad y la atención aparece como básica para saber cuáles son sus estrategias de reproducción.

En la medida en que la alimentación constituye un comportamiento cotidiano fuertemente medicalizado y que la desnutrición infantil se encuentra incluida en el campo de intervención médica, se sostiene que las prácticas, conocimientos y valoraciones sobre alimentación y salud de los conjuntos sociales están permeadas por una construcción hegemónica de la salud/enfermedad/atención que corresponde al 
Modelo Médico Hegemónico el cual, descriptivamente, refiere a la biomedicina. Dicho modelo es una construcción metodológica que permite entender la racionalidad biomédica y el funcionamiento de la ideología técnica dominante en el saber médico. Expresa, en un alto nivel de abstracción, las representaciones y prácticas que manejan los profesionales y las instituciones médicas.

Los conjuntos sociales "legos" participan de esa relación sustentándola en tanto "cómplices", pero también como sujetos que resignifican o impugnan el saber hegemónico.

El concepto de hegemonía pues, resulta útil en la medida que permite detectar las visiones dominantes así como sus límites y contradicciones.

Se utiliza así un modelo dicotómico, pese a los riesgos de simplificación que ello implica, centrado en los conceptos de "hegemonía" y "subalternidad" para aprehender las prácticas y representaciones de dos agentes vinculados a la problemática nutricional: los servicios de salud y conjuntos sociales de sectores pobres.

A través de relaciones de hegemonía, la especialización médica "produce consumidores", "genera pautas de consumo" entendidas como el uso o apropiación de saberes y prácticas, de bienes y servicios destinados a resolver sus problemas de salud.

De aquí la pertinencia de explorar cómo intervienen los saberes médicos (representaciones y prácticas) sobre desnutrición en las representaciones y prácticas legas.

Concibiendo al trabajo médico asistencial como una actividad científico/técnica impregnada de procesos sociales, ideológicos, económicos e institucionales, los interrogantes planteados refieren a las características básicas del saber de estos profesionales respecto a la desnutrición, en qué principios teóricos y técnicos basan su actividad profesional.

Dentro del término desnutrición se incluye, además de un estatuto biológico de crecimiento inadecuado, un conjunto de estereotipos de uso frecuente en la vida cotidiana que integra representaciones de la desnutrición como problema social, como enfermedad, como patología de la pobreza, como abandono, descuido, anormalidad, etc. sintetizados a través del uso social y técnico en los diferentes contextos, incluido el de la relación médico-paciente.

Se postula de este modo que las enfermedades y las instituciones de atención médica no sólo expresan relaciones sociales estratificadas sino que pueden expresar también procesos de identidad, de diferenciación, de estigmatización en torno de posiciones y relaciones de clase. Las enfermedades inciden en la salud de los conjuntos sociales 
pero también simbolizan relaciones ideológicas y sociales más allá de la propia enfermedad.

Es necesario indagar entonces, en los saberes que permiten describir y entender cómo lo socioeconómico se articula con lo socioideológico/cultural y cómo ambos aspectos contribuyen, a través de las actividades cotidianas relacionadas a la alimentación familiar y a la salud/enfermedad/atención de sus integrantes, a la reproducción social.

\section{Trabajo de Campo y Resultados}

Las diferentes etapas del estudio abarcan un período de trabajo de campo de cuatro años, habiéndose iniciado en 1995 y finalizado en 1999.

Se considera a la unidad doméstica como unidad de análisis y a la mujer/madre como la principal fuente de información.

Aun cuando se incluye información cuantificable, básicamente la obtenida a través de las encuestas, el manejo metodológico predominante se da en términos cualitativos. Interesa no tanto la significación estadística de los datos obtenidos sino su sentido cualitativo para producir interpretaciones acerca del problema planteado.

Los instrumentos, elaborados de manera complementaria, son empleados en tres etapas: encuestas, entrevistas estructuradas y entrevistas abiertas, reduciendo progresivamente el tamaño de la población en estudio en función de la selección de informantes más estratégicas y de los problemas suscitados a partir del análisis de la información previa. En todos los instrumentos aparecen algunas preguntas similares a fin de poder controlar y detectar la coherencia, veracidad y calidad de la información, sobre todo por el hecho que la información acerca de las prácticas alimentarias se obtiene básicamente del relato de los informantes y no a través de la observación directa. La información referida a las prácticas de atención a la salud cuentan con la contrastación del discurso de las informantes con los datos asentados en las historias clínicas de los servicios de salud y en las libretas sanitarias así como la suministrada por los médicos.

La primera etapa del trabajo de campo se llevó a cabo entre 1995-1996 en dos universos diferentes y las condiciones de inclusión de las familias se basaron en: su residencia en barrios pobres del aglomerado Gran La Plata y tener al menos un hijo menor de 5 años.

Las familias con hijos desnutridos (GD) fueron identificadas en la Unidad de Rehabilitación Nutricional del Hospital de Niños de La Plata, encuestándose un total de 50 familias. 
Las familias con hijos eutróficos (GE) residen en los barrios: "El Molino", "Villa Rubencito" y "El Zanjón" ubicados en el área de influencia de la Unidad Sanitaria "El Molino", localidad de Punta Lara, partido de Ensenada. De las 70 familias encuestadas inicialmente, 50 fueron seleccionadas para su comparación con el otro grupo de familias.

Los temas acerca de los cuales se recogió información fueron: composición del grupo familiar, situación educacional y ocupacional de los miembros, ingreso familiar, características de la vivienda, reconocimiento de casos de desnutrición y de "pata de cabra", estrategias alimentarias autogeneradas por las familias, programas sociales estatales utilizados y evaluación de los mismos.

Del conjunto de características estructurales analizadas, las que diferencian a las familias GD y GE se relacionan con los siguientes aspectos:

Los niveles de escolaridad de los jefes y cónyuges son significativamente más bajos en GD.

Los aspectos vinculados con la vivienda refleja niveles de bienestar relativos que repercuten indudablemente en las condiciones de salud infantil. GD registra condiciones más desfavorables en la calidad de la vivienda en lo que hace a los materiales de construcción, en la relación personas por cuarto y personas por cama, sistema de abastecimiento de agua y servicios sanitarios. Asimismo, se registra que el tiempo de residencia en el barrio es mayor en GE que en GD y tal vez la mayor utilización de programas alimentarios estatales guarde relación con este hecho: la permanencia en el barrio permite un mejor conocimiento de los recursos urbanos disponibles y de los canales que posibilitan su utilización.

En relación a la situación ocupacional, el trabajo informal por cuentapropia en comercio, construcción y servicios caracteriza a los jefes de GD y mientras que en GE predominan las ocupaciones formales como asalariados en comercio, transporte y servicios.

En segundo término, en ambos grupos y en proporciones similares aparece la categoría obrero como trabajo más frecuente.

La problemática de la subocupación no parece incidir significativamente en el trabajo de los jefes de ambos grupos, sólo afecta a una cuarta parte. La tasa de dependencia, que refiere a la relación entre productores de ingreso y no productores dentro de la familia, se presenta más desfavorable en GD.

La estimación del ingreso para adquirir una canasta básica de alimentos muestra ser inferior en la mayoría de las familias de GD, mientras que en GE esto sucede en menos de la mitad de los casos. 
Asimismo, la distribución de las familias por estratos de ingreso refleja que las de GD presentan distribución más sesgada hacia los deciles inferiores respecto de GE. El gasto per cápita familiar destinado a la compra de alimentos es el indicador que refleja mayores diferencias: cada integrante de GE dispone casi la mitad más de dinero que un integrante de GD para comer.

Las características ocupacionales del jefe y de la familia en su conjunto, así como los niveles de ingreso familiar, imponen fuertes restricciones a las oportunidades y necesidades de los menores que crecen en su seno.

Las familias con situaciones demográficas, educacionales, laborales y de vivienda con las características descriptas anteriormente presentan limitadas posibilidades reproductivas, las que en relación a la alimentación se expresan en problemas de nutrición y salud en el conjunto más vulnerable del grupo familiar: los niños, como resultado de un acceso inadecuado e insuficiente al consumo alimentario.

La situación ocupacional presente en GD, en el que prevalecen en mayor grado las ocupaciones por cuenta-propia, precarias, de baja calificación e ingresos insuficientes para cubrir los costos de la canasta básica de alimentos, se corresponde con las peores condiciones de nutrición y salud infantil que presentan sus familias.

Los consumos no mercantilizados provenientes de la acción de las políticas públicas, de las fuentes de autoabastecimiento generadas por las propias unidades domésticas (animales, huerta) y de las redes informales de ayuda entre familiares y vecinos arrojan diferencias.

En GE es mayor el porcentaje de usuarios de los programas alimentarios estatales, destacándose el Plan País y el comedor escolar.

La leche provista por el Programa Materno-Infantil es la opción más utilizada en GD, en similares porcentajes que en GE, apareciendo en más de la mitad de las familias.

En GD se destaca la importancia de las redes informales de intercambio con parientes y de los recursos no gubernamentales provistos por iglesia y partidos políticos.

Puede afirmarse que en GE -cuyos componentes estructurales así como las condiciones de nutrición y salud infantil reflejan condiciones más favorables que las familias de GD-, se resalta la utilización más diversificada, intensiva y continua de los programas alimentarios estatales mientras que en GD éstos presentan, dentro del conjunto de estrategias alimentarias, escasa relevancia.

Esto lleva a sostener la importancia, pero a la vez cuestionar la focalización o implementación de las políticas públicas en materia alimentaria.

A partir de los hallazgos y considerando la dependencia de los consumos alimentarios mercantilizados de las características estructurales de las familias, la realización de entrevistas semiestructuradas en muestras restringidas de las poblaciones 
previamente encuestadas ( $G D=13 ; G E=12$ ), permitió profundizar el estudio de las representaciones y prácticas ligadas a la alimentación familiar: la organización de los consumos mercantilizados, la intervención y evaluación de los programas de asistencia alimentaria y de los recursos autogenerados, los conocimientos y valoraciones sobre la alimentación y las características de la dieta habitual.

La relación entre los componentes estructurales de las familias, el uso de estrategias alimentarias y las características de la alimentación familiar (la organización familiar de la alimentación, las comidas habituales así como el marco valorativo y cognitivo a partir del cual organizan y evalúan su alimentación), se observa en:

- el papel desempeñado por el trabajo formal del jefe de familia y la percepción regular del ingreso en la realización de las compras, la fuente de abastecimiento utilizada y periodicidad, posibilitando a GE adquirir en el supermercado una mayor variedad de alimentos y/o marcas y mejores precios, básicamente de alimentos no perecederos,

- el nivel de ingreso - más elevado en GE- se refleja en la estimación del gasto diario per cápita en alimentación: cada miembro de GD gasta diariamente un $25 \%$ menos de dinero que uno de GE para alimentarse. El "vivir al día" y la incertidumbre de los ingresos imponen el pago al contado, presentándose en GE la forma de pago mixta.

Los arreglos domésticos desplegados en situaciones de carencia tendientes a obtener comida son más frecuentes y variados en GD que en GE, interviniendo (y afectando a) todos los miembros de la familia quienes apelan a todo tipo de fuentes y de recursos formales o informales. Hay que destacar que en estas situaciones, tanto en GE como en GD, la primer variable de ajuste es la mujer/madre, que disminuye o anula su comida, sosteniendo el "deber ser" materno.

- De acuerdo al tipo de alimentos más utilizados en la dieta habitual, se observan diferencias en el sentido de un mayor aporte de carbohidratos en GD. Ambos grupos elaboran como comidas más frecuentes guisos de fideos o de arroz, puchero o pastas. Sin embargo en GE se aprecia mayor diversidad de comidas preparadas con verduras y carnes.

- La evaluación positiva de la alimentación familiar que realizan las mujeres entrevistadas revela una forma de pensar la alimentación dentro de los parámetros de las condiciones de vida y trabajo, del propio consumo, de los atributos alimentarios y de la construcción de identidades que contradictoriamente favorecen o niegan la condición de ser pobres.

Las familias con desnutrición representan aquellas que no llegan a sobrepasar una condición general de empobrecimiento y la presencia de una dieta pobre, pese a aspirar y valorar un patrón alimentario cualicuantitativamente más rico. 
- La alimentación valorada por sus propiedades nutritivas es la misma para las mujeres de ambos grupos: consiste en aquella que aporta proteínas, vitaminas y hierro. La alimentación representa pues, una condición de vida que contrasta con la aspiración a determinado patrón de consumo: los patrones alimentarios responden a una lógica en la cual opera, por un lado, una estrategia de subsistencia mediante la cual tratan de maximizarse los recursos y los factores de los que depende la reproducción de la fuerza de trabajo y la sobrevivencia de la familia y por otro lado, un sistema de principios y conocimientos valorativos por el cual tratan de optimizar la relación alimento/organismo.

El análisis aquí presentado muestra que la internalización de referentes hegemónicos sectoriales generan necesidades que tienden a modular el consumo y a establecer sistemas complejos y contradictorios de apreciación de la dieta, induciendo a prácticas que no se condicen con las posibilidades determinadas por el salario ni con las exigencias biológicas. Puede observarse así cómo el ámbito doméstico, en una actividad cotidiana como es la alimentación, sirve de escenario para consolidar los discursos y prescripciones hegemónicas que, constantemente renovados, imprimen y direccionan las prácticas de consumo de los sectores subalternos.

En una tercera etapa de campo, las entrevistas abiertas realizadas a las madres captan sus representaciones en torno a la desnutrición como problema de salud.

Analizando de manera articulada las dos dimensiones consideradas en este estudio: las representaciones (percepciones, conocimientos, opiniones, creencias, valoraciones) y

las prácticas de atención materna y de los diversos agentes y recursos de atención a la salud empleados para la detección, tratamiento y prevención de la desnutrición infantil, contrastan los siguientes aspectos:

- para la mayoría de las mujeres de GE, la mala alimentación y la desnutrición infantil obedecen a descuido materno.

En GD, las causas de la desnutrición refieren en un nivel abstracto, a problemas económicos, a la escasez de comida en la familia, y a la falta de asistencia alimentaria. Pero en un nivel concreto, referido al acontecimiento de desnutrición en su familia, las causas remiten a problemas orgánicos. No obstante, algunas madres -minoritariasasumen la responsabilidad por la desnutrición de sus hijos: la pobre calidad de la comida asociada a la desocupación del jefe de familia, el fracaso en la lactancia materna, el uso tardío de los servicios de salud y el suministro de yuyos precipitaron la desnutrición.

Para el resto, la mayoría, las parasitosis e infecciones están en la base de la misma. 
En términos abstractos, el asesoramiento médico es una intervención favorecedora de la prevención, lo mismo que la existencia de programas alimentarios.

Las informantes de GD, además de destacar el asesoramiento médico, abundan en consideraciones sobre el tipo de alimentación adecuada para la prevención, aunque reconocen que esto no siempre es posible, a veces se torna inviable y, de acuerdo con sus experiencias, los cuidados dispensados -y considerados adecuados- no siempre resultan satisfactorios en términos de la salud infantil. De allí que para algunas, la prevención sea imposible.

-En el relevamiento de las representaciones referidas al diagnóstico materno de la desnutrición, aparece en ambos grupos de mujeres una exhaustiva descripción de los síntomas, planteando además que "la buena comida" (valorada según su contenido en vitaminas y minerales) y "la comida a horario" son las formas de evitar la desnutrición, subestimando el rol del sistema sanitario en la prevención e incluso en la cura.

Los síntomas de la desnutrición que consideran más relevantes para identificarla son, en ambos grupos, el estado de ánimo, el decaimiento, la pérdida de fuerza, el cansancio y evidencias físicas tales como la delgadez, el color de la cara, los ojos hundidos y la distensión abdominal.

Cuando se indaga en las mujeres GD el reconocimiento de los síntomas presentes en sus hijos desnutridos, aparecen otros tales como los episodios de vómito, diarrea o parásitos. La demanda de asistencia a la salita muestra que la misma funciona la mayor parte de las veces como lugar de derivación. Son minoritarias las madres que reflejan haber demandado asistencia oportunamente.

Más de la mitad de los casos debieron ser internados en la primer consulta, lo que da la pauta de la gravedad del caso y del uso tardío y postergado de los servicios de salud en relación a la evolución de la enfermedad.

Respecto del tratamiento, desconocido para gran parte de las mujeres de GE, se impone en cambio para las mujeres GD el control médico y los medicamentos que éste indica; brindar la alimentación adecuada, rica en calcio, hierro y vitaminas.

Más de la mitad de las madres reconoce la eficacia del tratamiento médico consistente en la entrega de leche, vitaminas, antiparasitarios y hierro.

Algunas madres hacen evidente la disputa -en medio de la cual quedan presas- entre los "médicos del hospital" y "los médicos de la salita" siendo a menudo objeto de retos por parte de los médicos del hospital por la inadecuada atención del niño. En ese sentido lo que las madres valoran son las decisiones rápidas y la capacidad de cura asociadas a los médicos de hospital. Las recomendaciones preventivas de los médicos de la salita y la dilación de los tratamientos no tienen buena recepción por 
parte de las madres; sí en cambio la tienen para muchas las actitudes paternalistas, autoritarias y de control.

La impugnación o resistencia a la atención médica recibida se hace evidente en situaciones en las que las madres visualizan una práctica médica arbitraria, a veces equivocada o contraria a las normativas de control de salud conocidas por ellas.

La conceptualización de la desnutrición como descuido por parte de las madres de GE, hace que no se la conciba como enfermedad, excepto cuando deriva de otra patología. Para las madres de GD, la consideración de la desnutrición como enfermedad es ambigua: algunas la conciben como secuela de alguna enfermedad o producto de la pata de cabra; otras le niegan el estatuto de enfermedad en la medida que no resulta contagiosa, vinculándose más bien con descuido. Finalmente, el estatuto de enfermedad está ligado a la oportunidad de la atención: la demora en el tratamiento lleva a la internación e incluso muerte del niño; sólo en esos casos merece ser considerada enfermedad.

Así, la capacidad terapéutica de los médicos para resolverla se relativiza. Los médicos pueden hacer un diagnóstico diferencial de sus causas y con base en ello dar indicaciones alimentarias y resolver complicaciones que se derivan de ella, pero la curación depende de los padres. A ello contribuye, de manera significativa, la adquisición de conocimientos sobre alimentación infantil brindados por especialistas a través de programas televisivos. Sus recomendaciones, alerta y orientaciones para la acción son incuestionables.

La indagación de la presencia de "pata de cabra" en los hijos obedece a su relación con el estado de desnutrición. Esta enfermedad, que incumbe a la medicina popular es conocida por la mayoría de las madres de GE quienes la consideran un problema de salud que reviste gravedad, frecuente en el barrio y que produce desnutrición si no se la trata a tiempo. Niegan conocer el tratamiento porque no han tenido hijos con ese problema, enfatizando además su adscripción a la medicina científica pese a reconocer que los médicos son impotentes para curarla y al hecho de demandar atención del curandero, también accesible en el barrio, para el tratamiento del empacho y del mal de ojo, problemas de salud frecuentes en sus hijos. En general plantean que a él recurren cuando falla el tratamiento médico o la cura se demora más allá de sus expectativas. Así, la mayoría admite, con base en la experiencia de los resultados obtenidos con ese tipo de tratamientos, que "hay que creer más allá" de lo que permite la razón. También en el abandono de las prácticas médicas alternativas influyen los medios masivos, particularmente en la suspensión del suministro de infusiones con yuyos. 
Asimismo se refleja la activa participación del cónyuge en las decisiones sobre la atención de los hijos y el peso de sus opiniones respecto del servicio o recurso de atención a utilizar.

En GD la pata de cabra se registra en casi todos los casos asociada al hijo desnutrido así como a otros hijos. Algunas madres no logran precisar la naturaleza de la enfermedad, describen los síntomas y los tratamientos son diversos. La mayoría reconoce la eficacia de los mismos, siempre paralelos a los de la medicina oficial. Las causas mencionadas son heterogéneas y las medidas preventivas son desconocidas 0 imposibles.

La identificación de la pata de cabra se da en muchos casos luego de haber resultado ineficaces los tratamientos médicos. Distinguen claramente la desnutrición de la pata de cabra y su relación se plantea en términos de causalidad: la pata de cabra produce desnutrición en la medida que "lo bajó mucho de peso".

"Creer o reventar" resulta el corolario de la experiencia de curación y la relación de estas creencias y prácticas de atención no muestran ser contradictorias o conflictivas con la medicina científica.

Finalmente, una dimensión no contemplada inicialmente en el estudio que surge de las entrevistas como eje de indagación y potencial variable explicativa de los perfiles de salud/enfermedad diferenciales dentro de condiciones de vida pobres, se vincula con la adscripción religiosa. Muchas de las mujeres de GE manifestaron la importancia de su conversión y de las de otros miembros de la familia al culto evangélico o al de los Testigos de Jehová y su influencia en la modelación de estilos de vida "sanos".

A fin de contextualizar e identificar las representaciones teóricas y técnicas que orientan el trabajo médico, se recabó información sobre las normativas y programas vigentes en los niveles nacional, provincial y municipal relacionados con la problemática nutricional.

Los datos sobre la situación nutricional en la Argentina son asistemáticos, fragmentarios y discontinuos. La escasa información se debe a su falta de obtención, fallas en el registro, procesamiento y difusión. Las normas oficiales para las actividades de atención infantil, particularmente para el control del crecimiento, existen y son conocidas pero las mismas no son utilizadas rutinariamente en la asistencia pública hospitalaria.

La ausencia de normatización homogénea sobre alimentación infantil determina un vacío en el manejo de criterios que los pediatras adquieren en su formación. La alimentación constituye un tema banal al que se le brinda poca o nula atención en la formación de pre y post-grado. La capacitación de pediatras y equipo de salud sobre la alimentación en el primer año de vida queda relegada a sus intereses y posibilidades. 
Los programas de salud materno-infantil son discontinuos por dificultades presupuestarias y organizativas. Hay carencias de insumos básicos y de bajo costo en los distintos niveles asistenciales e inadecuada y/o insuficiente articulación entre los niveles asistenciales.

En instituciones públicas de salud (hospitales y unidades sanitarias) del Gran La Plata se realizaron entrevistas a médicos pediatras cuya a actividad se relaciona con la asistencia y prevención de la desnutrición.

A través de ellas se relevaron las representaciones y prácticas médicas respecto de la desnutrición, del desnutrido y su familia y de su actividad profesional: el control del crecimiento, los fundamentos de las prescripciones/proscripciones alimentarias destinadas a la población infantil, la prevención, el diagnóstico y tratamiento de la desnutrición, cómo explican su causalidad, la evaluación de la eficacia de su intervención, cuáles son sus representaciones profesionales acerca de las prácticas y representaciones de la comunidad respecto de la desnutrición, cuáles son sus conocimientos de las estrategias populares, cuál es su capacitación técnica para intervenir sobre población desnutrida.

Todos los señalamientos arriba mencionados se recuperan en mayor o menor medida, en los discursos de los médicos entrevistados, habiendo diferencias entre los dos grupos considerados: los que trabajan en unidades sanitarias y los que trabajan en hospitales públicos. Para estos últimos se refleja una mayor tendencia al no cumplimiento de normas destinadas al control de salud y del crecimiento, la pérdida de pacientes por imposibilidad de seguimiento vinculada a la atención despersonalizada y cambiante, un mayor peso de las determinaciones institucionales que imponen la atención de patologías, sesgos profesionales más marcados por la subespecialización, inespecificidad para abordar las problemáticas del crecimiento y del desarrollo por falta de insumos básicos, subestimación de la problemática reflejada en la inexistencia de un código específico destinado al registro del estado nutricional de los niños atendidos. Los pediatras de las unidades de atención primaria reflejan mayor interés en la problemática evidenciado por la puesta en marcha de programa de vigilancia y rehabilitación nutricional y de un censo nutricional. Demandan en mayor medida la posibilidad de capacitación y actualización y si bien expresan satisfacción por su trabajo dada su relación con los pacientes, reconocen a menudo escasa capacidad resolutiva: su mayor compromiso con los pacientes los lleva a un mayor grado de reflexión y conflicto acerca de su tarea.

Ambos grupos conocen las normas y reconocen su utilidad, reclaman una mayor articulación entre los niveles de atención, plantean su sobrecarga de trabajo, la escasa motivación para participar de programas debido a la discontinuidad de los mismos, la 
falta de recursos del Estado que permiten el cumplimiento de las normas y un adecuado tratamiento de la desnutrición, la falta de datos sistemáticos, la formación recibida que enfatiza el estudio de las patologías y no de la salud, la poca relevancia dada en su formación al control del crecimiento y a la alimentación, el sesgo asistencialista de su práctica.

- En relación a la caracterización y abordaje de la desnutrición, las diferencias entre ambos grupos de médicos refieren, para el caso de los pediatras de hospital, a: la ausencia de registros sobre desnutrición, mayor ambigüedad en la conceptualización de la desnutrición y de su cadena causal, escaso o nulo conocimiento del entorno del niño, mayor énfasis en características maternas negativas como factor desencadenante de la desnutrición, mayor contraste entre la representación técnica y las prácticas tanto de diagnóstico como de tratamiento, mayor escasez de recursos para el tratamiento y carencia de criterios unificados sobre alimentación. Los médicos de las unidades de atención primaria tienen datos estadísticos sobre el estado nutricional de la población que demanda asistencia. Realizan habitualmente los controles de salud -sobre todo en los menores de un año-, y destacan el cumplimiento por parte de las madres de los controles y de las recomendaciones médicas. Refieren en mayor medida preocupación de las madres por el estado nutricional de su hijo, consultando incluso cuando están eutróficos o no tienen signos evidentes de desnutrición. Los pediatras reconocen las categorías de subnutridos o malnutridos y proceden a la derivación al hospital en caso de sospechar alguna patología de base. Presentan un conocimiento bastante exhaustivo de la población que atienden, reconociendo idiosincracias según la nacionalidad, adscripción étnica o de clase social. El tiempo dedicado a la atención y a la prevención es mayor y destacan que su lugar de trabajo conforma un espacio familiar para la población. Las similitudes aparecen en la definición de la desnutrición, sus síntomas, el grado de desnutrición prevalente (primaria y leve) que asocian a carencias socioeconómicas y señalan fallas en el registro de datos. Destacan la importancia del conocimiento del entorno del niño, de la relación médico-paciente y del diálogo con las madres para afinar el diagnóstico e indicar el tratamiento.

- Respecto de la interpretación que realizan sobre la visión materna y el uso de medicinas alternativas, las apreciaciones de los médicos difieren en el sentido que los pediatras del hospital consideran que las madres carecen de signos de alarma, estigmatizan y sobredimensionan en mayor medida el uso de medicinas alternativas y la eficacia que les atribuyen se basa en principios y entidades reconocidas por la medicina científica (la cura coincide con la evolución natural de las virosis). Los pediatras de las unidades de atención primaria muestran un mayor conocimiento de la 
medicina popular y reconocen los principios activos de los "yuyos", así como los mecanismos fisiológicos que desencadenan ciertas prácticas curativas. Asimismo señalan no tanto la oposición sino más bien la complementariedad de ambas formas de atención.

Ambos grupos consideran que la reacción materna ante el diagnóstico de desnutrición es de preocupación y no de alarma y destacan su tendencia a negar limitaciones económicas familiares que imposibilitan una adecuada alimentación, estando presente en esta negación el estigma con el que la madre debe cargar. Las madres, de acuerdo con la apreciación de los entrevistados, consideran que la desnutrición es resultado de una patología o de la "pata de cabra" y la mayoría de ellas responde de manera satisfactoria a las recomendaciones médicas. Todos los entrevistados conocen y reconocen el uso de la medicina popular por parte de sus pacientes y adoptan una actitud de "respeto" con advertencias referidas a los riesgos de intoxicación con té de "yuyos". Plantean la dificultad de modificar o alterar dichas prácticas y creencias ya que forman parte de "su" cultura y en general, las remiten al campo de lo sobrenatural, de la magia y de la fábula.

Lo arriba expuesto lleva a recuperar dos modelos interpretativos de la desnutrición: uno teórico y otro instrumental, paradójicamente contrapuestos. Para el modelo teórico, la desnutrición es una patología social que reconoce razones estructurales. En el modelo instrumental, las causas sociales se diluyen en el terreno de lo individual o de lo familiar de modo que las condiciones de vida que están en la base de la desnutrición desaparecen del argumento causal. En el caso de las madres, varias son las entrevistadas cuyas apreciaciones reflejan la perspectiva instrumental. Lo que se rechaza -si no es la presencia de la desnutrición infantil-, es la causalidad social de la misma.

Los discursos predominantes para caracterizar a la desnutrición ponen el acento en desórdenes biológicos individuales causados por un agente externo: parásitos, infecciones, o en la familia -y básicamente en la madre- ya sea por malos hábitos, descuido, desinterés. Esto último sirve además para sustentar el carácter privado del consumo alimentario: con la desnutrición, "del consumo privado a la responsabilidad privada hay un solo paso". Tal como aparece en la mayoría de las entrevistadas: "una si es madre, siempre consigue algo", "uno siempre se la puede rebuscar para que no falte comida", son las apreciaciones más frecuentes, preponderantes en los discursos de aquellas madres sin hijos desnutridos.

En los médicos entrevistados, también es posible recuperar los dos modelos interpretativos sobre la desnutrición expuestos anteriormente. Los mismos expresan 
las representaciones y prácticas asociadas a su atención y ponen de relieve, en un nivel de generalidad, algunos rasgos del Modelo Médico Hegemónico (MMH).

Los mecanismos de reproducción ideológica dominantes y los mecanismos de transacción establecidos por los sectores subalternos con los hegemónicos, conducen a que la estructura dominante de las relaciones sociales se apoye en la subordinación asumida por los propios sectores subalternos, que se expresa en la autoestigmatización, autoinferiorización, autolimitación de estos conjuntos sociales.

El reconocimiento, por parte de las madres de GD, de la desnutrición de su hijo queda relegado en el discurso, mencionándola como un episodio eventual en la historia familiar derivada de un desorden orgánico que "lo/a tiró abajo" y enfatizando además que se trata de "el /ella nomás". Además, tal como lo señalan estudios sobre salud, los sectores populares presentan una tendencia a negarse como enfermos hasta tanto la señal corporal adquiera cierta intensidad, hecho que se registra con mayor fuerza en los adultos (que puede ser atribuido, dadas las condiciones de vida, al costo en tiempo y recursos que implica la atención).

Este comportamiento, para el caso particular de la desnutrición, se ve acentuado: sus características permiten su encubrimiento hasta que no aparezcan signos agudos (diarrea, fiebre, vómitos). Mientras tanto, suele estar enmascarada bajo un criterio de normalidad que se expresa en respuestas del tipo, "ya es así", "son menuditos", "le cuesta aumentar", etc.

Son minoritarios los casos en los cuales la demanda se relaciona específicamente con el control de peso. Esta actitud debe comprenderse en función de la apreciación que tienen las madres del sistema de salud y de su incumbencia y/o eficacia en la prevención/tratamiento de la desnutrición. Apreciación que refleja por otro lado, el modelo instrumental que desarrollan los médicos en su práctica asistencial: el médico centra su atención en la enfermedad infecciosa y/o parasitaria frente a la cual se siente capacitado y hacia la cual la industria farmacéutica y la infraestructura sanitaria brindan soluciones eficaces.

La conjunción de los elementos arriba planteados dificultan la visión de la desnutrición como patología social y empujan en dirección de la búsqueda de soluciones alternativas frente a su presencia: la "pata de cabra" aparece como una conceptualización popular, alternativa, que refiere casi siempre al niño desnutrido, que elimina todo sesgo culpabilizante.

\section{Comentario:}

Aún dentro de un contexto de carencia, los problemas relativos a la elección de alimentos, de gran vigencia en las sociedades actuales, radican en gran medida, en su 
vinculación con la salud y la estética. La medicina, basada en su particular concepción del hombre y sus necesidades, diferenciable de la antropológica, ha desempeñado un papel preponderante en el afianzamiento de tal relación.

Para la medicina y la nutrición, el hombre tiene necesidad y se nutre de proteínas, lípidos, hidratos de carbono y micronutrientes, en síntesis: come nutrientes, no alimentos. Han olvidado o se ha negado que el hombre piensa su comida de otra manera.

Las ciencias sociales destacan que la alimentación no sólo está hecha de nutrientes sino también de significaciones, no sólo desempeña una función fisiológica sino también funciones sociales ya que los "organismos" humanos construyen representaciones que orientan sus comportamientos, definen su lugar en el mundo social y modifican su conformación biológica.

Estas últimas deben tener en cuenta, el hecho que, cualquiera sea la importancia y la autonomía de la dimensión sociocultural, las sociedades humanas están constituidas por hombres que, en virtud de su sustrato biológico, tienen necesidades y padecen injurias, debiéndose subrayar que la desnutrición es en sí misma una condición biológica desfavorable ya que implica hambre para quienes ni siquiera pueden expresarla, e indeseable ya que aumenta la probabilidad de enfermar y morir. De aquí que las ciencias que intentan comprender al hombre no pueden quedar aisladas. 


\section{INTRODUCCION}

La alimentación es un aspecto central de la reproducción individual y social y un indicador de las condiciones de vida de las familias. La antropología destaca que la alimentación tiene un status particular dentro del simbolismo general de una sociedad, hecho que la convierte en objeto de indagación para analizar la expresión de prácticas, discursos e imaginarios sociales. Más allá de la diversidad de tendencias en las investigaciones antropológicas sobre el tema, la problemática alimentaria como objeto de análisis social, se ha convertido en un punto fundamental para la investigación de procesos macro y microsociales.

El enfoque que se adopta en esta investigación sobre la problemática de la desnutrición infantil plantea el análisis de las prácticas y representaciones relativas a la misma en relación a las condiciones de vida y a las estrategias de reproducción familiar en situaciones de pobreza urbana, problemática esta última que ha ocupado y ocupa un lugar importante en el campo de la investigación social en América Latina desde distintas perspectivas analíticas.

El presente estudio focaliza el análisis en las condiciones de vida de las familias que pertenecen a sectores pobres urbanos y su vinculación con la existencia -o no- de desnutrición infantil, considerada como un indicador sensible y temprano de inadecuadas condiciones de reproducción social.

En el proceso planteado, el primer eje de indagación consiste en describir y explicitar el conjunto de características estructurales presentes en dos conjuntos de unidades domésticas en situaciones de pobreza: uno con hijos desnutridos y el otro con hijos no desnutridos o eutróficos, así como el conjunto de prácticas -incluidas en el concepto de estrategias alimentarias- que despliegan para asegurar su reproducción y la evaluación de las mismas.

El enfoque se aleja de las explicaciones mecanicistas que conciben a las prácticas individuales o familiares como resultantes de la estructura social o como la imagen especular de un modelo y permite plantear qué es lo que hace que dos familias que ocupan iguales posiciones dentro de la estructura social actúen, sin embargo, de manera diferente, manifiesten comportamientos diferenciales o registren distintos perfiles de salud/enfermedad.

Como la reproducción material no se desenvuelve sólo en el plano económico, se enfatiza el estudio de las representaciones y prácticas referidas a la alimentación familiar, con particular interés en la nutrición/desnutrición infantil, a través del estudio 
de las pautas de consumo alimentario ${ }^{1}$ y del reconocimiento del estado nutricional de los niños de 0 a 5 años y su tratamiento dentro y fuera del campo médico.

Esto último se desprende de uno de los aspectos básicos sobre el que se centra el presente estudio: el que plantea que el alimento es el primer y principal medio de intervención sobre el cuerpo y por lo tanto un instrumento privilegiado para su dominio y control; de allí que la medicina lo reivindique como perteneciente a su área de incumbencia e intervención destacando la importancia de la alimentación para el mantenimiento de la salud.

Es en este punto donde el enfoque propuesto se aproxima a los estudios desarrollados en el campo de la Antropología y Salud, especialidad temática que se ocupa de los procesos de salud/enfermedad/atención que refieren a contextos sociales específicos y los expresan.

La desnutrición remite centralmente, en términos tanto de causalidad estructural como de prevención, a procesos económico-políticos y culturales. La pertenencia a determinados niveles socioeconómicos establecen los límites y las condiciones dentro de las cuales el proceso salud/enfermedad/atención adquiere características diferenciales, tanto en términos de morbimortalidad como de los saberes referidos a la misma. Se considera, entonces, que los procesos de salud/enfermedad no sólo son emergentes de las condiciones de vida -y en ese sentido la desnutrición es paradigmática- sino también objeto de construcción de representaciones y prácticas por parte de los conjuntos sociales. Todo conjunto social necesita producir y reproducir representaciones y prácticas respecto de los padecimientos, dolores, angustias, malestares, etc. que lo afectan.

En la medida que la alimentación constituye un comportamiento cotidiano fuertemente medicalizado y que la desnutrición infantil se encuentra incluida en el campo de intervención médica, las prácticas, conocimientos y valoraciones sobre alimentación y salud de los conjuntos sociales están permeadas por una construcción hegemónica de la salud/enfermedad/atención. Esto requiere indagar la visión que, sobre la nutrición/desnutrición infantil, sostiene el personal médico de los centros asistenciales en donde se atiende esta problemática así como las prácticas destinadas a la prevención/atención/tratamiento de la misma.

\footnotetext{
${ }^{1}$ El análisis de las condiciones de vida y del consumo alimentario en familias pobres urbanas del Gran La Plata ha sido objeto de dos estudios posteriores (1999 y 2001). En el capítulo metodológico se describe suscintamente el marco dentro del cual se desarrolló cada uno, las técnicas, las variables y las limitaciones encontradas. Sus resultados y comparación con aquellos que se desprenden del presente trabajo se exponen en el Apéndice: "Estudios recientes sobre alimentación familiar en cuatro barrios pobres del Gran La Plata".
} 
Se sostiene que las prácticas y representaciones relativas a la nutrición presentes en las unidades domésticas de los sectores pobres urbanos se articulan con aquellas constituidas como hegemónicas, que son vehiculizadas por los servicios de salud.

De aquí la pertinencia de explorar cómo intervienen las representaciones y prácticas médicas sobre la desnutrición. 


\section{OBJETIVOS}

\section{Objetivos Generales}

- Establecer la relación entre las condiciones familiares de vida dentro de la pobreza con la presencia de desnutrición infantil de causa primaria.

- Relacionar las condiciones familiares de vida con las prácticas y representaciones maternas sobre alimentación y desnutrición infantil.

- Identificar la articulación de las representaciones y prácticas médicas sobre alimentación y desnutrición infantil con aquellas registradas en las madres.

\section{Objetivos específicos}

- Identificar las variables que, dentro de las condiciones de pobreza en el Gran La Plata, diferencian a familias con y sin hijos desnutridos.

Preguntas empíricas:

¿Cuáles son las características sociodemográficas, ocupacionales, de vivienda y servicios de ambos grupos de familias?; ¿Con qué recursos alimentarios no mercantilizados (estatales, de ONG o autogenerados) cuentan?; ¿Cuál es la evaluación de los mismos?

- Describir las prácticas implementadas por las unidades domésticas de los sectores pobres urbanos relacionadas a la nutrición/desnutrición infantil.

\section{Preguntas empíricas:}

¿Qué comen?; Cómo comen?; ¿Cómo se arreglan para comer cuando les falta dinero o asistencia pública?; ¿A quiénes dan alimentación preferencial?; ¿Qué alimentos compran?; ¿A quién recurren para conseguir alimentos?; ¿Quién cocina?; ¿Dónde comen?; ¿Cómo reconocen que los niños están bien alimentados?; ¿Qué hacen frente a la desnutrición de un hijo?; ¿Tiene o tuvo alguna vez un hijo con desnutrición?; ¿Qué papel juegan los médicos en la solución del problema del niño?; ¿Qué papel juega el curandero?; ¿Y la iglesia?; ¿Y su familia?; ¿Y los vecinos?

- Indagar las representaciones sobre nutrición/desnutrición infantil sostenidas por las unidades domésticas de los sectores pobres urbanos. 
Preguntas empíricas:

¿Qué saben sobre los alimentos?; ¿Cuáles valoran?; ¿Qué consideran una alimentación adecuada?; ¿Qué piensan de su propia alimentación?; ¿Cómo evalúan su propia alimentación?; ¿Qué saben acerca de la nutrición/desnutrición infantil?; ¿Qué piensan sobre la existencia de chicos desnutridos?; ¿Qué saben los médicos sobre la desnutrición?; ¿Qué les parece que pueden hacer los médicos para resolver el problema de desnutrición?; ¿Qué saben los curanderos sobre la desnutrición?; ¿Cómo pueden ayudar a resolver la desnutrición de un niño?; ¿Qué otros agentes/instituciones de la comunidad pueden o podrían intervenir en los problemas de alimentación infantil?

- Describir las prácticas y representaciones sobre alimentación, crecimiento y desnutrición infantil sostenidas por el modelo biomédico.

\section{Preguntas empíricas:}

¿En qué se basan las prescripciones/proscripciones alimentarias para la población infantil?; ¿En qué criterio de normalidad se basan para distinguir a un niño desnutrido de uno eutrófico?; ¿Cómo definen los médicos a la desnutrición?; ¿Cómo la detectan?; ¿Cómo la diagnostican?, ¿Qué causalidad le atribuyen?; ¿Cuál es el tratamiento y su eficacia?; ¿Qué tipo de actividad curativa, preventiva se da en el primer nivel de atención?; ¿Cuál es la representación médica sobre las prácticas y representaciones de la comunidad referidas a la desnutrición?; ¿y sobre las familias con hijos desnutridos?; ¿Cuál es la representación médica sobre las estrategias populares relacionadas a la salud/enfermedad/atención y sobre el uso de prácticas populares? 


\section{METODOLOGÍA}

\subsection{Introducción}

El presente estudio llevado a cabo entre 1995 y 1999 es de carácter microsocial, exploratorio y basado en un diseño comparativo de casos y controles.

Se tomaron como referentes empíricos para la comparación dos poblaciones de 50 familias cada una, las cuales fueron encuestadas en su totalidad. Se procedió luego a seleccionar submuestras de ambos grupos a fin de realizar entrevistas semiestructuradas y abiertas, hecho que posibilitó abordar en detalle la problemática planteada desde una perspectiva cualitativa.

Aun cuando se incluye información cuantificable, básicamente la obtenida en la primera etapa del trabajo a través de las encuestas así como aquella contextual que aportan las fuentes secundarias, el manejo metodológico predominante de las etapas siguientes se da en términos cualitativos, recabándose información cuya calidad, significación y pertinencia permita producir interpretaciones sobre el sentido que los distintos agentes entrevistados asignan a los problemas planteados.

En ese sentido se analizan los significados y sentidos que producen y manejan los diferentes actores sociales involucrados o comprometidos con la problemática en cuestión.

Los instrumentos, elaborados sucesivamente de manera complementaria, son empleados en tres etapas: encuestas, entrevistas semi-estructuradas y entrevistas abiertas, reduciendo progresivamente el tamaño de la población en estudio en función de la selección de informantes más estratégicos y de los problemas suscitados a partir del análisis de la información previa. En todos los instrumentos aparecen algunas preguntas similares a fin de poder controlar la calidad de la información, sobre todo por el hecho de que en este estudio la información acerca de las prácticas alimentarias se obtiene básicamente del relato de las informantes y no a través de la observación directa $^{2}$. En la medida en que se pretende incorporar de manera articulada el estudio de las prácticas y representaciones de todos los actores que intervienen significativamente en la problemática nutricional infantil, se incluyó a los médicos como población objeto de estudio. La realización de entrevistas a médicos que trabajan en el servicios públicos del Gran La Plata, fundamentalmente a aquellos que se

\footnotetext{
${ }^{2}$ La contrastación de los relatos de las madres con los relatos de los médicos que atienden a sus hijos, así como con la información asentada en las historias clínicas y libretas sanitarias, posibilitó controlar la información referida a ciertas prácticas como por ej.: lactancia, controles de salud, internaciones, tipo de alimentación, uso de programas alimentarios, la trayectoria de atención del niño desnutrido, cumplimiento de indicaciones médicas, etc. En ese sentido, cabe destacar que no se identificaron marcadas discrepancias.
} 
desempeñan en el primer nivel de atención, se debe a la centralidad de este nivel para desplegar actividades de prevención/asistencia y tratamiento al desnutrido.

Interesa obtener su perspectiva profesional acerca del propio sistema de representaciones y prácticas técnicas, así como del sistema de representaciones y prácticas de la población a la que atiende.

Se plantea la posibilidad de construir la racionalidad del saber médico acerca de la desnutrición a partir de los propios actores sin reducir la interpretación a la dimenisón émica, tratando de articularla con el contexto.

Finalmente, cabe destacar que el marco metodológico elegido desconfía de la validez de la información que pretende extenderse más allá de las condiciones particulares de cada contexto. La descontextualización de la información facilita una mayor capacidad de generalización, pero puede opacar la interpretación de situaciones específicas.

\subsection{Fundamentación de criterios y de conceptos operativos}

\subsubsection{Criterio para delimitar muestras}

El estado nutricional de la población infantil de 0 a 5 años constituye un indicador sensible y temprano de inadecuadas condiciones de reproducción alimentaria. La vulnerabilidad biológica en los primeros años de vida está dada por la acelerada velocidad de crecimiento y por el requerimiento de aportes nutricionales más variados y específicos. Este reconocimiento hace que se adopte al estado nutricional como criterio diferenciador.

\subsubsection{Acerca de las muestras}

Tratándose de un diseño de casos y controles, el carácter de los dos ámbitos facilitó la captación de las poblaciones en estudio siendo un dato relevante en el análisis de la información recabada: uno constituye un centro de salud del primer nivel de atención y el segundo constituye un centro del tercer nivel de atención y por lo tanto, un lugar de derivación y de referencia para los restantes niveles asistenciales. En ambos se utilizaron, para la evaluación del estado nutricional, las Tablas elaboradas por la Dirección Nacional de Maternidad e Infancia del Ministerio de Salud y Acción Social de la Nación aprobadas por la Sociedad Argentina de Pediatría como estándares nacionales (Lejarraga et al., 1985).

Antecedentes favorecedores para la identificación de familias sin episodios de desnutrición infantil.

En un trabajo anterior realizado en el Gran La Plata (Colman y colaboradores,1992), se analizaron las estrategias alimentarias de reproducción de unidades domésticas pertenecientes a sectores populares urbanos. Uno de los casos estudiados fue el de tres barrios: "El Molino", "Villa Rubencito" y "El Zanjón” ubicados en el área de 
influencia de la Unidad Sanitaria "El Molino", localidad de Punta Lara, partido de Ensenada. El trabajo de campo se llevó a cabo durante 1988, realizándose en una primera etapa 100 encuestas a madres que concurrían por consulta pediátrica a la Unidad Sanitaria. De ellas se obtuvo información sobre determinados "componentes estructurales"3 de las familias (características sociodemográficas, situación ocupacional de sus miembros, nivel de ingresos, características habitacionales, etc.), así como sobre su participación en los programas públicos de asistencia alimentaria (Eguía, 1992).

Simultáneamente al desarrollo del mismo, se llevó a cabo un Programa de Estudio sobre Enteroparasitosis Infantil en el cual se realizó, entre otras actividades específicas, la medición antropométrica de todos los niños de las familias encuestadas $^{4}$. Dado que desde esa fecha hasta el inicio de este trabajo, permaneció trabajando en la Unidad Sanitaria la misma pediatra, quien continuó evaluando periódicamente a dicha población, fue posible reconstruir el perfil nutricional de la misma. Este universo permitió entonces, identificar familias sin hijos desnutridos en todo el desarrollo de su ciclo vital.

\section{Condiciones que facilitaron la captación de familias con desnutrición infantil de causa primaria.}

Durante catorce años (1985-1999), he desarrollado mis trabajos de investigación como profesional de apoyo de la Comisión de Investigaciones Científicas de la Pcia. de Bs. As. y como becaria de la UNLP, teniendo como sede la Unidad de Rehabilitación Nutricional del Hospital Interzonal de Agudos especializado en Pediatría "Sor María Ludovica" de La Plata. Dicho servicio cuenta con pediatras especializados en nutrición infantil que asisten a niños con desnutrición primaria o mixta ${ }^{5}$ de 0 a 5 años. Este universo permite acceder al estudio de las familias con casos de desnutrición declarada institucionalmente.

Encontrándose dentro de un hospital de alta complejidad en el que se realizan todos los estudios complementarios, el diagnóstico sobre la naturaleza de la desnutrición es certero y relativamente rápido. Además, los médicos de esa Unidad han realizado actividades de capacitación en distintas Unidades Sanitarias del Gran La Plata a fin de homogeneizar criterios diagnósticos, procedimientos técnicos de medición

\footnotetext{
${ }^{3}$ Se las denomina así porque se han constituido en el largo plazo como resultado de la historia individual de los miembros de la familia y de ésta en su conjunto y, fundamentalmente, porque su constitución depende de la situación de la que los miembros participan y sobre la cual tienen escasa posibilidad de incidir: mercado de trabajo, niveles salariales, acceso a servicios públicos, políticas del Estado en materia alimentaria, de vivienda, etc. (Hintze, 1989).

${ }^{4}$ El Programa de Enteroparasitosis fue realizado por Eduardo Cueto Rúa, Ricarda Cagnoli y Catalina Vernengo (médicos pediatras); Raquel Feldman y colab. (bacteriólogos) de la Cátedra de Parasitología Comparada de la Fac. de Ciencias Veterinarias de la UNLP; Silvia Attademo, Amalia Eguía y Susana Ortale (antropólogas) de la Fac. de Humanidades y Ciencias de la Educación de la UNLP.
} 
antropométrica, utilización e interpretación de las tablas de evaluación y establecer normativas de derivación. Cabe destacar que a fin de anular el sesgo interobservador/interevaluador, se incluyeron los niños desnutridos atendidos por una de las médicas pediatras.

La antropometría, como método para evaluar el estado nutricional de poblaciones infantiles, está muy difundida ya que la información que provee es fácil de comprender para madres y agentes sanitarios, es de bajo costo y relativamente sencilla de obtener, en particular el peso. La antropometría permite la realización de estudios transversales para identificar niños desnutridos, para hacer un diagnóstico de situación en una comunidad, mediante puntos de corte para establecer prevalencias. Es útil para el seguimiento clínico de niños ya que la disminución de la velocidad de crecimiento es un indicador bastante sensible de deficiencias nutricionales o de enfermedades (WHO, 1997). ${ }^{6}$

Dado que no es posible extrapolar la interpretación de inequidad social que implica una elevada prevalencia de baja talla en una población al estudio de un individuo con baja talla (ya que la antropometría no brinda información específica sobre la causa del déficit), en la interpretación del caso individual, el criterio clínico, la curva de crecimiento y una anamnesis cuidadosa suelen ser las mejores herramientas para discriminar las causas que determinan esa condición.

\subsubsection{Unidad de análisis}

Se considera a la unidad doméstica ${ }^{7}$ como unidad de análisis. Esta puede definirse como un "grupo de personas que interactúan en forma cotidiana, regular y permanente, a fin de asegurar mancomunadamente el logro de uno o varios de los siguientes objetivos: su reproducción biológica, la preservación de su vida, el cumplimiento de todas aquellas prácticas, económicas y no económicas, indispensables para la optimización de sus condiciones materiales y no materiales de existencia" (Torrado, 1983).

\footnotetext{
${ }^{5}$ Se la define como aquella derivada de un insuficiente aporte alimentario, asociada a enfermedades banales, que se da en un mal medio socioeconómico (Viteri, 1981).

${ }^{6} \mathrm{La}$ antropometría no permite identificar los procesos causales del deterioro del tamaño corporal. El significado de los hallazgos antropométricos dependerá del indicador en particular, del proceso productor de la deficiencia y del contexto ambiental, sanitario, nutricional y familiar de la población en estudio. Sin embargo, donde la prevalencia de baja talla para la edad es alta, es factible que la mayoría de los niños padezcan o hayan padecido alguna deficiencia nutricional en algún período temprano de su vida. La edad de los niños es un factor de interpretación del indicador baja talla/edad pues en razón de la velocidad de crecimiento, en los menores de 2 años refleja un proceso activo y vigente, mientras que en los niños mayores debe interpretarse como secuela de un proceso pasado (Cesni, 1998).

${ }^{7}$ La distinción entre unidad doméstica u hogar y familia es importante analíticamente en la medida que la segunda se define por lazos de parentesco y la primera no. Debido al predominio de hogares que constituyen familias en sentido estricto, en la redacción se utiliza frecuentemente tal designación por economía de palabras y para evitar la reiteración de términos.
} 
Además, se concibe que ésta "se constituye y acota en función de sus interrelaciones con las demás instituciones sociales, nunca fue ni podrá ser un espacio ajeno o aislado de las determinaciones sociales más amplias: en este sentido, la familia no constituye un mundo "privado". Más bien, el mundo privado de cada sujeto social se construye a partir de las relaciones y los controles sociales dentro de los cuales se desarrolla la cotidianeidad. El ámbito doméstico incluye básicamente las actividades de producción y consumo cotidiano de alimentos y otros bienes y servicios de subsistencia, así como las actividades ligadas a la reposición generacional, es decir, tener hijos, cuidarlos y socializarlos. La elección de la familia no implica concebirla como unidad aislada del mundo social ni identificar "lo doméstico" con "lo privado" en contraposición con el ámbito público "exterior" a la intimidad de la familia. Esta se ve conformada en relación al mundo público de los servicios, de la legislación, del control social, de la cambiante definición del ámbito de aplicación de la medicina, de los mecanismos de regulación de las imágenes sociales prevalecientes sobre la familia y la normalidad, de las instituciones educativas, etc." (Jelin, 1994).

En el marco de la temática de estudio, la unidad doméstica constituye el grupo social que establece en forma estructural el mayor número y tipo de relaciones con aspectos significativos del proceso salud/enfermedad/atención: en ella se da la mayor frecuencia y recurrencia de padecimientos y de enfermedades, es el lugar donde se inicia la carrera de enfermo, donde se da el mayor número de detecciones, diagnósticos, actividades de atención y tal vez de curación (Menéndez,1992).

La familia conforma la unidad en donde en forma directa o como mediadora se constituyen y operan alguno de los principales determinantes de la morbilidad y de la mortalidad, en particular en los menores de cinco años. Es además la unidad en torno a la cual se organizan las principales redes sociales respecto del proceso salud/enfermedad/atención. Estos y otros reconocimientos, ya sea que acentuemos los caracteres positivos o negativos de la familia en términos de la salud de sus componentes, ponen énfasis en la recuperación de la misma respecto de las estrategias de acción contra la enfermedad. Ella puede considerarse así no sólo como variable dependiente de determinaciones político económicas sino también como potencial variable explicativa con base en la descripción y análisis de la dimensión ideológica-cultural, ámbito que establece las mediaciones entre las estructuras macrosociales y los problemas de salud específicos (Menéndez, 1992).

\subsubsection{Informantes de la unidad doméstica}

Dentro de la familia, la división sexual del trabajo en nuestra sociedad establece que es la mujer/madre la encargada de generar el mayor número de actividades ligadas 
específicamente al proceso salud/enfermedad/atención: ella es quien detecta los malestares, realiza los primeros diagnósticos, desarrolla los primeros tratamientos incluyendo la búsqueda de ayuda especializada, decide la continuidad del tratamiento, etc. La mujer es el principal y más frecuente informante del médico. En virtud de lo expuesto, ella misma constituye la principal fuente de información.

\subsection{El estudio de las representaciones y prácticas médicas}

El análisis de estos aspectos se basa en una estrategia que implica dar cuenta del saber médico sobre desnutrición tanto en términos del modelo abstracto (modelo médico hegemónico) así como de los contextos particulares (unidades sanitarias, hospitales públicos) en los que se pone en juego dicho saber.

El mismo intenta incluir la articulación de dos niveles: uno que corresponde a la particularidad del conjunto de médicos seleccionados y el segundo que corresponde al Modelo Médico Hegemónico (MMH) (Menéndez, 1987, 1989, 1991).

En el saber de cada grupo se intenta encontrar no sólo su saber particular sino también reencontrar en él -o no- al mismo modelo médico, ya que es el saber de cada grupo el que produce y reproduce las características del $\mathrm{MMH}$ y no una determinación externa al mismo.

Dar la palabra a estos actores significativos implica reconocer que las concepciones culturales no pueden aparecer desarticuladas de los contextos institucionales dentro de los cuales desarrollan sus experiencias de trabajo.

Las respuestas de los médicos constituyen la expresión no de una muestra representativa de todos los médicos pediatras, sino de un conjunto organizado a partir de la unidad donde trabajan, de la institución a la que pertenecen, del universo de pacientes comunes, del área de intervención y de la vinculación con otros grupos de profesionales.

\subsection{Etapas del estudio}

\subsubsection{Etapa 1}

En 1994 se planteó la realización de un nuevo trabajo de campo en los mismos barrios de Punta Lara a fin de realizar un análisis comparativo de las condiciones de vida y reproducción alimentaria en las familias estudiadas en 1988.

Se procedió a re-establecer contacto con el personal a cargo de la Unidad Sanitaria "El Molino" para plantear el objetivo del trabajo y solicitar información referida a los cambios de residencia de las 100 familias estudiadas en 1988 y a los controles de salud de los niños.

Las actividades cumplidas en esta etapa fueron: 
- Identificación de las familias estudiadas en 1988 en el área de influencia de la Unidad Sanitaria "El Molino", que permanecían en ese período residiendo en la zona.

- Diseño de la encuesta, tomando como base para su reformulación aquella utilizada en 1988 (Anexo I).

- Realización del trabajo de campo en los barrios "Villa Rubencito", "El Zanjón" y "El Molino" pertenecientes al área de influencia de la Unidad Sanitaria "El Molino" con aplicación de la encuesta en los domicilios particulares y en la Unidad Sanitaria a 70 de las 100 familias encuestadas en el estudio anterior. La misma releva información referida a:

- Componentes estructurales de la unidad doméstica (sociodemográficas, de la vivienda, ocupacionales), estrategias alimentarias autogeneradas y/o utilización de recursos provistos por el Estado $\mathrm{u}$ otros organismos no gubernamentales.

- Valoración de los distintos participantes sobre las diversas opciones que, en materia alimentaria son ofrecidas por el Estado, así como sus expectativas y necesidades.

- Reconocimiento de casos de desnutrición infantil y de casos de "pata de cabra" (conceptualización popular vinculada a la desnutrición) por parte de la madre.

- Casos de internaciones por enfermedades infecciosas (gastrointestinales, broncopulmonares e infectocontagiosas) relacionadas a la desnutrición.

- Lactancia materna: Duración de la lactancia como alimentación exclusiva y edad de ablactación en menores de cinco años.

Cabe aclarar que de las 70 familias encuestadas en la localidad de Punta Lara, 61 no registraron casos de desnutrición actual y/o anterior habiéndose excluido 11 familias por encontrarse en una etapa mucho más avanzada del ciclo de vida familiar, quedando por lo tanto 50 familias dentro del grupo no desnutrido o eutrófico (G2).

El análisis realizado para seleccionar familias con la totalidad de los niños eutróficos en todo el desarrollo de su ciclo vital puede verse en el siguiente cuadro:

Cambios en la presencia de casos de desnutrición infantil: 1988-1994*

Familias encuestadas en los barrios de Punta Lara (partido de Ensenada)

\begin{tabular}{|c|c|c|}
\hline CAMBIOS & N & $\%$ \\
\hline Casos en 1988 y 1994 & 2 & 2,8 \\
Sin casos en 1988 y 1994 & 52 & 74,3 \\
Casos sólo en 1988 & 9 & 13,0 \\
Casos sólo en 1994 & 7 & 10,0 \\
\hline Total & 70 & 100 \\
\hline
\end{tabular}


Fuente: Datos antropométricos evaluados en la Unidad Sanitaria “El Molino" (Ensenada), 1994-95.

*Nota: De las 70 familias estudiadas en la localidad de Punta Lara (GE), 9 presentaron en el segundo período, algún hijo desnutrido, habiendo tenido hijos desnutridos en el estudio realizado en 1988 otras 9 familias, ninguna de las cuales presentó nuevos casos de desnutrición a partir de esa fecha. Hay dos familias que presentaron hijos con desnutrición tanto en 1988 como en 1995.

En 1988 se presentaron, dentro de las 100 estudiadas, 16 familias con algún hijo desnutrido (16\%), mientras que entre esa fecha y el estudio actual, 9 familias registraron algún episodio de desnutrición $(13 \%)$.

- En la Unidad de Rehabilitación Nutricional del Hospital de Niños de La Plata (URN) se procedió a delimitar, con la colaboración del personal médico, el grupo de familias susceptibles de ser estudiadas conforme a los criterios de inclusión propuestos: con casos de desnutrición infantil primaria y residentes dentro del área del Gran La Plata (GD).

- Realización de la encuesta a cincuenta familias residentes en barrios pobres del Gran La Plata que asisten a sus niños en la URN.

- Codificación de las respuestas, carga y procesamiento de los datos.

- Análisis de las encuestas: análisis comparativo de las características de las dos poblaciones y su relación con la presencia -o no- de casos de desnutrición infantil actual.

- Formulación y prueba piloto de las entrevistas semiestructuradas tendientes a profundizar el estudio de las pautas de consumo alimentario familiar: organización de la comida, dieta habitual, conocimientos y valoraciones alimentarias (Anexo II).

La evaluación antropométrica de los niños de las dos poblaciones bajo estudio estuvo a cargo de la Dra. Catalina Vernengo, médica pediatra de la Unidad Sanitaria "El Molino" y de la Dra. Adriana Sanjurjo, médica pediatra de la Unidad de Rehabilitación Nutricional del Hospital de Niños de La Plata. Conforme a las Tablas aceptadas como estándares nacionales (Lejarraga, 1985; SAP, 1986), se utilizó la clasificación de Gómez modificada para evaluar el indicador peso/edad el cual establece como punto de corte el percentilo 10; para evaluar en los mayores de dos años el indicador talla/edad se consideró como punto de corte el percentilo 3.

\subsubsection{Etapa 2}

Con posterioridad al análisis de las encuestas de las 100 familias, se realizaron entrevistas semiestructuradas a muestras restringidas de las dos poblaciones para profundizar el estudio de las pautas de consumo alimentario familiar. Partiendo de la homologación de las edades de los niños y de ciertas características de los hogares, fueron entrevistadas 13 madres con la totalidad de los hijos eutróficos y 13 madres de niños desnutridos. 
Las 26 entrevistas se realizaron durante los meses de abril y julio de 1996, llevándose a cabo en los domicilios y, en algunos casos, en las instalaciones de la Unidad Sanitaria "El Molino".

Las entrevistas de tipo semiestructurado profundizaron los siguientes aspectos relacionados al consumo alimentario:

- Organización de los consumos mercantilizados: se incluyeron tópicos tales como responsable de realizar las compras, lugar donde realizan las compras, forma de pago, periodicidad, estimación del gasto semanal, proporción del gasto en comida en relación con el ingreso mensual en comparación con la proporción destinada en 1988, arreglos domésticos desplegados para la obtención de alimentos ante la imposibilidad de obtenerlos por falta de dinero y su comparación con los arreglos implementados en 1988, cambio en la forma de hacer las compras, influencia de la estabilidad y de la edad de los hijos en el trabajo doméstico alrededor de la comida.

- Características de la dieta habitual: basada en el relato de aquellos alimentos que utilizan más frecuentemente para preparar las comidas, la evaluación de sus propiedades nutricionales, comidas que se preparan más frecuentemente, preferencias de los niños y de los adultos, evaluación de la calidad de la comida familiar, reconocimiento de alimentos valorados que no forman parte de la dieta habitual así como de aquellos que consideran que se consumen en exceso, número de comidas diarias, importancia de las comidas, preparación de comida especial para niños u otros miembros y, en virtud de la relación formulada en numerosos trabajos entre duración de la lactancia y desnutrición infantil, se relevó el dato referido al tiempo de lactancia como alimentación exclusiva y edad de ablactación para todos los hijos menores de cinco años.

Se analizó la información a fin de identificar las diferencias predominantes en los patrones alimentarios de las familias con niños eutróficos y desnutridos.

- Conocimientos y valoraciones sobre la alimentación: se relevaron aspectos generales sobre alimentación referidos a la apreciación de lo que, desde la perspectiva de las informantes, constituye una alimentación completa, alimentos nutritivos, mala alimentación, mal hábito alimentario, alimentos perjudiciales y/o rechazados, criterios utilizados para establecer una alimentación diferencial entre los miembros que integran la familia y los criterios de evaluación de una adecuada alimentación infantil.

Una vez finalizado el trabajo de campo se procedió a la desgrabación y análisis de las entrevistas semiestructuradas para encontrar las diferencias presentes en los puntos antes mencionados y cómo intervienen en las familias los problemas de escasez y elección. 


\subsubsection{Etapa 3}

Analizadas las entrevistas semiestructuradas se realizaron entrevistas abiertas a madres de los dos grupos a fin de aprehender sus representaciones ligadas a la nutrición/ desnutrición infantil, formas de evitarla así como sus causas y tratamientos posibles.

Los relatos de las dieciseis mujeres entrevistadas fueron desgrabados y analizados comparativamente así como en relación al contenido de las entrevistas semiestructuradas.

\subsubsection{Etapa 4}

- Búsqueda de datos e información de fuentes secundarias.

En ámbitos institucionales públicos de salud -nacional, provincial y municipal- se recolectaron datos de informes técnicos y de reuniones de expertos. En ellos se plasma la apreciación que presentan los especialistas y los funcionarios del sector salud de la desnutrición y de las normativas vigentes, la evaluación que realizan sobre los programas vinculados a tal problemática así como las propuestas a desarrollar.

Asimismo se recolectaron datos estadísticos que apuntan a construir una epidemiología de la desnutrición -ya sea a nivel nacional, provincial o local- e información cuantitativa provista por el Ministerio de Salud Pública de la Pcia. de Bs. As. surgida de encuestas sobre alimentación en la infancia temprana realizadas a médicos de la Pcia. de Bs. As.

- Realización de entrevistas semiestructuradas a médicos pediatras y/o generalistas para indagar su conceptualización de la desnutrición, de su práctica relacionada al tratamiento de dicha problemática. Las preguntas tienen por finalidad aprehender las representaciones médicas en torno a la desnutrición, a los desnutridos y sus familias, y de su propia actividad profesional relacionada con dicha problemática: el control del crecimiento, los fundamentos de las prescripciones/proscripciones alimentarias destinadas a la población infantil, la prevención, el diagnóstico y tratamiento de la desnutrición, cómo explican su causalidad, la evaluación de la eficacia de su intervención, cuáles son sus representaciones profesionales acerca de las prácticas y representaciones de la comunidad respecto de la desnutrición, cuáles son sus conocimientos de las estrategias populares, cuál es su capacitación técnica para intervenir sobre desnutridos.

La selección de médicos pediatras responde a la necesidad de enriquecer/complejizar los problemas surgidos del análisis de la información de las entrevistas realizadas a las madres y lograr una mejor comprensión de sus relatos; posibilita además obtener 
información más estratégica y contrastarla con aquella provista por fuentes secundarias..

Se entrevistaron médicos pediatras que trabajan en diferentes niveles asistenciales de instituciones públicas que dan servicio a población carente de obra social/mutual del Gran La Plata:

- 5 de ellos trabajan en diferentes hospitales públicos de la zona, dependientes del Ministerio de Salud de la Pcia. de Bs. As.

- otros 10 médicos pediatras trabajan en diferentes unidades de atención primaria dependientes de la Municipalidad de La Plata, las cuales representan al $25 \%$ del total de estos centros asistenciales.

La ponderación de médicos que trabajan en el primer nivel de atención responde a que las instituciones de salud pública consideran que este nivel es el decisivo para desplegar actividades de prevención/asistencia y tratamiento al desnutrido.

La inclusión de un grupo más restringido de médicos pediatras que atienden en hospitales públicos con consultorios pediátricos se deriva de reconocer que en ellos se asiste a un volumen considerable de población, ya sea derivada de los servicios de atención primaria o bien con problemas de salud que no requieren de gran complejidad y podrían resolverse en el otro nivel de atención.

Interesa obtener su perspectiva profesional ya sea acerca de su propio sistema de representaciones y prácticas técnicas como también del sistema de la población que atiende.

\subsection{Etapa 5. Actualización de información (1999-2001)}

\section{Estudios recientes sobre alimentación familiar}

Algunos de los aspectos considerados anteriormente fueron explorados en dos estudios posteriores llevados a cabo en cuatro barrios pobres del Gran La Plata:

1) Durante 1999-2000 se llevó a cabo un trabajo de campo en las áreas de influencia de las Unidades Sanitarias (US) "El Molino", N 184 (localidad de Punta Lara, partido de Ensenada) y $\mathrm{N}^{\circ} 15$ (localidad de Tolosa, partido de La Plata). Mediante encuestas semiestructuradas (que incluyeron asimismo una serie de preguntas abiertas) realizadas a 272 mujeres que concurrieron a la consulta pediátrica de dichos centros asistenciales, se relevó información sobre diferentes aspectos de las condiciones de vida familiar: trabajo, ingreso, vivienda, políticas sociales, alimentación, organización 
doméstica, procesos de salud/enfermedad/atención ${ }^{8}$. El criterio de selección muestral adoptado obedece a la necesidad -planteada inicialmente en el proyecto- de incluir hogares en etapa de expansión con algún hijo menor de 5 años a fin de tomar a la desnutrición infantil como eje diferenciador de condiciones de vida de los hogares. Cabe destacar que dicha aproximación se vio seriamente afectada ya que, más allá de una apreciación global de los pediatras que trabajan en dichos centros asistenciales, no fue posible acceder a los datos antropométricos actualizados de la población infantil menor de 5 años de dichas familias, situación que impuso limitaciones al proceso de análisis y recaudos en la interpretación de los resultados por contar sólo con la información suministrada por las madres -con el subregistro potencial que esta estrategia implica-.

Con relación a la dimensión alimentaria, dicha limitación condujo a circunscribir el estudio a los siguientes ejes de análisis:

- la participación de las familias en programas alimentarios estatales y la evaluación de los mismos,

- la utilización de otros recursos y estrategias para la obtención de alimentos (redes, huerta, animales, iglesias),

- la organización del gasto familiar y el presupuesto destinado a la alimentación,

- las características de la comida habitual,

- la evaluación cuali-cuantitativa de la misma.

Los mismos fueron considerados teniendo en cuenta la incidencia que sobre ellos tienen: la composición y organización familiar, la situación laboral y el nivel de ingreso de las familias.

Los resultados presentan la información derivada del análisis conjunto de los tres barrios.

Sólo como referencia -y no como eje analítico central- se incluye la apreciación de las informantes sobre la presencia de niños desnutridos o con pata de cabra ${ }^{9}$ en sus familias y en el barrio.

2) En el mes de junio de 2001 se llevó a cabo un censo en el Barrio "La Unión" (partido de La Plata $)^{10}$. El cuestionario utilizado relevó datos sobre: características de la vivienda, composición familiar, educación, situación ocupacional, recursos del hogar,

\footnotetext{
${ }^{8}$ Eguía, A.; Ortale, S.; Weingast, D.; Dionisi, K.; Pagnamento, L. (2000) "Estudio integral de las condiciones de vida en tres barrios pobres del Gran La Plata". Informe Programa de Incentivos a la Investigación, Dpto. de Sociología, Fac. de Humanidades y Ciencias de la Educación de la UNLP.

9 La "pata de cabra" es una enfermedad encuadrada dentro de lo que se conoce como "medicina tradicional, folk, o popular" que se presenta en los niños y se relaciona estrechamente con episodios de desnutrición (Ortale y Rodrigo, 1996).
} 
organización doméstica y alimentación, procesos de salud/enfermedad/atención, participación comunitaria y política.

Siguiendo con la línea de estudio arriba señalada, uno de los aspectos incluidos en la encuesta realizada a 128 familias, fue el alimentario y la información recabada fue la siguiente:

- la participación de las familias en programas alimentarios estatales y la evaluación de los mismos,

- la utilización de otros recursos y estrategias para la obtención de alimentos (redes, huerta, animales, iglesias),

- gasto diario en comida

- cantidad de veces que se cocina por día

- importancia de las comidas principales

- comidas más frecuentes

- evaluación de la alimentación familiar y razones de la misma

- reconocimiento, por parte de las mujeres encuestadas, de desnutrición infantil en la familia y en el barrio.

En este estudio, tampoco fue posible el análisis basado en la diferenciación de familias con o sin hijos desnutridos.

Ambos estudios permiten aprehender, en el marco de la información comparable, en qué medida se ha mantenido o modificado la alimentación de las familias pobres y aventurar posibles hipótesis. Los resultados encontrados y su comparación con los del presente estudio se presentan en el Apéndice.

\footnotetext{
${ }^{10}$ Eguía, A.; Ortale, S.; Piovani, J.; Dionisi, K.; Pagnamento, L.; Weingast, D. (2001): "Diagnóstico integral de las condiciones de vida en el barrio La Unión (La Plata)". Dpto. de Sociología de la Facultad de Humanidades y Ciencias de la Educación de la UNLP/Conicet.
} 


\section{MARCO CONTEXTUAL}

\subsection{El contexto socioeconómico}

Un estudio realizado para América Latina (Altimir, 1979) estima para 1970 en $8 \%$ el porcentaje de hogares pobres para todo el país y $5 \%$ en las áreas urbanas. La crisis y los cambios a partir de los '70 modifican este panorama: se inicia un persistente proceso que lleva más de 30 años de masiva movilidad descendente.

Durante la década de los 80 , gran parte de los países de América Latina enfrentaron una profunda crisis que implicó una aguda contracción económica, una disminución de los ingresos con mayor desigualdad en su reparto e inequidad en la distribución de bienes y servicios.

En 1980 la pobreza afectaba en América Latina al 38\% de la población y en 1990 a una cifra cercana al $50 \%$. La década del 80 al 90 ha sido una década de avance casi arrollador de la pobreza en la región (Kliksberg, 1994), preocupación que se refleja en la organización de reuniones internacionales y conferencias regionales como la realizada en Quito en 1990.

El contenido de las políticas de ajuste impulsadas desde el FMI y el Banco Mundial para enfrentar la crisis económica mundial, particularmente de las economías latinoamericanas, apunta a la desregulación de los mercados, la reducción del déficit fiscal y/o del gasto público, una clara política de privatizaciones, la capitalización de la deuda y un mayor espacio al capital internacional como condición para los préstamos. Las consecuencias sobre los salarios y la estructura del empleo, la recesión y el abandono por parte del Estado de una serie de actividades que mitigan el empobrecimiento, impactaron negativamente sobre las condiciones de vida de la población en general y de los más necesitados en particular (Cepal, 1994). Se observa además que el crecimiento económico no implica necesariamente equidad o superación de la pobreza. La teoría del derrame, fuertemente difundida en América Latina es radicalmente objetada por datos del informe del PNUD (1990) en la Conferencia Regional de los países de América Latina sobre pobreza.

Se constata que puede haber crecimiento, pero las desigualdades en la distribución de la riqueza y políticas sociales débiles llevan a que no se difunda y el problema social siga agravándose (Kliksberg/PNUD, 1990). El efecto "goteo" que se le adjudica al desarrollo económico como garante del bienestar general de la población, resta importancia a las características que asumen los procesos de producción y distribución, cuyas modalidades y manifestaciones se reflejan en la creciente polarización entre sectores de los países de la región, tendencia a la que no escapa nuestro país. 
La década de los 90 se inicia para gran parte de los países de América Latina en el marco de una recesión económica persistente y de una creciente pobreza para amplias conjuntos sociales, mientras surgen cada vez más evidencias de que la crisis de los 80 -y los procesos de ajuste que la acompañaron- han afectado con especial dureza a la infancia, socavando sus condiciones de salud, nutrición y educación (Minujin, 1993). "Es en esta década cuando, por primera vez, el Estado argentino debe instrumentar programas nacionales de ayuda alimentaria para un sector creciente de la población cuyos ingresos son insuficientes, incluso para satisfacer esa necesidad básica." (Golbert, 1994).

Los signos principales del proceso: concentración económica, contracción del Estado y retiro de las funciones redistributivas, modificaciones en el mercado de trabajo con aumento de la precarización y el desempleo, caída del ingreso, aumento de la pobreza configuran un panorama que afecta profundamente las condiciones de vida de la población y que ha producido significativas transformaciones en la estructura social de la Argentina.

El sector público, que cumplió históricamente, sobre todo a partir de 1930-40, un papel dinamizador y protagónico de procesos masivos de cambios sociales, signados fundamentalmente por la incorporación de sectores pobres a condiciones de vida y trabajo con protección social, cobertura educativa y posibilidades de mejora en sus condiciones de vida, se enfrenta a un proceso de estancamiento y recesión económica. Es cuestionada la legitimidad del accionar del Estado de Bienestar y a partir de este cuestionamiento se pasa a una política de desarticulación: el Estado abandona la meta de mejorar su accionar para cumplir con efectividad y eficiencia su papel redistributivo y garante de equidad y universalidad de los derechos y necesidades básicas de la población.

\subsubsection{A propósito de la desigualdad social en nuestro país}

En nuestro país, la crisis arriba mencionada se inicia a mediados de 1970 y su persistencia ha traído aparejado un fuerte deterioro en las condiciones de vida de importantes sectores de la población.

En la Argentina, desde los 80 , la preminencia del neoliberalismo y las políticas de ajuste implementadas para superar la recesión económica agravaron la situación, produciendo elevados índices de pobreza y profundizando el estancamiento.

Este ha afectado directamente al crecimiento del empleo, al comportamiento de los salarios y a la distribución del ingreso.

La estructura social del país ha sido modificada, produciéndose un empobrecimiento general y la incorporación de nuevos sectores al universo de la pobreza. 
Muchas familias de clase media han visto reducir sus ingresos hasta caer por debajo de la línea de pobreza ${ }^{11}$, conformando la categoría de los pauperizados, empobrecidos o nuevos pobres.

Los pobres estructurales o población con necesidades básicas insatisfechas ${ }^{12}$ que llevan consigo una historia de pobreza profundizan sus carencias, revelando de un modo incontrastable la miseria que incide en los sectores de menores recursos; los sectores medios en su mayoría se hunden y un pequeño grupo ocupa una posición aún más privilegiada.

El comportamiento dispar que muestra la aplicación de ambos métodos para la medición de la pobreza (LP y NBI), permite una valiosa aproximación para relevar los cambios en los perfiles de pobreza, distinguiéndose los nuevos pobres 0 pauperizados, caracterizados por tener ingresos inferiores a la LP pero no registrar $\mathrm{NBI}$ y los pobres estructurales, definidos por registrar NBI.

Beccaria (1993), que centra su mirada sobre los ingresos, señala que el retroceso productivo experimentado tuvo como consecuencias la reducción de las remuneraciones y la reducción de la capacidad de generar empleo, afectando negativamente a su vez la distribución del ingreso.

Los estudios realizados en el marco de "La Pobreza en la Argentina" (INDEC, 1984) han mostrado incrementos significativos en la proporción familias con ingresos inferiores a la línea de pobreza, es decir con ingresos que no les permiten atender, de acuerdo con pautas culturales de consumo de la sociedad, las necesidades de alimentación, salud, transporte, vivienda y educación.

Para el Gran Buenos Aires el incremento de la pobreza se debe básicamente al aumento de hogares bajo LP o empobrecidos, que pasan del $4.3 \%$ en 1980 , al $16.8 \%$ en 1988 y a $18.4 \%$ en 1990 triplicando su incidencia. Los pobres estructurales medidos a través del método de las necesidades básicas insatisfechas (NBI) mantienen su peso relativo ( $16 \%$ de hogares NBI). Sin embargo, si bien este grupo no creció, sufrió una dura caída en sus ingresos. En 1980, pertenecer a este sector no

\footnotetext{
${ }^{11}$ La línea de pobreza presupone la determinación del valor de una canasta básica de bienes y servicios. Serían pobres aquellos hogares con ingresos inferiores al valor de la línea de pobreza, en la medida en que no pueden cubrir con sus ingresos, el costo de esa canasta. La línea de indigencia, cuyo valor representa aproximadamente la mitad del de la línea de pobreza, alude a los ingresos de los hogares necesarios para cubrir sólo el costo de la canasta básica de alimentos.

${ }^{12}$ Las necesidades básicas insatisfechas o NBI remiten a aquellas manifestaciones materiales que evidencian carencias o falta de acceso a cierto tipo de servicios vinculados con la vivienda (calidad de la vivienda, sistema de abastecimiento de agua y de eliminación de aguas servidas, hacinamiento), educación, capacidad de subsistencia, etc. En tanto la medición y determinación del hogar como NBI se basa en el criterio de co-realización de las necesidades básicas, la no satisfacción de alguna de ellas clasifica al hogar como pobre. Las necesidades básicas insatisfechas o NBI remiten a aquellas manifestaciones materiales que evidencian carencias o falta de acceso a cierto tipo de servicios vinculados con la vivienda (calidad de la vivienda, sistema de abastecimiento de agua y de eliminación de aguas servidas, hacinamiento), educación, capacidad de subsistencia, etc. En tanto la medición y determinación del hogar como NBI se basa en el criterio de co-realización de las necesidades básicas, la no satisfacción de alguna de ellas clasifica al hogar como pobre.
} 
implicaba tener un ingreso extremadamente bajo, es decir, todavía existían múltiples situaciones en las que si bien se tenían carencias de vivienda, abastecimiento de agua corriente, sanitarios, se ganaba lo suficiente para alimentarse, vestirse, etc..

A partir de entonces se verifica un aumento de hogares NBI que se hallan bajo LP: en 1974 el 14\% de los NBI tenían ingresos bajo LP, elevándose en 1990 a 64\% la proporción de pobres estructurales que tenían ingresos per cápita inferiores a la línea de pobreza (Minujin, 1993).

La información proporcionada por "La Pobreza en la Argentina" (INDEC, 1984) muestra para 1980 un país en el que la incidencia de la pobreza (englobando aquella medida tanto por NBI como por LP) es considerable, $22.3 \%$ de hogares, con alta concentración en las áreas urbanas; $51 \%$ de los hogares pobres se ubican en las localidades de 50.000 habitantes o más con fuertes disparidades regionales entre áreas menores, $7 \%$ Capital Federal vs. más de $40 \%$ en el NOA. Los datos correspondientes al Gran Buenos Aires permiten observar que el porcentaje de hogares pobres se elevó $70 \%$ entre 1980 y 1990.

Es interesante señalar que, en el Gran Buenos Aires, la probabilidad de los hogares NBI de tener ingresos bajo LP alcanza en 1988 a 7.7 hogares cada 10, mientras que esta probabilidad afecta a 2.7 hogares de cada 10 no pobres.

Si bien el comportamiento de los indicadores de NBI indican, con base en los datos del censo de 1991, continuó una tendencia al paulatino mejoramiento en las "condiciones de vivienda y servicios sanitarios" y "educación", el empobrecimiento por ingreso impactó significativamente en estos hogares. "Esta vuelta de tuerca en "la pobreza de los pobres" constituye una especie de consolidación de su estado y, de no mediar una mejora en sus niveles de ingreso, se verán imposibilitados de mejorar sus condiciones materiales de vida." (Golbert, 1994).

El incremento de los hogares pobres se explica además, en buena medida, por la incorporación de sectores medios que, en una suerte de descenso desordenado, sufren una pérdida de posiciones relativas.

Se registra además un incremento muy marcado de la proporción de hogares con ingresos que aunque superiores, se encuentran en niveles relativamente próximos a los de la línea de la pobreza, lo que implica una situación de particular incertidumbre en las que pueden caer más o menos rápidamente por debajo de la línea de pobreza. Además, es posible indicar que el incremento de los hogares bajo LP se correlaciona con un aumento de los hogares ubicados bajo la línea de indigencia, valorizada en el nivel de la canasta básica de alimentos.

La estructura distributiva del ingreso muestra que a partir de 1980 todos los deciles, salvo el más privilegiado, pierden posiciones relativas. Se desprende pues que es la 
sociedad la que se empobreció, no sólo en términos del PBI per cápita, sino que al mismo tiempo ese ingreso disminuido se distribuye en forma cada vez más inequitativa, siendo los tres deciles inferiores los que más han perdido posición relativa.

De modo que la pobreza urbana en la Argentina contemporánea se explica principalmente en términos de pérdida de ingresos (Golbert, 1994).

Analizando su incidencia a nivel nacional durante el período 1986-1990, que contiene los momentos de mayor hiperinflación y los que más afectaron el nivel del salario real, puede verse que ésta aumenta hasta alcanzar el valor de $47.4 \%$ en 1989.

El pico de la brecha entre la población con ingresos más altos y aquella con ingresos más bajos se produjo en ese año: el $10 \%$ de la población con ingresos más altos percibe 23 veces más que el $10 \%$ de la población más pobre, diferencia que obedece en parte al fuerte impacto de la escalada de precios en la población con ingresos fijos.

Los primeros años de los 90 reflejan el impacto del plan de estabilidad: la brusca disminución de la inflación tiene efectos relativamente inmediatos en el poder adquisitivo de los salarios, produciéndose un desplazamiento de la población situada por debajo de la LP con respecto a los años anteriores: mientras en 1989 el 36.5\% de los hogares del Gran Buenos Aires estaban bajo la línea de pobreza, en 1992 este porcentaje había descendido al 19.4\% (Minujin, 1995). En el período 1991-1993, que corresponde al inicio del Plan de Convertibilidad se revierte entonces la tendencia y la incidencia disminuye ininterrumpidamente a $16.9 \%$.

Es decir que, a partir de 1990, con la mayor estabilidad de los precios, hubo una mejora que duró poco. La disminución de los hogares bajo la LP refleja básicamente la recuperación del poder adquisitivo de los ingresos, consecuencia de la estabilidad de los precios, pero aún no se ha logrado revertir el proceso de polarización y fragmentación social. "Las pautas de inequidad en la distribución de los ingresos se mantienen y los indicadores de subutilización de la fuerza de trabajo no logran reducirse. Incluso en el período 91-92 hay un incremento en la tasa de desocupación y subocupación." (Minujin, 1993).

Con la recesión de 1994, la crisis del Tequila, la caída de los salarios y el aumento del desempleo, la distancia entre ricos y pobres volvió a crecer: a partir de 1994 la curva de distribución del ingreso profundiza la brecha llegando al $28 \%$ en 1996 y se sitúa en el $26 \%$ en 1997. Este tramo involucra la situación más grave de todas las experimentadas en el período, ya que por primera vez aumenta significativamente la incidencia de la pobreza en un momento de inflación nula poniendo en evidencia el elemento más grave de la evolución: el modelo económico induce aumento de pobreza sin inflación (Torrado, 1998). A partir de 1998 se supera el índice de 1989. 
Aunque a partir de 1991 hubo estabilidad de precios y en el 2000 se registra deflación, siguió aumentando la desigualdad social por la falta de empleo, los bajos salarios y el incremento de la desocupación ${ }^{13}$.

La creciente distancia entre ricos y pobres obedece a que la franja de menores recursos cada vez gana menos. Respecto del 2000 en el 2001 los ingresos totales del $10 \%$ de la población más pobre cayeron un $9 \%$. Considerando, según el INDEC, que en 1998 el 10\% más rico aumentó en un año sus ingresos reales en un 13\% (Diario Clarín, 1998) y que esa tendencia se ha mantenido, creció la desigualdad tanto en términos absolutos como relativos.

Según datos del INDEC (Diario Clarín, 2001), en la Capital Federal y el conurbano hay 3,5 millones de viviendas. En el $10 \%$ más pobre ingresan menos de $\$ 210$ por mes. En la otra punta ingresan entre $\$ 2.200$ y $\$ 17.000$ mensuales. Como en los hogares pobres vive más gente ( 5 personas por vivienda) que en los hogares ricos (2,3 personas por vivienda), en promedio cada integrante de una familia pobre dispone de $\$ 43$ por mes frente a un integrante de un hogar rico que puede gastar 33 veces más. Además, en el $30 \%$ de los hogares ingresan menos de $\$ 450$ por mes. Como el costo calculado por el INDEC de una canasta familiar tipo (4 personas) ronda los $\$ 480$, ya el $31 \%$ de la población porteña y del conurbano $-3,7$ millones- es pobre.

En síntesis, la distribución del ingreso en nuestro país en las últimas dos décadas muestra una tendencia relativamente constante hacia el aumento de la inequidad y la polarización.

El universo de los pobres se complejiza y se torna más heterogéneo con la incorporación de otras familias, algunas ex pobres estructurales que retornan a una indigencia que habían logrado abandonar y otras provenientes de los sectores medios, integrantes de los nuevos pobres, cuya conformación es muy disímil.

En función de ello, sin duda, las situaciones serán desiguales, según el tipo de inserción previa de la población de los hogares en cuestión y de sus características idiosincráticas. Pero en cualquier caso tendrán incidencia el nivel educativo, la trama de relaciones sociales, la acumulación previa y la capacidad de aprovechar alternativas y recursos existentes y sus pautas culturales (respecto de la educación, de la valorización de ciertas pautas de vida, etc), aspectos englobados en lo que Bourdieu (1990) denomina "capital cultural" y "capital social".

\footnotetext{
${ }^{13}$ La brecha de 2001 es un nuevo récord. Según informes del INDEC, la Argentina tiene la peor desigualdad de ingresos desde que se tiene registro: en el 2000 el $10 \%$ de la población más rica de la Capital y el Gran Bs. As. gana 24,8 veces más que el $10 \%$ más pobre (en los años '70 la brecha era de 12 veces). El $10 \%$ más pobre, más de medio millón de personas gana entre \$5 y $\$ 145$ por mes. El $20 \%$ más rico obtiene el $53 \%$ de los ingresos y el $20 \%$ más pobre sólo el $4 \%$. Significa que de cada 10 personas, dos ganan más que las 8 restantes juntas. Además, el $80 \%$ de la población porteña y del conurbano gana menos de $\$ 850$ por mes (Diario Clarín, 2001).
} 
Este panorama se potencia con la crisis del sector público, la disminución de los servicios sociales y la peor calidad de los mismos.

El nivel y la estructura del empleo constituyen, conjuntamente con el nivel y la estructura distributiva del ingreso, determinantes fundamentales de la condición de pobreza.

Los efectos de la crisis en el mercado de trabajo se han traducido no sólo en una pérdida de su dinamismo, incapacidad para generar nuevos puestos de trabajo y achicamiento, sino fundamentalmente en una profunda reestructuración.

Globalmente en nuestro país, la población económicamente activa (PEA) ${ }^{14}$ es del $41 \%$ del total de la población. Según las cifras oficiales de octubre de 1994, de cada cien habitantes, 41 estaba trabajando o buscando trabajo. De esos 41 , el $12.2 \%$ estaba desocupado (buscaba activamente trabajo) y el $10.4 \%$ subocupado $^{15}$ (trabajaba menos de 35 hs. semanales). Cabe destacar la creciente participación de la mujer en el mercado de trabajo: en 1991 en el 22\% de los hogares se registra a una mujer como jefa de hogar, hecho que indica cambios en el rol social y económico de la mujer que cada vez aporta más a la masa laboral del país. La participación de la mujer en el trabajo fuera del hogar se ha incrementado del $28 \%$ en 1980 al $39.7 \%$ en 1991 (INDEC, 1995).

Si bien para 1988 la tasa de desocupación ${ }^{16}$ de los jefes de hogares pobres (estructurales y pauperizados) era significativamente superior a las de los jefes de hogares no pobres, no puede perderse de vista que la proporción de hogares pobres con jefes desocupados no era muy elevada y tampoco lo era el porcentaje de desocupados en la población activa de hogares pobres, creció del del 2,6 \% en 1980 al $7,4 \%$ al final de la década y llega al $10 \%$ en 1993 . Si bien aumentó en todas las categorías de edad, los grupos más afectados fueron los jefes de hogar en edades centrales y el de los jóvenes.

Así, el aumento de la desocupación y subocupación se presenta dentro de un contexto en el que se verifica una caída del empleo asalariado industrial, incremento de la segmentación del mercado, aumento de la terciarización, precarización en las relaciones de trabajo, aumento de las actividades de escasa productividad y bajos

\footnotetext{
${ }^{14}$ La PEA comprende a las personas aptas físicamente para trabajar en una actividad económicamente productiva, de 14 años y más, que, en la semana anterior a la fecha del censo se hallaban ocupadas o desocupadas (buscando trabajo).

${ }^{15}$ El porcentaje de la PEA es en 1983 del $37.3 \%$ porcentaje que fue en paulatino ascenso: hecho indicativo no de que la gente salga a buscar trabajo alentada por la oferta disponible, sino de la insuficiencia de los ingresos para poder vivir. El aumento de no activos a activos se da básicamente en los estudiantes, que en el pasado podían completar su carrera antes de salir a trabajar y ahora necesitan un trabajo para poder estudiar y en las amas de casa que cada vez más necesitan completar los ingresos familiares.

${ }^{16} \mathrm{La}$ tasa de desocupación representa la proporción entre la población desocupada y la población económicamente activa. En la Encuesta Permanente de Hogares (INDEC) se considera desocupada la persona que durante la semana anterior al censo buscó activamente trabajo, no habiendo efectuado trabajo remunerado alguno en la misma.
} 
salarios: el empleo de escasa productividad y bajos ingresos concentra, a fines de la década pasada, el $34.3 \%$ de la ocupación total y el 32\% de la activa (Monza, 1992). Sumado a ello, la caída del salario real entre 1986-93 en los trabajadores no calificados es del $44 \%$, el doble de la caída registrada para los profesionales en el mismo período.

Desde el discurso oficial se sostiene que el desempleo y la precarización laboral son el producto de rigideces institucionales en el mercado de trabajo. Se propone su desregulación con el fin de reducir el costo laboral, disminuir el riesgo de contratación y moderar el poder de negociación de los sindicatos. Sin embargo, las políticas de este tipo que se han estado aplicando no han logrado recomponer los niveles de empleo y por el contrario, el mercado de trabajo acusa señales de mayor desestructuración (Giosa Zuazua,1999).

Otra de las particularidades del mercado de trabajo argentino es la disminución del nivel de ingresos medios percibidos por los trabajadores tanto cuentapropistas como asalariados del sector informal, sector que durante el 60 y 70 generaba ingresos superiores a muchos trabajos asalariados del sector formal.

En abril de 1991, el promedio del salario neto del trabajador industrial cubría $96 \%$ de la canasta de alimentos, es decir los gastos mínimos e indispensables para no caer en la indigencia. En septiembre de 1992, ese salario sólo cubría el 51\% de dicha canasta. Cabe destacar que el trabajo asalariado es, en nuestro país, el principal mecanismo de integración social (Beccaria y López, 1996), ya que mediante el mismo los sujetos garantizan su acceso a los bienes y servicios, consolidándose así una base que les proporciona un lugar en la sociedad. El achicamiento relativo del mercado de trabajo formal, el aumento de la tasa de desempleo, la peor calidad de los puestos de trabajo, los contratos por tiempo indefinido, la pérdida de derechos y garantías por parte de los trabajadores y su desafiliación a la seguridad social se conjugan para producir el debilitamiento de los lazos de integración social en nuestra sociedad y la consecuente vulnerabilidad que crecientemente enfrentan sus miembros.

La desocupación no sólo tiene directa incidencia en la pobreza, sino también en la organización familiar y en las relaciones sociales que se establecen (Eguía, 2001).

Frente a esta situación, es necesario preguntarse cómo se está reestructurando la sociedad y qué nuevas demandas sociales tienen los niños y las familias más desfavorecidas y en qué forma los distintos actores sociales, en particular el Estado, pueden responder a estas demandas.

Las políticas de ajuste económico y/o estabilidad han desencadenado una serie de procesos de profunda significación distributiva. Un modelo de economía abierta 
basada en una productividad creciente mediante una continua absorción tecnológica implica niveles explícitos de exclusión social.

La sociedad civil aparece fragmentada en una gran variedad de intereses y necesidades puntuales. El espacio social parece ser más heterogéneo: se habla de diversas franjas de pobreza. En ellas hay todo un espectro de situaciones que tienden a la desintegración social y que requieren un análisis específico.

En nada contribuye a la definición de las características de la pobreza ni a la formulación de políticas sociales afirmar que casi la mitad de la población es, genéricamente, pobre. Por el contrario, para el diseño de programas sociales resulta imprescindible definir las necesidades particulares de los distintos grupos a los que se pretende beneficiar.

En nuestro país, que estructuró la seguridad social en los marcos de un modelo centrado en la categoría de trabajador, el ataque que sufre la clase obrera con las políticas liberales tiene importantes consecuencias en el rubro de la política social. En este contexto de desagregación del sujeto colectivo -que definía la integración a la sociedad nacional (el trabajador protegido por la legislación)- en "individuos" librados a las fuerzas del mercado, las políticas sociales consolidaron su contenido asistencialista. Estas están más concebidas como un instrumento de control del orden que como producto de un derecho (Grassi et al., 1995).

Susana Torrado afirma que "las políticas sociales actuales, basadas en una definición de pobreza como carencia de capacidades ponen la responsabilidad -por ejemplo- de encontrar empleo exclusivamente en el desocupado y no en el mercado que no oferta empleo. Un pobre es alguien al que se le han negado ciertos derechos sociales. Esta definición crea una política no basada en el asistencialismo, sino, por ejemplo, en la renta mínima de subsistencia. Las políticas paliativas son actualmente imprescindibles, evidentemente se deben atender las emergencias. El problema es cuando no hay más que eso, porque nunca alcanzan. La mejor manera de evitar la pobreza es impedir que crezca, la mejor política es aquella que crea empleo y protege el nivel del salario." (Diario Clarín, 1997).

La cuestión de la dicotomía universalización-focalización refiere no tanto a una elección basada en elementos teóricos o de justicia social, sino de un paliativo determinado por las urgencias impostergables que necesitan de una atención especial. Con relación a la población infantil, la obligación de proteger los derechos humanos del niño es una razón fundamental y de peso para invertir en los programas de fortalecimiento del desarrollo en la primera infancia. La Declaración de los Derechos del Niño, adoptada por unanimidad en 1959 por la Asamblea General de las Naciones Unidas, reconoce entre sus diez principios: "El niño disfrutará de una protección 
especial y tendrá a su disposición oportunidades y servicios, brindados según la ley y por otros medios, que permitan el desarrollo físico, mental, moral, espiritual y social de forma sana y normal, con libertad y dignidad". En 1989 la Asamblea de las Naciones Unidas exhorta a que "se garanticen en la máxima medida posible la supervivencia y el desarrollo del niño" (Art. 6.2.) (...) "se prestará asistencia apropiada a los padres y a los tutores legales para el desempeño de sus funciones en lo que respecta a la crianza del niño y se velará por la creación de instituciones, instalaciones y servicios para el cuidado de los niños." (Art. 18.2.).

Además "los niños cuyos padres trabajan tienen el derecho a beneficiarse de los servicios e instalaciones que les correspondieren para su atención." (Art. 18.3).

La incapacidad y retraso del desarrollo de millones de niños cada año cuando se podría evitar es, entonces, la violación de un derecho humano básico. El hecho de que los niños dependan de los demás para ejercer sus derechos crea una obligación aún mayor, y en esto las familias necesitan apoyo. Sin embargo, la retórica de los derechos humanos en este caso específico necesita traducirse en acciones concretas cuyo fundamento se sostiene bajo diversas líneas de argumentación (Myers,1994) relativas a los derechos humanos, transmisión social de valores morales y sociales, valor económico, eficacia de los programas, justicia social, movilización social, argumentos científicos, etc.

\subsubsection{El contexto local: trabajo, educación y vivienda en el Gran La Plata}

En el aglomerado Gran La Plata ${ }^{17}$, la tendencia general en la composición de los hogares que refleja la Encuesta Permanente de Hogares (EPH), indica que en los últimos 10 años la mayor parte de los hogares (entre un 60 y 63,6\%) no está compuesto por menores de 14 años. A su vez entre el $13 \%$ y el $17 \%$ de los hogares está compuestos por sólo un menor de 14 años. Estos datos implican cierto envejecimiento de la pirámide poblacional del aglomerado (Eguía et al., 2001). Sin embargo, la desagregación de esos valores según indicadores de pobreza, muestra la elevada concentración de niños en hogares pobres, representando, los menores de 14 años, la mitad de la población NBI.

Con respecto a la situación ocupacional, en el período intercensal 1974/85, el proceso de desindustrialización ha sido particularmente importante en el Gran La Plata, disminuyendo en un $21.5 \%$ sus establecimientos y en un $28.5 \%$ el personal ocupado. En 11 años la industria perdió tres de cada diez empleos (el doble de los registrado a

\footnotetext{
${ }^{17}$ Eguía et al. (2001) realizan un análisis estadístico de las bases usuarios (EPH/INDEC) de las ondas de mayo correspondientes al período 1990-2000 del aglomerado Gran La Plata (integrado por los partidos de La Plata, Berisso y Ensenada). Toda la información de la EPH referida al Gran La Plata se toma de dicho estudio.
} 
nivel provincial). Entre 1985 y 1994 se agudiza el achicamiento del sector industrial, signado por la hiperinflación, privatización, racionalización, el aluvión de importaciones, falta de capacitación laboral y empresaria para responder a las exigencias de la competencia, en concomitancia con una creciente automatización de los procesos productivos.

Se produce así un trasvasamiento de puestos de trabajo al sector comercial, sobre todo en el cuentapropismo tentativo llevado a cabo por aquellos sujetos a retiros voluntarios, jubilaciones o despidos.

La población económicamente no activa $(P E n o A){ }^{18}$ del Gran La Plata es del $61 \%$ y en ella se destaca en relación al promedio provincial, la importancia del sector de jubilados con el $10 \%$ y estudiantes con el $7.3 \%$ (Municipalidad de La Plata, 1995).

Según datos del INDEC de Octubre de 1994, la desocupación en el Gran La Plata era del $12 \%$ y la subocupación del $7 \%$.

El problema laboral no reside sólo en la desocupación, sino en la calidad y estabilidad de la ocupación, constituyendo la subocupación (personas que trabajan menos de 35 hs. semanales y desean trabajar más) el primer elemento a ponderar. Otro aspecto a considerar lo constituye la ocupación precaria, cuya magnitud se diluye al computarla incorporándola a los distintos sectores: está integrada por aquellas actividades cuentapropistas del comercio informal, de los diversos oficios urbanos y de la construcción, servicios personales, y trabajos rurales sin cobertura social y de salud y sin previsiones para la vejez.

La PEA del partido de Ensenada era del $35.4 \%$, inferior a la del partido de La Plata. En ella, el porcentaje de desocupados/subocupados era del $19 \%$, registrándose un $55 \%$ de trabajos dentro del sector industrial, $16 \%$ dentro del sector servicios y un $10 \%$ en comercio (INDEC, 1994).

La conformación productiva del partido de La Plata es eminentemente terciaria, con pocas industrias grandes y medianas.

Ensenada por su parte, es un partido altamente industrial, caracterizado por la presencia de pocas empresas pero de envergadura y de carácter económico estratégico. Esta actividad ocupa un plano sobresaliente en su economía, aunque hoy esté en crisis y con un achicamiento sustancial en la generación de puestos de trabajo. La tendencia histórica del sector industrial para el Gran La Plata continuó siendo, entre 1985-1994 de achicamiento tanto en el personal como en establecimientos. El empleo productivo del Gran La Plata constituye la mitad que el promedio provincial,

\footnotetext{
${ }^{18}$ La población económicamente no activa (PEnoA) o inactiva está compuesta por las personas de 14 años o más ociosas, que no compiten en el mercado de trabajo con la PEA, es decir que en la semana anterior al censo, no aspiran a ejercer una ocupación (incluye en general a jubilados y pensionados, rentistas, estudiantes, amas de casa)
} 
teniendo una actividad comercial que duplica el promedio provincial por el incremento de empleos transferidos de la industria a ese sector por el achicamiento productivo de la región en esa década (Municipalidad de La Plata,1995).

El proceso dado en el partido de La Plata entre 1985/94 continúa luego esa tendencia y la incrementa, no sólo por el persistente achicamiento industrial sino también por el achicamiento del sector público y la privatización de las empresas del Estado con una fuerte expulsión del empleo, claramente reubicada en el sector comercial y de servicios privados.

El sector comercial y de servicios privados formales ocupa el 33\% de la población económicamente activa; en esa cifra no se incluyen ni los puestos generados por los servicios informales (plomeros, gasistas, albañiles), ni por los servicios profesionales que en su mayoría no se habilitan ni se registran, ni por los servicios públicos.

Estos últimos ocupan al 33\% de la PEA; el de otros servicios (como profesionales no contabilizados en el empleo público, albañiles y otros oficios) aporta el $9 \%$ sumando el $75 \%$ de la fuerza laboral. Esta se completa con un $7 \%$ de los sectores productivos $(6 \%$ industria y $1.2 \%$ agro) y un $18 \%$ de desocupados/subocupados (Municipalidad de La Plata, 1995).

En el análisis de las ondas de la EPH durante el período 1990-2000 (Eguía et al., 2001) puede verse que las políticas económicas implementadas a lo largo de la década 1990-2000 transformaron profundamente el mercado laboral del aglomerado Gran La Plata. En la evolución de su composición y de las condiciones de trabajo se ha observado, en cuanto al primero, un incremento de la población económicamente activa, vinculado especialmente con el aumento de la población desocupada y en cuanto al segundo, una tendencia a la precarización del empleo.

En líneas generales, la tasa de actividad ${ }^{19}$ en el Aglomerado osciló entre 37\% y 44\% en el período analizado, registrándose los mayores porcentajes a partir de 1996. La tasa de empleo ${ }^{20}$ se mantuvo entre el $34 \%$ y $38 \%$, con los valores más altos en los últimos tres años. La tasa de desocupación, en cambio, presentó un crecimiento sostenido.

De los datos presentados en dicho estudio se desprende que el gran aumento de la PEA está dado principalmente por las variaciones en los porcentajes de inactivos. En efecto, la población inactiva total disminuyó $2,7 \%$ en el período. Ella está compuesta básicamente por estudiantes, amas de casa y jubilados.

\footnotetext{
${ }^{19}$ De acuerdo con la Encuesta Permanente de Hogares, la tasa de actividad está calculada como porcentaje entre la población económicamente activa y la población total, entendiendo por población económicamente activa la integrada por personas que tienen una ocupación o la están buscando activamente.

${ }^{20}$ La tasa de empleo está calculada como porcentaje entre la población ocupada y la población total.
} 
La disminución del total de inactivos debe entonces adjudicarse a una o todas las causas siguientes:

- una mayor incorporación de jóvenes, y a edades más tempranas (parte de los que en otros períodos hubieran permanecido en el sistema educativo),

- una masiva incorporación de amas de casa,

- una permanencia de los ocupados que deberían pasar a la inactividad.

El total de personas ocupadas también creció considerablemente (de 208.750 a 269.575 personas) durante el período (29\%), y lo hizo a un ritmo mayor que la población total. Sin embargo, el total de personas desocupadas aumentó aún mucho más aceleradamente. La variación en la cantidad de personas asignadas a esta categoría fue en efecto notable; aumentó $229,5 \%$ (de 13.860 a 47.061) tomando al año 1990 como base.

Como ya se ha señalado, surge claramente que el aumento de la población económicamente activa en el aglomerado Gran La Plata está vinculado con el aumento de la población que busca trabajo sin encontrarlo. Comparando la evolución de la población ocupada y desocupada, puede afirmarse que la mayoría de los que dejaron la inactividad no lograron insertarse en el mercado de trabajo.

Los datos permiten afirmar que durante el período, con la excepción de los años 1994, 1996 y 1999, en los que hubo una destrucción neta de empleos, se registró en el aglomerado una significativa creación de puestos de trabajo, pero éstos aumentaron mucho menos que la demanda de empleo y el ingreso de nuevas personas al mercado laboral, que superó al que se daría naturalmente por la incorporación de jóvenes que terminan o dejan sus estudios. Quienes contribuyeron a este mayor aumento presionando masivamente sobre el mercado de trabajo fueron las amas de casa y los jubilados (Eguía et al., 2001).

La incorporación de estos grupos -amas de casa, jubilados, estudiantes- al mercado de trabajo respondió al modelo económico vigente, que a escala familiar se tradujo en un aumento de los hogares con pérdida del puesto de trabajo o reducción del salario del tradicional sostén. De la evidencia empírica se puede concluir que una parte importante de las amas de casa, estudiantes y jubilados que se incorporaron al mercado de trabajo encontraron empleo, pasando del $9.8 \%$ en 1999 al $34.4 \%$ en el 2000, aunque con un alto grado de precariedad. Esta situación se relaciona principalmente con la necesidad de cubrir el presupuesto familiar.

Murmis y Feldman (1993) afirman que "las reestructuraciones que se dan en capitalismos ricos corresponden a la presencia de un sector moderno poderoso pero con menor capacidad de generar ocupación y que irradia ocupaciones menos calificadas en el resto de la economía, dando lugar a una sociedad que se dualiza". Si 
bien en Argentina no podemos hablar de "sector moderno poderoso", en la década de los 90 se ha dado un proceso similar en cuanto a una demanda de mano de obra muy calificada pero limitada, y la creación de ocupaciones que no requieren una alta calificación o experiencia laboral.

La categoría ocupacional preponderante de los trabajadores del aglomerado es la de obrero o empleado, creciendo levemente en importancia a lo largo de los años (72 en 1990 a 73 en 2000). En segundo lugar, los valores de la categoría "trabajador por su cuenta" disminuyeron en el período estudiado de un $23,1 \%$ en 1990 a un $21,4 \%$ en el año 2000. En tercer y último lugar, la categoría ocupacional "patrón o empleador" ha crecido en 1,9 puntos, ya que sus valores alcanzaban en 1990 un 1,9 \% y en el año 2000 un $3,8 \%$.

Se observa en el período la disminución relativa de los grandes establecimientos como proveedores de fuentes de trabajo. El porcentaje de ocupados en establecimientos de más de 100 personas, sobre el total de los ocupados, cayó en el período de $31,7 \%$ a $13,5 \%$. Cabe consignar que no se trató simplemente de una disminución relativa sino que se produjo una destrucción neta de empleos: en 1990 los grandes establecimientos del aglomerado empleaban a 61.916 personas y en el año 2000 su planta se había visto reducida a 36.514 personas.

Entre los asalariados, por las características del aglomerado como capital provincial, las ramas administración pública y defensa concentraban los mayores porcentajes, registrándose un leve descenso en su presencia relativa entre 1990 y 2000. Como señala Rofman (1997) la reducción por parte del Estado de sus plantas administrativas no revistió a nivel provincial y municipal la misma intensidad que a nivel nacional; en dichos ámbitos las estructuras burocráticas siguen cumpliendo el rol de reserva ocupacional frente a la carencia de fuentes alternativas de trabajo.

Entre los cuentapropistas, en cambio, las ramas comercio, construcción y servicios personales agrupaban a la mayor parte de los trabajadores.

La estructura ocupacional en conjunto, entonces, se modificó fundamentalmente en dos aspectos: achicamiento del personal ocupado en la actividad industrial y crecimiento de la ocupación en las actividades de servicios y comercio. En el caso del comercio se registró una alta rotación de los negocios de pequeño tamaño y la presencia de hipermercados, con impacto limitado en la creación de puestos de trabajo (Suárez y colaboradores, 1997).

Aumentaron los porcentajes de población ocupada en las ramas servicios, construcción y comercio del año 1990 al 2000. En este sentido, cabe recordar que las indemnizaciones de los despidos en la administración pública fueron invertidas, en su mayoría, en el comercio y los servicios. En lo que respecta a la construcción, si bien la 
misma creció en el país a nivel general, también se relaciona en el caso de La Plata con el notable incremento de la obra pública asociada con la inversión de los fondos del Programa de Reparación Histórica del Conurbano Bonaerense ${ }^{21}$. Por otro lado, la significativa disminución de la ocupación en la industria muestra que esta rama de actividad se vio especialmente afectada por los cambios en la política económica: achicamiento del Estado, despidos, privatizaciones, leyes de flexibilización laboral, falta de incentivos a la industria, aumento de las importaciones, etc.

En cuanto a las categorías ocupacionales, de acuerdo con los datos relevados por la $E P H$, no se produjeron cambios significativos. Sin embargo, teniendo en cuenta la evolución de las ramas de actividad, puede afirmarse que la categoría predominante de obreros o empleados dejó de estar conformada por asalariados de la industria manufacturera $^{22}$. Si bien no se registraron cambios destacables en las categorías ocupacionales, se dio un proceso de precarización del trabajo que puede deducirse de varios indicadores: se observa un crecimiento del porcentaje de ocupados sin protección social. La población ocupada sin beneficios sociales se triplicó durante la década considerada pasando del $10 \%$ al $32 \%$, y también aumentó del $8 \%$ al $12 \%$ aquella que percibía tan sólo beneficios parciales.

Otro indicador del deterioro de los puestos de trabajo está dado por la evolución del porcentaje del ingreso del que se apropia la población ocupada a lo largo del período. La población ocupada correspondiente a los menores deciles de la distribución disminuyó su participación en el ingreso total, factor que planteó la necesidad tanto de incrementar la participación familiar en el mercado de trabajo, como de buscar ocupaciones complementarias: el porcentaje de trabajadores que desempeñaban más de una ocupación pasó de $7.5 \%$ en 1990 a $11.4 \%$ en 2000 y en este último año, el $11 \%$ de la población ocupada buscaba otra ocupación, en su mayoría para tener un trabajo complementario.

Tal como se expresa en los datos relevados por el análisis de las ondas de la EPH, en los últimos años del período considerado, el proceso de concentración de la riqueza da la pauta del deterioro de los ingresos (y consecuentemente las condiciones de vida) de los sectores pobres y medios. Este deterioro implicó la necesidad de reforzar los ingresos familiares a través de la inserción de miembros tradicionalmente inactivos del hogar al mercado de trabajo.

\footnotetext{
${ }^{21}$ A pesar de no formar parte del Conurbano Bonaerense (y no estar incluido en este aglomerado en las consideraciones del INDEC), el partido de La Plata fue receptor de los fondos mencionados.

22 "Sería importante que la encuesta también relevara si se trata de obreros o empleados para poder brindar un panorama más acabado de los cambios operados en el mercado de trabajo." (Eguía et al., 2001).
} 
En cuanto a la situación educacional, las cifras presentadas por el Ministerio de Educación de la Nación a la $43^{\circ}$ Conferencia Internacional de la UNESCO muestran que de cada 100 chicos que comienzan el nivel primario, sólo 60 comienzan el secundario, 18 la universidad y la finalizan 2 (Municipalidad de La Plata, 1995).

Análisis realizados y publicados relativos a la estructura social argentina muestran las cifras de desgranamiento educativo (deserción): 94 de cada 100 personas que acceden al nivel primario, 63 lo completan, 28 acceden al nivel secundario, 17 lo terminan, 6 acceden a los estudios superiores y casi 2 lo finalizan.

Los datos para la Pcia. de Bs. As. arrojan un 22\% de deserción primaria, un $50 \%$ de deserción secundaria y el Ministerio de Educación de la Nación admite que los niveles de deserción de la universidad rondan el $80 \%$.

Al desagregar estos datos según la condición socio-ocupacional de las familias, aparecen diferencias abismales en la posibilidad de acceder y permanecer en los distintos niveles educativos.

En el grupo de los profesionales, de cada 100 personas, ingresan 99 en el primario y lo terminan 98 , acceden 90 al secundario y lo terminan 85 e ingresan 65 en el nivel superior y lo terminan cerca de 50 .

Si se analiza el grupo de los obreros no calificados (el $75 \%$ de la población que ya no estudia no tiene título secundario) de cada 100 personas inician el primario 87, lo terminan 36 , inician el secundario 8 y lo terminan 3 y sólo el 0.4 ingresa a la universidad.

Estas cifras muestran las distorsiones existentes en sociedades como la nuestra, donde la igualdad de oportunidades se decide tempranamente en la historia educativa de una persona.

En la Provincia de Buenos Aires, de la oferta laboral de aquellos que ya no estudian, sólo el $22 \%$ tiene título secundario y $3 \%$ título universitario.

Además, datos del Ministerio de Educación de la Pcia. de Bs. As. (Dirección General de Escuelas y Cultura, 1992-93) muestran que la deserción promedio en el nivel secundario es del $70 \%$ en los colegios técnicos y del $50 \%$ en el resto. Información difundida por el Instituto Provincial del Empleo de la Pcia. de Bs. As., pone de relieve que sobre 6.400 inscriptos (desocupados), sólo el $43 \%$ cuenta con instrucción primaria completa, el $13 \%$ con instrucción secundaria completa y menos del $1 \%$ con instrucción terciaria. Además, en el sector de los jóvenes, la tasa de desocupación triplica la tasa promedio (Municipalidad de La Plata, 1995).

Si consideramos las exigencias que demanda actualmente el empleo, en los cuales el manejo de la computadora y el conocimiento de idioma pasó de ser un complemento a ser un requisito estructural, puede preverse las pocas posibilidades de inserción 
laboral no sólo para los actuales desocupados o subocupados sino también para las generaciones venideras en caso de acentuarse esta tendencia.

No obstante hay que tener en cuenta que el INDEC (1994) destaca que en Capital Federal y Gran Buenos Aires hay 180.000 desocupados con secundaria completa y 42.000 universitarios sin trabajo, hecho que relativiza el papel de la educación como garante de la inserción laboral y como pivote de la movilidad social. El desajuste entre educación y mercado de trabajo ya existe y se agudiza, no afectando sólo a los menos capacitados.

Al respecto, Tedesco (1995) plantea que la educación sigue siendo un factor de movilidad social, aunque no de la misma manera que en el pasado. La diferencia estriba en que si bien la educación tiende a democratizarse y a universalizarse, el mercado de trabajo tiende a achicarse y reducirse, coexistiendo una estructura educativa en forma de meseta con una estructura ocupacional piramidal.

En el aglomerado Gran La Plata, el comportamiento de las ondas de la EPH correspondientes al período 1990-2000 reflejan un paulatino aumento de la tasa de alfabetización visible no sólo en la proporción de población que sabe leer y escribir, sino también en el aumento de la población que asiste a las instituciones de educación formal y en los máximos niveles alcanzados (Tabla 1).

\section{Tabla 1. Nivel educativo alcanzado}

\begin{tabular}{|c|c|c|c|c|c|c|c|c|c|c|} 
máximo nivel alcanzado & 1990 & 1992 & 1993 & 1994 & 1995 & 1996 & 1997 & 1998 & 1999 & 2000 \\
\hline preescolar & 4,5 & 4,1 & 4,0 & 3,4 & 4,2 & 3,8 & 4,2 & 9,4 & 9,5 & 10,1 \\
primario completo & 24,2 & 22,3 & 20,5 & 21,0 & 20,2 & 19,9 & 19,5 & 16,5 & 16,7 & 15,1 \\
primario incompleto & 25,0 & 22,0 & 21,0 & 19,6 & 20,3 & 21,1 & 19,9 & 18,8 & 19,7 & 18,9 \\
sec.completo & 8,4 & 10,0 & 10,0 & 11,6 & 9,9 & 10,1 & 11,1 & 8,6 & 8,9 & 9,3 \\
sec. incompleto & 17,6 & 19,4 & 19,3 & 19,9 & 20,4 & 21,4 & 19,9 & 20,5 & 20,2 & 18,9 \\
sup. o univer. comp. & 8,2 & 8,4 & 10,2 & 9,9 & 9,7 & 8,9 & 9,8 & 9,5 & 8,5 & 10,5 \\
sup. o univer.comp. & 11,7 & 13,0 & 14,3 & 14,2 & 14,8 & 14,4 & 14,9 & 16,4 & 16,3 & 16,7 \\
desconocido & 0,5 & 0,9 & 0,7 & 0,5 & 0,5 & 0,4 & 0,7 & 0,4 & 0,1 & 0,4 \\
Total & 534237 & 606136 & 632414 & 614217 & 649215 & 629478 & 642384 & 694523 & 702608 & 711470 \\
\hline
\end{tabular}

Fuente: Elaboración propia con base en los datos de la Encuesta Permanente de Hogares, INDEC, mayo 1990-2000. (Eguía et al., 2001)

De las personas que no asisten pero asistieron, el $13.5 \%$ tiene primaria incompleta, $35 \%$ primaria completa, $15.5 \%$ secundaria incompleta, $15.6 \%$ secundaria completa, $4.5 \%$ terciario completo, $5 \%$ universitario incompleto y $10 \%$ universitario completo (Municipalidad de La Plata, 1995).

Es decir, de la oferta laboral de aquellos que ya no estudian en La Plata, el $35 \%$ cuenta por lo menos con un título secundario.

Ensenada presenta un $18.4 \%$ de jefes de hogar con primaria incompleta frente a un $14 \%$ de jefes de hogar del partido de La Plata dentro del mismo nivel educativo. Las 
mujeres jefas de hogar sin asistencia escolar verifican -en términos comparativos- un mayor porcentaje en Ensenada que en La Plata.

Este perfil señala las ventajas competitivas potenciales del partido dada su oferta de capacitación, con niveles muy superiores a los promedios nacionales y provinciales.

En cuanto a las condiciones de vivienda, la Pcia. de Bs. As. tiene un $13 \%$ de sus hogares y un $17 \%$ de población con NBI, con marcados contrastes entre su interior, donde se concentra un tercio de la población con un 12.8\% de la población en hogares con NBI, y el conurbano. Este concentra dos tercios de población provincial, presentando altos niveles de pobreza: el $19.5 \%$ de la población pertenece a hogares NBI (INDEC, 1991).

El Mapa de la Pobreza (INDEC, 1994a) determina para el partido de La Plata un $12,8 \%$ de población NBI.

Para el año 1990, en el partido de La Plata se registran 181.000 viviendas para 542.000 habitantes (Municipalidad de La Plata, 1995).

Del total de viviendas ocupadas, 99.000 son casas tipo "A" es decir con cañería embutida, retrete con descarga de agua y piso que no es de tierra y 37.000 son departamentos con características semejantes: juntos reúnen el $83 \%$ de las viviendas ocupadas y alojan al $79 \%$ de la población. El 17\% restante, donde vive el $21 \%$ de la población, son casas de tipo "B" -carentes de las condiciones presentes en las tipo "A"-, ranchos, casillas o inquilinatos.

Esta comparación no contempla la obsolescencia de las casas tipo "A", ni las familias que no tienen casa: 5.182 viviendas están ocupadas por más de un hogar y en ellas viven 34.000 personas con una densidad promedio de 6.6 habitantes por vivienda, cuando el promedio general del partido es de 3.4 habitantes/vivienda.

Se estima que cerca de 32.000 viviendas presentan deficiencias habitacionales, las que alojan a cerca de 110.000 personas, el $34 \%$ de la población en viviendas particulares.

Un $33 \%$ de los hogares de La Plata no son propietarios de la vivienda, correspondiendo el $18 \%$ a ocupantes por cesión, préstamo, intrusión u otras causas.

Sólo el $55 \%$ de la población cuenta con el servicio completo de agua potable y cloacas. El $16 \%$ sólo tiene agua corriente, el $2 \%$ sólo tiene cloacas y un $28 \%$ carece de ambos servicios. Entre el 12 y el $14 \%$ de la población carece de agua dentro de la vivienda y un $6 \%$ no tiene inodoro o retrete con descarga de agua.

Para establecer un piso crítico del déficit habitacional los hogares con NBI suman el $10.8 \%$ con el $13 \%$ de la población (cifras inferiores al promedio provincial): se trata de unos 14.700 hogares integrados por 70.000 personas. En 1984, los hogares NBI constituían el $12.5 \%$ y la población el $15.8 \%$. 
La desagregación de los indicadores de NBI muestra tanto para el partido de La Plata como para el de Ensenada, una mejoría durante el período 1980-1990 en la casi totalidad de los mismos, excepto el porcentaje de población que vive en viviendas deficitarias que asciende 1.5 puntos porcentuales en el partido de La Plata. No obstante, comparativamente, La Plata presenta mejores condiciones de la vivienda que Ensenada tanto en lo que respecta a su calidad como al hacinamiento. Ensenada por su parte, registra mejores índices que La Plata respecto al porcentaje de viviendas con acceso a red pública de agua.

Las tendencias registradas por la EPH, comparando el año 1990 con el 2000, muestran valores constantes con respecto al porcentaje de viviendas con servicio de agua corriente, y las oscilaciones sufridas entre estos años son poco importantes, no superando un 2\% (Tabla 2) (Eguía et al., 2001).

Tabla 2. Servicio de agua corriente

\begin{tabular}{|c|c|c|c|c|c|c|c|c|c|c|}
\cline { 2 - 10 } servicio agua corriente & 1990 & 1992 & 1993 & 1994 & 1995 & 1996 & 1997 & 1998 & 1999 & 2000 \\
\hline sí & 97,2 & 97,9 & 99,0 & 98,1 & 98,6 & 97,8 & 97,6 & 98,1 & 95,3 & 97,4 \\
no & 2,8 & 2,1 & 1,0 & 1,9 & 1,4 & 2,1 & 2,2 & 1,9 & 4,7 & 2,6 \\
Valor de $\mathrm{n}$ & 183656 & 202771 & 211126 & 207419 & 215817 & 210116 & 215770 & 217756 & 210890 & 215240 \\
\hline
\end{tabular}

Fuente: Elaboración propia con base en los datos de la Encuesta Permanente de Hogares, INDEC, mayo 1990-2000. (Eguía et al., 2001)

Con respecto al servicio sanitario, las viviendas sin instalación de baño descendieron del $5.1 \%$ al $4.4 \%$.

La instalación de baño de uso exclusivo también descendió del $94.9 \%$ al $93.6 \%$ y aumentaron aquellas con baño de uso compartido.

En relación a los materiales con que están hechas las viviendas se puede decir que la mayoría de las casas son de mampostería (un promedio a lo largo de los años de un $93 \%$ ), entre un 3 y $5 \%$ de las viviendas son de madera, y entre un 1 y $2,6 \%$ de las casas son de chapa o fibrocemento (Tabla 3) (Eguía et al., 2001).

Tabla 3. Materiales predominantes de la vivienda

\begin{tabular}{|c|c|c|c|c|c|c|c|c|c|c|}
\cline { 2 - 9 } \multicolumn{1}{c|}{ materiales } & 1990 & 1992 & 1993 & 1994 & 1995 & 1996 & 1997 & 1998 & 1999 & 2000 \\
\hline mampostería & 93,2 & 93,6 & 94,0 & 92,0 & 92,9 & 92,8 & 92,8 & 93,6 & 93,5 & 92,9 \\
madera & 3,8 & 4,8 & 4,9 & 5,5 & 5,0 & 4,9 & 5,5 & 4,6 & 5,4 & 5,5 \\
metal o fibr. & 2,6 & 1,6 & 1,1 & 2,3 & 1,9 & 2,0 & 0,8 & 1,8 & 0,6 & 1,4 \\
otros & 0,1 & 0,0 & 0,0 & 0,2 & 0,2 & 0,3 & 0,2 & 0,0 & 0,1 & 0,1 \\
desconocido & 0,3 & 0,0 & 0,0 & 0,0 & 0,0 & 0,1 & 0,7 & 0,0 & 0,3 & 0,0 \\
Total & 183656 & 202771 & 211126 & 207419 & 215817 & 210116 & 215770 & 217756 & 210890 & 215240 \\
\hline
\end{tabular}

Fuente: Elaboración propia con base en los datos de la Encuesta Permanente de Hogares, INDEC, mayo 1990-2000. (Eguía et al., 2001)

Por último, dada la similitud de la población y la contemporaneidad respecto del presente estudio, se recuperan datos obtenidos en un censo en barrios de extrema 
pobreza realizado en el partido de La Plata por el Instituto de Investigaciones Sociohistóricas (Flier et al., 1995). Sobre un total de 2900 hogares NBI, el 83\% de ellos tiene jefatura masculina y un 17\% jefatura femenina. Del total de 13.200 personas censadas el $47 \%$ tiene menos de 15 años correspondiendo un $19 \%$ a menores de 4 años.

En el $35 \%$ de los hogares habitan más de 3 personas por cuarto, el $91 \%$ de las viviendas son de construcción precaria. Las tres cuartas partes tiene piso de cemento o ladrillo y un $20 \%$ piso de tierra. El $65 \%$ son propietarios de la vivienda, un $24 \%$ propietarios de la vivienda y el terreno y la mitad de las viviendas tiene sólo una pieza, $38 \%$ dos piezas y un $10 \%$ tres piezas. Las tres cuartas partes tiene cocina como cuarto de uso exclusivo. Si bien un $79 \%$ presenta conexión de agua por red, el $65 \%$ la tiene ubicada fuera de la vivienda, además el $48 \%$ presenta retrete sin descarga de agua.

El $6 \%$ promedio de responsables adultos analfabetos asciende al $10 \%$ en el caso de las jefas de hogar. Un $34 \%$ de jefes tienen primaria incompleta; escolaridad primaria completa presentan el $44 \%$ de los varones y el $34 \%$ de las mujeres. Además, se presenta un $3 \%$ de niños de 6 a 12 sin escolaridad.

Este estudio muestra la distancia entre los valores que asumen los indicadores considerados en un contexto de pobreza con los valores promedio del aglomerado..

\subsection{La mirada atenta de la oferta y los estudios de mercado}

Los procesos descriptos anteriormente han repercutido en el consumo de distintos bienes y servicios tanto públicos como privados, afectando de manera e intensidad desigual a los distintos sectores sociales. La transnacionalización introdujo estrategias comerciales adecuadas a las nuevas situaciones distributivas. La industria alimentaria procura posicionarse en productos con alto valor agregado y fuertemente diferenciados; la segmentación de la oferta responde a la segmentación del consumo inducida por la caída de los ingresos (Green, 1990, cit. por Aguirre, 1995). Los ingresos medios declinan y los precios relativos de los alimentos aumentan. La consecuencia es una crisis de acceso por la que atraviesa un espectro social cada vez más amplio. Es posible observar cómo los estudios de mercado intentan adecuarse a las condiciones de pauperización creciente que afecta a capas cada vez más amplias de población.

Según una investigación de la Cámara Argentina de Supermercados, el $46 \%$ de los argentinos compra sus alimentos en los supermercados, institución nacida en la década de 1960. Hacia fines de 1990 existen 33 cadenas y se espera que ofrezcan precios más baratos. Según un estudio de la consultora Nielsen "en 1989/90 se tendía 
al almacenamiento, hacia 1999/00 se tiende a la planificación racionalizada". Por eso disminuyó la frecuencia de la compra registrándose mayoritariamente cada quince días y no una vez por semana; lo que falta se busca en el almacén del barrio. Otra estrategia es renunciar a las marcas conocidas, casi una herida en la identidad de la clase media. La investigación de CCR dice que entre 1998 y 1999 el consumidor medio "marquista" pasó del 55 al 40 \%, aumentaron los racionales -compran marcas no muy conocidas si son de calidad aceptable y buen precio- de un 35 a un $45 \%$ y los economicistas -compran sólo productos baratos- de un 10 a un 15 \% (Diario Clarín, 2000).

La recesión cambió los hábitos de compra de los argentinos y las empresas han debido lanzar nuevas estrategias para conquistar o retener a la clase media y captar consumidores en los barrios de menores ingresos. Tanto medido por precio como por cantidad, el consumo viene cayendo en la Argentina a tasas crecientemente empinadas. Así, los directores de marketing de uno de los hipermercados que domina el $33 \%$ del mercado local de super e hipermercados hablan de "un consumidor mercenario", hiperracional e infiel hasta el extremo, tanto con las marcas como con las cadenas de supermercados. Las categorías tradicionales del marketing se siguen usando por conveniencia, pero en la práctica no existen más. La capa de consumidores más codiciada por las empresas, aquella que derrama sus pautas de consumo sobre el resto de la sociedad ("leading edge") ha cambiado radicalmente. La movilidad social descendente hace que esa capa ya no sea referencia. La nueva clase media o nuevos pobres, segmento que ya representa un $20 \%$ del universo de los consumidores, teme descender y mira a los que ya bajaron, hoy el deseo está en el autocontrol y la inteligencia: la mayoría de las empresas se quedaron sin brújula. El nuevo "leading edge" pone énfasis en la austeridad y el control del gasto; es una clase venida a menos para la que pesa más el temor que la aspiración (Campanario, 2001). Estudios realizados en el contexto local indican que el $32 \%$ de la población de La Plata realiza las compras de todos o la mayoría de los alimentos en supermercados, el $32 \%$ en hipermercados, el $26 \%$ en comercios del barrio y el $11 \%$ en autoservicios (CEB, 1996). La mayor proporción de personas que compran en negocios del barrio y autoservicios reside en la periferia de la ciudad y son predominantemente de bajo nivel de instrucción e ingresos. Sus compras son de reducido importe y muy frecuentes. Los motivos que impulsan a la elección de los lugares de compras son: el precio, la cercanía, la variedad de productos -principalmente en personas de alto nivel de instrucción y ocupados-, el ahorro del tiempo y la calidad de los productos.

Si en el caso de los super e hipermercados, el precio es la razón más importante de asistencia, para el comercio del barrio la razón principal es la cercanía, seguida del 
precio y el ahorro del tiempo. Además para los sectores de menores ingresos, el "fiado" adquiere una relevancia significativa (CEB: Diario El Día, 1996).

\subsection{Globalización, pauperización y cambio de hábitos}

Los cambios en la dieta de los argentinos ocurrida durante los últimos 10 años obedecen al impacto de la globalización y la crisis económica. En muchos casos, la comida es un termómetro de la frustración y la tensión social. Los últimos diez años muestran variaciones en los menúes y los modos de consumir: hay mayor diversidad, más canales de ventas, nuevos criterios de compra y elección, si bien "sólo las clases altas pueden hacer un consumo reflexivo. Aunque la elección de un estilo de vida es una aspiración de todos, cuando ese estilo tiene que ver con el consumo, sólo muy pocos pueden acceder." (Maristella Svampa: Diario Clarín, 2000). La dieta de los 90 es una "suerte de bricolage de los tiempos globalizados que se basa tanto en la masiva incorporación de productos dietéticos y light como en el rescate de la comida étnica." (Alvarez y Pinotti: Diario Clarín, 2000). A esto se suma la explosión de los "fast food", de la cocina manufacturada de dudosa calidad pero de gran aceptación masiva.

La ampliación de la brecha entre ricos y pobres hizo que la clase baja y media empobrecida restringiera no sólo cuanto come sino la calidad de lo que come. "Lo que predomina es la fragmentación y la disgregación. Hoy es muy difícil hablar de la clase media, no hay homogeneidad, como lo había hace 20 o 30 años." (Marcos Novaro: Diario Clarín, 2000).

Durante la década del 90 , la problemática alimentaria en nuestro país compromete la salud de vastos sectores; la misma aparece reflejada en: la mayor participación de los alimentos en el gasto total de los hogares (Teubal, 1989; Aguirre, 1993); la disminución de la demanda efectiva de alimentos en la progresiva segmentación del consumo; el aumento de la desnutrición crónica en sectores de situación de extrema pobreza; la concurrencia creciente de la hipoalimentación en los índices de morbimortalidad (Unicef, 1992).

La crisis de acceso se relaciona con la declinación de los ingresos y con el aumento de los precios relativos de los alimentos. Esta relación se puede expresar operativamente con el índice de capacidad de compra de alimentos: la relación de los precios de los alimentos de una canasta básica nutricionalmente adecuada y el salario medio (Cesni, 1992).

Considerando la producción de alimentos y la disponibilidad calórica media, puede decirse que ésta es excesiva: de 2855 a 3027 kcal/hab./día. Este es un promedio estadístico. Los más pobres disponen de $2305 \mathrm{kcal} / \mathrm{hab} /$ día y el último nivel de ingreso tiene excedentes energéticos 3776 kcal (Indec, 1992). 
Es que la población accede a los alimentos, básicamente, a través de sus ingresos y de los precios de los productos. El tema de los ingresos ya ha sido desarrollado. Respecto de los precios, siguiendo la serie de los precios relativos de los alimentos y bebidas que componen la canasta básica de alimentos relevada por el INDEC desde 1960, éstos caen desde 1960 hasta 1976 y aumentan sostenidamente desde entonces (Teubal y Pastore, 1991; cit. por Aguirre, 1995). Desde el inicio del Plan de Convertibilidad la tendencia se ha acentuado: mientras que la inflación acumulada en marzo de 1993 fue del $44 \%$, los alimentos aumentaron en el mismo período 57,6 \% (Aguirre, 1995; Aguirre y Lesser, 1993).

El consumo de alimentos, como cualquier otro consumo, depende de los ingresos reales de la familia, sobre todo en la Argentina con un $85 \%$ de población urbana.

Cuanto más altos sean los ingresos, menor será la participación del gasto en alimentos en el gasto total de los hogares. El nivel de ingresos monetarios de las familias está determinado básicamente por la condición de actividad de los trabajadores, aunque éste no sea el único origen de los recursos. También generan ingresos las redes sociales y los programas de asistencia social o la autoproducción, si bien restringida por el carácter urbano de la población.

Ingresos y precios explican que en una banda de ingresos determinada, si los mismos suben o bajan, el consumo crezca o decrezca pero con una intensidad acotada. Esta es la propensión marginal al consumo que opera sobre un fondo cultural fuertemente inflexible, el patrón alimentario, que determina qué es comida y qué no lo es.

Los estudios de las estrategias domésticas de consumo de todos los sectores de ingreso del Area Metropolitana del Gran Buenos Aires (Aguirre, 1992) muestran que la lógica del consumo de los más pobres es alternar grandes consumos de cereales (21.6\% de la canasta) con altos consumos de carne (16\% de la canasta), lo cual, desde el punto de vista nutricional como económico es altamente favorable a la supervivencia. Organizando sus dietas de este modo las familias más pobres obtenían el $34 \%$ de la energía y el $93 \%$ de las proteínas con el $16 \%$ del gasto. El intento estratégico no es mantener la carne o el pan, ni siquiera el patrón alimentario, sino la "lógica de la estrategia". Es la eficiencia de las dietas ahorradoras, es la positividad de la relación costo/beneficio de la lógica de la potenciación (que permite optimizar recursos escasos) lo que induce a pensar que pan y carne -aunque subrepresentadosse mantendrán en las dietas de coyuntura y en el largo plazo en el patrón alimentario. Sin embargo, estudios de mercado más recientes muestran que, en la base de la pirámide social, los cambios son tan profundos como extendidos: una encuesta de la consultora CCR dice que, durante 1999, más de la mitad de las personas de sectores bajos modificaron sustancialmente sus hábitos, y este cambio siempre fue para peor. 
Cuando la situación económica se deteriora, explica un informe de ACNielsen-CEOP, lo primero que ese sector limita son alimentos y bebidas, los dos rubros que se llevan la mayor parte de sus ingresos.

En 1990 el consumo de carne vacuna era de $82 \mathrm{~kg}$. per cápita al año. Hacia 1998 la cifra descendió a 59 y en 2000 ascendió a 62. En 10 años el consumo de carne descendió 20 kg. per cápita.

Por el camino de la crisis, muchos rituales familiares se vieron conmovidos, por ejemplo la cena. Son pocos los hogares donde se mantienen las 4 comidas diarias, sobre todo en las familias de menores ingresos que dependen cada vez más de la ayuda social. Por razones de trabajo, la familia reunida en torno de la mesa familiar se convirtió en algo poco frecuente, en un evento del fin de semana. Un trabajo realizado por la Universidad de Lomas de Zamora sobre Capital Federal y Gran Buenos Aires (CEA-gro) afirma que la importancia que se le asigna a la cena es variable: en el nivel alto hay una mayor dedicación a la cocina, un menú más completo y una mesa mejor servida que la del mediodía. En los sectores más pobres los platos no varían, abundan los guisados de alto contenido calórico y la cantidad de carne es inversamente proporcional al número de comensales (Clarín, 2000).

Patricia Aguirre señala que las Encuestas de Gastos de los Hogares (de 1965 a 1996) muestran que los consumos de las dos puntas de la escala de ingresos se enfrentan especularmente. Los más pobres comen mucho pan, papas, cereales y pocas verduras, frutas mientras que los sectores de mayores ingresos consumen muchas frutas y verduras y poco pan, papas y cereales. En el caso de los sectores de menores ingresos, el principal problema cuando arman sus canastas de consumo es que simplemente no pueden: sus canastas desbalanceadas son el mejor arreglo posible entre los precios y sus menguados ingresos. $Y$ a medida que éstos descienden se sustituyen alimentos caros por otros más baratos hasta que al final sólo quedan estos últimos y poco o nada del resto, configurando una dieta monótona de guisos y sopas sin variedad. Aunque, por la caída de las ventas que sufrieron estos alimentos en los dos últimos años, puede pensarse que una proporción creciente de la población ya no sustituye sino que suspende alimentos y comidas enteras (la conocida "cena de mate cocido"). En la pobreza la estrategia de consumo exige alimentos rendidores: que sean baratos y procuren saciedad. En torno a ellos se ha construido un "gusto de lo necesario" que hace que se viva como elección lo que de todas maneras estarían obligados a comer.

Y la traducción biológica de las canastas se refleja en la forma en que modelan los cuerpos de manera que cada sector de ingresos tiene la oportunidad de tener un cuerpo a la medida de sus consumos. "Hoy los pobres son opulentos, no de 
abundancia sino de escasez: ocultan tras sus formas la imposibilidad de acceso a una alimentación adecuada." (Aguirre, 2000).

Según CCR Technology/Indec, en un estudio basado en 600 entrevistas en hogares de Capital Federal y Gran Bs. As. (1999), durante 1999 el 53 \% de los hogares de nivel socioeconómico bajo refiere haber cambiado sus hábitos de compra de alimentos (13 puntos más que los hogares del sector medio y 20 puntos más que los hogares de sectores altos). Un $22 \%$ refiere haber consumido menos y de menor precio, un $18 \%$ consumió menos pero mantuvo la calidad y un $13 \%$ consumió menos y no mantuvo la calidad. La misma fuente analiza el porcentaje de ingreso que se destina a la compra de alimentos según el nivel socioeconómico de los hogares argentinos -distribuidos en franjas del $10 \%$-: el $10 \%$ más pobre gasta el $55 \%$ en alimentos frente al $10 \%$ más rico que gasta $23 \%$ (el promedio general es del $34 \%$ ).

\subsection{La situación nutricional en la Argentina}

Hablar de problemática alimentaria como carencia resulta paradojal en nuestro país, con una producción excedente de alimentos y exportador de cereales. Ella no se vincula con la disponibilidad -un tercio superior a las necesidades de un argentino medio- sino con el acceso al consumo. Con relación a la descripción del contexto socioeconómico en nuestro país desarrollado anteriormente, la inequidad en la distribución del ingreso es grave desde el punto de vista sanitario, ya que se ha visto que los países que ostentan los mejores indicadores de salud y bienestar no son aquellos de mayor ingreso per cápita sino aquellos en los que las diferencias entre el ingreso de los más privilegiados y de los menos privilegiados son menores.

Si el aporte de los alimentos disponibles es inferior a las necesidades nutricionales, los individuos viven menos o en peores condiciones. La satisfacción de esta necesidad básica es una prioridad absoluta para la reproducción lo que torna fuertemente inelástico el gasto en consumo alimentario.

Unicef señala que hay 3 millones de personas en situación de riesgo alimentario y que el $60 \%$ de las muertes infantiles por criterio de evitabilidad tienen como causa la desnutrición infantil (Unicef, 1991).

A nivel sanitario puede observarse un descenso progresivo de las tasas de morbimortalidad infantil, lento pero constante (diez niños por mil cada diez años). Ese descenso se ha dado aun a pesar de la situación de crisis económica del país y de la incoordinación del sistema sanitario, cuyo gasto es, tanto en términos relativos como absolutos al PBI, uno de los más altos de Latinoamérica. Países con menos recursos humanos y económicos que el nuestro muestran tasas inferiores de mortalidad total (neonatal y post neonatal). El promedio nacional de 22.9 por mil en 1993 (Cesni,1998) 
esconde grandes desigualdades entre provincias, regiones y sectores: 34 por mil en Chaco y 14 por mil en Capital Federal.

Hay consenso acerca de que el potencial de crecimiento hasta los cinco años es similar en los niños de todas las etnías del mundo. Las principales diferencias en el crecimiento y en el tamaño corporal de países como el nuestro deben ser atribuidas primordialmente a diferencias en el nivel socioeconómico, situación nutricional y condiciones de vida en general.

Las experiencias de vida organizadas en torno a pautas de carencia ejercen gran influencia en la situación biológica y biográfica del individuo ya que se vulneran sus potencialidades físicas, psíquicas y sociales. Así, la pobreza vivida como una condición particular de los sujetos sociales, se experimenta de diversas formas (Herrera, 1998).

La alimentación/nutrición ligada estrechamente a la salud/enfermedad ofrece una imagen de desigualdad y polarización, pues la satisfacción de dicha necesidad aún no está resuelta para muchos ${ }^{23}$. Las formas de enfermar y morir y la condición nutricional de las personas se ve afectada a causa de la crisis y el ajuste (la flexibilización de las relaciones laborales, los incrementos en el desempleo y el subempleo, la contención salarial, la contracción del gasto social, la privatización de servicios y el desmantelamiento de las instituciones públicas).

Como se planteó anteriormente, la alimentación es un indicador elocuente de las condiciones de vida de las familias; particularmente el crecimiento y desarrollo infantil son un referente empírico de las mismas y una expresión particular del proceso de desarrollo económico de una sociedad. En condiciones de pobreza crecer menos constituye un estereotipo de adaptación, afectando diversas esferas del desarrollo biopsicosocial. Los perfiles de crecimiento y desarrollo infantil en las distintas regiones del país sirven para valorar la condición biosocial de la población así como el nivel de desarrollo social, económico y la distribución de la riqueza dentro del país.

La inadecuada nutrición en la infancia tiene repercusiones sobre el crecimiento, desarrollo y salud general de los niños.

El peso de nacimiento, en tanto factor asociado a las tasas de mortalidad en menores de un año, el tiempo de lactancia y las infecciones son factores vinculados con el estado nutricional. Otros aspectos vinculados a la ingesta de alimentos, se relacionan con el cuidado del niño: el tiempo que demanda en alimentarse, la disponibilidad de

\footnotetext{
${ }^{23}$ La alimentación/nutrición es concebida no como dos polos aislados entre los cuales existe vinculación por compartir factores comunes, sino como parte de un mismo proceso caracterizado por ser expresión y determinante de la salud/enfermedad y, en consecuencia de la calidad de vida.
} 
tiempo de la madre, su condición ocupacional, las raciones de comida que recibe, los horarios en que la recibe, la temperatura, presentación, variedad.

El estado físico y anímico de la madre tiene que ver con el cuidado del niño. En los países centrales, la casi totalidad de casos de desnutrición infantil se asocia con cuadros emocionales patológicos de las madres, depresión. La falta de dinero es otra causa que se asocia con maltrato y descuido infantil (Fendrich, 1990; cit. por O’Donnell, 1999).

Una madre anémica (28\% al $34 \%$ en mujeres argentinas en edad fértil, Calvo, 1991; Cesni, 1995) se sentirá fatigada, apática y con menor capacidad de concentración, lo que afectará el cuidado de sus hijos.

La monotonía de la alimentación es característica de las familias de menores recursos por lo que si algún nutriente o micronutriente es deficitario, la monotonía perpetuará y agravará la deficiencia; además es posible, en función de la distribución intrafamiliar, que no se alcance la densidad de nutrientes convenientes para los más pequeños (O’Donnell, 1999).

La información sobre el estado nutricional de los niños argentinos es muy escasa, aún la información más sencilla de obtener que es el peso y la talla. Ello se debe a que no se la obtiene, no se la difunde cuando existe, no se procesa, o no se lo hace adecuadamente utilizando distintos puntos de corte 0 diferentes indicadores antropométricos, lo cual impide hacer comparaciones entre regiones, estimar tendencias y evaluar el impacto de acciones de salud y asistencia nutricional. Existe todavía menos información alimentaria, fundamental para inferir la existencia de deficiencias nutricionales específicas en una comunidad y para instrumentar programas de fortificación. Escasa es aún la información sobre deficiencias de micronutrientes, uno de los pocos problemas nutricionales que pueden ser resueltos rápidamente y a muy bajo costo (O’Donnell, 1999).

De la información disponible, puede decirse que los problemas nutricionales de los niños argentinos consisten en:

- la desnutrición aguda (deficiencia de peso para la talla o la edad)

- la desnutrición crónica (deficiencia de talla para la edad)

- el sobrepeso y la obesidad (exceso de peso para la talla)

- la carencia de micronutrientes (denominada "desnutrición oculta").

La desnutrición aguda en la Argentina ha disminuido, teniendo cada vez menos relevancia epidemiológica. Se estima en no más del $3 \%$ el porcentaje de niños con deficiencias de peso para la talla con marcadas diferencias regionales. La prevalencia de desnutrición aguda (peso/talla) es baja cuando se la diluye en un denominador poblacional: su disminución se debe a que las condiciones sanitarias de la población 
en general han mejorado, a la existencia de un sistema sanitario alerta y entrenado para la detección temprana y que es accesible en términos generales a toda la población (O’Donnell, 1999).

Sin embargo, la concentración de esta severa e inadmisible forma de desnutrición social en bolsones de pobreza hace que adquiera en algunas regiones focalizadas una gravedad que no se compadece con los indicadores epidemiológicos.

En relación al indicador peso/edad, los sistemas de monitoreo del crecimiento en atención primaria toman como punto de corte el percentilo 10, particularmente en los menores de 2 años en quienes habitualmente no se informa el indicador talla/edad. El porcentaje de chicos de 0 a 6 años que se ubica por debajo de ese punto de corte es, en promedio, del 11.5\% (INDEC, 1995) aumentando con la edad. Una hipótesis plantea que ello se debe -seguramente- a que las consultas a los servicios de atención primaria de los niños son debidas a enfermedades o a problemas nutricionales, produciéndose de esta manera un sesgo debido a la población asistida.

La otra hipótesis, fundamentada en el análisis de la mayoría de las encuestas antropométricas transversales realizadas en el país propone que, como existe en la población infantil un déficit de talla para la edad que es progresivo, el indicador peso para la edad se comprometería como consecuencia de una alteración primaria de la talla con un peso para la talla normal o inclusive alto.

El déficit de talla se puede detectar ya en niños de 9 a 24 meses de edad, tal como surge de la encuesta del Gran Buenos Aires, Misiones y Tierra del Fuego (Cesni, 1995), explicando en gran parte el déficit de peso para la edad pues en todos esos estudios la relación peso/talla presenta una distribución normal. Otros estudios nacionales muestran la misma tendencia: en 4 asentamientos pobres del conurbano bonaerense aparece un $34 \%$ de niños con talla inferior al percentilo 10 del patrón nacional que era de temprana instalación pero muy leve el retraso del peso para la talla a pesar de las condiciones de vida extremadamente adversas (Godichet, 1989; cit. por Cesni, 1998). En una muestra de escolares de Córdoba se halló $22.5 \%$ de niños con desnutrición peso/edad, sin embargo por peso para la talla se reducía al 6 \%. En talla para la edad el déficit era del $21 \%$ (Roch, 1994). Otro estudio poblacional en menores de 5 años de familias NBI de Sante Fe encontró un $16 \%$ de desnutridos según peso/edad, la mitad de ellos tenía peso adecuado para la talla (Reeves, 1994; cit. por O’Donnell, 1999).

Un importante estudio longitudinal de cohorte de la ciudad de Córdoba (CLACyD) acota el momento de inicio del deterioro en talla al período comprendido entre los 6 y 12 meses (Sabulsky, 1997). 
La EPH en muestras representativas de niños de 2 a 6 años de edad en seis ciudades del país encontró un porcentaje relativamente alto de niños con baja talla para la edad y casi nulo de niños con bajo peso para la talla aún en familias con NBI (INDEC, 1995).

La desnutrición crónica (stunting), manifestada como retraso de la talla en relación a la edad del niño es la forma actualmente prevalente. Ella produce secuelas importantes per se y por la deficiencia de micronutrientes que la acompaña.

Se trata de niños con talla retrasada para su edad pero con un peso normal, o elevado para su talla actual. Ser de una talla menor a la que su dotación genética hubiese permitido implica que en etapas tempranas de la vida el niño ha debido hacer adaptaciones que le permitieron sobrevivir ante las situaciones carenciales que tuvo que afrontar, pero a costa de sacrificar parcialmente algunas funciones biológicas. El retraso del crecimiento en la infancia se asocia con mayor morbimortalidad, disminución de la actividad y patrones de interacción (desarrollo psicomotor, rendimiento escolar) menor tamaño corporal adulto y en mujeres de baja talla, menor tamaño pelviano y peor aptitud reproductiva.

La baja talla de origen social expresa la afectación del potencial genético de crecimiento y suele estar asociada a un ambiente con bajo ingreso familiar, dieta inadecuada, pobre inserción laboral de los padres, bajo nivel de instrucción, salubridad deficiente, familia numerosa, escaso acceso al sistema de salud, alta prevalencia de enfermedades infecto-contagiosas e inadecuados cuidados en la infancia. Todas estas condiciones determinan que los nutrientes indispensables para el crecimiento lleguen al nivel celular en deficiente cantidad, combinación, oportunidad y biodisponibilidad. Las consecuencias funcionales serán de distinta magnitud y repercusión de acuerdo con el momento evolutivo del niño y la intensidad de la deprivación. Entre las causas que pueden afectar el normal crecimiento de los niños, los factores alimentarios merecen especial consideración. La duración de la lactancia materna, el momento de introducción y tipo de alimentos empleados durante el destete, las prácticas alimentarias y cuidado infantil durante los primeros meses son fundamentales (Cesni, 1998).

Las cifras, de acuerdo con diferentes estudios, varían entre el 3 y el $9 \%$ tomando como punto de corte menos de 2 DS de talla para la edad. La OMS (ACC/SCN, 1997) da para la Argentina una cifra de 4,7\%. Como se dijo, las deficiencias de crecimiento que ocurren en situaciones de pobreza involucran complejas interacciones entre deficiencias nutricionales, enfermedades infecciosas y factores que tienen que ver con pautas y posibilidades en el cuidado de los niños. Si bien en el caso individual resulta a veces difícil establecer la causa de retraso del crecimiento, bajo el punto de vista 
epidemiológico-nutricional, los indicadores de salud, de desarrollo social, económicos y de disponibilidad de nutrientes se correlacionan con la prevalencia de deficiencia para cualquier nivel de corte en el indicador talla/edad. Por esa razón ese es un indicador antropométrico de inequidad social y refleja epidemiológicamente las condiciones en que se han criado los niños (Cesni, 1998).

Existen varios estudios con aceptable representatividad poblacional para avalar que la mayor prevalencia de desnutrición es de tipo stunting (Calvo, 1991; Cesni, 1995).

El Módulo Nutricional de la Encuesta Permanente de Hogares (INDEC, 1995) realizada en muestras representativas de niños de 2 a 5 años en seis localidades del país encontró un porcentaje relativamente elevado de niños con talla baja ( $21.6 \%$ en el conurbano bonaerense) y mucho menor de niños con bajo peso para la talla $(11.8 \%)$ aun en familias con necesidades básicas insatisfechas. En algunas localidades el sobrepeso era extremadamente común. Así como la forma prevalente de desnutrición es el déficit de talla, es notable la creciente incidencia de alto peso para la edad y sobre todo para la talla.

En términos clínicos esto puede definirse como sobrepeso (entre 110 y $120 \%$ de adecuación de peso para la talla e índice de masa corporal entre los percentilos 75 y 95) u obesidad (más de $120 \%$ de adecuación de peso para la talla o más del percentil 95 del IMC). Varios estudios realizados en adolescentes confirman la tendencia creciente a la obesidad en nuestro país (Abeya Gilardon, 1995; cit. en Cesni, 1998).

La elevada prevalencia de sobrepeso y obesidad de nuestro país muestra una tendencia creciente y tiene peculiaridades respecto a la que se observa en los países desarrollados. Se trata de un fenómeno sanitario relativamente reciente relacionado con la rápida urbanización, que conlleva sedentarismo, viviendas más pequeñas, comer lo más barato y lo más fácil de preparar que son alimentos de alto contenido en grasa y azúcar refinada, dificultades de acceso a actividades deportivas. En 1998 la OMS declara a la obesidad, en la Asamblea Mundial de Salud, como una enfermedad de trascendencia mundial disponiéndose a disponer de recursos contra ella.

El riesgo de padecer obesidad y sobrepeso es mayor en los niños con retraso de crecimiento que en los niños de talla normal (INDEC, 1995). La obesidad no es, pues, un indicador de opulencia ubicado en el extremo polar a la desnutrición. Ambas coexisten en los niños de las mismas regiones y estratos y en las mismas familias. 
La información disponible sobre desnutrición oculta ${ }^{24}$ (cf. Oms/Unicef) es muy escasa y referida a anemia por deficiencia de hierro, oscilando -en niños de 8 a 24 mesesentre un $30 \%$ y un $60 \%{ }^{25}$

La prevalencia de anemia comienza a disminuir a partir de los 2 años, a medida que disminuye la exigencia de sus requerimientos nutricionales; además, la dieta comienza a hacerse más variada.

Otra deficiencia sobre la que existe menos información es la de vitamina A, oscilando entre el $12 \%$ al $40 \%$ en niños menores y embarazadas (Carmuega, 1989; 1995).

El principal problema de los niños y adolescentes de nuestro país es la disminución del crecimiento longitudinal cuyo inicio puede rastrearse en los dos primeros años de vida, probablemente a partir de los 6 meses. Este retraso en talla, prevalente entre los niños de regiones y sectores desfavorecidos, se mantiene hasta el ingreso escolar y persiste hasta la adolescencia. La posibilidad de revertir el retraso una vez iniciado es un problema sin respuesta aún. Evaluaciones de niños que asisten a comedores escolares muestran que los mismos incrementan su peso pero no la talla. El riesgo relativo de padecer sobrepeso y obesidad es mayor en niños que presentan retraso crónico del crecimiento que en los niños de talla normal tal como se observa en un estudio de escolares de Neuquén (INDEC, 1995).

Puede decirse entonces que la transición nutricional en nuestro país se caracteriza por una disminución de la desnutrición aguda o proteino-energética (emaciación), un aumento de la obesidad y cifras relativamente estables de retraso crónico de crecimiento y especialmente de desnutrición oculta. La deficiencia de hierro en menores de 2 años constituye la principal carencia nutricional.

El stunting es un proceso crónico que puede continuarse hasta los dos o tres años de vida y todas las agresiones nutricionales e infecciosas que pueda sufrir un niño en estos años de la vida se manifestarán con retraso de crecimiento. La causa de este retraso madurativo se puede relacionar con el nutriente que es prioritariamente deficiente, o con varios mecanismos que pueden estar actuando simultáneamente. La desnutrición puede causar apatía y mal desarrollo motor, lo que puede privar a los niños de los beneficios de la exploración del medio ambiente (Levitsky, 1979).

El retraso de talla de causa nutricional/social no es recuperable aun cuando los niños puedan más adelante acceder a los programas de asistencia alimentaria: los 24-30 meses marcan un límite para la recuperación (O’Donnell, 1999), no habiendo posibilidad de crecimiento compensatorio en los retrasos tempranos del mismo.

\footnotetext{
${ }^{24}$ Definida como un conjunto de carencias específicas de micronutrientes que se caracterizan por ser altamente prevalentes, de importancia en la salud infantil y que requieren de cierta instrumentación para su diagnóstico. Las más importantes son la deficiencia de hierro, de yodo y de vitamina A.

${ }^{25}$ En países con programas masivos de fortificación de alimentos, la anemia no supera el $5 \%$.
} 
Cuando esos niños afectados acceden en forma sistemática a programas de asistencia alimentaria, no crecen en longitud lo que aumentan de peso, tendiendo a engordar sistemáticamente.

De esta manera se da la paradoja de que niños que han sido desnutridos en su más temprana infancia tienen más tendencia a padecer obesidad en la niñez, en la adolescencia y en la adultez con lo que tendrán más riesgo de enfermedades degenerativas en las cuales la obesidad es el factor de riesgo principal.

La "transición nutricional" se expresa por la modificación de los patrones de alimentación, por modificaciones en las necesidades promedio de la población y en la creciente importancia en relación a la desnutrición aguda de algunas enfermedades nutricionales como el retraso crónico del crecimiento, la obesidad, las enfermedades crónicas no transmisibles y las carencias de nutrientes específicos. La comprensión de este proceso transicional es el fundamento de una evolución en el pensamiento nutricional, paso previo para adecuar en tiempo y forma los programas de asistencia alimentaria, capacitar a los profesionales y satisfacer las demandas de nuestra sociedad actual (Cesni, 1998).

Respecto de los programas de asistencia alimentaria, su objetivo no es la recuperación de talla y se ha demostrado que los programas de comedores escolares son una alternativa de asistencia alimentaria con mejor índice de eficacia (costo/beneficio) (Britos, 1994). De allí la importancia de concentrar recursos en la población en mayor riesgo social y en el momento oportuno (6 meses a 2 años de edad). La promoción de la lactancia y la incorporación de alimentos de adecuada calidad durante la ablactación son particularmente relevantes en ese sentido.

\subsection{La desnutrición en la Pcia. de Bs. As. y en la localidad de La Plata}

En la Pcia. de Bs. As. una encuesta nutricional realizada en 1995 a 17.000 niños entre 0 y 6 años que consultaron espontáneamente en centros del sector público y privado arroja que en los menores de 2 años, se presenta una combinación de valores de déficit nutricional y de sobrepeso: un $13 \%$ con bajo peso para la edad y un $14 \%$ sobrepeso. En los niños de 2 a 6 años aparece un $21 \%$ de bajo peso y solo $6,6 \%$ con sobrepeso. El indicador talla/edad muestra un $22 \%$ con desnutrición crónica (Ministerio de Salud de la Pcia. de Bs. As., 1997).

La evaluación realizada en 1998 en los 37 centros de atención primaria del partido de La Plata sobre un total de 2.228 niños de demanda espontánea pone en evidencia que el $24 \%$ presenta algún tipo de desnutrición y un $10 \%$ registra obesidad:12\% presentan desnutrición aguda, $5 \%$ bajo peso, $5 \%$ baja talla, $2 \%$ desnutrición crónica y $10 \%$ sobrepeso. El porcentaje de niños normales desde el punto de vista nutricional fue del 
$66 \%{ }^{26}$. Un estudio previo realizado con base en un censo poblacional en áreas de pobreza urbana alerta sobre la gravedad de la desnutrición crónica, así como la magnitud de los retrasos en el desarrollo psicológico: los datos surgidos del "Proyecto colaborativo sobre estrategias de alimentación, crianza y desarrollo infantil " (Piacente et al., 1990) sobre el relevamiento antropométrico realizado en villas del Gran La Plata y sur del Gran Bs. As. indican, sobre una muestra aleatoria de 1.522 niños entre 0 y 5 años, que un $25 \%$ presenta desnutrición.

Un estudio antropométrico reciente realizado en el marco del Programa "Observatorio Calidad de Vida" de la Municipalidad de La Plata sobre una muestra de 668 niños menores de 6 años de zonas de riesgo biosocial de la Plata establece que hay poca desnutrición aguda y que se mantiene elevada la desnutrición crónica (retraso lineal del crecimiento o talla baja para la edad), llegando a cifras alarmantes en algunos asentamientos: mientras que lo normal sería un 2,6 \% se llega al 13,7 \% (promedio) y en algunos barrios al 26,7 \%, lo cual refleja padecimiento nutricional crónico. También surge un alto número de niños obesos pero malnutridos y de baja talla $(8,7 \%)$, producto de una dieta basada en farináceos pero sin los nutrientes para sus necesidades (Rodrigo, 2000). "Las polentas, los guisos, fideos, papas, escasa carne es la base de la dieta. Estos alimentos son insuficientes porque carecen de los nutrientes necesarios para su desarrollo: hierro, zinc, vitaminas. Además, los planes sociales contienen esos mismos alimentos porque pueden ser almacenados. Como resultado, los niños comen mal y la baja estatura, obesos o flacos, es por falta de nutrientes. Es la desnutrición oculta. A su dieta hay que agregar carne, huevos, verdura fresca, frutas y leche. Pero es difícil de distribuir. Hay que buscarles una solución a los planes conjuntamente con acciones que tiendan a cambiar los hábitos alimentarios." (Rodrigo: Diario El Día, 2000).

\subsection{Normativas y propuestas sanitarias vigentes}

Para los médicos, la normatización de actividades está destinada a asegurar la calidad científico-técnica del proceso de atención. Las normas consisten en un conjunto de pautas explícitas que reglan las actividades de los miembros del equipo de salud quienes deben participar en su elaboración y actualización. Deben resultar de la experiencia y la investigación. Nuestro país dispone de numerosos paquetes normativos para las actividades de mayor impacto en la salud infantil entre las cuales se encuentran la vigilancia del crecimiento y del desarrollo del niño y del feto además

\footnotetext{
${ }^{26}$ Datos proporcionados por el responsable del Programa Materno Infantil de la Municipalidad de La Plata y por el coordinador del Programa de Vigilancia y Rehabilitación Nutricional con base en un documento de circulación restringida.
} 
de las inmunizaciones, atención de patologías prevalentes, prevención de accidentes y promoción de la lactancia materna. No obstante el desafío es que esas normas se usen adecuadamente en la actividad cotidiana de los servicios.

Ya que, como se dijo, las necesidades nutricionales de los niños en los primeros años son más elevadas que las del resto de la vida y que las consecuencias de las carencias alimentarias sobre el crecimiento y el desarrollo son mayores, se requiere el diseño de estrategias educativas referidas a la lactancia y a la selección y preparación de los alimentos, tanto dirigidas al equipo de salud como a la población general, programas asistenciales específicos para los más pequeños, nuevos alimentos fortificados, acciones todas ellas que promuevan un crecimiento y desarrollo infantil que permita la plena expresión del potencial que todo niño encierra.

Los alimentos prescriptos, que en su conjunto complementan la lactancia natural o a los sucedáneos de la leche materna, tienen una calidad que de acuerdo con las encuestas alimentarias es pobre en relación con las necesidades nutricionales para mantener una adecuada velocidad de crecimiento. Esta información es consistente con observaciones de seguimientos longitudinales que demuestran que el retraso del crecimiento es coincidente con la introducción de alimentos diferentes de la leche materna (Carmuega, 1999). Por lo tanto, se plantea la necesidad de capacitar a los médicos y al equipo de salud en la alimentación del primer año a través de la generalización de un cuerpo normativo consensuado y adecuado a los hábitos, posibilidades y necesidades de los niños. Recién en 1992 la OPS encomienda al Centro de Estudios sobre Nutrición Infantil (Cesni) la responsabilidad de elaborar "Guías de alimentación" para niños menores de 6 años a raíz de la falta de criterios racionales en las pautas de alimentación de los niños menores de 2 años. En 1993 el Cesni publica las "Recomendaciones para la alimentación de los niños menores de 6 años" y posteriormente el Ministerio de Salud de la Pcia. de Bs. As. publica los "Lineamientos para la alimentación del niño menor de dos años" (Carmuega, 1999). Mientras tanto, la ausencia de una normatización única de carácter práctico pero asentada sobre principios técnicos y sobre los hábitos y posibilidades de nuestras familias, determinan un vacío sobre los criterios que los pediatras en formación adquieren en las escuelas de medicina y residencias médicas, etc. No debe extrañar entonces que la alimentación de los primeros años sea diversa, plagada de falsas creencias e incongruencias. La calidad de la alimentación de los primeros años es trascendente y los resultados de las prácticas actuales no son promisorias. Las normas de alimentación pueden hacerse operativas desde la formación de los profesionales de salud en pregrado, hasta la capacitación en las residencias o los programas de postgrado. Frecuentemente la introducción de semisólidos parece un 
tema banal, que se minimiza en los programas de residencia pediátrica y de formación del pregrado.

Las normas no son estáticas y a menudo cambian radicalmente. En el campo de la nutrición, su cambio a través del tiempo puede ejemplificarse con la difusión iatrogénica de las fórmulas lácteas ${ }^{27}$.

\subsection{Salud pública y desnutrición: problemas de diagnóstico y tratamiento}

En nuestro país, la falta de una adecuada respuesta del sector y la discontinuidad de los programas de salud maternoinfantil destinados a los grupos más desprotegidos contribuyen a acentuar los efectos adversos del ajuste. Una de las consecuencias inmediatas ha sido una disminución presupuestaria afectando los gastos en equipos, insumos básicos y una virtual desaparición de los gastos de supervisión y capacitación continua del personal, responsabilidad que ha quedado relegada al interés de los propios profesionales. Muchos son los factores que han contribuido a la existencia de un sistema de salud fragmentado, inequitativo e ineficiente derivado parcialmente de la diversidad de fuentes de financiamiento y la falta de coordinación y complementación de recursos de los diferentes subsectores (Moreno, 1999). Es creciente la población que debe asistirse en servicios con carencias de insumos básicos y con estructura tecnológica obsoleta. Esta situación es crítica en los niños, cuyos problemas de salud deben atenderse en el nivel de atención primaria, a menudo con deficiente capacidad resolutiva por falta de organización, horarios reducidos, falta de provisión regular de insumos y la inadecuada y azarosa referencia a los niveles más complejos. La ineficiencia surge sobre todo a causa del modelo de atención centrado en la reparación, cada vez más caro por efecto de la constante incorporación de tecnología, no siempre eficaz. A ese hecho se agrega el efecto de la sobrepoblación médica que tiende a perpetuar el modelo a través de la especialización y el manejo de tecnología incorporada que es mejor remunerada que la atención con contenido preventivo y promocional.

\footnotetext{
${ }^{27}$ En el '60 y '70 el $90 \%$ de las madres salían de la maternidad con indicación de pecho y complemeto y en numerosos casos, con una muestra de leche en polvo. La introducción de programas alimentarios masivos basados en la dación de leche de vaca en polvo para niños pequeños y mujeres embarazadas produjo la falsa impresión de estar reemplazando alimentos de calidad biológica similar e hicieron fracasar los primeros esfuerzos por sostener la lactancia, alimentación que presenta inigualables y múltiples beneficios para el niño y la madre (Ageitos, 1999).
} 


\section{ANTROPOLOGÍA Y ALIMENTACIÓN}

\subsection{Breve descripción de los estudios alimentarios en Ciencias Sociales}

La antropología reconoce que, dentro del simbolismo general de una sociedad, la alimentación ocupa un status determinado, hecho que la convierte en objeto de análisis de prácticas, discursos e imaginarios sociales.

Asimismo demuestra que la variabilidad de las elecciones alimentarias procede de la variabilidad de los sistemas culturales: si no consumimos todo lo que es biológicamente comestible se debe a que todo lo que es biológicamente comible no es culturalmente comestible. En este proceso subyace entonces una clasificación implícita: qué es un alimento y qué no lo es, ligada generalmente a categorías médicas, estéticas, religiosas. Los hombres eligen sus alimentos en función de sistemas culturales alimentarios que pueden llamarse cocinas, entendidas como el conjunto de elementos, alimentos y técnicas utilizadas en la preparación de las comidas y las creencias, representaciones y prácticas que están asociadas a ella y que comparten los individuos miembros de un grupo, sector, etnía o clase (Fischler, 1990).

Existen pues, diferencias considerables entre las preferencias alimentarias de los grupos culturales, entre los de las clases o entre las categorías que éstas contienen, y si bien las diferencias son de distinta naturaleza (económica, religiosa, etc.) la preocupación por la salud y el valor terapéutico de los alimentos ha estado en mayor o menor grado siempre presente en la construcción de las pautas nutricionales de cualquier cultura. El concepto antropológico de salud y enfermedad se sostiene y construye parcialmente a través de la información sobre alimentación -recogida en las diversas culturas- respecto no sólo del cuerpo sino también del "alma".

La alimentación y la medicina mantienen una relación muy peculiar e indisociable. La alimentación es un medio de ejercer control sobre el cuerpo, es decir, un instrumento privilegiado de intervención médica; de allí que la medicina reivindique un derecho de control sobre la alimentación.

Para la medicina y la nutrición, el hombre sólo se ha nutrido durante mucho tiempo de glúcidos, proteínas y lípidos. Sólo tiene necesidad de vitaminas, minerales, en síntesis, come nutrientes, no alimentos. Han olvidado o se ha negado que el hombre piensa su comida de otra manera. Las ciencias sociales, desde hace mucho tiempo, han insistido en el hecho de que la alimentación humana comporta una dimensión imaginaria, simbólica y social. Comer caviar o papa es incorporar no sólo nutrientes sino también una sustancia imaginaria, un tejido de connotaciones, de significaciones y de evocaciones. 
El estudio de los patrones alimentarios y de las propiedades de los alimentos forma parte de las descripciones holísticas desarrolladas por los antropólogos clásicos en pequeñas comunidades nativas.

No hay cultura alguna desprovista de un aparato de categorías y de reglas alimentarias, que no conozca prescripciones/proscripciones relativas a lo que hay que comer, a cómo hay que comer, etc. La variabilidad observada a través de la especie humana no concierne a la presencia/ausencia de categorías sino a su contenido.

Los padres fundadores de la antropología, a finales del siglo XIX, se interrogan sobre las prohibiciones y prescripciones alimentarias relacionadas al totemismo, el sacrificio, la magia y la religión. No obstante, su interés central se dirige sobre todo a la religión, interesándose por los aspectos rituales y sobrenaturales del consumo.

Ocasionalmente los etnógrafos prestaron especial interés a la alimentación, incluyendo la preparación de alimentos, como es el caso de Franz Boas quien recopila recetas kwakiutl a principios del siglo XX.

El desarrollo de la etnografía y el trabajo de campo llevado a cabo por el funcionalismo británico puso el acento, más que en los aspectos religiosos, en las funciones sociales de la alimentación, en su papel en la socialización de los individuos en el seno del grupo (Radcliffe Brown, 1952). Entre los nativos de las islas de Andamán, "la actividad social más importante es la búsqueda de comida" siendo la comida el eje del vínculo social: es alrededor y a propósito de ella que los sentimientos sociales son invocados y puestos en práctica. En esta tendencia funcionalista se sitúa Audrey Richards, discípula de Malinowski, quien integra en su análisis la visión más exhaustiva y holística de la alimentación. Señala que "en cuanto proceso biológico, la nutrición es más fundamental que la sexualidad", planteando que en la esfera de la sociedad humana "la alimentación determina, más generalmente que cualquier otra función fisiológica, la naturaleza de los reagrupamientos sociales y la forma que toman sus actividades". Cuestionando los reduccionismos biológico y social, intenta integrar ambas dimensiones. Explícitamente su objetivo es "describir y analizar el sistema nutricional de un pueblo primitivo, examinar las relaciones humanas en tanto están determinadas por las necesidades nutricionales" mostrando cómo el hombre forja los sentimientos que ligan entre sí a los miembros de cada grupo social.

Su trabajo "Hunger and work in a savage tribe" (A. Richards, 1932), dedicado al análisis de la alimentación y la nutrición entre los bantúes del sur, se convirtió en el fundamento de muchos trabajos posteriores. Por ejemplo, se inicia en EEUU la primera investigación aplicada sobre hábitos alimenticios, centrados en la incidencia de las condiciones socioeconómicas sobre la dieta prestando atención al contexto cultural de la misma. De estos trabajos surgen los conceptos de "comidas 
fundamentales", "núcleo secundario" y "comidas periféricas", categorías que han seguido siendo utilizadas como instrumentos de análisis. Bajo la dirección de Margaret Mead, el Comité de Hábitos Alimenticios continuó la tarea de comprender la dinámica de los usos alimenticios en ciertas comunidades norteamericanas (Mead, 1943).

Para Lévi-Strauss $(1965,1968)$, las categorías de lo culinario permiten la comprensión de las culturas y de las sociedades: la cocina de una sociedad es un lenguaje que "traduce inconscientemente su estructura". Señala que, en el pensamiento humano, la cocina es la ocasión de aislar categorías empíricas universales aun cuando los contenidos que se les asigna son propios de cada sociedad.

En América Latina el funcionalismo culturalista, ligado a los programas de Salud Pública con énfasis en la práctica aplicada más que en la investigación académica, se consolida durante la década del 50 a partir del trabajo de antropólogos del Instituto de Antropología Social de la Smithsonian Institution, entre los que se destaca el llevado a cabo por Richard Adams en Guatemala mostrando la asociación de las categorías frío/caliente con la nutrición y con las propiedades de los alimentos (Adams, 1955).

Los estudios de comunidad desarrollados en esta época constituyen las contribuciones empíricas y descriptivas más prolíficas en información sobre patrones alimentarios locales. Varias fueron las poblaciones rurales y urbanas estudiadas en la perspectiva de la comunidad, es decir, en cuanto agrupamiento homogéneo y orgánico. Los estudios focalizaron la descripción de las fuentes de consumo alimentario, predominantemente originadas en una economía de subsistencia o extractiva con baja dependencia del mercado, en las prácticas y creencias asociadas a la producción alimentaria, en la composición de la dieta y forma de preparación de los alimentos, en los hábitos de consumo y en los tabúes y creencias relacionadas a los alimentos.

La presencia o persistencia del conjunto de elementos constitutivos de la dimensión cultural (expresada en los patrones, creencias y valores) de las "culturas tradicionales", era interpretada por el culturalismo como la expresión de una mentalidad "atrasada" o de un "obstáculo" al cambio. El supuesto radicaba en el distanciamiento e inadecuación de los patrones culturales "tradicionales" de aquellos vigentes en las "sociedades modernas".

Las características que pueden desprenderse de sus análisis permiten inferir que:

a) predominó un enfoque microsocial centrado en la integración superestrucural/ cultural;

b) la perspectiva asumida dicotomizó el polo tradicional/moderno sustentando la escisión entre prácticas tradicionales y modernas (científicas);

c) focalizó el sistema tradicional como objeto de investigación privilegiado (del campesinado de extracción indígena y luego de las comunidades pobres urbanas); 
d) no se propone la articulación de los niveles macro y microsocial.

Es Bonfil Batalla (1962) quien, en el marco del Instituto Nacional de Nutrición de México, hace tempranamente la crítica más aguda a este tipo de enfoques con motivo de su estudio sobre los mecanismos que condicionan la desnutrición, a fin de dar soluciones que puedan ser aplicadas con carácter experimental en un pequeño poblado yucateco. Haciendo una revisión de los trabajos realizados en la zona, destaca que los antropólogos norteamericanos consideran a los factores subjetivos como primarios y determinantes, relegando a un segundo término la realidad material objetiva. La importancia otorgada a las creencias o ideas como motores de la sociedad está claramente representada en los estudios de Caudill (1953), Foster (1955) así como en el realizado por Richard Adams dentro de un programa del Instituto de Nutrición de Centroamérica y Panamá (INCAP); éste considera a los hábitos de los nativos y a las interferencias en la comunicación los responsables de los problemas comunitarios que motivaban al programa, así como de los conflictos acontecidos ante la negativa de los guatemaltecos a colaborar con el INCAP. Según Bonfil "El paso siguiente en el camino de este pensamiento irracional, es concebir el cambio de actitudes, de valores, de ideas, como aislado e independiente del cambio en la estructura social. Esta corriente de pensamiento denominada "psicologismo" por Wright Mills, descansa históricamente, como doctrina, en una explícita negación metafísica de la realidad de la estructura social (Mills, 1959, cit. por Bonfil Batalla, 1962).

El trabajo de Bonfil Batalla representa un inmejorable ejemplo de antropología aplicada al campo de la nutrición. Hace explícita su postura teórica y metodológica, sus diferencias no sólo -como se ha desarrollado anteriormente- con otros estudios antropológicos sino también con colegas de su equipo. Incluye el estudio de aspectos referidos a los ingresos familiares, la estratificación y las organizaciones sociales, la estructura del comercio local, la producción local de alimentos, la preparación y conservación de alimentos y los hábitos dietéticos de las familias proponiendo recomendaciones para cada uno de ellos con base en el diagnóstico realizado.

Tal como lo señala Pelto (1988), la investigación antropológica sobre alimentación y nutrición ha proliferado en los últimos 25 años moviéndose en diversas direcciones impulsada por factores extra-académicos tales como ${ }^{28}$ :

\footnotetext{
${ }^{28}$ Una aproximación al conocimiento desarrollado sobre esta temática a nivel mundial puede verse en

"Carencia alimentaria: una perspectiva antropológica" (Unesco,1988). Dentro del mismo, el trabajo de Gretel Pelto sistematiza el alcance de los estudios sobre alimentación y nutrición desarrolados por las ciencias sociales, sintetiza la historia de dichas investigaciones y plantea una clasificación de las tendencias actuales de investigación en antropología nutricional.
} 
- la crisis mundial de energía y alimentos de la década del 70, con las consiguientes discusiones acerca de la relación entre los patrones de consumo en las naciones ricas y el hambre del Tercer Mundo (De Castro, 1955; George, 1980; Moore Lappé y Collins, 1982).

Khare (1988) desarrolla, caracteriza y problematiza críticas antropológicas realizadas al etnocentrismo -presente en los conceptos de "progreso", "desarrollo", "modernidad" "modernización"-, así como sus consecuencias e implicancias para la alimentación y nutrición en las comparaciones entre el Occidente próspero y el resto del mundo acosado por la escasez de alimentos. Los antropólogos que trabajan en programas de alimentación advierten la importancia de tales críticas cuando tratan de prestar la misma importancia y validez tanto a los criterios indígenas como a los científicos. Sus intentos chocan por lo general contra la resistencia y el escepticismo de los otros expertos. En el mejor de los casos, el sistema alimentario local será tratado como un sistema de información de bajo nivel cuando no desechado. Los programas y políticas de alimentación se encuentran a merced de brechas y muros culturales entre pueblos occidentales/no occidentales, de allí que el estudio del etnocentrismo sea central tanto para las políticas alimentarias como para la antropología y otras ciencias afines;

- la importancia de la nutrición en el mantenimiento de la salud y en la etiología de muchas enfermedades ha cobrado interés creciente a partir de 1960. Con relación a la desnutrición numerosos estudios desarrollados en Latinoamérica se ubican en esta línea. En su orientación se destaca un enfoque epidemiológico, muchas veces socioestadístico, centrado en la "enfermedad" definida a partir de categorías médicas a fin de precisar su prevalencia e incidencia en términos cuantitativos, a estudiar su distribución y los factores determinantes referidos a comportamientos individuales o familiares dirigidos a identificar grupos de riesgo en diversas poblaciones, muchas veces con acciones de intervención basadas en diseños cuasi-experimentales ${ }^{29}$.

Por su parte, la epidemiología crítica centrada en las dimensiones económico-políticas de los procesos de salud/enfermedad no incluyen la dimensión de la significación social, la subjetividad ni la diversidad de prácticas de los sujetos y grupos sociales;

- la emergencia de la "etnicidad" como fenómeno social y político ha influido también en el interés por la comida. Como parte de los movimientos de revitalización cultural,

Una revisión similar, pero de naturaleza crítica, referida al contexto brasilero, pero que puede extenderse a la producción latinoamericana en general, es desarrollado exhaustivamente por Ana María Canesqui en su artículo "Antropología y Nutrición" (1988).

Fischler y de Garine (1988) directores del grupo europeo de la International Comission on the Anthropology of Food (ICAF) realizan una revisión de las principales tendencias europeas en las investigaciones sobre alimentación por medio de una sistematización de enfoques uni y multidisciplinarios.

${ }^{29}$ Pueden verse al respecto los trabajos de Jordán, J.; Mata, L.; Lejarraga, H.; Delgado y otros; Cravioto y Arrieta; Mardones Restat en Cusminsky, M. et al. (comp., 1988). Asimismo se destacan también dentro de Latinoamérca los estudios de Chaves (1992, 1994); Alvarez, ML. (1984). 
se propicia el rescate de la alimentación en la medida que constituye una expresión significativa de las tradiciones culturales.

Factores internos a la disciplina antropológica han intervenido asimismo de modo preponderante en el interés por los estudios de este tipo: el surgimiento de la ecología cultural que intenta relacionar los sistemas culturales con los ecosistemas ha contribuido al desarrollo de la antropología nutricional. La nutrición es un vehículo ideal para estudiar procesos adaptativos: muchas teorías que se refieren a la adaptación cultural son examinadas por medio de un análisis de los sistemas alimentarios.

Lo mismo puede decirse de la antropología simbólica: el análisis de los alimentos, incluyendo la manera de servirlos y comerlos puede revelar estructuras simbólicas. Ejemplo de este tipo de estudios lo constituye el trabajo de Mary Douglas y Khare sobre la alimentación en la India.

Mas allá de la diversidad de tendencias en las investigaciones antropológicas sobre el tema, la problemática alimentaria se ha convertido -en el marco de los análisis sociales- en un punto fundamental para la investigación de procesos de macro y micronivel.

Las investigaciones antropológicas recientes, con enfoques diversos, pueden situarse a lo largo de un eje que se extiende entre dos posiciones. Una de ellas propone la autonomía de lo social por la que "un hecho social sólo puede explicarse por otro hecho social": las reglas culinarias derivan de una suerte de arbitrariedad cultural y sólo pueden comprenderse dentro de la lógica intrínseca de la cultura de la sociedad en cuestión.

La otra posición es detentada por los defensores de una "sabiduría óptima" de las culturas alimentarias. Para estos últimos, toda particularidad alimentaria corresponde a una función adaptativa y presenta una ventaja práctica. Las reglas alimentarias están sujetas a la biología y constituyen una forma particularmente eficaz de adaptación cultural: la mejor solución posible para la sobrevivencia y el éxito del grupo, dictada por la necesidad. Este polo funcionalista-adaptacionista plantea que todo rasgo de la cultura alimentaria cumple una función específica. El medio para explicar esta función es asociar el rasgo a un fenómeno de orden extracultural, es decir biológico o físico. Este planteo ha sido utilizado durante mucho tiempo -y refutado empíricamente- para explicar por ejemplo, el tabú judío y musulmán sobre el cerdo (la carne de cerdo mal cocida es vector de la triquinosis).

Los antecedentes de esta perspectiva pueden rastrearse en Radcliffe-Brown quien, en su estudio sobre el totemismo, plantea la vinculación entre la importancia práctica y la importancia simbólica de las especies animales en las distintas culturas (1952), concepción ampliamente criticada por Lévi-Strauss (1962). 
Los análisis de Marvin Harris (1985), representante del materialismo cultural, se desprenden de la antropología ecológica y explican las reglas culinarias en términos de costo/beneficio. Si algunos alimentos son preferidos y se buscan especialmente, es porque presentan un balance favorable: el saldo de sus ventajas prácticas y de sus costos es positivo o al menos más favorable que el de aquellos alimentos evitados. Los alimentos que conforman el patrón alimentario reúnen en general más energía, proteínas y vitaminas o minerales que los evitados. Para el hombre omnívoro, no tiene sentido comer todas las cosas que se pueden digerir, algunos alimentos apenas valen el esfuerzo que requiere producirlos y prepararlos, otros tienen sustitutos más baratos y nutritivos, otros se pueden consumir a costa de sacrificar otros ventajosos. Todas sus explicaciones se formulan en términos de adaptación, de ajuste óptimo a las coacciones ecológicas y económicas. Los patrones alimentarios están formados por alimentos "buenos para comer" ya que "la comida debe nutrir el estómago colectivo antes que alimentar la mente colectiva". (...) "De manera que la conformación del patrón alimentario puede explicarse mediante elecciones racionales que tienen que ver con la nutrición, con la ecología, o con dólares y centavos." (Harris, 1985).

El extremo estructuralista-culturalista, cuya representante más destacada en esta temática es Mary Douglas (1979), plantea que "las reglas de comestibilidad sólo pueden comprenderse estructuralmente y no intentando reconstituir las relaciones de causa/efecto que una u otra de ellas, tomadas aisladamente, pueden implicar. La interpretación estructural revela cómo se reúnen las reglas de conducta para constituir un "pattern inteligible". Su tesis es que la cultura puede y debe explicarse en términos culturales y no apelar a determinismos naturales, como en el caso del adaptacionismo. Su posición se resume diciendo que los alimentos no son "buenos para comer" sino "buenos para pensar".

Ya se ha mencionado que Lévi -Strauss ha asignado un lugar importante a la cocina. Pero a diferencia de Mary Douglas, su investigación no se centra en la especificidad o variabilidad de los hechos culturales sino en cierto número de características universales del funcionamiento del espíritu humano que el etnólogo debe poder extraer de la gran masa de datos que obtiene. Quiere demostrar que existen categorías empíricas que son pertinentes y operatorias en todas las culturas, aun cuando el contenido que se les asigna localmente sea variable. Los hábitos alimentarios son "un lenguaje en el cual la sociedad traduce inconscientemente su estructura." (Douglas, 1964).

De aquí el conocido modelo del "triángulo culinario" ocupado en sus vértices por las tres categorías fundamentales: lo crudo (situado entre la Naturaleza y la Cultura) se opone en tanto elemento no elaborado a lo cocido (producto de una elaboración 
cultural, entendida como una transformación ejercida por la cultura sobre la naturaleza, dentro de la cual se distinguen dos modalidades básicas: lo asado y lo hervido) y a lo podrido (producto de una elaboración natural, entendido como una transformación natural de lo crudo). Los modos de cocción pueden inscribirse así en este triángulo pero, según Lévi-Strauss, para cualquier cocina no hay nada simplemente cocido ni simplemente podrido o crudo, sino que el alimento debe estarlo en tal o cual manera específica y en tal o cual grado. La cocina, según Lévi-Strauss, no es tanto la expresión de la variabilidad cultural sino más bien el producto local de ciertos modos de funcionamiento del espíritu humano. El triángulo culinario, en su aspecto más general, puede servir de marco formal para expresar otras oposiciones de naturaleza cosmológica o sociológica. El universo culinario es "la imagen en miniatura del universo cósmico" y por ello, las formas de tratar el alimento están fuertemente insertas en los sistemas simbólicos desde los cuales se interpreta el mundo. Las categorías que se aplican para ordenar el universo culinario están relacionadas con otras categorías sociales tales como hombre/mujer, familia/grupo, ahorro/prodigalidad, nobleza/plebeyez, sacro/profano.

El patrón alimentario, como expresión de la estructura profunda del inconsciente, nos remite a que los alimentos que contiene resultan de una selección en tanto significantes, por lo tanto su lógica es la lógica de la estructura subyacente del pensamiento y no la capacidad nutritiva del alimento.

El estructuralismo de Mary Douglas se ubica en un plano diferente, cercano al relativismo culturalista. Su aproximación parece estar orientada por un interrogante relativista que busca descodificar, descifrar lo que es único y exclusivo en la visión del mundo de las diversas culturas, de los grupos o de las clases.

Sahlins (1988) cuando desarrolla su idea acerca de por qué las personas eligen consumir determinado bien, critica al materialismo histórico diciendo que representa, en realidad "la toma de conciencia de sí misma de la sociedad burguesa, una toma de conciencia dentro de los términos de esa sociedad". Sahlins interpreta que Marx tuvo en cuenta la cualidad simbólica sólo para el objeto que toma la forma de mercancía dejando esa cualidad en su análisis de los valores de uso. "En la sociedad humana ningún objeto o cosa tiene existencia ni movimiento salvo por el significado que los hombres pueden asignarle". El consumo es un intercambio de significados, un discurso al que se la agregan sólo post facto virtudes prácticas, utilidades. Desde su perspectiva simbólica, analiza los motivos por los cuales el perro y el caballo en tanto participan de la sociedad norteamericana como sujetos, son animales no comestibles y por lo tanto, impuros. La violación del tabú representa un acto de canibalismo: si bien no se come carne humana, es "como si" se lo hiciera; el sistema alimentario es 
"modelado por un principio de metonimia que configura una sustancial metáfora del canibalismo." (Boivin et al., 1998).

Los defensores de la autonomía de lo cultural suelen priorizar el carácter más o menos arbitrario de ciertas prácticas alimentarias. Muchos ejemplos han sido presentados en este sentido, tal el caso del "consumo ostentoso" o el "despilfarro irracional" llevado a cabo en ceremonias, cuya razón de ser se vincula más con la afirmación del poder que con una racionalidad económica o nutricional (Lowie 1942; de Garine, 1978, cit. por Fischler, 1990).

La antropología ecológica plantea, por su parte, que si bien la alimentación puede parecer a veces "irracional" suele ocultar sabidurías secretas, ignoradas incluso por quienes son sus transmisores. A menudo, han contribuido a corregir ciertas interpretaciones y a demostrar que algunos fenómenos que hasta entonces se tenían como manifestaciones de arbitrariedad cultural presentaban aspectos realmente funcionales (Katz, 1982; Rappaport, 1984).

El problema planteado al polo adaptacionista reside básicamente en la noción de adaptación óptima u optimización sobre el cual se funda el materialismo cultural. Presumiendo a priori que un rasgo alimentario debe presentar un beneficio cualquiera oculto, que debe comportar un aspecto de adaptación, y que se trata más bien de adaptación óptima, se pierden unas cuantas oportunidades de encontrar uno alguna vez.

El polo estructuralista-relativista no se interroga nunca sobre la funcionalidad o disfuncionalidad de las características alimentarias, no busca explicaciones deterministas, siguiendo las críticas de Harris. De hecho, y en los términos de Mary Douglas, corresponde sólo "interpretar" o "descifrar" las redes de significación. No obstante, el hecho de descifrar esas redes de la trama cultural, no enseña nada, dice Harris, sobre su origen, sobre lo que ha regido su génesis, sobre su devenir.

La sociología de la cultura por su parte, se ha centrado especialmente en el análisis de los consumos alimenticios y de los "gustos", entendidos como sistemas normativos socialmente construidos a partir de prácticas y representaciones diferenciadas, como sistemas de clasificación "que clasifican en realidad a los clasificadores", apareciendo los conceptos de "gusto popular", "gusto burgués", etc. (Grignon y Grignon, 1980; Bourdieu, 1979), gustos que se enfocan desde el ángulo de la transmisión y la reproducción. Su cambio, sin embargo, es tenido poco en cuenta; cuando se lo incluye, se presenta desde la perspectiva de la movilidad social de los individuos o por el cambio en la composición social. Así, los "habitus" cambian poco y nada en su contenido; son sobre todo los individuos los que cambian o buscan cambiar de status social. Bourdieu opone el gusto de las clases populares, que define como "gustos de 
necesidad" a los de las clases acomodadas que define como "gustos de lujo" o "gustos de libertad".

El gusto de necesidad es "necesidad hecha virtud"; los gustos populares favorecen las comidas más nutritivas y las más económicas como resultado de la "necesidad de reproducir al menor costo la fuerza de trabajo que se impone al proletariado". Por el contrario los "gustos de lujo son propios de los individuos que aparecen como el producto de condiciones materiales de existencia definidas por la distancia de la necesidad, por la posesión de un capital". La idea de gusto, según Bourdieu, es de hecho típicamente burguesa ya que supone una libertad absoluta en la elección y no puede concebir las paradojas del gusto de necesidad (Bourdieu, 1979). El contenido de las preferencias en el gusto de necesidad se halla determinado por las relaciones de producción: obreros y campesinos siempre prefieren necesariamente los alimentos más económicos y nutritivos, los que presentan las características objetivas de procurar una sensación de repleción máxima a un costo mínimo. En el gusto de libertad, los alimentos considerados más ligeros, más refinados, prevalecerán pero será siempre la arbitrariedad desmedida la que presidirá su elección, ya que los cambios del gusto están inscriptos en la dialéctica incesante de la pretensión de los sectores ascendentes y de la distinción de las clases dominantes.

Al plantear el gusto de las clases populares como "gustos de necesidad" y los de las clases acomodadas como "gustos de lujo" o "gustos de libertad", otorga un virtuosismo al comportamiento alimentario de los sectores populares basado en criterios eficientistas y conservadores: el gusto de necesidad es "lo que hace que se tenga lo que se quiere porque se quiere lo que se tiene".

Sin embargo, el gusto, las prácticas y preferencias alimentarias, la cocina misma -al igual que la lengua y la cultura- también cambian.

"Una de las funciones de la cocina es regular las relaciones entre novedad y familiaridad, realizar la mediación entre la necesidad y el riesgo de innovar, la necesidad y la dificultad de conservar. Se podría decir que los elementos nodales de un sistema culinario sólo valen por lo mismo que significan y que cuando cesan de significar, cesan a la vez de ejercer su papel nodal y estructurante." (Fischler, 1990) ${ }^{30}$.

\footnotetext{
${ }^{30}$ En Europa, desde la Segunda Guerra Mundial, se ha producido por ej. una declinación del consumo de alimentos antes utilizados cotidianamente. Estos alimentos se califican como "populares" o son alimentos de "escasez" (Claudian, 1972) que dependen del "gusto de necesidad": legumbres, pastas, papas, sidra, etc. Su declinación se halla claramente ligada a la evolución de la estructura social del país desde entonces: los alimentos en decadencia son para la mayoría sobreconsumidos por categorías sociales también en decadencia y desdeñados por las categorías en ascenso (Grignon, 1986). Así, los productos crecen y decaen con las clases que los consumen: la decadencia de los campesinos y luego de los obreros explica en parte el declive de alguno de los alimentos más característicos del "gusto de necesidad" popular.

A largo plazo, el aumento del consumo de carne al menos hasta una fecha reciente, parecía constituir una tendencia fundamental e irreversible, tendencia que ha disminuido rápidamente por diversos factores y ha conducido a que la carne perdiera su preeminencia simbólica.
} 
Finalmente, dada la estrecha vinculación con la problemática nutricional infantil desde el enfoque de la Antropología Médica, es ilustrativo el estudio de Schepper-Hughes (1984) sobre el abandono nutricional en niños del nordeste brasileño así como sus observaciones referidas a la incumbencia de la antropología médica crítica, tendencia a la que adhiere: a ella concierne la síntesis entre los supuestos de macronivel de la economía política y la sensibilidad y la perspectiva de micronivel propias de la antropología convencional ${ }^{31}$. Existe entonces un fuerte interés en moverse desde las amplias generalizaciones hacia el estudio de configuraciones sociales y de salud particulares en los diversos sectores del sistema económico mundial, así como en los países que sufren transformaciones sociales y procuran separarse de este sistema. Mientras que la perspectiva crítica se distingue de la Antropología Médica Clínica por dar prioridad a la penetración de procesos y estructuras internacionales y nacionales, sostiene también que una comprensión pormenorizada de cualquier problema particular demanda una exploración completa de actividades y patrones en el micronivel. "Este enfoque evita lo que Giddens denomina la "guerra falsa" entre macromicroniveles, dado que ninguno es considerado como el nivel esencial de la realidad social. En la perspectiva de la Antropología Médica Crítica, el micronivel está imbricado en el macronivel pero no es reductible a él; separación que obedece a una división heurística -no empírica- que permite analizar la conexión entre configuraciones únicas y procesos generales. Aquí yace la contribución especial de la antropología, una disciplina destinada a conjugar las formas de vida, los sistemas de significados, las motivaciones para la acción y las experiencias cotidianas de poblaciones locales, con el marco holista del enfoque político-económico." (Singer, 1990).

\subsection{Estudios en nuestro país}

Circunscribiendo el análisis a la producción más relevante que sobre dicha problemática han generado las ciencias sociales en nuestro país, pueden citarse los trabajos de José C. Escudero $(1984,1985)$ quien, desde un enfoque que se asienta en el marxismo, plantea teóricamente y con base en información secundaria disponible sobre producción, distribución y consumo de alimentos, la paradójica existencia de la desnutrición en el mundo así como los efectos que ésta ejerce sobre los individuos.

Patricia Aguirre (1986) focaliza en el tema del encubrimiento de la desnutrición infantil. Trabajando en instituciones de salud contrasta y pondera hipótesis causales admitidas por los médicos. En trabajos posteriores $(1993,1997)$ utiliza el concepto de estrategias de supervivencia para analizar cómo se producen y reproducen los hogares pobres

\footnotetext{
${ }^{31}$ Las limitaciones del enfoque desarrollado por la Antropología Médica Clínica o convencional y las propuestas de la Antropología Médica Crítica son señaladas por Merrill Singer (1990).
} 
urbanos a través de las estrategias domésticas de consumo alimentario. A partir de allí, plantea cuestionamientos a los métodos usuales de medición de la pobreza. Asimismo en otro estudio basado en datos de fuentes secundarias (1995) analiza el patrón y la situación alimentaria en el Area Metropolitana de Buenos Aires en el período 1975-1992 mediante el estudio de los componentes de acceso al consumo (ingresos y precios de los alimentos) y de la composición de la demanda.

Pierre Ostiguy y Warwick Armstrong (1987), mediante un estudio empírico, reconstruyen la historia alimentaria en el país en el período 1974-1984, analizando las curvas de consumo de los principales alimentos de la canasta familiar en relación con la evolución de las principales determinantes macroeconómicas de la demanda durante el período.

Los indicadores que utilizan permiten vislumbrar grandes cambios que afectan la estructura de clase y la economía argentina, planteándose el insuficiente consumo alimentario para vastos sectores sociales.

Nora Garrote $(1988,1995,1997)$ realiza el estudio de las estrategias alimentarias ubicadas en el ámbito intrafamiliar: modalidades de alimentación infantil, reparto intrafamiliar de los alimentos, estructuración de la oferta diaria y patrones alimentarios. Haciendo una crítica a la medicalización de la dieta y al reduccionismo mercantilista del recurso alimentario, intenta restituir la alimentación a sus determinaciones sociales y a su distribución diferencial con el objeto de reflexionar sobre los procesos generales que hacen a la constitución de las prácticas alimentarias. Cabe destacar su estudio realizado en La Plata ${ }^{32}$ acerca de los factores biológicos, psicológicos y sociales que operan en situaciones de desnutrición y de desamparo de niños pequeños atendidos en esa institución. Su aporte se basa en un diseño que diferencia familias con y sin desnutrición para ver cómo operan las estrategias familiares definidas como modelos de acción que resuelven de alguna manera particular la relación "acceso/usos" de los recursos. Operacionalizando el concepto de estrategias a través de las siguientes dimensiones: los alimentos que se consumen, el contexto o matriz relacional de actores, las prácticas y procedimientos para su obtención, preparación, reparto, las representaciones sociales, ordena las prácticas de alimentación infantil en cuatro modalidades cuya combinatoria explica la presencia de desnutrición.

Susana Hintze (1989) provee un enfoque teórico-metodológico para analizar empíricamente la situación nutricional y el consumo alimentario en sectores populares urbanos. Plantea que las estrategias que las familias de los sectores populares generan para satisfacer sus necesidades alimentarias sólo pueden ser comprendidas dentro del espacio macrosocial que define sus condiciones de reproducción. El 
concepto de estrategias alimentarias de reproducción permite rescatar los nexos entre las alternativas que el contexto social ofrece a los sectores populares en relación a la posición que ocupan en la estructura social en términos de ocupación, niveles educativos, niveles salariales, acceso al consumo, constitución de la familia, etc. y condiciones diferenciales de vida que se expresan en el estado nutricional infantil ${ }^{33}$.

Boivin y Rosato (1998) estudian, a través del concepto de reciprocidad, el conjunto de relaciones sociales puestas en juego en una ciudad de la Pcia. de Entre Ríos ante la presencia de la crisis social iniciada en 1989 cuando se implementa a nivel nacional el plan alimentario de asistencia social llamado "Bono Solidario".

Arribas, Cattaneo y Ayerdi (1998) analizan el discurso que se gestó a través de los medios de comunicación en 1996, en torno al consumo de gatos en Rosario mostrando los límites de tolerancia hacia la pobreza en tanto se convierte al pobre en caníbal, en una amenaza al orden moral. Plantean a su vez que una sociedad que sacrifica personas en pos del crecimiento y desarrollo de otras, muestra la imagen de canibalismo social. Frente a la crisis que evidencia las contradicciones de la sociedad, surge la ambivalencia: piedad o temor hacia el otro, las dos posiciones simultáneamente. Otro estudio de Arribas y Ayerdi (1998) también realizado con base en el análisis de los medios de comunicación muestra cómo se recurre al mundo animal para afirmar lo que el hombre no es o para encontrar en la animalidad algún principio a partir del cual pensarnos en tanto hombres. El discurso publicitario no escapa a la necesidad de trazar la línea divisoria entre el hombre y los animales cuando construye una noción de hombre desde el punto de vista del consumo alimentario. Desarrollan las características, supuestos e implicancias que reviste la apelación a la animalidad en publicidades de alimentos para dar cuenta del consumo humano de dos maneras diferentes: homologándolo o contrastándolo con el mundo natural.

Otros estudios antropológicos se relacionan específicamente con otras problemáticas de salud, explorando, por ejemplo, las brechas comunicacionales entre médicos y pacientes vinculadas con el incumplimiento dietario en los tratamientos diabetológicos (Saslavski, Sinay y Rabey, 1995) o los trastornos de conducta alimentaria relacionados a la diabetes (Cagide y Saslavski, 1997).

Finalmente, para la aprehensión y problematización de la desnutrición como enfermedad se recuperan los valiosos aportes que realiza el equipo de Antropología y Salud de la Facultad de Filosofía y Letras de la Universidad Nacional de Buenos Aires

\footnotetext{
${ }^{32}$ Estudio interdisciplinario dirigido por Marcos Cusminsky en el Hospital Zonal Noel Sbarra de La Plata, 1986

${ }^{33}$ Desde dicho enfoque se llevó a cabo el trabajo realizado en 1988 en la localidad de Punta Lara, partido de Ensenada, en el que se basa una parte del presente estudio.
} 
(Grimberg, 1995,1997) a través de las observaciones que realizan a la Antropología Médica Clínica norteamericana (Kleinman, 1978, 1980; Eisenberg, 1978) y a la Epidemiología crítica, como así también el eclecticismo de Menéndez y las propuestas de la Antropología Médica Crítica (Schepper-Hughes, 1990; Bibeau, 1994; Frankemberg, 1994).

De la bibliografía analizada se consideran las siguientes contribuciones:

a) Generales

- La relevancia de los estudios intensivos y localizados en pequeños grupos (no constructos teóricos o estadísticos).

- La necesidad y utilidad de los enfoque que integran los niveles macro y microsocial. -Indagar "problemas" utilizando categorías surgidas de la perspectiva de los actores estudiados.

- Focalizar la indagación en la experiencia subjetiva e intersubjetiva de las problemáticas a analizar, en los sentidos culturales y en las relaciones sociales que constituyen esa experiencia.

- Incorporar la significación cultural y los aspectos subjetivos a las condiciones materiales del contexto histórico social (no escindir lo material y lo simbólico).

- Privilegiar aproximaciones metodológicas centradas en el contexto de construcción de los problemas y no en la causalidad lineal.

- Articular conocimientos abundantes de cuestiones de reducido nivel o magnitud.

- El carácter específico y circunstanciado de las conclusiones antropológicas.

b) Específicas

- La incidencia de las condiciones socioeconómicas sobre la alimentación enfatizando el contexto cultural de la misma, considerando la organización alimentaria en una economía mercantil y su incidencia en la conformación de prácticas y creencias, en la composición de la dieta, en la forma y preparación de los alimentos, en su distribución diferencial dentro del hogar.

- La utilidad del concepto de estrategias alimentarias para la aprehensión de la dinámica intra y extrafamiliar y sus efectos en la salud de sus miembros.

- La relevancia del sistema simbólico en el estudio del consumo alimentario (así como en el estudio de cualquier otra práctica social).

- La consideración de la alimentación como sistema normativo socialmente construido a partir de prácticas y representaciones diferenciadas.

- La importancia de restituir la alimentación a sus determinaciones sociales y su relación con la constitución de prácticas alimentarias diversas. 
- El distanciamiento respecto de posturas eficientistas, de ajuste a las coacciones económicas o de ajuste a las necesidades calórico-proteicas definidas científicamente, (crítica al reduccionismo mercantilista del recurso alimentario y a la medicalización de la dieta).

- El reconocimiento de que la alimentación cumple también funciones sociales

- La influencia de prescripciones/proscripciones alimentarias basadas en la relación alimentación/salud (medicalización de la alimentación).

- La necesidad de evitar reificaciones que reducen la enfermedad a construcción cultural o a metáfora, en tanto dejan de lado la materialidad del sufrimiento. Es decir, eludir una construcción cosificada y naturalizada de cultura, un enfoque estático de una cultura sin sujetos, sin cuerpos, sin dolores o padecimientos (Grimberg, 1995, 1997). 


\section{LAS NARRATIVAS DEL CONSUMO ALIMENTARIO Y LOS MODELOS DE HOMBRE}

\subsection{Discursos actuales sobre la problemática alimentaria}

Dejando momentáneamente de lado los estudios antropológicos, se resumen ahora algunos discursos -coexistentes- sobre la problemática alimentaria que integran actualmente nuestro acervo de representaciones sociales compartidas. Ellos cristalizan además, en términos de la evolución histórica, la manera en que a la situación de incertidumbre de muchos por la escasez se suma la incertidumbre de otros por la elección, esta última situación impulsada por la medicina hegemónica.

Respecto del primer tipo de discurso, se puede recurrir al primer "manifiesto del hambre" del que se tiene registro:

"El trigo es escaso. Faltan víveres. Los hombres, transformados en ladrones, saquean a sus vecinos. La gente quiere correr y no puede caminar. Los niños Iloran. Los jóvenes se tambalean como viejos. Sus piernas se doblan y se arrastran miserablemente. Sus espíritus están rotos. El Consejo de los Grandes está desierto. Los cofres de provisiones, vacíos. Sólo contienen viento. Todo ha terminado."

Como señala Esteva (1988) "éste constituye el documento más antiguo que se ha escrito sobre el hambre y está escrito en una piedra, cerca de lo que hoy es la actual Etiopía unos siglos antes de Abraham. Un faraón quiso escribir en el granito, su grito de desesperación. El testimonio, por demás dramático, ha sido empleado, con muchos otros, para demostrar la constancia del hambre y la escasez, viejas compañeras del hombre".

En el otro extremo, formulaciones actuales enfatizan el hecho que "ya no domina a nadie el temor de la escasez ni la obsesión del abastecimiento. (...) La inquietud contemporánea es doble: está la de los excesos y de los venenos de la modernidad y, ante ese peligro, la de la elección y sus criterios. La abundancia, la plétora: ese es el peligro inédito que debemos afrontar. El comensal moderno no debe administrar ya la penuria, sino la profusión. Debe optar entre solicitaciones múltiples, agresivas, tentadoras, contradictorias. Debe realizar selecciones, hacer comparaciones, establecer prioridades, combatir pulsiones, resistir impulsos, desplegar en definitiva todos sus esfuerzos, no para procurarse lo indispensable, sino para rechazar lo superfluo sabiendo discernir" (Fischler, 1990). Ambas afirmaciones pueden reconocerse como válidas según sean los sectores sociales a los que se les adscriban.

No obstante, el problema del hambre, sigue inquietando y siendo un problema central en la vida de amplios conjuntos sociales. Como referentes del primer discurso se 
sitúan vastos sectores, mayoritarios en Latinoamérica en los cuales la carencia alimentaria, autonomizada de las incertidumbres estacionales, resulta de la escasez de dinero. La disminución del valor adquisitivo del salario hace que se modifique la estructura del gasto con mayor incidencia en bienes y servicios básicos y el desplazamiento de los más prescindibles. $Y$ quienes se acercan a la indigencia enfrentan desfavorablemente lo más elemental de la reproducción cotidiana: la alimentación.

En la Argentina actual la problemática alimentaria compromete la salud de vastos sectores pobres, en algunos casos hasta amenazar la reproducción biológica de la familia (Aguirre, 1993).

La misma se refleja de manera irregular pero cada vez más pronunciadamente en:

a- la mayor participación de los productos alimenticios en el gasto total de los hogares, siendo más alta en los deciles inferiores de la distribución de ingresos (Teubal, 1989; Aguirre, 1990, 1993);

b- la disminución de la demanda efectiva de alimentos en la progresiva segmentación del consumo (Aguirre, 1990);

c- el aumento de la desnutrición crónica en sectores de situación de extrema pobreza;

d- la alta concurrencia de la hipoalimentación en los índices de morbi-mortalidad (Unicef, 1992).

Es decir que, al hecho de seguir presentándose como un problema vital en medio de la seguridad y de la abundancia, se suma el de la pluralidad de discursos que actualmente se generan sobre los alimentos: la medicina (oficial y alternativas), el consumismo, los mass media, la literatura, la estética y la gastronomía tratan constantemente de ella.

A principio de los 70 se hace visible un proceso que polariza la distinción entre dietética/cocina, salud/placer. En las sociedades modernas urbanas e industrializadas, las llamadas "sociedades de la abundancia" que padecen problemas de sobrealimentación o de desequilibrio debido a sus hábitos alimentarios, se definen modelos estéticos fuertemente basados en la dieta y apoyados en el discurso médico, lo que da lugar a la explosión de sustitutos alimentarios sin calorías destinados a eliminar el hambre. Nuevas prácticas culinarias, la "preparación natural", la "nueva cocina" conforman un ajuste cultural entre los modelos estéticos y los modelos dietéticos.

Según Baudrillard (1976), después de mucho tiempo de puritanismo, parece haberse descubierto el cuerpo como preocupación de una cultura egocentrada en la que el culto a lo higiénico, lo dietético, lo terapéutico, la búsqueda de la eterna juventud, la 
negación de la muerte y el envejecimiento construyen los rasgos de una cultura eminentemente narcisista.

Crecen las prescripciones/proscripciones, los modelos de consumo y las advertencias. "En esta cacofonía el individuo desorientado, en busca de criterios de elección, logra sobre todo nutrir su incertidumbre. (...) Frente a la nebulosa de informaciones heteróclitas coexisten influencias culinarias muy diversas y sincréticas; las recetas puestas en práctica no están formalizadas o ligadas a automatismos familiares sujetas a un largo hábito de repetición de gestos y habilidades manuales, tal como se presentan en sociedades simples en donde las informaciones utilizadas provienen de la tradición culinaria local o familiar" (Fischler,1990) ${ }^{34}$.

Podría creerse que la cultura de masas y la sociedad simplemente han interiorizado demasiado bien el mensaje dietético de los médicos.

La comida cotidiana se ha vuelto tan problemática que el qué comer y el cómo comer son problemas que se plantean como si el acto alimentario fuese, en esencia, un problema delicado, difícil, acaso insoluble para el individuo.

\subsection{Por qué el dilema? Conceptualización médica y antropológica del hombre}

Los problemas relativos a la elección de alimentos, de gran vigencia en las sociedades actuales, radican en gran medida, en su vinculación con la salud y la estética. La medicina, basada en su particular concepción del hombre y sus necesidades, diferenciable de la antropológica, ha desempeñado un papel preponderante en el afianzamiento de tal relación.

Cabe destacar que los planteos que se adscriben a continuación a cada una de las disciplinas responden a sus tendencias o sesgos relativos; ortodoxia y heterodoxia marchan juntas en todos los campos de la vida social, entre ellos, el del pensamiento y la actividad científica. Debido a ello, no se elimina el reconocimiento de la diversidad e incluso discrepancias existentes dentro de las disciplinas en cuestión. Así, por ejemplo, debe recordarse que desde los escritos hipocráticos, pasando por Galeno, Paracelso, Ramazzini, se le atribuye a la vida social un papel etiopatológico. Sin embargo, el pensamiento científico médico-social es de reciente desarrollo destacándose en esa línea -entre muchos otros- la figura de Virchow (1848) cuyas propuestas, desarrolladas en un contexto de grandes descubrimientos en el campo de la medicina clínica asentada en un modelo de trabajo científico positivista, no lograron dominar el pensamiento y la actividad médica.

\footnotetext{
${ }^{34}$ En 1990 un estudio realizado en California muestra que dos de cada tres habitantes del estado, agobiados por la información contradictoria, no llegan a formarse una idea clara de lo que debe ser su alimentación (Fischler, 1990).
} 
En el campo antropológico, la sociobiología de E. Wilson (1975) con su planteo de subsumir las ciencias sociales y humanas a las ciencias naturales bien podría alinearse dentro de una perspectiva biológica. No obstante, sus propuestas no han hegemonizado el campo antropológico.

\subsubsection{La medicina y la reducción orgánica del hombre}

El saber sobre el hombre construido por la medicina es, básicamente, un saber sobre el organismo (Le Breton, 1995); la elección de su mirada ilumina ciertos hechos y deja a otros en la sombra (Lores Arnaiz, 1986).

Descartes, en el siglo XVII establece los métodos para pensar al cuerpo humano como una máquina creando la dicotomía entre la mente (una concepción fuera del alcance de la ciencia) y el cuerpo (un organismo imperfecto que obedece a leyes naturales).

La invención del cuerpo en el pensamiento occidental responde a la distinción entre hombre y cuerpo, alma y cuerpo, materia y espíritu, organismo e intelecto; recorte que implica la separación del hombre de sus relaciones sociales, separación del hombre de la naturaleza, separación del hombre del universo, separación del hombre de sus deseos.

En el mundo renacentista el hombre no era distinguido de la trama comunitaria y cósmica, pero con la epistemología mecanicista cartesiana el hombre surge como sujeto individualizado y la noción de cuerpo fue el factor de individuación, de ser sí mismo, el cuerpo es la frontera precisa que marca la diferencia de un hombre a otro. La definición moderna de cuerpo implica que el hombre sea separado del cosmos, de los otros, de él mismo, adquiriendo de este modo existencia material, externa y autónoma. El cuerpo expropiado del sujeto es concebido como máquina cuyas leyes de funcionamiento pueden ser conocidas y sus desajustes controlados.

En ese esquema, la enfermedad aparece como un disturbio en alguno de los componentes de la máquina humana pasible de ser reparado por la intervención de una medicina que detente el conocimiento de las leyes que en ella operan.

Los malestares, padecimientos, molestias, enfermedades se despersonalizan: se los ve como la falla anónima de una función o un órgano y no como la aventura individual de un hombre contextualizado.

No obstante, al perder el cuerpo humano su carácter divino e intocable se libra abiertamente, sobre todo a partir de la obra de Comte (1842), la lucha por eliminar los conceptos religiosos y filosóficos que habían sofocado por largo tiempo el desarrollo de la medicina. El hombre se enfrenta a procesos orgánicos que pueden ser conocidos y regulados. La nueva actitud significó transformar a la medicina en una ciencia natural, con su campo propio de observación y experimentación: la consulta, la clínica, 
el laboratorio. Fundada en las premisas del positivismo, la enfermedad resulta identificada con el signo anatómico o fisiológico que la pone en evidencia y, a su vez, los estudios etiopatológicos cobrarán extraordinario auge gracias a los avance de Pasteur (1822-1895) y Koch (1843-1910) en el campo de la microbiología que hacen ver en la enfermedad, el signo de una lucha entre el organismo y sus invasores.

En pos de una mayor objetivación, se separa el sujeto del objeto de conocimiento: el cuerpo y la enfermedad grabada en él constituyen la base del saber.

En la elaboración gradual de su saber y de su hacer, la medicina dejó de lado al sujeto y a su historia, su medio social, su relación con el deseo, con la angustia, para considerar solamente al mecanismo corporal. En pos de una eficacia propia, la medicina construyó una representación del cuerpo que coloca al sujeto en una especie de posición dual respecto de sí mismo. El enfermo es sólo un epifenómeno de un acontecimiento fisiológico que sucede en el cuerpo. El lenguaje registra este dualismo que diferencia hombre/cuerpo a partir del cual la medicina estableció sus procedimientos y su búsqueda de eficacia, al mismo tiempo que sus límites.

No se trata de un saber sobre el hombre, sino de un saber anatómico y fisiológico acentuado actualmente por la hiperespecialización que fracciona al cuerpo en extremo.

La medicina subestima el hecho que el hombre es un ser de relaciones y de símbolos y olvida que el enfermo no es sólo un cuerpo al que hay que arreglar.

Las fisuras que se abren dentro de la medicina provienen del psicoanálisis y de la antropología y se vinculan con el postulado que afirma que, a partir de las representaciones, los hombres actúan sobre el mundo y el mundo sobre el hombre.

La antropología destaca que hay una pluralidad de cuerpos: el cuerpo es una construcción social y cultural y su "realidad última" no está dada. El cuerpo mezcla sus acciones y sus constituyentes con el simbolismo de su sociedad y sólo puede comprendérselo en relación con una representación.

Marcel Mauss (1971) estudió la fuerza de esas representaciones a partir de la idea de muerte sugerida por la colectividad. El ejemplo muestra el efecto de la palabra colectiva evidenciando la porosidad del cuerpo frente a la acción del símbolo.

La noción de eficacia simbólica presente en el estudio de Lévi-Strauss (1968) muestra que si la palabra o el rito pueden terminar con un síntoma o provocar la muerte es porque encuentra eco en el cuerpo, resonancia en la carne. La materia prima es la trama simbólica, que difiere en los objetos de acción (la vida, el síntoma, etc.).

No obstante, para la medicina, lo cultural se configura como obstáculo, resistencia o barrera a normas y prácticas sanitarias instituidas; como complemento se sostiene la recuperación de saberes y el uso de recursos comunitarios para una medicina 
simultáneamente barata y disciplinaria.

Las críticas formuladas al reduccionismo biológico de la ciencia médica expresan que las necesidades e impulsos biológicos y el medio ambiente físico al que tienen que ajustarse los hombres proporcionan la materia prima de la vida humana, pero la cultura particular determina la configuración de esa materia prima. Vargas (1988) señala en ese sentido y con relación al tema de este estudio, la importancia de analizar el contexto socioantropológico del crecimiento infantil. Propone que las regularidades encontradas en el nivel biológico son insuficientes para la comprensión de esta problemática. Dicho planteo, sin embargo, no supone obturar la cuestión biológica. La polémica herencia/ambiente en tanto variables condicionantes del crecimiento infantil está claramente expuesta en el trabajo de Penchaszadeh (1988), quien destaca la esterilidad de la oposición y el peso de los componentes genéticos en el crecimiento y desarrollo de las poblaciones.

\subsubsection{La antropología y la naturaleza variable del hombre}

La postura antropológica general, asentada en bases empíricas, afirma que las características humanas son resultado de un proceso evolutivo en el que el factor biológico ha ido perdiendo peso en la determinación de su biología y conducta: la emergencia de la vida social, del trabajo y de la comunicación simbólica han influido de manera creciente en la biología humana. En ese proceso, el hombre, al transformar y adaptarse a la naturaleza, se transforma a sí mismo. Clifford Geertz (1978) desarrolla la cuestión, mediante su concepción sintética de la naturaleza humana, en los siguientes términos: el nacimiento del concepto antropológico de cultura permite entender que lo que el hombre es se relaciona con tiempo, lugar y circunstancia.

Dado que no existe una regulación precisa de la conducta provista por la biología, el hombre requiere y depende de fuentes simbólicas para orientarse en el mundo y ordenar su conducta. Si no estuviese dirigida por dichos mecanismos, la conducta del hombre sería caótica y su experiencia amorfa, siendo la cultura la condición esencial de la existencia humana. Como no existe naturaleza humana independiente de la cultura y la misma es variable, no es posible pensar en la idea de una naturaleza humana constante y universal.

El apoyo de tal afirmación es provista por la paleoantropología, la que permite plantear que no existe una secuencia evolución biológica/evolución cultural sino interacción y que el hombre es físicamente un animal incompleto, que se diferencia del resto de los animales por las particulares cosas que debe aprender antes de ser capaz de funcionar como hombre. 
"Al someterse al gobierno de programas simbólicamente mediados para producir artefactos, organizar la vida social, el hombre determinó su destino biológico. La cultura, más que agregarse a un animal, fue el elemento constitutivo, central en la producción del animal mismo." (Geertz, 1978).

La frontera entre lo que está innatamente controlado y lo que está culturalmente controlado es una línea fluctuante y mal definida; toda expresión humana es producto de la interacción biología/cultura: entre lo que nuestro cuerpo exige y permite y lo que tenemos que saber para funcionar existe un vacío que es cubierto por información suministrada por la cultura.

"Así, en la definición del hombre se pone el acento no tanto en las potencialidades comunes a la especie o en los caracteres empíricamente similares (la "naturaleza humana", "la constante psicobiológica") sino en los mecanismos a través de los cuales la amplitud e indeterminación de las potencialidades inherentes al hombre quedan reducidas a la estrechez y al carácter específico de sus realizaciones concretas." (Geertz, 1978).

De aquí la crítica reiteradamente realizada al enfoque sobre la naturaleza humana adoptado por la Ilustración (su arquetipo de "hombre natural") y por la Antropología clásica ("hombre del consenso") en tanto proponen un modelo de "hombre" frente al cual los hombres reales son aproximaciones, deformaciones, reflejos o desviaciones.

Ante la concepción universalista de "un" hombre, se destaca la concepción particularizada de hombres concretos, con pautas diferentes y variables históricamente.

Así como la cultura constituye al hombre como especie, así también la cultura le da forma como grupos diferenciados: ser hombre es ser una clase particular de hombre. Los hombres son variados porque están orientados por esquemas culturales específicos, por sistemas de significados históricamente creados, en virtud de los cuales conforman y dirigen sus vidas.

En función de la variación de experiencias y de situaciones en las que nace y se desarrolla, el hombre no modificado no existe, no puede existir como ser uniforme o standard. Ellas condicionan su biología y determinan que enferme de un modo particular, que tenga determinada estructura corporal, altura, es decir, determinado patrón de normalidad.

Se ha definido a la cultura como modo de vida, herencia social, manera de pensar, sentir, creer, abstracción de la conducta, depósito del saber colectivo, conducta aprendida, normas que rigen la conducta, ambiente hecho por el hombre. 
El concepto semiótico de cultura concebido como urdimbre de significaciones, como el fundamento simbólico de la vida social, permite comprender cuáles son los mensajes compartidos y cuáles son los códigos socialmente establecidos de interpretación.

Pero en el estudio de las diversas formas de pensar, sentir y actuar presentes en nuestras sociedades modernas, urbanas y complejas, dicha diversidad cobra sentido y debe ser entendida como desigualdad: desigual acceso a los recursos, servicios, bienes y valores compartidos o la falta de participación en la distribución de los mismos.

La complejidad en la división y organización social del trabajo, en la distribución social del conocimiento y la variedad y complejidad de los elencos socializadores, son factores a ser tenidos en cuenta en el análisis y comprensión de las diferencias existentes dentro de sociedades actuales.

Tal como señala Balandier (1975) incluso para el caso de sociedades "simples", "una sociedad no puede presentarse como un conjunto homogéneo, indiferenciado. Toda sociedad presenta un orden que resulta de jerarquías complejas y superpuestas, toda sociedad asegura un reparto desigual de los bienes, del poder y de los signos que expresan el status."

De aquí la importancia de estudiar cómo las diferencias/desigualdades se configuran en el proceso de apropiación y uso del capital cultural de una sociedad, definiendo lo que se considera públicamente valioso y las maneras en que los grupos e integran y se distinguen en la sociedad.

Cada grupo humano crea y actualiza en sus relaciones sociales sus propios códigos comunicacionales y de interacción, sus valores, sus gustos, sus expectativas, su visión de la realidad, sus creencias, diferenciable a la de otros grupos. La cultura hace referencia a prácticas concretas de individuos integrantes de un grupo social determinado incluido en una sociedad ${ }^{35}$.

En la medida en que la diferenciación de los grupos dentro de las sociedades se da por posiciones estructuralmente desiguales, implica situaciones potencialmente conflictivas o susceptibles de ser leídas en esos términos. Es necesario entonces incorporar la dimensión política que ellas asumen en las sociedades complejas, teniendo en cuenta que la situación de clase es fuente básica pero no determinante ni excluyente de otros tipos de desigualdades sociales y conflicto. En este sentido el concepto de hegemonía recupera la centralidad de la dimensión cultural en los

\footnotetext{
${ }^{35}$ Dentro de la perspectiva antropológica actual, el concepto de identidad posibilita revitalizar el concepto de cultura. Cada grupo social, en cada momento histórico, crea y reproduce un orden social significativo que da cuenta de su identidad. Este concepto permite aprehender de forma más concreta y operativa a la cultura: la cultura es el cuerpo de la identidad (Aguado y Portal, 1992).
} 
procesos de dominación política: constituye una forma de definir las relaciones de poder cultural o poder simbólico.

La noción de cultura no ha sido privativa de los enfoques culturalistas ni de la antropología. A través de diversos aportes se incorporó a la tradición marxista en donde la cultura fue asignada frecuentemente al campo de la superestructura quedando determinada, por lo tanto, por lo económico.

Uno de los aportes es el de Gramsci quien enfatiza el carácter de clase de toda cultura y utiliza los conceptos de "concepción del mundo" y "sentido común" para manifestar la contradicción entre la concepción del mundo de las clases subalternas y la cultura hegemónica. La "cultura universal" es cultura de clase, expresión de los valores de la clase dominante.

Los sistemas simbólicos forman parte de la cultura en la medida en que son continuamente utilizados como instrumento de ordenación de la conducta colectiva, es decir, en la medida en que son absorbidos y recreados en las prácticas sociales.

Según Gramsci hay hegemonía cuando una clase dominante o un sector en alianza con otras clases, logra una apropiación diferencial de las instancias de poder, persuade a una clase subordinada a conformarse a sus intereses, admitiendo espacios donde los grupos subalternos desarrollan sus prácticas independientes. Hay hegemonía no sólo porque las fracciones dominan sino también porque dirigen y conducen: no sólo poseen el poder coercitivo sino que se organizan activamente para obtener el consenso de los sectores subordinados y en esa aceptación se basa la legitimidad del poder. La hegemonía depende de una combinación de fuerza y consentimiento que se logra mediante la contención de las clases subalternas dentro de la "superestructura". Las definiciones de la realidad favorables al sector hegemónico se institucionalizan en las esferas de la vida civil y del Estado, son el cemento de una sociedad, preservando la unidad.

La cultura aparece recuperada, entonces, como espacio de hegemonía, como lucha por el poder de sentido. Para que la cultura dominante pueda aparecer como "cultura universal" no basta la imposición externa, deben estar también representadas las aspiraciones e intereses de las clases subalternas.

Según R. Williams (1980) en un período particular hay un sistema central de prácticas, significados y valores dominantes y efectivos. La hegemonía es un sistema de poder dinámico, un proceso a través del cual se eligen y enfatizan ciertos significados y valores disponibles. Toda sociedad contiene muchos más sistemas de significados y valores que los incorporados en su sistema central u orden dominante. Lo que asegura la hegemonía de los significados y prácticas dominantes son los mecanismos que 
permiten seleccionar, incorporar y también excluir elementos de toda la gama posible existente.

Muchos de los significados y valores que están marginados de la selección son reinterpretados o diluidos de modo de apoyar o por lo menos no contradecir los elementos de la cultura dominante. El sistema dominante debe hacerse y rehacerse continuamente para contener a los significados, prácticas y valores que le son disfuncionales o se le oponen.

Como la hegemonía nunca es total ni definitiva, necesita ser renovada, recreada, defendida y modificada porque se encuentra permanentemente resistida, limitada, alterada o desafiada por fuerzas contrahegemónicas. De modo tal que las clases dominantes se esfuerzan por enmarcar y atraer todas las alternativas a su horizonte de definición de la realidad: la hegemonía ha de ser ganada y asegurada porque puede perderse, en tanto nunca se da la total incorporación o absorción de la cultura de las clases subalternas. La hegemonía no representa la desaparición total de experiencias de clase subalterna sino la complementariedad lograda entre clases dominante/subalterna y sus culturas.

La incorporación del concepto de hegemonía al análisis cultural tiene por finalidad comprender cómo se crea y reproduce un orden social significativo, cómo es incorporado por diferentes grupos sociales y la participación de los mismos en su mantenimiento, impugnación o transformación, teniendo en cuenta que las formas de ordenamiento del mundo material/simbólico de un grupo responden al tipo de experiencia y a su manera particular de apropiación de ella en tanto colectivos que comparten condiciones que derivan de posiciones diferenciadas en la estructura social.

En el capítulo siguiente se complejiza este planteo inicial, mediante la puesta en relación de los conceptos de reproducción social, condiciones de vida, representaciones sociales, poder, ideología e identidad.

\subsubsection{A modo de reflexión}

Con base en las concepciones de "hombre" propuestas por ambas disciplinas, podría afirmarse que la separación entre ciencias humanas y ciencias de la naturaleza constituye un obstáculo para el desarrollo del conocimiento. Las ciencias denominadas "duras" deben admitir, en relación al tema de este estudio, que la alimentación no sólo está hecha de nutrientes sino también de significaciones, que no sólo tiene una función fisiológica sino también funciones sociales y que los "organismos" humanos construyen representaciones que orientan sus comportamientos, definen su lugar en el mundo social y modifican su conformación biológica. Las ciencias sociales, por su 
parte, no pueden seguir desarrollándose sin tener en cuenta el hecho que, cualquiera sea la importancia y la autonomía de la dimensión sociocultural, las sociedades humanas están constituidas por hombres que, en virtud de su sustrato biológico, tienen necesidades y padecen sufrimientos, de allí que las ciencias que intentan comprenderlo hombre no pueden quedar aisladas.

Las críticas al determinismo cultural enfatizan que si bien la cultura del hombre es constitutiva de su "naturaleza", hay que evitar aquellas posturas reificadoras o cosificadoras que conciben a la cultura como algo "dado", externo al hombre y que se le impone a él. De ese modo, poco tiene que ver o puede hacer el hombre para modificar el contenido o el curso del proceso sociocultural. Esto llevaría a pensar que el hombre se ve alienado, atrapado y/o "víctima" (cuando "su" mundo le produce padecimientos, injurias, desventajas, enfermedades, muerte, etc.) del mundo en el que vive.

Además, como señala Menéndez (1997) el discurso y la práctica antropológica, particularmente en Latinoamérica, parecen no haber tomado en cuenta las amenazas epistemológicas e ideológicas derivadas del avance de las teorías biológicas sobre el campo de la subjetividad, la sociedad y la cultura. La antropología clausura la cuestión biológica a través de la producción de un modelo explicativo según el cual el sujeto y las construcciones humanas son explicables por la cultura. "El notorio silencio de nuestra disciplina refleja parte de sus crisis teóricas para enfrentar las amenazas a su modelo tradicional. La antropología social sigue desarrollando sus trabajos como si la ingeniería genética no existiera o como si el cólera fuera sólo una metáfora.

Parte del silencio debe referirse al proceso de institucionalización de la antropología social. Las tendencias operan dentro de un proceso académico caracterizado por el continuo incremento de especialidades y subespecialidades, por el contacto cada vez menor entre los teóricos y lo que ocurre en los trabajos empíricos, a la entrada en crisis del enfoque holístico, al incremento del profesionalismo, la productividad y la determinación de problemas por el aparato académico-productivo".

En ese sentido Menéndez (1997) señala la dirección potencialmente positiva que puede acarrear el actual contexto de especialización y fragmentación que se verifica en los diversos campos científicos, pudiendo conducir a una reorganización de los campos de interés orientada en función de problemáticas particulares y no de comportamientos disciplinarios. 


\section{LA CENTRALIDAD DE LAS PRÁCTICAS Y REPRESENTACIONES EN LOS PROCESOS DE REPRODUCCIÓN SOCIAL}

\subsection{Nuevos términos para viejos problemas: el concepto de reproducción social} Niveles de análisis (macro/micro) y dimensiones de la realidad (material/simbólica)

Tal como plantea Menéndez (1989) las ciencias sociales y antropológicas en América Latina han desarrollado su trabajo teórico en torno a determinados problemas y conceptos, de los cuales el de reproducción social ${ }^{36}$ ha evidenciado una notable continuidad.

El problema nuclear que se trata de explicar a través del concepto de reproducción social refiere a la relación estructura/sujeto o a la relación de los niveles "macro"/"microsociales", así como a los procesos de permanencia/transformación que permiten seguir reproduciendo una sociedad determinada.

La discusión que desarrolla referida a los trabajos sobre reproducción social se reduce a dos cuestiones, una de ellas de naturaleza teórica-metodológica ${ }^{37}$.

El énfasis puesto en la dimensión económica en gran parte de los estudios de reproducción y la utilización de modelos abstractos, impide dar cuenta de los mecanismos particulares, de los diferenciales reproductivos dentro del mismo estrato o clase social e imposibilita aprehender las estrategias cotidianas y sus posibles efectos transformadores.

Esta última problemática fue y es central en la práctica antropológica: ella generará la descripción más diversificada y en profundidad de los procesos reproductivos. En todas las líneas de investigación, la unidad de análisis será microsocial: las estructuras parentales constituirán no sólo temáticas en sí, sino también unidades de trabajo y frecuentemente en ellas se encontrará la teoría explicativa (Menéndez,1989).

En la década del 60 y del 70 con el "descubrimiento" de la pobreza, se desarrolla como objeto nuclear de investigación una notable etnografía de la familia urbana de clase baja, emergiendo conceptos centrados en la alternativa familiarista, de la cual es tributario el concepto de estrategias familiares de reproducción, estrategias de supervivencia, etc.

El concepto de estrategias familiares intenta explicar por qué, pese al incremento de las condiciones de pobreza, crisis prolongada, etc. no se generaron los efectos

\footnotetext{
${ }^{36}$ El concepto de reproducción comprende tres dimensiones: la biológica (cómo se reproduce la vida en términos, por ej. de natalidad); la material (cómo se procuran los recursos necesarios para la mantención de los miembros del hogar) y la social (cuáles son las relaciones sociales, las valoraciones, las normas y pautas culturales que guían y dan sentido a la vida cotidiana en el hogar) (Raczynski y Serrano, 1985).

${ }^{37}$ La otra observación de carácter temático que realiza Menéndez a los estudios sobre reproducción social, se desarrolla más adelante en el parágrafo "Reproducción Social y Salud".
} 
esperados por parte de determinados sectores sociales. Es esta tendencia la que utilizará conceptos y técnicas de la antropología de la pobreza.

Diversos trabajos contribuyeron a encontrar en dichas unidades los nexos de articulación entre las condiciones económico-políticas generales y las condiciones específicas de producción y reproducción social.

La unidad doméstica emerge como la institución privilegiada para estudiar las estrategias, enfoque que condujo a recuperar la problemática de las mediaciones, referida a la relación "macro"/"microsocial".

Mientras que los enfoques macrosociales suponen las características de la vida cotidiana y las suelen reducir a indicadores globales, el enfoque centrado en las estrategias necesita explicitar la información cualitativa. No obstante, en muchos estudios sobre estrategias familiares de reproducción, no se incluye la subjetividad en la descripción y análisis de los procesos de reproducción social.

Se ha planteado anteriormente que el componente simbólico de la acción humana, más que parte integrante, es el elemento constitutivo de la vida social. La dimensión simbólica ya sea verbalizada en el discurso, cristalizada en los objetos, en los gestos, en las acciones, siempre está presente en cualquier práctica social.

La Antropología, prisionera de un trabajo de campo en el cual la acción y la representación aparecen indisolublemente ligadas en una cierta concepción de práctica significante, no desarrolló ninguna tendencia para oponer formalmente las "condiciones reales de existencia" a las representaciones, ni para percibir a estas últimas como epifenómenos de aquellas. Dentro de la orientación antropológica resulta imposible relegar el universo simbólico, en su totalidad, a la instancia de la superestructura, desde el momento en que dicho universo es indisociable de cualquier práctica social, incluyendo la producción material, y constituye un instrumento fundamental para descifrarla. Orientada hacia el nivel de las prácticas sociales concretas, la antropología jamás operó satisfactoriamente con la oposición infraestructura/superestructura (Durham,1984).

Sin embargo, a menudo la carencia de integración teórico-metodológica condujo a soluciones de tipo psicologistas o a la pulverización de procesos y estructuras sociales.

Así es como numerosos estudios eliminan o subestiman alguna de las dimensiones -ya sea la referida a la estructura social, ya sea la dimensión cultural- o las convierten en epifenómenos (Menéndez, 1989).

El término "reproducción" no queda restringido a "producir lo mismo", como si las condiciones estructurales eliminaran todo margen de autonomía y creatividad de los agentes sociales y con ello, toda posibilidad de modificarlas. 
Por cierto, el margen de autonomía es variable y será más o menos amplio o más o menos estrecho según los límites fijados por las condiciones objetivas. Ese margen de autonomía está en relación con la posición que ocupan las familias dentro de la estructura social; las condiciones sociales constituyen limitaciones y posibilidades (Gutiérrez, 1994).

$\mathrm{Si}$ concebimos que las prácticas ponen en acto -de manera indisoluble- un comportamiento significado y que se desarrollan en un contexto que expresa condiciones de vida, es posible entender a estas últimas como medio y resultado de las prácticas, por lo que se puede decir que están objetivamente dadas, subjetivamente significadas y construidas por los sujetos.

Es decir que, además de las condiciones objetivas externas, intervienen también en la definición de las estrategias familiares de reproducción, los habitus (cf. Bourdieu): las condiciones objetivas incorporadas por los agentes sociales. Se trata de aquellas disposiciones a actuar, a percibir, a pensar y a sentir de una cierta manera más que de otra, ligadas a definiciones referidas a lo posible y lo no posible, lo pensable y lo no pensable, lo que es para nosotros y lo que no es para nosotros. Se trata de las disposiciones que han sido interiorizadas por el individuo -en el curso de su historia y dentro de los límites y posibilidades brindadas por las condiciones objetivas de vidaque actúan como principio de estructuración de prácticas. Definido como "lo social incorporado", "interiorización de la exterioridad", el habitus constituye un principio de generación y estructuración de las prácticas sociales y de percepción y apreciación de la realidad. Conforma una suerte de bisagra entre lo social y lo individual, lo objetivo y lo subjetivo y, en la medida en que "es historia hecha cuerpo" permite explicar qué es lo que hace que dos agentes sociales que ocupan iguales posiciones dentro de un campo determinado actúen, sin embargo, de manera diferente (Gutiérrez,1994).

"Las prácticas actualizan las disposiciones del habitus pero también son el vínculo dialéctico entre habitus y coyuntura: no son solamente la ejecución y/o apropiación pasiva del habitus. A través de las prácticas el habitus se construye o actualiza, y al mismo tiempo el habitus estructura las prácticas cotidianas.

En la organización de dichas prácticas se manifiestan procesos complejos como la socialización, la construcción de gustos y pertenencia de clase. También se pueden analizar situaciones canalizadoras de "necesidades" y "gustos" diferenciados por clase y grupo social" (Lima Barrios, 1992).

Menéndez propone incorporar sistemáticamente los niveles macro/microsociales para observar en el juego de las relaciones sociales, la construcción de los procesos reproductivos, reconociendo que las prácticas, los saberes e ideologías intervienen y 
son constitutivas de las estrategias de reproducción. Ellas se construyen en el juego de relaciones complementarias y contradictorias entre distintos conjuntos sociales.

\subsection{Las representaciones sociales}

Sperber plantea que todas las ciencias humanas y sociales, psicología, psicología social, sociología, antropología, economía, lingüística, ciencia de las religiones, estudios literarios, etc., tienen, en mayor o menor medida, que tratar con las representaciones culturales, aunque las conceptualicen de diferente manera. Entre estas disciplinas la antropología ocupará un lugar privilegiado en tanto las representaciones culturales constituyen su objeto, si no el único, el principal. Tanto si los antropólogos estudian una religión, una mitología, una ideología, una clasificación, un saber técnico, como si estudian las instituciones sociales o económicas, lo hacen en función de las representaciones culturales allí implicadas.

El abundante trabajo de los antropólogos no siempre ha desembocado en una concepción unificada de las representaciones culturales, ni tampoco en una problemática o una terminología común. Junto al término "representación", diversamente precisada con los adjetivos "colectiva", "social", "simbólica" o "cultural", encontramos "signo", "significación", "símbolo" o "saber". Muchos autores prefieren llamar a las representaciones culturales según su género y hablar según sea el caso de creencias, de normas, de técnicas, de mitos, etc. Al mismo tiempo, la mayor parte de las tentativas teóricas expresan no las representaciones en general, sino un tipo o sistema de representaciones: los mitos o la religión por ejemplo (Sperber, 1989).

La noción tiene una larga historia. Vale destacar la polisemia seminal del concepto introducida por la escuela lingüística: copia fiel o descripción de la realidad/interpretación de los actores, que como en el teatro, crean un mundo imaginario, reflejo del mundo en que vivimos, un ejemplo, como plantea Wittgenstein, del poder del lenguaje de crear al mundo. Desde sus planteos, queda claro que el modo en que se manifiesta el mundo de significaciones es discursivo, pragmático. El lenguaje es portador de interpretaciones, tradiciones, formas de ver el mundo, definiciones, máximas, usos y costumbres, instituciones, etc. Este lenguaje es código de recetas, reglas, procedimientos, por tanto, es sedimento de formas de vida, tradiciones culturales; y por otra parte, es condición de posibilidad de la comunicación social humana.

El concepto de representación aparece como reunificador en las ciencias sociales.

Situado en la frontera de lo psicológico y de lo social, se lo encuentra en trabajos de diversas disciplinas estudiado en sus relaciones con la ideología, con los sistemas simbólicos y con las actitudes sociales que reflejan las mentalidades. 
El estudio de las representaciones define un espacio interdisciplinario, cada uno con sus especificidades (Spink, 1995). Dichos espacios disciplinarios pueden distinguirse entre sí mediante la identificación de conceptos con los cuales la noción de representación se relaciona: cognición, conocimientos, creencias, visión del mundo, mundo de vida, conocimiento natural, conciencia discursiva, sentido común, ideología, cultura, identidad.

Su posición mixta en la encrucijada de una serie de conceptos sociológicos y psicológicos implica que sea puesta en comunicación con procesos que dependen de una dinámica social y psíquica y que sea elaborado un sistema teórico complejo que tome en cuenta el funcionamiento cognoscitivo del aparato psíquico y, por otro, el funcionamiento del sistema social, de los grupos y de las interacciones." (Jodelet, 1985).

"Las representaciones sociales circulan en los discursos, son llevadas por las palabras, transmitidas en los mensajes e imágenes de los medios de comunicación, cristalizadas en las conductas y disposiciones materiales o espaciales. Las representaciones sociales son fenómenos complejos siempre activos y actuando en la vida social. En su riqueza fenoménica se observan elementos diversos los cuales son, a veces, estudiados de manera aislada: elementos informativos, cognoscitivos, ideológicos, normativos, creencias, valores, actitudes, opiniones, imágenes, etc. Pero estos elementos están organizados bajo la especie de un saber que dice algo sobre el estado de la realildad, es esta totalidad significante que, en relación con la acción, se encuentra en el centro de la investigación científica." (Spink, 1995).

Durkheim $^{38}$ (1898, 1912; cit. por Berian, 1990) fue el primero que determinó la función constitutiva de las representaciones colectivas como el contenido del mundo instituido de significado de toda sociedad, un saber colectivo fundacional socialmente disponible que se despliega en los conceptos de ciencia, en las normas y máximas morales, en las regulaciones jurídicas, en las creencias populares, mitos, etc..

Las representaciones colectivas son los instrumentos que posibilitan el representar/decir sociales en tanto incorporan esos sólidos marcos o categorías del pensamiento y son portadoras de significaciones sociales: la esfera de lo sagrado como centro simbólico de la conciencia colectiva, la sociedad como ser moral, como nomos colectivo.

Para Durkheim, las características de las representaciones colectivas serían:

\footnotetext{
${ }^{38}$ Denomina conciencia colectiva a la estructura simbólica de sociedades simples y representaciones colectivas al universo simbólico descentrado que compone la estructura social de las sociedades complejas. En la evolución de la sociedad, el mundo instituido de significado encuentra una primera formación discursiva: la religión, que es la protorepresentación colectiva por excelencia.
} 
a) la normatividad legítima como autoridad racional articulada sobre dos factores: el deber de la norma (obligatoriedad/coerción) y el bien (deseabilidad/legitimidad) ${ }^{39}$

b) la externalidad de las representaciones colectivas, existentes más allá e independientemente de los individuos

c) la intersubjetividad: las representaciones colectivas son el acervo de conocimiento simbólicamente estructurado de una sociedad y por ende la "memoria colectiva" en la cual encontramos las definiciones intersubjetivas tipificadas de la normatividad social.

Durkheim y Weber identifican un proceso de racionalización/universalización de las representaciones colectivas en el siglo XVIII: la cosmovisión unificada y centrada en la religión o en un imaginario social radical (Dios) se desmorona y deja paso a una pluralidad de formaciones discursivas autonomizadas de la religión (ciencia, moral, arte), las que conforman una visión descentrada de la sociedad en la modernidad en correspondencia con un concepto tridimensional del mundo: natural (racionalidad cognitivo-teorética), social (racionalidad normativa/moral), subjetivo (racionalidad expresiva).

Según Weber (1958; cit. por Berian, 1990) el proceso de modernización occidental muestra una ambivalencia característica, mientras que la racionalización cultural (de las cosmovisiones) se manifiesta en la progresiva diferenciación y autonomía de los problemas cognitivos, normativos y expresivos, la racionalización societal como incorporación institucional selectiva, significa un estrechamiento de las posibilidades simbólico comunicativas.

Berian (1990) recupera el concepto durkhemiano para explicar el proceso de producción instituyente de ese mundo de significados normativos, cognitivos, expresivos; dialoga con Weber para determinar las características inherentes al proceso de racionalización cultural de las representaciones colectivas que acontece en Occidente, planteando bases de discusión con las interpretaciones sobre el racionalismo occidental de Habermas y con Adorno y Horkheimer -interlocutores de Weber- quienes ponen de manifiesto la dialéctica de la racionalización sociocultural occidental. Plantea la plausibilidad constitutiva del concepto de representaciones colectivas en la estructura simbólica de las sociedades modernas desde la estrategia de concebir un concepto de sociedad en dos niveles: mundo de la vida/sistema social (cf. Habermas).

\footnotetext{
${ }^{39}$ En su enfoque evolutivo para explicar el desarrollo de normas morales distingue dos tipos de solidaridad: mecánica y orgánica. La primera tiene como estructura normativa al campo religioso y se asienta sobre la conciencia colectiva como principio de organización (con sus propiedades de alto volumen, alta intensidad y alta determinación). La estructura normativa que conforma la solidaridad orgánica con su específico principio de organización: la división del trabajo presenta como caraterística, una conciencia colectiva con contenido secular, de bajo volumen e intensidad y bajo poder de determinación.
} 
Habermas (1981, cit. por Berian, 1990)) retoma el concepto de mundo instituido de significado de Durkheim, complejizándolo. El mundo de la vida conserva el saber colectivo, pero además incorpora órdenes institucionales y estructuras de personalidad. Es un espacio de conjunción simbólico cognitivo, normativo y socializador. Considera al sujeto en relación comunicativa con otro sujeto, capaz de habla y acción, con el que hay que entenderse sobre algo en el mundo, que puede darse en el mundo objetivo (el mundo de los objetos), en el mundo social (relaciones sociales instituidas) y en el mundo subjetivo (representaciones individuales). Pretende dar respuesta a la relación entre racionalidad cultural y la racionalidad sistémica: económica, burocrática, político administrativa. Detecta en la modernidad la específica mediación entre mundo de vida/sistema social.

Su análisis de las representaciones colectivas radica en una reconstrucción de tal "mundo de significado" como "mundo de la vida", atribuyéndole las funciones constitutivas de: a) producción de la identidad cultural en torno a mitos, creencias, proyectos, ideales, b) de despliegue de un principio de integración social y c) formación de las identidades individuales en el proceso de socialización. Bajo el aspecto de la búsqueda de la comprensión en el mundo de la vida, la acción comunicativa sirve a la transmisión y renovación del conocimiento cultural; bajo el aspecto de coordinación de la acción, sirve a la integración social y al establecimiento de la solidaridad del grupo y bajo el aspecto de la socialización sirve a la formación de las identidades individuales.

En la selectiva mediación entre los dos principios de integración: social (mundo de la vida) y sistémica, es donde radica para Habermas la crisis de la modernidad, en la forma de colonización/desterritorialización del mundo de la vida por la lógica de los sistemas sociales; es decir, radica en la penetración de las formas de racionalidad económica y administrativa en ámbitos de la comprensión cultural, de la integración social y de la socialización.

Como herramienta relevante con carácter heurístico, Berian (1990) define a las representaciones colectivas como "estructuras psicosociales intersubjetivas que representan el acervo de conocimiento socialmente disponible y que se despliegan como formaciones discursivas más o menos autonomizadas (ciencia/tecnología, moral/derecho, arte/literatura)."

Con la reconstrucción del concepto de representación colectiva, dicho autor plantea que en tanto ellas conforman un "mundo instituido de significado", son constitutivas para la existencia de toda sociedad, lo son para la producción de un ideal de sociedad, de un nosostros colectivo "más allá" de las conciencias individuales, que emerge en el encuentro ritual de las sociedades no diferenciadas a la manera de una conciencia 
colectiva homogénea, así como también lo son para la reproducción simbólica en la modernidad tardía, en la forma de una pluralidad de representaciones culturales autónomas, desacralizadas que posibilitan el hacer/decir sociales dentro de una cosmovisión secularizada.

Jodelet (1985) afirma que el concepto de representación social -o más bien colectivaaparece en sociología, pero su teoría va a ser esbozada en el campo de la psicología social. Dentro de él, Moscovici (1989) renovó el análisis durkhemiano insistiendo sobre la especificidad de los fenómenos representativos en las sociedades contemporáneas caracterizadas por la intensidad y la fluidez de los intercambios y comunicaciones, el desarrollo de la ciencia, la pluralidad y la movilidad sociales.

A principios de 1960 Moscovici recupera el concepto de Durkheim, no sólo en una perspectiva crítica sino más bien con un objetivo constructivo: revitalizar el concepto, promover el estudio de las representaciones y suscitar el interés de los psicólogos sociales.

A dicho objetivo se asocian dos ejes de preocupación: uno se relaciona con la fabricación del conocimiento "popular", con la apropiación social de la ciencia por una "sociedad pensante" compuesta por "sabios amateurs" y con el estudio de los caracteres distintivos del pensamiento "natural" en relación con el pensamiento científico; el segundo concierne a la difusión de los conocimientos ${ }^{40}$.

"Las representaciones sociales deben ser estudiadas articulando elementos afectivos, mentales y sociales e integrando al lado de la cognición, del lenguaje y de la comunicación, la toma en cuenta de las relaciones sociales que afectan las representaciones y la realidad material, social e ideal sobre la cual ellas tienen que intervenir." (Jodelet, 1989). Es con este fin que Moscovici ha formulado su teoría, focalizando la relación de la representación con la ciencia. "No sólo la ciencia sabe mucho, explica mejor los fenómenos y de manera más precisa. Además, emplea una lógica y una teoría, nacidas en condiciones no corrientes. Es pues fácil comprender que las personas, al recibir sus informaciones, al intercambiarlas, les hagan sufrir modificaciones con el propósito de comunicar y actuar. En resumen, las representaciones que entran en el dominio común, revelan otra estructura y cualidades particulares. Lo que en la ciencia aparece como "sistemas" de nociones y de imágenes se encuentra en las representaciones asociada a una "red" más o menos extensa pero coherente." (Moscovici, 1989).

\footnotetext{
${ }^{40}$ Una teoría de las representaciones sociales está habitualmente asociada con su trabajo y el de sus seguidores. La teoría francesa de las representaciones sociales se aplica a los usos mundanos, de sentido común, del conocimiento científico en la vida cotidiana, por ej. en los usos legos del psicoanálsis. En cuanto abordaje, las representaciones sociales han sido trabajadas por él y sus colaboradores de las más diversas disciplinas quienes han contribuido con un importante trabajo empírico.
} 
En el estudio de las representaciones se plantea como postulado fundamental que existe una interrelación, una correspondencia entre las formas de organización y de comunicación sociales y las modalidades del pensamiento social, considerada desde el punto de vista de sus categorías, de sus operaciones, y de su lógica.

Las representaciones son a la vez generadoras y adquiridas, de allí que se las despoje del sesgo estático, pre-establecido presente en la visión clásica: no son los sustratos sino las interacciones lo que cuenta. Por eso, lo que permite calificar como sociales a las representaciones son menos sus soportes individuales o grupales, que el hecho de que ellas son elaboradas en el curso del proceso de intercambios e interacciones. En resumen, la necesidad de hacer de la representación una pasarela entre el mundo individual y el mundo social, de asociarla a la perspectiva de una sociedad que cambia, motiva su modificación. No se trata de comprender tanto la tradición sino la innovación, ni una vida social ya hecha, sino una vida social en tren de hacerse.

Desde que se propone que la representación debe ser entendida como campo estructurado y estructurante y que presenta una organización vinculada con procesos de intercambio e interacción, se indagan los mecanismos psíquicos y de comunicación que producen fenómenos específicos en el curso de esa multiplicidad de actos de contar, pedir y volver a contar efectuados por tantos individuos. Al representarse una cosa o una noción, uno no se hace únicamente sus propias ideas e imágenes. Se genera y se transmite un producto progresivamente elaborado en innumerables lugares según reglas variadas. "Al estudiarlas, la psicología social se vuelve una antropología de la cultura moderna. Lo mismo que la antropología parece ser una psicología social de las culturas llamadas primitivas. Si nuestras representaciones son sociales, no es sólo a causa de su objeto común o del hecho que ellas son compartidas sino también porque ellas son el producto de una división del trabajo que las marca con una cierta autonomía. Sabemos que hay categorías de personas que se dedican a fabricarlas: son las que se consagran a la difusión de los conocimientos artísticos y científicos: médicos, terapeutas, trabajadores sociales, animadores culturales, especialistas en medios y en marketing político. En muchos aspectos, se emparentan con los fabricantes de mitos de las civilizaciones más antiguas. Su 'savoir-faire' es codificado y transmitido confiriendo a los que lo poseen, una indudable autoridad. Sería necesario acordar más atención a esta división del trabajo y a los especialistas que ponen en marcha métodos que suponen un conocimiento de la vida psíquica y una visión del aspecto colectivo del más alto interés." (Moscovici, 1989).

"Las representaciones, como fenómenos cognitivos comprometen la pertenencia social de los individuos con las implicancias afectivas y normativas, con las interiorizaciones de experiencias, de prácticas, de modelos de conducta y de pensamiento socialmente 
inculcados o transmitidos por la comunicación social a la que están ligadas. Desde este punto de vista, las representaciones sociales son abordadas a la vez, como el producto y el proceso de una actividad de apropiación de la realidad exterior al pensamiento y de elaboración psicológica y social de esta realidad. Es decir que interesa por ser una modalidad de pensamiento en su aspecto constituyente -los procesos- y constituido -los productos o contenidos-“ (Jodelet, 1985).

Remitir la cognición a las condiciones sociales de producción, de circulación y a la finalidad de las representaciones, crea una diferencia radical en tanto las representaciones sociales no pueden ser pensadas según el modelo dominante del tratamiento de la información ${ }^{41}$.

Jodelet dice que "las representaciones sociales se presentan bajo formas variadas, más o menos complejas: imágenes que condensan un conjunto de significados; sistemas de referencia que nos permiten interpretar lo que nos sucede, e incluso, dar un sentido a lo inesperado; categorías que sirven para clasificar las circunstancias, los fenómenos y a los individuos con quienes tenemos algo que ver. Cuando se les comprende dentro de la realidad concreta de nuestra vida social, las representaciones son todo ello junto."

Se trata de "una manera de interpretar y de pensar nuestra realidad cotidiana, una forma de conocimiento social. $Y$ correlativamente una actividad mental desplegada por individuos y grupos a fin de fijar su posición en relación con situaciones, acontecimientos, objetos y comunicaciones que les conciernen. Lo social interviene ahí de varias maneras: a través del contexto concreto en que se sitúan los individuos y los grupos; a través de la comunicación que se establece entre ellos; a través de los marcos de aprehensión que proporciona su bagaje cultural; a través de los códigos, valores e ideologías relacionados con las posiciones y pertenencias sociales específicas.

Así pues, la noción de representación social nos sitúa en el punto donde se intersectan lo psicológico y lo social ${ }^{42}$.

Concierne a la manera en que nosotros, sujetos sociales, aprehendemos los acontecimientos de la vida diaria, las características de nuestro medio ambiente, las informaciones que en él circulan, a las personas de nuestro entorno próximo y lejano. En pocas palabras, se trata del conocimiento 'espontáneo', 'ingenuo', lo que tanto

\footnotetext{
${ }^{41} \mathrm{Su}$ estudio permite soslayar las dificultades que éste plantea, a saber: el riesgo de reducir el funcionamiento mental al de la computadora.

${ }^{42}$ En el desarrollo del concepto, la psicología social recurre a distinguir el concepto de representación social del concepto de cognición social en donde, en el marco del primero se considera al conocimiento como proceso y no como contenido. La diferencia que puede plantearse entre ambos radica en la centralidad del contexto para el análisis del primero y del procesamiento individual de la información para el segundo. En el segundo, el contexto representa
} 
interesa en la actualidad a las ciencias sociales, ese que habitualmente se denomina conocimiento de sentido común, o bien pensamiento natural, por oposición a pensamiento científico. Ese conocimiento se constituye a partir de nuestras experiencias, pero también de las informaciones, conocimientos, y modelos de pensamiento que recibimos y transmitimos a través de la tradición, la educación y la comunicación social. De este modo, este conocimiento es, en muchos aspectos, un conocimiento socialmente elaborado y compartido. Bajo sus mútliples aspectos intenta dominar esencialmente nuestro entorno, comprender y explicar los hechos e ideas que pueblan nuestro universo de vida o que surgen en el actuar sobre y con otras personas, situarnos respecto a ellas, responder a las preguntas que nos plantea el mundo, saber lo que significan los descubrimientos de la ciencia y el devenir histórico para la conducta de nuestra vida, etc. En otros términos, se trata de un conocimiento práctico. Al dar sentido a acontecimientos y actos que terminan por sernos habituales, este conocimiento forja las evidencias en nuestra realidad consensual, participa en la construcción social de nuestra realidad (cf. P. Berger y T. Luckman, 1966; cit. por Jodelet, 1985)."

Más adelante Jodelet aclara:

"El concepto de representación social designa una forma de conocimiento específico, el saber de sentido común, cuyos contenidos manifiestan la operación de procesos generativos y funcionales, socialmente caracterizados. En sentido más amplio designa una forma de pensamiento social.

Las representaciones sociales constituyen modalidades de pensamiento práctico orientados hacia la comunicación, la comprensión y el dominio del entorno social, material e ideal.

La caracterización social de los contenidos o de los procesos de representación ha de referirse a las condiciones y a los contextos en que surgen las representaciones, a las comunicaciones mediante las que circulan y a las funciones a las que sirven dentro de la interacción con el mundo y los demás." (Jodelet, 1985).

Las representaciones son esencialmente dinámicas, producto de determinaciones históricas y construcciones que tienen una función de orientación: conocimientos sociales que sitúan al individuo y situándolo, definen su identidad social y su modo de ser particular. En la vertiente que estudia las representaciones sociales el contexto es un aspecto fundamental del estudio, sea porque las representaciones son campos estructurados por los habitus o por los contenidos históricos que impregnan el imaginario social, sea porque son estructuras estructurantes de ese contexto $\mathrm{y}$, como

una serie de variables independientes que deben ser controladas: quién y dónde son controlados, por qué afectan el producto - "qué" y "cómo"-. 
tal, motores del cambio social. El contenido de las representaciones sociales es producto y productor del orden simbólico.

Siendo conocimientos prácticos están orientadas hacia el mundo social haciendo y dando sentido a las prácticas sociales.

Jodelet caracteriza la representación como una forma de saber práctica que relaciona un sujeto con un objeto, en donde las características de ambos tendrán una incidencia sobre lo que ella es.

En tanto forma de saber, la representación se presentará como una modelización del objeto, directamente legible o inferida en diversos soportes lingüísticos y de comportamientos.

Calificar este saber como práctico remite a la experiencia a partir de la cual este saber es producido dentro de los marcos y condiciones en los que se da y, sobre todo, al hecho de que la representación sirve para actuar sobre el mundo y los demás. Esto condiciona sus funciones y su eficacia social.

Las cuestiones que plantean la articulación de estos elementos pueden ser condensadas en la fórmula siguiente: ¿quién sabe y de dónde se sabe? ¿qué y cómo se sabe? ¿acerca de qué se sabe y con qué fin?

Destacado su carácter práctico, la representación se orienta a la acción y la gestión con relación al mundo. Permanece, como modo de conocimiento sociocéntrico, al servicio de las necesidades, deseos e intereses del grupo. Esta finalidad, el hecho de que la representación sea una reconstrucción del objeto, expresiva del sujeto, ocasiona un desfasaje con su referente ${ }^{43}$.

Jodelet aclara que el contenido de las representaciones puede aprehenderse, como se dijo, como campo estructurado y como campo estructurante, no excluyentes entre sí.

En un nivel, la representación se arraiga en una red de significaciones que permite situarla en el marco de los valores sociales y darle coherencia, inscribiéndola en un sistema de nociones ya pensado y aceptado. Por un trabajo de la memoria, el pensamiento constituyente se apoya sobre el pensamiento constituido para ordenar la novedad en esquemas antiguos, en lo ya conocido. En otro nivel, la formación representativa sirve para la instrumentación del saber, confiriéndole un valor funcional para la interpretación y la gestión en el entorno. Se ubica en continuidad de la

\footnotetext{
${ }^{43}$ El desfasaje puede deberse a la intervención de los valores y códigos colectivos, de las implicancias personales y de los compromisos sociales de los individuos. Produce tres tipos de efectos en el nivel de los contenidos representativos: distorsiones, suplementos y desfalcos.

En el caso de la distorsión, todos los atributos del objeto representado están presentes pero acentuados o atenuados de manera específica (ej.: imagen del niño auténtica es: reflejo invertido de la del adulto en sociedad). El suplemento consiste en conferir al objeto representado atributos, connotaciones que no le pertenecen en sentido propio, surge de un agregado de significación, resultado del imaginario del sujeto o de la proyección sobre el otro de rasgos que uno posee que se consideran son evaluados desfavorablemente (la proyección sobre el otro de esos rasgos sirve para
} 
objetivación. La naturalización de las nociones les da valor de realidades concretas, directamente legibles y utilizables en la acción sobre el mundo y los otros. Por otra parte, la estructura imaginaria de la representación se vuelve guía de lectura y teoría de referencia para comprender la realidad.

Pensar la cognición como algo social, abre vías de investigación para el abordar cómo "las instituciones piensan" y cómo "el proceso cognitivo individual más elemental depende de las instituciones sociales" (Douglas, 1990). De este modo, "las representaciones sociales, según la definición clásica presentada por Jodelet, son modalidades de conocimiento práctico orientadas hacia la comunicación y comprensión del contexto social, material e ideativo en que vivimos. Son formas de conocimiento que se manifiestan como elementos cognoscitivos (imágenes, conceptos, categorías, teorías), pero no se reducen a los componentes cognitivos. Siendo socialmente elaboradas y compartidas, contribuyen a la construcción de una realidad común, que posibilita la comunicación. De este modo, las representaciones son fenómenos sociales que tienen que ser entendidas a partir de su contexto de producción" (Spink, 1995).

Dentro del campo antropológico, Sperber (1982) insiste en la importancia de considerar la circulación y los procesos de difusión de las representaciones y destaca la importancia primordial de la comunicación en los fenómenos representativos incidiendo sobre los aspectos estructurales y formales del pensamiento social, en la medida que compromete procesos de interacción social, influencia, consenso, disenso y polémica. Finalmente, destaca que la comunicación forja representaciones que son pertinentes para la vida práctica y afectiva de los grupos e instauran versiones de la realidad comunes y compartidas.

"Toda representación pone en juego una relación entre al menos tres términos: la representación misma, su contenido, y el que la utiliza, tres términos a los que puede sumarse un cuarto: el productor de la representación que es diferente del que la utiliza $^{44}$.

restaurar la estima de uno mismo). El desfalco proviene del efecto represivo de las normas sociales y corresponde a la supresión de atributos que pertenecen al objeto.

${ }^{44}$ Una representación puede existir en el interior del que la utiliza; el que la utiliza y el productor de la representación mental son uno: se trata entonces de una representación mental (un recuerdo, una hipótesis, una intención). Una representación puede existir también dentro del contexto del que la utiliza, como por ejemplo el texto, un discurso en una asamblea: se trata ahora de una representación pública. Una representación pública es generalmente un medio de comunicación entre el productor y el que la usa, distintos uno del otro. Una representación pública puede tener varios "usuarios". La reproducción estricta de una representación pública a través de técnicas como la impresión o la televisión supone la producción de representaciones semejantes unas de otras -hablamos de versiones- por medio de la trasmisión.

Entre las representaciones mentales, algunas -una pequeña proporción- son comunicadas en forma repetida y conducen a quien las usa a producir una representación pública que conducirá a otro individuo a construir una representación mental de similar contenido al de la representación inicial y pueden terminar por ser distribuidas dentro del grupo entero, es decir, hacerlas objeto de una versión mental en cada uno de sus miembros. 
Las representaciones que son ampliamente distribuidas en el grupo social y residen en forma duradera son representaciones culturales. Las representaciones culturales son una subunidad en los contornos desvaídos de la unión entre las representaciones mentales y públicas de un grupo social." (Sperber, 1982).

Dicho autor realiza señalamientos metodológicos respecto de cómo representar las representaciones culturales planteando que "no podemos, en la práctica, representar el contenido de una representación que, de un modo $u$ otro, tenga un contenido similar. No describimos el contenido de una representación, la parafraseamos, traducimos, resumimos, desarrollamos, en una palabra interpretamos ${ }^{45}$. Una interpretación es la representación de una representación por otra en virtud de la similitud de contenido. En este sentido, una representación pública en la que el contenido es semejante al de una representación mental que se engarza para comunicar, es una interpretación, y lo mismo sucede con la representación mental resultante de la comprensión de una representación pública. El proceso de la comunicación se descompone en dos procesos de interpretación: uno del mental hacia el público, otro del público hacia el mental.

La interpretación no es una forma de representación reservada a los especialistas. Expresar o comprender es interpretar, de manera al menos implícita. Por otra parte, hacemos todo un trabajo de interpretación explícita cuando respondemos a preguntas como: ¿qué tiene él?, ¿qué piensa ella?, ¿qué quieren ellos?. Para responder, representamos el contenido de las palabras, pensamientos 0 intenciones en enunciados de contenido semejante.

El estudio antropológico de las representaciones culturales no puede ignorar su contenido; y éste está dado al menos en gran parte, por un estudio interpretativo."

Desde otras posturas teóricas, el concepto de representación se halla ligado al concepto de ideología así como al concepto de identidad. Su relación con el primero tiene que ver con el desarrollo, a mediados del siglo XX, de nociones más inclusivas y menos peyorativas de ideología entendidas ahora como "sistemas políticos o sociales de ideas, valores o preceptos de grupos u otras colectividades que tienen la función de organizar o legitimar las acciones del grupo." ${ }^{46}$ (van Dijk, 1998).

Las ideologías no se refieren a aquello que es verdadero o falso sino sobre la forma en que las personas representan sus creencias sobre sí mismas y sobre el mundo social.

\footnotetext{
${ }^{45}$ La distinción entre descripción e interpretación está desarrollada en El saber de los antropólogos (Sperber,1982).

${ }^{46}$ van Dijk se centra en el estudio, menos familiar, del núcleo cognitivo de las ideologías; luego ubica las ideologías en sus contextos sociales y destaca su reproducción discursiva.

Continúa y renueva la tradición de la teoría crítica en las ciencias sociales iniciada por la Escuela de Frankfurt hace 60 años. Ubica su enfoque en el triángulo conceptual que relaciona: cognición, sociedad y discurso.
} 
El término representación social es aplicado por van Dijk sólo a conjuntos organizados de creencias socialmente compartidas. Consisten en aquellas creencias sociales generales y abstractas compartidas que controlan $u$ organizan el conocimiento y las opiniones más específicas de un grupo para llevar a cabo las prácticas sociales cotidianas, el actuar y comunicar. Generales, abstractas y pertinentes a un grupo, deben ser funcionales al grupo como un todo y reflejar las condiciones de su existencia y reproducción.

Las ideologías serían aquellas creencias socialmente compartidas por colectividades sociales específicas o grupos de algún tipo. Refiere al conjunto de creencias fácticas y evaluativas -conocimiento y opiniones- de un grupo, que definen la base de su identidad.

No se concibe entonces de manera negativa a las ideologías ni se las restringe a la estructura de dominación: hay ideologías de oposición, de resistencia, de competencia, de cohesión, etc. ${ }^{47}$

Pretende analizar las formas en que las ideologías socialmente compartidas se manifiestan en un tipo específico y esencial de práctica social: el discurso, y cómo las representaciones sociales basadas en la ideología y compartidas por un grupo influyen en el texto/conversación situados, reales, de los actores y explica cómo las ideologías se construyen, cambian, cuestionan y reproducen a través del discurso y de su uso en prácticas cotidianas.

Aunque los discursos no son las únicas prácticas sociales basadas en la ideología, son fundamentales en su formulación y en su reproducción social. El discurso (lenguaje, texto, conversación, etc.) se usa para aprender, adquirir, modificar, confirmar, articular y trasmitir ideologías. Las manifestaciones discursivas permiten observar cómo ellas funcionan, se crean, cambian y reproducen ${ }^{48}$.

El discurso involucra representaciones mentales (significados, conocimiento, estructuras abstractas) y al mismo tiempo es una forma de acción social, política o cultural.

Las ideologías exhiben o controlan las relaciones de poder y dominación entre los grupos y constituyen la base de las representaciones sociales compartidas por los miembros de un grupo que les permiten organizar la multitud de creencias sociales acerca de lo que sucede según ellos y actuar en consecuencia. Ellas operan en el

Sus objetivos consisten en encontrar una teoría amplia y multidisciplinaria de ideología, contribuir en el estudio de las estructuras y estrategias del discurso, en la cognición social y en la inserción social de las mismas e intenta desarrollar una nueva noción de ideología que sirva de interfase entre la estructura social y la cognición social.

${ }^{47}$ Hay que examinar en forma crítica las ideologías cuando legitiman el abuso del poder o la dominación. Pero eso no significa que toda legitimación, como tal, sea negativa (van Dijk, 1998). 
nivel global de la estructura social, pero también en el nivel de las prácticas sociales cotidianas como "monitor" mental o marco compartido de creencias sociales; ellas organizan y coordinan las interpretaciones y prácticas sociales de grupos y sus miembros guiando y regulando las relaciones de poder entre grupos sociales.

Eagleton (1997) también vincula las representaciones sociales con el concepto de ideología y se opone a concebir a esta última como falsa conciencia: considera que no es una ilusión carente de base sino una sólida realidad, una fuerza material activa que debe tener al menos cierto contenido cognitivo para contribuir a organizar la vida práctica de los seres humanos.

Aunque se pueda sostener que la ideología a menudo o normalmente supone falsedad, distorsión y mistificación, no todo discurso ideológico supone necesariamente falsedad; además tampoco es cierto que todo compromiso con el orden social dominante suponga engaño. Por tanto, la ideología no está inherentemente constituida por la distorsión (adoptando la noción amplia de ideología que denota cualquier síntesis nuclear entre discurso y poder).

Es posible que un orden dominante haga pronunciamientos que son ideológicos (refuerzan su propio poder), pero no son falsos en ningún sentido.

Si extendemos el término ideología a los movimientos políticos de oposición, muchas de sus manifestaciones ideológicas son verdaderas ya que fomentan sus intereses; ésto no significa que tales movimientos no puedan incurrir en distorsiones y mistificaciones.

La gran mayoría de las personas tienen una conciencia muy sensible de sus propios derechos e intereses y la mayoría se sienten incómodas ante la idea de pertenecer a una forma de vida muy injusta: o creen que esas injusticias están en vías de ser corregidas o que están compensadas por beneficios mayores, o que son inevitables o que en realidad no son injusticias.

Eagleton brinda varias acepciones de ideología, pasibles de homologar a la noción de representaciones sociales.

Una de ellas alude al proceso de producción de ideas, creencias y valores en la vida social. Se trata de una definición políticamente neutra, próxima al concepto semiótico de cultura. Denota todo el complejo de prácticas de significación y procesos simbólicos de una sociedad, alude a la manera en que las personas viven sus prácticas sociales: refiere a los signos, significados y valores codificados en las prácticas. Otra de las definiciones de ideología que puede relacionarse con representaciones sociales remite

\footnotetext{
${ }^{48}$ Los discursos son formas de acción social situados en contextos sociales en los cuales los participantes son miembros de grupos y culturas. Las reglas y normas del discurso son socialmente compartidos. Las condiciones, funciones y efectos del discurso son sociales y la competencia discursiva se adquiere socialmente (van Dijk, 1998).
} 
a las ideas y creencias que simbolizan las condiciones y experiencias de vida de un grupo o clase concreto (Eagleton, 1997) y, en tal sentido se aproxima a la desarrollada por van Dijk.

Giménez (1997) vincula las nociones de cultura, identidad y representación social atravesadas por relaciones de poder.

"La cultura influye sobre las dimensiones económica, política y demográfica de cada sociedad; define las finalidades, las normas y los valores que orientan la organización de la producción y el consumo, la cultura orienta y controla la acción y en ella se basa la legitimidad del poder. La cultura es operativa a través de los actores sociales que la portan y sólo puede proyectar su eficacia por mediación de la identidad. En cuanto dimensión subjetiva de los actores sociales, la identidad no es más que el lado subjetivo de la cultura resultante de la interiorización distintiva de símbolos, valores y normas."

Distingue analíticamente tres dimensiones -imbricadas entre sí e indisociables- en el conjunto de hechos culturales: la cultura como comunicación, la cultura como stock de conocimientos, la cultura como visión del mundo. La cultura específica de una comunidad implicaría una síntesis original de las tres dimensiones. La cultura hace existir una colectividad en la medida en que constituye su memoria, contribuye a cohesionar a sus actores y permite legitimar sus acciones.

La identidad sería el lado subjetivo de la cultura considerada bajo el aspecto de su función distintiva: ella emerge y se afirma sólo en la confrontación con otras identidades durante la interacción social la cual implica frecuentemente relaciones de desigualdad, luchas y contradicciones.

Es la identidad la que permite a los actores ordenar sus preferencias y escoger alternativas de acción (función selectiva de la identidad). El concepto de identidad permite comprender, dar sentido, reconocer y explicar una acción. Asimismo, también es útil para la comprensión/explicación de los conflictos sociales en la medida en que todo conflicto pone en evidencia un conflicto de identidad.

La pertenencia social, pertenecer a un grupo o a una comunidad, implica la apropiación/interiorización, al menos parcialmente, del complejo simbólico-cultural ${ }^{49}$, es decir, del núcleo de representaciones sociales que los caracteriza y define.

Concibe a la representación social como una construcción sociocognitiva propia del sentido común que puede definirse como el conjunto de informaciones, creencias, opiniones y actitudes a propósito de un objeto determinado. Sería una forma de

\footnotetext{
${ }^{49}$ La pertenencia social reviste distintos grados. Los colectivos concretos a los que se puede pertenecer son, en sentido estricto -según categorías de Merton-: grupos (aldea, vecindario, club), colectividades (nación, iglesias). Pero en un sentido más amplio también se pueden incluir a las redes sociales (relaciones de interacción coyunturalmente actualizadas) y a determinadas categorías sociales (género, edad, profesión) (Giménez, 1997).
} 
conocimiento socialmente elaborado y compartido y orientado a la práctica, que contribuye a la construcción de una realidad común a un conjunto social.

Las representaciones sociales sirven como marcos de percepción y de interpretación de la realidad y como guías de los comportamientos y prácticas de los agentes sociales.

Si se plantea que la identidad es una construcción interactiva y una realidad intersubjetiva, se desprende que ella requiere de contextos de interacción estables: "mundos familiares" de la vida ordinaria conocidos por los actores con fines prácticos; el "mundo de vida" se da por sentado. Es ese contexto lo que permite a los sujetos administrar su identidad y sus diferencias por medio de un orden legítimo, interpelarse mutuamente, etc. Estos mundos dan un marco cognitivo y normativo capaz de orientar y organizar interactivamente sus actividades ordinarias. Hay una relación de determinación recíproca entre la estabilidad de los contextos de interacción y la identidad de los actores ${ }^{50}$.

Pero en tanto la sociedad es un sistema hecho de campos diferenciados, las interacciones sociales están ligadas a la estructura de las relaciones objetivas entre posiciones en los diversos campos sociales.

Similar articulación conceptual establecen Aguado y Portal (1992) quienes proponen un concepto de ideología positivo y no valorativo que sirve para aprehender los mecanismos de reproducción cultural y para analizar cómo los grupos sociales, en cada momento histórico, crean y reproducen un orden social significativo que da cuenta de su identidad. Las formas de ordenamiento del mundo material/simbólico de un grupo responden al tipo de experiencia colectiva y a su manera particular de apropiación de ella.

Al referirse a la parcialidad de clase plantean que la clase hegemónica subordina la reproducción material e ideológica del resto de los grupos y clases sociales. Esa subordinación señala los diversos lugares -determinados por la estructura económicadesde donde se ordena la práctica social; los diversos grupos y clases sociales se apropian del capital cultural común desde el lugar particular que ocupan.

Con base en ello, la identidad concentra diversas experiencias relativas a la conservación o reproducción (permanencia), a los procesos colectivos que recrean la diferenciación (de clase, étnica) y a las prácticas culturales que permiten la identificación.

\footnotetext{
${ }^{50}$ En ese sentido, la sociedad moderna se caracteriza por la pluralidad de los mundos de vida con consecuencias en la configuración de la identidad, cada vez más abierta, reflexiva, múltiple, diferenciada, proclive a la conversión. Lo que caracterizaría a las sociedades modernas sería la ausencia de un universo simbólico unitario capaz de integrar las normas y los ámbitos institucionales y de conferir significado a la vida de los individuos. La sociedad moderna sería una sociedad culturalmente descentrada, caracterizada por la multiples referentes simbólicos, heterogéneos, no integrados entre sí.
} 
Reproducir una identidad particular implica tener un lugar desde donde apropiarse y ordenar la experiencia vivida, confiriéndole sentido a un grupo y dotándolo de una estructura significativa para asumirse como una unidad. Hablar de reproducción cultural implica que se debe abordar desde el análisis de grupos sociales concretos.

Destacan que si bien cada grupo social tiene sus prácticas diferenciadas y diferenciables, su reproducción como tal está determinada por su relación con otros grupos y particularmente con el hegemónico. Así es que hablan de una doble parcialidad, ya que no sólo encontramos un lugar particular desde donde se ordena la experiencia sino también la imposición simbólica de la parcialidad hegemónica.

La ideología como nivel de ordenamiento de prácticas e inmersa en relaciones de poder tiene el carácter de representación concreta en dos sentidos: porque se alimenta de la experiencia inmediata y porque esto posibilita la acción.

La eficacia simbólica de la ideología radica en su capacidad de múltiple interpelación, dado que cada mensaje emitido es descontextualizado y recontextualizado a partir del lugar desde donde el receptor ordena su experiencia.

En síntesis, y caracterizando brevemente la noción de representaciones sociales compartidas por la comunidad científica puede afirmarse que: es una forma de conocimiento socialmente elaborado y compartido, teniendo un fin práctico y participando en la construcción de una realidad común a un conjunto social. Designado a veces como "saber de sentido común", "saber inocente" "natural" esta forma de conocimiento se distingue del conocimiento científico con el que mantiene múltiples relaciones a través de su apropiación, impugnación, resemantización, transformación. Es tenido como objeto de estudio tan legítimo como este último, en razón de su importancia en la vida social por ser constitutivo de los procesos cognoscitivos y de las interacciones sociales. Las representaciones sociales, en tanto sistemas de interpretación que determinan nuestra relación con el mundo y con los demás, orientan y organizan las conductas y las comunicaciones sociales. Asimismo intervienen en procesos tan variados como la difusión y asimilación de conocimientos, el desarrollo individual y colectivo, la definición de las identidades sociales y personales, la expresión de los grupos y las transformaciones sociales (Jodelet, 1989).

"El concepto de representación no pertenece a una disciplina más que a otra. Numerosos especialistas de las ciencias humanas lo utilizan y dan definiciones diferentes, es decir, recortan un núcleo de sentido dentro de una totalidad empírica extremadamente vasta. En nuestra opinión corresponde a la antropología mostrar que la representación, cualquiera sea el aspecto que se privilegie, se sitúa siempre: 1) en la unión de lo individual y lo social; 2) en tres dimensiones: el campo del conocimiento; 
el campo del valor, el campo de la acción. Una representación no es reductible a sus aspectos cognitivos y valorativos. Simultáneamente expresión y construcción de lo social, consiste no solamente en un medio de conocimiento, sino también en un instrumento de la acción." (Laplantine, 1984). 


\section{ESTRATEGIAS FAMILIARES Y CONSUMO ALIMENTARIO}

\subsection{Introducción al concepto de estrategias familiares}

En los puntos anteriores se ha planteado que entre el campo de las situaciones objetivas y el de su representación, se constituyen los sujetos, definidos en parte por su inserción en la estructura social y en parte por su percepción de esa situación y del lugar que en ella ocupan.

La categoría reproducción social, utilizada como eje articulador del estudio y ubicada en el plano de mayor abstracción, permite abordar los procesos de producción y consumo en tanto condicionantes directos de la calidad de vida de los miembros de cierta colectividad o de sus clases (Brehil, 1989).

Una de las manifestaciones de dicho abordaje se encuentra en la emergencia de una perspectiva analítica que intenta rescatar el estudio de las relaciones entre fenómenos del nivel macrosocial (estructural) y del nivel microsocial (microcomportamientos), a través de instancias mediadoras tales como las clases sociales y la familia (Torrado, 1983).

Dentro de esta perspectiva se individualiza el enfoque que ha organizado su reflexión alrededor del concepto de estrategias familiares de vida o estrategias de supervivencia.

El tema de las condiciones de reproducción social en los sectores populares urbanos es motivo de interés de las ciencias sociales desde ángulos diversos. "¿Cómo logran reproducir su existencia ciertas clases, fracciones y grupos sociales a pesar de las restricciones en términos de trabajo, ingreso y consumo que les impone el modelo de desarrollo de las sociedades capitalistas atrasadas?" (Hintze, 1989).

Las ciencias sociales latinoamericanas desarrollan el concepto de estrategias de sobrevivencia para dar respuesta a este interrogante; concepto que engloba la articulación de un conjunto de mecanismos, comportamientos y relaciones desplegadas para darle viabilidad a un objetivo fundamental: alcanzar un cierto nivel de satisfacción de necesidades básicas: alimentación, educación, vivienda, vestido, salud, etc.

Este concepto no tiene un significado único, asume diversos contenidos y ha sido utilizado por diferentes vertientes teóricas.

En ese camino y para recuperar su utilización, se revisarán los contenidos implícitos en él.

La expresión "estrategias de supervivencia" nace en un trabajo de Duque y Pastrana (1973), quienes se plantean el estudio de las formas de sobrevivencia de familias de pobladores de campamentos en Santiago de Chile, preocupándose fundamentalmente 
de la supervivencia económica de la familia. El concepto alude aquí a las estrategias objetivas de subsistencia económica.

El concepto es posteriormente redefinido incluyendo los "comportamientos encaminados a asegurar la reproducción material y biológica del grupo" (PISPAL, 1978).

Torrado, partícipe de la definición arriba mencionada, realiza una enumeración exhaustiva de los comportamientos que estarían incluidos en las estrategias, para el caso de la clase obrera que pretende estudiar, constituyendo en realidad dimensiones alrededor de las cuales puede nuclearse toda una serie de comportamientos. Estas dimensiones aluden nuevamente a comportamientos dirigidos a la reproducción biológica y material, pero lo que se hace evidente es que el campo se limita de por sí al estudio de aquellos grupos que se encuentran al nivel de subsistencia (Torrado, 1981).

Al fundamentar las limitaciones del concepto de estrategias de supervivencia (Torrado,1981,1985) señala que el término restringe su uso a los comportamientos ligados a "la subsistencia mínima, básica, fisiológica" y, por lo tanto, a los grupos sociales más desfavorecidos de la sociedad.

Propone entonces un abordaje más abarcativo utilizando el concepto de "estrategias familiares de vida" definidas a partir de la inserción de clase de las familias, permitiendo así efectuar análisis comparativos en función de la posición socioeconómica de las mismas (Bloch, Torrado y otros, 1984).

Sin embargo, los grupos sociales sobre los que tratan la mayoría de los estudios de este tipo son aquellos denominados "subordinados", "pobres urbanos", "marginales", "sectores populares", etc.

Podrían citarse los trabajos de Lomnitz (1975) en sectores marginales de México, Bartolomé (1983) en Posadas, Argentina, de Raczynsky y Serrano (1985) en familias de trabajadores cesantes de Santiago de Chile, de Margulis $(1981,1986)$ en colonias populares de México, de Hintze (1989) en sectores populares de Villa La Cava, Pcia. de Bs. As., de Eguía (1992) en sectores populares urbanos de la localidad de Punta Lara, Partido de Ensenada, de Gutiérrez (1993) en familias de la pobreza urbana de Altos de Yapeyú, Pcia. de Córdoba, etc.

Estas investigaciones difieren de aquellas realizadas hace más de treinta años atrás en que "parten de un consenso no demasiado explicitado: la ausencia de preguntas sobre la génesis de estos sectores, ampliamente explorada por las ciencias sociales del período anterior a través de las diferentes teorías de la marginalidad. De hecho, ya no interesa saber qué los origina; parece bastar con saber que aquí están y sin conflictos demasiado evidentes ni tensiones masivas logran sobrevivir." (Hintze,1987). 
Las estrategias familiares pueden definirse en términos generales como "aquellos comportamientos de los agentes sociales de una sociedad dada que -estando condicionados por su posición social- se relacionan con la constitución y mantenimiento de las unidades familiares en el seno de las cuales pueden asegurar su reproducción biológica, preservar la vida y desarrollar todas aquellas prácticas, económicas y no económicas, indispensables para la optimización de las condiciones materiales y no materiales de existencia de la unidad y de cada uno de sus miembros." (Torrado,1981).

Las familias de acuerdo con su situación de clase, fracciones o grupos "organizan sus recursos para el logro de ciertos objetivos referidos a la unidad o a sus miembros, cualquiera sea el grado de conciencia que éstos tengan acerca de esa organización y objetivos. El concepto de estrategias permite la reconstrucción de la lógica subyacente en estas acciones y opera como nexo entre la organización social de la reproducción de los agentes sociales y las familias responsables de esta reproducción." (Borsotti,1981).

"Los comportamientos de los sujetos sociales son conformados (pero a su vez conforman) alternativas que se les presentan como posibilidades objetivas y es en este punto que el concepto aparece efectivamente como nexo entre las elecciones individuales y estructuras sociales, en tanto remite más que a acciones racionales guiadas por normas y valores interiorizados, a opciones posibles." (Hintze,1987).

La aproximación intenta alejarse tanto de las explicaciones mecanicistas que conciben a las prácticas individuales o familiares como la imagen especular de un modelo, cuanto de aquellas que suponen las acciones como el producto de una actividad racional que realiza cálculos en términos de costo/beneficio. Permite plantear qué es lo que hace que familias que ocupan similares posiciones dentro de la estructura social actúen, sin embargo, de manera diferente o manifiesten condiciones diferenciales de vida.

En este contexto interesa resaltar que los comportamientos individuales y familiares, a pesar de la amplia variedad que puedan presentar y la especificidad que adquieren dentro de cada familia, no pueden ser comprendidos al margen del espacio macrosocial en que su accionar se inscribe (Hintze,1987).

La relación entre ambos niveles debe ser establecida desde una perspectiva dual:

- A través de la identificación de aquellos aspectos del estilo de desarrollo en una determinada sociedad que inciden más directamente sobre los comportamientos de los individuos y familias de cada grupo social. 
- Mediante la detección de las formas en que las estrategias familiares típicas de cada clase o fracción condicionan los procesos sociales que tienen lugar en esa sociedad, así como la viabilidad de su estilo de desarrollo particular.

En este caso particular se parte del supuesto de que las familias de la pobreza urbana, a fin de reproducirse y optimizar sus condiciones de existencia, adoptan una serie de comportamientos tendientes a constituir unidades dentro de las cuales pueden asegurar su reproducción biológica, preservar la vida y desarrollar aquellas prácticas indispensables para optimizar sus medios de subsistencia y la socialización de sus hijos.

No obstante, el análisis ideal que requiere estudiar tal multiplicidad de dimensiones conductales, sus interrelaciones a lo largo de la historia familiar y la naturaleza y peso de los condicionantes que influyen en cada comportamiento, no puede ser adoptado en la práctica por la mayoría de los estudios en virtud de las limitaciones de los recursos disponibles, información básica existente, etc.

Así, el presente estudio se centra en el análisis de las estrategias implementadas por familias de la pobreza urbana del Gran La Plata, incluyendo los comportamientos y los significados relacionados a la problemática alimentaria, cuyas modalidades se expresan en la existencia -o no- de desnutrición en sus niños.

\subsection{Estrategias familiares, necesidades y consumo alimentario}

La alimentación es un aspecto central de la reproducción individual y social y un indicador elocuente de las condiciones de vida de las familias.

El abordaje de las condiciones materiales para la existencia constituye un punto de partida: incluye aspectos tales como las condiciones de trabajo, el consumo de bienes y servicios y remite al análisis de la satisfacción/insatisfacción de necesidades básicas en tanto mediadoras del desarrollo de capacidades y potencialidades humanas. El trabajo es clave por el papel que cumple como determinante de los niveles y tipos de consumo.

Se considera que el trabajo es el mecanismo principal para la reproducción familiar; de allí que en este trabajo se incluya el estudio de la participación económica y su articulación con otras actividades desarrolladas por las familias para asegurar su reproducción cotidiana -tales como la participación en programas sociales y la implementación de estrategias autogeneradas ${ }^{51}$.

\footnotetext{
${ }^{51}$ La producción de bienes y servicios para el autoconsumo desarrolladas en la esfera doméstica constituye una actividad económica básica, inclusive en las sociedades altamente mercantilizadas. La reproducción de los miembros de la sociedad está basada en una cuota nada despreciable de trabajo invisible, no contabilizado socialmente, que se desarrolla en el ámbito privado de la unidad doméstica (Eguía et al., 2000).
} 
La sociedad moderna se caracteriza por la heterogeneidad que prevalece dentro de la división social del trabajo con la existencia de diversas clases entre las cuales hay marcadas diferencias que se expresan en el acceso al consumo. Esa diferenciación se constata en el acceso al alimento, regulado por el mercado, condicionando la adquisición de satisfactores y redefiniendo la noción de necesidades humanas. Una alimentación adecuada estará mediada, por lo tanto, por las oportunidades reales que ese espacio brinda a cada grupo conforme a su participación en la producción. La satisfacción colectiva de la alimentación recrea patrones de heterogeneidad y polarización y las desigualdades en la accesibilidad al alimento tienen manifestaciones concretas en la condición nutricional del grupo. El acceso a una alimentación adecuada en cantidad y calidad dependen en gran medida de la capacidad adquisitiva de cada grupo, que obedece a su vez, al tipo de inserción en los procesos productivos. En la ciudad, el dinero representa la principal vía para obtener satisfactores en el mercado y constituye el elemento más importante para la reproducción del grupo doméstico (Rivera y Ruiz, 1998).

Tal como se afirmó, la alimentación constituye un consumo relativamente inelástico y representa -dentro del presupuesto familiar de los sectores pobres- el gasto relativo más importante.

Si la crisis y el ajuste han significado un alto costo social para las grandes mayorías urbanas, seguramente sus condiciones de alimentación-nutrición se han visto afectadas por la dificultad que entraña la percepción de un ingreso suficiente en tales circunstancias.

Particularmente para los sectores pobres, las repercusiones de la crisis y las políticas de ajuste estructural implementadas por el Estado se presentan como extremas por la vulnerabilidad social de la población (Eguía y Ortale, 2000).

Trabajando en una dimensión microsocial, donde se concretan los resultados de las políticas económicas, pueden comprenderse las modalidades y causas de ciertos comportamientos de los grupos sociales que viven en situación de pobreza, pues ahí toman cuerpo las desigualdades e inequidades sociales.

Numerosos informes y datos económicos, sociales y epidemiológicos -algunos de los cuales se señalan en el marco contextual- revelan la manera e intensidad con que se ve afectada la alimentación dentro de condiciones de pobreza estructural así como en situaciones de pauperización.

Asimismo, en el estudio del conjunto de los condicionantes y de las estrategias desplegadas por las familias para su alimentación, se incorporan las representaciones de las informantes sobre la misma. En ese sentido se analizan los conocimientos y las valoraciones sobre la alimentación familiar, considerando que la valoración de los 
patrones alimentarios familiares y la evaluación de los programas sociales y de otros recursos para la obtención de alimentos o comida se basan en códigos culturales que organizan la "lógica subyacente" vinculada con las estrategias (Borsotti,1981).

Retomando líneas teóricas planteadas en "La problemática agroalimentaria en la Argentina: 1970-1988" (Colman et al., 1992), se intenta analizar las modalidades que asume la reproducción alimentaria en familias de la pobreza urbana.

A partir de los planteos desarrollados por Topalov (cit. por Hintze,1989), se consideran dos vías posibles de acceso al consumo alimentario:

a) consumos obtenibles con dinero (compras particulares de las unidades domésticas y compras en conjunto, resultado del agrupamiento de familias que eventualmente realizan compras en comercios mayoristas tendientes a reducir gastos)

b) consumos no obtenibles con dinero, resultado de formas propias de organización familiar y como producto de la intervención estatal y organismos no gubernamentales (Hintze, 1989).

Las conductas que las familias despliegan a lo largo de su ciclo de vida tendientes a obtener satisfactores para sus fines productivos y reproductivos, se eligen dentro de un rango de alternativas disponibles determinadas por las restricciones paramétricas que les son propias por su inserción social (Przeworski,1982).

Las restricciones paramétricas aluden a variables tales como ingresos familiares, condiciones ocupacionales, niveles educativos, políticas públicas, etc.

Con el objeto de delimitar el concepto de estrategias familiares vinculadas al consumo alimentario en familias pobres, se propone que "la unidad doméstica genera o selecciona satisfactores por medio de la combinación de posibilidades a su alcance, realizando actividades que las relacionan con los demás agentes sociales y a distintos niveles:

a- Internamente, a partir de una determinada división del trabajo en términos sexuales y generacionales, pero también en actividades que producen ingresos y aquellas que producen bienes por medio del trabajo doméstico.

b- Con otras unidades familiares a través de redes vecinales, de amistad, de parentesco.

c- Con el mercado de trabajo y consumo

d- Con diversos miembros e instituciones de la sociedad civil

e- Con el Estado " (Hintze, 1987).

Todo grupo de distinta posición socieconómica y fundado en estructuras familiares de distinta composición tiende a desarrollar internamente pautas de alimentación, creencias y valoraciones en cuanto a la adquisición, selección y preparación de alimentos; normas de comensalía en su distribución y roles asociados a las funciones 
alimentarias que organizan la relación recursos/usos, tanto en la salud como en la enfermedad (Garrote, 1995).

Las estrategias son producto de una lógica subyacente más que de un cálculo explícito en términos de acciones planificadas para lograr la reproducción doméstica.

Son las condiciones económico-sociales imperantes las que obligan a amplios sectores de la sociedad a implementarlas.

La estructura social, el nivel macrosocial, opera como "restricción paramétrica" (Przeworski, 1982) de los comportamientos microsociales aunque éstos, dentro de ciertos límites, son indeterminados desde el punto de vista social.

Las estrategias de reproducción alimentaria son definidas por Hintze (1989) como el conjunto de actividades que los sectores populares realizan para satisfacer sus necesidades alimentarias, las que no pueden cubrir plenamente vía ingreso monetario. Las estrategias alimentarias incluyen los "comportamientos, arreglos y mecanismos implementados por estos sectores tendientes a lograr la satisfacción de sus necesidades alimentarias dentro y al margen de los circuitos mercantilizados a los que tienen acceso por medio del ingreso familiar."(Hintze,1987).

Los mecanismos a los que acceden o que implementan las familias tendientes a asegurar la alimentación diaria y la satisfacción de otras necesidades son muy diversos. Algunos implican un aumento de los recursos monetarios y no monetarios, otros significan hacer estirar los recursos disponibles, algunos se apoyan en los beneficios del sector público, otros se sustentan en una red social informal, algunos consisten en una incorporación al mercado de trabajo de una mayoría de miembros, etc. (Raczynski y Serrano, 1985).

Como señala Hintze (1989), el sistema de relaciones sociales impone restricciones al comportamiento alimentario de las familias, por lo menos en tres niveles:

a- El referido a aquellos aspectos que son determinantes del consumo de los alimentos

(ingreso, y por consiguiente la temática del empleo y precio de los alimentos).

En las sociedades en las que las relaciones capitalistas de producción son dominantes, el análisis de las estrategias familiares requiere la indagación de las condiciones de reproducción de la fuerza de trabajo, dado que esta última es condición necesaria para la reproducción de la unidad doméstica (Margulis,1980).

A partir de caracterizar la inserción laboral de los miembros de las unidades domésticas estudiadas, se puede brindar una aproximación a las posibilidades de los consumos obtenibles con dinero.

b- Las opciones o recursos locales disponibles para las familias cuando las limitaciones impuestas por estos aspectos las obligan a recurrir a alternativas que 
exceden el marco del salario y los consumos mercantilizados. Si bien se reconoce que la adquisición de alimentos se da fundamentalmente a través del mercado, los efectos de la situación socioeconómica por la que atraviesa nuestra sociedad sobre aspectos que son determinantes del consumo (empleo, decaimiento del salario real, etc.), restringen el poder adquisitivo de la población -sobre todo en los sectores que se analizan- y los consumos alimentarios no mercantilizados adquieren importancia creciente para la reproducción familiar. De aquí que se utilice el concepto de estrategias alimentarias para aludir a los consumos alimentarios no mercantilizados producto de la organización doméstica y de las acciones públicas estatales y/o civiles. Las estrategias alimentarias familiares refieren a los recursos alimentarios utilizados por las familias provistos por programas sociales estatales, organizaciones no gubernamentales o autogenerados por éstas a partir de su inserción en un contexto de pobreza. Las opciones generadas por el Estado, conforman, desde la perspectiva doméstica, alternativas a las que se recurre en la estructuración de sus estrategias y son, en países como el nuestro de larga trayectoria de intervención estatal, de vital importancia en la reproducción social de estos sectores.

En la medida en que se profundiza sobre un complemento del consumo alimentario global de las familias, cabe explorar si el salario indirecto en materia alimentaria y las estrategias autogeneradas permiten la reproducción de manera medianamente satisfactoria. Esto es, en la actual situación de crisis, ¿es posible mejorar las condiciones alimentarias a través de consumos no mercantilizados?

Es justamente este interrogante el que se tratará de responder analizando los componentes estructurales de las familias y las estrategias por ellas utilizadas y/o implementadas a fin de identificar su importancia relativa y el impacto sobre las condiciones de nutrición y salud infantil.

c- Los condicionantes culturales e ideológicos que afectan los patrones de consumo, en la medida en que los bienes consumidos no son simples objetos destinados a satisfacer necesidades biológicas.

Cabe destacar que gran parte de los trabajos sobre alimentación y nutrición han enfocado la problemática de una manera reduccionista e incluso mutiladora de los procesos culturales implicados. Fischler (1990) plantea que "dos ilusiones han dominado el terreno: por un lado, que las prácticas alimentarias son sólo hábitos o un comportamiento; por otro, un positivismo ingenuo (o perverso) que sostiene implícitamente que ciencia y verdad se confunden".

Muy a menudo, en efecto, no se ha querido ver más que "comportamiento alimentario" allí donde, en efecto, había prácticas sociales; "supersticiones" e ignorancia, donde había creencias y representaciones. 
La noción de "superstición" es entendida como un tejido de creencias primitivas que deberían retroceder ante la clarificación creciente de la ciencia de la nutrición.

Debido a ello, el fracaso de numerosos programas implementados en los países subdesarrollados tendientes a modificar la alimentación de las comunidades, fue atribuido a las supersticiones, ignorancia o prejuicios de las poblaciones locales. Las intervenciones, ignorantes del peso de la cultura en la alimentación, privilegiando los aspectos nutritivos de los alimentos, tendían a imponer por decreto o de manera voluntarista una nueva forma de alimentarse. De ahí que se encuentre arraigada una concepción conservadora en la apreciación de los sistemas alimentarios locales. Sin embargo, puede constatarse que las prácticas alimentarias cambian en proporciones considerables y a veces muy rápido. Factores económicos, el valor de uso, la comodidad de empleo, la valoración simbólica o gustativa pueden, en general, dar cuenta de los cambios ${ }^{52}$.

La noción de hábito alimentario, a su vez, parece incorporar algo que se asemejaría a un comportamiento "puro", aprendido mecánica e inconscientemente. Además, para explicarlo se ha recurrido con frecuencia a una combinación de reduccionismo y finalismo invocando determinismos y funcionalidades biológicas, genéticas $\mathrm{o}$ fisiológicas (Fischler, 1990).

En este sentido, retomando los planteos críticos realizados por García Canclini a la concepción naturalista de las necesidades, se destaca que las necesidades no son atributos de una naturaleza humana inmutable; no hay necesidades naturales en el hombre. "Las necesidades surgen como interiorización de determinaciones estructurales y como elaboración psicosocial de los deseos. La necesidad surge porque las estructuras sociales nos habitúan a necesitar de una cierta manera, a necesitar comer de una cierta manera, en una mesa, con cubiertos, a cierta hora del día, con ciertos rituales. Luego no hay necesidades naturales, la necesidad es un producto cultural." (García Canclini, 1984, 1993).

En segundo término, se cuestiona la concepción instrumental de los bienes, basada en la idea de que los mismos son producidos básicamente por su valor de uso. Desde esta concepción parecería que hubiera una organización "natural" de la producción de bienes en la sociedad. La concepción instrumental de los bienes se derrumba cuando advertimos, por ejemplo, la paradójica existencia de desnutrición en medio de una plétora de alimentos disponibles.

\footnotetext{
${ }^{52}$ A menudo la sustitución suele proceder de una situación de carencia que obliga a conformarse con otro alimento como mal menor. Asimismo, hay cambios que conciernen a movimientos ascendentes, es decir, en favor de productos que presentan ventajas de una u otra naturaleza, sean prácticas, gustativas o simbólicas.
} 
Consumir es -siguiendo a García Canclini (1984,1993)- un proceso pasible de ser entendido y analizado desde cuatro perspectivas:

a) el consumo es un lugar de reproducción de la fuerza de trabajo y de expansión del capital. Comer, descansar, habitar una casa son medios para renovar la fuerza laboral del trabajador y para expandir el capital.

Detenerse en este aspecto supone un reduccionismo economicista del consumo.

b) el consumo es un lugar de diferenciación social y distinción simbólica entre las clases; el consumo es el área fundamental para comunicar las diferencias entre los grupos sociales, diferenciación ubicada básicamente en la forma en que se realiza la apropiación de los bienes y en la forma de utilizarlos.

En este espacio del consumo se construyen las diferenciaciones sociales, las clases se distinguen simbólicamente unas de otras.

c) el consumo constituye un sistema de integración y comunicación. Para que el consumo pueda ser un elemento de diferenciación entre los grupos, debe constituir primero un sistema de comunicación ampliamente comprensible, ya que si no se compartieran los significados atribuidos a los bienes de consumo, su apropiación no sería un elemento de diferenciación social. El consumo permite adquirir, al menos simbólicamente, tal o cual atributo de una condición o de un estado considerado deseable o marcar su posesión efectiva. Los objetos consumidos son portadores de significaciones y se adquieren en parte por esas características.

Es así que consumir es intercambiar significados culturales y sociales. Desde esta perspectiva, el consumo no sólo tiene por finalidad la posesión de un objeto o la satisfacción de una necesidad, sino también definir o reconfirmar significados y valores comunes, crear y mantener una identidad colectiva; el consumo se convierte en un lugar clave para la conformación de las identidades sociales.

d) el consumo es un lugar de objetivación de los deseos. Los hombres tenemos, además de necesidades, deseos que son distinguibles de las necesidades por carecer de objeto material preciso. El deseo es errático, insaciable, inabarcable por las instituciones que aspiran a contenerlo (Baudrillard, cit. por García Canclini, 1984).

El consumo alimentario así concebido se enfoca, para el caso de las familias pobres urbanas, desde el problema central de regular la relación entre necesidad, gusto y posibilidad de obtención de aquellos alimentos que consideran importantes en la dieta cotidiana.

La creciente homología en los discursos de la cocina, de la medicina y de los mercados de la salud, que se manifiestan en el discurso y en las prácticas de regulación de la alimentación relacionada a la salud, posibilita comprender que 
selección y restricción estén en el centro de la preocupación alimentaria actual (Fischler, 1990).

Reconociendo la vigencia de un modelo alimentario hegemonizado por el sector salud que promueve representaciones y prácticas en todos los sectores sociales, la indagación de las representaciones y prácticas sobre el consumo alimentario y sobre la desnutrición infantil en familias pobres urbanas permite explorar, describir y entender cómo lo "macro" se articula con lo "micro", contribuyendo a entender los procesos de reproducción social en materia alimentaria y de salud infantil. 


\section{REPRODUCCIÓN SOCIAL Y SALUD}

Siguiendo las observaciones realizadas por Menéndez a los estudios sobre reproducción social, es posible recuperar en el uso del concepto toda una serie de problemáticas y distintos marcos teóricos. En el caso de la producción latinoamericana, como se ha visto, se ha focalizado en la descripción de las estrategias ocupacionales y/o de natalidad/fecundidad, sin reparar en las condiciones de vida que incluyen enfermedad, muerte, alcoholismo, desnutrición, etc, caracterizándose pues por la subestimación de los procesos de mortalidad, morbilidad y atención de la enfermedad, procesos que expresan algunos de los problemas de mayor gravitación para los conjuntos subalternos tanto en épocas normales y más aún en épocas de crisis.

Los estudios antropológicos se han interesado principalmente en la medicina popular o folklórica y han subestimado durante mucho tiempo el estudio de los procesos de mortalidad, morbilidad y atención de la enfermedad.

"La subestimación de esta problemática en la mayoría de las investigaciones sobre reproducción social contrasta con el hecho de que es a través de la descripción de alguna de estas problemáticas que podría observarse la articulación y mutua determinación de procesos que operan en el nivel "micro" (como por ej. estrategias familiares frente a la enfermedad) y el nivel "macro" (por ej. políticas sanitarias estatales). Su exploración permitiría constatar no sólo la incidencia de las políticas sanitarias en el abatimiento o no de los problemas, sino las funciones de articulación social e ideológica que se generan a partir de asegurar -o no- la reproducción no sólo biológica sino también sociocultural de los sujetos." (Menéndez, 1989).

En téminos generales, la revisión de las investigaciones sobre reproducción en América Latina permite concluir que tanto la morbilidad como la mortalidad son consideradas generalmente como variables dependientes de procesos económicopolíticos, enfoque que imposibilita describir y analizar los procesos de salud/enfermedad/atención en sectores concretos. El manejo predominante de información socioeconómica y sociodemográfica muestra el alcance y las limitaciones dentro del cual se mueve en la práctica el concepto de estrategias de reproducción: la enfermedad se considera determinada por lo económico. Llama la atención que los trabajos centrados en la reproducción familiar, no incorporan en sus descripciones y análisis a las dimensiones socio-ideológicas/culturales referidas a los problemas de morbilidad/mortalidad, desechando el estudio de las representaciones y las prácticas que permitirían describir y entender cómo lo socioeconómico se articula con lo 
socioideológico/cultural y cómo ambos contribuyen, a través de las actividades cotidianas relacionadas a la salud/enfermedad/atención, a la reproducción social.

$\mathrm{Si}$ las representaciones y prácticas en torno a la salud/enfermedad/atención son estructurales y estructurantes en la reproducción de los grupos domésticos, su detección es central para saber cuáles son las estrategias de reproducción.

Los procesos de salud/enfermedad/atención son hechos sociales para los que se desarrollan representaciones y prácticas, incluida la construcción de un saber técnico especializado-profesionalizado.

La indagación de la experiencia de enfermedad (subjetiva, étnica, laboral, comunitaria) las definiciones locales de los conjuntos, su modo de problematizar, definir y establecer cursos de acción, permite una mayor complejidad en la comprensión de la construcción diferencial del sufrimiento humano.

En el capítulo 13 se focaliza el análisis de las prácticas y representaciones sobre la alimentación familiar y la aproximación al estudio de la desnutrición a través de dichos conceptos que se presenta en el capítulo 14 intenta: a) aprehender cómo opera, tanto en los legos como en la propia profesión médica, el sistema de valores en la percepción y categorización de la desnutrición y b) revelar el rol constructor de la enfermedad por parte de la medicina así como el rol normativo en relación a las prácticas sociales (funciones de control y legitimación).

En este estudio, se parte de una noción de representaciones ${ }^{53}$ y prácticas basada en los desarrollos planteados en el capítulo 7 así como en las definiciones más operativas y específicamente referidas al campo de la salud formuladas por Grimberg y de Menéndez.

Las representaciones abarcan los modos de percibir, categorizar y significar la enfermedad; los modos globales de interpretar, de asignar sentidos en la vida social sin plantear a priori oposiciones entre ciencia/ideología o ciencia/sentido común. Se incluyen procesos tanto cognitivos como valorativos e ideológico-políticos, tales como los de categorización (producción de conocimientos técnicos, teóricos), institucionalización, organización de la atención, así como el saber y la experiencia acumulada por los conjuntos sociales.

Las prácticas incluyen las estrategias en relación a las mismas que no necesariamente responden a criterios explícitos de la medicina o que no se presentan como una mera reproducción de los mismos. Las prácticas comprenden los modos de acción,

\footnotetext{
${ }^{53}$ El concepto de representaciones dentro del estudio de los procesos de salud/enfermedad/atención es utilizado por Sevalho (1993), quien realiza un abordaje histórico de las representaciones sociales referidas a la salud y la enfermedad en el marco de la historia cultural en largos períodos de tiempo en donde las permanencias son más evidentes que los cambios, incorporando aportes de la historia de las mentalidades de la escuela francesa de los Annales.
} 
organización y respuesta social e institucional (Grimberg, 1988) no sólo referidas al saber desarrollado por la medicina sino también a las prácticas de los conjuntos sociales, vinculadas en una relación activa de apropiación, reelaboración y reinterpretación (tanto dentro del propio campo médico como entre distintos actores sociales).

Se parte de un modelo dicotómico, pese a los riesgos de simplificación que ello implica, centrado en los conceptos de "hegemonía" y "subalternidad" para hacer referencia a las prácticas y representaciones de los dos grupos vinculados a la problemática nutricional: los servicios de salud y la población. La referencia a los conceptos de prácticas y representaciones alude a la forma en que se construye determinada "mirada" -despojada de toda intencionalidad o maniqueísmo- referida a un específico problema de salud, a través de ellos se tiende a recuperar la unidad entre teoría y práctica, conocimiento científico/conocimiento popular, instituciones de salud/ conjuntos sociales.

La división del trabajo y la acumulación de conocimientos específicos han llevado a la especialización del campo de la salud, ampliando cada vez más el ámbito de su intervención -medicalizando incluso la alimentación-, siendo los especialistas quienes administran el conocimiento científico contenido en gran parte de los conocimientos y prácticas de los legos (sobre todo por la importancia que adquiere en la vida cotidiana el manejo de estos conocimientos).

A través de relaciones de hegemonía, la especialización médica "produce consumidores", "genera pautas de consumo" entendidas como el uso o apropiación de saberes y prácticas, de bienes y servicios destinados a resolver sus problemas de salud. Los conjuntos sociales "legos" participan de esa relación sustentándola en tanto "cómplices", pero también como sujetos que resignifican o impugnan el saber hegemónico.

El concepto de hegemonía pues, resulta útil en la medida que permite detectar las visiones dominantes así como sus límites y contradicciones. Es clave para analizar las relaciones de poder que explican la construcción de formas de problematizar, interpretar, significar y resolver procesos de salud-enfermedad-atención. Supone una relación dinámica, de tensión, entre mecanismos diversos que van desde la coerción hasta el consenso.

La indagación de las teorías, los conocimientos prácticos y las técnicas relacionadas a la definición de un problema, sus criterios diagnósticos, la causalidad, el tratamiento, las propuestas de prevención, de promoción, de solución, etc., proporcionan una vía fértil para identificar los elementos que intervienen en la prevención o resolución de 
determinado problema de salud, en la demanda de asistencia, en el tipo de asistencia,etc.

"A partir de la articulación expresa de las dimensiones económico-políticas y socioideológicas, los procesos de salud-enfermedad-atención constituyen procesos privilegiados para explicar procesos reproductivos, procesos fundamentales -si se quiere- desde la misma perspectiva económica (por ej. muerte en edad productiva, incapacidad laboral por enfermedad, etc.)" (Menéndez, 1989) que frecuentemente los elimina como ejes de análisis.

\subsection{La desnutrición como proceso social}

Como se ha sostenido anteriormente, se considera al proceso de salud/enfermedad atención como una expresión particular de la problemática de la reproducción social.

Se reconoce que los determinantes de la salud/enfermedad de la población son componentes propios de los procesos de producción y reproducción social, los que conforman condiciones diferenciales de vida y procesos diferenciales de morbimortalidad.

Estos planteamientos tienen sustento a partir de trabajos emprendidos en el seno de una corriente epidemiológica crítica que, alrededor de los años 70 , cuestiona el carácter puramente biológico de la enfermedad y de la práctica médica dominante y sostiene que la salud/enfermedad debe ser analizada como un hecho social (Breilh,1980; Laurell,1978; Sempertegui y Salazar, 1985). Es así que se propone problematizar la articulación de la salud/enfermedad con otros procesos sociales (por ej. la inserción de los grupos en el aparato productivo, acceso a determinada cantidad y calidad de bienes, etc); reconociendo su incidencia en la etiología de la enfermedad y su distribución diferencial.

Se cuenta ya con una abundante cantidad de datos que reflejan la naturaleza social de la problemática en cuestión en lo que se refiere a los distintos perfiles patológicos de países con distinto grado de desarrollo, entre diferentes clases sociales y en diferentes momentos históricos (Laurell, 1984; Unicef-Cenep, 1985; Banco Mundial, 1994/5).

Laurell (1984) sostiene que el carácter social de la salud/enfermedad se manifiesta empíricamente de forma más clara en la colectividad que en el individuo, dado que "la salud/enfermedad colectiva determina las características básicas sobre las cuales gravita la variación individual. La historia social del individuo condiciona su biología y determina cierta probabilidad de que enferme de un modo particular (...)".

"Por el proceso de salud/enfermedad de la colectividad entendemos el modo específico como se da en el grupo el proceso biológico de desgaste y reproducción, destacando como momento particular, la presencia de un funcionamiento biológico 
diferenciable con consecuencias para el desarrollo regular de las actividades cotidianas, esto es, la enfermedad, manifestándose en expectativas de vida, condiciones nutricionales, tasas de morbi-mortalidad, etc." (Laurell, 1984).

En el contexto socio-económico en el que se inserta la problemática de salud de la infancia pobre en nuestro país, se destaca la existencia de un complejo de factores histórico-estructurales que tienen un rol fundamental en la emergencia de condiciones de salud/enfermedad específicas para dicho sector.

Cabe mencionar la riqueza de este enfoque en la contribución realizada por el Centro de Estudios Sanitarios y Sociales de Rosario (Bloch y otros,1984) en su estudio sobre el primer año de vida, cuyos resultados expresan las formas típicas de riesgo o protección en relación a la salud/enfermedad según las condiciones de reproducción social de las distintas clases analizadas.

La desnutrición es paradigmática en este sentido. No es casual que desde hace más de 30 años ya se la reconociera como "síndrome de privación social" (Ramos Galván,1966) o "patología de la pobreza" según otros autores.

"La desnutrición es la enfermedad por antonomasia del Tercer Mundo (...), aquella en la cual la paradoja de su existencia en medio de una plétora de conocimientos y de alimentos se pone más en evidencia." (Escudero, 1984).

Los índices de desnutrición en la población infantil constituyen un indicador de la situación social global. Pero, por otra parte, los índices son en realidad valores promedio que ocultan situaciones que, en última instancia, son diferentes entre grupos sociales respecto a atributos específicos tales como los niveles de ingreso, ocupación, educación, etc.

La desnutrición calórico-proteica de causa primaria incide en aquellos sectores sociales que sufren las mayores privaciones de bienestar y de servicios indispensables para la vida y se vincula de manera incuestionable con las tasas de morbimortalidad.

La desnutrición -excepto en grados extremos- no produce mortalidad en forma directa sino a través de enfermedades infecciosas, parasitarias, etc. que se asocian a ella. Tal asociación se verifica con mayor probabilidad, en todo caso, hasta los dos años de edad; luego, la desnutrición se arrastra (Cecchi, 1988). Sus huellas se observan en las consecuencias que se continúan de por vida con los daños ya conocidos: alteraciones del crecimiento somático con respecto a parámetros "normales", alteraciones en el desarrollo, etc.

Desde el enfoque propuesto, es posible observar e interpretar los hechos biológicos individuales en términos de un referente colectivo: el de su clase de pertenencia. Pero esto no implica suponer que se adhiera a una determinación absoluta relacionando en 
forma directa y causal la inserción de un grupo social en el aparato productivo y la existencia -en este caso particular- de desnutrición.

Se asume la relevancia que adquieren un conjunto de mediaciones, integrado por las condiciones materiales de la vida familiar, la dinámica de dicha unidad y sus posibilidades de optimizar el manejo de los recursos disponibles para provecho de sus miembros a través del desarrollo de una serie de estrategias tendientes a la reproducción familiar, que posibilitan desplegar las potencialidades vitales de los niños nacidos en su seno. Este constituye uno de los niveles de análisis de la problemática desde la ciencias sociales: refiere a los problemas de salud que se dan en la población independientemente de lo que la población piense o perciba acerca de ellos. Asimismo, las prácticas y representaciones relacionadas a las pautas de consumo alimentario, al reconocimiento del estado de nutrición infantil, a los procesos de salud/enfermedad/atención, a la desnutrición y su eventual tratamiento, adquieren centralidad en la exploración de las condiciones de nutrición/desnutrición infantil. Este enfoque o recorte analítico es el que se vincula más específicamente con la mirada desarrollada por la antropología social y/o cultural.

\subsection{La construcción de los conceptos de enfermedad y enfermo}

Con base en los dos modelos de hombre presentados en el capítulo 6: ¿qué tipo de conceptualización del proceso salud-enfermedad permite explicar los diferenciales de salud/enfermedad/atención y la forma en que son percibidos, interpretados, valorados? No como fenómeno biológico/individual. Considerar exclusivamente el aspecto biológico significa no tomar al hombre como un ser integral, cuya condición biológica es uno de sus componentes. Como vimos, el factor biológico no puede ser separado de lo social en la medida en que es imposible determinar la normalidad biológica independientemente del contexto histórico y las condiciones de vida. Plantear el doble carácter no es contradictorio, en la realidad se presentan de manera única. Asimismo las características socioculturales condicionan el reconocimiento de la enfermedad como tal y las respuestas a desarrollar: qué es salud, qué es enfermedad y cómo debe tratarse; los ejemplos de variación intercultural abundan en este sentido.

La salud/enfermedad/atención han dado lugar en todo tiempo y espacio a la construcción de representaciones y prácticas sobre los mismos.

Muchos historiadores, filósofos y sociólogos han rastreado la construcción histórica de las nociones colectivas de enfermedad y enfermo. Vinculan la construcción social de estas nociones con procesos de transformación de la patología, con cambios institucionales, con las visiones del mundo predominantes y, a partir del siglo XIX, con los procesos de industrialización (Herzlich y Pierret,1989; Foucault, 1990; Sevalho, 
1993). En general señalan que la experiencia individual de la enfermedad y la concepción que los profanos tienen de ella no son independientes del conjunto de fenómenos sociales más amplios.

Ellos proponen que la enfermedad constituye actualmente una forma de vida y que la aparición de las enfermedades identificables y de los enfermos es reciente, contrastando tal situación con la concepción de enfermo durante la época de las epidemias en la Edad Media (la enfermedad, fundada en la concepción religiosa del mal, era considerada como destino/castigo).

Los dispositivos implementados en la Edad Media para dominar las epidemias amenazantes del orden social y reveladoras de las relaciones sociales (generando reacciones colectivas contra diversos sectores o grupos), se basaban en la función de la Iglesia, en las prácticas supersticiosas, en la lucha colectiva de la medicina e higiene de carácter autoritario y policíaco mediante el aislamiento y el encierro.

¿En qué consiste la construcción del status del enfermo actual? La enfermedad se convierte para el individuo en condición social y nueva estructuración de sus relaciones con la sociedad. Para ello, la enfermedad deja de ser un fenómeno de masa, constituye una forma de vida (situación que deja entrever la tuberculosis) y no una forma de muerte, la medicina muestra ser una intervención eficaz sustituyendo la visión y la respuesta religiosa, se desarrollan leyes sociales que relacionan enfermedad/trabajo dado que durante el siglo XIX los procesos colectivos de salud/enfermedad se vinculan con la capacidad/incapacidad de trabajar.

La Antropología sostiene por su parte, que si la cultura alcanza todos los aspectos de la vida del hombre, son entonces relativos y cambiantes los conceptos de salud y enfermedad. Los problemas de salud, los padecimientos y daños, comprometen el centro de la subjetividad y la reproducción de cualquier sociedad y en ese sentido caben recuperar las generalizaciones empíricas sobre las que se basa la Antropología Médica (Wellin, 1977):

- la enfermedad es un hecho universal en la experiencia del hombre

- todos los grupos humanos desarrollan técnicas y asignan roles para enfrentarla

- todos los grupos humanos poseen un sistema de creencias, conocimientos y valores para explicarla.

Cada sociedad tiene sus propias definiciones, las cuales no son estáticas, sino que se modifican en tanto cambian las circunstancias particulares y las cosmovisiones dominantes que les dieron origen (puede citarse como ejemplo al enfermo mental que pasó de ser considerado un poseído por el demonio a ser un desposeído de razón). La concepción cultural/relativista propone que una enfermedad es tal sólo si es reconocida y definida por la cultura, habiendo sobrados ejemplos de la enorme 
variabilidad en la definición e interpretación de los fenómenos fisiológicos. Podría afirmarse que, en la naturaleza, no hay enfermedades. Los fenómenos biofisiológicos son utilizados como base para etiquetar una condición u otra como enfermedad, por lo que la enfermedad es una construcción social basada en el juicio humano acerca de cierta condición existente en el mundo y son juicios sociales negativos porque la enfermedad es indeseable (Conrad, 1982).

La enfermedad puede ser concebida como anormalidad en el sentido de constituir una amenaza inintencional, privativa del rol de enfermo (Parsons, 1951).

La definición de un fenómeno o de un evento como enfermedad es un proceso de rotulación que realiza algún segmento de la sociedad.

¿Qué es la enfermedad? Con base en lo desarrollado anteriormente, no se va a proponer una definición. Existen, en efecto padecimientos, dolores, daños, molestias o fenómenos morbosos muy diferentes entre sí: tumor, resfrío, esquizofrenia, diarrea. Existen además diferencias profundas entre grupos y pueblos en lo que hace al sufrir $o$ al modo de reaccionar ante las enfermedades. Existen cuadros morbosos que dominan una época y las naciones, clases, personas son afectadas en medida muy diferente.

Siguiendo a Berlinguer (1994) ninguna definición de enfermedad es satisfactoria, por ende es necesario partir de los sufrimientos, de las diferencias y anomalías, de los peligros, de las señales y los estímulos que cada proceso morboso desencadena en la vida de los individuos y en las relaciones sociales.

Entre los deberes que la sociedad atribuye a las medicinas y a los distintos médicos/curadores (curar, consolar, ilusionar, controlar, prevenir, educar) hay uno específico que es omnipresente: combatir las enfermedades. Cambian las formas organizativas, los métodos científicos, los instrumentos para obtener el objetivo pero no la finalidad. Pero cuando hay que definir la enfermedad, se entra en un campo complejo.

En función de la variación de los conocimientos, de las apreciaciones científicas, de la cultura en general, de las relaciones de poder, cambia el valor de los hombres. Además, es muy variable también el ojo del observador: es distinta la enfermedad según sea juzgada por la persona afectada o por parientes y amigos, o por quien debe evaluarla para un trabajo, una revisión de la conscripción, una pensión por discapacidad o por los médicos para curarla. Aun respecto a un solo individuo, a menudo no es fácil juzgar si está sano o enfermo; ni siquiera si está vivo o muerto ${ }^{54}$.

\footnotetext{
${ }^{54}$ Incluso los parlamentos discuten qué es la vida y cuándo comienza; en muchos casos es necesaria una apreciación legalmente válida acerca de la salud o enfermedad (en el campo de los seguros, penal, enfermedades del trabajo, la distinción entre enfermedad y accidente).
} 
En el fenómeno enfermedad se entrecruzan por lo menos tres componentes: a) un hecho objetivo corpóreo, es decir, una alteración de algún órgano, aparato, función, más o menos demostrable; b) una mayor o menor conciencia individual del mal; c) una idea derivada de los conocimientos, los prejuicios y los intereses de la época; en consecuencia, un juicio de valor, una interpretación ética, además de científica, que sirve como guía operativa.

Cada cultura expresa sus definiciones. Sin subestimar la importancia que adquieren en otros contextos aquellas que provienen de oriente, de Africa o de América precolombina, las que conocemos generalmente provienen del pensamiento teóricocientífico que se afirmó en occidente a partir de los siglos XVII-XVIII. Todas las definiciones tienen una finalidad explicativa pero indican también conductas, decisiones que influyen sobre la existencia de cada uno. Sería más fértil hablar de enfermedades en plural y superar la clasificación dicotómica habitual de los fenómenos morbosos según la cual las enfermedades se dividen en bloques que existen de a pares: endógenas/exógenas, infecciosas/no infecciosas, mentales/somáticas, orgánicas/funcionales, idiopáticas/traumáticas, agudas/crónicas, congénitas/adquiridas. Ante las enfermedades es el hombre mismo quien las clasifica y las sufre, quien las quiere combatir o ignorar, es objeto pero también sujeto del conocimiento.

Existen cuatro dimensiones del fenómeno para el individuo:

-estar enfermo: las desigualdades se presentan en la mayor o menor probabilidad de enfermarse y sanar

-sentirse enfermo: la percepción de las enfermedades está influida por la cultura, la clase de pertenencia, la cultura somática

-identificar la enfermedad: a menudo, aunque se perciban síntomas singulares, no ocurre la síntesis diagnóstica que lleva a la búsqueda de una terapia, o de medidas que impidan el avance de la enfermedad

-poder estar enfermo: dimensión en la que entran en juego discriminaciones sociales.

Ubicándonos en el punto de vista del enfermo se puede ver cómo la enfermedad es vivida y afrontada, preguntar qué consecuencias tiene para el sujeto y qué comportamiento suscita en los otros. Desde ese punto de vista Berlinguer (1994) trata de esquematizar las caras de todo proceso morboso: sufrimiento, diversidad, peligro, señal y estímulo. Los tres primeros expresan la faz negativa, doliente, agresiva y opresiva de la enfermedad, los dos últimos tratan de rebatir, hasta donde sea posible, tales manifestaciones ${ }^{55}$.

\footnotetext{
${ }^{55}$ Plantea para cada uno, ejemplos, análisis y algunas líneas de acción.
} 
El sufrimiento o el padecimiento que acarrea la enfermedad, no es culpa, idea presente en mayor o menor grado en casi todas las culturas.

La persistencia de la culpa asociada a la enfermedad se debe a que, frecuentemente, el enfermo estorba, a veces es odioso, hasta repugnante y se lo acusa de su mal. La idea del enfermo como sujeto responsable y transgresor, se representa continuamente en nuevas formas. Se acusa a todos los que tienen estilos de vida morbígenos. Se abre camino la idea de que cuando hay una complicidad del enfermo en el origen de la enfermedad el Estado debería suspenderle la asistencia, ya que de lo contrario recibiría servicios que no le corresponden. La culpabilización de la víctima no tiene en cuenta los condicionamientos y las presiones que determinan, aun dejando espacio a las elecciones personales, el estilo de vida o el impulso autodestructivo de cada uno. Las acusaciones dirigidas sólo a los individuos muestran cómo la relación entre enfermedad y culpa reaparece continuamente en la historia, en formas siempre variadas y por ello está muy enraizada en el ánimo popular ${ }^{56}$.

No es culpa pero tampoco es privilegio como afirman varias religiones (los dolores y sufrimientos son un signo de elección, un don divino, un medio de salvación) o quienes proponen que, en tanto el enfermo se encuentra eximido de muchos deberes, se le otorga una posición preferencial.

T. Parsons (1951) ha tomado el rol de enfermo como ejemplo de la especialización de las funciones sociales. La enfermedad no es funcional porque hace a los individuos incapaces de cumplir con los deberes preestablecidos. El rol de enfermo, por coacciones externas y decisión propia, implica una serie de consecuencias: la exención del rol social normal, el reconocimiento de que es imposible sanar por la propia voluntad, la obligación de querer estar bien y buscar ayuda competente. Así se establecería un nuevo equilibrio fundado sobre el papel del enfermo.

La enfermedad representa también una diferencia: más que como diversidad, la enfermedad es definida habitualmente como anormalidad o desviación, o como inferioridad respecto al promedio de la población. Pero ¿cuál es la norma?: la respuesta es difícil de evaluar: la distinción normalidad/anormalidad y luego la asociación anormalidad/patología es complicada y a menudo arbitraria. Las zonas de frontera son variables y a veces inciertas.

Es necesario considerar a la enfermedad como variedad más que como desviación. Puesto que no todas las anormalidades son enfermedades, sería erróneo afirmar lo opuesto: que las enfermedades son algo carente de objetividad y sostén biológico y

\footnotetext{
${ }^{56}$ En algunos cursos dictados por médicos especialistas en problemas nutricionales, he escuchado el concepto de "madre desnutriogénica" para hacer referencia a atributos individuales generadores de desnutrición en los niños.
} 
psíquico. Hay que reconocer las variaciones del equilibrio que pueden resultar nocivas y reducir las causas de tales anormalidades.

Algunas enfermedades, en todas las épocas, han sido consideradas un peligro: el riesgo directo para la salud de los otros, la búsqueda de un chivo expiatorio sobre el cual descargar las miserias de la comunidad y las angustias y dificultades que la enfermedad conlleva para la convivencia familiar y social.

La motivación del contagio es más razonable en tanto se apoya en una evidencia empírica: el mal se puede transmitir de uno a otro hombre directamente o por medio del agua, aire, etc. (aunque sólo se demuestra científicamente en el siglo XIX). Pero la exigencia legítima de aislar la fuente de contagio real se mantiene junto con otras razones o prejuicios extrasanitarios. Cuando las epidemias hacían estragos por causas desconocidas, la misma era fácilmente atribuida a culpas personales de individuos perversos.

Cuando en los siglos XIX y XX se descubrió que los causantes de las infecciones eran los microbios y no los hombres, el concepto de peligro social se siguió usando, más que como medidas específicas de prevención, como un pretexto para el control de las personas y no de las enfermedades. Se hizo un uso cultural y político negativo de hallazgos positivos. En ese período se desarrolló como eje de intervención pública en salud el sector de Policía Sanitaria; ésta no ha sido una perversidad política, también ha sido una necesidad preventiva (cuarentenas, vacunación obligatoria).

La enfermedad es una señal colectiva pero también individual que indica la ruptura de un equilibrio: la enfermedad de una persona determinada, íntimamente ligada a su existencia, rara vez es una caso aislado. Iguales procesos morbosos se verifican en otras personas y expresan las condiciones de vida que actúan sobre la colectividad. La interpretación de estos fenómenos proporciona muchos datos de naturaleza económica y social, ayuda a comprender lo que ocurre en varias sociedades humanas y lo que ha ocurrido en el pasado; orienta para prever mejor el futuro.

Pero la señal puede permanecer oculta y distorsionada, con frecuencia las enfermedades son negadas ${ }^{57}$ o mal interpretadas ${ }^{58}$. Son muchos los ejemplos en los que la organización sanitaria contribuye a soslayar las señales colectivas de enfermedad. Esto sucede porque la acción médica se circunscribe y orienta a la curación individual y esa relación individual con el enfermo impide reconocer la

\footnotetext{
${ }^{57}$ Ejemplos de ocultamiento puede verse en los problemas de hematuria en obreros de una fábrica de colorantes en base de anilina en Turín. No se reconoció como señal de condiciones de trabajo malsanas (Berlinguer, 1994).

${ }^{58}$ Ejemplos de distorsión ocurren cuando señales del fenómeno morboso colectivo asumen tal evidencia que por gravedad, número y simultaneidad de los casos ya no se puede esconder, entonces la búsqueda de los culpables es desviada hacia fenómenos naturales extraños a la historia concreta y a las responsabilidades de los hombres. Ello puede observarse en los episodios de neumonías en España causados por el aceite de colza químicamente alterado producto de la estafa de productores en complicidad con los organismos de control estatales (Berlinguer, 1994).
} 
continuidad entre el individuo y el ambiente y la conexión entre la enfermedad del individuo y las enfermedades de la colectividad.

El ejercicio de la profesión transfiere a las instituciones sanitarias sólo datos económicos. Las estadísticas de los servicios sanitarios registran datos gruesos de la actividad médica: consultas, internaciones, días/cama, gastos, mientras que el dato sanitario: qué enfermedades, en qué zonas y grupos de población, es a veces completamente ignorado.

La exigencia fundamental a la epidemiología es que ponga de relieve la señal. Y esta función de ampliar la señal no tendría que ser privativa del sector salud sino que deberían participar los ciudadanos ${ }^{59}$.

\footnotetext{
${ }^{59}$ En Brasil, frente a graves carencias sanitarias y ausencia de asistencia médica, se han desarrollado organizaciones de base desde 1978 coordinados en los Encuentros de Medicina Comunitaria. Una de las experiencias más interesantes nace de grupos católicos progresistas que promueven la "pastoral de la salud". La premisa es que la salud es un don de Dios dirigido a todos. Hay, por tanto, una inversión del concepto de culpa. Quien transgrede la ley divina no es el enfermo sino quien crea las condiciones sociales que favorecen las enfermedades. Los temas de la pastoral son, la falta de higiene, de alimentos, habitación insalubre. En San Pablo hay experiencias interesantes llevadas a cabo por los sindicatos de trabajadores. En todas las actividades hay una base común: ya que muchas enfermedades tienen su origen en la incongruencia de maquinarias, habitaciones, materiales, etc., debe convertirse en conciencia y acción común la posibilidad de partir de los fenómenos morbosos para transfomar las condiciones de vida (Berlinguer, 1994).
} 


\section{MODELO MÉDICO HEGEMÓNICO Y DESNUTRICIÓN INFANTIL}

\subsection{Modelo Médico Hegemónico}

La revisión bibliográfica y el conocimiento directo del campo de estudio muestran que existen varios modelos de atención: uno es el hegemónico el cual, descriptivamente, refiere a la biomedicina. Algunos autores hablan de medicina cosmopolita para identificar al sistema de conocimiento, organización y práctica profesional que emerge de occidente, pero que deviene transcultural y preeminente en muchos contextos no occidentales. Dicho modelo es una construcción metodológica que permite entender la racionalidad biomédica y expresa, en un alto nivel de abstracción, las representaciones y prácticas que manejan los profesionales y las instituciones médicas.

Menéndez enmarca la construcción de una forma dominante de entender y atender la enfermedad en un proceso amplio de relaciones históricas, la que denomina Modelo Médico Hegemónico (MMH).

El concepto de $\mathrm{MMH}$, fue creado para describir y analizar los procesos de institucionalización de la biomedicina estableciendo relaciones en términos de hegemonía/subalternidad entre la medicina científica y los otros saberes médicos, los que fueron subordinados, transformados, excluidos o negados por su expansión (Menéndez, 1983, '85,'87,'90). En sus trabajos sobre MMH enfatiza las características, las funciones y la crisis del $\mathrm{MMH}$.

Sus rasgos característicos son: biologicismo, ahistoricidad, asocialidad, individualismo, concepción evolucionista/positivista, eficacia pragmática, función curativa, concepción de la salud/enfermedad como mercancía, exclusión del saber médico, relación médico/paciente asimétrica, subordinación social y técnica del paciente, el paciente como ignorante, el paciente es responsable de su enfermedad, tendencia al consumismo médico, medicalización creciente, racionalización científica como criterio de exclusión de otras prácticas médicas ${ }^{60}$.

El $\mathrm{MMH}$ engloba al conjunto de saberes generados por el desarrollo de la medicina científica hasta lograr identificarse como la única forma correcta de diagnosticar, explicar, atender, solucionar los problemas de enfermedad. ${ }^{61}$ Cumplió y cumple funciones curativo/preventivas pero también de control, de normatización y de legitimación, que en determinadas coyunturas políticas pueden tener más relevancia que las funcioines reconocidas como "estrictamente médicas" (Menéndez, 1985).

\footnotetext{
${ }^{60}$ Dentro de él, reconoce tres submodelos cada uno con particularidades: a)individual-privado, b)corporativo público, c) corporativo-privado.

${ }^{61}$ Sólo en el mayor nivel de abstracción los rasgos y funciones emergen como absolutos, ya que en el análisis de problemas específicos aparecen algunos rasgos y/o funciones más destacados que otros (Menéndez, 1990).
} 
En la construcción de su preminencia, participa no sólo la legitimidad brindada por la ciencia y el Estado sino también el criterio de realidad de los los distintos conjuntos sociales que encuentran, en la eficacia pragmática de esa medicina, soluciones a los problemas que padecen, mostrando una mayor eficacia comparativa respecto de otras formas de atención, las que fueron excluidas ideológica y jurídicamente. El MMH alude, en síntesis, al conjunto de teorías, categorías, técnicas y prácticas que, identificándose con la ciencia positiva, han subalternizado otros saberes y prácticas sociales.

El concepto de hegemonía resulta útil en la medida que permite detectar las visiones dominantes sobre la salud/enfermedad/atención, sus límites y contradicciones, las relaciones de consenso y coerción sobre las que se asienta, excluyendo toda intencionalidad o maquiavelismo por parte de los sectores hegemónicos

Los conjuntos sociales "legos" participan de esa visión sustentándola en tanto "cómplices", pero también como sujetos que resignifican o impugnan el saber hegemónico.

La hegemonía se plantea como apropiación y transformación de otros saberes y prácticas "médicas" a partir de su subordinación ideológica y técnica al $\mathrm{MMH}$, no obstante, la medicina moderna nunca dispuso de una total unanimidad.

Esto hace que incluya el estudio de otros dos modelos: el Modelo Médico Alternativo Subordinado (MMAS) y el Modelo de Autoatención (MA). El MMAS incluye al curanderismo, espiritismo, quiropraxia, médicos hueseros, medicina ayurvédica, homeopatía, y presenta muchas caraterísticas similares al $\mathrm{MMH}$, con tendencias crecientes a la identificación aunque con mayor peso de los siguientes rasgos: eficacia simbólica, socialidad y atención con intención globalizadora. EI MA es el que asegura la reproducción sociobiológica de las familias. Se funda en la frecuencia, recurrencia y continuidad de los padecimientos/daños/molestias/enfermedades que afectan a los sujetos y en la necesidad de acciones inmediatas que den solución a esos episodios que son cotidianos. Tiene una función preventiva, curativa y socioeconómica, se asienta en la eficacia pragmática y en una concepción de salud como bien de uso, en una participación simétrica del curador/enfermo basada en la apropiación de saberes/prácticas del MMH. El diagnóstico y la atención son llevados a cabo por la propia persona o algún familiar/vecino/amigo, no habiendo curador profesional. De hecho, éste constituye el primer nivel de atención.

La legitimación del MMH y su postulada universalidad derivan del hecho de que sus bases se asientan en el conocimiento científico: el énfasis en una visión objetiva y despersonalizada de los hechos ocasionó que factores esenciales relacionados a su práctica fueran desplazados o negados. Este énfasis en lo biológico y en lo científico, 
en un saber sin sujeto ocasiona una tensión entre el saber, derivado del modelo, y el sentir, expresado en las prácticas cotidianas de los médicos que lo ponen en acción ${ }^{62}$. Paradójicamente, en el momento en que la ciencia y la tecnología médica demuestran su mayor penetración y poderío, la misma se cuestiona y autocritica y en ese clima escéptico surge la posibilidad de cambio. La medicina comienza a tener conciencia de las limitaciones de la racionalidad científica y tecnológica en el campo de la salud. Es a partir de 1970 que se suscita la crisis de la noción de salud -asociada al consumo de recursos y servicios médicos- en el marco del Estado benefactor, ya que se hace evidente que una mayor atención médica no conduce necesariamente a una mejor sanidad. Mc Keown (1979) muestra que la mejora en los niveles de salud de la población occidental ocurrida en los últimos siglos se debe a la disponibilidad de alimentos, a la salubridad del medio ambiente y al control de la natalidad. La medicina tuvo un papel mucho menor del que se le atribuye; asimismo el control de enfermedades infecciosas resulta principalmente de la modificación de las condiciones en que ellas ocurren y apenas secundariamente por la acción de fármacos.

Sus límites se vinculan con la visión del hombre que defiende, con la representación del cuerpo en que se basa y con la exclusión de los procesos económico-políticos e ideológicos-culturales en la explicación de la etiología y la solución de las enfermedades.

La institución médica se ve entonces desbordada internamente (por las exigencias de cambio de muchos médicos), externamente (emergencia de nuevos terapeutas que compiten en el mercado de la salud) y por el resurgimiento de las medicinas populares utilizadas por clase media en el contexto urbano.

Esto se correlaciona con la emergencia de hechos sociales que cuestionan la eficacia del modelo: problemas nutricionales, alcoholismo, drogadependencia, neurosis laborales, farmacodependencia, problemas derivados de la contaminación ambiental, accidentes, la morbimortalidad de la violencia, se profundiza la brecha en la esperanza de vida entre el hombre y la mujer, aumentan las muertes en edad productiva, las enfermedades ocupacionales, entre otros. No cabe duda que las acciones médicas abatieron numerosas enfermedades, aumentaron la esperanza de vida, redujeron la mortalidad, etc. Pero es a partir de 1960, y sobre todo 1970 que, en países con alto grado de desarrollo, surgen hechos que orientan la búsqueda de otros factores explicativos.

Paralelamente en ese panorama, que en todos los contextos aparece relacionado con la producción social de la enfermedad, dentro del sistema médico se evidencia: aumento de costos en la atención; aumento del consumo de equipos y fármacos,

\footnotetext{
${ }^{62}$ Esta tensión estructurante refleja los efectos que sienten los médicos desde la etapa de su formación profesional.
} 
aumento de la intervención médica, aumento de la iatrogenia, predominio de criterios de productividad y rendimiento en detrimento de la calidad de la atención, predominio de acciones curativas sobre las preventivas, es decir no se observa relación entre el aumento de intervención y aumento de costos, el perfil epidemiológico vigente y capacidad de control del mismo.

Es decir, se refleja con contundencia que el abordaje de la enfermedad como proceso biológico lleva a que, en tanto sus causas no se encuentran en el individuo, tanto más la práctica médica se limita a los efectos sin referirse al complejo de causas.

Así, la década del 70 se caracterizó por el énfasis puesto por la Organización Mundial de la Salud (OMS) en la extensión de los servicios de salud al conjunto de la población. La declaración de Alma-Ata (1978) y los diferentes programas de extensión de cobertura que se desarrollaron en Latinoamérica con sus propuestas basadas en el desarrollo de recursos comunitarios para el fortalecimiento del primer nivel de atención, el desarrollo de medidas preventivas de bajo costo y de sencilla aplicación, en el escalonamiento de los niveles de atención y de incorporar la participación comunitaria como acciones clave del sector salud, es un claro testimonio de la reorientación del enfoque médico, independientemente de los resultados en su aplicación.

Estas propuestas van a ser retomadas y reformuladas conforme se agudiza el deterioro económico social de los países latinoamericanos y será el Banco Mundial quien en 1980 proponga las siguientes medidas para los problemas de salud de los países en desarrollo: incremento de la producción de alimentos básicos tradicionales del área, extensión de la escolaridad primaria, planificación familiar, extensión de cobertura basada en recursos humanos de escasa preparación formal, eliminación de enfermedades transmisibles aplicando la tecnología sanitaria y médica moderna, desarrollo de programas de educación para la salud. Estas medidas son planteadas respecto de un modelo médico cuyas acciones están basadas en un incremento de la más reciente tecnología médica, en el aumento del personal de salud y en estrategias curativas. Además, lo propuesto por el Banco Mundial y la OMS supone la aceptación, por parte de la institución médica, de la delegación "oficial" de funciones médicas en practicantes que no lo son. ¿Hasta qué punto este modelo no supone la aplicación de una atención diferencial referida a la estratificación social dominante? En términos abstractos estas propuestas pueden ligarse a muchas propuestas antropológicas y sociológicas incluso radicales, también pueden vincularse con las propuestas comunitarias antimedicalizadoras del interaccionismo simbólico o aquellas de autogestión. Esto puede parecer aún más relevante cuando se asiste, en todas partes, a un aumento de las tendencias que favorecen la concentración del poder en el 
Estado, en sus instituciones, en instituciones paraestatales e incluso en organizaciones que dicen cuestionar los sistemas dominantes. La concentración del poder y el burocratismo son tendencias que las propuestas de bajo costo pueden potencialmente cuestionar. Es en esta articulación en donde confluyen las viejas tendencias antropológicas y las nuevas tendencias antropológicas y no antropológicas y cuyo resultado puede ser un uso poco discriminado o tendiente a encubrir sus funciones en base al bajo costo y la posible eficacia. Los procesos propugnados por la antropología que podrían articular con el aparente modelo "no médico" serían entonces (Menéndez, 1985):

a) la importancia y legitimidad de la racionalidad cultural y social de los grupos

b) la importancia de las estrategias populares que implicarían un saber colectivo

c) la importancia del núcleo familiar o comunal como el primer nivel real de atención

d) la importancia de la apropiación pragmática de las clases subalternas y del conjunto de las clases sociales, del saber y práctica médicos

e) la incidencia de los mecanismos de reciprocidad junto con los mecanismos de desigualdad social

f) la ponderación de las funciones de control y normatización de todas las prácticas curativas y la necesidad de cuestionamiento institucional, o por lo menos la apropiación colectiva de esos controles.

Todos esos procesos son reales y pueden favorecer el desarrollo de estrategias respecto de los problemas de salud/enfermedad que remitan al menos parcialmente a la participación popular o al desarrollo autónomo de las comunidades. Pero varias de esas propuestas ya habían sido planteadas tempranamente por antropólogos funcionalistas, fueron ellos quienes entre 1930-50 insistieron en los programas de parteras empíricas, de auxiliares de salud, de recuperación de las terapias populares y en la autogestión autónoma y colectiva. Pero eso no se incluyó en ningún proyecto político, sino en una estrategia económico-política que fue luego reconocida como "desarrollista". Es decir, esas propuestas fueron apropiadas en función de objetivos diferentes de los que aparentemente ellas parecían implicar. Es absurdo discutir la importancia de la educación en sí o de la participación comunitaria en sí. Lo que se puede discutir y discriminar es la contextualización de dichas estrategias que propenden ya sea al abaratamiento de costos, a nuevas formas de control social, a delegar en los sujetos el cuidado de su salud, a funcionar como paliativos momentáneos. Si no se precisa el significado y los objetivos de esos términos, se retomarán las viejas propuestas funcionalistas o materialistas que, barnizadas con nuevas terminologías, podrán cumplir funciones de abaratamiento, de control, de legitimación, etc. hasta que el ensayo concluya nuevamente (Menéndez, 1985). 


\subsection{Proceso de medicalización}

La expansión del $\mathrm{MMH}$ forma parte del proceso de reproducción económica e ideológica del desarrollo capitalista y debe relacionarse con el proceso de medicalización, conforme al cual cada vez más áreas del comportamiento social son patologizados y sujetos a control y normatización (Foucault, 1977).

En su lucha por definir un comportamiento como desviado, Conrad y Schneider en el estudio del etiquetamiento de la desviación social (1982), destacan cómo la desviación social en las sociedades contemporáneas es cada vez más conceptualizada como enfermedad.

EI MMH propone modelos de control de conducta frente a la enfermedad pero también respecto de la salud e induce a practicar y concebir las relaciones sociales y con el propio cuerpo a partir de fundamentos médicos.

Conrad presenta una visión crítica sobre el rol constructor de enfermedad por la clase médica profesionalizada. Aborda el problema de la medicalización de la anormalidad y la absorción creciente del comportamiento individual y social bajo incumbencia médica. Analiza las funciones no médicas de la medicina que se relacionan con el mantenimiento de normas y valores sociales (control social).

La intervención médica como control social en nombre de la salud consiste en limitar, modificar, regular, aislar o eliminar el comportamiento anormal utilizando medios médicos.

La medicina constituye una institución de control social legitimadora del rol de enfermo cuyo objetivo es reestablecer la normalidad.

Para llegar a la medicalización de la anormalidad entendida como enfermedad, se han transitado, como ya se ha mencionado, una serie de cambios históricos en los dispositivos de control: religioso, moral, estatal, médico científico.

La expansión del área de control médico representa una respuesta terapéutica y no punitiva frente a la anormalidad.

Siguiendo a Conrad y Schneider (1982) tales son las condiciones para la medicalización de la anormalidad:

- un comportamiento debe definirse como anormal y como problema que necesita remedio por parte de algún segmento de la sociedad;

- ineficacia o intolerancia de formas previas o tradicionales de control;

-disponer de algúna forma médica de control social;

- un factor necesario para la medicalización de la anormalidad es la existencia de algunos datos orgánicos ambiguos sobre la fuente del problema.

La división del trabajo y la acumulación de conocimientos específicos han llevado a la especialización del campo de la salud, ampliando cada vez más el ámbito de su 
intervención -medicalizando incluso la alimentación- siendo los especialistas quienes administran el conocimiento científico contenido en gran parte de los conocimientos y prácticas de los legos (sobre todo por la importancia que adquiere en la vida cotidiana el manejo de estos conocimientos).

La medicalización se presenta entonces como un fenómeno paradójico pues si bien supone un distanciamiento de los saberes y prácticas no científicas, al mismo tiempo implica y requiere de una articulación inteligible con los conjuntos sociales: deben existir mínimas correlaciones entre la teoría médica y los conjuntos sociales a partir de una situación subordinada de los pacientes estructurada en torno a saber/no saber.

Es en la relación institución/paciente o curador/paciente que se constituye el espacio en el cual se dará tal articulación mediante procesos de esquematización y simplificación a partir, a su vez, de un empobrecimiento y esquematización previos constituidos entre el "saber teórico" y el "saber aplicado" de los médicos. Este primer proceso se da en la actualización teórica de los médicos prácticos.

En todos los casos no sólo existe una relación potencialmente subordinada y dependiente, sino que el tipo de relaciones supone una necesaria enseñanza (la prescripción médica) y una necesaria apropiación (saber cumplir dicha prescripción) la cual se actualiza en la práctica donde el objetivo es la cura. Dicha transformación en la práctica cotidiana tiene como referencia no sólo al aprendizaje teórico de principios abstractos sino también su puesta a prueba por los curadores y por los pacientes, aunque en diferentes posiciones y con diferentes saberes.

La carencia de un saber teórico y técnico específico para explicar y dar soluciones a determinados problemas prioritarios, no anula la orientación biologicista, aun cuando muestra limitaciones evidentes. La jurisdicción que la medicina ha establecido se extiende mucho más allá de su capacidad demostrable para curar (Friedson,1978) ${ }^{63}$. Tal jurisdicción se establece aun cuando el conocimiento de la etiología y de un método previsiblemente exitoso están tan ausentes de la medicina como lo están en la religión o en el derecho (op cit.).

Mediante la medicalización, la práctica médica patologizó amplias áreas de problemáticas sociales y culturales (Menéndez, 1990). De allí que, desde la perspectiva médica, llamar recursos para la salud a aquellos que están destinados a combatir la enfermedad no sea una mera confusión terminológica: supone que la salud se obtiene eliminando la enfermedad y el médico se erige como el principal "dador" de salud, permaneciendo "ocultas" las condiciones -saneamiento, alimentos, vestido, educación, trabajo- que garantizan la salud (Módena, 1990).

\footnotetext{
${ }^{63}$ Justamente la concepción de una causalidad estructural constituye una guía para distinguir cuándo el acto médico se transforma en un acto medicalizado (Menéndez, 1990).
} 


\section{SABER MÉDICO}

\subsection{Proceso de atención y saber médico}

En cada sociedad la producción social de curadores oficiales asume características particulares, habiendo una división técnica del trabajo que los diferencia y jerarquiza. En todas las sociedades, ellos son los que sintetizan y reproducen la ideología y teorías dominantes respecto de la salud/enfermedad. En función de su especialidad curativa y controladora, los curadores se irán diferenciando del manejo técnico e ideológico popular de la enfermedad y de los enfermos. Sin embargo, sus prácticas curativas no pueden quedar desarticuladas de los conjuntos, ya que encuentran en éstos, al menos parcialmente, su posibilidad de eficacia. El conocimiento teórico puede alcanzar una alta complejidad relativa pero necesita estar articulado en un espacio ideológico y social común de reconocimiento para actuar eficazmente y para servir como cura y control. Es a partir de un trabajo especial con la enfermedad, la cura y la muerte, que el curador profesional se hace necesario y su actividad curativa puede opacar las operaciones de control. Los conjuntos sociales reconocen y comparten -al menos parcialmente- los mecanismos básicos que provocan la enfermedad y la curación, poseen esquemáticamente ciertos principios teóricos y técnicos y es dentro de este espacio común que pueden funcionar los curadores profesionales. Los conjuntos sociales acceden al saber médico a través de los médicos aplicativos. En tanto el saber médico se verifica en actividades tanto teóricas como técnicas, supone una división del trabajo que cada vez se profundiza más entre los investigadores y los médicos asistenciales así como entre los especialistas (Menéndez, 1996).

Dado el distanciamiento creciente entre la investigación médica y la actividad asistencial, se concibe al trabajo médico como una actividad profesional y técnica que utiliza concepciones e instrumentos que provienen parcialmente de la investigación biomédica.

El trabajo médico asistencial constituye no sólo una actividad científica sino también una actividad técnica saturada de procesos sociales, económicos e institucionales.

El saber médico incluye tanto aspectos científicos como aspectos socioculturales: expresa lo que los profesionales han ido acumulando y sintetizando en su proceso de socialización profesional, las representaciones y prácticas aprendidas en una escuela de medicina y las costumbres adquiridas en su trabajo institucional.

En general predomina el sobreentendido según el cual la representación expresa isomórficamente a la práctica o a la inversa; sin embargo pueden presentarse diferencias y hasta discrepancias entre representaciones y prácticas. La 
representación constituiría algo así como la "teoría" del proceso y la práctica lo que realmente se realiza.

Las primeras conforman un sistema de expectativas, un marco de referencia para la intervención clínica y establecen una guía para la acción, siendo en la práctica donde ellas se realizan y se modifican. Las prácticas no reproducen a las representaciones ni mecánica ni idénticamente; mientras que la representación médica se refiere básicamente a la enfermedad, la práctica se refiere básicamente al enfermo. La relación no es unívoca. La posible discrepancia es parte de esta relación, pero asumiendo que también expresa regularidades.

Las representaciones técnicas son previas al sujeto y al grupo de profesionales, refieren al esquema dominante en la profesión e institución de la que son parte. El médico necesita adquirir habilidades técnicas para poder intervenir, pero ellas favorecen más la homogeneización que la diferencia y hallan su fundamentación en la objetividad científica (Menéndez, 1996). La profesión médica tiene una representación de sí misma que apela a la ciencia como mecanismo de legitimación y diferenciación respecto de los conjuntos sociales y de los curadores populares.

El análisis de la actividad médica supone reconocer la potencialidad de cada profesional para intervenir con matices diferenciales que expresan, simultáneamente, al sujeto y a las instituciones donde trabaja. La representación médica tiende a enfatizar las características abstractas del saber médico y a opacar la estructuración institucional de sus prácticas y representaciones.

El análisis del saber médico debiera incluir entonces, la articulación de dos niveles: uno que corresponde a la particularidad del conjunto de médicos estudiados y otro que corresponde al Modelo Médico Hegemónico.

En el saber de cada grupo se intenta encontrar no sólo su saber particular sino también reencontrar en él -o no- al mismo modelo médico, ya que es el saber de cada grupo el que produce y reproduce las características del $\mathrm{MMH}$ y no una determinación externa al mismo.

Los procesos institucionales actúan sobre las prácticas y representaciones profesionales; gran parte de la actividad médica es trabajo rutinizado, organizado por pautas administrativas y por un comportamiento de rol que condicionan la intervención individual.

El incremento de instituciones de atención altamente burocratizadas, organizaciones en las que el quehacer profesional está rutinizado y normatizado en alto grado ha favorecido el proceso de uniformidad del sistema de prácticas y representaciones.

El saber médico también crea representaciones acerca del enfermo, de la familia o la comunidad. Es difícil establecer diferencias claras entre los contenidos técnicos y 
socioideológicos del saber médico, ya que toda práctica médica asistencial se ideologiza necesariamente al establecer relaciones con sujetos y grupos.

El concepto de saber resume la articulación del conocimiento científico-técnico aprendido en el proceso formativo, del conocimiento y las técnicas aprendidas en el trabajo profesional, de las costumbres ocupacionales incorporadas en las instituciones y la apropiación de las representaciones y prácticas sociales medicalizadas.

El uso del concepto de saber supone reconocer que podemos encontrar incongruencias entre las representaciones y las prácticas, entre las representaciones entre sí y entre las prácticas.

El saber médico establece su diferenciación con el saber de los conjuntos sociales y es a partir de ello que funcionan los procesos micropolíticos de distanciamiento técnico con el paciente o la normatización y el control de la conducta del mismo.

La homogeneización organizada a partir de proponer a la medicina como científica y al saber médico como "uno" -no obstante las diferencias entre las especialidades y los distanciamientos entre teóricos y prácticos-, no impide reconocer que las prácticas médicas están saturadas de saberes y prácticas tradicionales y que además son fuente de la creación de "nuevas concepciones populares".

"El centralismo de la medicina no dejó de ser cuestionado por los disidentes que surgieron de ella misma y por las medicinas tradicionales. La medicina científica nunca conoció el monopolio que la ley le concedía. (...) Los recursos para la salud no constituyen compartimentos estancos. El cambio que se da actualmente consiste en la oficialización de una gran cantidad de prácticas, restituyéndole al usuario la posibilidad de una elección a partir de la información que él mismo se ha procurado" (Le Breton, 1995).

El grupo/paciente se reserva un margen de decisión que parece inalienable, que permite elaborar juicios de pertinencia sobre cuándo recurrir o no a los servicios, cómo acceder a ellos y hasta dónde obedecer las prescripciones recibidas. El paciente como sujeto cognoscente acepta o rechaza, cumple o no, pacta diagnósticos aunque estos procedimientos sean ignorados por el equipo de salud; formula hipótesis, las pone a prueba, coteja resultados y decide. Salva las discrepancias entre diferentes sistemas médicos o las mantiene.

La medicina, anclada en bases "científicas" y "objetivas" se ha alejado del recurso de la eficacia simbólica que podría potenciar sus efectos. Con esto no se quiere decir que la dimensión simbólica esté ausente en el acto médico: siempre está presente, pero la instauración de esta eficacia está limitada por la posición cultural y social del médico, por el carácter técnico de las terapias que éste recomienda. 
Así, por ejemplo, el conflicto entre médicos y curanderos es, ante todo, un conflicto de legitimidad que opone el saber elaborado por la cultura erudita a los conocimientos menos formalizados de los curanderos, provenientes del saber popular y de la experiencia particular del practicante.

Por eso las condiciones de eficacia de la medicina son también las razones de sus límites. El haber apostado a la eficacia técnica le impide asociarla a eficacias y funciones de otro orden. Estudios sobre el efecto placebo muestran la fuerza del imaginario, es decir, de las significaciones que el enfermo atribuye a los medios curativos que se usan en él. La noción de efecto placebo es la reformulación médica del vector simbólico asociado con las curas.

El efecto placebo muestra las proyecciones imaginarias del enfermo al acto médico y subraya los límites de la relación terapéutica cuando ésta es de carácter eminentemente técnico. La interpretación médica del efecto placebo, en tanto éste da cuenta de las "necesidades psicológicas" de los individuos, retoma el dualismo cuerpo/mente. La cura, argumentan, "se dio en la cabeza", "porque creían en ella". Lejos de estos argumentos, se debería ahondar sobre el sentido de esta eficacia (Le Breton, 1995).

La acción simbólica potencializa los efectos fisiológicos que el acto médico induce.

Como se ha dicho, todo proceso de atención médica es además de un hecho técnico, un proceso de construcción social e ideológico que los grupos necesitan generar para manejar la enfermedad. La autoatención constituye de hecho el primer nivel de atención; representa el procesamiento microgrupal de la enfermedad, y en ella la práctica médica desempeña un papel decisivo en la definición de sus modalidades y contenidos.

La autoatención es una de las principales estructuras sociales generadas en especial por el grupo doméstico para asegurar mínimamente el proceso de reproducción sociobiológica de sus integrantes, pudiendo incluirse la alimentación familiar en tanto comportamiento medicalizado.

El problema reside en analizar la autoatención y la automedicación no como fenómenos incorrectos o negativos, sino en precisar y explicar la inevitabilidad de los mismos y de los procesos no sólo curativos sino también sociales que cumple. El punto de partida es considerar a la autoatención no como un hecho negativo o positivo en sí, sino como hecho estructural a todo sistema social.

"Para su análisis se propone considerar teóricamente dos espacios: a) el de las creencias, valores y prácticas oficiales o constituídas por el sistema médico en función de determinada estructura social b) las prácticas y las formas de pensamiento que algunos sectores crean para sí mismos, para concebir y manifestar su realidad." 
(Garrote, 1995). Ambos comparten parcial y esporádicamente un espacio de interacción en el cual se generan decodificaciones diversas, opciones diferentes pero imbricadas de tal forma que toda manera de enfrentar la enfermedad es en parte construcción propia y en parte apropiación de la manera médico-oficial. Esta diferenciación connota la propia dimensión cultural, ya que interesa sostener que tanto médicos como pacientes deben ser analizados de manera conjunta y relacionada en un mismo proceso.

En los dos espacios circulan interpretaciones de la realidad y formas diversas de manifestarla. Ambos sostienen implícita o explícitamente valores y creencias que hacen a sus tradiciones y a sus diferentes posiciones en la institución. No se limitan por su saber científico o vulgar, sino que lo poseen diferencialmente. Lo que caracterizaría al primero es lo oficial y lo legal, pero eso no impide que emerja en él lo mágico, lo lego, lo casero. Es el espacio del poder cultural, de la política hegemónica desde donde se imponen las normas, se suscita el consenso y se reproduce la adaptación al orden dominante. El otro espacio sustentado en el sistema de referencia lego no representa un saber vulgar, "inculto", popular o tradicional. Incluye saberes y prácticas vulgares y científicas, en contradicción constante con el otro espacio, generando apropiaciones, reproducciones y transformaciones de las pautas impuestas.

El acceso al servicio de salud es una negociación entre ambos espacios culturales que genera procesos transaccionales. Estas transacciones responden a una lógica de utilización de los servicios que supone implícitamente el ingreso voluntario del paciente. Este queda comprometido con su elección a cierto juego institucional conformado anteriormente y al cual debe integrarse para ser atendido. Pero esta integración se organiza no sólo desde una rutina que impone la institución, sino también desde el espacio cultural del que consiente.

Waittzkin y Waterman (1981) sostienen que la estratificación en la medicina tiene como fuente importante la distribución diferencial del saber o de la información y que por lo general los médicos conservan el control sobre los pacientes reteniendo información sobre la enfermedad o el tratamiento. De esta idea se puede deducir cierta alienación del paciente a partir de su propia ignorancia, que implicaría renunciar al papel de adulto independiente y transferir el control del cuerpo a otra persona (Garrote,1995).

Los pacientes, a partir de la apropiación del conocimiento científico participan, promueven, interfieren y modifican sus propios procesos de atención de la enfermedad.

Con relación a ello, Grimberg $(1995,1997)$ señala ciertos problemas teóricos de la 
Antropología:

a) la permanencia de una visión reduccionista de las relaciones sociales: frecuentemente la relación médico-paciente sigue siendo concebida como relaciones interpersonales en un marco general de intercambio recíproco, a través de redes y soportes sociales. El ejemplo más claro es el de Kleinmann sobre los aspectos de negociación en la relación médico-paciente. Ellos se encuentran como iguales y son los pacientes los que en definitiva deciden si siguen o no las indicaciones médicas. La relación queda planteada como un sistema social diádico balanceado y automantenido. Esta noción de relaciones sociales opaca la estructuración política del significado en la práctica médico-clínica a la vez que desocializa las relaciones entre el hombre y el ambiente, tal como se manifiesta en las definiciones que proponen a la salud y enfermedad como una medida de la efectividad de adaptación al ambiente de los grupos humanos. Las relaciones médico-paciente son relaciones de poder referidas a la clase, etnía, género y de relaciones que se derivan de líneas institucionales $y / o$ que se construyen a través de las distintas políticas sociales/organización de los servicios de atención.

b) Otro problema teórico refiere a la exclusiva focalización en el significado cultural de la enfermedad basada en la suposición de que médicos y pacientes tienen diferencias semánticas y de significaciones. Esta visión provee a la biomedicina de metodologías y estrategias para enfrentar aquellos problemas más pobremente contenidos por los modelos tradicionales, colocar los problemas con los pacientes en el ámbito de la educación para la salud, explorar problemas de cumplimiento en los tratamientos, negociar alianzas terapéuticas con los pacientes.

\subsection{Saber médico y desnutrición infantil}

En la medida que la alimentación constituye un comportamiento cotidiano fuertemente medicalizado y que la desnutrición infantil se encuentra incluida en el campo de intervención médica, se sostiene que las prácticas, conocimientos y valoraciones sobre alimentación y salud de los conjuntos sociales están permeadas por una construcción hegemónica de la salud/enfermedad/atención. Esto requiere indagar la visión que, sobre la nutrición/desnutrición infantil, sostiene el personal médico de los centros asistenciales en donde se atiende esta problemática, así como las prácticas destinadas a la prevención/atención/tratamiento de la misma.

La desnutrición remite centralmente, en términos tanto de causalidad estructural como de prevención, a procesos económico-políticos y culturales. ¿Cuál es la capacidad técnica y teórica de los médicos para describir, analizar y resolver dicho problema? 
No obstante constituir un problema de salud prevenible, de diagnóstico técnicamente sencillo y tratamiento eficaz y barato y de hallarse estrechamente asociado con el aumento en las tasas de morbi-mortalidad, existe, a nivel poblacional, un notable vacío de información epidemiológica. Estudios puntuales y/o discontinuos alertan sobre la incidencia de la misma en la población más vulnerable desde el punto de vista biológico-social: niños de 0 a 2 años de hogares pobres.

Abordar la complejidad del contexto sociocultural en donde se procesan la salud, la enfermedad y la atención puede contribuir a explicar tal situación.

De aquí la pertinencia de explorar cómo intervienen los saberes médicos (representaciones y prácticas) sobre la desnutrición.

En esa dirección, se describen las representaciones y prácticas médicas respecto de la desnutrición, del desnutrido y su familia y de su actividad profesional.

Concibiendo al trabajo médico asistencial como una actividad científico/técnica impregnada de procesos sociales, ideológicos, económicos e institucionales, los interrogantes planteados refieren a las características básicas del saber de estos profesionales respecto a la desnutrición: sobre la manera en que definen el problema; cómo lo detectan o diagnostican; a través de qué indicadores lo hacen; cómo explican su causalidad; cuáles son los tratamientos y la evaluación de su eficacia; cuáles son las acciones preventivas que desarrollan; qué características presentan las prácticas y representaciones técnicas que limitan/favorecen la detección, tratamiento y cura del sujeto; cuáles son las representaciones profesionales acerca de las prácticas y representaciones que tiene la comunidad respecto de la desnutrición; cuáles son sus conocimientos respecto de las estrategias populares de atención; cuál es la formación profesional en relación con la desnutrición y cuál es su capacitación técnica para intervenir en atención primaria. 


\section{LAS FAMILIAS ESTUDIADAS}

Con base en la información recabada por medio de encuestas, se presentan los resultados del análisis comparativo establecido entre las dos poblaciones estudiadas integradas por familias pobres urbanas, una con presencia de desnutrición infantil en todos los casos (GD) y la otra sin hijos desnutridos en todo el desarrollo de su ciclo vital (GE). Se realiza una breve caracterización acerca de las condiciones de salud de los niños menores de cinco años, peso de nacimiento, lactancia materna, enfermedades, internaciones por enfermedades infecciosas y presencia de pata de cabra.

\subsection{Condiciones de salud de los niños de 0 a 5 años según su estado nutricional}

Las 50 familias cuyos niños son asistidos en la Unidad de Rehabilitación Nutricional del Hospital de Niños de La Plata (Grupo D= GD) presentan 52 niños $^{64}$ con desnutrición actual. Un $52 \%$ registra además del caso actual, 28 hijos con desnutrición previa, lo que representa un total de 80 niños desnutridos. Considerando que el número total de hijos es de 202 , habría un $40 \%$ de niños desnutridos en este grupo (Tabla 1).

Tabla 1. Hogares según número de hijos con desnutrición actual y/o anterior

\begin{tabular}{|c|c|c|c|c|}
\hline \multicolumn{5}{|c|}{ GRUPO D } \\
\hline & \multicolumn{2}{|c|}{$\begin{array}{c}\text { SITUACIÓN } \\
\text { ACTUAL }\end{array}$} & \multicolumn{2}{|c|}{$\begin{array}{l}\text { SITUACIÓN } \\
\text { ANTERIOR }\end{array}$} \\
\hline NUMERO DE HIJOS DESNUTRIDOS & $\mathrm{N}$ & $\%$ & $\mathrm{~N}$ & $\%$ \\
\hline 0 & 0 & 0 & 24 & 48 \\
\hline 1 & 48 & 96 & $22^{*}$ & 44 \\
\hline 2 & 2 & 4 & 1 & 2 \\
\hline$\geq 3$ & 0 & 0 & 3 & 6 \\
\hline Total & 50 & 100 & 50 & 100 \\
\hline
\end{tabular}

Fuente: Encuestas realizadas en Punta Lara y en la Unidad de Rehabilitación Nutricional del Hospital de Niños de La Plata, 1995.

* Incluye 10 familias cuyos hijos con desnutrición anterior coinciden con el que presenta desnutrición actual. Habría 12 familias con un hijo anteriormente desnutrido que no es el que actualmente presenta desnutrición.

El peso al nacimiento de los niños asistidos en la URN con desnutrición actual es superior a los 2.500 grs. en el $84 \%$, duplicando -y más- el $6 \%$ de nacidos con bajo peso propuesto como meta nacional. La duración total de la lactancia es inferior a tres meses en la mitad de los casos (Tabla 2). 
Tabla 2. Duración total de la lactancia en niños desnutridos (URN)

\begin{tabular}{|c|c|c|}
\multicolumn{1}{c}{} & \multicolumn{2}{c|}{ GRUPO D } \\
\hline TIEMPO (en meses) & $\mathrm{N}$ & $\%$ \\
\hline 0 & 7 & 14 \\
$1-3$ & 18 & 36 \\
$>3-6$ & 9 & 18 \\
$>6-12$ & 7 & 14 \\
$>12$ & 8 & 16 \\
No contesta & 1 & 2 \\
\hline Total & 50 & 100 \\
\hline
\end{tabular}

Fuente: Idem Cuadro 1.

La edad de ingreso a la URN es en el $76 \%$ de los niños, menor a los 18 meses.

De acuerdo al indicador Peso/Edad la severidad de la desnutrición es de tipo leve en el $52 \%$ de los casos y moderada en el $48 \%$ de los mismos (Tabla 3 ).

Tabla 3. Severidad de la desnutrición de acuerdo con el sexo (según clasificación P/E)

\begin{tabular}{|c|c|c|c|c|c|c|}
\multicolumn{1}{c|}{} & \multicolumn{2}{c|}{ GRUPO D } \\
\cline { 2 - 7 } \multicolumn{1}{c|}{} & \multicolumn{2}{c|}{ FEMENINO } & \multicolumn{2}{c|}{ MASCULINO } & TOTAL \\
\hline SEVERIDAD & $\mathrm{n}$ & $\%$ & $\mathrm{~N}$ & $\%$ & $\mathrm{~N}$ & $\%$ \\
\hline II & 13 & 62 & 13 & 45 & 26 & 52 \\
& 8 & 38 & 16 & 55 & 24 & 48 \\
\hline Total & 21 & 100 & 29 & 100 & 50 & 100 \\
\hline
\end{tabular}

Fuente: Idem Cuadro 1.

Respecto al reconocimiento del estado de desnutrición en los hijos, de las 50 madres encuestadas un $48 \%$ no reconoce la situación de desnutrición actual en su hijo, mientras que un $4 \%$ refiere no saber. Además el $54 \%$ niega haber tenido algún hijo desnutrido anteriormente (Tabla 4), porcentaje que se corresponde en la casi totalidad de los casos con aquellas familias que efectivamente no registran hijos con desnutrición anterior.

Tabla 4. Hogares según reconocimiento de casos de desnutrición actual o anterior

GRUPO D

\begin{tabular}{|l|c|c|c|c|c|c|}
\cline { 2 - 7 } \multicolumn{1}{c|}{} & \multicolumn{2}{c|}{$\begin{array}{c}\text { DESNUTRICION } \\
\text { ACTUAL }\end{array}$} & \multicolumn{2}{c|}{$\begin{array}{c}\text { DESNUTRICION } \\
\text { ANTERIOR }\end{array}$} & \multicolumn{2}{c|}{ TOTAL } \\
\hline \multicolumn{1}{c|}{ RECONOCIMIENTO } & $\mathrm{n}$ & $\%$ & $\mathrm{~N}$ & $\%$ & $\mathrm{~N}$ & $\%$ \\
\hline Presencia de casos & 24 & 48 & 23 & 46 & 47 & 47 \\
Sin casos & 24 & 48 & 27 & 54 & 51 & 51 \\
No sabe & 2 & 4 & 0 & 0 & 2 & 2 \\
\hline Total & 50 & 100 & 50 & 100 & 100 & 100 \\
\hline
\end{tabular}

Fuente: Idem Cuadro 1.

${ }^{64}$ En el análisis se consideran los datos de 50 niños desnutridos dado que los dos restantes fueron diagnosticados con posterioridad a la realización de la encuesta. 
Al ingreso, la totalidad de los niños desnutridos presentaban enfermedades intercurrentes tales como anemia, parasitosis, gastroenteritis, broncopulmonares (Tabla 5), conjugando tres o más intercurrencias el $52 \%$ de los niños (Tabla 6).

Tabla 5. Tipo de enfermedades intercurrentes en la población desnutrida $(n=50)$

\begin{tabular}{|c|c|c|}
\hline \multicolumn{3}{|c|}{ GRUPO D } \\
\hline ENFERMEDADES & Frecuencia & $\%$ \\
\hline Anemia & 42 & 84 \\
\hline Parasitosis & 33 & 66 \\
\hline Gastrointestinales & 32 & 64 \\
\hline Broncopulmonares & 9 & 18 \\
\hline Otras & 14 & 28 \\
\hline
\end{tabular}

Fuente: Idem Cuadro 1.

Tabla 6. Número de enfermedades intercurrentes en la población desnutrida (URN)

\begin{tabular}{|c|c|c|}
\hline \multicolumn{3}{|c|}{ GRUPO D } \\
\hline Número de enfermedades & Frecuencia & $\%$ \\
\hline 1 & 8 & 16 \\
2 & 16 & 32 \\
3 & 15 & 30 \\
$\geq 4$ & 11 & 22 \\
\hline Total & 50 & 100 \\
\hline
\end{tabular}

Fuente: Idem Cuadro 1.

Asimismo, dada la vinculación entre lactancia, estado nutricional y morbilidad, se consideró el tiempo de lactancia exclusiva y la edad de ablactación para todos los niños menores de 5 años, con el objeto de identificar regularidades -o no- dentro de cada uno de los grupos analizados (desnutridos y eutróficos). Sobre el total de hijos menores de 5 años de GD, el tiempo de lactancia materna como alimentación exclusiva es de tres meses o menos en las tres cuartas partes de los casos.

El patrón de lactancia materna en GE, es inferior a los tres meses en el $60 \%$ de los casos (Tabla 7).

Tabla 7. Tiempo de lactancia como alimentación exclusiva en los hijos $\leq \mathbf{5}$ años

\begin{tabular}{|c|c|c|c|c|c|c|}
\cline { 2 - 7 } \multicolumn{1}{c|}{} & \multicolumn{2}{c|}{ GRUPO D } & \multicolumn{2}{c|}{ GRUPO E } & \multicolumn{2}{c|}{ TOTAL } \\
\hline DURACION (meses) & $\mathrm{n}$ & $\%$ & $\mathrm{n}$ & $\%$ & $\mathrm{~N}$ & $\%$ \\
\hline$\leq 3$ & 90 & 75,0 & 33 & 60,0 & 123 & 70,3 \\
$4-6$ & 25 & 20,8 & 10 & 18,2 & 35 & 20,0 \\
$\geq 7$ & 5 & 4,1 & 12 & 21,8 & 17 & 9,7 \\
\hline Total & 120 & 100 & 55 & 100 & 175 & 100 \\
\hline
\end{tabular}

Fuente: Idem Cuadro 1. 
Considerando el momento de ablactación, se observa que en el $51 \%$ el destete se produjo en GD luego de los 4 meses mientras que en GE tal situación se registra en el $67 \%$ de los niños (Tabla 8).

Tabla 8. Duración de la lactancia en hijos $\leq$ de 5 años (edad de ablactación).

\begin{tabular}{|c|c|c|c|c|c|c|}
\cline { 2 - 7 } \multicolumn{1}{c|}{} & \multicolumn{2}{c|}{ GRUPO D } & \multicolumn{2}{c|}{ GRUPO E } & \multicolumn{2}{c|}{ TOTAL } \\
\hline DURACION (meses) & $\mathrm{n}$ & $\%$ & $\mathrm{n}$ & $\%$ & $\mathrm{~N}$ & $\%$ \\
\hline$\leq 3$ & 57 & 48,7 & 17 & 32,0 & 73 & 42,9 \\
$4-6$ & 15 & 13,0 & 10 & 18,8 & 25 & 14,7 \\
$\geq 7$ & 45 & 38,3 & 26 & 49,0 & 72 & 42,3 \\
\hline Total & 117 & 100 & 53 & 100 & 170 & 100 \\
\hline
\end{tabular}

Fuente: Idem Cuadro 1.

El $68 \%$ de las familias presentaron niños hospitalizados por infecciones banales (broncopulmonares, gastrointestinales, infecto-contagiosas), asociadas a un deficiente estado nutricional. El número de niños internados es de 51: considerando el número total de hijos, el $25 \%$ de ellos ha tenido internaciones por las causas mencionadas. Respecto de los niños eutróficos ${ }^{65}$ (GE), puede observarse que las internaciones se dan en el $14 \%$ de las familias con 8 niños internados lo cual constituye un $5 \%$ sobre el total de hijos (Tabla 9).

Tabla 9. Hogares según número de hijos con internaciones (gastroenteritis, broncopulmonares)

\begin{tabular}{|c|c|c|c|c|}
\cline { 2 - 5 } \multicolumn{1}{c|}{} & \multicolumn{2}{c|}{ GRUPO D } & \multicolumn{2}{c|}{ GRUPO E } \\
\hline NUMERO DE HIJOS & $\mathrm{n}$ & $\%$ & $\mathrm{~N}$ & $\%$ \\
\hline 0 & 16 & 32 & 43 & 86 \\
1 & 25 & 50 & 6 & 12 \\
2 & 6 & 12 & 1 & 2 \\
$\geq 3$ & 3 & 6 & 0 & 0 \\
\hline Total & 50 & 100 & 50 & 100 \\
\hline
\end{tabular}

Fuente: Idem Cuadro 1.

La asociación entre internación y estado nutricional, muestra que el $82 \%$ de los niños que fueron hospitalizados presentaron desnutrición (Tabla 10).

\footnotetext{
65 El estudio realizado en 1988 simultáneo y tributario del Programa de Diagnóstico y Tratamiento de Enteroparasitosis Infantil (Cueto Rúa, Feldman,1989) registró, sobre un total de aproximadamente 265 niños entre 0 y 14 años de 100 familias estudiadas, una prevalencia de enteroparasitosis del $60 \%$, tratándose en la mayoría de los casos de niños poliparasitados.

No obstante, el porcentaje de niños desnutridos fue inferior al $10 \%$, hecho que niega la posibilidad de establecer imputación causal alguna de la desnutrición a las enteroparasitosis. En el re-estudio hecho en 1994 limitaciones en la disponibilidad de recursos materiales y humanos así como dificultades operativas imposibilitaron realizar un nuevo diagnóstico de enteroparasitosis en la totalidad de los casos previstos. Según información de la Dra. Catalina Vernengo, pediatra de la Unidad Sanitaria "El Molino", la misma muestra una incidencia decreciente en ese período.
} 
Tabla 10. Niños internados en relación a la presencia de desnutrición actual y/o anterior

GRUPO D

\begin{tabular}{|c|c|c|c|c|c|c|}
\hline & \multicolumn{4}{|c|}{ INTERNACIONES } & & \\
\hline & \multicolumn{2}{|c|}{$\mathrm{Si}$} & \multicolumn{2}{|c|}{ No } & \multicolumn{2}{|c|}{ TOTAL } \\
\hline DESNUTRICION & $\mathrm{n}$ & $\%$ & $\mathrm{n}$ & $\%$ & $\mathrm{~N}$ & $\%$ \\
\hline $\mathrm{Si}$ & $\begin{array}{c}42 \\
9\end{array}$ & $\begin{array}{l}82,5 \\
175\end{array}$ & 39 & 100 & $\begin{array}{c}81 \\
9\end{array}$ & $\begin{array}{l}90 \\
10\end{array}$ \\
\hline Total & 51 & 100 & 39 & 100 & 90 & 100 \\
\hline
\end{tabular}

Fuente: Idem Cuadro 1.

Cabe resaltar que, de acuerdo con la información suministrada por el Area Contable del Hospital de Niños de La Plata, el costo aproximado de internación por día es entre 200 y 270 dls., sin evaluar el costo social para la familia en términos de desatención del grupo familiar, abandono de tareas, impacto psicológico, costo emocional, etc.. Asimismo, con base en los registros del Departamento de Estadística del mismo hospital, el promedio de días de internación de un paciente en la Sala de Lactantes es de 14.2 días, datos que deberían servir para analizar y reflexionar en torno a los criterios utilizados para la asignación de los recursos y la distribución del gasto público en salud.

La presencia de la "pata de cabra", enfermedad reconocida en el ámbito de la medicina popular cuyas manifestaciones permiten relacionarla a la desnutrición, es reconocida en el $60 \%$ de las familias. Considerando que en ellas el número de niños con pata de cabra es de 40 , afecta a un $20 \%$ de población infantil de las familias de GD.

En GE, la pata de cabra se registra en el $8 \%$ de las familias, presentándose en 5 niños lo cual representa un $3 \%$ sobre el total de hijos (Tabla 11).

Tabla 11. Hogares según presencia de hijos con pata de cabra

\begin{tabular}{|c|c|c|c|c|c|c|}
\cline { 2 - 7 } \multicolumn{1}{c|}{} & \multicolumn{2}{c|}{ GRUPO D } & \multicolumn{2}{c|}{ GRUPO E } & \multicolumn{2}{c|}{ TOTAL } \\
\hline PATA DE CABRA & $\mathrm{n}$ & $\%$ & $\mathrm{n}$ & $\%$ & $\mathrm{~N}$ & $\%$ \\
\hline $\mathrm{Si}$ & 30 & 60 & 4 & 8 & 34 & 34 \\
$\mathrm{No}$ & 20 & 40 & 46 & 92 & 66 & 66 \\
\hline Total & 50 & 100 & 50 & 100 & 100 & 100 \\
\hline
\end{tabular}

Fuente: Idem Cuadro 1.

La correspondencia entre pata de cabra y desnutrición se da en el $60 \%$ de los casos, no pudiéndose establecer una asociación biunívoca entre ambas por encontrarse 56 niños con episodios de desnutrición -actual o previa-, sin pata de cabra (Tabla 12). 
Tabla 12. Asociación entre desnutrición y presencia de pata de cabra

GRUPO D

\begin{tabular}{|c|c|c|c|c|c|c|}
\cline { 2 - 7 } \multicolumn{1}{c|}{} & \multicolumn{2}{c|}{ Con pata de cabra } & \multicolumn{2}{c|}{ Sin pata de cabra } & \multicolumn{2}{c|}{ TOTAL } \\
\hline DESNUTRICION & $\mathrm{n}$ & $\%$ & $\mathrm{n}$ & $\%$ & $\mathrm{~N}$ & $\%$ \\
\hline $\mathrm{Si}$ & 24 & 60 & 56 & 100 & 80 & 83,5 \\
$\mathrm{No}$ & 16 & 40 & 0 & 0 & 16 & 16,5 \\
\hline Total & 40 & 100 & 56 & 100 & 96 & 100 \\
\hline
\end{tabular}

Fuente: Idem Cuadro 1.

\subsection{Características demográficas de las unidades domésticas}

Se utilizó la siguiente clasificación para definir a las unidades domésticas:

-Hogar nuclear: formado sólo por un núcleo familiar, entendiendo por éste a la familia constituida por el matrimonio sin hijos o al matrimonio con uno o más hijos solteros.

-Hogar nuclear extendido: formado por un hogar nuclear y otras personas emparentadas y/o no emparentadas con el jefe del hogar.

-Hogar monoparental: formado por padre o madre con uno o más hijos solteros.

-Hogar monoparental extendido: formado por padre o madre, hijos y otras personas emparentadas y/o no emparentadas con el jefe de hogar.

En GD, el hogar nuclear aparece en el $54 \%$ de los casos, habiendo un $32 \%$ de hogares nucleares extensos. Para GE hay un $86 \%$ de hogares del primer tipo y un 8 $\%$ del segundo (Tabla 13).

Tabla 13. Tipo de hogar

\begin{tabular}{|l|c|c|c|c|c|c|}
\cline { 2 - 7 } \multicolumn{1}{c|}{} & \multicolumn{2}{c|}{ GRUPO D } & \multicolumn{2}{c|}{ GRUPO E } & \multicolumn{2}{c|}{ TOTAL } \\
\hline & $\mathrm{n}$ & $\%$ & $\mathrm{n}$ & $\%$ & $\mathrm{~N}$ & $\%$ \\
\hline Nuclear & 27 & 54 & 43 & 86 & 70 & 70 \\
Nuclear extendido & 16 & 32 & 4 & 8 & 20 & 20 \\
Monoparental & 2 & 10 & 2 & 4 & 4 & 4 \\
Monoparental extendido & 5 & 4 & 1 & 2 & 6 & 6 \\
\hline Total & 50 & 100 & 50 & 100 & 100 & 100 \\
\hline
\end{tabular}

Fuente: Idem Cuadro 1.

En cuanto al tamaño del hogar, no se registran diferencias significativas ${ }^{66}$ aunque el promedio de miembros es de 6.8 en GD, superior al de GE cuyo promedio de miembros es de 5.8 (Tabla 14).

\footnotetext{
${ }^{66}$ Para el análisis estadístico se empleó el Test de Chi cuadrado, cuyo cálculo estuvo a cargo de la Ing. María Inés Urrutia, profesional del Centro Superior para el Procesamiento de la Información de la UNLP (CeSPI).
} 
Tabla 14. Número de miembros del hogar

\begin{tabular}{|c|c|c|c|c|c|c|}
\cline { 2 - 7 } \multicolumn{1}{c|}{} & \multicolumn{2}{c|}{ GRUPO D } & \multicolumn{2}{c|}{ GRUPO E } & \multicolumn{2}{c|}{ TOTAL } \\
\hline \multicolumn{1}{c|}{ PERSONAS } & $\mathrm{n}$ & $\%$ & $\mathrm{n}$ & $\%$ & $\mathrm{~N}$ & $\%$ \\
\hline$<4$ & 2 & 4 & 4 & 8 & 6 & 6 \\
$4-6$ & 26 & 52 & 32 & 64 & 58 & 58 \\
$7-9$ & 18 & 36 & 13 & 26 & 31 & 31 \\
$>9$ & 4 & 8 & 1 & 2 & 5 & 5 \\
\hline Total & 50 & 100 & 50 & 100 & 100 & 100 \\
\hline
\end{tabular}

Fuente: Idem Cuadro 1. $p>0.05$

Tampoco se presentan diferencias estadísticamente significativas en lo que hace al número de hijos, siendo el promedio de 4.0 en GD y de 3.8 en GE (Tabla 15).

Tabla 15. Número de hijos del hogar

\begin{tabular}{|c|c|c|c|c|c|c|}
\cline { 2 - 7 } \multicolumn{1}{c|}{} & \multicolumn{2}{c|}{ GRUPO D } & \multicolumn{2}{c|}{ GRUPO E } & \multicolumn{2}{c|}{ TOTAL } \\
\hline NUMERO DE HIJOS & $\mathrm{N}$ & $\%$ & $\mathrm{~N}$ & $\%$ & $\mathrm{~N}$ & $\%$ \\
\hline$<3$ & 15 & 30 & 9 & 18 & 24 & 24 \\
$3-5$ & 25 & 50 & 35 & 70 & 60 & 60 \\
$6-8$ & 8 & 16 & 5 & 10 & 13 & 13 \\
$>8$ & 2 & 4 & 1 & 2 & 3 & 3 \\
\hline Total & 50 & 100 & 50 & 100 & 100 & 100 \\
\hline Fuente: Idem Cuadro 1.
\end{tabular}

Puede establecerse que, respecto al momento del ciclo de vida familiar, las dos poblaciones en estudio se encuentran en etapas diferentes. La totalidad de las familias de GD se hallan en etapa de expansión mientras algunas de las de GE -detectadas en el estudio realizado en 1988 y reencuestadas en 1994- se encuentran en una etapa más avanzada, habiendo registrado cambios por nacimiento en ese período un $55 \%$ de las mismas.

En GD el $52.5 \%$ de la población total tiene menos de 10 años, siendo del 34 \% en GE. Las edades de los jefes y cónyuges evidencian la tendencia arriba mencionada: una mayoría de ellos se concentran entre los 20 y 30 años en GD, distribuyéndose GE en grupos de edad más elevados (Tabla 16).

Tabla 16. Edad del jefe y cónyuge

\begin{tabular}{|c|c|c|c|c|c|c|c|c|c|c|}
\cline { 2 - 11 } \multicolumn{1}{c|}{} & \multicolumn{4}{c|}{ GRUPO D } & \multicolumn{4}{c|}{ GRUPO E } & \multicolumn{2}{c|}{} \\
\cline { 2 - 12 } \multicolumn{1}{c|}{} & \multicolumn{2}{c|}{ JEFE } & \multicolumn{2}{c|}{ CONYUGE } & \multicolumn{2}{c|}{ JEFE } & \multicolumn{2}{c|}{ CONYUGE } & \multicolumn{2}{c|}{ TOTAL } \\
\hline EDAD & $\mathrm{n}$ & $\%$ & $\mathrm{n}$ & $\%$ & $\mathrm{n}$ & $\%$ & $\mathrm{n}$ & $\%$ & $\mathrm{~N}$ & $\%$ \\
\hline$<20$ & 0 & 0 & 3 & 7 & 0 & 0 & 0 & 0 & 3 & 1,5 \\
$20-30$ & 27 & 54 & 32 & 73 & 10 & 20 & 13 & 29 & 82 & 43 \\
$31-40$ & 12 & 24 & 7 & 16 & 24 & 48 & 23 & 51 & 66 & 35 \\
$>41$ & 11 & 22 & 2 & 4 & 16 & 32 & 9 & 20 & 38 & 20 \\
& & & & & & & & & & \\
\hline Total & 50 & 100 & 44 & 100 & 50 & 100 & 45 & 100 & 189 & 100 \\
\hline
\end{tabular}

Fuente: Idem Cuadro 1. 
Contrasta en GE el $40 \%$ de familias con hijos mayores de 14 años frente a un $20 \%$ de casos en GD (Tabla 17).

Tabla 17. Número y composición etarea de los hijos GRUPO D GRUPO E

\begin{tabular}{|c|c|c|c|c|c|c|c|c|}
\cline { 2 - 9 } \multicolumn{1}{c|}{} & \multicolumn{2}{c|}{$<14$ años } & \multicolumn{2}{c|}{$>14$ años } & \multicolumn{2}{c|}{$<14$ años } & \multicolumn{2}{c|}{$>14$ años } \\
\hline $\mathrm{N}^{\circ}$ de hijos & $\mathrm{n}$ & $\%$ & $\mathrm{~N}$ & $\%$ & $\mathrm{n}$ & $\%$ & $\mathrm{~N}$ & $\%$ \\
\hline 0 & 0 & 0 & 40 & 80 & 0 & 0 & 30 & 60 \\
1 & 3 & 6 & 4 & 8 & 5 & 10 & 9 & 18 \\
2 & 13 & 26 & 3 & 6 & 10 & 20 & 8 & 16 \\
3 & 10 & 20 & 1 & 2 & 18 & 36 & 2 & 4 \\
4 & 7 & 14 & 1 & 2 & 11 & 22 & 1 & 2 \\
5 & 7 & 14 & 1 & 2 & 4 & 8 & 0 & 0 \\
$\geq 6$ & 10 & 20 & 0 & 0 & 2 & 4 & 0 & 0 \\
\hline Total & 50 & 100 & 50 & 100 & 50 & 100 & 50 & 100 \\
\hline
\end{tabular}

Fuente: Idem Cuadro 1.

Analizando el tipo de familia en función del número de miembros, puede decirse que mientras que en GD aquellas con cuatro a seis miembros representan poco más de la mitad, en GE éstas constituyen el $70 \%$. A su vez GD registra un mayor porcentaje que GE de familias con siete miembros y más: $44 \%$ vs. $30 \%$ respectivamente. En GD, las familias con 7 a 9 miembros corresponden en el $50 \%$ a las extensas, concentrándose en estas últimas el $75 \%$ de las que poseen más de 9 miembros.

En GE, dada la predominancia del tipo de familia nuclear, no se encuentran variaciones del tipo de familia en función del número de miembros.

\subsection{Características educacionales}

En GD pueden observarse niveles inferiores de escolaridad tanto del jefe como de la cónyuge, respecto de los encontrados en GE, presentándose diferencias significativas en el caso de los jefes $(p<0.05)$ y altamente significativas para las cónyuges $(p<$ $0.01)^{67}$.

Tabla 18. Nivel educativo del jefe y cónyuge

\begin{tabular}{|c|c|c|c|c|c|c|c|c|c|c|}
\hline \multirow[b]{3}{*}{ NIV/FI EDIC } & \multicolumn{4}{|c|}{ GRUPO D } & \multicolumn{4}{|c|}{ GRUPO E } & \multirow{2}{*}{\multicolumn{2}{|c|}{ TOTAL }} \\
\hline & & & $\mathrm{CON}$ & JGE & & & $\mathrm{COI}$ & JGE & & \\
\hline & $\mathrm{n}$ & $\%$ & $\mathrm{n}$ & $\%$ & $\mathrm{n}$ & $\%$ & $\mathrm{~N}$ & $\%$ & $\mathrm{~N}$ & $\%$ \\
\hline Sin instr. o PI & 20 & 40 & 27 & 61 & 12 & 25 & 16 & 36 & 75 & 40 \\
\hline Prim. Compl. & 25 & 50 & 15 & 34 & 27 & 55 & 19 & 43 & 86 & 46 \\
\hline $\begin{array}{l}\text { Secund. Inc. o } \\
\text { más }\end{array}$ & 5 & 10 & 2 & 5 & 10 & 20 & 9 & 20 & 26 & 14 \\
\hline Total & 50 & 100 & 44 & 100 & 49 & 100 & 44 & 100 & 187 & 100 \\
\hline
\end{tabular}

\footnotetext{
${ }^{67}$ Para satisfacer la condición para la aplicación del Test de Chi cuadrado de que la frecuencia mínima sea $\geq 5$, se agruparon las dos últimas categorías (primaria completa y secundaria incompleta y más) por tener valores inferiores.
} 
En GD el $40 \%$ de los jefes tiene primaria incompleta y el $61 \%$ de las cónyuges incluye las categorías de analfabetos y con primaria incompleta. La mitad de los jefes y el $34 \%$ de las cónyuges presentan primaria completa en GD.

En GE el $25 \%$ de los jefes carece de primaria completa y lo mismo sucede con un 36 $\%$ de las cónyuges, presentando primaria completa el $55 \%$ de los jefes y un $43 \%$ de las cónyuges (Tabla 18).

Respecto del total de hijos de ambos grupos de familias, el nivel educativo alcanzado expresa, en primer lugar, la mayor edad relativa de los mismos en GE respecto de GD. En ese sentido, considerando la situación educacional, hay un $45 \%$ de niños en GD que no asiste por no tener edad suficiente para el ingreso escolar frente a un $12.5 \%$ en GE.

El $25 \%$ de los niños de GD asiste regularmente a la escuela frente a un $52 \%$ en GE. La repitencia aparece en el $11 \%$ de los casos en GD, hecho que se verifica en el $13 \%$ en GE. No obstante, en GD hay un mayor porcentaje que en GE de niños que teniendo la edad suficiente para concurrir al ciclo pre-escolar o escolar, no lo hace.

\subsection{Características de la vivienda}

El tiempo de residencia en el barrio es inferior a los tres años en el $56 \%$ de los casos en GD, mientras que la totalidad de GE tiene un tiempo de residencia en el barrio superior a los 7 años $^{68}$.

El 66\% de GD no son propietarios del terreno en el que se asientan (Tabla 19), compartiéndolo con otras viviendas en un $45 \%$ de los casos.

Tabla 19. Viviendas según regimen de tenencia del terreno

\begin{tabular}{|c|c|c|c|c|c|c|}
\cline { 2 - 7 } \multicolumn{1}{c|}{} & \multicolumn{2}{c|}{ GRUPO D } & \multicolumn{2}{c|}{ GRUPO E } & \multicolumn{2}{c|}{ TOTAL } \\
\hline TERRENO & $\mathrm{n}$ & $\%$ & $\mathrm{n}$ & $\%$ & $\mathrm{~N}$ & $\%$ \\
\hline Propio & 17 & 34 & 5 & 10 & 22 & 22 \\
Prestado & 17 & 34 & 2 & 4 & 19 & 19 \\
Fiscal & 15 & 30 & 42 & 84 & 57 & 57 \\
Alquilado & 1 & 2 & 1 & 2 & 2 & 2 \\
\hline Total & 50 & 100 & 50 & 100 & 100 & 100 \\
\hline
\end{tabular}

Fuente: Idem Cuadro 1.

La propiedad de la vivienda se da en el $70 \%$ de los casos en GD (Tabla 20), presentando la mitad de ellas un solo cuarto para dormir.

La casi totalidad de los hogares de GE no son propietarios del terreno, siendo propietarios de las viviendas el $92 \%$ de los mismos (Tablas 19 y 20).

\footnotetext{
${ }^{68}$ Este resultado obedece al criterio de selección muestral.
} 
Tabla 20. Tenencia de la vivienda

\begin{tabular}{|c|c|c|c|c|c|c|}
\cline { 2 - 7 } \multicolumn{1}{c|}{} & \multicolumn{2}{c|}{ GRUPO D } & \multicolumn{2}{c|}{ GRUPO E } & \multicolumn{2}{c|}{ TOTAL } \\
\hline VIVIENDA & $\mathrm{n}$ & $\%$ & $\mathrm{n}$ & $\%$ & $\mathrm{~N}$ & $\%$ \\
\hline Propia & 35 & 70 & 46 & 92 & 81 & 81 \\
Prestada & 14 & 28 & 2 & 4 & 16 & 16 \\
Alquilada & 1 & 2 & 2 & 4 & 3 & 3 \\
& & & & & & 100 \\
\hline Total & 50 & 100 & 50 & 100 & 100 & 100 \\
\hline
\end{tabular}

Fuente: Idem Cuadro 1.

El número de personas por cuarto es superior a 4 en el $68 \%$ de GD, mientras que en GE el $80 \%$ presenta una relación de menos de 4 personas por cuarto (Tabla 21). Las diferencias en esta variable son altamente significativas al igual que la relación personas/cama que se presenta en el cuadro siguiente.

Tabla 21. Hogares según número de personas por cuarto

\begin{tabular}{|c|c|c|c|c|c|c|}
\cline { 2 - 7 } \multicolumn{1}{c|}{} & \multicolumn{2}{c|}{ GRUPO D } & \multicolumn{2}{c|}{ GRUPO E } & \multicolumn{2}{c|}{ TOTAL } \\
\hline PERSONAS & $\mathrm{n}$ & $\%$ & $\mathrm{n}$ & $\%$ & $\mathrm{~N}$ & $\%$ \\
\hline$<3$ & 6 & 12 & 24 & 48 & 30 & 30 \\
$3-3,9$ & 10 & 20 & 16 & 32 & 26 & 26 \\
$4-4,9$ & 11 & 22 & 5 & 10 & 16 & 16 \\
$\geq 5$ & 23 & 46 & 5 & 10 & 28 & 28 \\
\hline Total & 50 & 100 & 50 & 100 & 100 & 100 \\
\hline
\end{tabular}

Fuente: Idem Cuadro 1.

Así, el número de personas por cama es en GD superior a dos en el $66 \%$ de los casos, habiendo un $64 \%$ de casos en GE en el que la relación es de 1 a 1,4 personas por cama (Tabla 22) ${ }^{69}$.

Tabla 22. Hogares según número de personas por cama

\begin{tabular}{|c|c|c|c|c|c|c|}
\cline { 2 - 7 } \multicolumn{1}{c|}{} & \multicolumn{2}{c|}{ GRUPO D } & \multicolumn{2}{c|}{ GRUPO E } & \multicolumn{2}{c|}{ TOTAL } \\
\hline PERSONAS & $\mathrm{n}$ & $\%$ & $\mathrm{n}$ & $\%$ & $\mathrm{~N}$ & $\%$ \\
\hline $1-1,4$ & 3 & 6 & 32 & 64 & 35 & 35 \\
$1,5-1,9$ & 14 & 28 & 8 & 16 & 22 & 22 \\
$2-2,9$ & 18 & 36 & 9 & 18 & 27 & 27 \\
$3-3,9$ & 10 & 20 & 1 & 2 & 11 & 11 \\
$\geq 4$ & 5 & 10 & 0 & 0 & 6 & 6 \\
\hline Total & 50 & 100 & 50 & 100 & 100 & 100 \\
\hline
\end{tabular}

Fuente: Idem Cuadro 1.

\footnotetext{
${ }^{69}$ Para satisfacer la condición para la aplicación del Test de Chi cuadrado de que la frecuencia mínima sea $\geq 5$, se agruparon los tres últimos rangos de la tabla.
} 
La presencia del cuarto de cocina con uso específico se da en el $78 \%$ de las viviendas de GD y en del $100 \%$ de GE (Tabla 23).

Tabla 23. Hogares según posesión de cuarto de cocina

\begin{tabular}{|c|c|c|c|c|c|c|}
\cline { 2 - 7 } \multicolumn{1}{c|}{} & \multicolumn{2}{c|}{ GRUPO D } & \multicolumn{2}{c|}{ GRUPO E } & \multicolumn{2}{c|}{ TOTAL } \\
\hline CUARTO DE COCINA & $\mathrm{n}$ & $\%$ & $\mathrm{n}$ & $\%$ & $\mathrm{~N}$ & $\%$ \\
\hline Uso exclusivo & 39 & 78 & 50 & 50 & 89 & 89 \\
Uso compartido & 7 & 14 & 0 & 0 & 7 & 7 \\
No tiene & 4 & 8 & 0 & 0 & 4 & 4 \\
\hline Total & 50 & 100 & 50 & 100 & 100 & 100 \\
\hline
\end{tabular}

Fuente: Idem Cuadro 1.

Los materiales predominantes de la vivienda muestran peor calidad relativa en GD que en GE, tanto en el piso como en las paredes y techo (Tabla 24).

Tabla 24. Viviendas según materiales predominantes en su construcción

\begin{tabular}{|l|c|c|c|c|}
\hline TECHO & \multicolumn{2}{|c|}{ GRUPO D } & \multicolumn{2}{c|}{ GRUPO E } \\
\hline \multicolumn{1}{|c|}{ MATERIALES } & $\mathrm{n}$ & $\%$ & $\mathrm{~N}$ & $\%$ \\
\hline Losa & 7 & 14 & 2 & 4 \\
Madera & 4 & 8 & 0 & 0 \\
Chapa & 27 & 54 & 23 & 46 \\
Fibrocemento & 3 & 6 & 3 & 6 \\
Cartón & 0 & 0 & 0 & 0 \\
Chapa y cartón & 8 & 16 & 15 & 30 \\
Tejas y chapa & 1 & 2 & 4 & 8 \\
No consignado & 0 & 0 & 3 & 6 \\
\hline Total & 50 & 100 & 50 & 100 \\
\hline
\end{tabular}

\begin{tabular}{|l|c|c|c|c|}
\hline PAREDES & \multicolumn{2}{|c|}{ GRUPO D } & \multicolumn{2}{c|}{ GRUPO E } \\
\hline \multicolumn{1}{|c|}{ MATERIALES } & $\mathrm{n}$ & $\%$ & $\mathrm{n}$ & $\%$ \\
\hline Ladrillos o bloques & 18 & 36 & 12 & 24 \\
Madera y chapa & 1 & 2 & 5 & 10 \\
Cartón & 2 & 4 & 0 & 0 \\
Chapa y cartón & 0 & 0 & 1 & 2 \\
Madera & 21 & 42 & 12 & 24 \\
Chapa & 8 & 16 & 7 & 14 \\
Material y chapa & 0 & 0 & 5 & 10 \\
Madera y material & 0 & 0 & 5 & 10 \\
No consignado & 0 & 0 & 3 & 6 \\
& & & & \\
\hline Total & 50 & 100 & 50 & 100 \\
\hline
\end{tabular}

\begin{tabular}{|l|c|c|c|c|}
\hline PISO & \multicolumn{2}{|c|}{ GRUPO D } & \multicolumn{2}{c|}{ GRUPO E } \\
\hline \multicolumn{1}{|c|}{ MATERIALES } & $\mathrm{n}$ & $\%$ & $\mathrm{n}$ & $\%$ \\
\hline Cemento & 28 & 56 & 28 & 56 \\
Tierra & 17 & 34 & 1 & 2 \\
Mosaico, baldosas & 3 & 6 & 8 & 16 \\
Tierra y cemento & 2 & 4 & 1 & 2 \\
Cemento y baldosas & 0 & 0 & 6 & 12 \\
Madera & 0 & 0 & 3 & 6 \\
No consignado & 0 & 0 & 3 & 6 \\
\hline Total & 50 & 100 & 50 & 100 \\
\hline
\end{tabular}

Fuente: Idem Cuadro 1. 
En cuanto a la provisión de agua, puede observarse que en GD es corriente en el 60 $\%$ de las viviendas, ubicada en el $72 \%$ de los casos fuera de las mismas y compartiéndola con otras familias en el $34 \%$ de los casos. En GE la presencia de agua corriente abarca la casi totalidad de las viviendas, conectada en el interior en el $84 \%$ de las mismas (Tablas 25, 26 y 27). Tanto en lo que hace al sistema de provisión de agua como a su ubicación, las diferencias entre ambos grupos arrojan diferencias altamente significativas.

Tabla 25. Provisión de agua potable de las viviendas

\begin{tabular}{|l|c|c|c|c|c|c|}
\cline { 2 - 7 } \multicolumn{1}{c|}{} & \multicolumn{2}{c|}{ GRUPO D } & \multicolumn{2}{c|}{ GRUPO E } & \multicolumn{2}{c|}{ TOTAL } \\
\hline \multicolumn{1}{c|}{ AGUA POTABLE } & $\mathrm{n}$ & $\%$ & $\mathrm{n}$ & $\%$ & $\mathrm{~N}$ & $\%$ \\
\hline Con conexión & 30 & 60 & 49 & 98 & 79 & 79 \\
Sin conexión & 20 & 40 & 1 & 2 & 21 & 21 \\
\hline Total & 50 & 100 & 50 & 100 & 100 & 100 \\
\hline
\end{tabular}

Fuente: Idem Cuadro 1.

Tabla 26. Ubicación del sistema de abastecimiento de agua

\begin{tabular}{|l|c|c|c|c|c|c|}
\cline { 2 - 7 } \multicolumn{1}{c|}{} & \multicolumn{2}{c|}{ GRUPO D } & \multicolumn{2}{c|}{ GRUPO E } & \multicolumn{2}{c|}{ TOTAL } \\
\hline \multicolumn{1}{c|}{ ABASTECIMIENTO } & $\mathrm{N}$ & $\%$ & $\mathrm{n}$ & $\%$ & $\mathrm{~N}$ & $\%$ \\
\hline Interno & 14 & 28 & 42 & 84 & 56 & 56 \\
Externo & 36 & 72 & 8 & 16 & 44 & 44 \\
\hline Total & 50 & 100 & 50 & 100 & 100 & 100 \\
\hline
\end{tabular}

Fuente: Idem Cuadro 1. $\mathrm{p}<0.01$

Tabla 27. Propiedad del sistema de abastecimiento de agua

\begin{tabular}{|l|c|c|c|c|c|c|}
\cline { 2 - 7 } \multicolumn{1}{c|}{} & \multicolumn{2}{c|}{ GRUPO D } & \multicolumn{2}{c|}{ GRUPO E } & \multicolumn{2}{c|}{ TOTAL } \\
\hline \multicolumn{1}{c|}{ ABASTECIMIENTO } & $\mathrm{n}$ & $\%$ & $\mathrm{~N}$ & $\%$ & $\mathrm{~N}$ & $\%$ \\
\hline Propio & 33 & 66 & 49 & 98 & 82 & 82 \\
Compartido o comunitario & 17 & 34 & 1 & 2 & 18 & 18 \\
\hline Total & 50 & 100 & 50 & 100 & 100 & 100 \\
\hline
\end{tabular}

Fuente: Idem Cuadro 1.

Respecto al sistema de eliminación de excretas, se da a través de pozo en el $88 \%$ de las viviendas de GD y en el $90 \%$ de las viviendas de GE (Tabla 28). Hay un mayor porcentaje en GD de servicios sanitarios compartidos con otras familias apareciendo esta situación en la cuarta parte de los casos (Tabla 29) y la letrina -si bien minoritaria en ambos grupos-, se presenta en un tercio de las viviendas de GD mientras que en GE la proporción es algo inferior (Tabla 30). 
Tabla 28. Sistema de eliminación de excretas

\begin{tabular}{|l|c|c|c|c|c|c|}
\cline { 2 - 7 } \multicolumn{1}{c|}{} & \multicolumn{2}{c|}{ GRUPO D } & \multicolumn{2}{c|}{ GRUPO E } & \multicolumn{2}{c|}{ TOTAL } \\
\hline ELIMIN. DE EXCRETAS & $\mathrm{N}$ & $\%$ & $\mathrm{~N}$ & $\%$ & $\mathrm{~N}$ & $\%$ \\
\hline Cloaca & 6 & 12 & 5 & 10 & 11 & 11 \\
Pozo & 43 & 88 & 45 & 90 & 88 & 88 \\
\hline Total & 49 & 100 & 50 & 100 & 99 & 100 \\
\hline
\end{tabular}

Fuente: Idem Cuadro 1.

Tabla 29. Propiedad del servicio sanitario

\begin{tabular}{|l|c|c|c|c|c|c|}
\cline { 2 - 7 } \multicolumn{1}{c|}{} & \multicolumn{2}{c|}{ GRUPO D } & \multicolumn{2}{c|}{ GRUPO E } & \multicolumn{2}{c|}{ TOTAL } \\
\hline SERVICIO SANITARIO & $\mathrm{n}$ & $\%$ & $\mathrm{n}$ & $\%$ & $\mathrm{~N}$ & $\%$ \\
\hline Propio & 38 & 77,5 & 46 & 92 & 84 & 84 \\
Compartido & 11 & 22,5 & 4 & 8 & 15 & 15 \\
\hline Total & 49 & 100 & 50 & 100 & 99 & 100 \\
\hline
\end{tabular}

Fuente: Idem Cuadro 1.

Tabla 30. Tipo de servicio sanitario

\begin{tabular}{|l|c|c|c|c|c|c|}
\cline { 2 - 7 } \multicolumn{1}{c|}{} & \multicolumn{2}{c|}{ GRUPO D } & \multicolumn{2}{c|}{ GRUPO E } & \multicolumn{2}{c|}{ TOTAL } \\
\hline SERVICIO SANITARIO & $\mathrm{n}$ & $\%$ & $\mathrm{n}$ & $\%$ & $\mathrm{~N}$ & $\%$ \\
\hline Inodoro & 35 & 70 & 39 & 81 & 74 & 75,5 \\
Letrina & 15 & 30 & 9 & 19 & 24 & 24,5 \\
\hline Total & 50 & 100 & 48 & 100 & 98 & 100 \\
\hline
\end{tabular}

Fuente: Idem Cuadro 1.

En lo que hace al equipamiento del hogar, la posesión de heladera se registra en el 66 $\%$ de las viviendas en GD y en el $87 \%$ en GE.

La mitad de las cocinas de GD tienen hornallas y horno utilizando como combustible gas envasado la casi totalidad de las viviendas, mientras que en GE la presencia de cocina con horno y hornalla aparece en casi las tres cuartas partes; el tipo de combustible utilizado es el mismo que el utilizado en las viviendas de GD.

\subsection{Situación ocupacional}

Como se ha señalado anteriormente, a partir de la década del 70, en el marco de las políticas económicas implementadas en el país, se ha venido produciendo una caída en el nivel de actividad, un proceso de desindustrialización y de terciarización de la fuerza de trabajo, así como una tendencia al decrecimiento del ingreso medio, proceso que tuvo diferentes repercusiones en los tres partidos que integran el Gran La Plata (Eguía, 1994). 
En GD trabaja el $82 \%$ de los jefes y el $8 \%$ de las cónyuges, presentándose un $42 \%$ de familias en las que trabajan otros miembros o hijos (30\% de familias con otros miembros que trabajan y un $12 \%$ en las que trabajan los hijos).

En GE trabaja el $84 \%$ de los jefes y el $32 \%$ de las cónyuges, habiendo un $16 \%$ de familias en las que trabajan hijos y otros miembros considerados conjuntamente.

Considerando la distribución de la población mayor de 14 años que trabaja, vemos que para GD ésta se halla representada por un $62 \%$ de jefes de familia, un $6 \%$ de cónyuges, un $9 \%$ de hijos y un $23 \%$ de otras personas que conviven en el hogar (parientes o allegados).

Dentro de GE el $64 \%$ de la población trabajadora corresponde a jefes de familia, el $24 \%$ a cónyuges y el $10 \%$ a hijos (Tabla 31 ).

Tabla 31. Tipo de integrante ocupado de la unidad doméstica

\begin{tabular}{|c|c|c|c|c|}
\cline { 2 - 5 } \multicolumn{1}{c|}{} & \multicolumn{2}{c|}{ GRUPO D } & \multicolumn{2}{c|}{ GRUPO E } \\
\hline INTEGRANTES & $\mathrm{n}$ & $\%$ & $\mathrm{n}$ & $\%$ \\
\hline Jefe & 41 & 62 & 42 & 64 \\
Cónyuge & 4 & 6 & 16 & 24 \\
Hijo & 6 & 9 & 7 & 10,5 \\
Otro & 15 & 23 & 1 & 1,5 \\
& & & & \\
\hline Total & 66 & 100 & 66 & 100 \\
\hline
\end{tabular}

En cuatro familias de GE, trabajan sólo hijos: en dos de ellas lo hace un solo hijo y en las otras dos, dos hijos. En la familia restante trabaja una hija además del padre. Hay dos familias en las que trabaja un hijo además del jefe y cónyuge. Dentro de las cónyuges, tres funcionan como jefas por estar sus maridos desocupados.

Cabe destacar que hay 9 familias de GD con jefes que no trabajan (seis de ellos desocupados) y, en el caso de las cónyuges, resalta la elevada proporción de aquellas que no trabajan ni buscan trabajo, situación que podría explicarse por la etapa del ciclo de vida familiar y por la imposibilidad de contar con reemplazo para las tareas domésticas y el cuidado de los hijos.

El porcentaje de mujeres de GE que no trabaja ni busca trabajo, si bien inferior a GD, comprende a más de la mitad de los casos y representa a la casi totalidad de la población inactiva del grupo, lo mismo que en GD (Tabla 32).

Tabla 32. Inactividad y desocupación de jefes y cónyuges GRUPO D GRUPO E GRUPO D GRUPO E \begin{tabular}{|l|l|l|l|}
\hline NO TRABAJAN & NO TRABAJAN & DESOCUPADOS & DESOCUPADOS \\
\hline
\end{tabular}

\begin{tabular}{|l|c|c|c|c|c|c|c|c|}
\hline INTEGRANTES & $\mathrm{n}$ & $\%$ & $\mathrm{n}$ & $\%$ & $\mathrm{n}$ & $\%$ & $\mathrm{n}$ & $\%$ \\
\hline Jefe & 3 & 8 & 2 & 7 & 6 & 54,5 & 4 & 57 \\
Cónyuge & 35 & 92 & 28 & 93 & 5 & 45,5 & 3 & 43 \\
& & & & & & & & \\
\hline Total & 38 & 100 & 30 & 100 & 11 & 100 & 7 & 100 \\
\hline
\end{tabular}

Fuente: Idem Cuadro 1. 
Analizando la condición de ocupación de acuerdo al tipo de integrante de la unidad doméstica puede observarse en GD -en relación a GE- una diferencia significativa en el porcentaje de otros miembros que trabajan, posibilitado por el mayor porcentaje de familias extendidas en ese grupo. En GE en cambio, el peso relativo de las cónyuges que trabajan cuadruplica el porcentaje encontrado para esos miembros en GD.

En la Tabla 33 se observa que en la mitad de las familias de ambos grupos trabaja exclusivamente el jefe. Las familias en las que trabajan jefe y cónyuge constituyen la cuarta parte de los casos en GE frente al $8 \%$ en GD adquiriendo importancia en este último la modalidad de combinación de jefes e hijos $u$ otros miembros que trabajan (22\%). Finalmente aparece en GD un $10 \%$ de familias en las que ningún miembro trabaja, situación que se da en el $4 \%$ de GE.

Tabla 33. Hogares según integrantes que trabajan

\begin{tabular}{|l|c|c|c|c|c|c|}
\hline \multicolumn{9}{c}{ GRUPO D } & \multicolumn{2}{c|}{ GRUPO E } & $\mathrm{N}$ & $\%$ \\
\hline Trabaja/n: & $\mathrm{n}$ & $\%$ & $\mathrm{n}$ & $\%$ & 53 & 53 \\
\hline Sólo el jefe & 26 & 52 & 27 & 54 & 16 & 16 \\
\hline $\begin{array}{l}\text { Jefe y } \\
\text { Cónyuge }\end{array}$ & 4 & 8 & 12 & 24 & 2 & 2 \\
\hline $\begin{array}{l}\text { Jefe,cónyuge } \\
\text { e hijos u otro }\end{array}$ & 0 & 0 & 2 & 4 & 2 & 2 \\
\hline Sólo cónyuge & 0 & 0 & 2 & 4 & 12 & 12 \\
\hline $\begin{array}{l}\text { Jefe e hijo/s u } \\
\text { otro }\end{array}$ & 11 & 22 & 1 & 2 & 8 & 8 \\
\hline Sólo hijo/s/otro & 4 & 8 & 4 & 8 & 7 & 7 \\
\hline Nadie trabaja & 5 & 10 & 2 & 4 & 100 & 100 \\
\hline Total & 50 & 100 & 50 & 100 & & \\
\hline
\end{tabular}

Fuente: Idem Cuadro 1.

Con el objeto de relevar la problemática de la subocupación, se registró el número de horas semanales del trabajo remunerado.

El porcentaje de jefes que trabajan más de 35 hs. semanales es similar en ambos grupos: el $78 \%$ y $76 \%$ de GD y GE respectivamente. La mitad de las cónyuges de GD trabaja más de 35 hs. semanales, situación que se da en el $25 \%$ de las cónyuges de GE, la mayoría de las cuales se encuentra subocupada.

Entre los otros miembros que trabajan, tanto en GD como en GE, alrededor de un $36 \%$ lo hace más de 35 hs. semanales encontrándose el resto subocupados (Tabla 34). 
Tabla 34. Población que trabaja según número de horas semanales de trabajo GRUPO D

\begin{tabular}{|l|c|c|c|c|c|c|c|c|}
\hline \multicolumn{1}{c|}{ HORAS } & \multicolumn{2}{|c|}{ JEFE } & \multicolumn{2}{c|}{ CONYUGE } & \multicolumn{2}{c|}{ HIJO/OTRO } & \multicolumn{2}{c|}{ TOTAL } \\
\cline { 2 - 9 } SEMANALES & $\mathrm{n}$ & $\%$ & $\mathrm{n}$ & $\%$ & $\mathrm{n}$ & $\%$ & $\mathrm{~N}$ & $\%$ \\
\hline$\leq 15$ & 2 & 5 & 2 & 50 & 4 & 18 & 8 & 12 \\
$16-34$ & 5 & 12 & 0 & 0 & 6 & 27 & 11 & 16 \\
$\geq 35$ & 32 & 78 & 2 & 50 & 8 & 36 & 42 & 63 \\
Variable & 2 & 5 & 0 & 0 & 3 & 14 & 5 & 7 \\
No consignado & 0 & 0 & 0 & 0 & 1 & 4,5 & 1 & 1 \\
\hline Total & 41 & 100 & 4 & 100 & 22 & 100 & 67 & 100 \\
\hline
\end{tabular}

GRUPO E

\begin{tabular}{|l|c|c|c|c|c|c|c|c|}
\hline \multicolumn{1}{c|}{ HORAS } & \multicolumn{2}{|c|}{ JEFE } & \multicolumn{2}{c|}{ CONYUGE } & \multicolumn{2}{c|}{ HIJO/OTRO } & \multicolumn{2}{c|}{ TOTAL } \\
\cline { 2 - 9 } SEMANALES & $\mathrm{n}$ & $\%$ & $\mathrm{n}$ & $\%$ & $\mathrm{n}$ & $\%$ & $\mathrm{~N}$ & $\%$ \\
\hline$\leq 15$ & 2 & 5 & 4 & 25 & 1 & 9 & 7 & 10 \\
$16-34$ & 2 & 5 & 5 & 31 & 2 & 18 & 9 & 13 \\
$\geq 35$ & 32 & 76 & 4 & 25 & 4 & 36 & 40 & 58 \\
Variable & 6 & 14 & 3 & 19 & 4 & 36 & 13 & 19 \\
\hline Total & 42 & 100 & 16 & 100 & 11 & 100 & 69 & 100 \\
\hline
\end{tabular}

Fuente: Idem Cuadro 1.

Respecto a la antigüedad en el trabajo de jefes y cónyuges se registra en GD una menor antigüedad de los jefes: el $41 \%$ desempeña el trabajo actual desde hace tres años o menos -diez puntos más que en GE-. En este último grupo, la proporción de jefes con una antigüedad superior a los 11 años triplica el valor hallado en GD para esa antigüedad. Entre las cónyuges de GD dos trabajan hace menos de tres años y las dos restantes lo hacen desde hace 7 a 10 años. En GE más de la mitad presenta una antigüedad inferior o igual a los 3 años mientras que el porcentaje restante trabaja desde hace más de 3 años (Tabla 35).

Tabla 35. Antigüedad en el trabajo principal de jefes y cónyuges GRUPO D

\begin{tabular}{|l|c|c|c|c|c|c|}
\hline ANTIGüEDAD & \multicolumn{2}{|c|}{ JEFE } & \multicolumn{2}{c|}{ CÓNYUGE } & \multicolumn{2}{c|}{ TOTAL } \\
\cline { 2 - 7 } EN EL TRABAJO & $\mathrm{N}$ & $\%$ & $\mathrm{~N}$ & $\%$ & $\mathrm{~N}$ & $\%$ \\
\hline$\leq 3$ años & 17 & 41,5 & 2 & 50 & 19 & 42 \\
$3-6$ años & 10 & 24 & 0 & 0 & 10 & 22 \\
$7-10$ años & 9 & 22 & 2 & 50 & 11 & 24 \\
$\geq 11$ años & 4 & 10 & 0 & 0 & 4 & 9 \\
No consignado & 1 & 2,5 & 0 & 0 & 1 & 2 \\
\hline Total & 41 & 100 & 4 & 100 & 45 & 100 \\
\hline
\end{tabular}

GRUPO E

\begin{tabular}{|l|c|c|c|c|c|c|}
\hline ANTIGüEDAD & \multicolumn{2}{|c|}{ JEFE } & \multicolumn{2}{c|}{ CÓNYUGE } & \multicolumn{2}{c|}{ TOTAL } \\
\cline { 2 - 7 } EN EL TRABAJO & $\mathrm{N}$ & $\%$ & $\mathrm{~N}$ & $\%$ & $\mathrm{~N}$ & $\%$ \\
\hline$\leq 3$ años & 13 & 31 & 10 & 62,5 & 23 & 40 \\
3-6 años & 12 & 28,5 & 1 & 6 & 13 & 22 \\
7-10 años & 4 & 9,5 & 3 & 19 & 7 & 12 \\
$\geq 11$ años & 13 & 31 & 1 & 6 & 14 & 24 \\
No consignado & 0 & 0 & 1 & 6 & 1 & 2 \\
\hline Total & 42 & 100 & 16 & 100 & 58 & 100 \\
\hline
\end{tabular}

Fuente: Idem Cuadro 1. 
Los trabajos desempeñados por los jefes fueron clasificados en las siguientes categorías ocupacionales (Colman, 1992):

1) personal doméstico: personas dedicadas a trabajar a domicilio, generalmente sin relación de dependencia estable.

2) obrero: trabajadores manuales en una empresa industrial o de servicios, en relación de dependencia.

3) empleado: trabajadores administrativos en relación de dependencia.

4) cuentapropista: trabajadores que no dependen de un patrón y ejercen por su cuenta una profesión, oficio o actividad, sin empleados a cargo.

5) patrón-socio: personas que, dirigiendo una empresa o ejerciendo por cuenta propia una profesión u oficio, tienen uno o más empleados remunerados a cargo.

Respecto a la categoría ocupacional del jefe, las diferencias encontradas entre ambos grupos son altamente significativas. En GD hay un predominio de las categorías de trabajadores por cuentapropia (49\%), obreros (34\%) y una minoría de empleados. Este orden se invierte para el caso de los jefes de GE, en los que prevalecen las categorías de empleado (38 \%), obrero (26\%) y trabajadores por cuentapropia (17\%) (Tabla 36).

Tabla 36. Categoría ocupacional del jefe

\begin{tabular}{|l|c|c|c|c|c|c|}
\hline CATEGORÍA & \multicolumn{2}{|c|}{ GRUPO D } & \multicolumn{2}{c|}{ GRUPO E } & \multicolumn{2}{c|}{ TOTAL } \\
\cline { 2 - 7 } OCUPACIONAL & $\mathrm{n}$ & $\%$ & $\mathrm{n}$ & $\%$ & $\mathrm{~N}$ & $\%$ \\
\hline P. doméstico & 1 & 2 & 4 & 9.5 & 5 & 6 \\
Obrero & 14 & 34 & 11 & 26 & 25 & 30 \\
Empleado & 5 & 12 & 16 & 38 & 21 & 25 \\
Cta prop sin I/v & 20 & 49 & 7 & 17 & 27 & 35 \\
Cta prop con I/v & 1 & 2 & 4 & 9.5 & 5 & 6 \\
& & & & & & \\
& & & & & & \\
\hline Total & 41 & 100 & 42 & 100 & 83 & 100 \\
\hline
\end{tabular}

De las cuatro cónyuges que trabajan de GD, tres lo hacen como personal doméstico. Las cónyuges de GE se distribuyen en la casi totalidad de las categorías ocupacionales, habiendo un $44 \%$ de personal doméstico, $25 \%$ de empleadas y un $19 \%$ de trabajadoras por cuenta propia.

Para el resto de miembros que trabajan, las categorías ocupacionales predominantes en GD son el cuentapropismo y personal doméstico mientras que en GE predomina la categoría de empleado (64\%).

Analizando la forma en que se expresa el trabajo de acuerdo a la rama de actividad, determinada por la naturaleza del trabajo que se realiza y por el tipo de bienes y servicios que se produce, se desprende también que las diferencias entre ambos 
grupos son altamente significativas. Los jefes de GD trabajan en un $39 \%$ en construcción, $24 \%$ en comercio, y $17 \%$ en servicios. En GE las ramas de actividad del trabajo de los jefes están representadas por un $50 \%$ en servicios, $21 \%$ por la construcción y un $12 \%$ comercio (Tabla 37 ).

Tabla 37. Rama de actividad del jefe en el trabajo principal

\begin{tabular}{|l|c|c|c|c|c|c|}
\hline \multicolumn{1}{|c|}{ RAMA DE } & \multicolumn{2}{c|}{ GRUPO D } & \multicolumn{2}{c|}{ GRUPO E } & \multicolumn{2}{c|}{ TOTAL } \\
\cline { 2 - 7 } ACTIVIDAD & $\mathrm{N}$ & $\%$ & $\mathrm{n}$ & $\%$ & $\mathrm{~N}$ & $\%$ \\
\hline Ind. Manuf. & 2 & 5 & 3 & 7 & 5 & 6 \\
Construcción & 16 & 39 & 9 & 21,5 & 25 & 30 \\
Comercio & 10 & 24 & 5 & 12 & 15 & 18 \\
Servicios & 7 & 17 & 21 & 50 & 28 & 34 \\
Servicios pers. & 2 & 5 & 4 & 9,5 & 6 & 7 \\
Otros & 4 & 10 & 0 & 0 & 4 & 5 \\
\hline Total & 41 & 100 & 42 & 100 & 83 & 100 \\
\hline
\end{tabular}

Fuente: Idem Cuadro 1.

La mayoría de las cónyuges de GD se desempeñan dentro de la rama de servicios personales, mientras que las de GE lo hacen en las ramas de servicios personales (44\%) y servicios (31\%). En GD los otros miembros que trabajan lo hacen fundamentalmente en comercio y servicios, mientras que los otros integrantes de GE trabajan en servicios (64\%) y el resto en comercio.

Respecto al tipo de trabajo que desempeñan los jefes pueden observarse diferencias entre ambos grupos: mientras que en GD el $59 \%$ trabaja como autoempleado en comercio, construcción y servicios y en el 17 \% como obrero en producción de bienes. Los jefes de GE se desempeñan en un $36 \%$ como empleados en comercio, transporte y servicios, en el $26 \%$ como autoempleados en comercio, construcción y servicios y un $17 \%$ como obreros en limpieza, transporte, comercio y servicios (Tabla 38).

Tabla 38. Tipo de trabajo de jefes de hogar

\begin{tabular}{|c|c|c|c|c|c|c|}
\hline \multirow{2}{*}{ TIPO DE } & \multicolumn{2}{|c|}{ GRUPO D } & \multicolumn{2}{c|}{ GRUPO E } & \multicolumn{2}{c|}{ TOTAL } \\
\cline { 2 - 7 } TRABAJO & $\mathrm{n}$ & $\%$ & $\mathrm{n}$ & $\%$ & $\mathrm{~N}$ & $\%$ \\
\hline \multirow{2}{*}{1} & 7 & 17,0 & 4 & 9,5 & 11 & 13,2 \\
2 & 4 & 10,0 & 15 & 36,0 & 19 & 22,9 \\
3 & 2 & 5,0 & 1 & 2,4 & 3 & 3,6 \\
4 & 1 & 2,5 & 3 & 7,0 & 4 & 4,8 \\
5 & 24 & 58,5 & 11 & 26,0 & 35 & 42,1 \\
6 & 3 & 7,3 & 7 & 17,0 & 10 & 12,0 \\
7 & 0 & 0,0 & 1 & 2,4 & 1 & 1,2 \\
\hline Total & 41 & 100 & 42 & 100 & 83 & 100 \\
\hline
\end{tabular}

Fuente: Idem Cuadro 1. 
NOTAS

1. Obrero en producción de bienes

2. Empleado en industria, servicios, transporte, comercio

3. Asalariado bajo condiciones de subcontratación en industria y comercio

4. Empleado en servicios personales no contractuales

5. Autoempleado en comercio, construcción y servicios

6. Obrero en limpieza, transporte, comercio, servicios

7. Autoempleado en cualquier tipo de trabajo

Las cónyuges por su parte, trabajan en servicio doméstico en la casi totalidad de los casos de GD mientras que las de GE, si bien este tipo de trabajo es desempeñado por un $44 \%$, trabajan en un $25 \%$ como empleadas en servicios, transporte y comercio y en un $25 \%$ como autoempleadas en comercio y servicios. Los demás miembros que trabajan en GD -hijos y otros considerados conjuntamente- se desempeñan en actividades como autoempleados en comercio, construcción y servicios y como empleados en servicios personales no contractuales fundamentalmente.

En GE dichos integrantes desarrollan trabajos como empleados en servicios, transporte y comercio y como asalariados bajo condiciones de subcontratación en la industria y comercio.

Cabe introducir en el análisis del trabajo del jefe de la unidad doméstica, las categorías de formalidad e informalidad. El concepto de informalidad ha cobrado creciente significación en los últimos años para reflejar y redefinir la naturaleza de las situaciones de pobreza urbana en América Latina. "Este concepto conlleva la idea de que los pobres no están simplemente colocados ahí, como masa inerte excluida de la participación en la sociedad moderna. Por el contrario, da la imagen de una clase dinámica, comprometida con una miríada de actividades que, si bien no altamente remuneradas, por lo menos proveen para su subsistencia y la de sus hijos. Esta imagen se hace más clara en investigaciones recientes, contrapuesta al concepto de "marginalidad", término favorecido en los últimos años para designar la pobreza, y que denota más bien una exclusión pasiva que una presencia económica dinámica" (Portes, 1984).

Siguiendo a Portes, el concepto de informalidad es definido como "la suma total de las actividades que producen ingreso, a las que se incorporan los miembros de una familia, excluyendo los ingresos provenientes de empleos contractuales y legalmente regulados. El sector formal, por su parte, se caracteriza por el empleo contractual con deberes y derechos explícitos, líneas de transmisión de la autoridad y condiciones de contratación y despido. Los trabajadores están protegidos por la legislación laboral existente y vigilada en su cumplimiento y promovida por sus propias organizaciones. Bajo estas condiciones, los individuos venden su fuerza de trabajo a las empresas por 
una cantidad determinada de tiempo, recibiendo regularmente a cambio una compensación monetaria. Las relaciones de producción en el sector informal son completamente opuestas a las anteriores. A menudo, la contratación y el despido se hacen verbalmente, sujetos a arreglos bastante vagos. Los trabajadores no tienen ninguna protección laboral en lo concerniente a las horas de trabajo, salario mínimo, accidentes, enfermedad y jubilación. Las condiciones de trabajo y las prestaciones cambian continuamente y la cantidad y el ritmo del pago de los salarios es a menudo impredecible." (Portes, 1984).

Los indicadores utilizados en la encuesta para relevar esta característica fueron:

-percepción de salario familiar

-existencia de aportes jubilatorios retenidos por el empleador

-disponibilidad de obra social

Las diferencias observadas en el sector de trabajo entre GD y GE son altamente significativas, predominando el trabajo informal en GD, con un $64 \%$ de casos frente al $28 \%$ de trabajadores informales en GE. En este último grupo, más de la mitad de los jefes trabaja dentro del sector formal. El porcentaje de jefes que no trabaja es similar en ambos grupos: 18 y $16 \%$ en GD y GE respectivamente (Tabla 39).

Tabla 39. Sector del ocupación del jefe

\begin{tabular}{|l|c|c|c|c|c|c|}
\hline & \multicolumn{2}{|c|}{ GRUPO D } & \multicolumn{2}{c|}{ GRUPO E } & \multicolumn{2}{c|}{ TOTAL } \\
\cline { 2 - 7 } & $\mathrm{n}$ & $\%$ & $\mathrm{n}$ & $\%$ & $\mathrm{~N}$ & $\%$ \\
\hline Sector Formal & 9 & 18 & 28 & 56 & 37 & 37 \\
Sector Informal & 32 & 64 & 14 & 28 & 46 & 46 \\
No trabaja & 9 & 18 & 8 & 16 & 17 & 17 \\
\hline Total & 50 & 100 & 50 & 100 & 100 & 100 \\
\hline
\end{tabular}

Fuente: Idem Cuadro 1.

El tipo de trabajo que desempeñan dentro del sector informal - tanto los jefes de GD como los de GE- es el de autoempleados en comercio, construcción y servicios. Dentro del sector formal los jefes de ambos grupos trabajan como empleados en servicios, transporte o comercio o como obreros en producción de bienes mayoritariamente.

En ambos grupos, las tres cuartas partes de los otros miembros que trabajan, lo hacen en condiciones de informalidad. 
Analizando la categoría ocupacional de acuerdo al sector, si bien la totalidad de los que presentan trabajo formal pertenecen a las categorías de obrero y empleado, la primera predomina entre los jefes de GD y la segunda entre los jefes de GE.

En el sector informal el cuentapropismo concentra más de la mitad de los jefes de ambos grupos. No obstante en GD hay un mayor número de jefes que trabajan como obreros. Los trabajadores por cuenta propia con local y/o vehículo aparecen dentro de GE en mayor proporción, lo mismo que el trabajo como personal doméstico dado por la presencia de mujeres jefas de hogar.

En cuanto a la rama de actividad, dentro del sector formal prevalece la rama servicios en ambos grupos. Dentro del sector informal tanto de GD como de GE los jefes trabajan fundamentalmente en las ramas construcción y comercio.

Considerando la antigüedad del jefe en el trabajo principal de acuerdo con el sector de ocupación, puede observarse que dentro de GD los que trabajan en el sector informal tienen una mayor antigüedad en el trabajo que aquellos que trabajan dentro del sector formal. A la inversa, en GE las tres cuartas partes de los trabajadores formales tienen una mayor antigüedad en el trabajo respecto de aquellos que se desempeñan dentro del sector informal.

\subsection{Nivel de ingreso familiar}

Respecto a los ingresos, la Encuesta Permanente de Hogares (EPH-INDEC) establece, para analizar la distribución del ingreso, tres estratos: inferior, medio y superior, los cuales agrupan los montos correspondientes a la división por deciles de la población ${ }^{70}$.

Los deciles están ordenados por nivel de ingreso creciente. En octubre de 1994 determina, para el caso de los ingresos percibidos por el jefe de familia, que el estrato bajo (deciles 1 a 4) comprende los ingresos de hasta 350 pesos, el medio incluye a los deciles 5 a 8 con ingresos comprendidos entre los 350 a 800 pesos y el estrato superior (deciles 9 y 10) con ingresos superiores a 800 pesos.

Los jefes de GD presentan ingresos que coinciden con aquellos correspondientes al estrato inferior, duplicando el porcentaje hallado en GE. En este último grupo es mayor la proporción de ingresos del jefe dentro del estrato medio presentándose, aunque escasamente, ingresos dentro del estrato superior. Cabe destacar que en GD se registra además un $11 \%$ de jefes que no producen ingreso alguno frente al $4 \%$ en GE (Tabla 40).

\footnotetext{
${ }^{70}$ En el cálculo de las escalas decílicas de ingreso, el $10 \%$ de la población perceptora genera los límites del intervalo.
} 
Tabla 40. Estrato de ingreso del jefe de familia

\begin{tabular}{|l|c|c|c|c|c|c|}
\cline { 2 - 7 } \multicolumn{1}{c|}{} & \multicolumn{2}{c|}{ GRUPO D } & \multicolumn{2}{c|}{ GRUPO E } & \multicolumn{2}{c|}{ TOTAL } \\
\hline ESTRATOS DE INGRESO & $\mathrm{n}$ & $\%$ & $\mathrm{n}$ & $\%$ & $\mathrm{~N}$ & $\%$ \\
\hline Inferior & 19 & 41 & 9 & 20 & 28 & 31 \\
Medio & 17 & 37 & 21 & 48 & 38 & 42 \\
Superior & 0 & 0 & 2 & 4,5 & 2 & 2 \\
Variable & 3 & 6,5 & 6 & 13,5 & 9 & 10 \\
No sabe/no contesta & 2 & 4 & 4 & 9 & 6 & 6,5 \\
No trabaja/sin ingreso & 5 & 11 & 2 & 4,5 & 7 & 8 \\
\hline Total & 46 & 100 & 44 & 100 & 90 & 100 \\
\hline
\end{tabular}

Fuente: Idem Cuadro 1

La tasa de dependencia o índice consumidores/productores, que refleja la relación entre el número total de integrantes de la unidad doméstica y el número de miembros que producen ingresos muestra diferencias significativas entre ambos grupos, siendo más desfavorable en GD que en GE.

GD presenta un $44 \%$ de familias con más de 5 consumidores por miembro que produce y un $10 \%$ de familias sin productores de ingreso. GE muestra en el $68 \%$ de las familias una relación de hasta 5 consumidores por miembro que genera ingresos, situación presente en el $46 \%$ de GD (Tabla 41) ${ }^{71}$.

Tabla 41. Hogares según relación c/p de ingresos

\begin{tabular}{|l|cc|cr|}
\multicolumn{2}{c}{ GRUPO D } & \multicolumn{3}{c|}{ GRUPO E } \\
\hline \multicolumn{1}{|c|}{ INDICE C/P } & $\mathrm{n}$ & $\%$ & $\mathrm{n}$ & $\%$ \\
\hline$\leq 3$ & 8 & 16 & 15 & 30 \\
$3,1-5$ & 15 & 30 & 19 & 38 \\
$5,1-8$ & 17 & 34 & 15 & 30 \\
$\geq 8$ & 5 & 10 & 1 & 2 \\
Nadie produce & 5 & 10 & 0 & 0 \\
Valor de $\mathrm{n}$ & 50 & 100 & 50 & 100 \\
\hline
\end{tabular}

Fuente: Idem Cuadro 1.

$\mathrm{p}<0.05$

Finalmente para el tratamiento del monto global del ingreso familiar y su relación con la pobreza, se utilizaron dos procedimientos para su estimación:

a- De acuerdo con la encuesta FIDE (Fundación de Investigaciones para el Desarrollo Económico), que releva mensualmente el valor de un presupuesto básico familiar, en mayo de 1995 se precisaban 440,24 pesos para comprar solamente los productos alimenticios que forman parte de la canasta básica de alimentos, monto definido para una familia tipo de trabajadores integrada por dos adultos y dos niños.

\footnotetext{
${ }^{71}$ Para satisfacer la condición para la aplicación del Test de Chi cuadrado de que la frecuencia mínima sea $\geq 5$, se agruparon los tres últimos rangos de la tabla.
} 
La estimación de la canasta de subsistencia que comprende -además de alimentos- un conjunto mínimo de bienes y servicios, es calculada para mayo del mismo año en 986 pesos mensuales.

El $64 \%$ de las familias de GD tienen ingresos inferiores a los necesarios para adquirir una canasta básica de alimentos, situación que aparece en el $40 \%$ de las familias de GE (Tabla 42). Además, en GD se presenta un $10 \%$ de familias sin ingreso frente a un $4 \%$ en GE.

Tabla 42. Hogares según ubicación de su ingreso en relación al valor de la canasta básica de alimentos (FIDE, mayo de 1995)

\begin{tabular}{|l|c|c|c|c|c|c|}
\cline { 2 - 7 } \multicolumn{1}{c|}{} & \multicolumn{2}{c|}{ GRUPO D } & \multicolumn{2}{c|}{ GRUPO E } & \multicolumn{2}{c|}{ TOTAL } \\
\hline \multicolumn{1}{c|}{ FAMILIAS } & $\mathrm{n}$ & $\%$ & $\mathrm{n}$ & $\%$ & $\mathrm{~N}$ & $\%$ \\
\hline $\begin{array}{l}\text { Ingreso inferior al valor de la } \\
\text { canasta básica de alimentos }\end{array}$ & 32 & 64 & 20 & 40 & 52 & 52 \\
$\begin{array}{l}\text { Ingreso inferior al valor de la } \\
\text { canasta básica de subsist. }\end{array}$ & 8 & 16 & 16 & 32 & 24 & 24 \\
Ingreso variable & 2 & 4 & 8 & 16 & 10 & 10 \\
Sin ingreso & 5 & 10 & 2 & 4 & 7 & 7 \\
No sabe/no contesta & 3 & 6 & 4 & 8 & 7 & 7 \\
\hline Total & 50 & 100 & 50 & 100 & 100 & 100 \\
\hline
\end{tabular}

Fuente: Idem Cuadro 1.

b- La Encuesta Permanente de Hogares (EPH-INDEC) estima para octubre de 1994, que en el estrato bajo se distribuyen los ingresos de hasta 480 pesos, el medio incluye ingresos comprendidos entre los 480 y 1090 pesos y el estrato superior, ingresos superiores a 1100 pesos.

Las familias de GD presentan la siguiente distribución por estratos de ingreso:

el $44 \%$ corresponde a los ingresos del estrato inferior, un $36 \%$ al estrato medio y ninguna al estrato superior. Dicha distribución no arroja diferencias significativas respecto de la encontrada en GE.

En este último grupo, las familias cuyos ingresos coinciden con los del estrato inferior, representan el $34 \%$, un $38 \%$ se corresponde con el estrato medio y ninguna con el superior. En el $24 \%$ de los casos no pudo computarse el monto de ingreso: muchas familias presentan ingresos variables relacionados a actividades inestables, de baja calificación y escasamente remuneradas y otras no saben o no contestan (Tabla 43). 
Tabla 43. Distribución de los hogares por estratos de ingreso

\begin{tabular}{|l|c|c|c|c|c|c|}
\cline { 2 - 7 } \multicolumn{1}{c|}{} & \multicolumn{2}{c|}{ GRUPO D } & \multicolumn{2}{c|}{ GRUPO E } & \multicolumn{2}{c|}{ TOTAL } \\
\hline ESTRATOS DE INGRESO & $\mathrm{n}$ & $\%$ & $\mathrm{n}$ & $\%$ & $\mathrm{~N}$ & $\%$ \\
\hline Inferior & 22 & 44 & 17 & 34 & 39 & 39 \\
Medio & 18 & 36 & 19 & 38 & 37 & 37 \\
Superior & 0 & 0 & 0 & 0 & 0 & 0 \\
Variable & 2 & 4 & 7 & 14 & 9 & 9 \\
No sabe/no contesta & 3 & 6 & 5 & 10 & 8 & 8 \\
No trabaja/sin ingreso & 5 & 10 & 2 & 4 & 7 & 7 \\
\hline Total & 50 & 100 & 50 & 100 & 100 & 100 \\
\hline
\end{tabular}

Fuente: Idem Cuadro 1

Considerando el ingreso per cápita y siguiendo los cortes de población por deciles establecidos por la EPH para 1994, se puede ver que en el estrato inferior (con ingresos comprendidos entre 16 y 200 pesos) hay una mayor porcentaje de casos en GD, en el estrato medio (de 201 a 500 pesos) si bien comprende pocos casos, se concentra una mayor proporción en GE y en el estrato superior (501 pesos y más) no se registran casos para ninguna de las dos muestras (Tabla 44).

Tabla 44. Distribución de los ingresos per cápita familiar por estratos de ingreso

\begin{tabular}{|l|c|c|c|c|c|c|}
\cline { 2 - 7 } \multicolumn{1}{c|}{} & \multicolumn{2}{c|}{ GRUPO D } & \multicolumn{2}{c|}{ GRUPO E } & \multicolumn{2}{c|}{ TOTAL } \\
\hline ESTRATOS DE INGRESO & $\mathrm{N}$ & $\%$ & $\mathrm{n}$ & $\%$ & $\mathrm{~N}$ & $\%$ \\
\hline Inferior & 39 & 78 & 32 & 64 & 7 & 71 \\
Medio & 1 & 2 & 4 & 8 & 5 & 5 \\
Superior & 0 & 0 & 0 & 0 & 0 & 0 \\
Variable & 2 & 4 & 7 & 14 & 9 & 9 \\
No sabe/no contesta & 3 & 6 & 5 & 10 & 8 & 8 \\
No trabaja/sin ingreso & 5 & 10 & 2 & 4 & 7 & 7 \\
\hline Total & 50 & 100 & 50 & 100 & 100 & 100 \\
\hline
\end{tabular}

Fuente: Idem Cuadro 1

Dada la homogeneidad que presenta la distribución de los ingresos siguiendo los estratos de la $\mathrm{EPH}$, y considerando los ingresos per cápita mínimos y máximos hallados en ambos grupos, se establecieron, sólo para los ingresos cuyos montos se especifican, intervalos más reducidos, los cuales arrojan diferencias más marcadas: mientras que el $40 \%$ de GD registra ingresos per cápita mensuales inferiores a los 50 pesos, en GE esto se da en menos de la mitad y se eleva la proporción de familias con más de 150 pesos (Tabla 45). 
Tabla 45. Distribución de los ingresos per cápita familiar

\begin{tabular}{|l|c|c|c|c|c|c|}
\cline { 2 - 7 } \multicolumn{1}{c|}{} & \multicolumn{2}{c|}{ GRUPO D } & \multicolumn{2}{c|}{ GRUPO E } & \multicolumn{2}{c|}{ TOTAL } \\
\hline ESTRATOS DE INGRESO & $\mathrm{n}$ & $\%$ & $\mathrm{n}$ & $\%$ & $\mathrm{~N}$ & $\%$ \\
\hline Menos de \$ 50 & 16 & 40 & 7 & 19.4 & 23 & 30.2 \\
\$ $51-$ \$100 & 16 & 40 & 15 & 41.6 & 31 & 40.8 \\
\$101 - \$150 & 7 & 17.5 & 7 & 19.4 & 14 & 18.4 \\
Más de \$150 & 1 & 2.5 & 7 & 19.4 & 8 & 10.5 \\
& & & & & & \\
\hline Total & 40 & 100 & 36 & 100 & 76 & 100 \\
\hline
\end{tabular}

Fuente: Idem Cuadro 1

En ambos grupos, la mayor proporción de familias -aproximadamente el $60 \%$ - tiene ingresos per cápita familiar mensuales entre 51 y 150 pesos.

El promedio de este indicador muestra para GD un valor de $\$ 71.8$ (\$2.4 per cápita diarios) y para GE de $\$ 102.6$ (\$3.4 per cápita diarios), por lo que cada integrante de GE dispone mensualmente de $43 \%$ pesos más que un integrante de GD.

\subsection{Estrategias alimentarias de las unidades domésticas}

El concepto de estrategias alimentarias parte de considerar que hay dos vías posibles de acceso al consumo alimentario:

a- Consumos mercantilizados.

b- Consumos no obtenibles con dinero, resultado de formas propias de organización familiar (autoabastecimiento, redes informales) y como producto de la intervención estatal y de organismos no gubernamentales (iglesias, partidos políticos, etc).

Se trata de las opciones locales con las que cuentan las familias cuando se ven obligadas a recurrir a alternativas que exceden el marco de los ingresos.

No se soslaya la relevancia y el conocimiento empírico de las posibilidades de consumos mercantilizados, de los cuales el nivel de ingreso familiar se toma como indicador indirecto.

En el presente trabajo el análisis de las estrategias alimentarias se restringe al segundo punto. En este sentido, se definen las estrategias alimentarias como "el conjunto de actividades que los sectores populares realizan para satisfacer sus necesidades alimentarias, las que no pueden cubrir plenamente vía ingreso monetario." (Hintze,1989).

Las familias con situaciones demográficas, educacionales, laborales y de vivienda con las características descriptas anteriormente presentan limitadas posibilidades 
reproductivas, las que en relación a la alimentación se expresan en problemas de nutrición y salud en el conjunto más vulnerable del grupo familiar: los niños, como resultado de un acceso inadecuado e insuficiente al consumo alimentario.

Frente a una situación de crisis estructural como la que atraviesa nuestro país, es predecible que la reproducción vía ingreso directo se vea recortada tanto por la retracción del mercado de trabajo como por la capacidad adquisitiva del ingreso. En estos términos interesa resaltar la incidencia de los consumos no mercantilizados en la reproducción familiar (Colman y colaboradores, 1992).

Estos consumos provienen de la acción de las políticas públicas, apareciendo tres circuitos básicos de satisfacción de necesidades alimentarias en los grupos estudiados: el Programa Materno-Infantil que provee leche en polvo a través de las Unidades Sanitarias, los Comedores Escolares y el Programa Alimentario Integral y Solidario (PAIS).

Las otras fuentes son las opciones generadas por las propias unidades domésticas, tanto en el plano del autoabastecimiento (animales, huerta) como a través del desarrollo de redes informales de ayuda entre familiares y vecinos.

\subsubsection{Caracterización de los programas alimentarios de la Pcia. de Buenos}

\section{Aires}

El gobierno de la Pcia. de Buenos Aires reorganiza, a partir de julio de 1992, los programas alimentarios. Mediante decreto 1685 se dispuso la integración de los mismos en el Programa Social de la Familia Bonaerense "Eva Perón", encomendándose a la Subsecretaría de Organización Comunitaria, dependiente del Ministerio de Salud y Acción Social, la formulación, administración y ejecución del Programa (Eguía, 1995).

El objetivo general del Programa consiste en promover e implementar un sistema de ejecución integral de la política social en la Pcia. de Buenos Aires, destinado a la atención de las familias en condiciones de pobreza que persiga:

1- satisfacer sus necesidades de alimentación y de salud materno-infantil

2- fomentar mecanismos de asistencia y promoción que privilegien el ámbito familiar y el fortalecimiento de redes solidarias en la comunidad

3- promover y apoyar el desarrollo de capacidades laborales o de gestión de unidades económicas que tiendan a aumentar sus ingresos monetarios y no monetarios.

La población destinataria del Programa Eva Perón se halla constituida por los hogares cuyo ingreso se sitúa por debajo de la denominada "línea de pobreza", que además se hallen en una de las siguientes situaciones: tengan "necesidades básicas insatisfechas" o se verifiquen en su seno situaciones de riesgo por condición biológico- 
social (al menos un niño menor de 2 años, al menos dos niños menores de 6 años o mujer embarazada o amamantando). Las categorías "línea de pobreza" y "necesidades básicas insatisfechas" son las definidas por el INDEC para la medición de la pobreza en la Argentina.

El criterio de focalización que propone el Programa determina la admisión a partir de la evaluación que se realice de una solicitud de ingreso al mismo, en las que se consignan las condiciones del grupo familiar.

El Programa se estructuró con base en la redefinición de programas que estaban previamente en marcha, resignificándolos en el marco de una nueva estructura. Abarca los siguientes componentes:

1- Componente materno-infantil

2- Componente emprendimientos de cuidado infantil

3- Componente comedores escolares

4- Componente grupos alimentarios multifamiliares (PAIS)

5- Componente mejoramiento de ingresos y capacitación para el trabajo

6- Componente relevamiento de necesidades de infraestructura social.

Se caracterizarán los componentes 1, 3 y 4 por ser los vigentes y utilizados por las dos poblaciones en estudio.

- Componente materno-infantil.

Tiene su origen en la Dirección Nacional de Maternidad e Infancia, creada por Ley en el año 1937, con aplicación en todas las jurisdicciones del país a través de las jefaturas de programas provinciales.

El objetivo del programa es disminuir la morbimortalidad del grupo materno-infantil. Se propicia mejorar la cobertura del sistema de atención primaria de la salud, facilitando el acceso de la población a los servicios sanitarios y sociales del primer nivel de atención. El programa comprende las siguientes acciones:

- atención de la embarazada, captación precoz, control clínico, asistencia alimentaria, control odontológico, psicoprofilaxis obstétrica, atención y tratamiento de patologías de baja complejidad, derivación a niveles de mayor complejidad de patologías que así lo requieran;

- atención de niños de 0 a 1 año, control del crecimiento y desarrollo, detección precoz del recién nacido, atención de patologías prevalentes, promoción de la lactancia materna, estimulación temprana, derivación a mayor complejidad de patologías que lo requieran;

- atención de niños de 1 a 5 años, control del crecimiento y desarrollo, atención de patologías prevalentes. Optimización de los sistemas institucionales de cuidado del niño; 
- recuperación nutricional y rehabilitación nutricional en desnutridos mediante complementación alimentaria, educación nutricional, controles programados, derivación a otros niveles de complejidad.

Como actividad complementaria se realiza la entrega de $2 \mathrm{~kg}$. mensuales de leche en polvo a embarazadas, $3 \mathrm{~kg}$. a lactantes y $2 \mathrm{~kg}$. a niños desnutridos de 1 a 5 años. La entrega se realiza en los Centros de Salud, en el momento de los controles sanitarios. La subsecretaría de Organización Comunitaria señala -en un documento de 1989problemas organizacionales a nivel provincial que disminuyeron sus posibilidades de ejecución. Se destaca la irregularidad en la entrega de los recursos en cantidad y tiempo y la carencia de recolección sistemática de datos que permitan la evaluación del impacto del programa.

\section{- Comedores escolares.}

Este programa nacional, de larga data en nuestro país, pasa a depender en 1992 de cada provincia. La asistencia alimentaria consiste en la copa de leche, almuerzo o merienda reforzada.

Este es el principal programa alimentario de la provincia, tanto por la magnitud de sus beneficiarios y los montos asignados, como por la cantidad y complejidad de los recursos humanos intervinientes. El objetivo específico es reforzar el nivel nutricional de la alimentación que recibe el niño de 6 a 14 años dentro de la población objetivo, favoreciendo su crecimiento, desarrollo, normal estado de salud y generando al mismo tiempo acciones integrales que motiven la participación comunitaria en el sostén del componente.

Se desarrolla en la Pcia. de Bs. As. en el área de Educación bajo la dependencia de la Dirección de Cooperación Escolar de la Dirección General de Escuelas. La Subsecretaría de Organización Comunitaria ejerce, hasta comienzos de 1994, las funciones de giro de fondos a los Consejos Escolares para la prestación del servicio, según los cupos asignados por la Dirección de Cooperación Escolar.

Las resoluciones que han regulado su funcionamiento coinciden en señalar como objetivo del mismo la asistencia alimentaria a los alumnos carenciados que por su edad puedan resultar más gravemente afectados por la sub-alimentación.

Los problemas detectados en el diagnóstico efectuado por el proyecto de Asistencia Técnica para la Reformulación del Servicio de Comedores Escolares, realizado entre 1993 y 1994, con el apoyo financiero del Banco Mundial y el apoyo técnico del Programa de Seguimiento y Evaluación de la Política Social de la Pcia. de Bs. As. (Ministerio de Economía, PNUD) fueron los siguientes: 
- la descentralización del servicio a nivel de escuelas resulta la forma más utilizada de gestión, lo que da por resultado un alto grado de heterogeneidad en la calidad de la dieta y en la utilización de los recursos;

- los recursos humanos son insuficientes. Esto se expresa en la utilización de porteros en tareas de cocina, en la participación de los maestros y directivos en la gestión de diversos aspectos de la prestación;

- no hay una metodología de determinación de beneficiarios que posibilite captar correctamente la población potencialmente necesitada. Para la Pcia. de Buenos Aires se encontró que un tercio de los niños en situación de riesgo nutricional, de acuerdo al indicador talla/edad, no reciben ninguna asistencia alimentaria en escuelas que brindan el servicio;

- en relación a los contenidos nutricionales, se encontró bajo cumplimiento de las pautas programáticas (situación agravada en el caso de la prestación vianda), en especial en el Conurbano Bonaerense;

- bajo desarrollo de criterios organizativos explícitamente normatizados, de mecanismos de comunicación formal e informal, así como la inexistencia de sistemas de información y bancos de datos específicos que aseguren la disponibilidad de información en tiempo y forma para el seguimiento de los beneficiarios, la aplicación de los fondos y el monitoreo.

- Programa Alimentario Integral y Solidario (PAIS).

Surge en 1989, en plena etapa de hiperinflación, frente al problema de la subsistencia de los sectores más afectados. Este programa promueve la creación de un sistema integral tendiente a dar solución al problema alimentario atendiendo la necesidad de asistencia de los sectores en situación de pobreza crítica y posibilitando a las organizaciones comunitarias la implementación de proyectos de autoabastecimiento y producción.

Este programa fue conducido por la Subsecretaría de Acción Social del entonces Ministerio de Acción Social de la Pcia. de Buenos Aires.

Los requisitos necesarios para incorporarse al programa consisten en: estar sin trabajo o contar con un trabajo temporario y tener un salario mínimo como único ingreso.

Se planteó dar cobertura alimentaria al $65 \%$ del sector de los denominados "pobres estructurales" en una primera etapa, dando prioridad al Conurbano Bonaerense por su concentración de población en situación de riesgo.

Las etapas que el programa contempla desarrollar son las siguientes:

- la formación de los llamados comedores multifamiliares,

- las acciones de autoabastecimiento, 
- los emprendimientos productivos.

La primera fase del programa consiste en el acuerdo de un mínimo de cinco familias que reciben una subvención dineraria para la compra de alimentos. El programa aporta al presupuesto familiar una cantidad de dinero per cápita calculada en términos del valor de una comida diaria, según un menú preparado por nutricionistas.

El monto fijado es de 5.5 \$ mensuales por ración desde diciembre de 1990.

La unidad conformada por el grupo organizado de hogares (que oscila entre 50 y 100 personas) suscribe un compromiso solidario renovable automáticamente, que abarca la inclusión y el mantenimiento de los miembros. Para ingresar al mismo debe completarse una encuesta que funciona como una declaración jurada, sobre el número de miembros y los ingresos. Cada grupo designa, como único control efectivo, dos apoderados que administran el dinero que se les entrega. Con ese dinero deben efectuar sus compras en forma comunitaria. Los apoderados deben presentar periódicamente una rendición de cuentas, con los comprobantes y la conformidad de todos los miembros.

Como segunda etapa, se plantea que mediante el proceso de capacitación se organicen grupos familiares para producir elementos de autoabastecimiento familiar y en algunos casos, excedentes económicos a través de trabajos en huertas comunitarias, cría de pequeños animales, hornos de pan, fabricación de pastas, etc. Para apoyar este proceso se les brinda insumos. La última etapa, de consolidación del grupo, se promueve a través de la organización de unidades productivas, la superación de las condiciones estructurales de pobreza, brindando asistencia técnica y financiamiento.

Se señala que el programa no cuenta con un adecuado mecanismo de control y monitoreo a nivel central, sin suficiente explicitación de los criterios de ingreso y egreso.

La ración otorgada a los comedores multifamiliares, considerando los valores de la canasta familiar actual, resulta insuficiente. No hay periodicidad en los pagos y la cobertura alcanzada es baja.

En el marco del Programa Eva Perón, el PAIS se incorpora manteniendo sus objetivos básicos, intentando extender la cobertura. En enero de 1994, el Gran La Plata aglutinaba el $11 \%$ de los grupos PAIS de la provincia, con 38.541 beneficiarios.

En cuanto a los microemprendimientos, en el Gran La Plata se registraron 94 unidades productivas, que representan el $18.8 \%$ del total de microemprendimientos de la región.

Se trata de microempresas de subsistencia, cuyo principal obstáculo de acuerdo con información suministrada por el personal a cargo del subprograma, radica en la fase 
de comercialización. La mayoría son talleres de costura, criaderos de pollos, fábricas de pastas y pañaleras, entre otros.

\subsubsection{Uso y evaluación de las estrategias alimentarias}

La diferencia más marcada entre GD y GE en la utilización de opciones provistas por el Estado se da en el Plan País, apareciendo duplicado en GE el porcentaje de usuarios de GD, de los cuales sólo la cuarta parte son beneficiarios de dicho programa.

La leche suministrada por el Programa Materno Infantil es la opción más utilizada por GD: aparece en el $62 \%$ de las familias, porcentaje levemente superior al de GE.

En GE la opción más usada es el comedor escolar ya que aparece en el $62 \%$ de las familias, siendo utilizada por el $36 \%$ de las familias de GD.

Considerando el total de familias de ambos grupos, el promedio de estrategias alimentarias estatales utilizadas es de 1.2 en GD y de 1.7 en GE. El promedio sólo de aquellas familias que usan alguno de estos tres recursos ( 43 de GD y 42 de GE) se eleva a 1.4 en GD y a 2.0 en GE, manteniéndose el diferencial a favor de GE.

Respecto a las estrategias autogeneradas se destaca un $72 \%$ de familias de GD que refieren utilizar redes informales con parientes y/o vecinos como así también el apoyo de iglesias (englobadas en la categoría "otro"), sobre todo si se considera que este tipo de estrategias no suele ser captado en su real magnitud mediante la técnica de encuesta.

Respecto a la disponibilidad de animales de cría para el consumo familiar, no se observan diferencias entre GD y GE, presentándose en el $25 \%$ de las familias. Las diferencias se hacen marcadas en el caso de las huertas familiares, las cuales, si bien con una baja frecuencia, se presentan en mayor porcentaje en GD que en $\mathrm{GE}^{72}$.

Cabe señalar que hay un $16 \%$ de familias GE que no utiliza ninguna estrategia, apareciendo igual situación en el $14 \%$ de las familias GD (Tabla 46).

Tabla 46. Hogares según utilización de estrategias alimentarias

\begin{tabular}{|l|c|c|c|c|}
\multicolumn{1}{c}{} & \multicolumn{2}{c}{ GRUPO D } & \multicolumn{2}{c|}{ GRUPO E } \\
\hline \multicolumn{1}{|c|}{ ESTRATEGIAS } & $\mathrm{n}$ & $\%$ & $\mathrm{n}$ & $\%$ \\
\hline Plan País & 12 & 24 & 25 & 50 \\
Leche de la sala & 31 & 62 & 30 & 60 \\
Comedor escolar & 18 & 36 & 31 & 62 \\
Huerta & 8 & 16 & 1 & 2 \\
Animales & 13 & 26 & 12 & 24 \\
Otro sistema & 36 & 72 & 16 & 32 \\
No utilizan & 7 & 14 & 8 & 16 \\
\hline
\end{tabular}

Fuente: Idem Cuadro 1.

$p<0.01$

\footnotetext{
72 Dada la proximidad al río, los terrenos en donde residen las familias estudiadas de Punta Lara, sufren inundaciones periódicamente, lo que los torna poco aptos para el cultivo.
} 
El análisis estadístico arroja diferencias altamente significativas en el uso de estrategias entre ambos grupos.

Asimismo, la totalidad de las familias GD, con motivo de la asistencia del niño desnutrido en la Unidad de Rehabilitación Nutricional del Hospital de Niños de La Plata, reciben quincenal o mensualmente -de acuerdo con la severidad de la desnutrición del niño y las características familiares- una ración de alimentos consistente en aceite, azúcar, fideos, polenta, lentejas, harina, arroz, puré de tomate, arvejas y dos kilos de leche, que se otorga hasta dos meses después de la salida de riesgo nutricional (recuperación peso/talla), proceso que ocurre en un tiempo de tratamiento promedio de 4 meses. El hecho de ser un aporte coyuntural, explica la ausencia mayoritaria de su mención en las respuestas.

Respecto a la prioridad asignada por las informantes a las distintas opciones como aporte para la alimentación familiar los programas alimentarios estatales no parecen tener gran importancia en GD, mencionándose prioritario el comedor escolar en el $19 \%$ de los casos. La leche del programa Materno-Infantil, pese a tener una amplia cobertura en el grupo, no es considerada como aporte prioritario para la alimentación familiar.

GD prioriza en primer y segundo término a las opciones englobadas en la categoría "otro" que consisten en ayudas provenientes de parroquias, unidades básicas y fundamentalmente de las redes familiares.

El suplemento alimentario obtenido de la Unidad de Rehabilitación Nutricional es mencionado como prioridad en un bajo porcentaje, hecho que obedece seguramente a su consideración como una ayuda eventual y transitoria. Además, esto es mencionado por aquellas mujeres cuyas familias no utilizan otra opción pública.

El $48 \%$ de las informantes de GD no usan y/o no priorizan en segundo lugar ninguna otra opción.

En GE, el comedor y el plan País son considerados como los programas más importantes que aportan a la alimentación de la familia: $57 \%$ y $33 \%$ de las mujeres encuestadas respectivamente. Los aportes provenientes de las redes de ayuda familiar y/o vecinal $u$ obtenidas de organismos no gubernamentales son priorizadas por una minoría de las informantes (Tabla 47). 
Tabla 47. Hogares según valoración del aporte de las estrategias en el gasto familiar

\begin{tabular}{|c|c|c|c|c|c|c|}
\hline & \multicolumn{6}{|c|}{ PRIMERA OPCIÓN } \\
\hline & \multicolumn{2}{|c|}{ GRUPO D } & \multicolumn{2}{|c|}{ GRUPO E } & \multicolumn{2}{|c|}{ TOTAL } \\
\hline Prioridad & $\mathrm{n}$ & $\%$ & $\mathrm{n}$ & $\%$ & $\mathrm{~N}$ & $\%$ \\
\hline Plan PAIS & 6 & 14 & 11 & 33 & 17 & 23 \\
\hline Comedor & 8 & 19 & 19 & 57,5 & 27 & 36 \\
\hline Leche & 2 & 5 & 0 & 0 & 2 & 2,5 \\
\hline Otro sist. & 26 & 62 & 3 & 9 & 29 & 39 \\
\hline Total & 42 & 100 & 33 & 100 & 75 & 100 \\
\hline
\end{tabular}

Fuente: Idem Cuadro 1

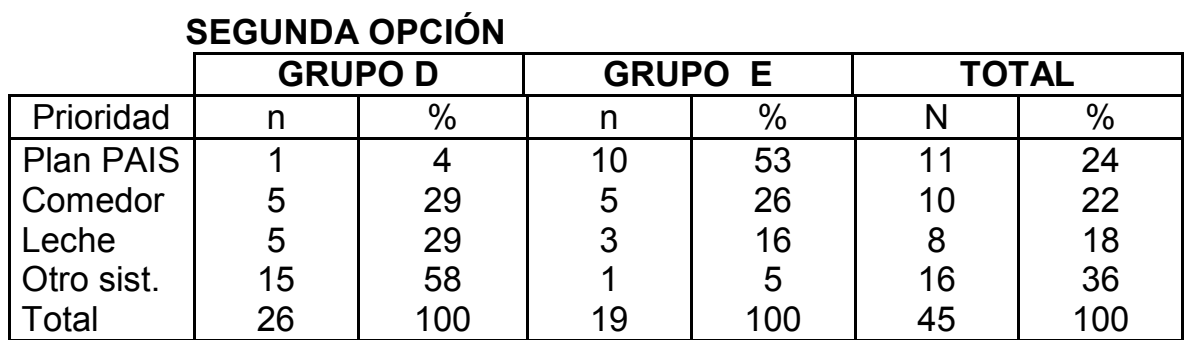

Fuente: Idem Cuadro 1

GRUPO E:

No usan ningún sistema: 8 familias

Consideran a todos por igual: 1

No saben/no contestan: 2

La evaluación realizada por las mujeres encuestadas sobre los programas alimentarios estatales es buena en más de la mitad de los casos, tanto en GD como en GE, siendo mejor calificadas -en términos relativos- en GE que en GD (Tabla 48).

Las informantes manifestaron valorar especialmente el comedor escolar, ya que permite asegurar una comida diaria para sus hijos, considerando de buena calidad la alimentación que brindan.

En el caso del plan País, las ventajas de este programa se basan en el establecimiento de su comparación con la Caja Pan: el primero permite la elección de las mercaderías para el consumo de todo el grupo familiar. No obstante, si bien valoran las características de esta modalidad, señalan la irregularidad de su recepción así como las dificultades en las posibilidades de acceso, situación enfatizada por las mujeres encuestadas de GD.

Tabla 48. Evaluación de los recursos alimentarios estatales

\begin{tabular}{|l|c|c|c|c|c|c|}
\multicolumn{1}{c|}{} & \multicolumn{2}{c|}{ GRUPO D } \\
\cline { 2 - 7 } \multicolumn{1}{c|}{} & \multicolumn{2}{c|}{ PLAN PAIS } & \multicolumn{2}{c|}{ LECHE SALA } & \multicolumn{2}{c|}{ COMEDOR } \\
\hline Calificación & $\mathrm{n}$ & $\%$ & $\mathrm{n}$ & $\%$ & $\mathrm{n}$ & $\%$ \\
\hline Bueno & 7 & 58 & 22 & 71 & 14 & 78 \\
Regular & 4 & 33 & 9 & 29 & 3 & 16.5 \\
Malo & 0 & 0 & 0 & 0 & 1 & 5.5 \\
No consignado & 1 & 8 & 0 & 0 & 0 & 0 \\
\hline Total & 12 & 100 & 31 & 100 & 18 & 100 \\
\hline
\end{tabular}


GRUPO E

\begin{tabular}{|l|c|c|c|c|c|c|}
\cline { 2 - 7 } \multicolumn{1}{c|}{} & \multicolumn{2}{c|}{ PLAN PAIS } & \multicolumn{2}{c|}{ LECHE SALA } & \multicolumn{2}{c|}{ COMEDOR } \\
\hline \multicolumn{1}{c|}{ Calificación } & $\mathrm{n}$ & $\%$ & $\mathrm{n}$ & $\%$ & $\mathrm{n}$ & $\%$ \\
\hline Bueno & 17 & 68 & 23 & 76 & 25 & 81 \\
Regular & 7 & 28 & 5 & 16.5 & 6 & 19 \\
Malo & 0 & 0 & 0 & 0 & 0 & 0 \\
No consignado & 1 & 4 & 2 & 6.5 & 0 & 0 \\
\hline Total & 25 & 100 & 30 & 100 & 31 & 100 \\
\hline
\end{tabular}

Fuente: Idem Cuadro 1

\subsection{Síntesis y comentarios del análisis comparativo}

Del análisis comparativo establecido entre las dos poblaciones estudiadas integradas por familias pobres urbanas, una con presencia de desnutrición infantil en todos los casos (GD) y la otra sin prevalencia de desnutrición (GE), se desprende que:

\section{a) Respecto del estado nutricional y las condiciones de salud asociadas:}

En GD la mitad de las familias presentan más de un hijo desnutrido.

La desnutrición -actual o pasada- se presenta en el $40 \%$ de los hijos de las familias de GD mientras que en GE, el porcentaje de niños desnutridos actuales y anteriores encontrado en las 70 de las 100 familias recuperadas del estudio anterior realizado en 1988 es del $5 \%$. Dichas familias fueron eliminadas de este estudio así como aquellas que por encontrarse en una etapa más avanzada del ciclo de vida familiar no tenían niños menores de 5 años. Por tanto, en el estudio actual el estado nutricional de los niños es normal en la totalidad de las familias.

A través de las enfermedades infecciosas, que en el presente estudio se detectaron como causas de internación, se evidencia el papel de la desnutrición como factor precipitante de las mismas: en la mitad de las familias de GD aparecen casos de hijos internados por infecciones banales, la mayoría de los cuales presentaron desnutrición. GE por su parte, registra un número mucho menor de familias con niños hospitalizados, presentando además un número significativamente inferior de hijos internados por dichas causas.

Hay autores que consideran a las enfermedades infecciosas, particularmente a las enfermedades diarreicas, no sólo como factor agravante de la desnutrición sino también como factor causal directo. Aún cuando confundidas con las repercusiones de la morbilidad a través del círculo vicioso de la infección y la desnutrición, las implicaciones de la desnutrición sobre el mayor riesgo de mortalidad se han demostrado ampliamente. Existe una relación directa entre la severidad de la 
desnutrición y la mortalidad en niños menores de seis años, la cual es especialmente notable en el segundo año de vida (Puffer y Serrano, 1973).

Otros estudios plantean que se ha adjudicado a las infecciones un rol muy importante como causa de desnutrición, malabsorción e inapetencia. Estudios poblacionales realizados en diversos lugares del mundo (India, Bangladesh, México, Ruanda, Costa de Marfil) demuestran que las infecciones no alcanzan a explicar estadísticamente más del $10 \%$ del retraso en el crecimiento de los niños. Como los mecanismos que condicionan el retraso del crecimiento forman un proceso continuo y crónico es difícil pensar que los niños estén permanentemente enfermos como para producir ese deterioro nutricional. Sin embargo es posible, de acuerdo con hipótesis que se están investigando, que los niños criados en condiciones desventajosas de higiene y saneamiento ambiental padezcan un estado de infección crónica subclínica que no es detectable con los métodos de laboratorio o clínicos actuales (Cesni, 1998).

El peso de nacimiento es otro valioso indicador nutricional y puede asociarse a compromiso nutricional de la madre o tardío y mal control gestacional.

Lamentablemente en nuestro país las estadísticas de peso de nacimiento tienen limitaciones por subregistro y deficiente información de la edad gestacional.

La prevalencia de bajo peso al nacer (menos de $2500 \mathrm{gr}$ ) tiene un promedio nacional de 6\% (MSAS, 1995) con importantes diferencias regionales. La prevalencia de peso insuficiente 2500-2999 gr. tiene un promedio de 17 \%. Para la Pcia. de Bs. As. (Ministerio de Salud Pcia. de Bs. As., 1995) se halló, sobre la base de un registro de 17.000 niños en consultas espontáneas de centros asistenciales de diferente nivel de complejidad y pertenecientes a todos los sectores (público, privado, seguridad social), un $6.9 \%$ de bajo peso al nacer -inferior al promedio provincial que es de $7.7 \%$ - El peso insuficiente (entre 2.500 y $3000 \mathrm{gr}$.) fue del $19.5 \%$, similar al promedio provincial estimado hasta entonces (19\%). De esta información resulta que el $73.4 \%$ de los niños nacidos en la Pcia. de Bs. As. presenta un peso al nacimiento superior a los $3000 \mathrm{gr}$.

El peso de nacimiento está relacionado con el riesgo de mortalidad infantil: el $50 \%$ de las defunciones en el primer año de vida ocurren en niños con un peso de nacimiento inferior a los 2500 gr. Datos de la EPH (INDEC, 1995) confirman que aún dentro de los promedios provinciales existen diferencias muy amplias entre los distintos estratos sociales. Entre las mujeres con NBI el riesgo de tener un hijo de bajo peso de nacimiento es de 50 a 500 veces mayor que entre madres no NBI (Cesni, 1998).

Los niños de GD con desnutrición actual -asistidos en la Unidad de Rehabilitación Nutricional del Hospital de Niños de La Plata (URN)- no presentan en su mayoría bajo 
peso al nacimiento, aunque el porcentaje encontrado de bajo peso es superior en 10 puntos al promedio nacional (que es del $6 \%$ ).

Además se destaca el insuficiente tiempo de lactancia en la mitad de los casos, apareciendo la desnutrición tempranamente -antes de los 18 meses- . La severidad de la desnutrición que presentan es de tipo leve y moderada.

Respecto a la lactancia, estudios realizados en nuestro país tales como la encuesta del Gran Buenos Aires (Calvo, 1989) y de Misiones (Calvo, 1987) mostraron una mayor duración y prevalencia de la lactancia en los niveles sociales más bajos, mientras que en Tierra del Fuego (Cesni, 1995) y Córdoba (Sabulsky, 1995) los datos son opuestos.

Para la Pcia. de Bs. As. se estima una media provincial de lactancia exclusiva de 4.14 meses, habiendo un $36 \%$ de niños que llega al cuarto mes con lactancia materna exclusiva. La encuesta provincial nutricional realizada en Región Sanitaria XI muestra que el 39.7 \% recibió pecho hasta el cuarto mes (Ministerio de Salud Pcia. de Bs. As., 1995).

Considerando la práctica de lactancia (estimada para la totalidad de hijos menores de 5 años de las familias encuestadas), se desprende que la duración de la lactancia materna y el tiempo de ablactación muestran un período más prolongado en GE que en GD. En GD la alimentación materna exclusiva se verifica por un tiempo igual o superior a los 4 meses en el $25 \%$ de los niños, mientras que en GE esto sucede en el $40 \%$. La duración total de lactancia o edad de ablactación se da antes de los tres meses de edad en el $50 \%$ de GD y en el $32 \%$ de GE.

Ambos grupos se alejan de los valores fijados en las Metas Nacionales en Favor de la Madre y el Niño (Ministerio de Salud y Acción Social de la Nación, 1996) que establecen que el $60 \%$ de niños sean amamantados por lo menos hasta el cuarto mes de vida en forma exclusiva. No obstante, superan los datos poblacionales recabados por la Encuesta Permanente de Hogares (INDEC, 1996) en cinco conglomerados urbanos del país, en los cuales la meta se cumple en el $23.5 \%$ de los casos registrados.

Alrededor del $6^{\circ}$ mes de vida la calidad de los alimentos que se introduzcan en la dieta infantil es trascendente. Se ha demostrado que los lactantes más pequeños no pueden compensar con mayor volumen de ingesta la baja densidad energética de un alimento. Como la mayoría de las papillas de vegetales que se eligen en nuestro medio como primer alimento tienen una baja densidad energética, si no se las enriquece con leche, azúcar o grasas, existe el riesgo de ocasionar una ingesta energética insuficiente.

Respecto de las proteínas, la leche humana es abundante en aminoácidos esenciales. El reemplazo de la leche materna o su complementación con alimentos de escaso 
contenido de nitrógeno total y/o de aminoácidos esenciales puede ser un factor interviniente en el origen del acortamiento que se observa en los niños de niveles sociales menos favorecidos (Cesni, 1998).

Cuando la leche de vaca u otros alimentos sustituyen a la leche materna antes de los 6 meses, situación que se da a partir del tercer mes en el $52 \%$ de los niños del Gran Buenos Aires y en el $44 \%$ de los de Tierra del Fuego, existe riesgo de deficiencia de hierro, de zinc, cobre y ácidos grasos esenciales, tal como podría ocurrir, dada la similitud de los hallazgos, en los niños de GD.

De hecho, la anemia es la enfermedad intercurrente más frecuente en los niños desnutridos del estudio. Asimismo, se registra la presencia de enfermedades intercurrentes tales como anemia, parasitosis, infecciones gastrointestinales 0 broncopulmonares; la mitad de los niños conjuga tres o más intercurrencias simultáneamente al momento de ingreso a la URN.

En GE, las enteroparasitosis constituyen una patología ambiental prevalente que se encuentra en paulatino descenso en los últimos años.

La consideración de la "pata de cabra" -enfermedad reconocida en el ámbito de la medicina popular- obedece a su vinculación con episodios de desnutrición. A fin de minimizar el subregistro de casos de desnutrición se la intentó detectar a través de dicha terminología.

En GD, la "pata de cabra" se presenta en más de la mitad de las familias, hecho que sucede en una minoría de las familias GE.

Por lo expuesto, se desprende que las condiciones de nutrición y salud de los niños de GD son más desfavorables de las que se presentan en los niños de GE. Asimismo se evidencia la estrecha asociación de la desnutrición con otras patologías y su papel agravante.

Dado que ambos grupos pertenecen a sectores de la pobreza urbana, se analizaron las características estructurales de las familias a las que pertenecen con el objeto de identificar aquellos aspectos que se muestren discriminatorios dentro del conjunto, asociados a peores condiciones de salud.

\section{b) Componentes estructurales de las familias}

b.1) Las características sociodemográficas de la unidad doméstica tienen relevancia en el análisis dado que la apreciación del sistema de salud sobre la relación entre familiasmonoparentaless con madre a cargo y desnutrición se halla bastante difundida. Por otra parte hay autores que consideran a las familias extendidas y fundamentalmente a las numerosas, como una estrategia exitosa para hacer frente a las precarias condiciones de vida. 
"La estructura del grupo doméstico constituye no sólo un objetivo de la estrategia adaptativa, sino también un componente instrumental de dicha estrategia. Los grupos domésticos más resistentes son los que consiguen una composición en la que se maximiza el número de hijos $u$ otros parientes en edad de trabajar. Ya sea mediante el aumento de la fertilidad o por la incorporación de parientes productivos al grupo doméstico, la presión adaptativa empuja en dirección de la familia extensa o ampliada." (Ashton, citado por Bartolomé,1983). "Así, se utiliza trabajo intensivo y no remunerado familiar y se depende de las redes sociales para canalizar recursos. Esta estrategia, denominada "sistema de seguridad social informal" (Lomnitz,1975) confiere un valor adaptativo a la familia numerosa, minimizando la vulnerabilidad frente a la incertidumbre y agresión del medio." (Bartolomé,1983).

Contrastando con las formulaciones arriba planteadas, se resalta en primer lugar la diferencia en el tipo de familia en ambos grupos, presentándose en GD un elevado porcentaje de familias extensas.

En GE, las familias de tipo nuclear son mayoritarias, mientras que en GD éstas constituyen la mitad.

El promedio de miembros por familia es de 6.8 en GD, levemente superior al de GE, siendo el promedio de hijos de 4, similar en ambos grupos.

Por lo tanto, no puede sostenerse que el tipo de familia extensa juegue en la dinámica familiar un papel atenuante de su situación adversa. Asimismo, considerando la similitud en el número de hijos y dado el desfasaje en el ciclo de vida familiar de ambos grupos, más avanzado en GE, pueden aventurarse como hipótesis explicativas de tal situación ya sea un menor intervalo intergenésico o bien un más temprano inicio de la natalidad en $\mathrm{GD}^{73}$.

La estructura de edad de ambas poblaciones muestra la mayor edad relativa de GE.

Las familias de GD y GE se encuentran en diferentes etapas del ciclo familiar: las primeras se hallan en la etapa de expansión y algunas de las segundas han entrado en la etapa de fisión (Margulis, 1981), con independencia de los hijos mayores del núcleo familiar.

Respecto a los niveles de escolaridad de los jefes y cónyuges, puede verse que este factor se presenta discriminatorio, habiendo diferencias estadísticamente significativas entre GD y GE: considerando conjuntamente a jefes y cónyuges, en GD la mitad de ellos son analfabetos o presentan primaria incompleta.

Esta variable tiene relevancia ya que la educación, desigualmente distribuida en nuestra sociedad, tiene una importancia particular -entre otras cosas- como instrumento que posibilita al hombre un mejor aprovechamiento de los recursos 
materiales disponibles (Bloch, 1984). No obstante el acceso creciente y masivo a la educación formal, la estructura y la lógica del mercado de trabajo excluyen a capas relativamente calificadas. La posesión de niveles elevados de educación formal no garantizan la inserción en el mercado de trabajo; pero su carencia sí asegura la imposibilidad de inserción en trabajos estables y con una remuneración aceptable.

b.2) En cuanto a la vivienda, se registra que el tiempo de residencia en el barrio es mayor en GE que en $\mathrm{GD}^{74}$.

Tal vez la mayor utilización de programas alimentarios estatales guarde relación con este hecho: la permanencia en el barrio permite un mejor conocimiento de los recursos urbanos disponibles y de los canales que posibilitan su utilización.

Más de las tres cuartas partes de ambos grupos carecen de la titularidad del terreno en el que viven. En GD se destaca el hecho de que casi la mitad de las familias comparten el terreno con otros hogares.

La propiedad de la vivienda, si bien mayoritaria en ambos grupos, se registra con mayor fuerza en GE.

La relación personas por cuarto y personas por cama presenta diferencias altamente significativas entre los grupos: GD muestra valores más desfavorables en ambos indicadores y presenta asimismo en menor medida cuarto de cocina con uso exclusivo. Los materiales de construcción de la vivienda denotan una peor calidad relativa en GD.

El sistema de provisión de agua así como su ubicación también arroja diferencias estadísiticamente significativas: en GE se da a través de cañería y se ubica en el interior de la vivienda en casi todos los casos. Más de la mitad de las familias de GD dispone de agua corriente, pero la fuente de abastecimiento se ubica mayoritariamente fuera de la vivienda, compartiéndola con vecinos o parientes.

El sistema de eliminación de excretas se realiza a través de pozo en casi todos los casos tanto de GD como de GE. GD muestra un mayor porcentaje de sanitarios compartidos y mayor porcentaje de letrinas.

El equipamiento del hogar muestra ser más diversificado en GE que en GD, hecho indicativo de niveles de bienestar general más elevados en el primer grupo.

Los aspectos descriptos constituyen parte de las condiciones en las que se reproducen las familias de la pobreza urbana. La calidad de la vivienda refleja niveles de bienestar relativos que repercuten indudablemente en las condiciones de salud infantil.

\footnotetext{
${ }^{73}$ Puede suponerse que las familias G1 crecerán en tamaño por natalidad cuando avancen en el ciclo de vida.

${ }^{74}$ Este resultado no puede considerarse un hallazgo ya que está ligado al criterio de selección muestral.
} 
b.3) En relación a la situación ocupacional, en GD el 18\% de los jefes se encuentran desocupados o no trabajan, registrándose un porcentaje levemente inferior en GE, un porcentaje marcadamente menor de cónyuges que trabajan y un mayor porcentaje de otros miembros (parientes o allegados e hijos) ocupados.

En GE casi la tercera parte de las cónyuges trabaja, presentando hijos y otros miembros que trabajan en menos de la mitad de casos que GD.

En cuanto al tipo de trabajo que desempeñan los jefes, pueden marcarse diferencias entre GD y GE: los jefes del primer grupo se desempeñan fundamentalmente como autoempleados en comercio, construcción, servicios y en segundo lugar como obreros.

Los jefes de GE trabajan básicamente como empleados en comercio, transporte y servicios y, en segundo término, como autoempleados en comercio, construcción y servicios.

En la categoría ocupacional del jefe se reflejan diferencias altamente significativas: en GD predomina el cuentapropismo y en GE la categoría de empleado. En segundo término, en ambos grupos y en proporciones similares aparece la categoría obrero como trabajo más frecuente.

La rama de actividad que aglutina a los trabajos de los jefes de GD es la de construcción y comercio, siendo para los jefes de GE las de servicios y construcción. Esta variable también diferencia significativamente a los grupos analizados.

Cabe resaltar las diferencias altamente significativas en el sector de ocupación. La presencia de trabajadores informales en GD es elevada: ellos constituyen más del doble de los casos registrados en GE. En este último grupo, más de la mitad de los jefes se desempeñan en el sector formal.

Respecto al trabajo de las cónyuges, predomina el servicio doméstico en GD, trabajando las cónyuges de GE como empleadas en servicios, transporte y comercio o como autoempleadas en comercio y servicios.

Respecto de los otros miembros que trabajan, el tipo de actividad de aquellos que lo hacen en GD es el de cuentapropia y personal doméstico, mientras que en GE los otros miembros que trabajan lo hacen como obreros o empleados.

La problemática de la subocupación no parece incidir significativamente en el trabajo de los jefes de ambos grupos: las tres cuartas partes de los jefes de GD y GE trabajan más de 35 hs. semanales. La subocupación se da básicamente en las cónyuges, sobre todo de GE. La mayoría de los otros miembros que trabajan -en ambos gruposregistran subocupación. 
La tasa de dependencia, que refiere a la relación entre productores de ingreso y no productores dentro de la familia, se presenta más desfavorable en GD y con diferencias significativas respecto de GE.

b.4) La estimación del ingreso correspondiente al que define la Fundación de Investigaciones para el Desarrollo Económico (FIDE,1995) para adquirir una canasta básica de alimentos muestra ser inferior en la mayoría de las familias de GD, mientras que en GE esto sucede en menos de la mitad de los casos.

Asimismo, la distribución de las familias por estratos de ingreso -tal como los plantea la EPH/INDEC- refleja que las de GD presentan distribución sesgada hacia los estratos inferiores de ingreso, presentando las familias de GE menor presencia en los niveles inferiores de ingreso. El ingreso per cápita familiar es el indicador que refleja mayores diferencias: cada integrante de GE dispone casi la mitad más de dinero para comer que un integrante de GD.

Las características ocupacionales del jefe y de la familia en su conjunto, así como los niveles de ingreso familiar, imponen fuertes restricciones a las oportunidades y necesidades de los menores que crecen en su seno. La situación ocupacional presente en GD, en el que prevalecen en mayor grado las ocupaciones por cuentapropia, precarias, de baja calificación e ingresos insuficientes para cubrir los costos de la canasta básica de alimentos, se corresponde con las peores condiciones de nutrición y salud infantil que contienen sus familias.

c) Tal como se ha delimitado en el marco conceptual, se circunscribe la exploración de las estrategias alimentarias a los consumos no mercantilizados provenientes del "sistema de opciones provistas por el contexto exterior a la familia y autogenerados por ésta a partir de su inserción en tal contexto" (Hintze,1989), a fin de relevar la importancia que presentan para explicar perfiles diferenciales de nutrición infantil en familias de sectores pobres urbanos.

En GD y en GE se registra un porcentaje similar (14\% y $16 \%$ ) de familias que no utilizan ninguna estrategia alimentaria.

En GE es mayor el porcentaje de usuarios de los programas alimentarios estatales, destacándose el Plan País y el Servicio Alimentario Escolar o comedor escolar. En tanto las familias de GE duplican el número de familias de GD que participan de estos programas, las diferencias estadísticas son altamente significativas.

La leche provista por el Programa Materno-Infantil es la opción más utilizada en GD, en similares porcentajes que en GE, apareciendo en más de la mitad de las familias.

En GD se destaca la mayor utilización de las redes informales con parientes y de opciones no gubernamentales tales como iglesia y partidos políticos. 
Los animales de cría para consumo familiar se presentan en la cuarta parte de las familias de ambos grupos. La huerta, si bien con una presencia muy baja, es más frecuente en GD que en GE.

En las familias de GD cuyo índice $c / p$ es de 5 a 8 personas, se verifica un uso intensivo de las redes de ayuda informal y el autoabastecimiento. Llama la atención la ausencia de plan País en la mayoría de las familias de GD, sobre todo en aquellas con una tasa de dependencia superior a 8.

Las familias de GD consideran como prioritarias las opciones provistas por organismos/agentes no gubernamentales, destacando como fundamentales las derivadas de la ayuda de parientes o amigos.

La leche, pese a tener la mayor cobertura -dentro de los programas estatales- no es considerada por las informantes de GD como una opción que aporte a la alimentación familiar.

En GD la mitad de las mujeres no usan o no priorizan en segundo lugar ninguna otra opción.

En GE, los sistemas priorizados por las mujeres encuestadas son el Plan País y el comedor escolar, no teniendo relevancia otros sistemas de ayuda.

En GE -cuyos componentes estructurales así como las condiciones de nutrición y salud infantil reflejan condiciones más favorables que las familias de GD-, se resalta la utilización más diversificada, intensiva y continua de los programas alimentarios estatales. 


\section{ORGANIZACIÓN DOMÉSTICA Y ALIMENTACIÓN FAMILIAR: PRÁCTICAS Y REPRESENTACIONES SOBRE LA COMIDA HABITUAL}

A fin de trascender el estudio de las características familiares y el uso de estrategias alimentarias y de indagar su incidencia en aspectos específicos de la alimentación familiar, se realizaron entrevistas semiestructuradas a informantes seleccionadas de ambos grupos.

Las mismas incluyen aspectos relacionados con:

- la situación familiar con respecto al trabajo y su influencia en la organización del consumo alimentario,

- la evaluación de los programas alimentarios utilizados,

- los conocimientos y las valoraciones sobre alimentación.

- las características de la comida habitual y evaluación de la misma.

La aprehensión de tales aspectos permite complementar y articular los resultados de la encuesta (vinculados con las posibilidades de acceso al consumo) y profundizar el análisis comparativo del consumo alimentario en un nivel de mayor complejidad.

En función del instrumento utilizado, del número de mujeres entrevistadas y de la naturaleza de la información así obtenida, los resultados de esta etapa se presentan para cada uno de los grupos de familias, respondiendo a los tópicos interrogados.

Las mujeres entrevistadas presentan como características generales:

- el componer familias mayoritariamente de tipo nuclear,

- no desempeñar trabajos remunerados (excepto dos casos de G2),

- haber alcanzado un nivel de escolaridad que no llega a cumplimentar el primario completo en el $83 \%$ de $\mathrm{G} 1$ y en el $63 \%$ de G2,

- tener un promedio de hijos de 4.9 en $\mathrm{G} 1$ y de 4.4 en G2, destacándose que el número de miembros por familia es superior en G1: 8.2 vs. 6.6 en G2 (diferencia que obedece al peso de dos familias extensas en $\mathrm{G} 1$ con 15 y más miembros),

- el índice c/p es similar en ambos grupos: 5.5 en G1 y 5.3 en G2 y superiores al estipulado por el Indec como indicador de capacidad de subsistencia en la definición de $\mathrm{NBI}^{75}$.

- el trabajo del jefe de familia se ubica en el sector informal en la mayoría de G1; en G2 en predominan las actividades formales, tal como se observa en la tendencia reflejada en los datos de la encuesta.

- Respecto a la utilización de programas alimentarios, en G1 la ausencia del Plan País es casi generalizada, recibiendo la mayoría la leche suministrada en la Unidad Sanitaria a través del Programa Materno Infantil. No obstante, en la URN se provee 
quincenal o mensualmente a la familia -dependiendo del grado de desnutrición del niño allí asistido y de la situación de riesgo nutricional de sus hermanos- una caja de alimentos (aceite, leche, azúcar, fideos, arroz, polenta, lentejas). El comedor escolar interviene como asistencia alimentaria en la mitad de los casos. Las estrategias autogeneradas, carecen de relevancia en ambos grupos. En G2 más de la mitad de los casos no recibe el Plan País, la misma situación y proporción aparece para el caso de la leche entregada a través del Programa Materno-Infantil; el comedor es el programa alimentario de uso más generalizado, apareciendo en las tres cuartas partes de las familias entrevistadas.

- La disposición para la entrevista, la locuacidad y la confianza establecida con las madres fueron asimismo elementos considerados a la hora de su selección como informantes.

\subsection{La alimentación de las familias con niños eutróficos}

\subsubsection{Trabajo, situación familiar y organización de la alimentación}

Si bien en este grupo de familias la ocupación formal de los jefes es preponderante, se presenta una diversidad de situaciones que van de la desocupación al trabajo estable y formal, que influyen en la organización de las compras, en las comidas y en los arreglos que deben desplegar las familias para comer. De este modo, las citas $^{76}$ reflejan los efectos de la privatización de empresas públicas, los despidos masivos, la precarización del empleo, las dificultades crecientes de los trabajadores por cuentapropia para conseguir trabajo, la disminución del poder adquisitivo del salario y la desaparición de la capacidad de ahorro, destinado en algún momento a mejorar la vivienda, a su equipamiento o a reponer la vestimenta de los integrantes de la familia.

Tal es la situación de las familias con jefe desocupado:

"No, él no puede conseguir trabajo, él acá hace changuitas, por una semana, dos semanas, a veces agarra de más tiempo, pero son changuitas que agarra; tendría que entrar a Astilleros, pero en Astilleros se suspendió no sé qué cosa, él no pudo entrar, así que está constantemente con eso.

Trabajó como armador en empresas, o como mecánico, trabajó como albañil, no hizo de todo, lo único que vago no es, trabajo que se presenta lo hace. No, no escapa de ningún trabajo.

Sin trabajo fijo hace un año, más de un año, siempre con changuitas, así estuvimos; pero hace como 2 meses que no tiene nada, nada de nada, a veces él agarra una changuita (su hijo mayor). Cuando él sale a buscar trabajo sale desesperado, sale en bicicleta, va hasta Villa Elisa, la vez pasada, va a dar vuelta por todos lados, va a buscar, y él sale 6 de la mañana o 5,30 y de ahí hasta las 3, 4 de la tarde y todo en bicicleta y no consigue nada." (Araceli)

\footnotetext{
${ }^{75}$ Más de tres consumidores por productor de ingresos.
} 
En otros casos, las posibilidades de conseguir trabajo no cuentan ya con la red de relaciones que posibilitó en otros momentos reducir los lapsos de desocupación:

"Ahorita no está haciendo nada, desde hace dos semanas. Pero él renunció porque no le pagaban. En una empresa de gas trabajaba, Game o algo así. Era un poco injusto que esté trabajando y...

Sí, pero él hacía trabajo de vereda, de albañilería.

Pero tuvo problemas desde el principio mismo. Y ahora está renegando, ¿viste?

Claro, si tiene que andar detrás de ellos para que se lo paguen.

Mirá, él siempre consigue changuitas...pero lo que pasa que ya hace 17 años que está acá, y tiene muchos amigos, $y$, así que...Eso es lo que yo no entiendo por qué, porque uno, eh, andando un poco consigue trabajo, no sé por qué, la verdad que yo no entiendo". (Gabriela)

Las familias con trabajos informales han visto restringir sus trabajos e ingresos, sobre todo aquellos dependientes de ritmos estacionales:

"No estamos bien. Porque, ahora hay mucho problema, ahora hay problemas. Por empezar no hay trabajo como antes. Mi hija que cosía, no cose más, porque ella era modista, estaba trabajando en María Auxiliadora, pero la Hermana dice que ayuda, pero no le pagan lo que tienen que pagar. O sea, hace trabajar a las chicas pero le paga poco, y eran muchas horas. No, en invierno, la verdad, no fue tan fácil porque en invierno hay menos trabajo. Porque mi marido corta pasto, arregla luz, todos esos trabajos hace, cuida algunas casas. Y tengo al chico de 23 años que trabaja con él y el otro nene que se me enfermó que tiene 16, así que esos tres nomás, trabajan. Bueno por suerte se me casó una. Si, la más chica, de las chicas, la más chica, se me casó, si, una bendición. En octubre ya va a hacer un año. Bueno, por suerte, aleluya digo, se me casó una.

Y el trabajo ese que tiene no es fijo, que si sale de ahí no lo toman en ningún lado, y más si tiene muchos chicos, menos. Sí, sí, o el trabajo, a veces tiene albañilería, lo llaman porque lo conocen, albañilería, cortar pasto, $y$, en fin, nos arreglamos con eso pero no es estable. No tengo salario de los chicos, no tengo nada, nada, nada. Dependemos del trabajo que hace. Ya le digo, a veces cuida tres casas, nos ayudan en algo, siempre nos regala algo. Eso es que tiene, que tiene ahí, que cuida casas, que limpia algunas casas, bueno con eso nos arreglamos. Y el chico que me corta pasto, y él también. No tiene muchas casas, pero tiene en verano tiene, si, pero ahora en invierno, no. Y así vivimos nosotros." (Celeste)

La etapa del ciclo de vida familiar posibilita la incorporación de la madre al mercado de trabajo y su reemplazo en las tareas domésticas por parte de los hijos:

"Había más fuentes de trabajo... por lo menos mi marido, tenía trabajo, estábamos bien. Ahora yo, recién desde que nació el nene estoy trabajando. Me fui a trabajar yo, porque él está sin trabajo, es decir agarra changuitas viste pero se le cortan y... yo hace seis meses que estoy trabajando.

Él estaba en el Ministerio de Educación, ya va hacer... cuatro años que no está más...y ahí empezó a trabajar por su cuenta en changas en albañilería.

Y por ahí le agarran etapas buenas pero... son de diez, quince días o un mes a lo sumo... Ahora, ponele hace diez días que está haciendo un trabajito, ya hoy lo termina. Ahora lo vinieron a ver otro... bueno, tiene que pasar presupuesto y si lo agarra bien, y si no tiene que esperar, y así. Así que es difícil...con la nena. El mío es mensual, es de limpieza, una empresa de limpieza... paga salario. Es lo que me salva... como tengo cinco chicos...

$Y$ con los chicos, ahora el mayor, se queda con él. El que tiene catorce años. A la tarde, porque yo trabajo a la tarde." (Agustina)

La incorporación a un trabajo estable es considerada un logro:

\footnotetext{
${ }^{76}$ A fin de preservar la confidencialidad de las informantes, en las citas se utilizan nombres sustitutos.
} 
"Él logró trabajo estable... Sí, bueno, digamos que... como se mantiene, porque... los precios todo eso más o menos se mantienen así que en eso... digamos ahorro. Ahora hace un tiempo digamos recién que fue una escalada en los precios, pero anteriormente se...

Ahora estamos mejor porque ya uno teniendo el dinero yo... por ejemplo trato de ir y comprar ya más o menos y tener..." (Olga)

Aunque los ingresos sean bajos, la formalidad en el trabajo del jefe permite planificar gastos:

"El sueldo de mi marido son 370 pesos, más las asignaciones, 110 me parece que son las asignaciones. Bueno, de eso hay que hacerle los descuentos que les hacen(...). Yo hubiese llegado a fin de mes franca y sinceramente tirando, tirando, porque trabajamos nosotros con la chequera municipal que le descuentan cada 45 días. Y sacamos de Pinocho las cosas. $A$ veces yo no tengo para el micro y él cuando no va en la moto, va en la bicicleta, viste al trabajo. Entonces él cuando viene llega a Pinocho y más o menos ya aprendió a comprar ahora, viste, antes no sabía; ya busca lo más económico y me trae." (Sofía)

A raíz de los despidos originados en la privatización de las industrias locales se rescata, como aspecto positivo para los consumidores, la gran competencia entre aquellos que, indemnización mediante, se volcaron a la actividad comercial por cuentapropia:

"Bueno, mi marido sigue en el mismo trabajo que en el 94, gracias a Dios, está en el Río de La Plata. Y bueno, seguimos con tres chicos, no tenemos más y la situación sí, es más problemática ahora que hace dos años. La falta de trabajo en general creo que es más en este momento. Claro, en general nosotros nos arreglamos, pero bueno no es que nos sobre, llegamos, tratamos de llegar a fin de mes.

Bueno, no sé, así en lo económico te digo en general no te digo que estamos re-bien ni estamos mal, estamos como todo el mundo, viste, aparte yo trato de hacer cosas, yo tejo, vendo cosméticos y tejo para afuera.

Yo creo que ahora hay mucha más falta de trabajo que hace dos años atrás. A lo mejor la cuestión de la privatización también es lo que dejó mucha gente sin empleo. Vos fijate el problema de YPF. Está bien cobraron su buena plata, pero si no la sabés invertir o utilizar. Vos fijate lo que es Ensenada. Antes no había un taxi, y ahora no sé, entre taxis y remisses se pelean y no trabajan. Negocios viste lo que es. Acá mismo, acá mismo. Es así, viste, uno al lado de otro.

A nosotros en parte nos conviene, viste, bajan los precios. Pero es tanta la competencia que no sé qué porcentaje podrán llegar a sacar." (Fidela)

El haber sorteado la etapa de despidos masivos y el mantenimiento del tamaño familiar posibilita hacer frente a una situación económica cada vez más desfavorable.

Las situaciones de estabilidad laboral y la percepción regular del ingreso, posibilita la planificación de compras, por escasas que sean, y la obtención de mejores precios en supermercados:

"No, no, no, nunca tuvimos problema con la alimentación. Yo siempre me organizo para hacer las compras. Digamos: el mes que no tengo facturas que pagar, digamos luz, o comprar gas y esas cosas, bueno aprovecho de que me lleve mi yerno que tiene vehículo para hacer por ejemplo una compra así más o menos en Carrefour o en algún supermercado que...y aprovechando las ofertas siempre. Él cobra quincenalmente, entonces aprovecho las ofertas, todo. No soy una persona de ir y de comprar acá nomás exactamente. Me gusta ir aprovechando ofertas, mirar precios acá, allá, uno puede comprar bueno, un poco más y...y ayuda muchísimo eso." (Olga) 
"Acá, ponele, en la zona ésta de Punta Lara las cosas son re-caras. Ahora yo me estoy organizando... lo que yo cobro me voy a La Plata, me hago un surtido más o menos, y con eso viste, tiro. Lo esencial. Sí, sí, todos los meses me saco una cierta cantidad de plata voy, me anoto todo lo esencial que uso en la casa, y entonces voy y lo compro. Ya lo tengo, ¿viste?" (Agustina)

Las condiciones del trabajo estable, que fijan un tiempo de trabajo determinado en un mismo lugar de trabajo permiten la participación del jefe de familia en la realización de las compras, el conocimiento de comercios cercanos al lugar de trabajo, de los precios de diversos alimentos, su eventual compra así como la obtención regular de alimentos $u$ otros bienes regalados por sus patrones:

"Y sí a medida que va trabajando, aparte uno va comprando donde sale menos a veces uno va a un supermercado, en fin, porque acá es un desastre, acá te cobran todo de más. Si, no te cobran mucho, pero 3, 4 moneditas te lo cobran, igual la carne, la verdura, todo eso, entonces aprovechamos cuando uno va así a La Plata, o mi marido trae del supermercado de La Plata o de Ensenada, del supermercado. Y la carne es más barata... será porque hay más carnicería todo viste, y la calidad de la carne, todo mejor." (Celeste)

"Pero ahora no, voy con $80 \$$ con una chequera a Pinocho y qué es lo que traigo. Son pocas cosas las que traigo. Traigo la carne, papa, verdura. Todo tienen. Lo único que compro de acá es el pan.

La leche les trae mi marido. Tiene un jefe que les manda, casi todos los meses les manda un paquete, dos paquetes." (Sofía)

La pérdida estabilidad laboral ("cuando él trabajaba”) y la inestabilidad de los ingresos se refleja de esta manera en el lugar de compra:

"Yo siempre, sí. Todo. Por ahora la hago por acá en el barrio nomás. Pero anteriormente cuando él trabajaba... a veces sí, nos íbamos juntos al supermercado...a Ensenada o al Carrefour. Y, hace más de un año que yo no voy a ningún supermercado.

Y acá compraba leche, pan...y todo lo demás lo tenían en el supermercado." (Gabriela)

Asimismo, la desaparición del trabajo secundario de los jefes debido a la merma de "changas" que proporcionan dinero "extra" a las familias repercute en la modalidad de compras.

La posibilidad de sacar fiado, pese a los precios más elevados, y la consiguiente acumulación de deudas, no deja resto para las compras periódicas:

"Yo. Sí, sí, siempre. En el almacén. No, antes iba al supermercado... iba a Malacalza. Y después ya no, no... te digo empecé viste ...cuando empecé a sacar fiado ya no. Iba y compraba, viste, ponele, qué sé yo... compraba diez kilos de azúcar, un kilo de yerba ponele, cinco paquetes de arroz así, cuatro paquetes de fideos ¿viste?, más o menos para variar. Que por lo menos sacaba a lo mejor qué sé yo, lo necesario, el pan. Pero llegó un momento viste que después ya al otro mes ya no te alcanzaba para pagar y así viste y...ya después no, ya empecé a sacar en el almacén y lo que cobraba pagaba el almacén. Y es más caro el almacén que el supermercado, mucho más caro. Y porque ya te digo, que a lo mejor te falta una cosa $o$ te falta otra y ya vas y sacás, y en vez de sacar el pan y la leche ya sacás otras cosa. $Y$ sacabas una galletita, o sacabas...ya cuando tenés libreta, ya...En el negocio ya es distinto, ¿me entendés? No resulta para nada, para nada! No voy al supermercado porque tengo que 
pagar el almacén y no me queda después para pagar eh...para ir y hacer una compra grande. $Y$ hace como seis años ya que no voy al supermercado.

Claro, porque ya te digo, lo que pasa que como agarraba changas, mi marido...te la pagaban en el día, y yo con esa plata compraba, y ya te quedaba el sueldo libre." (María)

La discontinuidad, en tiempo y monto, en la percepción de ingresos hace que la única alternativa sea la compra en los comercios del barrio:

"Yo administro la plata que entra. Y supongamos que él me trae \$ 20 hoy; mañana por ahí no me trae nada así que con los $\$ 20$ tengo que comprar un poquito más. Las compras las hago por lo general acá, hay un kiosquito que tienen los precios más o menos económicos en comparación de los que tenemos acá, acá a pocas cuadras." (Araceli)

Igual que en la situación anterior, la búsqueda de precios por parte de la mujer/madre en los negocios del barrio es la alternativa utilizada en esos casos, la que se acompaña de otros agentes y recursos:

"Las compras las hago acá nomás, porque no hay mucha diferencia de precio, es decir, si encuentro economía en ese almacén, compro lo que está en oferta ahí. Después voy a otro almacén. Pero en la libreta tengo el pan de todos los días, la carne me la trae mi marido de La Plata y después recibo el Plan VIDA, así que... "(Gabriela)

Los comercios del barrio son el lugar de compra habitual de aquellas familias que dependen del ingreso diario. En función de él, se decide qué y cuánto comprar:

"No, no, todos los días. Todos los días. Voy...para todo. Azúcar, yerba.

Cuando me falta voy y compro, sí. Y sí, porque cuando no te hace falta aceite, cuando no te hace falta...pero yo ya te digo, lo que pasa que cuando uno ya está acostumbrado así..." (María)

"Y lo esencial que compro es el pan, carne...normalmente todo por día que...lo que compro por día. Y cuando necesito, fideos, embutidos, todas esas cosas ¿viste?” (Agustina)

Muchas de las familias que aún recurren al supermercado reconocen comprar cada vez menos productos, sacrificando aquellos que consideran prescindibles:

"Yo siempre en el supermercado, en Ensenada. Siempre ahí, cada vez que tengo plata prefiero irme allá. Porque en el '88 cuando yo iba al supermercado me traía cuatro, cinco seis bolsas pero para todo el mes, para que no le falte en todo el mes nada a los chicos. Ahora cosa que no puedo hacer. Compro más azúcar, fideos, víveres que...lo de antes. Ahora compro menos cosas. Pero pura comida. Pura comida, no...ya no me doy el lujo de darle las galletitas... eh... dulces.

Y del día en un almacén de acá compro el pan, la leche, la carne. Al contado.

Sí, yo lo tenía a mi compadre... de mi nena, estaba comiendo conmigo, y la libreta de él sacar... con la libreta de él sacaba yo, pero ahora no. Porque ahora él está con la hermana.

$Y$, sí, todos los días. Tengo pan, sí. Hay veces me dan...me da mi vecina un de un día para... de un día por ejemplo, de ayer el pan me lo alcanza hoy día, y si están buenos yo no lo... no lo tiro para la gallina, así que eso les doy a los chicos. Un kilo compro de pan, sí. Dos sachets. Y... hay veces medio kilo de carne, hay veces un kilo para todo el día. Hay veces... cuando tengo un kilo, cuando no tengo medio kilo. No, últimamente no estoy comprando nada de fruta. Verdura sí, fruta no."

(Araceli) 
pan, la leche y las verduras son alimentos recurrentemente comprados en comercios del barrio aun en aquellos casos que hacen compras mensuales de alimentos no perecederos en el supermercado. La frecuencia en la adquisición de la carne depende en mayor grado de la evaluación de su calidad y precio, motivando una mayor variabilidad de las fuentes de abastecimiento. Para esto, la disponibilidad de heladera es esencial.

"Lo primero que hago es un pedido en el supermercados todos los meses, cuando él cobra lo primero que hago es un pedido en el supermercado y bueno, después qué sé yo te arreglás. Por lo general...voy al supermercado con mi esposo, pero sí, soy yo la que voy más a Mingo, a Berisso Después lo mismo la verdura, la leche, el pan digamos lo de todos los días sí lo compro en el barrio, y ahora últimamente no estaba comprando la carne, porque tenemos una sola carnicería que es un desastre en precios, entonces por ahí me voy a Ensenada y traigo para toda la semana, pero después en lo cotidiano sí lo compro acá en el barrio.

Y sí, siempre es un poco más caro que ir a un supermercado, no es mucho lo que yo compro acá, el pan, la verdura esas cosas, después del supermercados nos traemos todo para el mes, nos traemos hasta el jugo, más que nada es costumbre también, siempre, hace rato que vamos al supermercado. La verdura, este, por ejemplo, bueno, no usamos mucha verdura. Ahora hay como cinco verdulerías alrededor, así que...

Sí, el pan, la leche y las cosas que te hacen falta del día y la verdura.

Mirá, nosotros tenemos un almacén en el barrio que la verdad que trabaja muy bien...

Está...muy buenos precios, sí. Sí, lo que pasa que la gente de Punta Lara está equivocada, viste, porque se cree que es una zona turística y no piensa que, tres meses pueden vivir del turístico pero los 9 meses tiene que vivir del barrio...entonces...te mata.. No, no este almacén, la verdad que... una barbaridad." (Fidela)

En otros casos, la periodicidad de adquisición de alimentos depende de una combinatoria fluctuante de fuentes del mercado y estatales. La planificación en estas situaciones se torna problemática y el consumo de alimentos considerados importantes como la fruta y la leche es aleatorio: gira en torno al lugar de trabajo momentáneo del jefe o de la insistente exigencia por parte de los hijos:

"Pan, leche no te digo que compro todos los días, compro cada... cuando puedo.

Y ponele...cada tres, o día por medio. Cuando me piden mucho los chicos, el más chiquito eh... le compro un litro. La carne compro...también, todos los días.

O a veces cuando... a veces él me trae de allá porque dice que es más barato, que está trabajando en Lomas de Zamora él. Sí. Y ahí dice que es más barata la fruta y la carne entonces me trae de allá. Me trae cada vez que puede. Sí. Cuando es necesario compro de acá, de la carnicería.

Es mucho más cara según él me decía, de allá...acá es mucho más. Las verduras, la que siempre compro es... cebolla, zanahoria, papa, eh... morrón...

Fruta es lo que trae mi marido. Fruta yo no compro casi acá porque es carísima, porque él a veces trae dos kilos de uva, dos kilo de pera, dos kilos de manzana y dice que le sale tres pesos con cincuenta. Sí. Dice él ahora está trayendo... no te digo cada fin de semana pero cada vez que puede trae. Una vez cada quince días más o menos. Y la carne también, igual cada quince días.

Y acá no...compro...qué se yo, día por medio... porque todos los día tampoco no comemos carne.

Aceite compro...cada quince días un litro y medio... de dos litro y medio. Me duran quince días. Yo no lo...y si traigo de la cooperativa que son dos litro que me dan, es...igual compro, viste... 
Azúcar compro cada cinco días me dura un kilo de azúcar, sí. Porque nosotros no tomamos mate con azúcar, mate amargo tomamos. Yerba, fideos, arroz, ese lo compro de vez en cuando porque los chicos no le gusta mucho comer fideos ni arroz." (Gabriela)

En cuanto a la forma de pago, la deuda en los comercios del barrio permite sortear la falta de dinero de aquellas familias con ingresos esporádicos y cada vez más escasos, sobre todo de aquellas que han establecido, dada la antigüedad de residencia en el barrio, relaciones de confianza con los comerciantes:

"Y no, eso es lo que pasa. Lo que pasa es, ¿qué quieren?, si no hay trabajo...

Bueno, yo ahora, nunca saqué en la carnicería, pero saco de la carnicería, la verdulería. Cuando tengo pago y cuando no, no, con eso me arreglo.

Saco y pago después cuando más o menos yo tengo la plata le pago. Eso cuando no tengo plata, cuando tengo...compro. Bueno, ya le digo, cuando tengo plata pago, la verdulería o la carnicería. Con eso nos arreglamos. Siempre fue...creo que hay épocas buenas y épocas malas.

Y sí, no, yo..., qué sé yo, saco fiado en el almacén y después cuando tengo plata pago.

Sí, qué sé yo, hago así, en el almacén o en la carnicería." (Celeste)

"...sí, aparte que yo voy y pido prestado viste en lo de...no...no hay drama ¿viste?.

Claro, al...almacenero viste, no hay problema, así que ...yo después voy y lo devuelvo, qué sé yo, a fin de mes o cuando cobra... está bien que nos conocen porque como yo vivía cuando era soltera vivía acá, entonces me conocen y lo conocen a mi marido también de que ya va a hacer que él vive acá, treinta y nueve años." (María)

El abandono de esa modalidad de pago se presenta en familias cuyo jefe ha perdido el trabajo estable y los ingresos regulares. La incertidumbre del trabajo por cuentapropia y el temor a un endeudamiento imposible de pagar imponen la compra al contado:

"Antes libreta, ahora contado. Tuve libreta, usé pero ahora no...cuando él estaba trabajando en Cablevisión y Techint, tenía libreta, porque... sabía que lo iba a pagar, ya ahora no.

Sí, yo... bah, lo decidimos los dos juntos porque siempre que tenés libreta parece que no pero... parece que no salís adelante con la libreta, siempre que tenés que pagar y tenés que pagar y tenés que pagar y no, entonces decidimos que no. Hace más de un año de esto. Y no lo vamos a sacar más tampoco según me dijo bah, nos arreglamos así como nos estamos arreglando ahora porque..." (Gabriela, 1997)

El relato de la misma informante durante la etapa de trabajo estable refleja la racionalidad en el uso de la libreta y las expectativas de ahorro -aunque sea mínimo-:

"Mira yo tengo una libreta del almacén, trato de no sacar mucho, trato de cuidarme, llegó el teléfono también hace poco, tengo que sacar para pagar la luz, para teléfono y para el almacén. $Y$ tratar de ahorrar no te digo mucho, porque como está ahora la situación, no se puede ahorrar; además...así que ya te digo trato de administrar lo más que puedo, lo mínimo.” (Gabriela, 1996)

Otras familias -de menor tamaño- con ingresos regulares, nunca necesitan endeudarse y optan por el pago al contado:

"No, no, siempre al contado, siempre...y lo que sea leche, pan, todos los días..." (Olga) 
Respecto al gasto en alimentos y proporción del ingreso destinado a la comida, puede observarse que la elasticidad del gasto muestra variaciones diarias importantes, pese a tener un tope máximo bastante exiguo: \$4 per cápita diarios en las familias de menor tamaño y con ingresos fijos. En todas las familias todo o casi todo el ingreso se destina a la alimentación de la familia:

"Y hablando eh... hay veces me gasto diez pesos, hay vez cinco pesos, compro lo que me alcanza, porque no puedo decir que compro un kilo de carne todos los días porque... no alcanza hay veces que no... se va todo comida. Antes podía ahorrar algo, y por ejemplo para comprar unas zapatillas para los chicos." (Araceli)

Pocas situaciones son las que permiten ahorrar o destinar regularmente dinero para vestimenta, mejoramiento o equipamiento del hogar.

En algunos casos casos, la disponibilidad de dinero para adquirir otros bienes de uso es posible por la incorporación de los hijos al mercado de trabajo:

"Y en comida acá gasto más que yendo al mes que me hago un surtidito, ponele. Con el surtidito allá en La Plata la otra vez compré y gasté eh... sesenta pesos. Y yo acá en el día estoy gastando diez pesos... Sí, por eso te digo que acá es recarísimo.

Me queda algo para mi viaje. La mayoría es de...sí, se va en comida. Comida y este mes que le pude comprar una ropita al más chiquito. El mayor inclusive, el de catorce años, tuvo que... viste con los vecinos así que lo conocen, él sabe algo de albañilería que le enseño el padre. Y fue y se hizo un pedazo de veredita... después le hizo otra veredita a otro vecino y así ¿viste? fue juntando plata y se compró la ropa él de fútbol. Antes me quedaba más. Por lo menos llegaba al mes y yo tenía plata. Porque él hacía viste... hacía viajes afuera entonces eso era otro sueldo más." (Agustina)

Las familias que menos gastan en comida destinan poco más de la mitad de los ingresos. Sin embargo, la libre elección de qué y cuánto comer está restringida aunque nunca llegan a situaciones de privación:

"Yo más o menos, tengo un cálculo diario...te podría decir que con veinte pesos por día este...vivimos bien; ponele que gastaremos, qué se yo, \$600 pesos...ponele...

Sí...no, un poco más de la mitad del sueldo. Lo que pasa que vos sabés cuánto tenés y cuánto podés gastar y buscás la forma de cocinar, viste cuando tenés poco, de hacer algo más económico y cuando tenés un poco más de darte un gusto...

Si te quedás con poca plata y, bueno, a lo sumo hacés unos fideos hervidos ¿viste? Gracias a Dios no...así de faltarnos para comer no, nunca. No, por suerte, eh...pedir plata prestada, este... no, viste, es rara la vez. Aparte, como te decía, no tengo familiares que me puedan ayudar." (Fidela)

Ante la falta de comida o de dinero para su adquisición, se presentan una serie de arreglos tendientes a asegurar el sustento diario.

Algunos, utilizados en una etapa previa del ciclo de vida familiar, implican una diversificación y/o mayor intensidad del trabajo doméstico mediante la producción de alimentos para el autoconsumo, el trueque o la venta en el barrio o en el lugar de trabajo: 
"Pero ahora, eh, no hay nada ya, tenés que trabajar las ocho horas, y cobro 600, 700...

En ese tiempo era algo que, yo trabajaba, ¿te acordás que haciamos pan los dos?

Hacíamos pan casero. Él amasaba para llevar a vender en Astilleros, porque ¿te acordás que tampoco te pagaban? Claro, porque, en ese tiempo hacíamos pan, yo había hecho una huerta ahí en el fondo, teníamos de todo, ¿te acordás que teníamos choclo?...

De todo, de todo. Y criaba gallinas, y hacíamos pan para vender, a mí me encargaban tapas de empanadas, hacía empanadas, y no, en ese tiempo trabajábamos los dos, luchábamos los dos para que a los chicos no les faltara nada, porque, aparte yo vengo de una crianza que la mujer tenía que luchar y criar a sus hijos, y apoyar al marido....así que ya eso uno ya tiene la mente, ya uno ya se formó así, y bueno...

Soy de Tucumán, pero del campo. Y él también. Y bueno, y él ha amasado...

Él se..., él amasaba al llegar a la una de la tarde, venía, yo ya a la mañana amasaba, ya repartía lo que podía repartir acá, la gente venía a comprarnos, o sino los chicos se iban y entregaban en las casas. Y... este..., y cuando él venía, preparaba para llevarse al otro día, y llevaba su bolso, me acuerdo que había veces que llovía y nos costaba, ¿te acordás?, nos costaba calentar el horno, y él tenía que hacer el pan. Ya los compañeros no compraban en otro lado, estaban esperando, cargaba el bolso y se iba por el medio del barro, porque no teníamos el auto, nada.

Y así luchamos los dos ¿eh?, y así mismo nunca permití que a los chicos les faltara nada.

Nada de nada. Yo me acuerdo que algunas veces me faltó azúcar y la señora del almacén, Clara de ahí, yo le mandaba huevos, lo que ella me hacía pedir y ella me mandaba el azúcar, la yerba, lo que me faltara... Pero nunca pedí fiado, ni prestado a nadie." (Perla)

La asistencia continua del Estado contribuye a resolver las necesidades alimentarias de muchas familias:

"No, lo que pasa es que, yo tengo la ayuda del gobierno, siempre recibí, ¿viste?, si es caja de Pan o mercadería, siempre, no tuve problema en eso de...

Así que yo me arreglo como sea. Aparte los chicos míos no son delicados como otros.

Si no hubiera tenido esa ayuda se me hubiera hecho más difícil, porque todo, ¿viste?, mi marido no tiene un trabajo efectivo, él..., pero gracias a Dios, también, jamás le faltó trabajo, si le faltó, le faltó un mes, dos meses, pero... " (Gabriela)

Y en esos pocos episodios de desocupación, se activan las redes:

"Un compañero de trabajo buenísimo de él, nos ayudó...prestó plata...

Gracias a Dios...ahora no nos volvió a pasar más. Ahora, qué se yo, tengo muchos conocidos, conocidas... pero no. Ahora no te digo...no nos queda para ahorrar, pero tampoco nos falta." (Gabriela)

El dinero prestado por parientes, la reducción de compras, el ingenio y enseñanzas culinarias de vecinas hábiles a la hora de cocinar se combinan para amortiguar las crecientes dificultades:

"Pido prestado a mi hermano, un poquito acá otro poquito allá... plata pido.

Ahora se me hace más difícil porque no ... no tengo la facilidad así para conseguir tanto. Si a mí se me acaba el comestible, ponele y ya... si no tengo plata, y bueno, tendré que agarrar o leche o... o ingeniármela, viste... porque yo ahora compro menos. Y antes ponele en el día sí, podía ir y decir bueno, gasto esto, y ahora no, porque ahora menos. Compro menos porque yo ponele, día por medio así, hago los gastos del día. Y antes todos los día lo podía hacer... ahora no. Ahora como quien dice se priva uno...con el cinturón así...

Para hacer comida, con el que tiene muchos chicos se las tiene que ingeniar para que alcance, porque ahora mucho no podés comprar como antes. Yo a veces vengo viste, conocidas mujeres grandes que me enseñan, porque yo de cocina no, mucho no sé. Como ser, la señora... mi vecina, que es una mujer grande..." (Agustina) 
Otros casos, reflejan claramente cómo la importancia de las redes, se pone en evidencia cuando dejan de funcionar. Así, esta informante relata en una primera entrevista que:

"No la comida no varía porque yo lo poco que tengo siempre he sabido repartir para los diez que tienen que comer. No varía la comida...siempre me arreglé, traté de arreglarme lo más lo más que pude en la comida" (Araceli).

Luego, frente a un cambio en la red de relaciones sociales, que le permitió en un momento hacer uso de la libreta para sacar fiado en los comercios del barrio, expresa:

"No sé ahora que haré, porque ahora recién, hace hace días... hace como... recién va a hacer un mes que mi compadre se ha ido...no saco ya con la libreta, así que... no sé que voy a hacer cuando se me termine la plata porque lo poquito que tengo estoy estirando como un elástico." (Araceli)

La mayoría de las mujeres reconoce haber tenido restricciones alimentarias pero no ausencia total de comida:

"Y épocas sí, que nos ha faltado la comida, sí. Y, siempre un arroz, algo le hacía a los chicos. Así de no tener nada no, gracias a Dios nunca. Siempre algo les preparaba." (Celeste)

"No, siempre tengo. Aunque sea fideos. Para esas cosas siempre...sí, siempre. Yo creo que alimento no, nunca falta, siempre uno se la arregla con un huevo, una papa, no...sí, siempre hay." (Olga)

La mención de otros consumos, la aspiración de otros y el ahorro manifiestan situaciones en las que dichos arreglos nunca se presentan y tampoco parecen incluirse en el horizonte de lo posible:

"Yo te digo eh...a fin de mes llegamos, gracias a Dios llegamos siempre...

A lo sumo a los últimos días...qué se yo...te la arreglás más o menos, viste, pero...no, lo que pasa que yo tengo tres chicos que van creciendo, de distintas edades y no nos podemos dar el... un gusto...no te digo irnos de vacaciones porque todavía no llegamos a eso, pero qué se yo...un par de zapatillas de marca a los chicos ¿viste? A los nenes más chiquitos los cambié a la escuela privada...

Como para guardar no, no nos sobra nada...pero eh... de a poquito se hace algo en esta vida. Lo poquito que ahorramos ¿viste? lo...tratamos de invertirlo en la casa...qué se yo viste...comprarle algo a los chicos o...no sé." (Fidela)

\subsubsection{Estrategias alimentarias}

La utilización de programas alimentarios del Estado, de organizaciones no gubernamentales, la autoproducción de alimentos mediante huerta o cría de animales $y$, como ya se ha mencionado, la apelación a las redes de intercambio entre parientes y vecinos, son estrategias que intervienen en todos los casos y de diversa manera, en la alimentación familiar. 
Dentro de los programas alimentarios estatales, el Programa Materno Infantil (PMI), el comedor escolar o Servicio Alimentario Escolar (SAE), el Plan Pais (plan de asistencia destinado al grupo familiar vigente durante la etapa de realización de las encuestas), el Plan VIDA (sustituto del anterior, cuyos inicios coincide con la etapa de realización de las entrevistas) son usados por la mayoría de las familias que cumplen con los requisitos de focalización de dichos programas. Asimismo, la Secretaría de Acción Social de la Municipalidad de Ensenada, provee mensualmente, a través de lo que las mujeres denominan "Cooperativa Municipal" una bolsa de alimentos no perecederos de contenido variable. No hay criterios fijos de focalización y los padrones de beneficiarios son fluctuantes, estando supeditada su entrega a la disponibilidad de alimentos, a la evaluación que el personal a cargo de la dación hacen de la situación coyuntural de las familias y, según algunas informantes, de relaciones clientelares.

La leche del Programa Materno Infantil, de entrega regular, es de uso frecuente para quienes realizan el control en la salita:

"Acá me la dan. Sí, siempre...Siempre para mí bien porque yo siempre he venido... siempre traigo los chicos acá..." (Agustina)

"A mí me entregaron....siempre, sí, hasta que los chicos cumplieron los dos años.

Sin problema. Y cuando necesito por ahí ... voy le pido a la asistente, sí me lo da, sin ningún problema." (Gabriela)

Las razones de aquellas que no la retiran obedecen al rechazo de los niños a la leche en polvo:

"No, vine creo que dos veces a retirar. Después como a mi hijo no le gustaron no vine más. No, no le gustaba la leche.Y como ordeñaban allá y me daban leche, viste..." (María)

o a la autoexclusión de la madre del programa por evaluar que hay quienes más lo necesitan:

"No el nene, le doy leche de vaca yo. Toma leche de vaca, tomaba en caja también, me daba la doctora para él cuando era chiquito, pero no la retiré porque empecé con leche de vaca, y a veces había en la salita y a veces no había. Ese es el problema. Y había otros nenitos más chiquitos que el mío y veía que no había y digo no, no le voy a sacar una caja, que el nene éste toma leche de vaca. La verdad que la dejé.

No, no porque hay otros, miro, ¿no? hay otros más necesitados que yo, digo no, dejalo para el que necesita, la leche no le hace falta al mío. Yo voy al almacén y le digo mirá necesito la leche, y no hay drama, bueno llevate y cuando tengas me pagás. Y otros nenitos quizá son bebés que quizá la madre no puede; porque hay muchas chicas jóvenes embarazadas y no tienen. "(Celeste)

El comedor es de uso también generalizado y representa una ayuda fundamental para las familias.

“... y el comedor para mí es una ayuda bárbara. Aparte que ha mejorado mucho el comedor 
Sí, aparte ellos a la mañana en casa no toman nada, porque llegan y tienen mate cocido, leche, café , le dan pan con dulce. Y al medio día comen ahí. Le dan la comida y le dan el postre." (Sofía)

"Sí, los chicos ahora van a la escuela 10. Van al comedor, fueron el año pasado cuando por poco se nos quema la casa, que vino el asistente social y me dijo que los mande, fueron". (Perla)

Tal es la comida que reciben:

"Y a veces, una vez me dan arroz amarillo con pollo, me dan postre, a veces... no me dieron hoy.

A veces nos dan fideos con tuco y en cada mesa ponen pan cortado, algunas veces nos dan milanesas." (relato del hijo de Araceli)

La racionalización de este servicio está restringiendo la inclusión de beneficairios quedando sólo "los más necesitados", grupo con el que se identifica:

"Pero ahora por ejemplo, allá en la escuela 6 pusieron grupos, es decir, aquellos que sí directamente necesitan están en el comedor y aquellos que directamente no necesitan no están porque es como decía la asistente social de la escuela, que van muchos chicos a comer pero en su casa tienen para comer y en vez de comer agarran, tiraban la comida y es hacer daño, sí; y por eso es que van esos que necesitan y es porque han sacado muchos chicos, han sacado del comedor.

Son el grupo más necesitado. Porque hay chicos que sí, hay muchos chicos que salen de sus casas sin tomar una taza de té o una taza de algo y a la mañana les dan puro mate cocido solo.

El comedor está bien. Ella, ella come en el comedor, siempre viene satisfecha y en la tarde sí les doy la comida, a los, todos comemos." (Araceli)

Todas se muestran conformes con la comida brindada en la escuela:

"Sí, sí, sí, le dan comida muy buena. Siempre fue bueno. Yo creo que se esforzaban, porque como hoy se siguen esforzando de darle... de dar comida buena...

Les dan por ejemplo guisos, fideos con tuco, les dan arroz con pollo...creo que hasta milanesas les dan, así que... Yo por ejemplo sí, sí siempre... estuve conforme. Inclusive el comedor sigue en verano también, así que es... es una ayuda. Yo tengo uno solo ahora al comedor..." (Olga)

"Sí la nena me dijo que ahora es mejor la comida, sí. Me dijo que a veces... lo que ella me cuenta ravioles eh... tartas, pescado, que a ella no le gusta pero lo tiene que comer, dice, sopa, o... qué más que me dijo... guiso de mondongo... todo eso, polenta con tuco..." (Gabriela)

No obstante su uso, aunque continúe en verano, se restringe al período escolar ya que existe control por parte de las autoridades. Fuera del mismo, la seguridad y el perfil de conducta de los asistentes cambia:

"Ellos dos comen acá, en el comedor. El de nueve y el de seis vienen acá. Está muy bien el comedor ahora. La Directora es muy buena, se ocupa mucho. Están contentos, si. Les dan muy bien de comer. Comen bien, si. Yo le digo al nene mío, ¿querés algo?, 'no, mami, no quiero porque ya comí en el comedor'.

Eh, en invierno, en época de colegio sí, van los dos. Ahora en verano no los mando. No, porque no es lo mismo. No, porque yo cuido a los chicos, y hay muchas cosas ahí, bah, el colegio no, porque no tengo nada que hablar del colegio, pero fuera del colegio es embromado ahí, a veces con los chicos. Sí, sí, hay muchos chicos, muchos patoteritos, todas esas cosas. Entonces yo no los mando en verano. Me arreglo con lo que tengo y chau." (Celeste)

En otros casos, el almuerzo en el comedor se utiliza todo el año: 
"Y el comedor es... ahora está yendo él acá, porque lo pasé acá. A la escuela 7 este año.Y el nene chiquito de cinco años que lo puse en la guardería. Le dan... ayer, ponele comió arroz con salchicha... por ahí hacen milanesa, pastel de papa... variado. Y en el verano también van, sí sí, todo el verano." (Agustina)

Algunas comidas, como la polenta, son rechazadas por los niños quienes, en esos casos, regresan a comer al hogar con la anuencia de sus madres. En estas situaciones predomina el gusto sobre la necesidad:

"Allá el comedor sí lo usaron. Sí, al menos ellos viste les gustaba la comida. Lo único que no les gustaba era polenta. Para lo único que te digo que cuando había polenta directamente mis hijos no comían y comían en mi casa. O sea nunca los obligué tampoco que se quedaran en el comedor, eh. Eh...y le dan por ejemplo, a veces le dan pizza, a veces le dan guiso, fideos con tuco, pollo. Aparte le daban leche a la mañana con pan, o mate cocido con pan, ¿viste?." (María)

Actitudes agresivas de discriminación xenófoba por parte de los niños y la indiferencia de los responsables del comedor hacen que se desaliente su uso en los hijos de inmigrantes:

"Mh... no lo traje... una sola vez le traje pero... no los mando. Porque yo los mandaba antiguamente a los chicos, anteriormente los mandaba a mis dos hijos, a mis tres chiquitos...

En ese entonces María, Angel y Jorge. Pero los agarraban ahí en el campo y les pegaban a los chicos míos. Dos veces ahí los chicos, les trataban de bolitas, de todo. Una vez me lo pegaron a mi hijo y de esa vez nunca más lo mandé. Y hasta que en la escuela dice que también se tiraban con la comida...no, no. Nunca lo hablé con nadie este y... directamente nunca los volví a mandar más a los chicos. No, porque... una vez vine a hablar con una señora, que me atendió, no sé quién era... una era una señora que estaba parada en la puerta, y me dijo de que los problemas de los chicos no se metían el personal del comedor. Es lo que me dijo, después me fui y... y no los mandé más." (Araceli)

El plan Pais ya descripto, ampliamente utilizado durante la etapa de encuestas, es objeto de objeciones en lo que hace a los criterios de focalización y a la modalidad de instrumentación:

"A mí no me lo daban el plan País, se lo daban a mi hermana. A mí no me lo habían dado porque mi marido era empleado de gobierno, por eso no me lo daban, no me pertenecía. Y en ese entonces eran 170, 180 de sueldo... Después como mi hermana ya no lo precisaba, ella habló con la jefa y me lo pasó.

Y con eso sí, porque me daban diez kilos de azúcar, me daban yerba, aceite, todo eso, puré de tomates, arroz, lentejas. Con eso me arreglaba. Sí, me arreglaba bien." (Sofía)

Para los extranjeros, razones burocráticas se anteponen a las necesidades básicas quedando excluidos del universo de beneficiarios. De todas formas esa situación no es mal vista: el asistencialismo opera como freno a la iniciativa y responsabilidad individual.

"Lo único que yo recibo es la caja de la cooperativa, nos dan ahí, sino no. El único que recibo es eso, sí. Yo nunca recibí el Plan Pais... porque no me lo quisieron dar al Plan Pais. Cuando yo 
vine a anotarme me dijeron que él tenía que tener el documento argentino, $y$ en ese entonces no tenía el documento.

A mí me parece bien. Hay momentos que sí, pero hay veces que... la gente nos acostumbramos tan mal que no conseguimos después trabajo porque nos acostumbramos a tener alimentación gratis. Para mí está muy bien en casos de que lo sabemos aprovechar, pero hay otra gente que no lo aprovecha. Yo le digo, si yo cuando tengo trabajo y tiene trabajo mi marido, cuando trabajábamos los dos, yo no necesitaba ir a la cooperativa a traer mercadería, porque yo tenía y me la arreglaba con lo que tenía. Pero durante estos dos meses que...desde a partir de diciembre hasta ahora, fui las dos veces a pedir mercadería porque no tenía. Me han dado. Pero no tenía, ¿sabe qué es no tener nada en casa? No tenía nada y tuve que ir a pedir la mercadería y no tenía ni plata para... para ir a la Municipalidad, a averiguar trabajo. Me habian dado una carta de recomendación, que fui dos veces, me dieron... fui dos veces, pero ya después de la fecha que me habían citado...fui y no lo encontré y...le dije no puedo viajar por falta de dinero." (Araceli)

Pese a la irregularidad creciente en su recepción, la importancia de este tipo de programas se pone de manifiesto cuando dejan de funcionar, sobre todo cuando la falta de trabajo torna imposible la adquisición "digna" del alimento :

"El plan Pais, sí. Me estaba dando el plan Pais, y después se cortó eso y nunca más, en alimento no tenemos ayuda. A mi me venía bien eso. Por la leche, todo. Tengo chiquitos, chiquitos todavía, tres chiquitos. No, no... yo me desespero, que falte otra cosa, pero los alimentos de ellos, no. Los alimentos no me faltan. Gracias a Dios no me falta. Me faltan otras cosas, que me falta arreglar la casa que tengo, no puedo comprar ladrillos, no puedo comprar cemento, de a poquito nos vamos arreglando.

Si, el plan País me ha ayudado mucho, pero se cortó eso.

Ultimamente... se fue cortando, o sea me daban pero se fue cortando eso y hasta que llegó un día que bueno, acá, se cortó.

En el Plan VIDA, me anotaron, pasó una chica en el barrio, hay un lugar que dan y otros lugares que no dan. O sea, en el barrio para allá, no sé si conoce, por Piria más para allá, hay una chica que entrega mercadería del Plan VIDA, da leche, huevos, no sé, para los chicos.

Bueno, algunas mamás reciben, otras no. O sea una de esas soy yo, que no recibo y otras mamás que he hablado también, que no, que no les dan. Es cuestión de suerte a veces.

Si, porque vino a casa. Me anotó una chica que era de la zona de nosotros y quedó en la nada. No sé. En la zona de nosotros, ninguna señora nos entregó. Acá incluso hablamos en el Colegio, ahora que me iban a ayudar, la Directora nos dijo que venía el plan ese, que quién era que tenía chiquitos; bueno, yo me anoté porque la verdad que tengo chiquitos. De dos a cinco años... me parece que era. Quedó en la nada. Sí, porque yo, la verdad, que la leche, huevos, todo eso, uno lo que no quiere; yo lo que le digo a las nenas mías, yo trabajé siempre uno no quiere limosna, quiere trabajo, la verdad, qué más lindo que ganarse con el sudor de su frente. Pero no hay nada, señora, mi marido no consigue nada." (Celeste)

La entrega de leche es el componente más valorado de los programas alimentarios, tal es el caso del Plan VIDA:

"Porque el chiquito si no tiene leche no vive el más chiquito, ¿vio que en ese plan VIDA?, ahí le dan medio litro por día, así que ese tiene la leche." (Araceli)

"No, por ahora se están, es como que, con esta ayuda de la leche que les están dando, es como que las criaturas se están alimentando más, por el hecho de que quizás antes los padres no podían comprarles la leche. Pero ahora es todos los días un litro de leche...

Tienen huevos, tienen para comer, porque con los huevos, la leche, todos los cereales..., azúcar." (Perla)

Por poco que sea, mientras contribuya a asegurar la comida de los niños, todo ayuda: 
"No, si es medio litro de leche y tres huevos por semana, un kilo de arroz o medio kilo de fideos. Y todo lo que uno puede... hace alcanzar, no me voy a quejar, no estoy descontenta con nada, porque mientras tengan los chicos para comer..." (Araceli)

La bolsa o caja de alimentos de la municipalidad es otro recurso muy utilizado por estas familias, sobre todo en épocas de desocupación:

"Yo me arreglo así, siempre yendo a buscar a la Cooperativa que me den la caja del Pan y ahí en el fondo que hay como un Socios Voluntarios me dan mercadería. Y con eso me estoy manejando. En la Cooperativa nos dan una caja. Este mes nos ha dado un puré de tomate, uno de arroz, dos bolsas de fideos, una de polenta y una de lenteja, azúcar y aceite. Una vez por mes. Sí, eso vengo sacando hace mucho, eso. Yo, cuando mi marido trabaja y estamos bien, no necesito ir a retirar de allá ni de ningún lado, pero ahora sí, nos está llegando la necesidad." (Araceli)

Los alimentos entregados no siempre cumplen con las expectativas de las familias:

"...y hace mucho que estoy anotada a la cooperativa, pero cuando yo necesito voy a retirarlo sino... si yo tengo trabajo y mi marido tiene trabajo yo no... no retiro la caja. Porque hay otra gente que también necesita. Nos dan dos bolsas de fideos, una de arroz, una de polenta y una de lenteja, y un litro de aceite y uno de azúcar. Leche no vino este mes." (Araceli)

En otros casos, la asistencia de la municipalidad se usa como forma de ahorro para prevenir probables situaciones de futuro desabastecimiento:

"De la Cooperativa mensualmente, sí, siempre hay. Y dan fideos, arroz, aceite, polenta, lentejas, puré de tomate, no te digo que es poco, es una gran ayuda también.

Si, porque también como le decía a mi vecina yo no le voy a sacar; yo no le saco porque a mí, yo le uso lo que me dan, porque en vez de comprar lo que ellos te dan ya te ahorrás unos pesitos. Como yo le digo, mi marido dice tenemos que ahorrar un poco porque no siempre tiene trabajo, ponele ahora hace cinco meses que esta trabajando y después cuando sale de ahí no sé cuánto tiempo estará sin trabajo." (Gabriela)

Dentro de las ONG, los recursos brindados por las agrupaciones políticas son objeto de críticas por estar supeditados a relaciones clientelares:

"Sí, si, está bien que haya ...no si yo veo que hay mujeres solteras, solas que necesitan, sí... $y$ de eso se tiene que ocupar una asistente social, que veo que a veces no se ocupa. Eh...porque yo veo gente que a lo mejor eh...no sé ahora. Pero no veo gente responsable en eso...Y eso lo que me da rabia. Por eso te digo, yo hay...gente que no sé, a lo mejor porque es amiguismo, o porque son parientes o porque...eso es lo que a mí no me gusta. Viste. Eh, eso es lo que a mí me revienta, que me da rabia." (María)

Las expectativas de reconocimiento y devolución de favores se frustran la mayor parte de las veces:

"Yo estoy de acuerdo con lo que está, porque...como están dándoles ahora.

Si, porque había una temporada que han trabajado las Unidades Básicas, y llevaban los chicos a la Unidad Básica y había quilombo, que daban menos, que no daban nada. Porque yo le voy a decir: a mí me llevaban para campañas, a un lado, y caminaba en todos, yo, para poder conseguir algo para mi casa, trabajo, alguna cosa, nunca conseguí nada, nada. El domingo también, nos fuimos a la fiestita que hicieron para los chicos, los llevé y ahí reconocieron, ahí me dijeron a mí:"vos siempre estás en todas partes con nosotros", y yo le digo, "Y si", le digo, y mi vecina Liliana le dice "Si nosotros siempre estamos, pero de trabajo nada que ver a nosotros, otra gente sí les han dado trabajo". Y le digo, "te van a dar una carta de 
recomendación para una empresa que se cierra", Liliana le digo. Así me hicieron a mí, me dan una carta de recomendación, voy a ver al trabajo y me dice: "Señora, quién me manda esto?", le digo "del intendente", "Señora, el Intendente sabe muy bien que estoy cerrando la empresa", le digo yo: "Pero si me mandó. Ahí está la firma de él", "No señora, no hay" dice. Me tomaron por tonta, "no sé cómo decirle señora", dice "pero esto, esta empresa se está cerrando.

Yo no le pido nada, yo lo único que le pedí trabajo encuentre para mí, ya no para mi marido, para mí. Yo no le pido un trabajo de secretaria, porque nunca lo voy a hacer, si no sé secretaría, que me de para algo que sepan de hacer, limpiar escuelas." (Araceli)

En otros casos, no es la conducta del "patrón" sino el oportunismo y la conducta parasitaria respecto del estado del "cliente" la que se impugna.

"Lo que pasa que a veces, este...la gente es abusiva ¿viste?, creen que...tiene obligación de dar...y no es así.... No es así, este...acá se dio mucho y yo... así, dando así, pienso que es pérdida para el país. No le veo eh...la ganancia, porque por lo general bueno, eso se usa por política. Pero desgraciadamente esa gente aprovecha la situación y después se te da vuelta como nada ¿viste?

Hay gente que merece realmente que uno lo ayude, y hay gente que te da bronca, porque por ahí vos, qué se yo, das una bolsa de ropa que no te sirve en buen estado, y la usan y la tiran ¿viste?, qué se yo...todo depende de cada uno... ¿viste?...a veces pasa. A veces hay gente que no progresa porque no tiene interés..." (Fidela)

Cabe destacar que en todos los casos, la autoselección (exclusión/inclusión) para el uso de programas alimentarios depende de la situación ocupacional de la familia y de los ingresos. La posibilidad de consumo a través del mercado, la consideración de grados de necesidad y evaluación de mayores carencias en otras familias, genera una dinámica de redistribución de programas:

"Sí, sí. Entonces, no, yo lo único que recibí fue la Caja del Pan en ese tiempo, y bueno después... no era porque yo no lo necesitaba, sino porque había personas que quizás lo necesitaban más que yo. Yo, él ya había empezado a trabajar, a hacer extras, ya habíamos dejado de hacer pan, hacíamos facturas, de todo." (Perla)

"Tienen (comedor) pero no van. Pero lo que pasa es que el colegio de ellos tiene para doscientos chicos nada más. Y para los que necesitan nada más. Es para los que necesitan demasiado. Hay chicos que pasan solamente con lo que comen en la escuela. Pero ellos tienen, gracias a Dios no les falta, así que... Sí, ella sí, iba. Cuando había lugar para ella. Pero como me dijo a mí la asistente social que si necesita demasiado, porque hay, como me dijo ella: "Hay chicos que pasan con lo que comen acá". Entonces, te da no sé qué. Si ellos tienen. Si no les falta....no tengo por qué mandarlos." (Gabriela)

"Yo tenía uno... este el plan Pais. Eh... digamos hace... un año más o menos será que yo como ya estaba mejor lo doné a mi hermana. Es poquito lo que se... pero para mí era... cuando yo lo necesité era una ayuda. Que era que ¿vio que le dan el dinero?...y después, bueno la que se hace cargo de ahí va y se compra. No era mucho como uno hubiese preferido pero... ayudaba, porque se hizo hace ya varios años y se sigue con la misma cantidad, y eso varió muchísimo porque los precios son ahora totalmente distintos...sí." (Olga)

"Si, porque yo veo que es ... son muchos, mucha gente que necesita lo...no es porque no quieran trabajar sino que realmente que no consiguen trabajo y...es una buena ayuda.

No sé, no sé cómo fue el Plan País, porque ya te digo, yo me anoté en esa época, pero no me preocupé más cuando a mí no me salió porque estaba trabajando bien y... y era como sacarle a los demás que necesitan y entonces..." (Gabriela) 
Para evitar que la recepción quede librada a criterios burocráticos o de autoselección de las familias, algunas mujeres proponen la realización de un seguimiento de las familias a fin de monitorear su situación y determinar la lista de beneficiarios:

"Y, yo creo que para el que lo necesita sí, son importantes, porque a mí me ayudó en su momento.

Me parece que tendría que hacerse un... cómo le puedo decir... una nueva lista, no sé, algo... porque... Hay gente quizás que ya lo está recibiendo y no lo precisa tanto como lo precisaba en su momento. Yo, por ejemplo fui una de ellas que... digamos que no estoy en la abundancia, pero mi situación está un poco mejor, y yo lo seguía teniendo. Entonces yo misma, como veía que otra persona no estaba bien... como es entonces se lo di. Y... y pienso, no sé, quizás haya otros en ... en mi situación que están lo mismo...y que no lo dan y que hay gente que quizás..." (Olga)

Casi todos los programas alimentarios son evaluados positivamente. El plan Pais es el que recibe más cuestionamientos por el manejo de los cheques y la compra de alimentos centralizado en una puntera barrial.

"Sí, era bueno el Pais, sí, había cosas también que no iban, pero... porque una señora agarraba todos los cheques que le daban... Pero esos cheques a nosotros nunca nos los mostraba. $Y$ todo así. Por eso pienso que se termina todo esto... Sí, y todos siempre agarran la ventaja, siempre hay un ventajero que quiere ventajar y no, no es sano eso. Y, por eso está todo así. No te van a dar nada si no te sacan." (Celeste)

La recepción continua de programas es en muchos casos fundamental.

"Si, tuve, si. La caja Pan, el plan País y ahora tengo el plan VIDA. Y eso ayuda mucho. Sí, es de gran ayuda." (Cintia)

Aunque actualmente no sean beneficiarios, se reconoce la ayuda que representaron en algún momento:

"Yo creo que todas esas cosas ayudan, sí. Yo en un momento tuve, cuando estaba la situación bastante difícil y desde allá me daban pero... ahora creo que ahora siguen ayudando, sí, inclusive en la cooperativa a las mujeres que realmente necesitan creo que le dan un bolso con... bastante surtido de cosas Sí, sí, el comedor es una ayuda, si. El comedor está ahora en verano y está en invierno, continuamente está el comedor Y ayuda bastante, sí." (Olga)

"La entrega de leche de acá de la salita me parece...eh...excelente, excelente que...porque la leche es algo indispensable, viste, es una zona de que hay muchos chicos, y realmente hay gente...

Yo nunca saqué...No, no...gracias a Dios no porque mis...mis hijos tomaron pecho hasta el año y pico, dos años, así que... La caja del PAN sí la tuve...en un tiempo la retiré." (Fidela)

Las redes de ayuda entre parientes, vecinos y amigos aseguran el intercambio de bienes y servicios de manera asistemática y no siempre equivalente. Los alimentos, la comida o el dinero constituyen algunos de los recursos objeto de circulación, aunque cada vez menos frecuentes.

"No, cada uno...vive su vida porque todos tienen problemas. No somos ricos los de por acá. Es que ya no se puede ayudar ahora tampoco. Antes sí, antes sí, pero ahora no hay. Antes, antes podía ser, sí, podías pedir, pero ahora ya..." (Celeste) 
Dada la situación por la que atraviesan la mayoría de las familias, la posibilidad de ayuda en recursos es cada vez menor. La mayoría de los "favores" dados o recibidos no implican recursos materiales. La información sobre fuentes de trabajo o recomendaciones para conseguirlo son cada vez más relevantes y la confianza establecida con compañeros de trabajo favorece el préstamo de dinero:

"Y él tiene muchos amigos consigue changuitas de albañilería, todo. Siempre, gracias a Dios. No, cuanto mucho él está sin trabajo un mes, dos meses, y eso ya es mucho para él. Porque él trabajó ya en muchas empresas, lo conocen. Mi marido también es paraguayo, ya hace 17 años que está acá, tiene ya muchos conocidos, aparte como es muy trabajador lo aprecian mucho." Yo acá no tengo ni un pariente... amigos sí. Bah, los mismos compañeros de trabajo de mi marido si se ve en aprieto él sí, les pide, le prestan y..." (Gabriela)

Finalmente, la autoproducción de alimentos no es una actividad frecuente; la mala calidad de la tierra es una de las razones por las cuales no se hace huerta y, en el caso de la cría de animales, las razones se vinculan con el robo, la falta de espacio y la falta de higiene. Algunas mujeres aluden a su crianza en el campo y hacen referencia a que, pese a la pobreza, el trabajo de la tierra aseguró sustento a su niñez y el alimento nunca faltó. El hambre, es una novedad de la vida en la ciudad que afecta a muchos niños.

"Sí, está difícil, sí. Está muy difícil para todos, no para mí sola, para todos en general, porque yo hablo con otra mamá y me doy cuenta lo mismo. Ya le digo, la señora esa que tiene muchos chicos. Los chicos, la verdad que el marido tenía trabajo, pasan hambre los chicos.

Dice no tengo pan para los chicos tengo que darle algo. Eso es lo que pasa señora, lo que está pasando es eso. Los chicos jóvenes ahora, yo digo, yo me crié en el campo, en Entre Ríos, me crié en el campo, nosotros éramos pobres pero repobres, y nosotros no pasábamos hambre, porque íbamos a la chacra, naranjas, mandarinas, carpíamos las plantas, no nos faltaba la comida. Teníamos, pero acá no hay nada.

La tierra acá es malísima, tengo mi vecina que plantó también ahora. Tuvo que traer carretillas y carretillas del río para poder sacar alguna lechuguita, algo.

O gallinas, o lo que sea. Gallinas no se puede porque en casa no tengo lugar.

Aparte de eso, tengo que, no tenerlas sueltas porque si las suelto, no las veo más. Y no se puede vivir en verano, junta las moscas y encima que tenemos que andar luchando con los mosquitos, no no se puede, con las moscas, no." (Celeste)

No obstante en algún momento ha sido y en algunos casos sigue siendo una contribución importante a la alimentación familiar, particularmente para algunas familias provenientes de zonas rurales del interior del país o de países limítrofes.

Pero, lejos del tono nostálgico e idílico del relato anterior, la huerta y la cría se presentan como estrategias coyunturales a las que no se quiere volver:

"Ahora, no tenemos quinta, no tuve más, después dejé, cuando yo empecé a trabajar...Dejé todo. Hace cuatro años que trabajo en casas de familia. Sí, así que..., y voy a trabajar, y yo dije, si alguna vez, Dios no permita, ¿no?, vuelvo a caer en la misma, de que tenga, tenga que faltar y tengo que volver a criar gallinas por lo que sea, vuelvo, pero..." (Perla) 
Un solo caso, de una familia con jefe desocupado, muestra satisfacción por la realización de esta actividad a la que se califica de "vicio":

"Mi marido se ha hecho su siembra ahí, por poquito que pone pero para nosotros, la tierrita es chiquita, un canterito tiene. El año pasado comimos bastante tomates chiquititos, zapallo calabaza, morrón y ahora no sé qué cosas, no me pregunte porque él trabaja con la tierra ahí.

Si, él hace todo, el único vicio es trabajar la tierra y trabajar. Mientras él trabaja parece que es feliz.

Y tenemos gallinas que nos podemos ayudar mucho con las gallinas... ahora esta temporada, da cualquier cantidad de huevos, así que... sí, gallinas, gansos, patos y tres perros que cuidan la casa, que es lo más importante...." (Araceli)

\subsubsection{Conocimientos y valoraciones alimentarias}

Se ha visto cómo la combinatoria de los componentes estructurales considerados afecta las modalidades de adquisición de alimentos y el uso de recursos alimentarios estatales o autogenerados. No obstante, la canalización de las necesidades alimentarias se hallan orientadas por un aspecto básico: el que se relaciona con las representaciones acerca de lo que constituye una adecuada alimentación.

Así, la buena alimentación consiste en tener cuatro comidas diarias, en las que no pueden estar ausentes la leche, el huevo, las verduras, carne de vaca (consumida con moderación), pollo, pescado y frutas.

"Un buen desayuno...Y la leche, pan con una manteca, un dulce, y después a la media mañana que tomen un yogur o...qué se...almuerzo, al mediodía...la merienda y luego la cena." (Araceli)

Muchos relatos refieren a la propia alimentación destacando la importancia del desayuno como comida para los niños, las propiedades del yogur y algunas reflejan una franca internalización de las actuales recomendaciones médico-nutricionales:

"Yo de alimentación sabía muy poco porque comía todo lo que había, (...) comía mucho fideos, pastas toda esas cosas. Y comencé a ir a...en el Gutiérrez hay un... una como es, una doctora de obesidad, y ahí, prácticamente ya hace unos meses que voy y comencé a aprender, a seleccionar alimentos, mucha verdura, este... utilizar el germen de trigo, salvado de trigo, este... la avena de salvado, que yo esas cosas no las utilizaba para nada, no las conocía prácticamente. Sabía que existían pero...Y ahora no, ahora comemos mucha verdura, bueno comemos eso, por ejemplo en vez de utilizar en albóndigas todo eso pan rallado, utilizo germen o salvado, quedan riquísimas y... y no tan engordantes. Se compra en la dietética y son productos baratos... y uno no lo sabe!

Bueno, que tenga verdura, incorporar germen y salvado de trigo en vez de otras cosas...el pescado por ejemplo...Pollo, a veces no tanta carne, sino pescado, pollo...que se cocina de varias maneras, hay mucha alternativas..." (Olga)

Los alimentos más valorados son aquellos que aportan vitaminas, proteínas, hierro y calorías, alguno de los cuales son objeto de promoción médica:

"Sí...churrasco con puré...A él le gusta y... no sé por qué, yo digo porque aparte porque la doctora me dijo que un pedazo de churrasco es bueno para los chicos.

Polenta, la polenta...porque tiene mucho hierro dice...También les hago lenteja. 
Sí, porque yo ... yo le pregunto siempre a la doctora viste, ella siempre me dice que... que le de polenta, lenteja, cuando pueda viste que le haga un churrasco de cuadril, que... es... que tiene el alimento que necesitan los chiquitos..." (Gabriela)

"Y es...tiene que ser la leche, los huevos, la verdura, hay veces que uno no incluye mucha verdura y la verdura es importante por la fibra y por todo lo que tiene no? a veces... y la fruta. A veces uno dice bueno, le compro un caramelo, pero es más importante en vez de ese dinero, juntar y comprar una fruta que dar ese caramelo. Así que es una situación de que...que incluye todo.

A mi en el Gutiérrez, sí, aprendí mucho... porque como yo estaba demasiado... ida en peso, entonces comencé a... como es... y entonces ahí enseñan a aprovechar la verdura, todo, y uno aprende. Y claro, porque yo lamento mucho antes que...si bien yo siempre usaba la verdura no? pero... no tanto. Vio que uno hace una ensalada, o esto para hacer un guiso y nada más, a veces no le da cabida en otras comidas, un montón de cosas que la acelga, que la zanahoria, que la remolacha, uno a veces tiene ahí como para una ensaladita y nada más. Y ...los nutrientes tienen por ejemplo... es una comida completa es... una ensalada de verduras y un pedazo de pollo es mucho más nutrientes que pongalé, un plato grande de guiso...porque lo otro engorda pero no alimenta. Por lo menos eso es lo que yo estoy aprendiendo..." (Olga)

La promoción mediática alienta el consumo de alimentos que se presentan como de elevado valor nutritivo pero inaccesibles económicamente, los que intentan ser reemplazados:

"Yo no sé....sí, pienso que...tienen...alimentos que tienen otras...más calorías que otros, pero...por ahí...esos yogures con cereales, o frutados...pero eso es como que se te va un poco del presupuesto, comprándolo todos los días.

Porque en mi caso, fijate, yo tengo tres, tendría que comprar tres yogures y qué son, 200 gramos, y son tres pesos más a diario. Que por ahí vos reemplazás eso, qué se yo, con un buen café con leche con pan y manteca.

Yo creo...la fruta también tiene mucha nutrición. Sí...eh...ahora hay muchos alimentos con hierro, también, vistes que salieron nuevos alimentos lácteos..." (Fidela)

Sin hacer referencia a fuentes de información calificadas, vuelve a aparecer la leche, el huevo, el pescado y las verduras:

"Y... qué se yo...eh que sí o sí tienen, yo para mí tienen que tomar leche. Leche, viste qué se yo... comer huevo, comer eh pescado, eso sí, pescado viste comen...y a veces comemos pescado tres veces por semana... frito, en filet. A veces comen chupín también viste que hacen." (María)

"Mirá, yo lo que tengo en la casa le doy a los chicos, pero... si se trata de comer verdura, les doy verdura, si se... quieren comer fideos les doy fideos...Y sí para mí el alimento... está más en la verdura porque tiene más nutrición... más vitaminas..." (Araceli)

La inadecuada alimentación, más allá de comer poco o no comer, es concebida siguiendo criterios de calidad (embutidos, envasados, grasas), carencia (leche), monotonía (fideos) y modalidad de cocción (frituras, comidas recalentadas), y preparación (picantes).

"No comer...o comer menos... Mirá, yo le tengo un poco de desconfianza a los embutidos...

Porque a veces este...no es bueno, qué se yo, los chicos, vos fijate que las salchicha son exquisitas pero para mantenerse le meten un producto químico... ¿viste que a veces está el agua media oscurita? Los alimentos envasados para mí, son caros y, y no a...a mí no me 
sirven, yo soy más de las cosas caseras, digamos, viste...lo que vos sabés lo que hacés." (Fidela)

"Y bueno, una mala alimentación, para los chicos especialmente son los fritos...

Hay algunas mamás, que papa frita y huevo frito todos los días...eh paty y salchicha, aunque a los chicos les gusta, a los míos les re-encanta...pero, viste. Pero, este...depende de las edades de...de los chicos. Yo pienso que un plato de guiso les va a hacer mil veces mejor que...más vale que no le va a dar guiso todos los días! pero de que un sanguche o... o papa fritas..." (Fidela)

"Y una mala alimentación... qué se yo... mucho frito...viste cuando ya no tenés y decís bueno, les hago torta frita, es malísimo...porque les hace mal al hígado...les revienta a los chicos mucho frito, yo medio... yo me daba cuenta... a los grandes mismo..." (Gabriela)

Los fideos son considerados poco nutritivos:

"Cuando no tienen por ejemplo la leche, que les falta la leche a los chicos y... tienen que estar con una taza de té y en la tarde un fideo hervido o qué se yo...para mí la mala alimentación sería eso." (Araceli)

"Y, es comer por ejemplo un poco de fideos y decir que uno comió bien.

Porque el fideo no... como le decía anteriormente, no... tiene que tener todo su vitamina, maneras de vitaminas." (Olga)

La comida recalentada es evaluada negativamente:

"Por ejemplo hacer la comida, qué se yo, decir bueno hago un buen guiso, lo dejo... eso es en el verano, te digo, y que quede para la noche, y... ya no es bueno. A mí me gusta todo fresco, es decir...al instante, igual que los...eh los chicos están acostumbrado así a comer.” (Gabriela)

Los fiambres no sólo son mal considerados por su costo, sino también poco nutritivos:

"A eso del fiambre, para mí es mala alimentación a mí no me gusta eso. Yo en vez de comprar fiambre lo primero que hago es comprarle un pedacito de carne, o una bolsita de fideo o corto un poquito de papa y eso hago un buen guiso que se que van a comer bien los chicos, en vez de comprar fiambre." (Araceli)

"Bah, y... yo sabés que le evito a los chicos? Los fiambres. No me gusta que coman mucho... muy de vez en cuando les doy. A veces una salchichitas, pero no te digo todo los días, eso es de muy de vez en cuando. O unos fiambres con queso..." (Gabriela)

Respecto de los hábitos, aparece la importancia de la rutina de horarios para las comidas y la condena al derroche de comida, respuestas que obedecen a situaciones bien diferenciadas: en la primera la disponibilidad de comida no es problemática, contrariamente a lo que sucede en la segunda.

Así, las dos primeras citas correspondan a familias en las que la obesidad está presente en alguno de sus integrantes.

"Los deshorarios. Los deshorarios te matan. Eh...yo pienso que la preocupación por tus hijos es todo ¿viste?. Tenés que respetar, no estrictamente, pero...si bien...un desayuno o un almuerzo y una merienda...porque los míos...por ahí el gordo por ahí llegan las ocho de la noche las nueve y rendido no cena. Pero es una máquina de comer..." (Fidela)

"Y, es comer siempre a deshoras y comer lo que venga... abrir la heladera y sacar..." (Olga) 
"El derroche. Sí, qué se yo...y... bueno... es lo que mi marido decía, dice él "no hay que derrochar..." yo no soy de derrochar mucho, viste, porque no, no me gusta, por ahí derrochás mucho, viste, y...con el tiempo lo necesitás." (Gabriela)

La mayoría de las mujeres considera que ningún miembro de la familia requiere una alimentación preferencial, debiendo alimentarse todos por igual aunque respondiendo a las necesidades de las diferentes etapas del ciclo vital:

“...y, mirá, yo pienso que...la alimentación tiene que ser para todos iguales, sí!

Porque, este...por ahí, eh...los chiquitos porque están creciendo, los grandes porque están en la edad del desarrollo, y nosotros porque necesitamos para trabajar." (Fidela)

La alimentación de los niños se prioriza atendiendo a su dependencia de los adultos y a la necesidad de crecimiento y desarrollo:

"A todos. Yo pienso que los chicos...qué se yo, porque los chicos están en la edad del crecimiento y...qué se yo si vos...un grande tiene hambre...o...tiene hambre porque quiere. 0 pasa hambre porque quiere. Pero un chico ¿qué puede hacer si tiene hambre? O ir y pedir a lo mejor al vecino, o ir...qué se yo, no sé...de algún lado, qué se yo, pero vos un grande o te la aguantás o tenés hambre porque querés." (María)

Asimismo son mencionadas las situaciones de enfermedad:

"A los que están anémicos...a los que está eh... a esa gente que necesita... o está anémica o están enfermos, que necesitan alimento." (Araceli)

El reconocimiento de una adecuada alimentación infantil, con base en la flacura/gordura no siempre es clara para estas madres ya que la distinción entre delgadez y desnutrición es incierta y la gordura puede ligarse a carencia de nutrientes. La salud/enfermedad y el dictamen médico son los criterios que orientan o determinan la apreciación.

"Mh...ahí me mataste. Ahí me mataste, porque...este...por ahí hay chicos que son de ser delgaditos, y son de buen comer ¿viste? y...ahí...no sé si me daría cuenta...

Pienso que sí, que se debe notar, viste, el chico que es delgado y el chico que ya está desnutrido, que vos lo ves... Ya te digo, supuestamente eh...por ahí no te das cuenta en el físico pero hay esos nenes de que...viven resfriados, que vos los ves todo el tiempo que...peste que anda caminando se la pesca, es obvio que ese chico...le falta una alimentación o una vitamina o... o tiene un mal cuidado, o vive descalzo o..." (Fidela)

"Y por control médico. Porque tampoco puedo decir sí, el mío está bien alimentado porque está gordo, por ahí tiene alguna otra cosa y está gordo mi hijo, yo lo veo que está gordo pero el mío igual tiene anemia." (Araceli)

Pocas son las que aseguran reconocer la buena alimentación de los niños por su crecimiento, usando la ropa como patrón de comparación.

"Yo me doy cuenta eh... en el peso... yo misma me doy cuenta cuando la ropa le queda chica, o lo veo yo; yo misma me doy cuenta cuando está mal alimentado." (Gabriela) 


\subsubsection{La comida habitual}

La organización de las comidas -definida en gran medida por las posibilidades y restricciones materiales- junto con los conocimientos y las valoraciones alimentarias de las mujeres entrevistadas, que son quienes están a cargo de la obtención de alimentos y la preparación de las comidas, se plasman, en la comida habitual. ${ }^{77}$ Así, de acuerdo con los relatos de las informantes, los alimentos más frecuentemente utilizados son:

"Leche, huevo...carne...papa...fideos y arroz porque los míos son ¿viste?...en casa ni tomate ni lechuga...no, no son verduleros. Bueno por ejemplo queso se usa mucho, manteca...” (Fidela)

"Papa, fideo, carne...el pan ni que hablar, todos los días...eh... leche ¿viste?, ya te digo, arroz con leche, les puedo hacer un flan algo así pero leche sola no...o Vascolet, lo único que toman ¿viste? No te toman mate, leche sola no te toman, mate cocido con leche tampoco, té con leche tampoco, o sea que... Vascolet y frío, porque caliente no te lo toman tampoco. Es lo único que...eso. Pero después no. Sí, papa, también lechuga, y tomate también. Viste, lechuga, tomate, eh zanahoria...uso mucho cebolla, morrón." (María)

"El fideo, el arroz, la papa... a veces una verdura...eh... zapallito, calabaza.

$Y$ después acelga, lechuga, tomate zanahoria. A veces hago ensalada de zanahoria..." (Araceli)

"pollo, bueno carne, y después verduras: zapallo, eh... zanahoria, remolacha, bueno lechuga, acelga, poca papa. Esas serían las verduras.” (Olga)

"Qué se yo a veces...lo que más comen polenta, puré, eh...bah, yo trato de buscarle lo que le gusta viste... papas fritas muy de vez en cuando, porque te digo que... guiso de arroz, de fideos...

Eso es lo que más seguido hago, sí." (Gabriela)

"Les gusta la polenta, el arroz. Les gusta que les haga, bueno el arroz con leche les gusta siempre, les pongo en la heladera y ellos comen a cualquier hora. Por más que sea invierno.. están bien alimentados, viste, gracias a Dios están bien alimentados". (Sofía)

Las propiedades nutritivas que las mujeres adjudican a dichos alimentos, no se relacionan linealmente con los alimentos que más consumen o que dejan de consumir. Aunque muchas plantean la necesidad e importancia de los aportes específicos de los distintos alimentos, la mayoría destaca el valor nutritivo de los lácteos, carnes, lentejas, verduras y frutas, aunque no formen parte sustancial de su dieta:

"Y bueno, pero ahí, ahí tenés distintas proteínas, porque viste la carne tiene lo suyo, las harinas tienen lo...los lácteos tienen su propio...así todas tienen distintas vitaminas...

En casa si te lo ponés a decir, mirá: en casa dos veces por semana se come milanesa...cuatro también...este...bueno, una vez con huevos fritos, otra vez con arroz con manteca, otra vez este...qué se yo viste, no sé... ensalada, ya te digo, yo y muy poco, nada más.

Por ahí les hago papas con queso...viste, papas rellenas con queso y jamón...

$Y$ las verduras, directamente son nutritivas pero no las uso prácticamente porque no las comen."

(Fidela)

\footnotetext{
${ }^{77}$ Las particularidades individuales tales como el gusto, el deseo, etc. han sido excluidas de este estudio.
} 
"Pienso que el tomate. El tomate, la papa no sé si es nutritiva. Tomate, la zanahoria... porque me parece que tienen...tiene vitaminas." (María)

"La zanahoria. Tomate, eh... después zapallito y la calabaza. Porque son verduras... más diferente al fideo, y el arroz, que para mí es muy...que no tiene nada de...el fideo es pura masa." (Araceli)

"Qué se yo; churrasco, milanesa, asado que de vez en cuando hace mi marido... la lenteja también es muy nutritiva." (Gabriela)

Cuando hacen referencia a los menos nutritivos mencionan el té y el mate cocido porque "lavan"; los fideos, el pan, la polenta en tanto "llenan pero no nutren", y los guisos preparados al mediodía y consumidos a la noche por perder las propiedades nutritivas.

“...Y...bueno, el té ponele, en vez de una buena leche, mate cocido...

Eso te lava las tripas..." (Fidela)

"El pan. Qué se yo te...te debe engordar el pan, qué se yo digo yo que te engorda y no te debe alimentar." (María)

"Y los menos nutritivos ya te digo, qué se yo, una comida que hacés al mediodía y decís bueno dejo para la noche...son los menos nutritivos...Y yo... y, son los guiso, no? Porque el guiso... no sé.

Este...sí, o qué se yo, llenarse de pan todo el día te llena pero no te nutre...mucho. (Gabriela)

Asimismo, el consumo frecuente de carne es considerado perjudicial, apreciación que parece sustentarse en opiniones calificadas:

"la carne me parece que también no es no es muy...o sea tiene partes pero si vos la comés muy seguida...no es conveniente también ¿no?... ¿o sí?...así dicen” (María)

Los alimentos considerados importantes aunque escasos o inexistentes en la comida habitual son algunos lácteos, la fruta y la carne. La sustitución de la carne por el huevo muestra la internalización y cumplimiento de las recomendaciones nutricionales de reemplazo y equivalencia.

"Y ...eh... el alimento que me falta siempre es la leche de... comprarle algún yogur a los chicos... es lo que más me falta... Carne, la carne también, la carne ¿ves?, la reemplazo por un huevo, pero...a veces, cuando tengo que las gallinas ponen huevos ahí sí, pero cuando después dejan de poner ni hago." (Araceli)

En general, la mayoría de las mujeres niega el excesivo consumo de determinados alimentos, a excepción del pan.

Las veces que se cocina por día y la comida más importante está en función del uso del comedor, de la disponibilidad de alimentos y de la presencia de los miembros de la familia, especialmente del padre. 
"Tengo a Domingo y a José. Ellos comen, ellos con cualquier cosita se arreglan. Pero a la noche sí tengo que cocinar ya para todos. Está mi marido. Yo al medio día no almuerzo, pero a la noche sí.

Tomo mate, porque a mí me encanta el mate y el nene más grande mío también." (Sofía)

"Cocino dos veces. Sí, sí. Es al mediodía y a la noche. Digamos que la de la noche es más porque como mi marido no come al mediodía, digamos que come al la noche, entonces eso se...Digamos al mediodía hacemos para nosotros...

Claro. Eso no... no es tan elaborada tan preparada, pero..." (Olga)

De allí que, independientemente que se cocine una o dos veces al día, la comida más elaborada y considerada más importante es la cena.

"Yo, en realidad, al mediodía me arreglo con cualquier cosita, a la noche cocino porque vienen todos. Bueno a veces cocino grande, a veces cocino cualquier cosa, hago empanadas, en fin, sopa, les hago guiso, todas esas cosas. El de dos años, sí, al mediodía y la piba mía. Pero nosotros nos arreglamos con cualquier cosita. Y a veces a la noche bueno, cuando queda algo del mediodía, bueno, me libro, digo bueno no hago nada, pero a veces no queda y tengo que cocinar a la noche, y ya me pongo a cocinar." (Celeste)

"La cena, sí, la cena la hago, este...porque estamos todos juntos...viste, entonces este...la hago más complementada." (Fidela)

En otros casos, la calidad de las comidas principales se complementa, oscilando la importancia de cada una de ellas.

Pocas son las que consideran al almuerzo como la comida más importante, excepto aquellas situaciones que responden a la edad y los hábitos de sueño de los niños:

"Al mediodía. Porque a la noche por ahí ya están con mucho sueño y ya ni comen siquiera. No te digo que a veces prefieren tomar un vaso de leche fría y...le gusta mucho la leche en sachet... leche cultivada le dicen..." (Gabriela)

La necesidad de ahorrar combustible impide que la preparación de dos comidas sea habitual:

"No, hay días que cocino dos veces. Cocino a la noche y al... mediodía. No te digo todos los días...

Pasa que se ahorra gas." (Gabriela)

Respecto de las comidas habituales, si bien en este grupo de familias se prepara una gran variedad de comidas, las más frecuentes son aquellas consideradas más rendidoras: los guisos, el puchero, fideos y las milanesas con puré, papas o arroz. La mayoría plantea que la comida constituye una problemática familiar que angustia a los padres no obstante lo cual los miembros de la familia se caracterizan por la poca exigencia y la conformidad con las comidas económicas, reconociendo también la falta de alimentos importantes por problemas básicamente de gusto o por inaccesibilidad económica como es el caso del yogur. 
La repetición de platos es en muchos casos frecuente y el consumo de comidas preferidas se da a veces como excepción, algún fin de semana o con motivo de algún festejo familiar.

El reemplazo de carnes u pan es frecuente a través del consumo de huevo y la preparación de tortas fritas o buñuelos respectivamente. El gusto por la milanesa, cuando falta carne, es satisfecho mediante la preparación de berenjenas. El consumo de frutas es poco frecuente y el rechazo al consumo de leche sola por parte de los hijos se resuelve, cuando no es posible comprar chocolate en polvo, mediante su combinación con el arroz, la polenta y la avena. Hacen mención de las vitaminas y proteínas incluidas en la dieta habitual y de la incorporación del pescado bajo la forma que es mejor aceptado por los hijos.

"Sí. Realmente las cosas están, no sé, viste si porque los chicos son más grandes o porque está más difícil. Pienso a veces, envidio a la gente que me dice los chicos comen en el comedor y a la noche no comen. Yo no, yo tengo que hacerle la comida. Si es puchero tengo que hacerles una cacerola bien grande. Los varones son todos comedores. Si es guiso lo mismo. O así, viste, cualquier cosa. De vez en cuando les hago un asado, viste, los días domingo porque pobrecitos tienen comer un asado, una cosa así. Pero está difícil, está difícil.

$Y$ yo a veces no tengo para comprar el pan, eso sí viste. Y en casa se come kilo y medio, dos kilos de pan todos los días.

Son muy comedores de pan. Y cuando no tengo para el pan les hago tortas fritas, esas cosas, les hago buñuelos.

Y sí, los hago yo. Y así vivo. Fruta comen de vez en cuando, viste, cada tanto. A veces no tengo para comprarle. La leche sí, le dan a veces a mi marido los jefes, le dan uno o dos paquetes de leche. Pero no les gusta en mi casa. Yo les hago o sea con arroz o con polenta, con avena y así les gusta, así la comen. No les gusta ninguna clase de leche

Cuando eran chicos sí tomaban, pero ahora no. Sí, no les gusta. Sea sólo con chocolate, viste con Zucoa, pero tiene que tener mucha Zucoa para que la tomen, si no, no la toman.

... y así me doy maña yo. Porque hay que tener un sueldo. No son ni 500 pesos los que entran en casa. Antes sí más o menos me daba maña porque le daban horas extra. Pero ahora no hay, ni una. horas extra ni nada.

Aparte mi marido hacía changas, viste. Cortaba el pasto, cortaba un árbol. Pero ahora no te dan nada, nada de nada. No hay trabajo y se pone difícil. A veces viene él capaz que tira todo. Yo lo comprendo porque venir a la casa y que te falte esto, te falte lo otro es feísimo.

Además los chicos ellos nunca exigen nada, se conforman con lo poco que hay en la casa, quedan tranquilos. Así nomás.

Yo consumo mucho carne picada. La carne picada te rinde más, entonces le hago hamburguesas o albóndigas o les gusta mucho les hago polenta con un tuquito o arroz. Y a la noche ya tengo que cocinar para todos, si no, me comen a mí. Y me doy maña: compro carne picada esas cosas y cocino un guiso o si no compro carne para puchero, por ahí de vez en cuando una milanesa.

Pero en el invierno es más complicado porque tienen que comer mejor. Hago locro, comen locro. Y lo que les gusta mucho también son las empanadas que hago, que también les hago yo

Sí, sí, yo hago todo. Fideos también les hago; los tallarines los hago yo." (Sofía)

"Bueno, cómo me arreglo, mirá, a veces hago puchero, a veces hacemos guisos, a veces milanesas, según, varío un poquito, no todos los días lo mismo." (Celeste)

La frecuencia de estas comidas se debe a que son rendidoras: 
"Aparte yo hago mucho puchero, guiso, guiso de lentejas, también se come milanesas y pero en general hacemos más lo que nos rinde, que es esa comida, pero comen de todo, toman leche...". (Cintia)

"Los guisos, sí....porque rinden. Ya te digo, a veces hago al mediodía y ya te queda para la noche, que no es nutritivo pero qué va a hacer...."Otra vez esto!" dicen...no; los chicos ya te digo, le gustan churrasco con...con puré, una milanesa con ensalada lechuga y tomate...un asadito así nomás...así con papas y mayonesa...ensalada y asado.” (Gabriela)

Siempre se destacan los gustos económicos de los hijos, incorporando asimismo evaluaciones sobre el valor nutritivo de lo que es posible consumir, sea por gusto o por costo:

"Y...bueno y en invierno... me las arreglo, por ejemplo si preparo un guiso, saco aparte viste... un poco de líquido para cuando venga mi marido echar los fideos...

Depende lo que cocine...pero no, no son raros, gracias a Dios son económicos mis hijos en la comida. $Y$, yo pienso que tiene que tener un poco de todo...porque todas, distintas cosas tienen vitaminas y proteínas, porque... yo pienso que la carne, por ejemplo eh...es indispensable...

Vistes, eh...la verdura en el caso de que les guste también. En mi casa no le gusta a ninguno...

Bueno, no te digo que una fruta o un postre todos los días, pero sí de vez en cuando. La leche sobre todo, no, más vale...y depende, ¿viste? Yo por ejemplo no soy adicta a las galletitas...

Yo en casa yo galletitas es raro que compre. Pero porque no me rinde.

$Y$ te imaginás que con tres chicos...y es forma de que te...eso es tirar la plata.

Viste, yo prefiero de que todo ande...y sino sí, pan, pan con manteca, con mermelada, con dulce, porque no te lo comen solo. O tostadas, o unos buñuelitos, qué se yo." (Fidela)

No obstante constituir -el guiso y el puchero- las comidas más frecuentes, asimismo se menciona la presencia de una gran variedad de menúes. Ellos excluyen, sin embargo, ciertos cortes de carne (hígado, corazón) que son rechazados por todos los integrantes del hogar:

"Poné milanesas, eh...como mucho pollo, también es bueno...como venga ¿viste? ... con salsa, a la parrilla, al horno... este...eso respecto a las carnes, después, ya te dije, arroz, fideos, todas esas cosas...Bueno pero a...yo soy muy de lo casero, también, pero por los horarios, viste, por ejemplo hago mucho matambre...Por ahí soy de preparar mucho escabeche...ponés en los...

Sí, viste, hago berenjenas, mondongo, lengua, todo eso y lo guardo y es como que me salva del paso. No, los chicos no comen eso...es raro que coman eso. El pescado también les hago una vez por semana. Sí, pero el pescado te lo comen...viste, el filet frito. De otra forma no, no te lo comen...entonces...

Bueno, yo por ejemplo, lo que en casa nadie, ni mi marido, viste que hay mucha gente que el hígado, el corazón todo eso que es económico...en casa no te lo comen. A mí no me gusta de por sí. Se lo haga como se los haga no lo comen, sí, porque veces la culpa la tenemos nosotros..." (Fidela)

"Ahí les hago comida... si no tengo les hago un fideo tostado con huevo, cebolla picada, cebollita así una salsita preparo, un arroz tostado...me las arreglo como pueda cuando no tengo. Pero, comida no les falta a mis hijos. Una milanesa...

Después milanesa también de berenjena les hago...berenjena al horno, zapallito al horno...revuelto de zapallito, puré de calabaza...con papa... Los chicos comen todo, ellos sí que comen todo!" (Araceli)

"No, es variado lo que preparo. Bueno por ejemplo son las ensaladas, de lechuga y tomate o zanahoria y remolacha, si hay hervida como es... y huevos. Y después, bueno, sea con pollo, 
con churrasco, o con pescado. El pescado lo hago sea al horno o frito. Y después tartas de verdura y empanadas." (Olga)

En el desayuno y la merienda, la presencia de leche varía en función de la edad de los hijos. En general, sobre todo si se cuenta con la ayuda de programas alimentarios, ella está asegurada en la alimentación diaria de los más pequeños y disminuye a partir de los 4 o 5 años de edad. De lo contrario, queda supeditada a la posibilidad de compra, situación que se torna sumamente dificultosa en muchos casos:

"Los chicos toman leche. Sí, digamos los más... los dos más chicos.

Si, yo con la otra nena tomamos mate. Mate con pan negro tostado y el quesito blanco o mermelada dietética. Y la merienda lo mismo. Y a veces comen fruta o toman yogur. Ellos, yo no.

Yo siempre mate, esas cosas." (Olga)

"Té. Los chicos toman, sí, los chicos toman leche a veces en el desayuno o hay veces té. Generalmente es té." (Araceli)

"Té, mate cocido, o mate cocido con leche... pan tostado con... manteca o dulce o... lo que tenga, y sino con pan solo y ya está. Y a la tarde, siempre. Igual que a la mañana. Todos los día, eso sí que no le llegue a faltar, dice enseguida: "mami, la leche", las cuatro de la tarde y ya están." (Gabriela)

De allí que la composición de estas comidas secundarias varíe entre los distintos componentes, quienes exigen para consumirla, su combinación y por tanto disponibilidad de chocolate en polvo:

"Bueno, los nenes a la mañana toman leche. No son re-lecheros te digo, eh...No son esos chicos de dos o tres tazas... Una taza de leche con chocolate... ¿viste? y bueno, y por lo general ya te digo, pan con manteca o siempre yo les estoy haciendo...algo.

Sí, merienda toman, pero en la merienda no toman leche. Por ahí, este... bueno, un yogur...se comen...sí, este... o té...o...no, té no comen más. Comen yogur...o...sí, por ahí toman leche, como por ahí, ya te digo, como yo les vivo haciendo cosas, agarran un pedazo de torta, unos buñuelitos...viste como son los chicos." (Fidela)

"Mate cocido o té. Merienda también, sí, mate cocido o té o a veces cuando tienen gana van y se compran leche y toman Vascolet. Cuando tienen ganas. Después yogur, viste. Yogur a veces a los chicos... a bah a los más chico siempre le compro yogur." (María)

El pan y las tostadas acompañadas con manteca o dulce parecen ser habituales.

yogur, sobre todo a la tarde, representa más una aspiración que un componente habitual.

En cuanto a la alimentación preferencial de alguno de los componentes de la familia, se desprende que ninguno recibe una alimentación especial siendo una opinión generalizada que "los alimentos igual... a todos igual, los grandes y a los chicos...", "no, en sí en casa todos... todos igual, sí." 
Respecto a la evaluación de la alimentación familiar, la mayoría de las mujeres afirma tener una buena alimentación. Razones de cantidad, calidad, salud de los miembros, están en la base de tal evaluación:

"Yo pienso que es buena, sí. Porque pienso que comemos...comemos todos muy bien, comemos bien. No falta algún alimento importante, creo." (María)

"Porque ... qué se yo, siempre hay para comer, a la mañana, al mediodía, a la noche...y... No nos falta, por ahora no. No te digo todos los días comemos como un rey, pero..." (Gabriela)

"Ahora comemos mejor que hace unos años. Porque como le decía, ahora no utilizo tanto los fideos, polenta toda esas cosas que antes sí los lo usaba, hacía mucha papa, esas cosas. Ahora ya es más equilibrado, más verdura, toda esas cosas...es más completa la alimentación." (Olga)

"Y... buena sí, para mí sí, pero no sé si los chicos están creciendo tan bien... comen todo, pero... por ahí necesitan más, qué se yo. Sí, están creciendo bien! No, no todos están bien. Por el momento saqué a todos sanos. Que ninguno necesita más que el otro, todos están bien."

(Araceli)

"Porque estamos todos bien de salud, andamos bien y yo creo que eso ayuda, a que uno ande bien." (Olga)

\subsection{La alimentación de las familias con niños desnutridos}

\subsubsection{Trabajo, situación familiar y organización de la alimentación}

La problemática ocupacional de las familias con niños desnutridos se agudiza aún más respecto de la ya presentada en el caso de las familias con niños eutróficos. La desocupación, el carácter informal de la casi totalidad de los trabajos de los jefes y otros miembros ocupados así como la mayor tasa de dependencia, profundizan la situación encontrada en el otro grupo de familias pobres analizadas.

"Y, de todo, lo que encuentra. .. porque por ahí él consigue una changuita ponele una semana y ya pasa la otra semana y... ya el gas se me está terminando y ya de ahí ya tengo que empezar a juntar para el gas." (Norma)

"Sí, hasta ahora en... los día de lluvia no...no trabaja porque levanta pared. Como está siendo como un albañil así, levanta paredes y cuando llueve no... Hasta ahora sí, estuvo... trabaja de lunes hasta el sábado...a veces el domingo trabaja también o a veces viste... y a mi mamá la suspendieron en el trabajo del sanatorio. En Sanatorio Argentino. No, hasta ahora no...no le dieron nada." (Silvia)

Los magros ingresos de aquellos que tienen trabajo sirven para "ir tirando", siempre y cuando no se presente algún problema de salud que requiera la compra de remedios:

"Por lo menos, no es mucho que digamos, pero, por lo menos, ¿viste?, para ir tirando, como quien dice, porque hay veces que se enferman y que hay que comprarles, ¿viste?, remedios caros también. Como él no tiene mutual, y esas cosas, ¿viste?" (Cristina) 
En el caso anterior, a causa de enfermedad del jefe, la disminución del sueldo y la interrupción en la provisión de comida traída por él de su lugar de trabajo (matadero), se genera una profunda crisis familiar:

"Bueno no trabaja... ahora sí que andamos mal porque al no trabajar él, ni un pedacito de carne, nada puede traer nomás, el hijo trae pero a veces ¿viste?. Así que anda con carpeta médica...le están haciendo estudios ¿viste?, aparte tiene presión alta también...le encontraron mal que tiene... ¿cómo se dice eso? azúcar en la sangre y le levanta mucho el colesterol. Se pone nervioso.

Tiene varios años ahí adentro del matadero. Pero ahora, está con carpeta médica, hasta que baje un poco su enfermedad." (Cristina)

La incidencia de la desocupación, el "estar parado" en el momento de las entrevistas refleja la gran inestabilidad laboral de aquellos que, en el momento de la encuesta, declaran trabajar por su cuenta:

"Y...bueno, ahora está sin trabajo.

Ahora... o sea, lo que pasa que como al patrón de él le hicieron un.. una boleta porque se pasó un semáforo en rojo, bueno, está parado. Así que...eh...no, no, carga... camiones." (Mónica)

"Ahora él trabaja de albañil, pero ahora está parado, está parado el trabajo, se quedó sin laburo." (Celina)

"Sí, buen, mi marido había conseguido, pero estuvo ... y del depósito donde entregan chatarrras y todo había conseguido para limpiar los depósitos del Disco, juntando cartones y, claro estuvo poco tiempo porque había bajado mucho el cartón y no convenía y entonces bueno trabajó creo que 3 meses. Y bueno ahora el está sin trabajo. Eso era un negocio que había hecho el dueño del depósito con la gente del supermercado. Ellos tenían que ir a cargarlo nada más... después el hombre le pagaba el sueldo, le pagaba ... 50 pesos por mes pero lo que tenía la posibilidad era que sacaba por semana, no era que llegaba el mes y cobraba todo junto, sino que podía sacar en la semana plata y con eso bueno, íbamos tirando. Y ahora no tiene y para colmo..." (Mónica)

"No, mi marido hoy empieza a laburar. Va a lavar autos, bah... entra a la noche. Entra a la noche y sale a la mañana. Y antes no, no, nunca conseguía laburo. Siempre así, changas en el mercado.

$Y$ ahora ayer se fue a un laburo que lo mandó un muchacho y con una tarjeta y que hoy empieza a laburar." (Zulema)

La convivencia en el hospital a propósito de la internación del niño desnutrido permite la interacción con otras familias en análogas condiciones de vida, hecho que sirve para objetivar la propia situación y depositar en el contexto más amplio la responsabilidad de lo que sucede.

"Y uno, acá el otro problema que hay es que no hay trabajo.

No hay trabajo, acá y en ningún lado, ya sé yo, pero..., igual, ¿ viste?, ¿los chicos cómo hacen para entender? ¿Cómo le decís que no hay? ¿eh? Es decir, las madres, ¿cómo hacemos nosotras para decirles? Las madres lloramos, te digo, por ahí, estaban con suerito, si vos los vieras lo que es, el hospital es un desastre, te digo, últimamente con los chicos, los médicos, yo hablaba con los doctores, y me dicen que es impresionante la cantidad de chicos desnutridos, que han entrado al hospital. Los padres sin trabajo, no, no, no tienen una ayuda de nadie, un apoyo de nadie, te podés imaginar." (Estela) 
Los irregulares y escasos ingresos hacen que la planificación de compras sea imposible y la mayor parte de las compras, si no todas, las hagan generalmente las madres e hijas en los comercios del barrio:

"Yo. Y la hacen las chicas, como yo a veces ando jodida de asma van ellas, viste. Mi marido a veces sale, muy poco porque está enfermo así que no...Y tiene problema diabético está...está con problema con... mucho problema tiene.(...) Sí, en el barrio, sí. A veces, cuando nos sobra, vamos a la ciudad...de ahí, cerca de Abasto nomás vamos." (Cristina)

"Yo, sí, yo las hago, o sino va mi marido o mi hermana. Cuando yo no puedo ir, va uno sino va el otro. Al frente de mi casa hay un almacén. Sí, porque todo cerquita está." (Lola)

"Y, la carnicería, la verdulería, la almacén que tengo ahí, las hago yo.

Sí, sí, todo en el barrio, tengo el almacén. Tengo ahí todo en casa cerca así que, tengo un paso...

y como los precios son baratos... Por ejemplo compro 4 kilo de papa por un peso, lo veo a otro lado veo 3 kilo por un peso y me conviene." (Valeria)

Dentro del barrio, se eligen -en un radio no muy extenso- los mejores precios:

"Todas yo. Tengo la carnicería cerca de mi casa...y la verdulería al lado de la carnicería. Y después hay un supermercado, que bueno, es donde venden más barato. Antes sí compraba en la almacencita que está ahí a la vuelta pero bueno, venden demasiado caro, entonces bueno. Y como el otro no está tan lejos..." (Mónica)

La búsqueda de precios y la eventual compra fuera del barrio es una actividad frecuente llevada a cabo por los jefes en los comercios cercanos a sus lugares de trabajo -cuando los poseen.

"Carne y verdura, todo eso compra mi marido...porque en el trabajo queda más barata la carne..." (Ana)

"Mi padrastro compra. Así como es traer un poco de fideos... así un poco, como si fuera un pedido? se encarga él en el Centinela, un supermercado que a veces trae cosas medio baratas y entonces compramos ahí. Mi hermano tiene...se compró, como él trabaja sólo aparte, se compró una motito y le presta la moto a mi padrastro para que pueda hacer el pedido. Ahí va una vez por mes. En el barrio...el pan o...la papa, principalmente pan. Porque lo otro ya trae las papa, la carne él. Pero manda a comprar el pan o las cosas así, la manda a mi hermana de 12 años o a mí a la noche y compro a veces las papas..., leche me dan de acá." (Silvia)

"No, mi marido. Porque él va todo el supermercado, va a la canicería por el lado de la estación, está todo más barato. Sí, corre con bicicleta y va a todas partes." (Zulema)

"No, no, a eso va mi marido, va, cuando viene del trabajo así...va a uno de ahí, del barrio de mi papá. El supermercado Marcelo." (Lola)

Aunque en realidad, son pocas las situaciones que reflejan la realización sistemática de compras de alimentos no perecederos en el supermercado. En general, éstas son eventuales por estar supeditadas a la disponibilidad de trabajo y/o dinero.

"Si. No, las hacía en el supermercado, pero este mes nos fue tan mal que viste, pero yo voy al supermercado y me traigo todo, todo. Yo administro la plata pero no llego, con lo que gana no 
llegás, termino sacando fiado, siempre en el almacén, si no, no llego, es que con lo que gana, no llego." (Estela)

"Mh...a veces en la verdulería, en la carnicería... en el barrio voy, pero...en el barrio hay un supermercado grandote...A veces tengo que irme hasta 60 o hasta 1 y 70 . Porque ahí está más barato. Queda... son como veinte cuadras.

¿Al supermercado? Cuando tengo plata, cada vez que tiene trabajo él." (Norma)

Los comercios del barrio son los más frecuentemente utilizados dada la desfavorable evaluación costo/beneficio, en términos de tiempo, esfuerzo y dinero adicional para el transporte, que supone la compra de alimentos más baratos en el supermercado.

"Todos los días compro los fideos, la verdura, ¿qué más? nada más, el pan no porque el pan me lo trae mi papá.... Por ahí compro algunas conserva y azúcar. Azúcar compro una vez cada...

Porque no, por lo menos en el barrio donde estoy yo, para conseguir algo barato me tengo que ir caminando veinte cuadras o treinta cuadras, tomarme un micro y poder ir a comprar, porque donde estoy yo, el azúcar sale un peso, y donde la voy a comprar, sale 65 centavos... pero ¿viste' y tenés que hacer cuentas... más lo del micro y no sabés si te conviene o no.

Y carne sí, a veces todos los día, a veces día por medio...a veces no compro mucho, viste? Compro poquito, porque a veces ellos comen o no comen. $Y$ como ellos no comen mucha carne. La carne no compro casi." (Norma)

En las familias numerosas participan un mayor número de miembros en la adquisición de alimentos y recurren a una mayor diversidad de fuentes de abastecimiento:

"Los chicos van acá al almacén. No, todo no porque la verdura me la trae Marcelo de la feria y...la carne compro una vez por semana en el frigorífico, que me sale más barato. Y lo único que van a buscar los chicos es el pan... a veces así sí, me falta fideos y eso. Compramos todo en el almacén del barrio y cuando tengo sí, voy a Carrefour.

Y no sé, no sé cuánto que no voy, el otro día fue mi yerno y me compró las cosas ¿viste en Carrefour?, el aceite todo eso que es más barato. Muchas veces uno busca comprar más barato, pero.. yo muchas veces en el barrio compro algunas cosas...afuera cuando tengo, y otras compro en el almacén, porque yo cuando necesito...y no tengo plata viste, el almacén me tiene que dar y a veces es más caro..." (Juana)

La periodicidad con que se compran los alimentos ya sea diaria, semanal o mensual depende del ingreso y la mayor parte de las veces lo que se compra se define en el día:

"Y, según lo que vaya a cocinar, qué se yo... y la plata....Como ser, si hago milanesa, bueno compro para milanesa, pan rallado, bueno, toda esa... según. Y no, yo voy todos los días, pero compro... para el momento, no compro decir bueno, saco $\$ 50$ y hago todo un gasto." (Mónica)

"Carne compro sí, cuando tiene trabajo mi marido porque ahora se quedó sin trabajo y...

Y hace dos, tres, cuatro días que..." (Lola)

El pan es el alimento paliativo omnipresente; a falta de mejor comida, al menos, "llena":

"Una compra... una comprita más o menos ¿viste? cuando cobra el salario de los chicos, viste... 
Y... a veces lo que tenemos que comprar es el pan...viste, porque el pan los chicos comen mucho pan... Sí, al no comer bien, por el pan, comen ¿viste?

Y leche tesoro no compro, viste, vengo a veces acá mamá a buscar que me dan y... así que voy viste allá a la salita de Abasto." (Cristina)

"....y (en el día) compro fideo, azúcar todo eso ...pan." (y por semana), "yerba, aceite...jabón y por mes esas compras grandes, serían..." (Ana)

La adquisición de leche y fruta se realiza -cuando es posible- fuera del mercado y la carne se compra día por medio. En el día se compra:

"Papa, cebolla, el ají, el pan, azúcar cuando no tengo... o la garrafa cuando se me termina.

Leche no... consigo a veces leche en polvo así... y carne día por medio.

Mirá, la fruta a veces la trae mi marido, así picada. Se puede limpiar, viste, la trae de la verdulería que trabaja él." (Valeria)

La fruta, pese a ser mencionada, registra en todos los casos un escaso consumo:

"Fruta sí, comen ello sí, comen de todo, la fruta, toda le vienen bien, compro una vez a la semana.

Y verdura sí. Sí, porque son muy verduleros ellos así que todos los días..." (Norma)

Tan raro es su consumo, que incluso se la separa -como categoría- de la comida:

"Fruta no, casi nunca. No compramos...Porque a veces no le alcanza el dinero, entonces tiene que invertir en mercadería o... en las cosa para la comida. Y más o menos andamos..." (Silvia)

Por los montos de dinero que se destinan, la periodicidad y cantidad que se compra y el tipo de comida que se prepara, la carne parece estar presente en las comidas en pequeñas cantidades:

"Mm...él a veces le dan casi el sábado, todos los sábados cobra 20 \$ casi le están dando por cosa, entonces...hacé ponele diez pesos en carne y lo otro en mercadería que pueda traer.

Hasta ahora gracias a dios nunca nos ha faltado la carne, siempre tenemos carne.

Todo eh... por ahí llega se termina la carne el va y... le dice el...

No, todos los días estamos comiendo... Y a veces él hace como un guiso o... fideos con tuco así. O unas papita así livianito...con un poco de carne." (Silvia)

Los alimentos que se compran diariamente son, por lo que puede apreciarse, el pan, los fideos, el arroz, azúcar, puré de tomate y en algunos casos verdura:

"Compro todos los días: el pan, así cuando me falta fideos, o arroz, esas cosas, cuando no tengo lo compro todo los días o el puré de tomate. Lo que falta, algunas veces...compro un azúcar.

Una vez por semana porque compro...en el frigorífico compro la carne.

La verdura y la fruta la trae Marcelo de la feria... verdura me trae dos veces por semana y la fruta una vez por semana." (Juana)

La falta de heladera limita la compra de alimentos perecederos, al momento:

"No, todos los días no. No, yo ahora... esta semana no... tanto no puedo comprar porque no tengo heladera, se me pudre la carne." (Zulema) 
Respecto de la forma de pago, cuando el tiempo de residencia en el barrio es escaso, se anula la posibilidad de la compra con libreta: "al contado", "no, pago cada vez", "todo al contado", sobre todo si se trata de familias con pocos niños:

"Sí. Que yo sepa no, nunca... y tampoco pregunté viste porque como...siempre les tuve pagar... que siempre me quise anotar para que... para la libreta y nunca... me quisieron dar porque decía que tenía un nene sólo y después cuando nació ella también. Que tenía un nene... que eran ellos nomás y que no eran mucho..." (Norma)

El reducido monto de la compra no justifica en algunos casos el uso de libreta:

“No, no, no, al contado. Cosa sencillita...nada de lujo." (Valeria)

Además la convicción de que no es posible cumplir con las deudas hace que se compre todo en al contado:

"No. Nosotros ahí en ese barrio...y sacar y sacar, sabés que se te hace quinientas lucas o más de quinientos y ahora con eh. como no tiene trabajo no se puede estar mintiendo porque no tenemos cómo salir si nadie lo ayuda a pagar." (Silvia)

"Eh... no, no, lo pagamos, cuando tenemos lo pagamos directamente viste porque para tener libreta no se puede, porque a veces no lo podés pagar también viste...

No, no. Eso como quien dice además nos arreglamos con lo que uno pueda, viste porque...

No, porque imaginate que eso lo que... como yo te digo, capaz que te fiaron nomás y te pasás y después no tenés plata para pagar, no conviene. Más malasangre te hacés." (Cristina)

Pocos casos pueden recurrir al pago con libreta. Se trata, como se dijo, de familias con larga data de residencia en el barrio y además, numerosas.

"Si tengo pago y si no me dan anotado..." (Juana)

El gasto en comida y la proporción del ingreso que representa es más elevado que en el caso de las familias con niños eutróficos. Todo o casi todo el ingreso se destina a la compra de alimentos y la capacidad de ahorro o la disponibilidad de dinero para la compra de otros bienes es prácticamente nula, sobre todo cuando deben pagarse los servicios.

"Según como gane, porque las veces que ganan poco, lo que ganen, lo único que se trabaja es para la comida." (Juana)

"y a veces se gasta mi marido en el supermercado... 10 peso o $20 . .$. y casi toda la plata se va... en comida, mercadería." (Lola)

"Y, casi todo porque...cada día más ¿cómo te puedo decir?, más bajo, más jodido la mano porque no te alcanza." (Cristina)

"Yo, como ser, por lo general me manejo con 10 pesos, qué se yo... eh...compro la carne... según lo que haga de comer, no? Y si tengo... porque hay veces que tengo $\$ 10$, gasto, si tengo 15 gasto $15 . .$. , sí. Hay veces que tengo 5, y, bueno, gasto 5. Según lo que tenga. Lo poco que hay sí, o sea, los pesos que entran, salen...y no...no. No queda para nada." (Mónica) 
"Por semana según, a veces gasto 80,100 , es que somos seis nosotros.

De lo que gana queda para luz y gas. La garrafa nos dura mes y medio porque no tengo horno." (Valeria)

El pago de servicios, dada la clandestinidad de la conexión, no aparece generalmente como gasto y aquel destinado a lo que en este relato remite a "la casa", refiere a la comida:

"Y, yo, yo soy, bah, no sé, siempre de comprar cosas económicas. Y... más o menos gasto por semana \$30. Casi todo es para comer ¿viste?, porque no...a veces se necesita comprar alguna zapatilla cuando no tiene o...o alguna compra, pero casi siempre es todo para la casa." (Norma)

En las familias extensas y numerosas el promedio de dinero per capita disponible para la compra de comida disminuye drásticamente. Tal el caso de esta familia de 15 miembros que cuenta diariamente con $\$ 20$ para comer:

"Casi todos los días los $\$ 20$ gasto. Todos los días veinte pesos. Estamos...tengo 5 míos... no, 6 míos, cinco los de mi mamá y los más chiquititos comen. Cinco de mi mamá y más que tiene...mi padrastro son...mi padrastro, mi mamá y mi hermana grandota. Y más que mi hermano que también empezó a vivir con nosotros. Y unas veces también no... no le pagan mucho pero a veces con \$10 también puede ayudar entonces." (Silvia)

Tal es la estimación del monto que realiza una informante discriminado por tipo de alimento:

"No tengo idea porque como compro así, viste, o sea...la verdura no sé porque me trae Marcelo...

Pero la carne compro $\$ 20$ por semana. Puede ser la carne, \$ 5 o \$10 y \$10 de pollo.

Eso es lo que gasto. Después el pan... dos kilos todos los días...el azúcar...y más o menos por día en el almacén pienso que gasto \$10...lo que pasa que sí, somos muchos." (Juana)

Es decir, esta familia de 13 miembros gasta $\$ 90$ por semana en comida, resultando un promedio aproximado de un peso diario per cápita.

La frecuente falta de comida o de dinero activa formas de resolución particulares y diversas que van desde estrategias volcadas hacia el interior del hogar: la pauperización de la comida, la supresión de alguna de las comidas principales, el sacrificio de la madre quien anula parcial y temporariamente su alimentación, hacer fuego con leña para ahorrar combustible, hasta otras volcadas hacia el afuera que incluyen desde el pedir fiado, dinero prestado, ir a comer a la casa de familiares, pedir alimentos a familiares o pedir restos de comida en comercios del barrio.

La pauperización de la comida se da en aquellos casos en donde siempre hay alguna reserva de alimento:

"A veces sí, algunas veces sí, nos quedamos sin plata, y le hago fideos con aceite, cualquier cosa... Y, porque compro esa mercadería grande ...no, nunca me quedo sin nada." (Ana) 
La búsqueda de trabajo, aunque sea vana, evidencia el esfuerzo de los jefes por asegurar la comida diaria:

"Y, por ahí, eh, si uno no tiene porque se queda, porque yo veo que hay también ahí, vecinos que se quedan, "Ay, no tengo un pedazo de pan, ay, no tengo...", pero porque se quedan...

No salen a...., mi marido que tiene una bicicleta, se recorre todo...todo se recorre.

¿Sabés hasta dónde se ha ido?, hasta Ringuelet en bicicleta. Para conseguir trabajo allá en el..., cómo es, donde está, a donde están las verduras, todo ahí...al mercado.

Se fue ahí una vez, a las dos de la mañana se fue para ver si conseguía una changa.

y estaba ahí, esperando." (Camila)

Los que en algún momento trabajaron temporariamente en quintas, vuelven a ellas. Si no consiguen una changa, al menos vuelven con verduras que les regalan:

"Sí a veces sí. A veces mi padrastro se pone mal y trata de salir a buscar algo en las quintas o...trata de conseguir. Sí, no a veces nosotros trabajamos en las quinta. Algunas persona nos conocen y a veces dan. Sí. Nosotros estuvimos trabajando hace mucho entonces tratan de ayudarnos a veces con tomate, zapallito." (Silvia)

La afirmación "nunca tuve problemas importantes de comida", aunque "necesidades un montón de veces", hace referencia en todo caso a la situación de los chicos. sacrificio realizado por los padres de suspender sus comidas durante varios días, se presenta con orgullo:

"Tengo ocho hijos y la verdad que nunca tuve problemas. El más chiquito tiene dos años, va a cumplir ahora. Se crían solos, se van criando entre ellos. Y problemas de comida sí, sí como todos. Tuvimos... porque yo cuando ¿viste? la changa cómo es, a veces tiene o no. Sí tuve, pero problemas importantes de comida no. Tuve necesidades un montón de veces de comida; estuvo un tiempo sin trabajo, bastante embromado. Una vez yo y Dani estuvimos sin comer casi una semana, tomábamos mate y mate, pero ellos sí que no les falte el pan a ellos. Mientras ellos comían arroz hervido, pero comían, nosotros tomábamos mate. Bueno...yo tomaba a veces mate con pan, y él siempre se sacrificó.....no, decía: guardale a los chicos. Una semana estuvimos casi sin comer. Y no, no había nada de ayuda en ese entonces." (Marta)

El pedir fiado en los negocios del barrio unido al ingenio que permite al menos paliar el hambre, evita exponer las carencias ante los vecinos:

"Saco fiado. No! Jamás fui a pedir plata prestada, mirá...porque antes de ir a pedirle a un vecino prefiero empeñarme en el almacén y no pedirle a un vecino. No por orgullosa ni por nada, ¿eh?, es que no me gusta. Ahora cuesta, pero organizándote... yo la verdad que no me puedo quejar porque con lo poco que tengo ellos comen bien y se llenan y... por lo menos hambre no pasan.

Lo que pasa que a veces decía mi marido: 'yo no sé dice, cómo hacés' dice y...y siempre te está alcanzando, y, le digo yo y a veces la comida la verdad que cocinás horrible, pero lo que pasa que cuando uno tiene poco y lo hace con amor alcanza para todos." (Juana)

En otros casos, el préstamo de dinero de los vecinos es habitual:

"Yo a veces, qué se yo uno...pido a veces cuando... tengo que salir a pedir, por ejemplo ahora...pido plata a veces ¿viste? que me preste... le pido a algún vecino viste así." (Cristina)

Otra salida consiste en recurrir momentáneamente a los comedores barriales:

"No, bueno cuando mi marido estaba sin trabajo yo iba a los comedores y entre todo ... 
aunque sea para ellos había." (Mónica)

Otras familias con amplia experiencia en el cirujeo a través del cual adquieren bienes para el equipamiento del hogar, consiguen alimentos (sobras, restos) en los almacenes del barrio, a través de sus hijos:

"Va a pedir. En almacenes...fue va al almacén, le da fiambre, pan, factura...

Sí, el que está acá conmigo; el más grande de 9 años.

Va con mi marido, mi marido lo espera en la esquina, él va con la bicicleta, y con eso tiramos...todos los días va él...

Ahora van a tener que arreglar la camioneta porque le gusta a éste le gusta... cirujear de noche, juntar papeles, diario, botella... le gusta también cirujear. No le gusta a él de día...no le gusta, de noche sí. Él... de noche... Hay muchas cosas... sábanas, cunita...

Sí, de todo encontrás. Ropa linda. En la calle tira la gente...colchones, con la camioneta ahora esa que le regalaron Le falta una bombita para el freno y nada más. Es como camioneta, todo abierto. No ahora, hoy va a empezar a cirujear. Sí, porque no tenía el freno y no podía. Sí.. y antes con un carrito iba. Un carrito atrás de la bicicleta." (Zulema)

En todos los casos interviene el adiestramiento por parte de los padres para pedir:

"No, no. Sino, en el almacén a veces viste esas galletitas que ellos no la venden... así, se la dan al nene, o pan que queda del otro día... O sachet de leche...O sino esas fetas de fiambre que quedan...Sí, se lo dan a los nenes. Sí, sí. Como la nena a veces va, yo le enseñé... ellos van." (Valeria)

El regalo de alimentos o el préstamo de dinero se da generalmente entre parientes:

"A veces sí, a veces que el hijo trae, viste, del matadero, entonces sí...que no está conmigo, está juntado tiene un nenito, trabaja en el matadero también. Y a veces le dan y él me da." (Cristina)

“En ese caso, a veces, le pide a la abuela que le preste \$ 5, después se lo devue/ve." (Valeria)

La premisa "siempre algo se consigue" abarca las actividades de caza y pesca, asegurando alimentos poco convencionales, que son consumidos -pese al sentimiento de oprobio de la informante- porque "no queda otra":

"No, no sabe...es decir que si uno quiere siempre consigue....siempre algo tiene.

Eh, a veces hemos estado, qué sé yo, una semana sin carne, pero..., él, eh, algo siempre ha traído. No carne de carnicería pero por ahí el ha traído, qué sé yo, por ahí mi suegra me manda un pedazo de nutria...... con mi cuñado me mandan un pescado o algo.

Eh, lo que pasa es que con mi cuñado van y pescan. Entonces ya...o mi suegro se va de cacería con los hijos ¿viste? Siempre, por ahí...y..., bueno, por lo menos algo comen mis hijos. Hasta los pescados que más, que una vez mis hijos tuvieron que comer, la parte esa de la vaca.

Eso tuvieron que comer un día. Y yo lloraba, te lo juro por mis hijos que yo lloraba, porque veía comer eso a mis hijos.

$Y$, eh, y después reaccioné, digo: “¿Por qué si yo me pongo así, por lo menos ellos comen esto y tienen alimento...Porque los veías ya después a ellos, cómo se peleaban por los huesitos...

Estaban contentos, disfrutaban comer eso.... y yo cuando se estaban yendo lloraba, porque yo decía: "¿Por qué mis hijos tienen que comer eso?"

Y yo después los veía a ellos cómo se peleaban por los huesitos para comerlos.

Mirá, yo la semana esta no, la anterior, estuve cuatro días sin pan, no tenía ni siquiera cincuenta centavos para comprar medio kilo de pan...nada. Tenía harina, agarré e hice, un poco de tortas fritas. Todos los días tortas fritas. Tortas fritas, en vez de pan tortas fritas, ¿viste? 
...y la comida, ¿viste?, la leche, ¿viste?, eso, y..., yo tenía, iba a guardar unos pedacitos de panes duros en una bolsita... así retazos que dejan los chicos en la mesa...

Yo iba a guardarlos en una bolsita para hacer budín de pan, porque yo quería hacerles budín de pan, bueno, se terminó el pan, y estaban desesperados porque querían pan, les digo: "Ahí hay pan duro", les digo, "el que quiera comer eso lo come", les digo. Vos sabés que en medio, en media tarde se bajaron una bolsita, casi de un kilo de, de esos pedacitos de panes...

Se bajaron todo ese pan. Les digo: "¿Vieron?, esos son los panes que ustedes dejan"...(Camila)

Puede verse la mayor parte de las veces que los arreglos comprometen la dinámica intra y extrafamiliar. La exigencia del marido hacia la cónyuge de salir a pedir, el sentimiento vergonzante que tal conducta genera y la certeza de que no es posible conseguir nada, la falta de dinero para el transporte a fin de solicitar asistencia pública, el reemplazo de comidas por infusiones o por leche para los hijos, la elaboración de tortas fritas para sustituir el pan, se conjugan en el siguiente relato:

"Sí, a veces sí, nos falta. Sí, sí, y, tengo cuatro criaturas, cuatro, fijate, y cuando los más grandes, a veces comen más y no sé qué hacer, porque imaginate, y hay veces que sobra, la quincena se hace larga, ¿te das cuenta? Y a veces no sé qué hacer.

A veces dice mi esposo: "Tenés que pedir", ¿qué voy a hacer?, ¿pedir?, no hay un pescado, no es cierto, no hay. A veces, yo pido a veces no más, no..., a veces me, me voy, ¿viste?, no a veces no me voy a ningún lado, ¿viste?, aguanto. A veces le hago, qué sé yo, hago un té, si tengo, un té solo, o le hago leche...entonces toman más leche, ¿viste?, los grandes toman leche también, ¿viste?, le hago la leche, ¿viste?, a veces quiero venir hasta acá, pero ¿sabés qué pasa?, a veces me agarra que no tengo para el pasaje...entonces no vengo.

Porque al no tener para el pasaje, a mí me... hay choferes buenos, que a veces me dicen: "Diga cuando usted no tiene", pero a mí me da vergüenza decir el estado que tengo...entonces no vengo, ¿viste? Imaginate, somos cuatro y nosotros dos, ¿cuántos vienen a ser?

Sí, es jodido la mano. A veces quieren pan, a veces no tengo.

$A$ veces quieren pan, ¿viste?, y un kilo de pan no más en una casa, te das cuenta, con seis no sé, con seis personas no, no alcanza un kilo, ¿viste? Hay que ... ¿y si no tenés?, tenés que hacerles, a veces, si tenés, con un poco de harina tenés que hacerles tortas, porque sino...tienen hambre, ¿viste?” (Cristina)

La falta de comida genera angustia y conflicto familiar. La madre sale a pedir a disgusto, el jefe busca trabajo y no consigue, regresando a veces sólo con pan regalado en una panadería el que, en otros momentos, tenía como destino la alimentación de animales para la venta o autoconsumo:

"Cuando se terminó la plata me pongo a llorar. Me pongo loca. Me la agarro con mi marido.

Sí, le digo que se vaya a buscar más trabajo a otro lado, aunque no consiga que ya...y me revienta, no puedo, parar... por ahí tengo que estar pidiendo y no me gusta.

No, él va a buscar la comida para los chanchos y en la panadería ya le dan. Le dan el pan del día, todo. Sí, se lo regalan. Y la leche la llevo de acá. Porque ella toma la de soja ahora, y llevo la leche para él, la leche común." (Norma)

\subsubsection{Estrategias alimentarias}

En el tratamiento asistencial y el seguimiento realizado a los niños en la Unidad de Rehabilitación Nutricional del Hospital de Niños de La Plata, la entrega de leche y de una bolsa de alimentos se realiza en cada control, sea quincenal o mensual. Una vez 
que los niños han salido de riesgo y se derivan para su control a la unidad sanitaria correspondiente, la leche del programa materno infantil continúa siendo entregada allí, tal como se hacía antes del ingreso de los niños al hospital.

Sin embargo, muchas salitas han sufrido restricciones en la recepción de insumos básicos y discontinuidad en la entrega de leche, por lo cual su dación no siempre se hace efectiva. La necesidad de racionalización hace que se restrinja el universo de beneficiarios.

"Sí, yo ahora, el mes pasado fui a llevar al nene a control...y me encontré con esa sorpresa, que tenía que esperar porque me tenían que dar la leche y no había." (Camila)

"Por eso es que necesito ayuda más que nunca ahora. Por lo menos la leche, porque en la salita ahora con el asunto del plan, no hay leche porque sí o sí se les da a la mamá embarazada, a todos no dan, tiene que ser un caso muy especial." (Mónica)

La dilución intrafamiliar de la leche es todo un problema cuando hay varios niños y la que se entrega corresponde a uno solo. De esta forma, la cantidad entregada resulta insuficiente:

"Pasa que yo he visto gente que no precisa tanto y le dan dos paquetes, y a él le dan un solo paquetito, y a él no le alcanza más, no come bien. Se mantienen con leche, me entendés?

Y a veces mi esposo dice decíle vos, el otro día yo le dije, viste ahí la asistente, la llamé y le dije. Porque a veces uno no come bien, los más grande también agarran una taza de leche y toman, y...dice que los otros son más grandes, que pueden aguantar. Pero no es el caso de aguantar... Una nena de diez y el otro tiene once, al no comer bien, toman leche ¿viste? Así que yo a veces, eh...acá cuando me dan un paquetito no me alcanza, por lo menos tendría que ser dos paquetes para los chicos ¿viste?.Y allá con un solo paquetito ¿qué hago? Para el nene solo. La otra vez tuvimos una discusión por eso. Entiéndame le digo, estamos, yo estoy enferma, no puedo trabajar..." (Cristina)

El comedor escolar es utilizado por muchas familias, excepto por aquellas que, debido a su reciente asentamiento en el barrio, desconocen los servicios y recursos disponibles:

"No sabría decirte si por ahí hay alguno, no sé porque hace poquito que estoy ahí, no estoy al tanto de todo, tendría que averiguar." (Norma)

En el resto de los casos, el comedor garantiza el almuerzo de los niños y contribuye a disminuir gastos imposibles de afrontar y la carga de trabajo doméstico de la madre:

"Los chicos van al comedor, los dos más grandes van a la mañana, tienen el comedor, después vienen ellos, van los otras dos nenas al comedor, después yo me quedo con ellos, comida les hago a los otros porque saco fiado, no me falta viste de comer en ese sentido.

Sí, eh, aparte es una ayuda, ¿viste?, yo por ahí como ahora estoy ocupada y no hago a tiempo, qué sé yo, y ellos están..., "mami, dale, hacé la comida", y se rajan al comedor.

Van todos, porque van todos menos la mayor, después van todos.

Claro, y yo...no cocino, porque yo cuando me quedo con la mayor a veces tomamos mate, como ella, ¿viste? tiene quince años, ¿viste?, como que no quiere engordar." (Estela)

La ayuda del comedor se destaca cuando deja de funcionar durante las vacaciones. 
"Eh, ¿cómo es?, el comedor este de la escuela, como salió, terminó las clases...¿ ¿te das cuenta?, salieron de vacaciones. Seguro que ahora, en marzo de nuevo, empiezan de nuevo, no sé. Bueh, pero faltan unos días. Es una ayuda, por lo menos para los dos chiquitos que van a la escuela...me quedarían dos, ésta, el nene y la, la otra nena grande...pero ahora, claro, hasta que no empiecen las clases... "(Cristina)

Sin embargo, dada la cantidad de hijos de estas familias, la contribución del comedor es insuficiente en la medida que no permite el almuerzo de todos:

"Sí, tienen. Dos que tengo de tarde que son los que van. Ahí comen... le dan también a veces la merienda ¿viste? Lo que pasa que son los días más que... por ejemplo a la noche y a la mañana que hay que darle, viste. Van al comedor pero me queda el bebé y la otra chica 14 años." (Cristina)

"Eh... al comedor de la escuela sí. Pero igual me quedan tres." (Mónica)

La estrategia barrial de los comedores dirigidos a todo el núcleo familiar, organizado por grupos de vecinas, contribuyen a proveer al menos una comida cuando las necesidades apremian. El reconocimiento que hay muchos otros en el barrio en la misma situación, disminuye la vergüenza de reconocer que "yo he ido al comedor, ellos han comido en el comedor":

"Bueno, mi marido estaba sin trabajo, bueno o sea está ahora y...pero bueno, está bien, yo lo que traigo del plan, o sea capaz que traigo arroz, fideos y me falta el aceite... todo lo demás, este... pero entre todo trato de hacer los fideos hervidos, está bien que no es mucho alimento no? ... pero él se la rebusca también porque él va a la verdulería y por ahí trae verduras y si no voy al comedor, yo he ido al comedor, ellos han comido en el comedor.

Donde yo he ido era todos los días y el comedor que está enfrente de mi casa ahí cocinan las mamás y se llevan a su casa, no que tienen que ir los chicos a comer ahí entonces,

Claro, cocinamos nosotras las mamás y después se lleva cada cual su olla a su casa.

Se cocina en una olla grande y después se reparte, cada cual se lleva y así buen, porque por ahí por donde yo vivo la mayoría están sin trabajo ahora." (Mónica)

Como se planteó para el caso de las familias con hijos eutróficos, la etapa de entrevistas coincide con la transición del plan Pais al Plan VIDA, razón por la cual las familias beneficiarias del primero registradas en las encuestas han dejado de recibirlo y muchas aún no son beneficiarias del segundo:

"Tenía. No... ya hace bastante que no viene" (Valeria)

Del plan Pais se rescata la posibilidad de elección de alimentos ya que el monto de \$5 asignado a cada integrante de la familia garantizaba la compra de alimentos básicos de la canasta familiar:

"Después vino el plan PAIS, que a mí me salvó un montón. Porque yo, imaginate, agarraba \$ 35 cuando me daba el plan, \$5 por persona, yo agarraba 38,50...algo así. A mí me salvaba, compraba aceite y azúcar, harina, fideos. A mí me alcanzaba, pero después se cortó eso, porque decían que la gente no sabía comprar, sí a veces pasaba eso, porque yo por ejemplo ¿la conocés a Silvia, la flaquita, ella era la jefa de nosotros? Hasta que me avivé de los que me 
correspondía y Dani me dijo no te están dando ni 20 pesos con lo que te dan, digo no puede ser, vení vamos a sacar la cuenta al precio de acá, que los compraban al mayorista, más barato y eran \$20. Fui y grité, que no, que sí me estás pagando mal, bueno vamos a hacer una cosa le digo, cuánto me corresponde: ¿\$37?, me pagás la plata y yo voy a retirar mis cosas, delante tuyo, sí.

Y compré el doble. Le digo Silvia mirá: si vos sos la jefa, mirá las cosas que yo compré con \$38 y mirá lo que vos me dabas, acá está el papel. Seguro que se quedaba con plata o con mercadería. Ella dice que no, que ella no." (Marta)

La mala administración por parte de las responsables del plan llevó, entre otras cosas, a su desparición.

El dramatismo de la desprotección por parte del Estado en materia alimentaria se pone de manifiesto en la etapa de transición, cuando ni uno ni otro están en funcionamiento:

"Por eso es que a veces decía mi esposo ¿no?, bueno, que yo tendría que tener... no te digo todos los días, ¿viste?, pero siempre alguna ayudita para poder llegar hasta la quincena, más para darle de comer a él, ¿viste? que ¿cómo es que se dice?... el desnutrido, ¿te das cuenta? Porque a él no le puede faltar la comida a él, ¿viste?, los otros grandes, bueno, pero... y a él sí, a veces le falta.

Sí, sí, claro como le falta, en casa son muchos, ya te digo que a veces eso, eh, ¿te das cuenta?, de una quincena a suponele el veinte se hace, hay momentos, ¿viste?, que cierra antes o después....y se hace largo...

Claro, lo que pasa es que a veces uno se preocupa más por él, ¿viste?, y la otra, que a veces los sábados todos los otros grandes dicen: "Y mami", dicen, "tengo hambre", y a veces a mí me parte el alma, son grandes pero son chicos, quieren comer. $Y$ si no tenés, no podés robar, porque..." (Cristina)

Cuando el Plan VIDA se pone en marcha, aparecen cuestionamientos dirigidos a la restricción de beneficiarios: sólo brinda asistencia alimentaria a embarazadas y niños de hasta seis años. Si bien la entrega es regular y los alimentos responden a lo establecido oficialmente, la dilución intrafamiliar de los huevos, la leche, el azúcar, los fideos y el arroz lo torna insuficiente.

"Ahora salió ese Plan Vida, pero ese Plan Vida es hasta los seis años, y la mayoría de los chicos que... y después en edad escolar cuando más necesitan, es donde no te dan.

Está el comedor, sí, pero, el comedor..., ¿viste?, el comedor lo tenés al mediodía, y después a la noche, ¿qué haces con los chicos en tu casa?

No, el Plan Vida por ahora viene bien, ¿viste?, yo retiro por ellos, ¿viste?, y viene bien. Me dan media docena de huevos, un kilo de azúcar por cada uno por mes, y me dan, este, las cosas para los chicos, pero igual, eso es una vez por semana te dan un paquete de fideos, un kilo de cosas es. Pero bueno, hay muchos chicos y no alcanza.

Te tenés que dar cuenta, por ahí una madre retira para uno y tiene cinco.

Te podés imaginar. No se puede, eso es algo, ¿viste?, por un lado lo veo bien, pero por otro lado no sé." (Estela)

"A mí me dan sí, una, una, cómo es, un paquete de fideos, un sachet de leche...lo mismo que todos. Y eso ayuda. Me dan por ella y por el nene nomás.

Ella no entra porque tiene seis. Sí, algo hacés. Bien o mal pero es una ayuda, algo es." (Celina)

El alimento más valorado del plan VIDA es la leche, escasa en la mayoría de los casos, sobre todo cuando se presentan irregularidades en su entrega. La leche de la salita, cuando hay, sirve para compensar y equilibrar el valorado aporte de la leche: 
"El Plan Vida me dan por los dos chiquitos, pero por el nene y la nena me dan un litro de leche y por el otro me dan medio, pero si vos ves lo que come el gordo si vos lo ves, se la toma en un rato.

A mí no me sirve, decí que me dan la leche en la salita a mí, ahí viste es una ventaja más que tengo, pero viste. No te ayuda el Gobierno, más que el Plan Vida que no sé hasta cuando, porque a veces pasan días y no te lo dan acá, viste eso es como que en cualquier momento ya lo sacan, porque no va más, ellos están buscando que en cualquier momento eso no vaya más." (Estela)

Pese a los cuestionamientos, el saberse beneficiario de programas da tranquilidad, sobre todo cuando no se tiene trabajo fijo:

"Sí, por un lado me viene bien porque cuando alguien está muy corto de dinero, eso, digamos, lo tenemos fijo, ¿viste? Es, eh, la leche bueno, ya, a la mañana ya no nos alcanza para la tarde.

A la tarde yo les hago leche en polvo. Me dan un litro y medio.

Ya en este año nos van a sacar medio litro, nos sacan. Porque tengo, claro, ya salió la nena de jardín. Ahora, todavía me están dando por tres...después me van a dar por dos." (Camila)

La dificultosa accesibilidad para las mujeres y las trabas burocráticas tornan poco frecuente la ayuda directa de la municipalidad de La Plata. En este sentido, contrasta con la accesibilidad encontrada en el grupo de familias con niños eutróficos residentes en Punta Lara, las cuales muestran familiaridad con las instancias burocráticoadministrativas del municipio de Ensenada y con los responsables de los programas de asistencia social.

"No porque no... siempre me daban para investigar, qué se yo, que preguntara, que esto, lo otro, pero ... preguntabas en la salita ibas para un lado, ibas para el otro, y de la torre te mandaban para otro lado, y nunca me dijeron: andá a la Municipalidad, a mí tampoco se me ocurrió.

Me dijo no, pero andá a averiguar del...Plan País, qué se yo, tenés que ir a averiguar en la salita, anotate en tu salita donde te atendés...y qué se yo...y siempre quedó en la nada. No, no ayuda para nada. Muy poco." (Norma)

Resueltas dichas dificultades, algunas logran alguna ayuda:

"Sí, voy de vez en cuando, porque es una ayuda bastante. Y en la torre una vuelta me dieron azúcar, leche, harina, lenteja, jabón blanco...” (Valeria)

Las redes de ayuda entre parientes y vecinos adquieren más centralidad en este grupo de familias siendo más frecuente el préstamo de dinero, alimentos y comida. Se activan principalmente en las relaciones de filiación o entre hermanos:

"Y, en la casa de mi mamá comen churrasco, milanesa...ella come casi todos los días en la casa de mi mamá. No, mi mamá vive por el estadio y yo camino despacito con los dos coches y yo llevo uno y el otro me lleva el otro coche. Sí, sí. Porque dicen: 'vamos mami a la casa de la abuela, mami vamos la casa de la abuela'." (Zulema)

"A mi papá, o a la señora de mi papá, ella me da. Sí, o a mi hermana. Mi hermana es la que siempre me dio, pobre." (Norma) 
"Alguno mirá, a veces me da ¿viste? las hijas a veces me dan un poquito de fideos o azúcar ¿viste?, así. Porque uno de mis yerno trabaja en la cocina allá viste ... de Romero, pero no gana tampoco mucho que digamos, así que..." (Cristina)

El dinero siempre se devuelve, los alimentos se regalan y en general están destinados a los niños:

"Ahora, esta semana, que ahora que cobramos, venía a pagar a mi mamá porque mi mamá me prestaba plata. Entonces cobré, el otro muchacho también me prestó plata...

El amigo de mi marido. Que me prestó para garrafa, dice que no le gusta eso de romper cajones, hacer fuego ahí adentro que se van a quemar las nenas. Yo le pido, yo no tenía y él me daba.

Y ahora le tengo que dar cien palos. Y cien de mi mamá de la otra vez porque yo no tenía para comer." (Zulema)

"Y, me ayuda mi papá ahora.. es jubilado de la policía. Y trabaja de sereno. Y a veces el yogur, todo eso les compra...o la fruta. A veces mi papá nos presta plata y después le tenemos que devolver...Y sí, a veces él saca del círculo, nos manda mercadería o nos trae...eso es un supermercado que él saca. Sí, después le descuentan en el sueldo de él." (Lola)

La situación de aquellos a los que se puede pedir es precaria por lo que las redes de intercambio se activan o desactivan en función de la evaluación o apreciación que se tiene sobre las posibilidades del potencial dador. Pero la reciprocidad, no siempre equivalente, no se pone en duda, se pide pero también se da:

"No... o sea, tengo sí, pero bueno, algunos a veces están peor que yo, así que trato de no...

Bueno, sí, por ahí está, el esposo de mi mamá, por ahí me da una mano. Mi papá también trabaja con el carro así que... mucho no pueden...yo tampoco... hay veces que no quiero tampoco.

Según; como ser, yo tengo mi vecina y mi comadre y mi comadre que vive al lado, bueno, por ahí yo no tengo, le pido, o ella no tiene y me pide, pero... hay veces que, como el marido de ella también trabaja de albañil, él sí trabaja de albañil, por ahí tiene, por ahí no tiene. Estamos todos casi en la misma situación." (Mónica)

Cuando las necesidades son múltiples y la carencia extrema, amigos y vecinos brindan bienes y servicios sin compromiso o exigencia explícita de reciprocidad en el corto o mediano plazo:

"Por ese lado me salvé, un amigo le regaló al que ahora es mi marido una casilla de madera. Ahora lo que falta es un trabajo que no hay y que a veces uno le tiene que andar robando un pedacito de pan a un vecino y no te van a decir que no si tienen, porque te ayudan. Sí, los vecinos ayudan, ¿viste? por ahí al mediodía no tengo para darle de comer y ella [una vecina] me las manda a buscar a las nenas, las lleva, les da. Uno grande se arregla con cualquier cosa que coma." (Norma)

La evaluación de la ayuda brindada por otros se usa como patrón para dar ayuda cuando es solicitada por vecinos. En realidad, lo que se valora es el ofrecimiento espontáneo de la ayuda en el momento oportuno, actitud por demás infrecuente:

"Hay vecinos que no ayudan cuando uno necesita ¿viste?, por más que tengan, dicen que no. Entonces yo los, digamos les doy a las personas que realmente necesitan.

Por ahí yo tengo, me vienen y me piden, yo le saco de lo mío y le doy a la persona que necesita. Ahora las personas que no necesitan y vienen a pedirme, no tengo. Hago lo mismo que me hacen ellos a mí. Porque yo veo que cuando yo no tengo un pedazo de pan, ellos no te 
golpean las manos para decirte: 'Tomá Carmen, para tus chicos'. Entonces no. Yo les doy a los que más necesitan." (Camila)

En algunos casos, la falta de confianza con los vecinos limita las posibilidades de ayuda. La recepción de bienes se origina en el ofrecimiento por parte de vecinos que perciben la situación de necesidad extrema que se vive y no en la demanda:

"Pero ayer una señora al lado de mi casa que tiene... le sobra comida caliente... le manda a él una olla caliente y comida." (Zulema)

"A veces los vecinos, alguno a veces me ayuda, ¿viste?, yo no digo que no pero claro, a veces a uno le pasa, a veces me da vergüenza; yo no tengo carácter para ir así, a pedir...porque no sé, me daría vergüenza. A veces, compro ¿viste? fiado." (Cristina)

Pero el fiado, como se planteó anteriormente, implica un futuro incumplimiento de devolución, y su probable exposición pública, vergüenza:

"Fiar, pero claro, lo que pasa es que a veces también como que vos decís: fiar no se puede meter, porque después, se te hace jodido, y no podés pagar... ¿viste?, o sea, no ganás, no ganás la cantidad que uno ...que hay que gastar, ¿entendés? Entonces a veces uno no prefiere que no ir...

Porque vos, si no te alcanza para pagar... Lo que pasa es que después uno tiene vergüenza de entrar a decir ...y dice: "iMirá aquella no me pagó!", la que queda mal soy yo." (Cristina)

Las organizaciones no gubernamentales tales como Cáritas, y las agrupaciones políticas, tienen poca presencia y sus recursos son limitados:

"Y tengo que andar por más que a veces tengo que pedir una ayuda porque no puedo.

A veces no pido en ningún lado, a veces me dan, ¿viste?, a veces pido. Como ser yo en un lado me dicen por ejemplo que dan un calzado o una ropita...y a veces voy a una Cáritas allá.

Sí. Pero a veces como no hay, le dan a otro viste, que necesita más. Pasa que cuatro, imaginate que son cuatro criaturas, y van dos a la escuela..." (Cristina)

Las relaciones cara a cara con los responsables de la entrega de recursos, hace que se establezcan compromisos de solidaridad respecto del resto de familias, imponiéndose la autoexclusión cuando se tiene y retirando recursos sólo si se necesita:

"En la Unidad Básica también, eh, nosotros tenemos un lema con la gente de la Unidad Básica, con los dueños, que los, la mercadería que cuando yo tengo, yo no voy a ir a retirarla, que se la den a otra persona que necesita. ¿Por qué?, porque yo tengo. No quiero agarrar más de lo que...

Claro, si yo tengo, póngale, el modular lleno de mercadería, no voy a ir...a pedir a otro lado, sabiendo que yo tengo. Es hacer avaricia. Ahora, cuando yo necesito, sí. Voy, hablo con la gente de la Unidad Básica: "mire, necesito mercadería porque no tengo", y ya ellos saben que yo realmente voy porque necesito." (Camila)

La asistencia a parroquias barriales también ayuda, aunque es poco frecuente en este grupo de familias:

"Sí, voy a una católica que está ahí a pocas cuadras de mi casa.

Y ellos me ayudan sí, cuando hay algo también, ¿viste?, van y me llevan ellos, me mandan a mi casa. Sí, ahí son muy buenos." (Camila) 


\subsubsection{Conocimientos y valoraciones alimentarias}

La alimentación considerada por las madres adecuada, buena y completa, se apoya en referencias médico-nutricionales, hecho previsible, por otra parte, por el reciente contacto con los agentes de salud pública a propósito del tratamiento de sus hijos.

La comida variada que incluye verduras diversas, lentejas, fruta, carne y leche es la que predomina en los relatos. Sin embargo, pese a las re-preguntas, las respuestas referidas a los que creen, conocen, saben y valoran terminan siempre apoyándose en la práctica alimentaria particular:

"Comer fruta así...eso tiene buena alimentación para una criatura...o un buen plato de guiso completo, con lenteja, papa, zapallo, batata...o un buen puchero, o esa sopa de verdura, no con caldito sino a veces ponerle cosas distintas." (Valeria)

"Todos... de todo, no sé, bah, para mí...yo como si yo... a los chicos les doy... les doy carne, les doy huevo, le hago así, qué se yo, que tenga de todo un poco." (Juana)

"Y una alimentación tendría que ser...suponele un estofado ¿no?

Viste que un estofado lleva tomate, bueno o... lo que pueda uno lo hace, ¿viste?. Hay algunos que le gustan con zapallo, verdura ¿viste?. Yo cuando tengo por ejemplo lo hago así...con todo sí... un flan no es cierto? Alguna fruta. Para que ellos por lo menos tengan más eh fortalecido viste, que estén... Porque si vos le das a lo mejor una cosa sola, no están fortalecido, están debiluchitos, cómo te puedo decir, están delgados." (Cristina)

La carencia de recursos pareciera restringir también el horizonte de lo ideal y de lo que se debe: la buena comida es aquella que se hace con lo que se puede:

"Para lo que a mí me alcanza... completa, qué se yo, el pan, alguna fruta y... qué se yo... según lo que haga: un guiso, unas milanesa con papa, no sé. Sí, sí. En lo que se puede.” (Mónica)

y aluden a la buena comida haciendo referencia directa a aquella que es habitual:

“...el guiso, pastel de papas, churrasco..." (Zulema)

“La carne...los fideos...pollo...hígado..el huevo.” (Ana)

Frente al rechazo de carne por parte de los niños, se destaca el trabajo que implica la introducción del hígado (excluido de la categoría "carne"), el que termina siendo aceptado en la comida habitual:

"Yo para ellos mirá, a veces he tenido que hacerles comidas dobles porque son...por ahí yo hago una comida y a ellos no les gusta, entonces yo compro hígado, ellos el hígado se lo comen, y lo comen... Y por ahí si le también les tengo que dar pollo... todas esas cosas no la comen, carne casi no comen, el hígado sí. Porque se lo escondo casi no lo ven y también algún postre." (Norma)

En pocos casos, la sensación de repleción con el guiso y su complemento con alguna fruta, constituye la buena alimentación: 
"...como estamos acostumbrado nosotros, para nosotros eso ya... comimos bien y nos llenamos bien hasta que...o que lo hemos repetido a veces guiso, queremos comer bien hasta que nos llenemos, después si queremos... a la tarde darle una fruta, le damos una fruta y eso así para nosotros es como alimentarnos bien así." (Silvia)

Los conocimientos adecuados están sujetos a la constante dinámica del dictamen médico: a menudo, las recomendaciones médicas contrarían otras indicadas anteriormente, hecho que frecuentemente desconcierta a las madres:

"Porque la doctora que atiende dice: "Hacés bien, Mónica, es verano, no es verano, dales guiso, dales todo lo que tengas..., todas legumbres dales", me dice... "porque sino...", dice, y ellos te comen la zanahoria, yo, a ellos no les gusta la zanahoria rallada, pero yo se la doy igual.

Aunque la vitamina está más en la zanahoria, eh, cocida que en la otra, ¿viste? Porque dice que no se despierta bien...Sí, me dijeron los pediatras el otro día...que está más sí, en la cocida. Sí, porque yo le, yo le contaba que yo le daba cruda, "No, madre", me dice, "Dale, sí es bueno, muy bueno, pero está más en la cocida que en la cruda" dice. Sí, se concentra más, no sé.

Sí, y yo digo bueno, ¿viste?, ahora cuando alcanza les hago puchero, se enojan, por ahí hoy estoy para hacer puchero... pero empiezan, "iUh!", y se van todos para el comedor, ¿eh? Se van al comedor, se enojan y se van al comedor. Sí, porque ellos con la calor no quieren comer eso."

(Estela)

Otras, habiendo mencionado la carne, verduras, fruta y leche, reconocen no haber podido tener nunca una buena alimentación:

"No le puedo decir porque nunca fui así de una dieta así. Siempre nos conformamos así con poco o mucho, siempre nos conformamos y nunca tuvimos una alimentación así completa, no, nunca." (Silvia)

Los alimentos considerados más nutritivos son los que aportan hierro y vitaminas: carne, leche y verduras.

"El pollo, la carne. Porque tiene mucho hierro." (Ana)

"Sí, por ejemplo... lo que le alimenta más es la leche. Y ese otro que me daban acá, que le daban para el nene, que no sé si es Nestum.

Alverjas, sí. Y porque eso me parece que tiene más vitamina me parece eso.

Porque son sanas las vitaminas. No le enferma viste, no le hace nada, le asienta en el estómago.

La verdura a cualquiera le hace bien." (Cristina)

También, aunque en una menor proporción, señalan la necesidad de incorporar calorías:

"Sí, yo pienso que la carne, el pescado, pollo, no sé...y pastas, porque tienen más calorías, no sé.” (Mónica)

Para otras madres, todos los alimentos importan:

"No hay eso. Todos alimentan." (Zulema) 
Nuevamente, pese a concebirlos equivalentes, retornan a su práctica de alimentación habitual para resaltar los que, de todas, formas, consideran más nutritivos:

"Para mí todos son iguales. Me gusta más hacerle así... carne, huevo, o así a veces... ellos que les gusta comer tomate así en la ensalada ¿viste?” (Juana)

También se especifica que la calidad de la alimentación depende de la preparación e higiene:

"Y, darle una papa frita a un puré, digamos... hay mucha diferencia. Es mejor el puré, para mí es el puré. $Y$, porque lleva leche, sal, aceite, en cambio la papa frita es frito, un poquito de sal y ya está." (Valeria)

"Y, una alimentación sería cuando está mal hecho, que no se lava por ejemplo ¿me entendés? Que alguno ¿viste? que no lo lavan, lo ponen así nomás. Eso está mal hecho la alimentación, porque al no lavar, ahí van los microbios." (Cristina)

Las comidas que hay que evitar son las que tienen alto contenido en grasa, la comida picante, las frituras, los embutidos y las golosinas:

"No, mucha grasa no...poco de eso, lo mismo los picantes." (Silvia)

"Sí, cosas que caigan al hígado. El frito a mí me cae mal al hígado." (Lola)

"Lo que no me gusta que coman es el fiambre, mucha salchicha de vez en cuando sí pero mucho no." (Juana)

“y qué se yo, comer algún sanguche, eh... algo así a la ligera, no sé.” (Mónica)

También los alimentos ricos en hidratos de carbono son considerados poco nutritivos:

"Y, el arroz solo ponele, fideos... porque no tiene alimento." (Ana)

"No sé... mucho guiso así en fideos me parece que no es tanto alimento como las otras cosas.(...)

Que no coman porquerías. Las golosinas ...no sé, cosa así ... no me gusta que coman las cosa en la calle...que compren y comen en la calle no me gusta." (Juana)

La cantidad de comida, sea por carencia o por gusto, también es criterio de ponderación de la inadecuada alimentación:

"que comiera poco y que dejaras de comer...comer poco." (Silvia)

“Una mala alimentación que no coman nada. Que no le guste nada." (Norma)

En unos casos se plantea que los alimentos que deben evitarse no forman parte de la comida habitual:

"Yo pienso que no, por lo menos los que yo conozco, que hagan mal, no comemos." (Mónica)

En otros, por el contrario, sabiendo que hay comidas perjudiciales, admiten no seguir las proscripciones ya que "lo que puede, le da": 
"Por ejemplo huevo frito eso... para ella es malo. Mhmm, no, yo nunca le suspendí nada a ellos. Yo todo lo que le podía dar le doy. No me...Nunca me fijé si esto le hace mal... yo le doy." (Valeria)

Un caso -con reiterados episodios de parasitosis en su hijo- muestra preocupación por evitar el consumo de tierra y azúcar:

"No comer tierra, que no me coman azúcar... porque de eso le vienen los parásitos..." (Zulema)

Finalmente, la rutina de horarios para la comida es otro parámetro mencionado por las mujeres al hablar de la correcta/incorrecta alimentación:

"Que se la pasen comiendo todo el día. Que desde que se levantan que pidan comida o que esto...porque yo a ellos cuando se levantan no los dejo comer porque me piden pero a cada rato cuando llega el mediodía no me comen nada." (Norma)

En general plantean que, dentro de la familia, debe alimentarse "a todos igual." Otras mujeres piensan que son aquellos que trabajan, por el mayor desgaste o los que se encuentran más débiles, quienes necesitan una alimentación preferencial.

"Será al que trabaja... sí, me parece. Y...es el que se levanta más temprano, el que tiene que estar allá con las cosa y... no te digo que no los tenés que alimentar a los demás ¿viste? pero ellos van a trabajar, tienen más más desgaste... andar con la pala y..." (Juana)

"Y, yo pienso que a los que tienen menos defensas, que están más débiles, no?" (Mónica)

En cuanto a la evaluación de una adecuada alimentación en los niños, la gordura es mencionada de manera ambivalente:

"Por lo gordo." (Ana)

"...no, no sé por qué, porque igual si una persona es gordita o el nene es gordito y tiene problemas, a veces uno flaquito tiene menos problema que un gordito. Y sí, y porque a veces está más alimentado mejor un flaquito que el gordito y sl....que le falta vitamina, o le falta calcio..." (Camila)

Por eso, el control médico es la manera indicada para determinar la correcta alimentación infantil:

"Para mí llevándolo al médico y el médico que te explique bien, que informe, no sé." (Valeria)

\subsubsection{La comida habitual}

Los alimentos más frecuentemente utilizados para preparar la comida son los fideos, las papas, el arroz, la polenta, la carne picada, la carne de puchero, el pollo y las verduras -ya sean cocidas o crudas- estas últimas usadas estacionalmente y en menor proporción que las cocidas.

"...eh..los fideos, las papas eh, zanahoria, cebolla, todo eso. Y el puré de tomate, polenta de sopa o... sopa de arroz. Y a veces le hago como unos ñoquis para que coman." (Silvia) 
"La verdura, la papa...carne...churrasco. Tomate, lechuga, morrón, cebolla, zapallito, fideos, arroz, polenta. Lo que más uso es el fideo o la arroz o la polenta." (Lola)

"En mi casa come arroz, papa, puré. La otra ahora come puré. Arroz, guiso le hago. Puchero. Si no hago un guisito con... con carne picada ella come. Y sino hago puchero con pollo, lindos pollos que me trae el nene mío... La carnicería le da menudos." (Zulema)

"No te digo, la papa, la cebolla...el ají, ajo y perejil le echo en la comida, tomate picado... Tomate y puré...según la comida que haga. Quizá a un guiso le hecho eso.

A veces lo hago con arroz, a veces les hago fideos, con tomate y puré...y carne picada... Papa, batata..." (Valeria)

“Digo...la papa.....verdura... no mucho viste...pero...suelo usar ají, cebolla, zanahoria, la carne... yo compro en el frigorífico y compro la bola entera de lomo, bueno de ahí corto, ya sea o corto para milanesa o corto para churrasco... y después... pollo, el pollo es más barato que la carne. Arroz sí, le doy arroz...así en el guiso o arroz con mayonesa...y a veces le pongo alverjas... y también la papa la hago papa, mayonesa... zanahoria, todo así viste..." (Juana)

La fruta se consume esporádicamente, la carne en pequeñas cantidades y la papa es un componente básico:

"Eh... no, fruta, bastante alejado. Eh... mucha papa...más que todo uso papa...

Y, bueno, según lo que haga, porque si usé... si hago milanesa, hago papa con mayonesa...

Si hago guiso, lo hecho bueno, papa, batata, y zanahoria y cebolla, todo eso.

Y huevos...poco, sí. Carne sí para puchero o... para carnaza común...eh...

Fideos... bueno, arroz también...pero poco. Y, polenta hago poco porque nadie la come. Lentejas sí, cuando hago guiso, todo eso, le echo..." (Mónica)

El guiso y el puchero permiten cocinar una sola vez ya que pueden ser recalentados:

"Y...qué sé yo, guiso...puchero... sí. Cuando tengo poca plata hago para que quede para la noche." (Mónica)

Muchas madres consideran que todos los alimentos que utilizan son nutritivos. Sólo dos casos responden que no tienen idea, que no saben qué alimento es más nutritivo.

En el resto de los casos consideran más nutritivos al huevo, la leche, la carne, las lentejas y el hígado considerado en el discurso siempre como una categoría diferente a la carne.

"Ponele, el hígado, también la carne...también las lentejas...

Porotos, que ellos le gustan también esa... legumbres le gusta.

Así que yo siempre le doy y para mí, bah, es bueno para ella. También este... la leche no le doy porque no la toman, no... leche no la toman...tendría que ser pero no la toman, no le gusta. Eh...los yogures ¿ve? Sí, le gustan los postres... la fruta. Lo que yo más le doy a ello es el kiwi... a él le encanta y ella también. En la verdulería que yo compro cuando voy a la casa de mi hermana yo le digo que... lo venden 6 por un peso. Sí, sí. Igual que las mandarinas...mandarinas también comen mucho...ponéle el huevo también es muy nutritivo... la polenta." (Norma)

El valor nutritivo de los alimentos se conoce en muchos casos, por su difusión mediática. Su autoridad para modelar actitudes es, para el caso de la alimentación infantil, de gran peso: 
"Debe ser porque ya, qué se yo, que todos me dicen lo mismo, que es nutritivo, que esto que lo otro además, qué se yo... lo escuchás en la televisión. Yo por lo menos en el doctor Socolinski. Y...viste entonces trato cuando puedo por ahí hay una cosa que es cara ¿viste? y cuando puedo comprársela se la compro. Ponele... qué sé yo, el Nestum, yo no lo... me lo daban acá. Pero antes de que me lo dieran acá yo lo tenía que comprar.

Antes de que yo lo trajera al chico. Socolinski decía que el Nestum era bueno.

Yo se lo hacía a ella con leche no la tomaba, porque yo pensé no se hacía... no servía para hacerlo con sopa, y un día se me ocurrió por ahí y lo escuché y me dijo mi cuñada, que había dicho que sí, que se podía hacer con sopa que.. con todo eso que..." (Norma)

El aporte nutritivo de las verduras es destacado por todas las mujeres. Sin embargo, a veces es interpretado de manera ambivalente, sobre todo cuando los médicos insisten en la importancia de la alimentación farinácea del niño:

"la fruta comen... Mucha verdura. Todo lo que sea verdura, a él le dan allá. Y después: zapallo, papa, la zanahoria le gusta, así... Sí, es sano pero la doctora dice que no.

Que tiene que comer fideos también; sí -le digo-, comen, pero ellos son los enloquecidos de eso."

(Norma)

Así, los fideos y la polenta son valorados por algunas mujeres a propósito de recomendaciones médicas:

"Polenta...sí, porque a mí el médico que me atiende ahora me dijo que tengo que comer mucha carne y polenta con queso, o un puchero, así... porque yo estuve internada hace poco y..." (Lola)

En general, los que se nombran como menos nutritivos son los fideos, la papa, el arroz:

"el arroz y el fideo...yo creo que con el aceite no es alimento...alimenta con guiso, carne..." (Ana)

"Yo no sé, no, pero para mí...lo que menos me gusta usar es el arroz." (Juana)

"Menos nutritivos...para mí son los fideos...por ahí la papa que es muy pesada ¿viste' y no llena... por ahi te llena un ratito y..." (Norma)

"no, no...bueno no, yo creo que entre todos.. anda...

puede ser la papa, la cebolla, y... bueno, la zanahoria no sé.” (Mónica)

La mayoría de las entrevistadas admite cocinar una vez al día, siendo el almuerzo la comida más importante. La cena consiste en lo que queda del almuerzo; de lo contrario, se prepara algo liviano o se toma alguna infusión.

La asistencia al comedor escolar de alguno de los integrantes no implica que sea la cena la comida más importante. A menudo, la presencia en el hogar de varios miembros durante la hora del almuerzo hace que se deba cocinar al mediodía y que esa comida se guarde para la noche: 
"Al mediodía, sí. Y mi mamá deja para la noche y comemos lo mismo...ella sola come dos veces [la hija], los otros chicos comen también una sola vez. Hacemos una sola comida, pero porque comen en el colegio. Los grandes comemos una sola vez, solamente." (Ana)

A veces, la comida es entregada al niño en el comedor de la escuela para todo su núcleo familiar:

"Una vez sola, al mediodía y si sobra comida ya a la noche...

El sábado y el domingo sí tengo que hacer dos veces, porque sábado y domingo no tienen escuela ellos. De ahí él [hijo de 9 años] también me trae comida de la escuela, si sobra comida sí. Lleva esos taper de helado vacíos, con tapa y me trae. El otro día me trajo tres tartas, tres pizzas." (Zulema)

En otros, la preparación del almuerzo como comida única obedece exclusivamente a la falta de recursos:

"Como ahora, ahora yo le estoy dando al mediodía comer a ellos y si sobra algo del mediodía comen a la noche.Y, hace dos semanas ya que estamos así. Así que vuelve hace ya dos semanas que no encuentra nada, y lo poquito que tengo estoy acá. Vengo, voy, voy y vengo... hace un ratito me encontré a mi cuñado... le compró las galletitas esas, porque lloraba que quería comer. Digo: 'mirá si no lo encontraba', lo tenía que aguantar llorando. Sí, porque él cada vez que viene quiere comprarse algo, siempre, yo siempre traigo algo de más, pero ahora como estamos así, no conseguí nada... no se puede." (Norma)

A fin de racionalizar la falta de recursos y justificar la presencia de una sola comida, se recurre a criterios de desgaste energético desigual durante el día:

"Para mí es al mediodía; sí, cocino una... Porque se la pasan durmiendo toda la noche, toda la madrugada y...o sea están jugando todo el día y...entonces bueno el alimento del mediodía para mí ya es más...es como que le da más... más fuerza, no sé. Sí, a la noche por ahí a la tardecita toman el té, y a la noche por ahí si les agarra hambre le hago cualquier cosa. Lo que encuentro les hago...

Sí, un té con pan...a ellos les gusta el té." (Norma)

En algunos casos, la comida más importante varía, habiendo un equilibrio entre la cena o el almuerzo según la evaluación de lo que se haya comido en alguna de ellas:

"y... bueno, por ahí cocino nada más que al mediodía, y si me queda para la noche les doy a la noche, les caliento. Pero si al mediodía no comen, si comen mal, qué se yo sanguche una cosa así... bueno, a la noche les cocino, trato de cocinarle algo... eh... no sé, una buena sopa, o un buen guisito, una cosa así.

$Y$, bueno, si tengo para la noche les compro alguna cosa y les doy, ahora si no tengo les hago una taza de té y... (...) No, ninguna es más importante, depende.” (Mónica)

En otros, se cocina sólo para la cena. Lo que resta se consume en el almuerzo del día siguiente. Esta relación se invierte los fines de semana en donde se cocina para el almuerzo; si sobra se come el mismo plato a la noche; de lo contrario, la leche o las infusiones reemplazan la cena: 
"Cocino te digo una sola vez al día, no cocino dos veces al día como en todas las casas, porque si no...cocino una sola vez al día, por ej. a la noche, hago un guiso, por ahí me queda para el otro día y hago así, no estamos super-bien, pero al mediodía toman la leche o algo por el estilo.

No, y sino cuando llega el sábado les hago algo de comer y a la noche si queda algo bueno, comen eso, de lo contrario les hago café con leche, té o chocolate para los chicos, mayormente cocino una sola vez." (Marta)

Son minoritarias las situaciones en las que se cocina para el almuerzo y la cena:

"al mediodía y a la noche. Si no cocino dos veces al otro día están enfermos...porque se levantan todos descompuesto del estómago... y no, las dos son iguales." (Juana)

predominando una sobre la otra, sea la cena:

"A la noche y al mediodía.. para los nenes comer a las siete de la tarde, ya a las ocho, ocho y media ya ellos se quieren dormir. Sí porque los mediodías comen así y no...En cambio, a eso de las siete-ocho, que yo les hago comida, comen tranquilos, miran la tele tranquilos..." (Valeria)

"A veces al mediodía, me entendés? Después a la noche de vuelta, porque viste hay que darle a los chicos de vuelta... a los chicos cuando...a la noche, me entendés?

Sí, sí, sí, dos veces hago, me parece que la de la noche es más...porque este ... están más tranquilos para comer ¿viste?. Ya no están... estamos toda la familia, en cambio al mediodía siempre falta alguno, ¿viste?" [dos de los cuatro hijos asisten al comedor] (Cristina)

o el almuerzo:

"No, a veces para los chicos la del mediodía porque comen más y porque a veces soy de preparar un guiso o una ensalada así con varias cosas y comen doble...y a la noche casi a veces se llenan demasiado y no pueden dormir porque ya están que les duele el estómago...les duele mucho el estómago y no son de comer...comen menos de noche." (Silvia)

Si bien el doble turno para cocinar depende de lo que sobre, la monotonía de la comida diaria puede inferirse de la siguiente cita, en donde se cocine una o dos veces, la comida no varía:

"Al mediodía. Sí, y a la noche cocino a veces sí y a veces no. A veces queda y lo comemos a la noche, a veces cocino de vuelta. Las dos igual porque en las dos comemos lo mismo..." (Lola)

Las comidas más frecuentemente preparadas, algunas de las cuales se mencionan cuando se hace referencia a los alimentos son los guisos, pucheros, fideos, polenta, arroz y milanesas:

"Como el puchero...o...claro, nosotros a veces comemos polenta, así, con queso, o puré de papas con un bife. Y a veces hago milanesa, churrasco, o bife...no, no, ahora cocino así sopa con... o puchero, a veces cambiamos de comida todos los días y ahora es el puchero, porque como hace frío, así que..., o fideos al pesto." (Lola)

"Hago polenta con tuco y mi mamá por ahí hace guiso de fideos." (Ana)

"Guiso o milanesas o bifes, tengo la plancha, churrasco ¿no? a la plancha y..." (Juana)

En algunos casos se denota esfuerzo por combinar aportes nutricionales variados

preparando comidas de modo tal que logren aceptación por parte de los niños: 
"Durante la semana hago...dos veces hago guiso...una de fideos y una de arroz, le pongo unas lentejas... también les hago... algún puchero...estofado...eh... ¿qué más?... con papa y zapallo. Que yo le pongo carne, le pongo la papa y le pongo un poco de zapallo. Guisos y pucheros es lo que a ellos les gusta mucho...

Eh... la carne, pescado no porque no lo comen, le compro ¿viste la latita de sardinas?

se la mezclo en el puré yo. Porque no sé, la caballa no le gusta. Y es pescado, claro, para darles algo de pescado. Sí. Porque yo le iba a comprar...una vuelta que pasó el pescadero le compré un poquito y no comieron. $Y$ es que es bueno para la sangre eh, tiene hierro.

Y la polenta también comemos. Pero polenta sola porque con tuco no les gusta. Ellos comen polenta sola. Mmmm...también le doy huevo, cuando le hago la polenta le... piso huevo, así que le doy eso." (Norma)

"Polenta con leche que hacen... a veces a ellos también le es nutritivo...albóndigas con carne picada, el hígado, no sé si vos conocés, que le dicen a la marinera?

$Y$ eso es buen alimento, que hay a veces pero como no le puedo hacer a la marinera le hago, viste, no sé así...con cebolla?

Y, le cambio, un día le hago arroz, por ejemplo, otro día le hago polenta, otra vez le hago suponé ese que yo te dije viste, la lenteja a veces, así...viste, le cambio, no le doy... le doy viste así...guiso también. Puchero le gusta mucho eh...con unos pedacito de carne...y albóndigas hago así, por ejemplo viste un fin de semana viste? Así un sábado...les hago. Le compro viste la picada y le hago." (Cristina)

La posibilidad de utilizar determinados utensilios, aunque sea temporariamente, facilita la preparación de comidas variadas:

"Guiso, a veces le hago unas papas fritas o una tortilla. Les hago bombas de papa, o pastel de papa...porque como mi cuñada tiene la olla esa "Asi", no sé cómo le dicen, así que... dos por tres así me la presta. Entonces yo aprovecho, hago un pastel, una pizza, una tarta..y carne... anoche le hice una marinera con un puré. Los chicos no son delicados. Comen cualquier cosa. Comen cualquier... si le das polenta te lo comen..." (Valeria)

Asimismo, se pone en evidencia la descalificación de la polenta como comida.

La falta de exigencia por parte de los hijos se ejemplifica con su consumo en tanto representa comer "cualquier cosa".

Sencilla, barata y rendidora son las cualidades de la comida habitual:

"Nosotros buscamos lo más sencillito. Por ejemplo comer un guiso un día, o un pastel de papa que no nos sale muy caro, o una milanesa día por medio o dos veces...todas cosas sencillitas, nosotros nos arreglamos." (Valeria)

A menudo debe activarse el ingenio para recuperar comidas malogradas:

"Eh...a veces cuando a mi hermana le sale la... no sopa, sino el arroz seco, traemos harina, huevo y hacemos como unos bocaditos fritos. A veces cuando queda polenta sola, leche con polenta nomás. Para que tomen así los chicos." (Silvia)

En el reconocimiento de "haber comido bien" pesa la presencia de carne. Su mención, sea de vaca o de pollo, como comida habitual aparece -en muy pocos casos-, restringida a períodos de mejor situación familiar:

"Eh, y al respecto de los chicos, de la comida, comen su churrasco, esta semana han podido comer bien, ¿viste?, su churrasco, pollo, pollito así, eh, asadito, con papas, con ensalada de papas con lechuga, tomate, le pongo yo, zanahoria rallada, les hago una mezcla que ellos se la 
devoran. Por ahí les hago, eh, hiervo un poco de arroz, lo dejo que se enfríe, y después le echo tomate cortadito. Para que tengan más fuerza. Y eso se lo devoran. Con un churrasco, un pedazo de pollo asado, así, se comen todo." (Camila)

Un elemento que entra en juego en la incorporación de comidas y adquisición de gustos es la imitación de la conducta de los pares, en este caso, de los hermanos:

"Emanuel que no era de comer lechuga, ahora vive comiendo lechuga.

No sé por qué, los ve a los hermanos... ¿viste?, que porque los hermanos terminan de comer, eh lechuga, la ensalada de lechuga y piden más.

$Y$ él ve que los hermanos piden, y él se come, quiere que le sirvan y él mismo hace que se sirve, tira en la mesa, es el desordenado total." (Camila)

El comedor también cumple una función innovadora en lo que hace a la adquisición de gustos por comidas que luego son incorporadas en la familia:

"Que más... arroz, polenta; arveja. Fideos, polenta, esos porotitos... yo le digo porotitos, que es muy rico también eh... lenteja... sí, que son muy ricos, vos sabés que con el arroz es rico eso. Los chicos un día: "mamá, qué es esto?", porque dice que un día le dieron allá en el comedor. Que nunca sabian comer, me entendés? Y después dicen que se lamían las manos. Sí, son riquísimas. Sí, hay gente capaz que no le... pero dicen que es lo mejor que hay, que tiene vitamina. Y les gusta, vos sabés que no sabían qué ... no sabían comer porque no sabían qué era.

También les hago torrejas yo." (Cristina)

Los alimentos que faltan en la comida habitual son, según las mujeres entrevistadas, el pescado, los lácteos, las frutas y la carne de vaca o pollo, no por gusto sino por inaccesibilidad de distinto tipo. Problemas debidos al rechazo hacen que las verduras sean también alimentos escasos o ausentes. Sólo una mujer plantea que en la comida familiar, no falta incorporar ningún alimento importante. En el resto, limitaciones económicas están siempre presentes:

"No sé... lo que...lo que poco comemos es pescado. Pero no es porque no les guste, es porque... por ahí cerca el pescado no venden. Tienen que traerme del centro.

Sino... antes sabían vender, yo compraba pescado...ahora como no venden no, no compré más. Pienso que...porque como siempre recetan pescado, entonces digo que debe ser bueno." (Juana)

"ni la carne, ni la fruta ni el huevo. Eso no comen muy seguido." (Silvia)

"Nunca nos pudimos dar... sí, llegar un sábado, un domingo tomar... comer un asado, gaseosa fruta. No podemos, porque a veces o compra el asado, o nos compra la fruta o la gaseosa." (Silvia)

"Y fruta y verdura ellos no comen, nada. Nada más compramos cuando tenemos, y si no, no.

Sí. A todo el mundo, está mal... está muy difícil... muy difícil para vivir...así que...eh... ahora, ellos tienen que estar bien alimentados tendría que agregarle por ejemplo alguna fruta o un flan ¿viste? sea una frutita cada tanto, un flan, una gelatina que les gusta a ellos.

$Y$ a veces les falta el pan también, porque al no tener plata, no se puede comprar. Entonces yo, como no tengo ese, y tengo viste ahí una harina, le hago torta frita." (Cristina) 
A esos alimentos y comidas de los que se ven privados, pueden acceder eventualmente en encuentros familiares:

"Sí, a veces se necesitan mucho los lácteos porque no...a veces no los puedo comprar...casi nunca comen lácteos ellos. Muy pocas veces comen yogur...van a la casa de mi hermana que ella les compra siempre a los chicos por ahi..." (Norma)

"No, para nosotros el lujo es comer asado. Asado o pollo. Y no, no... hasta ahora nunca lo hicimos nosotros, no, no. Eso si nos invita a comer un familiar, o una fiesta, un cumpleaños..." (Valeria)

Las verduras y las legumbres, si bien se incorporan en las comidas, a menudo no se consumen porque son rechazadas:

"Ah, bueno, yo como ser, cuando hago puchero eso sí, le hecho todas clase de verdura, y bueno, no la comen, pero bueno el gusto queda, no?" (Mónica)

"Lo que no les gusta es la sopa y...la verdura. Acelga, únicamente cuando hago eh...las cositas de acelga, sino hervida no. Y zapallo no les gusta.

Ah, y después otra cosa que no les gusta es... lo que no les gusta es la alverja y la lenteja tampoco.

Sí...Le digo, el que quiere comer que coma y el que no que lo deje, pero ellos se comen todo lo demás y la lenteja me la dejan al costado del plato." (Juana)

En el desayuno y merienda familiar, la presencia de leche no es cotidiana, la mayoría de las veces aparece cortando infusiones. El consumo regular de leche es asegurado en aquellos que asisten a la escuela. Por lo general, cuando se puede, el vaso de leche se prepara con chocolate en polvo. El pan es el otro alimento que integra estas comidas, algunas veces acompañado de dulces. El consumo de galletitas es poco frecuente y el de manteca no se menciona.

"Y, bueno como ser... o té con pan...o...Zucao con leche, y buen, con pan también.

Y a la tarde no, ellos toman en la escuela, creo que le dan leche con pan..." (Mónica)

"Los chicos toman la leche. Sí, a veces le hago mate cocido o té. A la tarde igual. Sí. A la tarde comen pan." (Ana)

"Toman el té. Sí, té o té con leche así toman, a la tarde igual." (Silvia)

"El desayuno toman leche con Vascolet, leche con mate cocido, mate cocido sólo, con pan o con galletitas..." (Valeria)

El acompañamiento con dulces es excepcional:

"no, no, no, yo le hago por ejemplo...si tengo té, viste? Le hago té con leche.

A la tarde también le hago mate con leche también.

Sí, sí, a ellos les doy así un tesito con leche y un pedazo de pan, lo que tenga ya... ya pasan la tarde. Si tengo pan le doy con pan y a veces, cuando tengo le compro viste, mermelada viste, o dulce de leche, viste, para... para viste...y ellos le gustan, pero nosotros le hacemos entender que cuando tenemos le compramos, y sino no hay..." (Cristina)

La necesidad de racionalizar la leche hace que, de acuerdo a la edad del niño, varíe la cantidad que le es ofrecida: 
"Sí, mate tomamos. Mate con tostada, o...los chicos... ellos toman la leche.

Sí, a ellos le doy la leche con pan o... al otro le doy un té o...leche con té..." (Lola)

“...algunos toman té porque no les gusta la leche. Como ser Juanjo, Julio y esos toman leche con Nestum, las demás toman té.

Sí, comen pan con dulce...siempre el pan, si no comen pan parece que no pueden vivir.

Y la merienda igual." (Juana)

En algún caso las agrupaciones políticas de base proveen leche y factura a la hora de la merienda. Cuando durante el verano se interrumpe la asistencia, la leche se reemplaza por jugo:

"Sí, a la tarde sí, ya ahora la leche no la toma más en mi casa. Cae un muchacho, reparte la leche, la factura, todo... Vive a la vuelta de mi casa.

Va... viene de la escuela, ya llega a la casa y los llevo yo a las dos nenas y...no, no, una casa de... un hombre... peronista él...

Ahora cuando es verano y se corta, no da más, les doy acá yo. Jugo de...de la damajuana, no de plástico. El agua la hiervo yo." (Zulema)

El predominio del "gusto de necesidad" de la mayoría que se desliza en los relatos:

"No hasta ahora, cada alimento que traen comen... mhm...no sé, nunca compro cosas caras ni... siempre soy de traer conseguir cosas más baratas." (Silvia)

no anula la presencia del "gusto de libertad":

“Mi mamá siempre le gustó los ravioles y nunca pudo comprarse..." (Silvia)

"Ah, bueno, la milanesa el churrasco, las papas fritas... a los chicos y bueno, a mi marido también. A él le gusta mucho la carne, y papa frita si es por él todos los días." (Mónica)

La imposibilidad económica de consumir las comidas preferidas o deseadas, hace que -en el horizonte de expectativas- la madre anule su consumo en pos de los hijos. Con base en un criterio de realidad, la veda se extiende a los hijos. La progresión del relato muestra el descenso de las aspiraciones: lo que queda es la polenta "a veces con un tuco":

"Que a veces tenés que.. cómo te podría explicar? Cómo te podría poner? Que tenés que sostenerte de que... a veces yo quiero comer de lo que veo a otra persona, y de lo que puedo... quiero comer...Y qué voy a hacer, no se puede.

Qué se yo, por ahí que veo una milanesa, viste, un puré, y a veces ¿viste? prefiero comprarle a ellos, que coman ellos y me privo yo porque a mí me dan lástima que ellos quieren comer una de vez en cuando...o por ejemplo un estofado, que a veces ¿viste? quieren comer

Hay que tener la papa y eso ¿viste? A veces, cuando tengo, les hago. Pero claro, o le hago una polenta, a veces con un tuco ¿viste? para que ellos coman, me entendés?" (Cristina)

A propósito de la lógica de diferenciación que se juega en el campo alimentario, la generación de necesidades a través de una momentánea satisfacción, se vuelve en contra, no es conveniente alentar aspiraciones de aquello que nunca se va a poseer: 
"Da lo mismo, no son delicados como otros chicos. Lo real, porque si uno no...si vos lo acostumbrás, uno come otra cosa después a dónde va?" (Cristina)

El alimento, no siempre explicitado, que consumen en exceso, es el pan:

"Sí, mucho pan, capaz que dos kilos en una día te comen. Ellos, capaz que vos le das y van por ahí andan con un pan. Comen, pero no desperdician, eh? Lo comen todo." (Cristina)

En cuanto a la alimentación preferencial destinada a algún miembro de la familia en particular, puede decirse que las entrevistadas responden atendiendo al tipo de comida ofrecida. En ese sentido se ofrece "a todos por igual", "todos lo mismo", "hago comida para ... todos iguales, comen todos iguales, todo."

A menudo esa falta de diferenciación es sumamente precoz, pudiendo afectar la salud infantil:

"Todos comen lo mismo, no, todos comemos lo mismo. No, yo le doy todos igual. No, yo el nene tenía tres meses y ya le daba guiso. Ah, si le hacía mal no sé." (Valeria)

Aunque la comida sea la misma, algunos necesitan más; por lo cual el foco de preocupación son los niños pequeños, sobre todo los desnutridos:

"No...para todos igual. Todos por parejo van...No, comen igual... pero los chiquitos son... porque ellos están en su desarrollo de crecer, alimentarse más bien y..." (Silvia)

"A los más chicos. Yo siempre le doy más a los chicos que...que crezcan bien." (Lola)

sobre todo si están desnutridos:

"Ahora ella, porque ella es la que está así...ella que necesita más..." (Norma)

"Sí, al chiquito. Porque eh.. yo veo que si él al no comer bien, se viene abajo, se desnutre ¿viste?. Ya no tiene fuerza ¿me entendés? como que se cae ¿viste?, porque él al no comer bien se hace, se baja viste de peso, ¿me entendés? En cambio si come bien, bien, bien, como tiene que ser, anda bien él. O sea él al no comer bien ya... se siente parece como flojo, viste...?" (Cristina)

Alimentos que proporcionan nutrientes especiales como el hierro son ofrecidos en el hogar diferencialmente:

"Y, a los chicos. $Y$, porque son chiquitos, ellos tienen... necesitan hierro, comer carne todos los días...ellos comen carne porque tienen que comer mucho hierro." (Ana)

La evaluación de la alimentación familiar es buena "dentro de todo", ya que "con poco o mucho uno se arregla".

A veces el criterio de tal evaluación responde a la calidad de los alimentos consumidos destacándose en ese sentido las verduras:

"Yo pienso que sí...comemos las cosas que tienen verdura, así... comemos bien." (Valeria) 
En otros casos se basa en la sensación de repleción que la comida procura:

"Nosotros eh para nosotros sí. Porque a veces se llenan y comen hasta llenarse bien." (Silvia)

No obstante tal evaluación, señalan la carencia de algunos alimentos importantes como la carne:

"Sí, dentro de todo sí. Con poco o mucho se arregla uno. Faltaría sí, todo lo que sea lácteo, o carne... esas cosas siempre, porque a veces si no tengo carne y tengo la verdura, tengo que hacer la comida sin carne." (Norma)

En un solo caso la evaluación positiva se asienta sobre el frecuente consumo de carne:

“... es buena. Y, porque todos los días comen carne...o pollo." (Ana)

Algunas mujeres mencionan el consumo de dulce y manteca para ilustrar el elevado nivel de satisfacción respecto de la propia alimentación:

"Pienso que sí Por todo lo que...pienso que por todo lo que uno utiliza.

Además comen dulce, comen manteca, ..." (Juana)

Otras, rodeo mediante, apelan al pasado para afirmar que en su familia se come bien, pese a tener que privarse de alguna comida en los últimos tiempos:

"Sí, pienso que bien. Y no, entre todo, mal o bien, siempre de algún lado sale y bueno...es raro las veces que... que nos tenemos que acostar sin comer...aunque sea...

Ahora, últimamente sí, a veces nos pasa pero... ante no, antes era..." (Mónica)

Las mujeres cuya situación familiar es francamente adversa, dicen comer "lo suficiente".

Sin embargo, la suficiencia se mide dentro de "lo que se tiene", y lo que se tiene se da en el marco de las cada vez más restringidas posibilidades:

"Y mi marido... imaginate, mi marido no trabaja, está enfermo; yo estoy enferma también. Si yo pudiera trabajar... pero no se puede, que yo con el problema que tengo ¿viste?... y él que está enfermo. Siempre estuvo mal digamos pero antes por lo menos... .

Entonces comen lo que ellos...lo suficiente. Pero no se puede...digo qué va a hacer, comerán lo que tenés, porque no podemos...

No, es que está jodido...Allá en Abasto te digo está terrible... por todos lados, aparte yo tengo cuatro todavía conmigo y ahora mi marido que está enfermo, imaginate qué se hace..." (Cristina)

Respecto al reconocimiento de una adecuada alimentación en sus hijos, la mayoría lo describe en términos de fuerza, ánimo, semblanza, apetito, gordura, crecimiento, salud.

Algunas mujeres recurren a respuestas abstractas o incluyen la referencia a la etapa de recuperación de su hijo desnutrido: 
"Nosotros nos damos cuenta cuando está, viste como estás... como que viste cuando una cosa... cómo le puedo decir, ¿viste cuando una?...como una planta cuando prende ¿me entendés? Bueno, ahí nosotros nos damos cuenta cuando el chico está bien, como tiene fuerza, que se levanta con ánimo ¿me entendés?” (Cristina)

“Y, cuando empieza a comer más, o sino está más gordo..." (Lola)

"no sé, cuando tiene su ... para ir a jugar, tiene voluntad de andar, tiene no es un chico que está caído." (Juana)

Otras hacen hincapié en ambas situaciones experimentadas por su hijo relacionando la mala alimentación con bajo peso y decaimiento y la etapa de buena alimentación con el aumento de peso:

"Porque yo le veo gordo. Pasa que cuando está bien alimentado es más gordito y cuando no se alimenta bien se enflaquece de golpe, y baja de peso enseguida. Entonces ahí miro a veces cuando no come bien, se viene...baja de peso, y se viene caído y se va a la cama y no tiene ganas de jugar con nadie. Pero cuando está bien alimentado sí." (Silvia)

El apoyo en hijos no desnutridos y en su buen estado de salud sirve para hablar de la adecuada alimentación familiar. A lo sumo, la desnutrición de otros hijos ocurre por parasitosis:

"Porque ella come bien. Nunca está enferma. Ella nunca nos estuvo enferma...

Ella sí, la otra nena que estuvo tres veces internada sí, tuvo con parásitos, no me quería comer, tuvo bajo peso, se me dormía. Me comía tierra, se me acostaba durmiendo...

Sí, tierra y azúcar. Ahora escondo todo yo. Y ahora me empezó a comer el otro, el de tres años." (Zulema)

La inadecuada alimentación infantil se presenta en los casos que reconocen una deficiente alimentación familiar. La madre parece percibir de inmediato su traducción en la salud y ánimo de su hijo:

"Que yo a veces me doy cuenta que no come bien y no están como deben, me entendés? Por ejemplo el nene, tengo que llevarlo cuando tengo, y cuando me ... ande mejor... porque se siente como cansado, le duele la cabeza...Yo a veces, por eso yo a veces, cuando no comemos..." (Cristina)

Es a través de la consulta médica que se puede evaluar la adecuada alimentación infantil con mayor grado de certeza ya que la gordura no equivale a buena alimentación:

"Y bueno, porque lo veo bien, bastante rellenito, pero porque a veces eso no significa nada, porque yo en el embarazo de él estaba anémica y era un...regorda estaba. Y bueno, él está precisando ahora un control y bueno, la nena de siete, porque los otros..." (Mónica) 


\subsection{Síntesis comparativa de las representaciones y prácticas alimentarias en las familias estudiadas.}

Del análisis de la información surgida de las entrevistas semiestructuradas realizadas a madres de niños desnutridos (GD) y a madres de niños eutróficos (GE), se desprenden las siguientes consideraciones generales.

\section{En lo que hace a la organización familiar del consumo alimentario, se aprecia:}

- la intervención exclusiva de la cónyuge en la realización de las compras se realiza en la mitad de las familias de ambos grupos. En segundo lugar, la mujer/madre participa de esa tarea con la colaboración de otros miembros -hijos o esposos-, siendo minoritarias las situaciones en las que otros miembros de la familia la asumen de manera privativa. En GD la participación de otros miembros en la realización de las compras se debe a las posibilidades del jefe de conseguir mejores precios fuera del barrio, a problemas de salud de las mujeres que inhiben su desempeño en las tareas domésticas de manera regular, al hecho de vivir alejados de los comercios y disponer además de hijos en edad de ayudar en las tareas del hogar. Esta última constituye la explicación de la participación de otros miembros en GE, a la que se agrega la intervención regular de los maridos en las compras en el supermercado, razón ausente en GD.

- Los comercios del barrio como exclusiva fuente de abastecimiento de alimentos presentan mayor peso en GD (casi todas las entrevistadas) que en GE, apareciendo en este último grupo el supermercado como un lugar utilizado con frecuencia por la mayoría de las familias e interviniendo de manera decisiva en la posibilidad de esta opción, la formalidad en el trabajo del jefe de familia.

En GD el supermercado es utilizado escasamente, dependiendo de la disponibilidad temporaria de trabajo y/o de dinero. Frente a situaciones de desocupación o subocupación, el trabajo se vuelca en una constante búsqueda de precios y para esto, la disponibilidad de bicicleta juega un papel central.

- Los alimentos que adquieren diariamente son el pan, verdura y carne en ambos grupos, siendo adquiridos diariamente sólo por GD fideos, arroz y azúcar, mientras que en GE la compra de leche es mayoritaria y con un peso considerablemente mayor al encontrado en GD, sobre todo si se tiene en cuenta que este último grupo reconoce comprar en el día la mayor parte de los alimentos.

La compra semanal de alimentos consiste en carne, fruta y verdura, azúcar, yerba y fideos en ambos grupos. No obstante es más frecuente y variada la compra semanal en GD que en GE, habiendo 5 casos de este último grupo que refiere no comprar ningún alimento semanalmente. 
Es en la compra mensual donde aparecen las mayores diferencias: mientras que las tres cuartas partes de las mujeres de GD no comprar nada con esa periodicidad -sólo 3 casos realizan una compra mensual general-, en GE esto se presenta -como fue planteado anteriormente- en la mayoría de los casos mediante la compra de alimentos no perecederos en el supermercado.

- La forma de pago al contado es la más utilizada en ambos grupos. Sin embargo, en GE las formas de pago mixtas (contado/libreta) son más frecuentes. Sólo dos casos de GD refieren comprar con libreta el pan, el resto refiere pagar todo al contado. No obstante constituir una "salida" ante la falta de dinero, todas consideran desfavorable el pago con libreta o el fiado en tanto la deuda no siempre es posible de pagar en tiempo y forma y cuando se hace, impide la disponibilidad de dinero para otros gastos; de allí la decisión de que restringir o suprimir la alimentación cuando no se tiene.

- Un dato que debe destacarse, se desprende de la estimación del gasto diario per cápita en alimentos: mientras que en GE arroja un promedio de $\$ 1.75$, en GD es de $\$ 1.34$.

- Respecto a la apreciación de la proporción del ingreso destinada a gastos en alimentos surge que "todo" o "casi todo" lo que ingresa se destina a tal fin, apreciación que se corresponde al contrastar estos datos con aquellos relativos al ingreso familiar. La delimitación del "todo" o "casi todo" en situaciones de carencia es imprecisa, motivo por el cual no se destaca una tendencia predominante en ninguno de los dos grupos.

Puede afirmarse que aquellas mujeres que se encuentran en mejor situación por tener ingresos fijos plantean que generalmente destinan casi todo el sueldo a la compra de alimentos, pudiendo comprar calzado o ropa cada cuatro meses y/o pagar algún crédito correspondiente a la compra de un electrodoméstico o de materiales para el mejoramiento de la vivienda. En el resto de los casos, el gasto para la alimentación familiar depende en gran medida de la inestable situación ocupacional del jefe y de la eventualidad y escaso monto de sus ingresos; en estos casos todo el ingreso se destina a tal fin y a los gastos de transporte, no quedando resto para la compra de ropa..

- Los arreglos domésticos que se despliegan en situaciones de carencia extrema son más frecuentes y más variados en GD que en GE.

En las familias GE se aprecia una mayor proporción de situaciones en las que nunca sucede el quedarse sin alimentos para la preparación de las comidas resolviendo la escasez mediante la disminución del consumo tanto en cantidad como en calidad; otras mujeres recurren a la libreta o piden dinero prestado. 
En GD los arreglos cubren un amplio espectro que incluye el hacer fuego dentro de la vivienda para cocinar a fin de ahorrar gas, enviar a los hijos a pedir sobras a los comercios del barrio, reducir o anular la alimentación de los adultos de la familia, la ayuda de vecinos que se hacen cargo de alimentar a los más pequeños o enfermos, la demanda de ayuda en instituciones barriales, sacar fiado, pedir dinero o alimentos prestados a vecinos o parientes, etc.

Como puede observarse, la opción de "salir a pedir" alimentos, ya sea a los vecinos, a la Municipalidad, y/o a comercios de la zona, se da exclusivamente en GD.

Cuando nada de esto resulta, la presión acaba por generar conflictos familiares, particularmente conyugales.

Finalmente, en ambos grupos es recurrente el hecho que la madre sacrifique o empobrezca su dieta.

\section{Respecto de las estrategias alimentarias se desprenden las siguientes observaciones:}

- En GD, la entrega de leche del Programa Materno Infantil muestra mayor discontinuidad y una mayor restricción de los beneficiarios, cuya consecuencia lleva a que las mujeres planteen como problema la dilución intrafamiliar de la leche recibida. En GE, la leche es provista regularmente en la salita siempre y cuando los niños y embarazadas realicen allí sus controles de salud. Las razones de las que no la retiran obedecen a su autoexclusión o al rechazo de la leche en polvo por parte de los hijos.

- El comedor escolar o barrial es usado, para el caso de GD, por las familias que tienen un mayor tiempo de residencia en el barrio. Las mujeres de este grupo destacan su contribución no obstante lamentan el no poder enviar a todos sus hijos y también sienten la falta de apoyo del mismo cuando deja de funcionar con motivo del receso escolar. En GE, el comedor tiene más presencia y es altamente valorado por la calidad de la comida y por la atención brindada. Sin embargo, algunas mujeres alertan sobre las crecientes restricciones impuestas para su acceso dada la necesidad de racionalizar los recursos cada vez más escasos. Si bien continúa proporcionando comida durante el verano, la falta de control institucional sobre la conducta de los niños hace que se desaliente su uso, por parte de muchas familias, durante esa etapa. La discriminación hacia los hijos de inmigrantes lleva a que directamente no sea utilizado.

- El Plan Pais, menos utilizado en GD que en GE, es evaluado positivamente por la posibilidad de elección de alimentos y por el monto asignado a cada integrante de la familia. Su importancia para la alimentación familiar se pone de relieve en GD cuando deja de funcionar, reconociendo las familias que en esos períodos, se pasa hambre. El aspecto negativo que mencionan las mujeres de ambos grupos, se vincula con su 
instrumentación: la focalización de beneficiarios (excluye a los inmigrantes) y la dudosa administración por parte de la puntera barrial a cargo de las compras. Se cuestiona la irregularidad de su entrega en coincidencia con la etapa de su finalización. En la etapa de transición y cuando se inicia el Plan VIDA, las mujeres de GD cuestionan la reducción de beneficiarios que dicho programa impone y la dilución intrafamiliar de los alimentos entregados. La entrega diaria de leche es el componente más valorado.

De los programas alimentarios estatales puede decirse que son usados en mayor proporción por las familias de GE, siendo evaluados, más allá de las objeciones planteadas, positivamente por ambos grupos. Cabe destacar, sin embargo, que sólo en GE se presenta la autoexclusión de los programas cuando mejora la situación económica familiar y que esa dinámica permite la redistribución de los mismos entre las familias del barrio.

La entrega directa de alimentos por parte de las Secretarías de Acción Social de los municipios muestra ser más eficaz en el caso de GE, dado que todas las mujeres de este grupo hacen referencia a la bolsa de alimentos que se entrega mensualmente en la Municipalidad de Ensenada. Por contraste, para las mujeres de GD, el acceso a ese tipo de asistencia es infrecuente, ya sea por desconocimiento o por la dificultosa accesibilidad ya sea económica, de tiempo o burocrática que implica.

El escaso apoyo alimentario provisto por organizaciones políticas está presente en mayor medida en GE; la impugnación de su accionar apunta a las relaciones clientelares en las que se basa.

En GD la ayuda de las agrupaciones políticas y de iglesias es mínimo. Estas últimas tienen mucha incidencia en la vida de las familias de GE, particularmente las evangelistas y Testigos de Jehová.

No sólo porque brindan ayuda en recursos cuando se requieren, sino que muestran su influencia en la incorporación de valores, en la modelación de conductas y en el afianzamiento de estilos de vida "sanos".

Finalmente, las redes de ayuda entre parientes, amigos o vecinos, frecuentes en ambos grupos, adquieren centralidad en las familias GD, sobre todo por el préstamo de dinero, de alimentos o la preparación y entrega de comida. En GE, los recursos materiales son objeto de intercambio cada vez menos frecuentes, siendo habitual el intercambio de informaciones o recomendaciones relativas al trabajo.

En el punto sobre conocimientos y valoraciones alimentarias la entrevista apuntó a identificar las pautas de alimentación ideal internalizadas por las mujeres referidas a: aquellos alimentos que consideran valiosos y/o deseables ya sea por gusto, por facilidad en su preparación, por sus propiedades nutritivas; aquellos que discriminan 
como desfavorables por razones diversas; la consideración de inadecuados hábitos alimentarios, etc.

- Una alimentación completa es percibida por las informantes de distinta manera. En GD se apoya, en gran medida, en referencias médico-nutricionales destacando la importancia de la comida variada que incluye verduras, lentejas, frutas, carnes y leche. Sin embargo, en muchos casos, la carencia de recursos hace que se restrinja el horizonte de lo ideal, de lo valorado o de la norma; así, la buena comida es la que se hace con lo que se tiene y consiste fundamentalmente en el consumo de guisos 0 pucheros. En este sentido, muchas reconocen no haber tenido nunca una buena alimentación.

En GE, la apreciación también pondera las carnes de distinto tipo, verduras, frutas, leche y huevo en la preparación de las comidas, como así también la comida variada. Asimismo, la posibilidad de realizar cuatro comidas diarias, la importancia del desayuno y/o la comida con postre aparecen en la valoración de una alimentación completa.

- Los alimentos considerados más nutritivos son los mismos en ambos grupos: aquellos que aportan hierro, vitaminas, proteínas y, en menor medida, calorías siendo los más apreciados las carnes, verduras, legumbres y frutas. Muchos de ellos se conocen a propósito de su promoción no sólo médica sino también mediática. Hay un tercio de mujeres -en ambos grupos- que señalan el valor nutritivo de todos los alimentos y otras hacen depender su calidad de las condiciones de higiene y la forma de preparación.

- En relación a lo anterior, una mala alimentación es para GD "no comer bien" o "no comer nada" o bien "comer algo hervido sin nada", apareciendo como respuestas en GE razones basados en criterios de calidad, cantidad, monotonía, preparación y cocción como por ejemplo comer pan, fritos, fideos, embutidos, el no tomar leche o consumir comidas recalentadas.

- Al interrogar acerca de lo que consideran un mal hábito alimentario, la mayoría de las informantes de GD no contestan o refieren desconocer la respuesta. Un solo caso responde que "comer todo el día" constituye "una mala costumbre". Las informantes de GE responden que "comer fuera de horario", "comer embutidos", "derrochar la comida" o "no tener horario de comida fijo" son hábitos inadecuados. Sólo en la cuarta parte de las mujeres de GE aparece el "no tengo idea" como respuesta.

- En ambos grupos aparece que los alimentos que se deberían evitar comer en exceso por ser perjudiciales para la salud son los embutidos, picantes, fritos y grasas.

- Tanto en GD como en GE la mitad de las mujeres considera que la alimentación preferencial debe darse a los más pequeños y o más débiles por su dependencia de 
los adultos y sus necesidades de crecimiento y desarrollo, planteando la mitad restante que "todos deben alimentarse por igual".

- La pauta de reconocimiento de una adecuada alimentación infantil está dada para GD en el aumento de peso -de manera ambivalente- y en el ánimo y salud del niño, haciendo la salvedad algunas de que "hay gorduras falsas" ya que "puede estar gordo y que le falte alimento". En GE la evidencia se basa en que "no están flacos", "no piden más comida", "porque los llevo a control" agregando que el color de la piel, la cara, la mirada y el hecho de no bajar de peso o enfermarse dan la pauta de ello.

En ambos grupos, el reconocimiento de una adecuada alimentación infantil no se asienta tanto en criterios de delgadez/gordura sino más bien en la evaluación y el dictamen médico.

\section{En relación a la dieta habitual, puede observarse:}

- Un predominio en el consumo de fideos, arroz, polenta, papa, verdura y legumbres en GD y de carne de vaca o pollo, verdura, fideos y papa en GE.

- Con base en ellos, y en relación al reconocimiento de las propiedades nutritivas de los alimentos que consumen, la mitad de GD considera que "todos son nutritivos por igual", señalando minoritariamente que la leche, el hígado, las lentejas, la carne y los huevos son los más nutritivos, siendo los menos nutritivos los fideos, la papa y el arroz. GE, destaca las verduras, la carne, los huevos, los lácteos y el pescado y subestima el aporte nutritivo de los fideos, las papas, los embutidos, el pan y la polenta.

- Las comidas que preparan más frecuentemente consisten en aquellas que son "sencillas", "baratas", "rendidoras": guisos de fideos o de arroz, polenta, puchero y pastas en GD. En GE el guiso, los fideos y el puchero son asimismo comidas frecuentes, presentándose no obstante un mayor consumo de carnes y verduras frescas o cocidas en preparaciones diversas, destacando las pocas exigencias y la conformidad de los hijos con las comidas más económicas.

- Respecto a las preferencias alimentarias, algunos casos de GD plantean que "todo nos da igual", mientras que el resto aprecia la carne (asado, milanesas) lo mismo que GE.

- El número de veces que cocina diariamente es, en la mitad de los casos de ambos grupos, de una vez. Sin embargo, en GE esto se da por la mayor utilización del comedor por lo que la presencia de dos comidas diarias en los niños está asegurada en mayor proporción que en GD.

La comida considerada más importante es el almuerzo para GD, dado el menor uso del comedor. La necesidad de racionalizar recursos y la justificación del almuerzo como comida más importante se basa en los mayores requerimientos/desgastes 
energéticos de la vida diurna. En GE la comida más importante es -y en iguales proporciones- ya sea el almuerzo o la cena: la primera por ser la única comida o la más importante y la segunda por constituir el momento de encuentro familiar ya que "estamos todos juntos".

- La composición del desayuno y la merienda consiste en té o mate cocido con leche y pan en la mayoría de GD, variando la cantidad de leche según la edad de los hijos. En GE, el consumo habitual de leche aparece en una mayor proporción de familias -en relación a su mayor participación de programas alimentarios- aunque "cortando" infusiones en la totalidad de los casos y se destaca además el consumo generalizado de manteca, mermelada y galletitas -además de pan- fundamentalmente en el desayuno.

- Respecto al reconocimiento de las personas que se alimentan mejor dentro de la familia, en ambos grupos aparece mayoritariamente el que "todos se alimentan por igual", no habiendo privilegio marcado por la alimentación de ninguna categoría de edad y/o género en cuanto al tipo de comida.

- Frente a la indagación de la existencia de requerimientos alimentarios específicos para los niños, en GD contestan que "todos comen por igual, lo mismo" y en GE se presenta la misma tendencia. No obstante, en GD existe mayor preocupación por la alimentación de los hijos desnutridos ya que "los más chicos o los más flacos" reciben especial atención, sobre todo en la cantidad de carne que se les ofrece.

- La evaluación de la alimentación familiar realizada por las informantes de GD es positiva en más de la mitad de los casos. Esta evaluación se basa en criterios de calidad: "por todas las verduras que usamos", saciedad: "están llenos" o simplemente por su sola presencia ya que "la comida siempre de algún lado sale". Lo suficiente es lo que se tiene; sin embargo reconocen que tienen cada vez menos. Una minoría admite tener una alimentación "mala" o "regular", pero a continuación señalan que "dentro de todo nos arreglamos". En GE es casi mayoritaria la apreciación de tener una adecuada alimentación familiar, basada en criterios de calidad, cantidad y salud de sus miembros. Sólo dos casos refieren que no comen muy bien porque "el dinero no alcanza".

- En relación a lo anterior, la mitad de GD considera que no falta ningún alimento importante en su dieta, refiriendo los casos restantes la carencia de lácteos, fruta, huevo, carne de vaca y de pescado por limitaciones económicas. Similar tendencia aparece en las respuestas de GE: lácteos, fruta, carne. Asimismo la carencia de ciertas verduras y legumbres en la alimentación familiar, particularmente de GD, se explica por su rechazo por parte de los niños.

Ambos grupos reconocen el excesivo consumo de pan. 
Cabe finalmente agregar que la monotonía de la alimentación característica de las familias de menos recursos es causa de saturación sensorial y también de persistencia de deficiencias de algunos nutrientes, si es que la dieta es deficitaria en alguno de ellos (Brown, 1991).

Además, cuando existe un exceso de energía en el contexto de una dieta pobre en calidad, no se crece sino que se engorda, tendencia que se observa de manera creciente en las evaluaciones realizadas a población infantil de sectores pobres. 


\section{REPRESENTACIONES Y PRÁCTICAS MATERNAS SOBRE DESNUTRICIÓN INFANTIL EN EL GRAN LA PLATA}

La forma en que las madres conceptualizan, perciben y significan la desnutrición permite entender las prácticas sobre las cuales se han ido consolidando y las orientaciones que brindan a éstas.

Con independencia de tener un hijo desnutrido en la familia, dicho problema de salud forma parte, para las familias pobres, de un universo próximo y conocido. Sea por experiencia propia, de familiares cercanos, de vecinos, por contacto con dicha problemática en los servicios de salud, por comentario de agentes barriales de distinto tipo, o bien a través de información mediática -sea de naturaleza científica, política o comercial-, todas las mujeres algo saben, a menudo bastante. Dichas representaciones acerca de la problemática nutricional infantil pone de manifiesto procesos de identificación, diferenciación, manipulación, negación, estigmatización o impugnación.

La aprehensión de las representaciones realizada a madres con y sin hijos desnutridos puede dar cuenta de ello. Las prácticas han sido indagadas a través del discurso recogido en diversas entrevistas abiertas realizadas a las madres, por lo que se podría decir que se trata de las representaciones de las prácticas ${ }^{78}$. Aunque muchas de las prácticas indagadas no están presentes en las madres de niños eutróficos, la representación de la práctica aparece también en sus relatos.

Los aspectos considerados se relacionan con:

a) el reconocimiento de la desnutrición

b) sus causas, síntomas, tratamiento y prevención

c) su conceptualización como enfermedad

d) la capacidad terapéutica de los médicos y los servicios de salud

e) los saberes sobre la pata de cabra y su asociación con la desnutrición

f) la utilización y evaluación de los servicios de atención.

\subsection{Diferenciación y estigmatización en el discurso de las madres con hijos eutróficos}

En el caso de las madres con niños eutróficos, el reconocimiento del estado nutricional está respaldado por una autoridad competente. Esfuerzo, sacrificio de los padres e

\footnotetext{
${ }^{78} \mathrm{La}$ recurrencia de las respuestas obtenidas en las distintas entrevistas -incluyendo las contradicciones- da cuenta de la coherencia de las representaciones y prácticas relatadas por las madres.
} 
ingenio para asegurar la comida son emblemas de la buena crianza. Su resultado, la salud y el crecimiento del niño, es reconocido por los médicos:

"Eh, no, yo creo que depende mucho de los padres, de la forma como uno los cría a los chicos, y cómo los alimenta. Yo me acuerdo que yo les daba, eh, no podíamos comprarles leche, eh, hubo un tiempo que nos preparaban la Caja del Pan, pero después, como que eso fue disminuyendo, yo compraba el Quaker, les daba leche con Quaker, le hacía hervir el Quaker con una cucharadita de azúcar, les daba el agua, como si les diera jugo por ejemplo...

Claro, entonces, yo no les daba solamente verduras, la verdura estuvo, siempre estuvo y carne sí.

Yo me arreglo con un plato, por ejemplo la polenta con queso, una ensalada...berenjenas, acá los chicos comen todas las verduras. (...) Sí, la doctora siempre me decía, que cómo los estaba criando, qué es lo que les daba. Y luchando, no haciéndoles faltar nada, tratando que ellos coman lo mejor...no nosotros quitándoles a ellos tampoco." (Perla)

Pese a no tener hijos desnutridos, el estado nutricional ha sido objeto de preocupación por parte de algunas madres:

"Éste por ejemplo, ¿viste?, es flaquito...él para la comida es como todos los chicos. Sí, con él estaba preocupada pero la doctora me dijo sí, que está bien me dijo. Desnutrido no está." (Gabriela)

"Eh, ahora con el chiquito, me bajó, me bajó de peso el de dos años me bajó de peso. En realidad que tendría que estar doce, y pesa once. Lo llevé a la doctora y bajó de peso, pero me dijo que no, que está bien, me mandó análisis, todo, pero lo único que posiblemente él tenía parásitos.

Posiblemente hayan sido los parásitos, porque de alimentación, él, en realidad, sí, yo le doy, lo que puedo le doy. La leche..., lo que se come en casa. Pero me bajó de peso. Es chiquito, los otros no, los otros sí, siempre me pude arreglar. Sí, de alguna manera uno se tiene que arreglar con los chicos.

Yo, eh, hace mucho que no iba a la salita, lo llevé por el nene, que lo veía flaquito, qué sé yo, esas cosas,

Bueno, me lo pesó y me dijo que le faltaba...un kilo, más o menos. Y ahora le mandaron los análisis acá a Ensenada, pero en Ensenada no atienden porque dicen que esta semana van a tener paro, no atienden.

Porque no le pagan. No, lo voy a llevar al Hospital de Niños ahora, allá en el Hospital de Niños me hacen el análisis, me hacen todo. Yo no los llevo porque es lejos." (Celeste)

"La doctora me enseñó que en la piel y en el pelo también que se debilita...el pelo mismo, porque yo siempre le digo a la doctora, a mí me parece que Darío está flaco, le digo...¿está bien doctora? le pregunto. 'Mirá', me mueve el pelo y me dice que no, que no necesita, que está bien. Así que yo me guío mucho por lo que me dice la doctora." (Gabriela)

Las causas de la desnutrición obedecen, para la mayoría de las madres entrevistadas, a la mala alimentación por descuido materno:

"Por la mala alimentación que tiene en la casa. Y comer, qué se yo, fiambre, falta de cuidado a los chicos, que no se los atienda en la comida en el horario..." (Araceli)

La división sexual del trabajo está dada: crianza, alimentación, educación son atribuciones y responsabilidades maternas:

"Así que, yo digo que todo depende de la madre, no tanto del padre, porque el padre sale afuera 
a buscar trabajo...y depende de la madre que es la que se queda en la casa. Todo depende de nosotras, de las mujeres, cómo los vas a criar a los chicos, cómo los vas a educar...así que yo, fue siempre esa mi idea...y de hacerle por ejemplo un fideíto, con un dientito de ajo y un huevo batido, para cuatro criaturas, comen bien...Pero si no saben cocinar ese es el problema. Si una persona no sabe cocinar.

Que no se dé maña, por eso yo le doy gracias a Dios que al menos mi madre me educó y me crió así, y yo pude criar a mis hijos, y yo, eh..., luchamos muchísimo los dos...mucho, mucho para que no les faltara a ellos... Y no, gracias a Dios no le falta nada, no. Aparte es sanita." (Perla)

El abandono materno se hace visible en la higiene del hogar y esta repercute en la salud de los niños:

"Porque las madres son abandonadas. Sí. Porque no viven como uno, qué sé yo, dentro de lo pobre uno vive limpio. Yo te digo una cosa, soy pobre, ¿no? Pero, ¿viste?, en mi pobreza yo soy limpia. Lavo las ollas, limpio las ollas, baño, limpio el baño, porque el baño es, el baño, tengo inodoro, una piletita y nada más. Eh, ¿sabés por qué? Pienso que son muy abandonadas, y chicas jóvenes, ¿eh?

Los tienen sucios, ¿por qué los tienen sucios? No van a decir que un pedacito de jabón así chiquito...son abandonadas, por eso los chicos se les enferman. No se dedican a ellos. Y a veces les pasan algo porque no los cuidan. Son madres que no se ocupan. Porque uno ve, hasta lloran ellas, que yo soy pobre, pero a veces no se trata de la pobreza, se trata de que no se ocupan. Son muy pocas madres que se ocupan de los chicos.

Muchas veces también eso, está embromada la cosa. No hay trabajo. Pero aunque sea un caldito uno le va a poder dar a los chicos, un, qué sé yo, una polenta, o algo.” (Celeste)

Otras, más contemplativas de la experiencia vivida por otros, aventuran posibles situaciones (problemas económicos, mujeres abandonadas, poca inventiva para cocinar) que permiten comprender el descuido infantil:

"La desnutrición a veces viene porque a veces yo creo que las mamás también se dejan un poco. Porque yo creo que alimentarlos bien siempre se puede a los chicos, a menos que estén por ahí con alguna enfermedad que ya es mucho más difícil pero pienso que... porque nutrición es hacerles una polenta con queso o con unos huevos, ya es alimento y un buen alimento y hay mujeres que no se dan maña para hacer... es mi opinión ¿no? No sé exactamente, a veces cómo pueden llegar a que los chiquitos... porque uno a veces ve chiquitos que uno piensa ¿cómo pueden estar tan mal, no? pienso que depende de la madre, si, si.

No sé muy bien, yo principalmente veo acá en el barrio que hay mamás que tienen problemas quizá un poco económicos, se dejan estar... o porque tienen un problema, o están solas o porque el esposo se fue, y ellas es como que se abandonan porque lógico, la situación es difícil no? $Y$ entonces dejan de dar un poco de atención a los chicos y entonces cuando se dan cuenta ya la situación es como que es un poco más grave ¿no?” (Olga)

La estabilidad laboral del jefe permite la provisión regular de alimentos y evitar la desnutrición:

"Yo pienso que es el chico que no come bien, que no se alimenta bien, no sé yo al mío hasta ahora gracias a Dios, qué sé yo, ellos comen al mediodía, a la tarde, a la noche... así que (...) Y mi marido siempre trabajó y nunca les faltó, o a lo mejor comer salteado o algo así. Y mucho no sé, sé lo que: es que por ahí no están bien alimentados, no comen o sea las cosas que tienen que comer o sea las vitaminas que tienen que comer para estar bien alimentados.

Bueno, en algunas partes no sé. En partes he visto que le mezquinan por ahí así algún pedacito de pan, o pienso que debe ser eso, yo acá no mezquino, mientras haya que coman, si no hay, bueno, pero mientras haya hasta ahora gracias a Dios no me faltó y si por ahí a lo mejor me falta alguna vez que no tengo azúcar pero tengo a mi mamá que siempre me ayuda, así que no, no. 
Hay partes que, qué sé yo por ahí a lo mejor no trabajan los padres, qué sé yo, que no consiguen." (Cintia)

A esto contribuye también la falta de asistencia, menor que años atrás:

"Por más que dicen que te ayudan, que lo otro, hay lugares que no te dan nada.

Hay lugares que no reciben nada, como yo que acá, hace dos años que está el Plan Vida.

Bueno, me vino a anotar una chica de por acá, cuando recién empezó el Plan Vida: 'Sí, sí, que esto y que el otro, yo te voy a avisar cuando podés ir a buscar la mercadería a mi casa...'

No, no, antes, antes me ayudaban, antes...uno dice, cuando estaban los radicales, te digo la verdad...a mí me daban la caja...para los chicos. Sí, tres años me dieron la caja. Era una ayuda, era mucha ayuda." (Celeste)

Otras la adjudican a la inadecuada alimentación (carencia de leche, falta de horarios) sin hacer juicios de valor sobre conductas maternas:

"Y por la mala alimentación...porque no comen lo que tiene que tener un chico de cierta edad para alimentarse bien, no sé... pienso que lo principal es la leche, después hay que comer a horario...no sé." (María)

Respecto de los síntomas, los más mencionados son al adelgazamiento, al abdomen hinchado y al color de la cara:

"Y... porque no tiene color en la cara pienso yo, y pienso que me parece que tienen panza también...son flacos y panzones." (María)

"Y cuando empiezan a adelgazar. Para mí ¿no?" (Araceli)

Para el tratamiento que creen, corresponde a la desnutrición, se impone la consulta al médico con el fin de obtener asesoramiento nutricional:

"El tratamiento es ir al médico y ya... este...yo, en mi caso lo primero que haría es ir al médico. No meterle...empezar a meterle comida, comida, comida y...el médico te asesora qué es lo que tiene, si realmente está desnutrido qué es lo que podés hacer, donde tenés que llevarlo..." (Fidela)

Algunas por analogía fonética, aluden al tratamiento correspondiente a la deshidratación y dan una respuesta vaga:

“¿Qué tratamiento? Mucho líquido y...ah, no, no. Sí, tenés razón, me estoy confundiendo. Claro sí. Cuidarlos, un mejor cuidado en la alimentación...

Ah, no sé bien qué hay que darle, yo no tuve...eso no sé." (Gabriela)

Para prevenirla, algunas madres proponen intervenciones poco invasivas basadas en la educación dirigida a la madre y en la exploración de la vida familiar con vistas a modificarla:

"Y, yo pienso que principalmente hay que tratar de hablar con la madre, buscar las formas de ver la forma de vida, sí...en caso de ser de un chico de afuera...eh...que yo veo eh, buscar la forma de conectarme con la madre y de que...cómo poder explicarselo sin que lo tome a mal, porque a veces, viste..." (Fidela) 
La atenta vigilancia puesta en la alimentación infantil evita problemas nutricionales:

"Qué sé yo, cuidarlo lo más bien posible. Claro, yo lo cuido mucho en los alimento, los cuido en... qué sé yo, que no coman cosas por ahí... sí...los míos nunca tuvieron bajo peso por suerte..."

(Gabriela)

aunque para algunas los cuidados alimentarios se reducen a asegurar la comida:

“Evitar que deje de comer, darle la comida... (Araceli)

La provisión sistemática de leche hasta los cinco años es para otras fundamental, lo mismo que el consumo de huevo, carne y polenta:

"Qué sé yo, eh...dando...pienso que lo principal es que un chico de más o menos...bah, desde que nace más o menos hasta los cinco años, tiene que tomar la leche, aunque sea un vaso de leche, huevo hervido, pollo, pescado, esas cosas. O sea polenta con queso, pueden comer, qué sé yo, algo así en la... te digo en una familia más o menos que no pueda...no te digo tampoco pollo todos los días, pero, qué sé yo..." (María)

En síntesis, la prevención termina pivoteando, en la mayoria de los relatos, en el esfuerzo por brindar cuidados alimentarios: "si se es padre se sabe que la leche y la fruta..." y en el asesoramiento médico:

"Y bueno eso es... para que no se desnutra eso es fundamental. Yo creo que es hablar con alguien que sepa... y yo creo que eso ya es fundamental que los van a ayudar...va de la doctora y uno, como padre, sabe que siempre la leche...todas las cosas para el chico; la fruta... todas esas cosas... es necesario que tiene que tenerlo. $Y$ uno es el padre, como padre tiene que hacer el esfuerzo para que ese chico lo tenga." (Olga)

Algunas relacionan directamente la desnutrición con el descuido sin más. No se trataría de una enfermedad sino desatención porque por pobre que se sea, "uno siempre tiene" para dar algo de comer a sus hijos. No se trataría tanto de carencia sino de malos hábitos alimentarios:

"A mí me parece que la desnutrición es más bien descuido. Sí. Porque si..., uno siempre tiene, digo yo...sí, siempre tiene. Para mí que es descuido la desnutrición. Yo nunca tuve así que...no sé exactamente, ¿viste? No, a mí me parece que no es una enfermedad, es un descuido. Y porque ya va muy tarde al médico, ya cuando no da más el chico... No, nunca tuve problemas de...

Y, falta de alimento...Y como ya te dije, también falta de atención, qué sé yo.

Lo que pasa es que la gente se deja mucho, yo veo mucha gente acá que se pasan tomando mate, con galletitas, y eso no es alimento. A mí, prefiero hacerles un plato de guiso con tal de que coma aunque sea un poquitito, porque... ¿viste?, no les gusta tampoco nada de guiso y qué sé yo, pero te digo que yo que prefiero eso que sentarlos a tomar mate cocido con tortas fritas, qué sé yo...No, para mí no es alimento. Lo que pasa es que yo nunca pasé, y no sabría decirte por qué en algunas familias los chicos se desnutren. Mi familia, y tampoco en Paraguay, y mirá que en Paraguay hay zonas que también hay chicos desnutridos, pero mi familia nunca." (Gabriela)

La atribución de la desnutrición al descuido hace que no se la conciba como enfermedad, excepto cuando deriva de alguna enfermedad: 
"No sé, la verdad que no sé, como uno no la tuvo, no la conoce, a veces no sabe bien, no tengo idea, a veces qué sé yo... algunas sí debe ser por alguna enfermedad que se complica no? pienso, pero no tengo idea más que eso. Una enfermedad es cuando uno ya... cuando uno, como le decía anteriormente... pero si se deja, no cuida a los chicos, eso no es enfermedad eso es ya como decir ...ya es un poco de abandono. Enfermedad pienso que es cuando se va complicando, que ya tienen algunas otras cosas, eso sí." (Olga)

Al no ser considerada enfermedad, cuya resolución depende del accionar médico, muchas afirman que los médicos sólo pueden contribuir a curarla. Su curación depende centralmente de los padres (sobre todo la madre):

"Y pienso que sí, y después con una buena alimentación; y eso depende de los padres." (Cintia)

La función de los médicos se relaciona principalmente con el diagnóstico y la indicación de la alimentación que se requiere:

"Supongo que sí...pero también depende de la mamá, no? Supuestamente los médicos le van a hacer una serie de análisis y ellos se darán cuenta si está desnutrido sí o no, les cambiará...tienen que cambiarle por completo la forma de alimentación...porque ¿viste?" (Fidela)

La indagación de lo que conocen sobre la pata de cabra obedece a razones diversas: en primer lugar para confirmar la condición de no desnutridos de los hijos; en segundo lugar, para explorar las representaciones que tienen acerca de la misma, de las familias que la padecen y de los especialistas en curarla.

En general, la mayoría de las mujeres conoce este problema de salud por referencia de parientes o vecinos. Ninguna la ha experimentado en sus hijos, pero comparten la apreciación de que se trata de un problema serio y la convicción de que los médicos son impotentes para curarla.

"Sí, pata de cabra sí sé. Me dijo una chica conocida de acá, que la nenita, dice que se le vino un palito, era así, más gorda que el mío y tuvo pata de cabra, la chiquita. Así que la estaba haciendo tratar. En realidad, no sé qué es, los míos no tuvieron... pero sí que tuvo un sobrino mío. Sí, sí, y los médicos, suero y suero, y no te digo...si mi hermano lo sacó muerto allá en la Capital y lo llevó a una curandera y el chiquito revivió. Ni idea cómo lo cura. Porque yo ni idea. Sé que lo tuvo que llevar a una curandera para curarlo... sí, pero dice que los médicos no lo curan.

Se van, parece que se van, me quedo helada con lo que dicen de la pata de cabra, yo me asusto, porque lo tengo yo al chiquito...y no va a ser cosa que, dicen que a los chiquitos le agarra." (Celeste)

Pese a haber asegurado que en el barrio la desnutrición no es un problema importante, la pata de cabra, en cambio, sí constituye un problema de salud frecuente:

"Sí, se da acá. Se da, sí, mucho. En esta zona sí. Pero eso yo no sé por qué. Eso sí que no sé. No tengo idea de lo que es pata de cabra hasta ahora, mirá, pero me han hablado que es una enfermedad seria que lo puede llegar a matar a los chicos. Acá hubo dos casos hace poco, estaban muy flaquitos sí, muy flaquitos, se vino abajo, sí. Es lo que me decía la señora, ella los 
llevó al Hospital de Niños, le hicieron todos los estudios y no le encontraban absolutamente nada, hasta que por intermedio de una señora que vino y le dijo por qué no lo llevaba y le encontró que sí. No comía, lo que comía vomitaba....y era pata de cabra. Lo salvó, acá hay uno que cura, sí. ..." (Gabriela)

Consideran a la pata de cabra como una enfermedad grave de causa desconocida, que produce un abrupto adelgazamiento en los niños. Su determinación ocurre generalmente luego de haber resultado estériles los estudios diagnósticos o los tratamientos de la medicina oficial.

"Mmh, no vista, pero...tengo comentarios. Pero no sé de qué...eh...de qué proviene, si es verdad lo que dicen que es. Que es una marquita que se te forma en la columna.....y que hace que la criatura se le cierre el estómago, ¿puede ser? Sí, eso es lo que tengo entendido.

Yo no, gracias a Dios no. Pero ha habido muchos casos acá, eh?...

Pero supuestamente, pienso que si te va cerrando el estómago es lógico que el chico le agarre la desnutrición, si no lo agarran a tiempo...o la mamá no se da cuenta." (Fidela)

Describen algunos signos: marca en la espalda, vómitos, a veces derivados de un empacho mal curado que produce la oclusión del estómago. Aparte de no haber tenido hijos con ese problema destacan su adscripción a la medicina científica, reflejando además la participación del cónyuge en la selección de las acciones terapéuticas realizadas sobre los hijos:

"Sí. Dicen que es un empacho mal curado. Dicen, no sé, qué sé yo...Yo no, nunca me...

No, a mí nunca...y... siempre la traje a la doctora. Dicen que sí, que se cura, qué sé yo, pero no sé, yo no... te digo la verdad nunca tuve, no nunca tuve problema así en ese sentido los chicos. Aparte mi marido no cree en eso así que no..." (María)

Pese al desconocimiento o descreimiento de algunas sobre el tema, su existencia no se cuestiona:

"Mh... escuché, y mi sobrinita creo que lo tuvo, lo llevaron a curar, pero no sé mucho de pata de cabra. Porque pata de cabra en Paraguay no se conoce... Yo nunca tuve así que no sé...pero de existir existe, porque la señora de enfrente la tuvo a la nena con pata de cabra." (Gabriela)

En general, la relación que establecen entre pata de cabra y desnutrición es de causalidad:

"Sí, está relacionado porque la nena me dijo que en vez de aumentarle de peso iba bajando, iba bajando y ella ya se estaba desesperando y me hizo un comentario ¿viste?, lo llevó a curar y ahora está... después de curarlo la nena volvió a la normalidad digamos...

Lo llevó también al médico eh?, porque después me contaban también que estaba con una infección urinaria." (Gabriela)

Una mujer enfatiza el prolongado tiempo de lactancia de sus hijos, factor que actuó de manera directa en la salud de sus hijos. Debido a ello, la pata de cabra le es totalmente ajena: 
"No, no ninguno, ellos no, no, pata de cabra, no. No sé si acá en el barrio si hay. Yo no; será que los míos tomaron leche después del año, mientras tanto yo los crié con pecho y...para mí, sí, el pecho es importante, nunca tuvieron problemas de diarrea, nunca." (Cintia)

La presencia en el barrio de una salita, su fácil accesibilidad y la oferta continua de atención médica, favorece el control de los niños por lo que la desnutrición parece ser poco frecuente:

"No, me parece que no, no se ve, a pesar de que es un barrio bastante poblado de chicos no se ve.

Pienso, como le decía anteriormente, que es porque los médicos también ayudan, porque como está la salita cerca, siempre hay quien atienda, siempre que hay algún problemita van, porque hay esa posibilidad, a lo mejor que si se fuese un hospital que está mas lejos, quizá se producirían más cosas. Pero acá como en esta zona está la salita, que se hizo cuando acá en esta zona se comenzó a poblar...para el 78 yo ya estaba acá, y, más o menos para el 80 entonces, sí, sí, si tiene muchos años ya, entonces la gente está acostumbrada a ir y eso ayuda mucho. Aparte acá siempre hay médicos, todo... así que..." (Olga)

Otros problemas de salud habituales en los niños como el empacho o el mal de ojo, son resueltos con el curandero:

"Yo la verdad que yo a éste, al chiquito...lo llevo a curar de empacho. Lo llevo y el nene mejora. Yo siempre digo, tengo que creer o reventar. Muchas veces dije: 'ah, no, no creo'. Yo lo llevo; por acá cerca hay una señora que cura de empacho.

El nene estaba una día, pero, mirá, estaba..., lo llevé a la doctora, estaba descompuesto, no me quería comer, estaba re mal. Lo llevé a la doctora, que sé yo, me dio unas gotitas que... y el nene seguía, seguía. Yo digo, yo le dije a las chicas: 'Yo lo voy a llevar a curar el empacho'. Al segundo día, el nene me comía.

Lo mide la señora, no le tira el cuerito, nada, lo mide. Eh, se hace el Padre Nuestro y lo mide, y dice que... yo no entiendo, pero dice que cuando llega acá está empachado, y la cinta va corriendo.

Y al correr baja. Eh, el primer día que me lo curó, el nene, a la media hora que esta señora se fue, eh, el nene hizo como un hipo, que nunca me lo, nunca hizo hipo, hizo así. Y al otro día me volvió a hacer lo mismo, al segundo día lo llevo y se le había bajado todo. Sí, así que, mirá.

$Y$ con los otros chicos también, sí, cuando eran chicos los llevaba. Uno dice bueno, hay que hacer todo. A veces hay que creer en más allá, uno... "(Celeste)

La ineficacia del tratamiento médico precipita la consulta al curandero, también accesible. Tratándose de problemas de salud de los hijos, todo vale y la evidencia indica que hay que creer más allá de lo posible.

A menudo, la autoridad del criterio médico, cuando es emitido en los medios masivos de comunicación, conduce al total abandono de tratamientos alternativos como la herbolaria. El temor paraliza cualquier intento de contrariarlo. Además, es en las situaciones de elección de los tratamientos posibles, donde se pone de manifiesto la intervención del padre en las decisiones sobre la atención de los hijos.

"Mirá, yo te voy a decir una cosa, cuando los otros, cuando los nenes míos, los primeros que tuve...sí, que les daba mucho esos yuyos, pero después escuché a Socolinsky...que decía que no hay que darle yuyos a los chicos...Y a éstos más, éstos, los tres éstos nunca les di yuyos. No. Eso les saqué. Porque dije, lo escuché al médico éste, ¿viste?, que te orienta, todo, que te habla... 
Bueno, dice que eso que le dan tantos yuyos, qué sé yo. $Y$ dije: nunca más yuyos para ninguno.

Sí, no, les saqué los yuyos, dije, no, mi marido decía: ¿¿Por qué no les das té, como hacías antes, los yuyos?'. No, mirá, directamente nunca les di más yuyos. Un té, de té, sí; el té común les doy, pero yuyos les saqué a los chiquitos. Escuché eso, me asusté.” (Celeste)

Finalmente, cabe destacar una dimensión no contemplada como fuente explicativa pero que parece tener peso en las actitudes hacia la salud de algunas familias. Se trata de la adscripción religiosa. El culto evangelista y los Testigos de Jehová, particularmente los primeros, cuentan con muchos fieles en el barrio. Su compromiso activo con la palabra que profesan implica en muchos casos una suerte de resocialización: ruptura con todos los aspectos negativos del modo de vida anterior y asunción de nuevas actitudes y comportamientos respecto de sí mismos y un reacomodo en sus relaciones sociales. La vida sana, el orden y armonía familiar, el renunciamiento a los vicios y a la vida licenciosa y el respeto a las autoridades son los ejes que interesan a los fines de la problemática infantil. Los preceptos evangelistas no generan conflicto alguno con la ciencia y la actividad médica. Respetar a los médicos y a las autoridades instituidas, es respetar a Dios porque ellos son sus herramientas.

"Es el espíritu santo de Dios el que sigue haciendo la obra en este tiempo...eh, yo por ejemplo ahora, yo oré para sanarme...

Pero ponemos un tiempo, oramos, yo, por ejemplo, nosotros no dejamos de ir al médico...

Yo a mi hija no la dejé nunca de controlar. A ustedes mismos les consta en la Salita, que tenía todo al día. Este, no, no, no dejamos de respetar las leyes que Dios ha puesto sobre la tierra. Como el médico son las autoridades...el médico, los maestros. Eh, por ejemplo el gobierno. No, nosotros no dejamos, eh, de respetarlos a ellos.

Entonces nosotros por ejemplo, hacemos lo que a nosotros nos corresponde, nosotros hacemos nuestra parte, y Dios hará la otra parte. Yo voy al médico, que me va a operar....y Dios se va a encargar de que salga todo bien... pero, todo dejamos en las manos de Dios.

Eso es lo que nosotros hacemos, y de los médicos no dudamos. No, no, en ningún momento." (Perla)

Pero no todos los médicos, según las madres practicantes de los distintos cultos, comparten esta apreciación y pocos son los que solicitan la complicidad del paciente o de sus familiares para pedir a Dios le otorgue pericia a la hora de intervenir.

La oración y la ayuda con recursos forma parte de la actividad religiosa:

"Yo por ejemplo, nosotros, eh, a cualquier hora que oramos, oramos por el barrio...

Vemos un chico que necesita y nos ponemos a orar, y si podemos alcanzarle algo le alcanzamos." (Perla)

Sin subestimar la capacidad técnico-científica de los médicos, la experiencia de sanación de algún miembro de la familia, resultado de un ritual colectivo, refuerza la convicción del poder divino y del poder de los hombres cuando se lo invoca.

"Y...sí. Si yo le digo a él, por ejemplo, que a nosotros Dios nos ayuda muchísimo, yo verdaderamente creo que Jesucristo estuvo en la tierra, y que Cristo es el hijo de Dios, y que Cristo sana y sabe, y que resucita muertos, aún, la Biblia dice que Cristo resucitó a Lázaro, estando cuatro días de muerto... 
Este, nosotros no llegamos a resucitar muertos, porque no sé, sea la voluntad de Dios, pero sí llegamos que, por ejemplo yo tengo el testimonio vivo de mi hija que fue sanada...

Y se curó. O sea que para mí Dios es lo más grande que tengo en la vida...

Es lo más grande, porque lo que el hombre no puede hacer, Dios lo hace.

Respeté lo que el médico me dijo...la Biblia dice que hay que respetar a las autoridades 'porque están puestas por mi padre' dice Cristo. Eso seguimos nosotros...que nosotros tenemos que respetar a las autoridades, a mí no me gusta cuando por ejemplo critican al gobierno...No me gusta, me duele.

Yo sé que él está equivocado, pero es hombre. Cualquiera se equivoca." (Perla)

Encuentros semanales para charlar sobre temas de interés y preocupación general, son los que organizan los Testigos de Jehová, cuya moralidad basada en la Biblia, inculca enseñanzas de utilidad para la vida cotidiana fomentando el conformismo y la valoración de lo que se tiene:

"Porque me gustó, realmente fueron a visitarme, comenzaron a...comencé a conversar y bueno conversé cosas que... bueno. No sé, me gustó ... por todas las cosas. Y cuando fueron creciendo los chicos me gustó mucho más todavía. Porque tiene mucha moralidad, muchas enseñanzas que van quedando... que esto y que aquello y no porque ellos lo digan o porque yo lo diga sino porque se basa en la Biblia. No, no, no, porque usted va a la iglesia y a uno con los católicos no le enseñan más de lo que le dan en la misa y... váyase a su casa. No hay una conversación, una guía. Nosotros tenemos reuniones los jueves y los sábados, se enseña así, se dan muchos temas para los jóvenes. Y yo cambié porque había cosas que uno a veces pensaba de otra manera, bueno uno va incorporando ahí enseñanzas sanas, no piensa tanto en cosas que uno, bueno quiero tener esto y..., no, uno se conforma con lo que tiene y nada más y sabe valorarlo porque eso es lo importante, no solo conformarse porque uno se puede conformar y estar mal no?, sino valorar lo que uno tiene." (Olga)

\subsection{Identificación, diferenciación, manipulación y negación en el discurso de las madres con hijos desnutridos}

En los relatos aparecen, ponderados en mayor o menor medida, una serie de variables con los que se relaciona la desnutrición: biológicas, individuales, socioeconómicas y desamparo estatal.

La habitualidad con que se presenta la desnutrición en algunas familias hace que sea reconocida a través de la pérdida o estancamiento del peso de los niños. La coincidencia de ese proceso con el inicio de la etapa de deambulación se manifiesta en todos los hijos y forma parte del proceso natural de maduración.

"Sí, de bajo peso como siempre. Sí, sí. Llegan a cierta edad y empiezan a bajar los pesos y después me cuesta para que suban. Y, ya empiezan al año, ya, no sé, a mí me dicen los médicos que es porque empieza a caminar, ¿viste?, se mueven de un lado para el otro, los chicos, y bajan de peso. Pero me cuesta un montón hacerlos subir.

Con ella me pasó un montón y ahí, quedó... ahí, ahora dicen los médicos que está bien, está en el peso justo que tiene que estar. Pero me cuesta mucho hacerlos subir." (Estela)

Si esa etapa coincide con problemas laborales y económicos de la familia, el problema reviste gravedad. 
La identificación con otros que padecen el mismo problema prevalece en el relato. Sin embargo, la necesidad de diferenciación y las contradicciones aparecen reiteradamente: a otros les pasa lo mismo, han tenido hijos desnutridos pero como sea, "mal o bien", "nosotros nos la rebuscábamos para darle." Asimismo la explícita impugnación a las políticas sociales por la falta de asistencia y la carencia de una red de apoyo parental, permiten inferir su importancia en la contención de dichas problemáticas.

"Mirá, la desnutrición es algo jodido, yo vi en el hospital muchos chicos desnutridos.

Esta vuelta estuve internada mucho, y bueno, lo que pasa es que no hay trabajo, chicos mal comidos, ¿viste? Después, no sé...viendo esas cosas, sabés cómo me partía el alma.

Te juro. Vi muchas cosas, yo ya, yo ya estoy cansada de ver esas cosas, nadie hace nada, porque nadie te hace nada, nadie te da una mano, esa gente que no tiene su trabajo, yo la pasé, mis chicos estaban muy mal también, pero como sea nos rebuscábamos para darles de comer, ¿viste? Pero esos chicos, te digo la verdad, pobrecitos, los médicos, la doctora dice que están de muy bajo peso, están desnutridos, necesitan hierro, de todo..., ¿viste? Pero no hay ayuda, ¿cómo hace la gente? No hay ayuda, no hay trabajo, la madre sola no puede...y, no, a mi me duele mucho, ¿viste?

Yo me veo en esas madres un montón. Un montón porque yo también los pasé..., con la mayoría, con todos los problemas que pasan ahí en el hospital, con la mayoría de los problemas que estaban ahi yo me sentía identificada..., sentías que ibas a golpear una puerta y te la cerraban, sentías que decian: "Ah, sí, allá, acá el gobierno...", el gobierno no existe, ¿viste?, el gobierno dice que son de los chicos, es mentira, porque yo lo he comprobado, son todas mentiras, no ayudan a los chicos, los que menos están protegidos son los chicos, los que más protegidos tendrían que estar serían los chicos y los ancianos, y son esos los que vas al hospital y los tenés internados. Y eso es la bronca que a mí me da, ¿viste?, porque uno diga bueno, tal está sin trabajo, qué sé yo, ¿viste? ayudarlos, no te digo, qué sé yo, darles plata, pero darles una buena cantidad de cosas y alimentos. Yo, te digo la verdad, yo hasta ahora, gracias a Dios, ¿viste?, mal o bien nos la hemos rebuscado, pero yo me sentía muy identificada, porque yo te digo, mi esposo y yo no tenemos familias..., mi marido y mis hijos somos nomás." (Estela)

Asimismo, esta mujer deja de apelar a otros para hablar de la desnutrición y describe directamente el excesivo y repentino descenso de peso en sus hijos.

"A mí me pasó con ella y ahora...con él. Es decir, se me bajó de peso un montón. Perdió casi dos kilos y pico de peso. Y es mucho. Y ella no sé, llegó al año, estaba Catita y no la podíamos, había adelgazado y no había forma de hacerla subir de peso, le había comprado vitaminas, le abrieron el apetito, y no, nada, había quedado ahí, ¿viste? Y claro, ella comía lo que ella quería, ¿viste?

Y lo que ella quería no era lo que necesitaba el cuerpo...porque huevos fritos, papas fritas, esas cosas...no es lo que cuerpo necesita...

Pero igual, ya después quedó así flaquita, y no engordó más, quedó así. Yo la vez pasada que le pregunté a la doctora y me dijo: "Ay, no madre, ya debe ser una consistencia de ser flaquita de cuerpo, y va a ser asi”" (Estela)

Resignada a la flacura de otra hija, intenta ahora, frente a la desnutrición de su hijo menor, a rellenar su "carne floja" con mamaderas de leche con maicena o Nestum;

"Pero ahora tengo problemas con éste. Éste que me va a costar también, seguro, para hacerlo engordar, porque éste también...

Sí, como dicen los médicos lo que pasa es que tiene tan flojita, de lo gordo que estaba... 
Sí, estaba re gordo y eso sí. Los médicos no me dijeron en ningún momento que le saque el pecho. Me dijeron. "Seguile dando, hasta el año más o menos, que él empieza a caminar, y si toma más mejor". Y come. Se toma la leche con maicena, con Nestum, cada vez que le doy, ¿viste?, le doy así, ¿viste?, variado, no siempre le doy con Nestum o siempre con maicena." (Estela)

La necesidad de control médico se impone cuando el niño no come pese a la disponibilidad de comida.

“...yo pienso que se desnutre, se cae... se cae en el sentido de no comer él...la carita, pálido... Y hay que llevarlo a control. Y sí, porque si vos le das de comer y sigue el chico igual...para mí el control. Los médicos saben si tienen que medicarlo..." (Valeria)

Tal vez encuentren alguna enfermedad que obstaculice la nutrición o quite el hambre al niño:

"Y, la falta de alimentación o alguna enfermedad que no lo deje alimentarse.

Y, que no coma bien... como ser, en el caso de él no quería comer. No, inclusive ahora le cuesta bastante. De la sala lo mandaron para acá. Y él gracias a Dios se va recuperando... no. Y... eh, bueno él está...ahora como ser eh... la doctora me dijo que le faltaba poquitito." (Mónica)

La anemia de la hija es explicada por la inadecuada alimentación. Las recomendaciones culinarias dadas por los médicos facilita la incorporación de alimentos antes rechazados:

"Le faltaban glóbulos me había dicho la doctora...porque no comía tantas cosas como debía comer, de chiquitita yogur nunca quiso comer, igual que hígado, carne y ninguna grasa me comía, hasta que después la traje acá y me empezaron a decir: 'cortala bien chiquitita, que ni la vea' y entonces ahí recién empezó a comer. Sí, porque antes comía fideos y verdura y la carne no te la tocaba; nada quería saber." (Norma)

Como explicación de carácter general, la mala alimentación: "no tienen alimento", "son mal alimentados", es la base de la desnutrición. Pero, para este caso, la excepción hace la regla y el "rechazo" del organismo a los alimentos se origina en los parásitos o en la anemia.

"La mala alimentación. No sé, cuando ellos no comen y no quieren comer y están flaquitos.

O sea, están flaquitos no por que les falte alimentación, sino porque el mismo cuerpo lo rechaza al alimento. No, porque por ahí...están bien alimentados y...tienen algo ellos...que les produzca desnutrición como los parásitos...

Lo rechaza...y a veces por que tienen algún problema en el organismo; puede ser algún tipo de problema en la sangre o los mismos parásitos....también puede llegar a ser por falta de comida.

En el caso de ellos no, por que ella come, come bastante y estaba bajando de peso, era por parásitos.

Y yo te digo no era por falta de alimento, sino solamente porque tenía algún problema, tenía también anemia ella, pero hay mayoría que en la nutrición es por que no tienen alimento, no son bien alimentados. Pero en el caso de ella no fue eso." (Norma)

Para la misma informante, la desnutrición se produce por falta de alimentos básicos (fruta y carne) y por la preparación de comidas no nutritivas como los fideos. Ahora, 
admite haber tenido problemas alimentarios resueltos a veces con la ida a comer a casa de parientes, vecinos o amigos:

"La mayoría de las veces con los alimentos básicos, las frutas son necesarias y hay muchas comidas que no pueden comprar, igual que las carnes y todo eso. A veces que le tenés que dar un plato de fideos hervidos y que te alcance, y también por ahí viene la mano.

Al mío por lo menos me pasó así; a veces no he tenido para darle de comer y tenía que hacer lo que tenía, y ella lo comía igual.

A veces le he tenido que dar fideos hervidos porque no tenía otra cosa, a veces tenía un poquito de arroz y le hacía arroz con leche y capaz que era lo único que comía durante todo el día.

Pero después...pero por eso no tuve problemas con el alimento porque después por ahí a la noche iba a la casa de alguien y ya comía bien; entonces no tenía ese problema." (Norma)

La mala alimentación obedece tanto a la escasa y pobre oferta dentro de la familia como a razones individuales. El rechazo de la comida por parte del niño o la falta de apetito, cuya causa la madre desconoce, motiva -junto a la percepción de cansancio, pérdida de fuerza y desánimo-, la sospecha de probables problemas nutricionales, razón por la cual se consulta al médico:

"Y esto nomás le agarró cuando era muy chiquito, no crecía, siempre estaba lo mismo. Y no aumentaba de peso. Yo cuando lo llevaba primeramente, viste que lo llevaba a Romero, éste estaba nomás con dos kilos nomás.

Bueno. Después lo sacamos. Después lo trajimos de vuelta porque no aumentaba, siempre lo mismo.

Ahora, no me andaba comiendo ¿viste?, muy poquito come, ¿viste?, come dos o tres bocaditos y parece, parece que está como lleno, hace un tiempo atrás que come muy poquito, por eso lo traje a él acá...

Y no sé, eh, no sé, por qué come poquito, mirá, no sé qué es lo que tendrá, ¿viste?

Yo, por las piernitas, capaz que no está bien alimentados, capaz que no tiene fuerza esto, digo yo, me entendés? Nos damos cuenta como que no tiene ganas, como que está cansado, viste, como que le duele todo viste?

La desnutrición, podemos decir si no uno, no le alimenta bien, si es que, ¿te das cuenta?...otro es que por ejemplo ya nació así, ¿viste?, con bajo peso...eso ponele que no come lo realmente, o le falta, uno le da lo justo, si no tiene comida ya él baja esos...esos kilajes, ¿me entendés?...

Por ejemplo ahora yo lo traje porque él está comiendo muy poquito...me dio esos medicamentos, ¿viste?, o sea que mí, para mí parecer es que cuando no come bien, o no se lo alimenta bien se viene abajo...

Yo veo por él, ¿viste?, yo veo que él cuando ya un poquito que no come, o que deja de comer, ya él baja los kilajes que él tiene...

Y eso depende por la forma, según la forma de que uno cuida a un chico, ¿te das cuenta?, si uno lo tiene así nomás, ya el chico enseguida se enflaquece.

Si la persona que está arriba, no le importan los hijos, claro, se, eh, en seguida se, se viene abajo. En cambio a este chico, eh, no tanto porque estamos arriba, ¿viste?, ¿te das cuenta?

Porque un chico, así, de esta edad hay que estar, no es ir, tener y... ¿te das cuenta?

Además, más él, que necesita más...los otros, no es tanto, porque se saben desenvolver." (Cristina)

La mayoría enfatiza como causa de la desnutrición a las parasitosis u otras enfermedades: 
"Sí, pero no sabés lo que era, mucho más gordo, estaba pesando arriba de diez kilos y ahora me está pesando siete y pico. Es poco para lo que..., aparte estuvo muchos días con diarrea...y ahora me dijeron a mí que porque tiene una infección." (Estela)

Algunas, con vistas a minimizar la importancia del problema dentro del núcleo familiar, enfatizan que la desnutrición ocurrió a "ella sola nomás", a causa de desórdenes gastrointestinales:

"La nena, ella nomás. Ella sola nomás. Porque empezó con colitis, vómitos...y yo la veía muy flaquita. Sí, muy flaquita la veía. Eh... fui a la salita y me mandaron para acá..." (Ana)

La hinchazón del abdomen, es atribuido siempre a los parásitos, cuya habitualidad le hace decir que a su hija "la veo bien" porque "anda".

"No, panzona nomás. Puede que tenga otra vez parásitos. Ya tuvo. Este, lo que le veo a veces a Delia, sí, mucha panza. ¡Un día tenía una panza que madre mía! Yo la veo bien, ¿vio?, en el sentido que anda.

Y no sé cómo estará, no sé cómo será. No sé, muy, muy, muy blandita la carne, ¿ vio?

Sí. Porque ella estaba, cuando la llevaba al Hospital de Niños estaba con vitaminas, con hierro, estaba con todo. Y ahora como no fui más, no está con todo eso. Está comiendo bastante bien.... morfa una barbaridad. De comer es de comer bárbaro. Come de todo. De lo que venga. Así que no sé, se habrán metido parásitos.

La panza, ¿viste?, se le infla. Hay días que tiene mucha panza y hay días que no tiene nada.

Toma la leche. Almuerza también, y a la noche también.

Es de comer bien, bien. Sí, y ella es de comer bien. Por ahí le siguen faltando vitaminas o..." (Celeste)

Es en el diagnóstico médico donde se sustenta la relación causal parasitosisdesnutrición;

"Desnutrición era. Pero yo, para mí como dijo el médico, que eran los mismos parásitos que...por eso se vino bastante abajo." (Valeria)

Por eso, se concibe a la desnutrición como secuela: su hijo tiene peso adecuado pero ya quedó petiso, "enano" según los médicos:

"Primero le agarró una neumopatía....cuando me da la doctora el tratamiento, porque tenía que tomar unos antibióticos, los rechazó. Después cuando empieza a rechazar los antibióticos y yo lo veía, vos te das cuenta cuando los chicos te comen, yo veía que comía pero se venía abajo. $Y$ en menos de una semana se me venía abajo entonces por eso, ahí es cuando la doctora lo vio y me dijo urgente un análisis en el mismo día, y dijo: 'este chico está gritando que tiene parásitos', y ahí nomás me dieron el tratamiento. Y era una cosa increíble, no tenía ganas de jugar, no tenía ganas de nada.

Ahí es donde se me atrasó de crecimiento. Después mejoró un montón, al mes nomás mejoró un montón. A los dos años eso fue. Y se venía y se venía abajo, abajo, lo que comía lo devolvía y todo así, fue una cosa de loco. Pero estamos en tratamiento porque no crece, tengo que llevarlo el lunes temprano al especialista al Hospital de Niños porque le falta crecimiento, lo llevé la semana pasada para que le vea el peso y el crecimiento, el peso está bien, pero el crecimiento es poco, es petisito para la edad que tiene.

Ya me dijo la doctora que me dijo: está entre los petisos. Y cuando lo midió bien dijo: no, está entre los enanos. Pero vamos a ver lo que pasa, luego me dijo que enfermedad importante tuvo, y esa es la única enfermedad importante que se pueda decir importante pero después de eso no." (Marta) 
El descuido, referido a la desatención en la comida de los hijos o su atención en el curandero, a veces es asumido por la propia informante de manera indirecta. Todas las situaciones que menciona a la manera de recomendaciones y preceptos, estuvieron presentes en la desnutrición de su hija:

"Sí, es depende de cómo sea la madre también, a veces. Hay casos que hay madres que tienen los hijos y ni se acuerdan; los sienten llorar y por ahí les dan un pedacito de pan o una mamadera y ya está, y una mamadera toda aguachenta, a veces no les dan la mamadera como le tienen que dar. Las mamás tenemos que estar atentas porque por ahí, en un simple descuido el chico se nos viene abajo y no sabemos por qué y no simplemente recurramos a los curanderos, a veces por más que los lleves no resulta nada. Hay mucha gente que lo cree, pero yo me tiro más para los médicos. Por ahí solamente no necesitan dos o tres palabras si no que también hay que forzar el cuerpo "(Norma)

En términos abstractos se alude a la mala alimentación; en el caso particular la errada automedicación con yuyos motiva la internación y la pérdida de peso:

"Por falta de comida. Cuando no empiezan a comer. Cuando no quiere la leche, la devuelve. No, no. Solamente a ella. Estuvo internada porque le daba esa yerba de pollo, porque andaba con dolor de estómago, de panza. Y después cayó en el hospital. Estuvo como una semana internada acá. Y después no, no la usé más. Yo le daba al nene, pero él era más grande que ella. El otro tenía más defensa que ella." (Lola)

El descuido materno la mayoría de las veces refiere a otras mujeres:

"Sí, hay...chicos, que las madres no los cuidan, no miran, después se enferma, y no saben que hacer porque está, eh...destruido, porque no lo cuida la mamá. Muchos, allá por mi barrio hay muchos.(Abasto.) Eh, ¿viste?, no los cuida la mamá, y no van...

$Y$ así andan esos chicos que, ni te cuento, sucios...eh, comen lo que, jay, qué Dios no permita!, lo que le dan por ahí, ¿viste?, dicen: 'no, yo tengo...', yo los miro a veces, chicos chiquititos...

$Y$ vos las ves a las madres... y te das cuenta de los chicos desnutridos por las patitas, ¿viste? por las patitas y los bracitos, ¿viste cómo tiene mi hijo, así?

Bueno, y yo digo: 'ay', le digo a mi esposo, y vos las ves a las madres, ¿vos te pensás que se hacen problema?" (Cristina)

Aunque algunas asumen la apreciación que reciben de los médicos que atienden a su hijo:

"Se pone flaquito. Y, porque está desnutrido, porque no tiene leche, no está alimentado como tiene que ser. No tiene las proteínas que tiene... que necesita un chico, me entendés?

$Y$, de pronto por falta de causas que uno no tiene para darle, me entendés?

Por eso que yo ahora... estoy con problemas, porque... yo fui allá, a Romero, y me dijo: 'madrecita, qué chico más feo tenés!' " (Cristina)

La madre es la principal responsable del rebusque para asegurar un plato de comida:

"Mal atendido el nene. Porque si uno quiere para un plato de comida el nene se la rebusca. No asi digo de mala fama, no? Puede trabajar o pedir en las casas o.. como yo a veces cuando no tenía iba a buscar... Plan País así... Esto es todo la madre." (Valeria)

Descuido, falta de alimentos, falta de trabajo, están en la base de la desnutrición de los demás. En su caso particular, luego de negar desnutrición en sus hijos, sólo le falta "crecimiento a uno y peso a otro", la desnutrición es producto de enfermedades: 
"Es un.... ¿cómo se llama?... bueno, aparte es por falta de alimentos y también por descuido de la madre, las dos cosas están juntas, la falta de trabajo. Es lo principal, porque si no hay trabajo no se pueden alimentar, y así descuidado de la madre que tiene que correr bastante.

De desnutrición nunca tuve problema yo, no nunca, la verdad que nunca, no en ese sentido no.

No, le faltó peso a uno y crecimiento un poquito al que va a venir, pero porque tenía muchos parásitos, era una cosa increíble como tiró parásitos." (Marta)

La falta de destreza de la madre para incorporar, en la dieta del niño, alimentos que son rechazados tempranamente, refuerza la monotonía de las comidas:

"No sé, qué sé yo, yo pienso que por ahí muchas veces es la falta de alimento, o sea no sé, por ahí hay chicos que comen y comen pero no lo que realmente los alimenta, entonces ahí está el problema de la desnutrición del chico y eso es lo que pasaba con el nene mío. A Maxi le pasó después de los seis meses. O sea, se había acostumbrado a comer lo dulce y no quería comer lo salado, y entonces claro, comía yogur, manzana y la comida nada, entonces llegó un momento que ya eso no lo alimentaba.

Y bueno con ella, bueno pero ella comer comía, pero es flaquita, es chiquita (también fue atendida)" (Mónica)

La pobre calidad de la alimentación recibida se relaciona con episodios de desnutrición y de infecciones pulmonares que requirieron internación en uno de los hijos. En el caso de otro hijo, de menor gravedad, también comenta las dificultades para el aumento de peso:

"Bueno con ella tuve que andar bastante y con el también... estuvo internado, estuvo bastante mal, bah ...bueno aparte de la neumonía. Claro, o sea lo internaron por una neumonía y después bueno, estaba muy bajo de peso no subía casi y ella me costó bastante también porque subía muy poquito, capaz que aumentaba cien y bajaba doscientos. La verdad que no sé por qué ... le cuesta mucho a ella subir de peso." (Mónica)

La misma informante, en una segunda entrevista, momento en el que ejercía el cargo de manzanera suplente, (encargada en el barrio de distribuir el programa alimentario VIDA), vuelve sobre el tema del ingenio para cocinar:

"Lo que pasa que el problema es que hay mamás que no saben cómo utilizar las cosas entonces claro, los chicos se cansan a veces y no lo comen.

A veces traen quácker, fideos, tallarines, arroz, harina, polenta, pero claro, qué sé yo, hay gente que no sabe cómo utilizar el almidón, el quácker, la maicena también." (Mónica)

Finalmente, se da el reconocimiento de que la madre "inconscientemente no sabe desarrollarse" oportunamente a fin de responder a las necesidades del niño, ya que la comida que la madre considera nutritiva no es la que éste precisa:

"La desnutrición desde ya es por mal alimento, por ahí que come bien, que a la criatura le falta hierro, o alguna otra vitamina...y uno inconscientemente no..., no sabe desarrollarse en ese momento que le hace falta a la criatura, por ahí un buen guiso, un, una buena comida...bien polentosa, para una criatura por ahí no es suficiente..." (Camila) 
La autoculpabilización aparece en dos casos; en uno la madre siente angustia y vergüenza a la vez por su descuido y demora en el control; la culpa desaparece cuando el niño mejora:

"Uno mismo se desespera al, al ver a su hijo que está de bajo peso, que no come, qué es lo que tiene, que por qué se desnutrió, por qué se vino abajo, uno se hace muchas preguntas... Y uno mismo se echa la culpa: 'es culpa mía porque no lo llevé a tiempo a un médico, porque yo lo veía que no comía y no lo llevaba', uno mismo se echa toda la culpa.

Cuando ya empieza la criatura, digamos a recuperarse, ya uno se saca esta culpa, es un cargo.... uno mismo dice después ...ya dice: 'Y bueno, el chico ya empezó a andar bien'.

Hasta que te empiecen a decir las vecinas: 'imirá qué hermoso que está!', 'imirá cómo anda!, ¡mirá la energía que ya tiene!', o que por ahí lo levantan y: '¡eh, qué pesado que estás, hijo!', le dicen. Y ahí uno se pone contenta. Bueno, a mí me ha pasado con mi hijo.

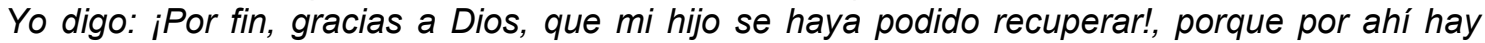
chicos que no se recuperan....si uno no lo agarra a tiempo, la criatura no tiene vida, porque la misma desnutrición la lleva a la muerte a la criatura.

Digamos, de..., yo he estado con gente que por ahí conoce un poco más, digamos, de la desnutrición, y les abre los ojos a otros. Yo les diría a las madres que por favor cuiden bien a sus hijos, que los lleven todos los meses al médico." (Camila)

Si bien la madre asume la responsabilidad por la desnutrición de su hijo, menciona la pobre calidad de la comida en el hogar. La carencia de pan, leche y carne con el consecuente aporte deficitario de vitaminas y hierro, la monotonía de la alimentación en base a fideos, coincide con etapas de desocupación del jefe:

"Porque por ahí le hace falta hierro para los huesos como a mí me ha pasado con mi nene.

Él ya a los ocho meses, le faltaba hierro, vitaminas, y yo lo veía que estaba bien, que él comía, lo que era que a él le pasaba que le faltaba vitaminas y hierro para darle más fuerza al cuerpito de él.

Me ha faltado comida, sí...Me ha faltado, que muchas veces le he tenido que dar a mi hijo un plato de fideos con aceite nada más, porque no he tenido otra cosa.

Me ha faltado el pan, que eso es esencial para la criatura que la criatura vive comiendo, pan aunque sea. Y eh..., he estado hasta dos semanas sin pan, o sin leche o..., un pedazo de carne para una semana...

Y para una criatura un pedazo de carne, un churrasco dado vuelta y vuelta, eso es vitamina...

$Y$ al no..., al no tener esos recursos que mi marido ha estado sin trabajo, los chicos se vienen abajo. A causa de eso.

Recién ahora en este año, ahora después de las fiestas mi marido agarró una, un trabajito, que yo te había explicado...pero, ¿ves?, ya el lunes no trabajó porque estuvo descompuesto y hoy por la lluvia. Y claro, le pagan por día, cobra lo que trabajó ayer." (Camila)

En el otro se plantea como causas la falta de lactancia y la dilación de tiempo en el control de salud. La madre reconoce no haber percibido la pérdida de peso en su hijo; lo que ella consideraba el buen comer del hijo, no incorporaba aportes necesarios como el hierro: Asimismo, su dependencia con el médico de la salita y la alteración de los turnos de atención durante el verano, hizo postergar las fechas de control. Sin darse cuenta, el niño "se me vino abajo", "se me fue yendo de peso":

"Mirá, ha estado desnutrido por uno, ha sido culpa mía porque no... yo lo veía que comía pero no..., nada que ver a los otros. Lo veía que comía bien, pero...

No los otros ninguno tuvo, ninguno. Me pasó con el cuarto...es el último.

Y, mirá, el Emanuel ha estado así porque por ahí yo lo veía que estaba bien. 
Pero no era que lo, que él necesitara de un plato bueno de comida sino que necesitaba hierro. Iba a la salita, sí. Pero yo estuve como dos, tres meses que no lo llevé.

Porque era, estaba justo para esa época que se van todos los médicos...¿iviste? de vacaciones...claro, eh, y no lo llevaba.

Y como a la tarde no se hace control...la mañana atiende la doctora para adultos nada más.

A la tarde atiende para lo general. Entonces..., no lo llevaba.

$Y$ por ese mismo motivo, el chico se me fue ¿viste?, yendo abajo de peso sin que yo me diera cuenta. Se me vino abajo. Ya a partir de los ocho meses, ya el nene empezó a tener bajo peso. Nunca tomó teta. Ni cuando nació, ya de entrada no...porque era, yo no tenía nada de leche. Nada, era como que se me habían secado los pechos. Con los otros no, los otros eran distintos, los otros tomaban, la nena encima, la que tiene cuatro años...me tomaba ya casi hasta los ocho meses." (Camila)

Pese a enfocar inicialmente el problema de desnutrición de otro caso, explica finalmente que en el suyo, el rechazo de la lactancia fue lo que llevó a la desnutrición de su hija. La "carrera de enfermo" muestra, sin embargo, el uso tardío de los servicios de salud:

"Más que la nena mía el nene de mi mamá....ah! ¿Indira? [su hija] porque no le daba el pecho. No me quería tomar el pecho entonces se vino abajo, y no me quería comer...no sé...eso hace... cuando nació Indira. Cuando nació qué tendría dos meses...cuando la traje...me la trasladaron acá. Y empezó ahí cuando la empezó a desnutrir. Porque le quería dar teta y no quería tomar teta.

La llevé a la salita de Abasto porque la empecé a ver mal. Viene el médico una vez que la vio la revisó y llamó y me dijeron que la ya venía la ambulancia para trasladarla." (Silvia)

El siguiente relato corresponde a una madre con un muy bajo umbral de percepción de las necesidades y de los problemas de salud de sus hijos. Expresa la naturalización de situaciones que debieran haber provocado preocupación y por tanto responde al estereotipo de descuido:

"Porque no quiere comer. Se me pasa durmiendo. Ya me pasó a uno, me estaba de bajo peso, todo y tenía dos meses. No, ahora no lo tengo más. No, la nena y el nene me lo sacó Casa Cuna. $Y$ dos que perdí. $Y$ dos... uno que perdí, que se me ahogó adentro del fuentón, me estaba bañando y se me cortó el cordón. Era un varón. Yo estaba embarazada, y me estaba bañando y se me cortó el cordón. Y se cayó... se me murió." (Zulema, tuvo 9 hijos)

Pese a esto, afirma tener hijos "grandotes" y asiste al hospital por el bajo peso de una hija que no come bien, con el resto, dice no haber tenido problemas:

"No. Yo nunca los tuve los chicos... Es lo que yo tengo los chicos grandotes, todo.

Acá vengo por la de bajo peso y le dan por los chicos que no come bien. La nena que está afuera... ella nunca. Mire que come... bah, nunca y ella no sé por qué está baja de peso. No, la nena, la otra, nunca eh? Nunca...no, los otros que yo tuve nunca." (Zulema)

La angustia que genera el saberse pobre y las dificultades para mantener la salud de sus hijos son motivo de angustia y preocupación permanente. Hasta los médicos presagian enfermedad de hijos futuros, sin brindar soluciones que apunten a la prevención: 
"Imaginate que yo que soy como yo digo, mamá, yo soy pobre, no sabés; él es enfermo, no sé de dónde agarrarme, porque hay días que tengo ideas y hay días que no... Yo me preocupo mucho por él, por eso que a veces un poquito, ya le levanta fiebre, ya esos kilajes que él tenía ya los pierde en dos o tres días, ¿viste?, por eso, que hablé en todos lados, allá los del Romero me dijo uno de los médicos: 'No tenga más, señora, usted no puede tener más, porque usted, usted y sus hijitos que va teniendo y siempre', ya van a nacer con problemas..." (Cristina)

Decaimiento, delgadez, falta de ánimo, cansancio, pérdida de fuerza, mal color en la cara, hinchazón abdominal, piel floja, ojos hundidos son los síntomas con los que vinculan a la desnutrición.

“...yo le veo flaquito, decaído, no sé, la otra chiquita tiene tres años y es flaquita así como éste. Pero si vos la ves, es una diabla." (Juana)

"Y, porque está muy delgado, muy...ya demasiado." (Mónica)

"Se siente decaído, y se empieza a decaer." (Silvia)

"...yo creo que cuando ya... te das cuenta cuando lo levantás y sentís que está más livianito...que no quiere comer, ya más debilucho...que no tiene ganas de hacer nada...no sé." (Norma)

"Están decaídos, los ojos así medios hundidos, medios amarillos, no tienen ánimo de nada, hay algunos que sí se dan igual el ánimo para andar, pero te das cuenta igual que les falta esa energía que tiene que tener un chico cuando está bien." (Norma)

"Con los chicos mal alimentados, sí, ¿viste?, no tienen calcio, ¿vos sabés que había un nenito de tres años que no tenía fuerza en las piernas en el hospital de la desnutrición que tenía...

No tienen fuerza ¿viste?, es como que se le hincha la pancita, pero, la panza, ¿eh?

Después están todos flaquitos, eh, el nene ese estaba todo pálido...

Yo no quería estar, ya a lo último le dije a la enfermera sí, que me averigüe con la doctora para que me cambiaran de sala porque no lo podía aguantar. Porque ya era tanto, como que él se quería levantar y como que las piernas se le aflojan, no tiene hierro, le falta vitamina y fuerza a esa criatura." (Estela)

A veces, los síntomas iniciales no generan alarma en la madre y la consulta deriva en una inmediata hospitalización:

"Pero a lo que la llevé a Delia, que a la Delia la llevé a la miseria, ¿vio?, que estaba piel y hueso esa nena...era distinto a lo de él porque ella vivía durmiendo y él no.

Ella vivía durmiendo día y noche, día y noche, vivía durmiendo. Se la llevé a la salita de Loreto, estaba linda, llegó a cumplir el año, estaba hermosa esa nena, pero re-gorda, hermosa, y después del año se me vino abajo. Me fui a llevársela a Loreto, y Loreto me sacó volando de ahí. Me dijo: 'ya te la llevás al Hospital de Niños.'

Sí, yo la vi, pero lo que pasa es que qué sé yo, yo la dejé también pasar un poco, porque yo la veía que esa nena ¿vio? Entonces vivía durmiendo." (Celeste)

"Era normal pero de bajo peso": la sospecha de alguna enfermedad provoca la reacción tardía de la madre. Derivación inmediata de la sala al hospital y el resultado, un niño petiso.

"Y empiezan a ponerse flacos, por lo mismo que les falta hierro, no comen vitaminas, eh, empiezan a ponerse medio amarillentos, medios flacuchos, ya no empiezan a levantar altura...

Quedan como siempre chiquititos y...ya no crecen, uno quiere que crezcan pero siempre es chiquito; a mí me pasó con Emanuel... Ahí fue cuando empecé a movilizarme... 
Que algo tenía que pasarle. Al menos porque, alguna enfermedad que tuviese, eh, análisis de sangre, análisis de orina, todo tipo de análisis que pudiera haber se le hizo a él.

De la Salita lo mandaron allá al hospital. Era un nene normal pero, estaba bajo de peso y... de altura, como para él, bueno, el doctor ahora, me dice que, que para la altura de él, está bien el peso pero es muy chiquito a la vez por la edad que tiene. Él tendría que ser más alto, por eso ahora le estaba dando, eh, hierro y vitaminas para que..." (Camila)

El tratamiento se basa en el seguimiento de las indicaciones médicas y en el suministro del suplemento nutricional que se les provea:

"Traerlo, hacer todo lo que tengas que hacer, no sé....hacer lo que te dicen que hagas." (Aguirre)

"Llevarlo al control que lo vean y que le den lo que el chico necesita. Y si necesita calcio o... potravita algo así...que le de." (Silvia)

"Con un buen tratamiento seguro que se curan, porque ella se curó con un tratamiento de los médicos." (Norma)

“...y el control del hospital, o de la salita." (Ana)

"Darle el medicamento, vitaminas. Hacerle el control todos los días." (Lola)

La buena alimentación en la casa, rica en calcio, hierro y vitaminas es el tratamiento recomendado:

"No sé, tratar de hacerlo engordar, no sé. Darle...y, con calcio, hierro, y la buena alimentación, no sé. Bueno por lo menos a los míos por lo menos con una buena dieta, con el nene que estaba anémico, con hierro vitaminas, nosotros ahora lo vemos que está bien, y con eso salió adelante." (Mónica)

En algunos casos, se subestima la capacidad terapéutica de los médicos ya que, sus recomendaciones resultan imposibles si no se tienen los alimentos indicados:

"Mirá, eso se cura con bastante hierro y comida, lo que sea que tenga bastante hierro.

Los médicos no pueden curar, ellos no, porque ellos lo único que te pueden decir, lo que van a darle de comer ellos, y si vos no tenés en tu casa..." (Estela)

Las analogías fonéticas entre "desnutrición" y "deshidratación" y la incidencia de ambas en algunos niños generan confusión respecto del tratamiento:

"Y alimentarlo, no es cierto? Hay que darle de comer. Hasta donde ... hasta donde quiera ¿no es cierto? $Y$ darle... para que no se desnutre, hay que darle mucho líquido también, no es cierto? Eso que yo veo que a veces escucho, que quiero que a veces me explique, hay que darle mucho líquido no es cierto? Aunque sea yo allá por ejemplo, yo a veces cuando tengo le compro jugo, ¿viste? De eso que se prepara, ¿me entendés? Le doy. Pero a veces, dice mi esposo le va a doler la panza. No, le digo, no le va a doler la panza. Si uno tiene miedo, le digo, el chico se deshidrata en .. que ahora a veces viene el calor se deshidrata enseguida. Hay que darle hasta donde quiera ¿viste?.” (Cristina)

No consideran recomendable la consulta a la curandera, hecho frecuente en estas familias. La sospecha de empacho cuando dejan de comer retrasa la consulta médica: 
"Primero consultarlo con el médico; aunque la mayoría no, lo ven así y por hay dicen que no, que es algún tipo de enfermedad que lo puede curar una curandera y qué sé yo y lo llevan.

Sí eso lo veo yo... sí, es común, muy común; por ahí la nena no come: sí porque está empachada, o no come por que esto." (Norma)

Tal es el caso de la siguiente niña:

"No, porque primero yo la llevé antes de acá, antes cuando estaba así, yo la llevé a curar a la nena, del empacho. La señora me dijo que era un empacho que tenía, estaba atacada el higado...

Que después se iba a recuperar. Bueno, la dejé como dos, tres días hasta que terminara y la nena estaba cada vez peor. Me tuve que ir a la Salita y no..., tenía sí ese problema de empacho, pero ya no era para tanto. Ya de ahí me sacó volando a mí de ahí.(...) me la internaron, pero era piel y huesos, chiquita, tenía... cumplió tres meses en el hospital, internada." (Celeste)

Respecto de la prevención, todas plantean la importancia de cuidar la alimentación y controlar el aumento de peso:

"y dar, la madre al nene no? darle de comer, atendiéndolo mejor...ahí está la madre, que tiene que estar." (Valeria)

"Y, alimentarlo bien. Con las cosas que corresponde. Y, darle... tratar de darle todas las clase de comida de...qué se yo, que tengan hierro, vitamina... El hígado, los huevos...y qué se yo, Vitina." (Mónica)

"Claro, y darle de comer todos los días. Darle pollo...postre...manzanas, yogur, gelatina...naranja, el jugo de la naranja." (Ana)

"Y eh, tenemos que estar los padres para ver si, si vemos que los hijos no aumentan de peso, porque ahí empieza la desnutrición, al no tener aumento de peso, porque mi nene en dos años estuvo casi con el mismo peso, más de diez kilos no aumentaba en dos años. Y es feo tener un hijo desnutrido." (Camila)

Cuidarlos especialmente en verano de las diarreas y proveerles líquido para hidratarlos:

"Para mí siempre yo...tratar de darle de comer, que no se me queden ahí, que no le agarre diarrea, que no...que los días de calor darle agua..." (Silvia)

"..y que coma, que coma cuando tiene que comer. También que tome líquido que tiene que tomar porque eso también..." (Norma)

Aunque frecuentemente reconocen que esto no es posible:

"Y sí, se puede, ya directamente desde que empiezan a comer alimentarlos como debe ser. Pero hay veces, por más que quieras...se hace el esfuerzo de alimentarlos pero no podés porque no tenés." (Norma)

Los cuidados dispensados no aseguran la salud de los hijos:

"Cuidarlo bien...no sé, dándole... mirá, yo les doy todo a ellos...

Cuidarlos, pero muchas veces por más que lo cuides se enferman igual...o no..." (Juana)

Y la abundancia de comida no garantiza el buen estado nutricional: 
"Eh... ¿usted dice por cuenta propia?...la verdad que no sé. Yo hasta ahora nunca probé, así que...por por ahí uno le puede dar mucho de comer y queda anémico. Como ser él... él está gordito, pero tiene que tomar bastante tiempo hierro y esas cosas..." (Mónica)

Así, una madre afirma que no es posible prevenir sin el asesoramiento nutricional de los médicos:

"Tratar con los médicos, preguntar ¿no es cierto?, a ver qué...si le podés dar ¿cómo es que se dice? alguna vitamina, qué es lo que tiene. Porque... por ejemplo que me explique qué puedo hacer, viste, qué le puedo dar, qué es lo que por ejemplo, qué vitamina le va a caer bien, qué le puedo... qué alimentación le puedo dar, ¿me entendés? No lo vas a dejar mucho porque después...no ¡cómo cuesta para levantarlo!" (Cristina)

Otras comentan la absoluta imposibilidad de prevención. Describen situaciones extremas de institucionalización o abandono de hijos a las que han llegado muchas familias; en ese caso la responsabilidad recae en la sociedad que no brinda protección y excluye del mercado de trabajo a las mujeres con niños:

"Acá, me estaba contando una doctora, que han encerrado a chicos en un colegio, las propias madres porque no los pueden mantener, antes que se les mueran en la casa lo quisieron encerrar en un colegio, ¿a vos te parece llegar a eso? $Y$ eso me lo han contado las mismas pediatras, cuando yo estaba ahí.

¿Cuántas madres hay que regalaron a los bebés porque no les pueden dar de comer?

O no la quieren recibir en el trabajo porque tienen un bebé.

Dicen: "No, no, porque tenés chicos no podés, porque un día se te enferma el chico y no podés venir a trabajar". Así te contestan, son desamoradas esas mujeres. ¿Te das cuenta?" (Estela)

La categorización de la desnutrición como enfermedad es ambigua.

El ser producto de la desatención y no resultar de un contagio, hace que algunas nieguen tal estatuto:

“¿Una enfermedad? No, no se podría llamar una enfermedad, lo que sí hay que estar atentos, nada más.

Porque no es contagiosa; es algo que pasa por desatención a los chicos o por que no tienen los padres para darles de comer. Porque si fuera una enfermedad contagiosa, todos tendríamos lo mismo." (Norma)

"Y, no sé, yo la verdad que no entiendo bien cómo será eso, si la desnutrición viene por falta de comida, o falta de atención, no, no sé explicarme bien cómo, de qué viene eso." (Celeste)

Al no ser enfermedad, la competencia médica interviene en la prevención o tratamiento de complicaciones que de ella se derivan:

"No, no, no. Esa es cosa de, ¿cómo te puedo decir?...cosa de alimentarlo, de cuidarlo un poco, ¿viste?, pero la enfermedad, la desnutrición no es una enfermedad, me parece, tan grave, digamos.... ¿no es cierto? Y, la tratan los médicos para ver que no le llegue a complicar otra cosa, ¿viste?

Porque yo a veces escucho, y pregunto si está bien o no, pero a éste por ejemplo, lo están tratando para que no se le complique otra cosa, como él tiene tanta cosa, que a él, por ejemplo, si un poquito que baja de peso, ya se le puede complicar otra cosa, entonces por eso lo traje hoy..." (Cristina)

La oportunidad de la consulta define el carácter de enfermedad: 
"Si está a tiempo no, pero si se deja estar mucho, sí. Hay muchos chicos que se murieron por el problema ese, por lo que uno escucha en los noticieros. Muchas veces puede ser responsabilidad de los padres porque... qué se yo, la verdad es que no se preocupan mucho por si los chicos comen o no comen y muchas veces por falta de trabajo." (Mónica)

La necesidad de internación fundamenta la convicción de que se trata de una enfermedad:

"Y yo pienso que si, porque a muchos chicos tienen que estar internados en muchos casos así que yo pienso que sí." (Mónica)

No obstante la ambigua consideración de la desnutrición como enfermedad, la mayoría opina que la participación de los médicos es fundamental en su curación. Las vitaminas, el hierro, calcio y las recomendaciones alimentarias forman la base del tratamiento.

Las vitaminas y el hierro son medicamentos altamente valorados por su efectividad:

"Sí. Y dándole remedio...hierro...calcio... vitaminas." (Ana)

"Sí, con medicamento. Y son vitaminas, nada más. Y darle más de comer. Y darle las mamadera a la hora." (Lola)

"Y, con la vitamina que le dan a los chicos... él tiene un montón de vitaminas que está reponiendo.

Lo veo por el ánimo, porque está más gordo, más inquieto." (Mónica)

Además, el diagnóstico diferenciado que realizan los médicos sirve para determinar el tratamiento conforme a las causas de la desnutrición:

"Si, yo pienso que sí,... o sea porque hay chicos que por ahí están desnutridos por otra enfermedad." (Mónica)

La preparación del hígado, la vigilancia durante las comidas, la imposición de horarios para comer, la supresión de las comidas a demanda fuera de horario son algunas de las recomendaciones que han dado resultado:

"Sí, se aprende y mucho, porque hay tantas cosas que uno no sabía.

Por ejemplo: yo no tenía ni idea de cómo se hacía el hígado y toda esas cosas que yo lo ponía a hervir, lo pisaba, no tenía ni noción de eso. Igual que si tiene más de 37 1/2, recién es fiebre; y también lo que le pasa, lo que come lo que no come, mirarla porque a veces dice que está comiendo y se lo tira al perro y no comen. Venía y me decía que ya comió y ya le había dado la comida al perro; le tenía que volver a servir, sentar a la mesa y hacerla comer mirándola yo, sino...no comía. No tengo hambre dice, quiero leche, ella quería mantenerse con la leche. Con el tiempo la doctora me dijo: 'tenés que tener un tiempo' para darle las comidas, después dice a la tarde la leche y después la cena, pero tenés que ponerle vos el horario.' No que ella, cada vez que quiera la leche, vos le tenés que estar dando." (Norma)

"Sí. Y, porque ellos saben más, ellos ya saben lo que, cómo se cura eso, todo y sí, los padres pueden ayudar. Sí, porque cuando yo la llevé a ella la llevé muy mal, y estuve tres meses en el hospital y salió bien la nena." (Celeste)

Si bien los médicos saben más, los padres cumplen un rol fundamental: 
"Yo pienso que sí. Vitaminas, así dando el medicamento; ayuda también de los padres porque si los médicos te explican todo como tenés que hacer, darle el medicamento a horario todo eso y vos no...tampoco no te importa, sos vos, no los médicos. Ahora espero que recupere su peso. Que sea un poquito más alta, porque muy chiquita la veo." (Valeria)

Aunque no intervengan medicamentos, el cumplimiento de la dieta médica da buenos resultados:

"Pienso que sí. Sí, curarla la curan, porque los míos se curaron, nunca más tuvieron... Le dieron la alimentación, la dieta lo que le dan ellos...lo que tienen que comer y todo eso lo que le tengo que dar." (Juana)

La función de los médicos es de "empuje y control": La de los padres, tributaria de la primera, es mucho más importante:

"Control...hierro, vitaminas... es digamos, es un poco más de empuje para que los chicos coman un poco más. Porque el mío tuvo hasta que tomar esas vitaminas, ¿eh?, como para que le abra el apetito.

Porque ya tenía como el estómago cerrado. Porque no, ya no lo comía.

Yo le recomiendo a todas las madres...cuando nosotros vemos a una criatura que está flaca...digamos...muy delgada, digamos, menudita, en seguida le decimos: 'Llevá a esa criatura al médico, llevá a esa criatura al médico, porque le falta comida, le falta hierro, le falta vitaminas. Porque después va a ser tarde, para lamentar.' (...)

Mirá, yo creo que entre los médicos y los padres porque, es eso lo que hay que ver.

Hay que cuidar todos parejos a los chicos; porque si uno tira para un lado y el otro tira para el otro, la criatura siempre...está en el mismo lugar. O se puede ir peor, más a pique digo.

Así que, sí... entre los médicos y los padres...mucho más los padres, los médicos dan un empujón,...

Y los padres tienen que seguir empujando ese pequeño empujón que dan los médicos.

Porque hay mucha, mucha, yo veo pocas, digamos noticieros...pero de lo poco que veo que hay muchos chicos, que ya por demás, yo lloro...veo chicos desnutridos, pero peor de lo que está mi hijo...

Pero yo me pongo a llorar...veo a esos chicos desnutridos...me pongo a llorar, mi marido me cambia de canal...me dice: 'vos no tenés que ver eso', me dice. Porque a mí me ha pasado, no ha estado tan mal', le digo, pero yo he tenido que andar con mis hijos de un lado para el otro." (Camila)

Para ello hay que tener una actitud de aprendizaje y cumplir las recomendaciones médicas:

"Y a veces pregunto, tenés que preguntar cómo tenés que hacer con un chico, cómo tenés que alimentarlo; ellos me explican y yo escucho; porque suponele que fuera yo una madre rebelde, y vos me explicás, y voy a casa y no hago, qué pasa? Porque si vos me decís: 'mirá, madre, hacé esto', y yo voy a mi casa y no te hago lo que vos me explicaste, ¿qué te parece? Entonces no tenías que haber hablado, no tenías que haber hecho nada...! Y después qué pasa, la que se perjudica soy yo." (Cristina)

Los programas televisivos son escuchados con el mismo fin de aprendizaje, oportunidad en la que también participa el padre:

"Ah, sí, yo escucho además en la televisión ¿viste que da a veces? Y a veces lo pongo a mi esposo... 
Ese que dan de los nenes de eso que ¿viste que a veces explica? Sí, sí, o a veces la información que dan los noticieros...

Y mi esposo pone... a veces pone atención, le digo: 'mirá lo que dice'. A veces habla de esos chiquitos... yo veo viste que pasa ... esos chicos denutridos ¿viste? a veces explica...ese que a veces hay un médico que a la mañana ese que da de la cocina, las comidas, ese...Borocotó, jah, sí!, que las hijas mías a veces escuchan. Y dice a las mamás, cómo se contraen las enfermedades los chicos. Y ellas... mis hijas me explican, dicen mamá, dicen: 'mirá, acá te venimos a explicar'." (Cristina)

Otras, opinan que los médicos no pueden curar la desnutrición y depositan en los padres la potencialidad de hacerlo. Asimismo, plantean la paradoja de la cura: aumentar la demanda de consumo en situaciones que imposibilitan aportar lo mínimo:

"pero ya te digo, es..., los médicos no te curan, los médicos lo único que te pueden decir es dale de comer esto, lo otro, eh, ¿viste?, darte vitaminas, ¿para qué te va a dar vitaminas, si las vitaminas te van a abrir el apetito, y no tenés para comer? (Estela)

Lo que cura, en definitiva, es la alimentación. Otra paradoja resulta de los mensajes contradictorios sobre la alimentación recibidos del médico:

"No, los médicos no, es la alimentación la que la cura. Lo que ellos te dicen es lo que más o menos ellos tienen que comer y todo eso. Ellos por ejemplo me dicen que le saque la teta...

Pero ahora me dijo la doctora que se la vuelva a dar porque como está así con diarrea.

Pero yo igual, ella ya estaba, lo dejaba porque ya estaba tomando de noche nomás y...

Y ahora que cayó otra vez, juh! empezar de nuevo a tratar de sacársela .. da un trabajo..." (Norma)

Excepto un caso, todas los niños desnutridos han padecido, al tiempo de la desnutrición, pata de cabra.

Algunos que en la encuesta, habían negado tenerla, la reconocen durante la entrevista.

La mancha en la espalda, las dos marcas que representan la huella de una cabra, es el signo característico. La demora en su tratamiento puede producir la muerte:

"La... una nena sí. La pata de cabra, dice que a mi esposo después le explicó...que acá en la espalda tiene dos manchitas, vendría a ser así como una cabrita. La mancha, dice que cuando tiene las dos dice que le sube hasta la... una vez que le sube a la cabeza dicen que le mata, no sé. La verdad que no sé de donde viene. De qué le viene, alguno dice que nacemos con eso, dicen..." (Cristina)

Vómitos y diarrea suelen acompañar a la marca:

"Dos tuve. Él...y la nena. Bueno, de él nos dimos cuenta nosotros y de la nena una señora. Porque era la primera así que yo no sabía. El porque empezó con vómitos, y con mucha diarrea, y se debilitó enseguida." (Mónica)

El tratamiento de pata de cabra, iniciado a raíz de episodios de vómito y la diarrea en tres hijos, parece ineficaz, debiendo ser hospitalizados. El diagnóstico de pata de 
cabra no se cuestiona, en todo caso cuestiona la eficacia de los diversos tratamientos

llevados a cabo por los distintos curanderos.

"Sí, porque un día estaba durmiendo Laura, la levanté y le di la leche, y así como la tomó la largó, entonces yo la llevé a ver si estaba empachada, y me dijeron que tenía pata de cabra.

Ahí tenía... creo que tenía 8 o 10 meses...y Julio y Juanjo casi todos el mismo tiempo les agarró.

Porque vomitaban y aparte... le agarró esa diarrea... verde verde viste?

No ahí no venía,...después los traje. Los llevé sí, a la salita, pero me daban por la diarrea, después... los llevé a hacerlos curar y después sí, cuando estuvieron internados y eso...los traje acá.

Después del tratamiento de pata de cabra estuvieron internados...seguía la diarrea y ..

Muy bien muy... no...Al Juanjo y al Julio, ya te digo a la Laura sí, porque a Laura la curó un hombre, y a ellos lo curó una señora en otro lado...Laura tardó un poquito en curarse. Sí, porque... yo ya la había llevado por otro lado...fui de otra señora y así anduve hasta que encontré ese hombre y la curó.

No, no, no, nunca más, después nunca más tuvieron." (Juana)

Algunas madres cuentan el conflicto que les genera la asistencia al curandero dada su poca convicción acerca de la pata de cabra, admitiendo la realización de tratamientos paralelos a los de la medicina científica, nunca impulsados por ella. También relatan el problema de lealtad que los mismos les generan con la pediatra de la salita, el que en general resuelven, confianza mediante. Sin embargo, experiencias previas con otros hijos, llevados a curar por otros familiares, refuerzan la creencia de su posible existencia; con tal de lograr la mejora del hijo, cualquier estrategia es válida:

"Mirá, hice lo que..., él estuvo empachado. (...) éste nació con ese moretón.

¿Viste?, recién ahora a la tarde...me van a mandar a un señor que dicen que cura, a ver si tiene la pata de cabra...es de ahí de la esquina es, dicen que el hombre ese cura. Porque no sé, porque el nene mío, el otro, que estaba ahí parado tuvo el macho y la hembra, que así no se me murió, y yo no creía en eso, y una vuelta mi suegra lo llevó, y dice que ya lo tenía por acá el macho, pero estaba a la miseria, no comía, vomitaba todo. No llegó a estar desnutrido porque lo agarramos enseguida, ¿viste?

Entonces como lo empezó a curar, y a medida que lo iba, lo curó, había que ir casi tres días, tres días pero casi dos veces por día...entonces lo llevábamos, y ya, ¿viste?, enseguida, aparte es de comer, no sabés ahora, come, come, y come. No sé cómo lo curaba, yo no lo llevé. Lo llevó mi suegra porque yo no creía. Ese era el drama mío, que yo no creo, ¿viste?, que yo no creo, entonces ella lo lleva...

La señora de la esquina me dijo: 'Mónica, acá hay un hombre que cura la pata de cabra, a lo mejor tu nene tiene la pata de cabra'.

Sí, le dije: 'no sé', le digo, 'porque él está con un antibiótico', qué sé yo, ¿viste?, yo ya, porque yo no creo mucho... ¿viste?, pero de aquél me acuerdo de que mi suegra lo llevaba, porque yo no creí y sí, se curó, se repuso, largaba unas cosas negras, porque dicen que según dicen ellos que era el bicho, yo no sé... y largaba ....sí, si yo lo cambié, eran como unos pedacitos como de cosa, ¿viste?, como carbón...pero ellos dicen que era el bicho... Sí, pero yo no le creo nada.

Sí, bueno, y entonces ahora, ¿viste?, digo bueh, y bueno que vaya, total, algunas veces como madre, ¿viste?, hacés cualquier cosa para que estén mejor...

Pero ahora ya está un poco mejor, porque ayer estaba recaído, ahora vamos a ver si come, lo que quiero es que empiece a comer bien.

Cata no me decía nada, Cata ni me miraba, no, aparte sabe que yo no creo...yo cuando lo llevaba a él le decía que era mi suegra la que lo llevaba, 'Y sí, me imagino', me decía, 'porque lo que sos vos' me dice, 'Sí, no, yo no', le digo." (Estela) 
Como queda reflejado en el relato anterior, la fe en la cura es fundamental. Evita conflicto de lealtades y permite la justificación racional de las diversas acciones.

"Yo pienso que hay que tener fe, confianza, es como las religiones y esas cosas. A él sí, a él sí, yo creo porque a él lo sacaron. Ahora le quedó así pero muy leve, tiene todo así violeta aparte de una mancha de antojo ¿no? pero éste ahora tiene más leve, no se le fue del todo la mancha pero no tiene tan oscuro porque antes le iba subiendo." (Mónica)

Sin embargo, la mayoría aclara "no creo mucho". Por los relatos, pareciera que la pata de cabra es frecuente en estas familias, ya que muchas comentan experiencias de varios hijos.

El tratamiento con el curandero los "sacó a flote" y muchas veces el buen estado actual de salud del hijo, se atribuye a esa cura. Desinteresadas por las causas, lo único que se espera es la curación. Cabe destacar que la misma incluye, a veces, remedios de la industria farmacéutica.

"No creo mucho, este, es cuestión de fe muchas veces las cosas, ¿no? (...)

Yo tuve el más chiquito, me lo curaron también. Me lo sacaron a flote, sí. Hace mucho, hace como cuatro años atrás. Ahora tiene cinco años. Tenía el macho y la hembra.

Me lo dijo el hombre, yo no sabía nada, el hombre me lo dijo... Tenía dos cositos acá negros.

Y me lo sacó adelante, ahora, era, pero era piel y huesos, era piel y huesos.

No, no, no lo había llevado a la salita, no, no. Vino una señora acá, y me dice la señora que tiene pata de cabra...yo no entendía nada.

Ahí viene, el nene mío... ahora es un bestia, cinco tiene. Mírelo, pero era piel y huesos...

Y a él lo curaron con un aceite. No sé qué aceite porque el hombre tenía ahí guardado en la heladera, no sé si era otro aceite especial...en siete días me lo curó.

El aceite nomás le pasaba. Después me hizo comprar un líquido que ahora no me acuerdo yo el nombre. Cuando él me lo curó los siete días, me dijo: 'Ahora al otro día, dale una cucharadita de café, chiquitita que tome'. No me puedo acordar el nombre de ese remedio que me dio.

Lo conseguí en la farmacia. Sí. No me acuerdo qué era. Y empezó, empezó a recuperarse, recuperarse, $y$ a engordar $y$ a engordar, $y$ a engordar como un chancho.

Ah, no, él no tenía nada. Estaba flaquito. Flaquito, piel y huesos.

No sé de qué viene. No, no le pregunté. Porque no, no...sé, no se me ocurrió.

Claro, yo no quiero aprender nada del hombre... yo quería que me curara al nene porque lo veía re mal.

Mirá lo que es ahora, un chancho número uno." (Celina)

Muchas veces, el diagnóstico se hace a través de la evaluación -en posición acostadodel acortamiento de alguna pierna, apareciendo nuevamente el total desconocimiento de las causas:

"Al principio le había agarrado principio de pata de cabra, pero lo agarraron a tiempo.

Se le empieza a formar como..., dicen -porque yo no lo entiendo bien eso- como una manchita azul...

Porque es, eh, digamos es un, en el pie, tiene que estar, cuando lo acostás a la criatura tienen que estar juntos los pies.... y cuando le ves un piecito más arriba que el otro... tienen que estar los dos pies a la misma altura, y cuando un pie está un poquito más corto....digamos...ahí es el principio de pata de cabra. Eso, la verdad que nunca supe, de los treinta años que voy a tener ahora el viernes no...

Eh, la verdad que no lo sé, por qué viene esa enfermedad. Nunca supe." (Camila) 
La ineficacia del tratamiento médico para eliminar algunos síntomas o la indiferencia frente a determinados problemas, estrecha la convicción en la pata de cabra y precipita la asistencia al curandero. El tratamiento se realiza por contagio en el caso de hallarse internado el niño y continúa luego del alta, a menudo voluntaria:

"Si, tuvieron los dos, estos dos. Si, estaban con mucha diarrea, yo al nene cuando estuvo internado por neumonía le había agarrado diarrea y claro... No, ya de la neumonía se había mejorado y le agarró diarrea y el médico que lo atendía me dijo que si vino sola se tenía que ir sola, y no lo medicaba y... le habían sacado las sales y en cuatro horas ya estaba totalmente deshidratado y... al otro día cuando vino mi marido yo le dije que fuera a un hombre que es adonde nosotros lo llevábamos y porque él fue a la tarde y ya para la noche que le llevó una batita de él y este... ya se le había cortado.

O sea después si, después que lo sacamos del alta si, lo llevamos a él.

Acá en la sala, porque el estaba en la sala y ya le estaban por dar el alta de la neumonía, y le había agarrado diarrea y era agua lo que hacía y el médico no le daba nada porque dijo que si había venido sola, se tenía que ir sola así que....le habian suspendido las sales porque dijo que no las necesitaba y después en cuatro horas se deshidrató y después la doctora que había de guardia lo vino a ver y parecía que se moría porque tenía todos los ojos hundidos y entonces cuando vino al otro día mi marido a la mañana yo le dije y el fue a la tarde, le llevó una foto de él y a la noche se le había cortado la diarrea." (Mónica)

A menudo el diagnóstico de pata de cabra, luego de haber probado suerte con tratamientos médicos fallidos, motiva el traslado de gran parte de la familia a la casa de parientes que tienen un curandero en la vecindad. Tampoco la siguiente informante conoce el origen; sólo sabe que se da en los niños pequeños, que produce bajo peso, pudiendo provocar la muerte y que en el barrio, es un problema de salud que afecta a muchos:

"Ella sí. María Paula. Era chiquita. Era un bebé. Y después tuvo ella y después que salió que estuvo internada también tuvo pata de cabra...la María Cristina. No, no, no, fue que salió de la internación. En alta. Fueron estas dos. Porque... le dio una manchita acá.

Sí, porque nosotros hace mucho vivíamos en Punta Lara, tenía a ella sola yo. Y no me quería... no me quería tomar la teta, no me quería tomar la leche, vomitaba todo...la llevaba al médico no le encontraba nada, bajaba de peso. Y la llevé Casa Cuna, porque yo tenía Casa Cuna con la chequera, todo, bah... por IOMA de ellos, ahí no me quería comer nada, no me quería tomar la leche, nada, nada, nada.

Y después... mi marido se quedó viviendo en Punta Lara, ya me fui a la casa de mi mamá que vive allá y yo sabía de una señora y me la curó en 9 días. Le pone una tinta china y con un anillito (...) no sé de qué. ¡Y ella sabía todo! Le agarró a ella y a la otra nada más, no sé. Porque hay muchos chicos... la señora al lado de mi casa también tenía la nena, y estaba baja peso y era pata de cabra. Porque hay muchos chicos que no lo.la madre no sabe que de la pata de cabra se muere. Baja el peso y se hace un palito. Viene solo a los más chiquititos." (Zulema)

La esperanza depositada en que, análisis de sangre mediante, encuentren "algo" que explique el estado del niño, hace que, de resultar normal, se busquen diagnósticos alternativos; los médicos "no saben", "no pueden", "no encuentran". La mancha oscura es omnipresente, no necesariamente así los síntomas restantes:

"Sí, los dos...y ahora a Cintia también la estoy por llevar...porque, si no le encuentran nada. Sí, no... le hicieron los análisis de sangre y no sale... 
Sí, ahora me volvieron a mandar hacer análisis, depende de lo que salgan, si no tiene nada la voy a llevar que alguien me la vea.

El tuvo a los ocho meses me parece y ella cuando era chiquita, a los cuatro meses, ahora tiene diecinueve meses.

Yo lo llevé. No, porque yo siempre decía mirá la espalda, y la mancha negra que tiene cada vez es más oscura. No, por ahí tienen vómitos, y todo esto viste, pero ella no llegó a tanto.

Él estuvo en un momento descompuesto, estuvo mal. No sabíamos... me decían que era el empacho, pero después una vuelta lo llevé y lo hice ver, y bueno...

Después a ella la llevé a otra señora y lo curó con palabra...con tinta china no sé, qué sé yo... dice que le cura, no sé...

A ella le volvió otra vez...así que la llevé a la señora esa que cura con palabras...nueve días

Le hacía así cruces y hablaba en palabra y nada más. Y ahí sí la curó bien." (Norma)

El caso anterior es el único que plantea la reincidencia de la pata de cabra y la asistencia a diferentes curanderos quienes aplican diferentes tratamientos, el último (“nada, cruces y palabras") eficaz.

En otros, el descreimiento es mayor. La insistencia de vecinos, la curiosidad respecto del tratamiento y la ansiedad por encontrar una cura, impulsan su asistencia:

"No. Tenía, pero no... no sé, porque yo eso no creo. La llevé a una...a esas... pero dijo que tenía dos pocitos, se le hace así la cintura... que tenía la hembra y el macho, y me la curó con tinta china. Yo no sé si es verdad, mentira no sé, yo no...para mí no creo. Fui para sacarme la duda.

Yo la vi siempre igual... estaba caidita... una vecina me dijo que tenía y la llevé por curiosidad." (Valeria)

Al desconocerse las causas, la prevención es prácticamente imposible. La heterogeneidad de explicaciones sobre el origen queda reflejada en la siguiente cita:

"No sé qué decirte porque uno me dice una cosa, otro me dice otra cosa viste y... no sabés si se puede prevenir porque hay algunos que me dicen que es por los animales, que cuando estabas embarazada que te acercaste con un perro, y bueno, ahí ya le agarra a ella...

Y otros me dicen... no sé. Otros me dicen que es porque la tengo que bautizar. Para que ella no le agarre le tengo que bautizar.

Y otro me dicen que es porque dejo la ropa de ella en la soga, y la agarra la luna llena...o qué se yo... y así, así sigue la cosa. En sí al final, uno nunca termina sabiendo de qué le agarra." (Norma)

"No, yo pienso que no, por lo menos, lo que a mí me enseñaron, no (...) algunos dicen una cosa, otros dicen otra..." (Mónica)

Las que sospechan que es posible, desconocen las modalidades:

"Sí, yo pienso que sí pero no...no, no me dijeron." (Valeria)

El origen de la pata de cabra es bastante incierto. El abanico de posibilidades incluye la envidia, daño, el empacho mal curado, el contagio de ropa, el origen en el nacimiento. Así, las causas son diversas y ninguna informante adhiere con convicción a alguna de estas razones:

"No, nunca pregunté... bueno, sí, me dijeron que era un daño... 
Que era un daño que me habían hecho a mí y lo agarró ella que era... como era más débil ella, le agarró a ella. Así me dijeron...sí, y muchos dicen por envidia." (Juana)

Muchas explicaciones poco convincentes para las madres, a las que, en definitiva, poco importan.

"Creer o reventar" es la muletilla con la que la mayoría termina su discurso sobre este tema:

"Qué se yo de dónde viene, algunos dicen... como la leyenda, dicen que de dejar la ropa al sereno... no sé y que pasa un bicho y bueno, ya queda... Qué se yo, no sé, nunca pregunté. Yo los llevé a curar, se curaron y bueno. Sí, hay que creer o reventar.

Bueh, no sé, a mí me decían que puede ser de que uno va a una casa que hay mucha mala onda, mucha maldad y bueno, les cae a los bebés, le cae... como ser él nació, con ... o sea él tenía una mancha. Tiene la mancha y bueno, él nació así. Entonces algunos dicen una cosa, otros dicen otra." (Mónica)

Otras ironizan sobre las explicaciones recibidas. No se comprende por qué se recurre a razones tan inverosímiles como lo son el contagio de la ropa caída en el suelo, pudiendo apelar a los tan difundidos, conocidos, aceptados y omnipresentes "virus":

"La verdad que no sé de qué viene. Hay gente, no, hay gente, dicen que cuando por ahí te cae una ropa al suelo, pasa un bicho o algo y ya uno se lo pone sin que se de cuenta, dicen.

$Y$ ya le agarra, le agarra que ponele que pase una víbora, dicen, y ya se agarró una enfermedad.

Le digo, 'porque a mí, que yo vivo casi en el medio del campo', ¿vos viste lo que es mi casa? Y vivo dos por tres, sacar la ropa del suelo...y nunca me pasó nada...le digo: 'Yo no entiendo esa metáfora de ustedes', le digo...'de al caerse una ropa que te agarrás un bicho'...

Le digo, 'al virus si lo agarrás, lo vas a agarrar con ... adonde sea', le digo...

Por ahí empezás a estornudar, y ya te viene, ya dicen, 'Ahí está el virus de la gripe'...

Si tuviste una gripe, o si estás, le digo, con un dolor de panza, estás con diarrea, ya está, te agarró el virus de la diarrea.... para todo hay un virus, le digo....vos no precisás que se caiga la ropa, le digo...o como ahora está el, éste de la, de conjuntivitis." (Camila)

El tratamiento de la pata de cabra incluye un espectro que va de la cura por palabra, al frotamiento en la espalda con velas, aceite, alcohol, saliva, imposición de manos, pudiendo duran entre 3 y 9 días según la gravedad.

"Después la otra la curó nomás ese hombre, ya te digo yo lo llevé ahí, no me pidió nada, la senté a Laura encima, le hizo así, un redondel así con la saliva de él...santo remedio..., se curó..." (Juana)

La efectividad del tratamiento se manifiesta en el hecho que, a partir de la cura, los hijos nunca más volvieron a tener problemas. Este resultado contrasta con las numerosas idas y venidas; internaciones y altas previamente experimentadas en su relación con el hospital:

"Bien, bien él en nueve días lo curó con un cuchillo. Se lo puso así acá y después no me acuerdo... Un cuchillo acá, así, y después le pasaba...y después en el mismo cuchillo le marcaba así. Y a la nena la curaron con tinta china....también nueve días. 
La verdad que no sé por qué curan distinto. Pero la nena, gracias a Dios, porque yo la tuve internada del mes hasta los tres meses, y bueno, no... o sea le daban el alta y al poquito tiempo entraba de vuelta, le daban el alta y entraba de vuelta, hasta que me dijeron y bueno, la llevé, y hasta ahora gracias a Dios nunca más." (Mónica)

Los "cortes" con un cuchillo realizados sobre la espalda del niño, tienen la finalidad de "cortar" al animal que consume por dentro al niño, llámese lombriz, víbora o virus.

"He visto cómo cortan esa, digamos, me ha dicho que la cortan, y la criatura vuelve a normal... Eh, yo he visto cómo lo hacen con un cuchillo, le parten a la criatura por la espalda...

$Y$ eso es que le cortan al animal.... eh, para ellos es un animal.... ¿viste? como una lombriz...le van haciendo tipo cruz y de esa forma...

Y los días de cura...eh... según cómo está la criatura...como pueden ser tres días, seis o nueve. Si está muy avanzada son nueve días...

Claro, según cómo tenga la marquita. Ellos se, se definen de esa forma.

Y según cómo se defina, a mí me explicaron, o sea, según cómo esté la mancha, se definen la altura de los días que haya que curarlo...la verdad que no sé de qué viene." (Camila)

Muchas veces la cura se realiza en el hospital ya que el diagnóstico se realiza durante la internación del niño:

"La curó de palabra y se sanó nomás, pero acá nomás en el hospital... si en casa...nosotros no nos dábamos cuenta." (Cristina)

Si bien la mayoría de las veces ambos tratamientos se dan simultáneamente, en algunos casos se recurre sólo al tratamiento con el curandero:

“¿Tratamiento médico?, no, no.” (Mónica)

No todas relacionan la pata de cabra con la desnutrición: ambos padecimientos son claramente distinguidos por algunas mujeres. La pata de cabra, si no se cura a tiempo, puede producir desnutrición. Además, la desnutrición, si no se acompaña de diarrea y vómitos no está causada por la pata de cabra.

"Me parece que una cosa no tiene que ver con la otra. Porque eh...a lo primero no, no están flacos... con el tiempo se van...a los días sí, que van pasando, a medida que lo vas alimentando al chico, se van... se van quedando flaquitos porque la leche -según dicen-el bicho que tiene adentro se la va tomando, y ellos van quedando flaquitos. Ahí entonces después sí necesita al médico porque queda tan flaquito que...

Y... puede ser, pero él no tiene pata de cabra...él no tiene pata de cabra [su actual hijo desnutrido].

No, no lo llevé pero él no te vomita la leche, él no tiene diarrea, él va de cuerpo una sola vez por día...y está flaco. Lo llevé una vez, que me lo vean, pero no, estaba empachado nada más.

Sí. Por eso yo te digo que no...porque si no él también tenía que ... porque a ella cuando le agarró la pata de cabra lo curaron, después estuvieron internados que seguía la diarrea, flaquitos, hasta que después yo lo traje a la doctora." (Ana)

En general en estos casos, pese a negar la relación, ubican a la pata de cabra como causal pero nunca la desnutrición antecede a la pata de cabra. Una vez desnutrido a raíz de las bajas defensas que produce la pata de cabra, se consulta al médico. 
"No creo. No creo que sea de eso. No, no, no, no llega bien al punto, digamos, la desnutrición al de pata de cabra. Con la pata de cabra sí, ahí sí, porque la criatura ya come menos...y se desnutre...ya tiene menos defensas propias la criatura...ahí sí.

Ahí sí puede agarrar desnutrición la criatura, al tener pata de cabra. Porque la criatura come, pero no se alimenta bien el cuerpo. Porque dicen que la pata de cabra es como una lombriz, que se va formando como una víbora de dos cabezas. Y ese se va alimentando. Yo no, nunca la vi, así dicen." (Camila)

Otras consideran que la desnutrición y la pata de cabra están relacionadas en el mismo sentido que aquellas que niegan tal relación. El "bicho" consume al chico por dentro, trabaja en el estómago, produce vómitos y su resultado es la pérdida de peso:

"Y sí, porque bajan de peso, todo eso los hace bajar de peso..." (Lola)

"No, me parece que no. No, jsí!, sí, podría ser eso, ella se venía chiquita, no crecía. Siempre... tenía siete meses y era una cosa así, y vomitaba, capaz que era de eso ¿viste? parecía que eso le iba trabajando en el estómago..." (Cristina)

Por eso las madres consideran importante creer en la pata de cabra. Su negación puede tener consecuencias graves:

"Sí, sí. Porque a él lo bajó muchísimo. Pasa que hay muchos padres que no creen, también. Y hay chicos que se mueren. Sí, porque cuando él estuvo internado, en la sala que él estuvo había una mamá, y no creía en eso, y los médicos no le encontraron nada y la nena era piel y hueso, estaba en tercer grado." (Mónica)

Otras en cambio, afirman desconocer la relación:

"No sabría decirte. Sí, él bajó un montón de peso. Él tuvo un tiempo.. dos meses, un problemita así pero era por parásitos, no era nada, pero ella...sigue y sigue. Sí, ella sigue y no...no sé, la verdad." (Norma)

La atención de salud de los hijos abarca la salita del barrio, el curandero, la autoatención y el hospital para problemas complejos o graves.

La mayoría de los relatos refieren a los recursos y servicios utilizados para la atención del niño desnutrido. La salita, lugar de control habitual, figura en muchos casos como fuente de derivación dada la gravedad con la que se llega a la consulta.

El bajo umbral de alarma, pese a verla flaquita, y las expectativas de atención por parte de "su" médico explican la gravedad que asume este caso:

"Cuando se me descompuso la llevé a una salita y de ahí de la salita, me la revisó el médico, y de ahí llamaron a la intermédica y me trasladaron acá. Sí, porque ya estaba... estaba muy flaquita ya.

¿En casa? ...habrá estado tres días, cuatro.

Y la llevé un jueves...no la llevé antes porque yo no sabía qué era, aparte el médico que la atendía a ella no estaba, no venía los días que yo iba." (Lola)

A menudo, las madres quedan presas de una disputa entre médicos de hospital y médicos de salita, con la descalificación, por parte de los médicos del hospital, de los médicos de la salita. En el medio, los "retos" de los médicos del hospital los reciben las 
madres y de ellas es la "culpa" por la demora en la atención. No obstante la madre destaca sus reiteradas consultas y el seguimiento de las recomendaciones del médico de la salita, bajo el supuesto -a menudo errado- de que "saben más" que ellas. Pese a la desconfianza de las afirmaciones del médico de la salita, su fidelidad al criterio de autoridad de la palabra médica agravó la salud de su hijo:

"Se me vino abajo, empezó con la diarrea, empecé mal ya. Primero no quería comer, lo que le dábamos no quería comer, le daba tres cucharitas y no quería más.

Fui y le dije a la doctora y me dice: 'no importa madre, es por el calor'. A mí me parece que por el calor ¿viste?, ya no es, ¿viste?. Bueno, entonces empezó con diarrea, estuvo diez días con diarrea, a mí me retaron en el hospital, porque yo no tengo la culpa, escuchame, si yo lo llevaba a la Salita, a mi Mónica me veía que todos los días lo llevaba.

En el hospital me retaron porque dicen que dejé pasar mucho y los chicos cuando son así de chiquititos más de tres días no pueden estar con diarrea.

Yo lo llevaba a la salita, sí, pero la doctora no me lo quería internar, ¿viste? y mi marido se enojó, dice: 'De acá en adelante, o te vas al Hospital de Niños, directamente te vas al hospital'. Y ahí me retaron. Yo no tengo la culpa, le digo, si yo iba todos los días a la Salita.

¿Viste?, el nene tenía, hacía tres veces a la mañana caca y yo a la tarde lo llevaba porque ella lo pesaba, lo controlaba, y yo veía que el nene bajaba el peso, y ella me dice: 'mientras no se deshidrata no pasa nada'. 'Pero el nene empezó con vómitos y vómitos ¿qué lo voy a seguir, dejando en mi casa?', le digo.

Y si voy al hospital me retan. ¿Viste?, y yo le digo, qué culpa tengo yo, si ellos son, si yo confío en un médico es porque yo pienso que sabe.

Me dicen: '¿sabés lo que pasa?', dicen, entonces agarró y saltó, ¿viste?, el jefe del hospital...

Bah, de ahí de la zona de pediatría...y me dice: '¿sabés lo que pasa?, no sé qué está pasando en las unidades sanitarias, que en ninguna unidad sanitaria hay un médico como la gente', yo digo: 'bueno, eso lo tienen que hablar acá', le digo...'nosotros no podemos hacer nada', le digo, 'y que podemos decir nosotros. A nosotros nos hacen falta médicos', le digo, 'pero médicos buenos', le digo, 'no así', le digo. 'Pero usted se la agarra conmigo y yo no tengo la culpa', le digo, 'usted llame a la Unidad Sanitaria, y que le digan en la historia clínica, que está todo anotado los días que yo he ido.', se lo dije ¿viste?, para que se den cuenta." (Estela)

En el relato siguiente, la insistencia de una médica de la salita respecto de la lactancia materna, pese a las dificultades manifestadas por la madre respecto de la misma, y su intento por seguir las recomendaciones recibidas, contribuyeron a la desnutrición de la niña. La segunda consulta en la salita por el bajo peso motiva, también en este caso, su urgente internación:

"Viene el médico y una vez que la vio, la revisó y llamó. Y me dijeron que ya venía la ambulancia para trasadarla. Cuando estábamos que vivía en Olmos la llevaba ahí, me quedaba más cercana, caminando, y me decían que la veían bien. Cuando nació la llevaba ahí a control y todo, y después la veían bien. Después que pasó, pasó los días y empezó después no me quiso tomar teta. La llevé y le dije que no me quería tomar teta y me dijeron: ponela que empiece a tomar...yo la ponía, pero no quería tomar. Y eh...la estaba atendiendo una doctora, después se fue la doctora, no sé... que salió de vacaciones, no sé...y cuando ahí la vio él a la nena, dice que la nena estaba mal, dice ¿que pasó? y yo le dije, que a mí yo la traje acá y me dijeron que le pusiera la teta, que le pusiera el pecho y que la insistiera que tomara. Entonces cuando él me la vio, la revisó, todo y dice: 'esperá un cachito afuera, no te vayas' y ahí fue cuando llamaron y me la trasladaron acá." (Silvia) 
De allí la evaluación diferencial que las madres hacen respecto de los médicos, valorando la pericia y celeridad en las decisiones. Las recomendaciones preventivas no resultan posibles y lo que se destaca es la capacidad terapéutica:

"El médico bien. Con la doctora no, pero con el médico sí.

Con el sí, la doctora parece que te da muchas vueltas para decirte las cosas, muchas vueltas. Cuando el médico la vio, la revisó, me dijo: "bueno, mamá, la nena tiene esto y esto y tenemos que trasladarla al Hospital de Niños', no te da muchas vueltas." (Silvia)

En general, los controles de salud en la salita se realizan correctamente:

"Sí, cuando hacen los controles sí, los pesan, los miden, les sacan toda la ropa." (Camila)

Aunque a veces las madres tienen que orientar el control para que sea completo:

"A veces le tenés que andar diciendo: tiene esto, tiene aquello. Porque a veces no los revisan bien." (Norma)

El problema de la salita parece ser no tanto la atención brindada por los médicos sino la organización y disponibilidad de los turnos y la falta de medicamentos.

"Había como un arreglo, hay veces que uno va y te dicen ya no hay más número. Hay muchas que se quejaron por eso y siempre dicen que a veces vas y no tienen ni un solo remedio." (Norma)

En otros barrios, el control de los niños y el conocimiento de las problemáticas familiares era absoluto mientras trabajó una pediatra, de larga trayectoria laboral en la salita. La dependencia de las madres y la naturaleza paternalista de la relación, impide recrear una nueva cuando aquella se disuelve. La salita es usada en menor medida, aumenta la asistencia al hospital y los niños están menos controlados:

"Es que, mirá, yo en la Salita cuando estaba Catita, ¿te acordás vos? porque ella estaba más sobre ella, estaba sobre las madres, ¿viste?, qué sé yo....no sé era otro cantar, o había trabajo como quien dice.

Pero ahora no sé, yo acá no las veo, acá, ¿viste?, será que las madres no van tanto a la Salita, se van directo al hospital y ya están mal.

Están mal, algunas también madres gastadas, de lo último, comiéndose el peor, y...Catita estaba arriba de nosotras, un mes que no íbamos al control, a los dos meses seguidos, ella mandaba al asistente o ya enseguida te hacía llamar ella, ¿eh? Y más cuando ella tenía bajo peso, llegaba un día, esperaba tres días y me veía por ahí y '¿qué esperás para traer la nena?', y así, a mí me tenía al taco. Hay que decir las cosas como son. Así, ella estaba arriba, en las vacunas, te miraba la libreta y si no estaba vacunada te reventaba, porque tenía la justa razón, acá no hay un chico, que cuando ella estaba, no hay un chico que le haya faltado una vacuna, porque ella te lo hacía vacunar como sea, si ésta tiene vacunas de más.

Lo que es, ¿viste? Ella se preocupó mucho por todos, ¿viste?, ahora, ¿viste? que ella no está no sé." (Estela)

La diáspora hacia el hospital se produce con motivo del nombramiento de un médico en la salita al que finalmente desplazan. En este caso, pesa la mala atención, la falta de respeto hacia los pacientes y la negativa a atender problemas de salud por considerarlos banales. La autoatención reemplaza la desatención médica, en 
colaboración con el personal administrativo que suministra el medicamento solicitado por la madre.

"Se van directamente al hospital, por eso yo te digo...sí, algunas se van al hospital, otras van acá al Cestino. Lo que pasa que el doctor que vino era un desastre...lo sacaron ahora...

¿Sabés qué mal que atendía? Porque entraban de a dos o tres en el coso, uno en la camilla, otro ahí arriba, dos ahí arriba, los atendía, los miraba así nomás y los mandaba.

Y a él no me lo quería hacerle el control porque estaba con gripe, ¿dónde se vio eso?, estuve como dos meses sin hacerle el control, sin controlarlo porque al nene se le había agarrado gripe, ¿viste?, y moco, y él no lo quería atender. 'Este me escucha, me le hace el control', le digo directamente, yo, le digo... No lo quería controlar..., preguntale a Mónica [administrativa], te lo juro.

Ni nebulizaciones le daba; decí que yo tengo el nebulizador, le hacía yo las nebulizaciones por mi cuenta. 'Y ahora', le digo a Mónica, 'dame Ventolin porque el chico está que no da más', yo le digo, 'que se calle este loco', le digo. Y Mónica me daba, con Mónica no hay problema, lo conoce, ¿viste?." (Estela)

El tratamiento realizado en el hospital es muy eficaz y los resultados observados por la madre justifican la agresividad de las prácticas:

"Sí, levantó y levantó muchísimo. Primero me quejaba al principio por que le hacían un montón de cosas, la pinchaban acá, la pinchaban de allá, pero después se notaban los resultados; viste, ya empezaba a comer, se sentía bien.

O sea, por que le tenían que hacer análisis de sangre y estaba anémica también, entonces dos por tres le tenían que hacer otra vez, porque estaba demasiado anémica y para ver si el hierro le hacía bien. Y bueno después con los análisis y qué sé yo, después yo ya la vi bien y me quedé conforme, ya estaba bien." (Norma)

La celeridad en los diagnósticos, la posibilidad de iniciar más rápidamente el eventual tratamiento y la mayor probabilidad de adquirir medicamentos, hacen que se privilegie la atención en el hospital:

"Hay que estar detrás de ellos. Sí, y si lo ves mal, en seguida disparar para el hospital.

Pero lo más esencial es el hospital, en una salita te puede decir el médico: 'sí, haga esto y lo otro', pero venir acá al hospital directamente, te ve la doctora, ya te mandan al laboratorio a hacer los análisis, ya salta más rápido.

Es más rápido...es, claro, porque no es, este...en el hospital a uno le hacen todos los estudios, los análisis...En la salita cada quince días va la ambulancia para los análisis, no es tan eficaz una salita a un hospital." (Camila)

Más allá de que el servicio de atención médica utilizado sea la salita o el hospital, aparecen reacciones de resistencia o impugnación, no tanto por tratarse de profesionales cuya idoneidad se pone en tela de juicio, sino sobre todo cuando se ejerce una práctica médica arbitraria, a veces equivocada y contraria a las normativas conocidas por las madres.

La exigencia de control por parte de una madre se impone sobre la voluntad del médico. Para eso enfatiza su derecho a retirar la leche. Si no le hace control, la priva de la leche del PMI.

"Por algo es que las madres se quejan. A esta doctora que vino ahora, nadie la conoce en el hospital, ¿viste? ni la otra que vino. No saben ni cómo trabajan. 
Le digo yo a los médicos del hospital: 'bueno, y ¿qué quiere que haga?'

Porque yo iba a levantar firmas para que volviera otra vez la otra pediatra, que era buenísima ¿viste? Al final no lo hice porque la perjudicaba a ella, por eso no lo hice...porque lo que es cuando vino ese pediatra, un desastre

Era un desastre, a él se le había confundido de remedio, decí que yo no se lo había dado y el problema no era mío, era del pediatra. Aparte el otro pediatra me dijo que cuando él cumplía los seis meses, que era cada dos meses, cada dos meses tenía que hacerle el control, 'Yo no estoy acostumbrada asi', le dije, 'a mí todos los chicos la otra doctora me los ve todos los meses, hasta el año'. Él no quería, llegó a los seis meses y dijo: 'bueno, hasta los ocho meses no tenés que venir, ahí le hacemos el otro control'. Entonces yo me quedé parada y le digo: 'mire, doctor, escúcheme, pero usted me parece que está equivocado, porque acá estamos acostumbrados todos los meses.'

Y él dijo: 'ah, no, yo trabajo así, si te gusta bien y si no andá a otro lado'. Y le digo, 'sí, voy a ir a otro lado no te hagás problema'.

Entonces ese día, la última vez que voy digo: yo le, le digo las cosas como son, no le falto el respeto, pero se las digo. Bueno, entonces agarré, ese día fui y le digo: 'mire doctor, vengo para que le haga el control'. Y me dice: 'Pero ya se curó de la gripe...', qué sé yo, le digo: 'a mí no me importa si está engripado el chico, quiero que me lo controle porque no me van a dar la leche por él, porque a usted no se le canta que me haga el control'... agarró y me lo hizo. Pero de mala manera...lo pesó con batita, con pañal, todo, así que te imaginás. Sí, los pesaba así a los chicos, ¿eh? no te los desnudaba ni nada, así nomás los pesaba, después les descontaba no sé cuántos gramos y ¿si no era eso?, te podés imaginar.

Bueno, agarré, ¿viste?, dejé de ir un tiempo, y después me enteré que no estaba más, que habian venido estas doctoras y lo empecé a llevar. Te digo, la salita es una comodidad bárbara..." (Estela)

El valor de la salita para el barrio no se pone en duda, la comparación de la situación de desprotección sanitaria existente en el barrio cuando no había aún salita moviliza su defensa por parte de los vecinos:

"Escuchame, yo no sé lo que es el hospital para ellos...porque ellos todos a la salita.

Acá cuando no había salita, a mí casi se me murió la nena grande porque le agarró un ataque de ¿cómo es, cuando tenía fiebre alta?, le agarró...convulsiones, estuvo cuarenta y cinco minutos casi muerta mi hija, que la llevaron, que no pasaba, que no venía un médico porque no había ambulancia, no había nada, no estaba la salita. Yo soy una de las que defiende la salita a muerte, porque yo sé lo que pasé con esa hija ¿eh?, porque si no hay salita no tenemos...pero eso no es por la salita, es por los médicos que mandan, un desastre." (Estela)

La otra forma de atención, con el curandero, es frecuente en el barrio, independientemente de que las madres crean más o menos en su eficacia o en los principios en los que basan su saber.

Facilidad de acceso -geográfico y económico-, rapidez en el diagnóstico y curación son posibles explicaciones de una madre escéptica respecto de lo que seguramente piensan aquellas que recurren al curandero:

"Sí en mi barrio hay.....y como yo no creo mucho en eso.

No, sí, los llevan al médico pero recurren más al curandero cuando lloran mucho, cuando lloran o cuando tienen algo. No sé, porque cada cual tiene su pensamiento viste, y no sé qué pensará esa persona que por ahí le conviene llevarlo ahí que es más fácil o le dicen algo más rápido o se pensarán que será más rápida la curación, no sé." (Norma)

La ineficacia del tratamiento realizado por el curandero hace que se pierda la débil convicción que se tenía. La recomendación de tratamiento con yuyos no siempre es 
cumplida por temor y desconfianza y en muchos casos el tratamiento con el curandero se abandona o sustituye por la atención médica:

"Y sí, la mayoría que yo conozco dicen que sí; pero yo nunca la llevé. La llevé una vuelta sí, a ella la llevé por la pata de cabra y yo no creía en eso, me dijeron que tenía pata de cabra pero la llevé como quinientas mil veces y siempre me decían lo mismo, entonces ya después dije no, no la llevo más.

Hay algunos que te cobran con plata y otros que le podés llevar algo, un paquete de azúcar o fideos.

Al que fui yo le tenía que llevar algo, cualquier cosa y si dejaba plata también, no tenía predilección con eso. Ahora como está la situación es medio difícil que cobren, la gente no tiene plata.

Y si uno no tiene qué dejarle, lo atiende igual. O sea, donde yo fui me atendió igual.

Por lo general curan de palabra, sí, por palabra en general.

Sí y esos yuyos que también me habían recomendado, por ahí se me descompone y no sabés. No, desde que la llevé no le vi mejoría porque después ya de la salita me la mandaron para acá, a rehabilitación nutricional, para que me la vieran." (Norma)

En términos abstractos, no hay una relación conflictiva entre la adscripción a una medicina u otra. Cada una aporta lo suyo, tiene su campo de incumbencia y de acción que es claramente reconocido y distinguido por las madres:

"No, yo a la nena la llevé a una señora para curarla de empacho...y ese día que la curaron a la nena del empacho, le tiraron el cuero, porque le tiran el cuerito...

Eh, se me descompuso la señora....se descompuso, la tuvieron que agarrar porque era que se desvanecía...de tan mal que estaba mi nena...le pasó a ella. Y eh, y nunca mi nena fue de levantarse de madrugada para hacer materia. En casa tengo el excusado para las nenas en la pelela, a las tres de la mañana de esa noche que la curó la señora, se levantó a las tres de la mañana mi nena para hacer materia, hizo media pelela....de todo ese tipo de...como diarrea, era como mucosidad....eh, como tipo de hilos de sangre. No, no, no, no había ido al médico. Porque la llevé a esa señora porque aparte que no comía bien, ya la nena, y estaba con dolor de cabeza, como ellos empiezan con dolor de cabeza y que no me comen ...y fui ahí recomendada, con una de mis cuñadas...con una hermana de mi marido. La llevé, la llevamos ahí con mi marido, hasta el día de hoy que tiene seis años la nena no le ha agarrado más eso. Y el médico le curó, tenía, ¿viste?, unos pequeños parásitos que...

Entre los dos me la curaron, pero con el nene mayor, él también estuvo para todos lados, digamos." (Camila)

Si ese mismo reconocimiento está presente en el médico, respetuoso de otras creencias, el conflicto desaparece:

"Mirá, estuvo cuatro meses y medio de diarrea. Él decía, él casualmente una vez había, estaban los estudiantes de él, decía: 'a ver', dice: 'el nene tiene esa medallita porque él, ella, tiene fe que esa medallita lo protege al nene, que es el protector de cada persona'.

'Tiene esa pulserita roja el bebé porque ella cree que eso le hace bien, cada uno tiene su fe', dice.

Dice, 'como vos tenés una pulsera que es porque te gusta y esas cosas porque te gusta, bueno, o creen en algo, bueno, la señora es creyente, así que tenga esa pulserita el bebé, para el mal de ojo, y el santito', dice...en ese tiempo lo tenía mi nene al San Jorge...

Dice: '¿ven? este es el santo, para ella es el protector del bebé', dice, 'como que las hay', dice, 'los curanderos, los hay', dice. Yo le dije a él que la iba a llevar a esta señora que me lo curó también al nene...y me dice: 'sí usted cree, llévelo, eso está en usted. Yo no le puedo decir que no lo lleve, porque si usted cree que su hijo tiene algo más.....llévelo.'

Y también te pone un apoyo digamos de él, porque yo iba....me daba más tranquilidad, porque es el médico de mi hijo, me daba ese apoyo que yo necesitaba también.

Y yo esperaba esa palabra que me lo dijera él... 
'Si lo necesita llevar, llévelo'. Porque hay muchos médicos a veces que no creen en eso... No hay médicos así... Y que no dejan ir.

Lo llevé, y después vine y le comenté a él cuando lo traje de nuevo al nene. 'No, no, está bien, ¿usted cómo lo ve al nene?', le digo: 'yo lo veo cambiante', 'yo también', me dijo...'lo veo mucho mejor', me dijo el médico. Entre los dos, también, entre esa señora y el doctor...que primero de instancia, está el doctor, para mí ¿viste?, porque me ayudó mucho..." (Camila)

En otros casos, no se comunica a los médicos el tratamiento llevado a cabo con los curanderos; en el siguiente, la omisión del comentario se justifica por la ausencia de interés por parte del médico. El diagnóstico de pata de cabra ocurre durante una prolongada internación, lo mismo que el inicio del tratamiento:

"No, no...porque...o sea hay médicos que creen y capaz que te dicen llevalo, igual que el empacho y todas esas cosas y hay otros que no así que ... tampoco me preguntaron así que... Y la otra nena también, ella estuvo internada a los 20 días y estuvo hasta los tres meses pero yo como era la primera no sabía y después una señora grande me dijo 'llevala que tiene tal problema' y después nunca más estuvo internada. Primero fue mi marido con la foto. O sea le cortó la diarrea pero después cuando yo lo llevé con el cuchillo le cortaba el bicho con el cuchillo, en nueve días." (Mónica)

La relación no conflictiva se da, fundamentalmente, en aquellas mujeres que tienen confianza y fe en el tratamiento. La experiencia, es en la mayoría de los casos, la base de sustentación de la fe:

"Pero yo creo que hay que tener confianza porque si uno no tiene confianza, porque si uno no tiene fe no sirve. Yo sí creo porque por lo menos los dos yo lo viví, por experiencia." (Mónica)

\subsection{A modo de síntesis: comparación de las representaciones y prácticas maternas sobre desnutrición infantil}

En este punto se entrecruzan dos dimensiones analíticas: una refiere a las representaciones (percepciones, conocimientos, opiniones, creencias, valoraciones) sobre distintos aspectos referidos a la desnutrición, la cual pudo ser recabada en los dos grupos.

La otra se vincula más estrechamente con las prácticas de atención materna y de los diversos recursos de atención a la salud y da cuenta del reconocimiento de la presencia actual o pasada de hijos desnutridos y las prácticas de detección, tratamiento y prevención de la desnutrición infantil.

En esta dimensión, el análisis de la información cualitativa debió restringirse a los casos entrevistados de familias con hijos desnutridos, ya que la mayoría de las informantes de GE en la totalidad de las cuestiones formuladas, se excusaron de brindar opinión por carecer de conocimientos adecuados sobre la desnutrición fundamentando que "no sé, nunca me pasó".

Contrastando las citas anteriormente transcriptas correspondientes a madres con niños eutróficos (GE) y madres con niños desnutridos (GD) surge que: 
- Para GE, el estado nutricional del niño se relaciona con la buena crianza dispensada por las familias, el esfuerzo y sacrificio de los padres y la preocupación materna por los controles de salud admitiendo que si bien el proceso de adelgazamiento refleja una inadecuada alimentación, la gordura no significa buena nutrición. Todas estas consideraciones se hallan respaldadas por el reconocimiento médico del rol de los padres en el adecuado crecimiento de los niños.

Así para la mayoría de estas mujeres, la mala alimentación obedece a descuido materno: y en menor proporción se hace mención de los problemas económicos de las familias y de la escasa asistencia estatal.

En GD, las mujeres refieren que el estancamiento o pérdida de peso del niño, en general repentino, da cuenta del proceso de desnutrición.

Ante la pregunta referida a la forma como identifican o reconocen la desnutrición actual o pasada de su/s hijo/s, la mayoría afirma tener hijos desnutridos apareciendo como muletilla en los discursos la aclaración de "el/ella nomás" o "solamente el/ella". No obstante, cabe recordar que en la casi totalidad de los casos entrevistados se presentan dos hijos desnutridos (el asistido en la URN durante la realización de este estudio y otro anterior).

Una minoría de madres responde de manera ambigua planteando que "no, desnutrido no" agregando a continuación que "le falta un poco nomás".

Como causas, es posible observar dos niveles: uno más abstracto, en el cual se identifican: los problemas económicos, la escasa alimentación, la falta de asistencia alimentaria, la inexistencia de una red de contención parental constituyen los argumentos explicativos. Sin embargo, en un nivel próximo al acontecimiento de desnutrición en su familia, las causas remiten al rechazo de alimento por parte de los hijos o a problemas orgánicos que impiden su asimilación y no porque les falte comida, diferenciándose así de "otras" familias ya que siempre "mal o bien nos la rebuscamos". El descuido materno alude a otras mujeres: aquellas que desatienden las necesidades alimentarias de los hijos y/o que recurren al curandero para atender los problemas de salud infantil. No obstante, algunas madres, minoritarias, asumen la responsabilidad por la desnutrición de sus hijos: la pobre calidad de la comida asociada a la desocupación del jefe de familia, el fracaso en la lactancia materna, el uso tardío de los servicios de salud y el suministro de yuyos precipitaron la desnutrición.

Para el resto, la mayoría, las parasitosis e infecciones están en la base de la misma.

- La prevención de la desnutrición debe basarse, para GE, en una alimentación "a horario" en la que la leche, carne y huevos no pueden faltar y en modificar hábitos familiares inadecuados. En ese sentido, el asesoramiento médico aparece como 
intervención favorecedora de la prevención, lo mismo que la existencia de programas alimentarios, particularmente los comedores infantiles o guarderías.

Las informantes de GD consideran que para evitar la desnutrición es importante "darle una buena alimentación" que comprenda leche, verduras, frutas y todos aquellos alimentos que contengan hierro y vitaminas, aunque reconocen que ésto no siempre es posible, a veces se torna inviable $y$, de acuerdo a sus experiencias, los cuidados dispensados -y considerados adecuados- no siempre resultan satisfactorios en la salud infantil. De allí que para algunas, la prevención sea imposible. Una tercera parte de los casos plantea que es fundamental darles líquido, sobre todo en verano, evidenciando la asociación de la desnutrición con la deshidratación. Este hecho podría deberse a reducciones analógicas de la terminología médica y a la experiencia vivenciada en el caso particular. En este grupo, también se incluye el consejo médico u otras intervenciones en la prevención, haciendo hincapié en el control del peso.

- Los síntomas de la desnutrición que consideran más relevantes para identificarla son, en la mitad de los casos GD, el estado de ánimo, el decaimiento, la pérdida de fuerza, el cansancio, apareciendo en el resto evidencias físicas tales como la delgadez, el color de la cara, los ojos hundidos y la distensión abdominal. Un solo caso refiere que sólo el médico la reconoce cuando lo pesa con motivo de los controles de salud y en otros casos minoritarios la delgadez, si no está acompañada de otros síntomas, no es motivo de preocupación: "es flaquito pero normal", "es normal, bajó de peso nomás". En GE se mencionan los mismos síntomas aunque hay una mayor proporción de aquellas que plantean un total desconocimiento porque "no sé, nunca vi".

Cuando se indagan en las mujeres GD los síntomas presentes en sus hijos desnutridos, aparecen otros tales como los episodios de vómito, diarrea o parásitos. La demanda de asistencia a la salita muestra que la misma funciona la mayor parte de las veces como lugar de derivación. Son minoritarias las madres que refieren haberse dado cuenta porque "no quería comer, lo veía mal" y haber demandado asistencia oportunamente.

Más de la mitad de los casos debieron ser internados en la primer consulta, lo que da la pauta de la gravedad del caso y del uso post-fáctico de los servicios de salud, esto es, tardío y postergado en relación a la evolución de la enfermedad. En este sentido se destaca como factor agravante de la desnutrición, la extrema dependencia de las madres respecto de un médico; la consulta se demora hasta tanto éste no esté presente en el servicio. Asimismo la inflexibilidad de las recomendaciones médicas preventivas basadas en las normativas de salud tienen efectos paradójicos, tal es el caso de la insistencia en la lactancia materna cuando la madre comunica reiteradamente las dificultades o la imposibilidad de tal tipo de alimentación. 
- Respecto del tratamiento, casi la mitad de GE responde "no tengo ni idea"; el resto considera que se debe ir al médico para recibir asesoramiento nutricional ya que pueden contribuir a su cura "enseñando a alimentarse" así como mediante un tratamiento especial con medicamentos y vitaminas.

La mayoría de GD considera pertinente el control médico y los medicamentos que éste indica; las opiniones restantes consisten en dar la alimentación adecuada, rica en calcio, vitaminas y hierro.

La evaluación del tratamiento médico recibido por los niños desnutridos es positiva en la mayoría de las situaciones: más de la mitad de las madres reconoce la eficacia de la intervención consistente en la dación de leche con vitaminas, antiparasitarios y hierro, mencionando los casos restantes que es "regular" en tanto al poco tiempo del tratamiento y tras una leve recuperación, vuelve a bajar de peso o bien por la excesiva demanda de tiempo para la salida de riesgo nutricional.

Así, algunas madres hacen evidente la disputa -en medio de la cual quedan presasentre los "médicos del hospital" y "los médicos de la salita", siendo a menudo objeto de retos por parte de los médicos del hospital por la inadecuada atención del niño. En ese sentido lo que las madres valoran son las decisiones rápidas y la capacidad de cura asociadas a los médicos de hospital. Las recomendaciones preventivas de los médicos de la salita y la dilación de los tratamientos no tienen buena recepción por parte de las madres; sí en cambio la tienen para muchas las actitudes paternalistas, autoritarias y de control.

La impugnación o resistencia a la atención médica recibida se hace visible en situaciones en las que las madres visualizan una práctica médica arbitraria, a veces equivocada o contraria a las normativas de control de salud conocidas por las madres. No obstante ello, la casi totalidad refiere que los médicos curan la desnutrición con vitaminas, hierro, calcio y dieta especial reconociendo limitaciones en sus conocimientos o errores que pueden cometer ya que "uno le puede dar mucho de comer y queda anémico igual" remarcando el papel pedagógico de la actividad profesional. Un solo caso plantea que lo que cura es la alimentación, no los médicos.

- La conceptualización de la desnutrición como descuido por parte de las madres de GE, hace que no se la conciba como enfermedad, excepto cuando deriva de otra patología. Para las madres de GD, la consideración de la desnutrición como enfermedad es ambigua: algunas la conciben como secuela de alguna enfermedad o producto de la pata de cabra; otras le niegan el estatuto de enfermedad en la medida que no resulta contagiosa, vinculándose más bien con descuido. Finalmente, el estatuto de enfermedad está ligado a la oportunidad de la atención: la demora en el 
tratamiento lleva a la internación e incluso muerte del niño y por eso, en esos casos, merece ser considerada enfermedad.

- Así, la capacidad terapéutica de los médicos para resolverla se relativiza. Los médicos, según las madres GE, contribuyen a curarla, ellos pueden hacer un diagnóstico diferencial de sus causas y con base en ello dar indicaciones alimentarias pero la curación depende de los padres. Para las madres de GD, también el diagnóstico diferencial así como el tratamiento de complicaciones que derivan de la desnutrición son los ejes de la actividad médica. Las recomendaciones alimentarias, a veces contradictorias con las que se tenían por ciertas, y el suministro de suplementos tales como las vitaminas, el hierro y el calcio forman parte del tratamiento esperado por haber sido el habitual en la experiencia de atención de su hijo desnutrido. Sin embargo, tal como lo plantean las madres de GE, la función de los médicos es de "empuje" pero las madres son las principales responsables de la rehabilitación nutricional. A ello contribuye de manera significativa, la adquisición de conocimientos sobre alimentación infantil brindados por especialistas a través de programas televisivos. Sus recomendaciones, alerta y orientaciones para la acción son incuestionables.

- La indagación de la presencia de "pata de cabra" en los hijos obedece a su relación con el estado de desnutrición (Ortale, 1996). Esta enfermedad, que incumbe a la medicina popular se manifiesta como "una mancha oscura arriba de la cola" -un hematoma producido por la disminución del panículo adiposo en la zona del sacro y la permanencia del niño en la cuna o cama- que da cuenta de la existencia de un "bicho" que, "a medida que va subiendo por el espinazo, lo va secando,", "lo chupa por dentro", pudiendo tener pata de cabra "macho" o "macho y hembra" (menos frecuente pero más grave). La "pata de cabra" se acompaña generalmente ya sea de diarrea, vómitos, llanto continuo, nerviosismo, sueño excesivo, etc.

Con relación a ella, la mayoría de las informantes de GE refieren conocerla de manera indirecta a través de comentarios, agregando que nunca tuvieron un hijo con ese problema. Pese a haber afirmado que la desnutrición no constituye un problema de salud importante en el barrio, dada la existencia de una salita cercana y accesible a todos los hogares, en donde se realizan controles de salud de manera regular y la continuidad de asistencia alimentaria, dicen que la pata de cabra es habitual. Consideran que se trata de un problema de salud que reviste gravedad si no se lo trata a tiempo ya que provoca un abrupto adelgazamiento en los niños: en ese sentido plantean que la pata de cabra causa desnutrición. Niegan conocer el tratamiento porque "no sé, nunca tuve" o bien algunas que enfatizan su adscripción a la medicina científica ya que siempre los llevan a la doctora. 
Todas plantean que los médicos son impotentes para curarla y unas pocas exponen que mediante palabras o tinta china la cura el curandero. Desconocen asimismo las causas y la forma de prevenirla.

Sin embargo, son bien conocidos los tratamientos correspondientes al mal de ojo y al empacho, problemas de salud frecuentes en sus hijos para los cuales sí recurren al curandero, también accesible en el barrio. En general plantean que a él recurren cuando falla el tratamiento médico o se demora más allá de las expectativas maternas. Así, la mayoría admite, con base en la experiencia de los resultados obtenidos con ese tipo de tratamiento, que "hay que creer más allá" de lo que permite la razón. También en el abandono de las prácticas médicas alternativas influyen los medios masivos, particularmente en el abandono del suministro de infusiones con yuyos tales como la yerba de pollo, paico, poleo o anís estrellado.

Asimismo se refleja la activa participación del cónyuge en las decisiones sobre la atención de los hijos y el peso de sus opiniones respecto del servicio o recurso de atención a utilizar.

En GD la pata de cabra se registra en casi todos los casos asociada al hijo desnutrido así como a otros hijos. Algunas no logran precisar la naturaleza de la enfermedad, refiriendo otras madres que se trata de un "bicho, no sé de donde viene. Sé que está atrás. Nunca le pregunté a la curandera, me da no sé qué" o explicitando los síntomas: "es una mancha violeta en la espalda", "una mancha atrás, no sé, pero se hace un palito", "no sé, pero se debilitó enseguida, se echaba para atrás".

Los tratamientos, llevados a cabo en lapsos que oscilan entre los tres y nueve días dependiendo de la gravedad del caso, son diversos: consisten en la cura por palabra, imposición de manos, frotamiento con velas, con aceites, realización de cruces en la espalda con tinta china, e indicación de ciertas prescripciones/proscripciones alimentarias. La mayoría reconoce la eficacia de los mismos, siempre paralelos a los de la medicina oficial. Las causas mencionadas son heterogéneas, pudiendo derivar de "un empacho mal curado", "envidia", "maldad", "un virus", etc. Las medidas preventivas son desconocidas o imposibles aduciendo por otra parte: "no sé, nunca pregunté".

La identificación de la pata de cabra se da en muchos casos luego de haber resultado ineficaces los tratamientos médicos y en las madres más escépticas la curiosidad lleva a la consulta al curandero. Lo mismo que las madres GE, distinguen claramente la desnutrición de la pata de cabra y afirman que se trata de problemas distintos. La relación queda planteada en términos de causalidad: la pata de cabra produce desnutrición en la medida que produce un brusco descenso de peso. El resto reconoce 
que la pata de cabra es "otra cosa", respondiendo que "no sé", "no creo", "no sabría decirte".

O, como sentencia una madre: "es como la leyenda de dejar la ropa al sereno; hay que creer o reventar".

"Creer o reventar" resulta el corolario de la experiencia de curación y la relación de estas creencias y prácticas de atención no muestran ser contradictorias o conflictivas con la medicina científica, aunque reconocen la tranquilidad que presta el consentimiento del médico sobre la demanda de atención en el curandero.

Finalmente, una dimensión no contemplada inicialmente en el estudio que surge de las entrevistas como eje de indagación y potencial variable explicativa de las condiciones diferenciales de salud, se vincula con la adscripción religiosa. Muchas de las mujeres de GE entrevistadas manifestaron la importancia de su conversión y de las de otros miembros de la familia al culto evangélico o al de los Testigos de Jehová y su influencia en la modelación de estilos de vida "sanos". Destacan el poder terapéutico de Dios invocado en los rituales colectivos y manifestado en múltiples casos concretos, desechando cualquier oposición ciencia/religión en la medida que los hombres (médicos) son herramientas a través de las cuales opera el "poder divino de sanación".

Lo arriba expuesto lleva a recuperar los modelos interpretativos de la desnutrición presentes en el sistema sanitario (Aguirre, 1986): uno teórico y otro instrumental, paradójicamente contrapuestos. Para el modelo teórico, la desnutrición es una patología social que reconoce razones estructurales. En el modelo instrumental, las causas sociales se diluyen en el terreno de lo individual o de lo familiar, de tal modo que las condiciones de vida que están en la base de la desnutrición desaparecen del argumento causal. Varias son las entrevistadas cuyas apreciaciones reflejan la transmisión de la perspectiva instrumental del sistema sanitario, a través de quienes lo personifican y tratan la desnutrición de sus hijos: médicos, enfermeras, asistentes sociales. Lo que se rechaza -si no es la presencia de la desnutrición infantil-, es la causalidad social de la misma.

Los discursos predominantes para caracterizar a la desnutrición ponen el acento en desórdenes biológicos individuales causados por un agente externo: parásitos, infecciones, etc. o en la familia -y básicamente en la madre- ya sea por malos hábitos, descuido, desinterés, etc. Este último sirve además para sustentar el carácter privado del consumo alimentario: con la desnutrición, "del consumo privado a la responsabilidad privada hay un sólo paso" (Hintze, 1989). Tal como aparece en las entrevistadas: "una si es madre, siempre consigue algo", "uno siempre se la puede 
rebuscar para que no falte comida", son las apreciaciones más frecuentes, preponderantes en los discursos de aquellas madres sin hijos desnutridos.

Los mecanismos de reproducción ideológica dominantes y los mecanismos de transacción establecidos por los sectores subalternos con los hegemónicos, conducen a que la estructura dominante de las relaciones sociales se apoye en la subordinación asumida por los propios sectores subalternos, que se expresa en la autoestigmatización, autoinferiorización, autolimitación de estos conjuntos sociales (Menéndez, 1990).

En el relevamiento de las prácticas relacionadas a la desnutrición infantil aparece, en primer lugar, una exhaustiva descripción -por parte de las madres de ambos gruposde sus síntomas, quienes además plantean que "la buena comida" (valorada según su contenido en vitaminas y minerales) y "la comida a horario" son las formas de evitar la desnutrición, subestimando el rol del sistema sanitario en la prevención e incluso en la cura.

El reconocimiento, por parte de las madres de GD, de la desnutrición de su hijo queda relegado en el discurso, mencionándola como un episodio eventual en la historia familiar derivada de un desorden orgánico que "lo/a tiró abajo" y enfatizando además que se trata de "el /ella nomás".

Además, tal como lo señalan estudios sobre salud, (Boltanski, 1976; Llovet, 1985), los sectores populares presentan una tendencia a negarse como enfermos hasta tanto la señal corporal adquiera cierta intensidad, hecho que se registra con mayor fuerza en los adultos (que puede ser atribuido, dadas las condiciones de vida, al costo en tiempo y recursos que implica la atención).

Este comportamiento, para el caso particular de la desnutrición, se ve acentuado: sus características permiten su encubrimiento hasta que no aparezcan signos agudos (diarrea, fiebre, vómitos). Mientras tanto, suele estar enmascarada bajo un criterio de normalidad que se expresa en respuestas del tipo, "ya es así", "son menuditos", "le cuesta aumentar", etc..

Son minoritarios los casos en los cuales la demanda se relaciona específicamente con el control de peso. Esta actitud refleja la apreciación que tienen las madres del sistema de salud y de su incumbencia y/o eficacia en la prevención/tratamiento de la desnutrición. Ella refleja a su vez, el modelo instrumental que desarrollan los médicos en su práctica asistencial: el médico centra su atención en la enfermedad infecciosa y/o parasitaria frente a la cual se siente capacitado y hacia la cual la industria farmacéutica y la infraestructura sanitaria brindan soluciones eficaces.

La conjunción de los elementos arriba planteados dificultan la visión de la desnutrición como patología social y empujan en dirección de la búsqueda de soluciones 
alternativas frente a su presencia: la "pata de cabra" aparece como una conceptualización popular, alternativa, que refiere casi siempre al niño desnutrido.

La medicina popular, constituye un elemento de integración y validación de la identidad. La medicina popular es una práctica de atención alternativa presente en mayor o menor medida en todos los sectores sociales, particularmente dentro de los sectores pobres, que constituye un ámbito de seguridad social y una fuente de recursos -subalternizados- en el que se originan, circulan, se aceptan y funcionan los diagnósticos y tratamientos considerados profanos excluidos jurídica $\mathrm{e}$ ideológicamente de la práctica médica hegemónica.

Es el contexto y el proceso de atención los que le dan su significado y los que permiten la permanente resignificación de una enfermedad en otra. Las prácticas de atención -científicas y populares- no constituyen dos órdenes opuestos y escindidos. Debe subrayarse la continuidad de las mismas en lo que hace a los signos y síntomas identificados, a la reformulación diagnóstica y a la eficacia o ineficacia real y simbólica ${ }^{79}$ del tratamiento o práctica seleccionada.

\footnotetext{
${ }^{79}$ La eficacia constituye un problema de delicada solución en la medida que la misma puede ser atribuida al instrumento, al contexto o a ambos. La medicina científica tiende a remitir la eficacia al instrumento. Sin embargo, la eficacia no puede ser reducida al mismo sino que debe ser referida al contexto macro o micro grupal en el que dicho efecto opera.
} 


\section{REPRESENTACIONES Y PRÁCTICAS MÉDICAS SOBRE DESNUTRICIÓN INFANTIL EN EL GRAN LA PLATA}

La presentación de la información obtenida en las entrevistas acerca del saber médico sobre desnutrición infantil se realiza mediante la articulación del análisis de sus prácticas y representaciones en torno a:

- el problema de las normas de control y evaluación del estado nutricional y de las condiciones de trabajo que posibilitan su uso así como la evaluación de las políticas sanitarias

- la caracterización de la desnutrición, del desnutrido y su familia y de la asistencia al desnutrido (causas, síntomas, diagnóstico, tratamiento, recomendaciones, prevención)

- percepción e interpretación materna de la desnutrición, cumplimiento de las prescripciones médicas y uso de medicinas alternativas.

A fin de poder aprehender con mayor claridad la posible diversidad o discrepancia de saberes, los discursos de los dos grupos de médicos entrevistados (los que trabajan en hospitales públicos y los que trabajan en los niveles de atención primaria de salud), se exponen en parágrafos independientes.

\subsection{La perspectiva y experiencia de los pediatras de hospitales públicos}

Normativas, condiciones de trabajo y políticas sanitarias

Las normas destinadas a controlar el crecimiento sirven, según los entrevistados, para "establecer un patrón de normalidad" y constituyen una "técnica para controlar desvíos de la normalidad", "para ver si hay alteraciones por trastornos orgánicos o por hipoalimentación en el crecimiento" y así poder "vigilar a la población, detectar cambios en el crecimiento y realizar un diagnóstico precoz".

Las normas estipulan controles de salud periódicos según la edad, y consisten en "bueno...eh, examen clínico general, mediciones del peso, la talla, el perímetro cefálico y la evaluación de pautas madurativas", destacando en todos los casos que "no lo evaluás detenidamente. No se puede. Es imposible". Pese a su conocimiento,

"No se usan por falta de tiempo pero en realidad está bastante normatizado que hay que usarlas. Es difícil; yo voy seis horas todas las tardes y en las seis horas tengo que ver veinticuatro chicos. Entonces de esos solamente a los primeros les hacés todo, a los últimos te digo que ya..." (Juan) 
La demanda por patología, la cantidad de pacientes, el escaso tiempo que pueden dedicarle a cada uno de ellos explican tal limitación así como la pérdida del paciente:

"Se pesan, se miden y entre comillas, porque es demasiado el volumen de gente. Estamos viendo de veinticuatro a veintiséis chicos cada uno por día pero en un lapso de 5 o 6 horas. $Y$ hay ocho médicos. Son ciento setenta, ciento ochenta chicos por día. Algunos que por ahí llama la atención, se los pesa, se los mide, pero no hay tiempo como para hacer un interrogatorio. La idea por ahí es poner a una persona...que después que se dedicara a esos chicos". (Juan)

Todos reconocen la importancia de los controles para la detección destacando además otros factores que obstaculizan su trabajo, tales como la no disponibilidad de insumos básicos (gráficos de crecimiento, historias clínicas), sesgos profesionales y limitaciones derivadas de la organización institucional de la atención:

"Mejorando los controles creo que los detectaríamos mucho antes. Nosotros no tenemos historia clínica asi que tendríamos que organizar mejor el control, el seguimiento para detectar antes." (Ana)

"De repente no todos los pediatras están compenetrados con este tipo de situación, por ahí no les falta conocimiento en la técnica pero sí por ahí les falta en actualizar las normas y el manejo de este tipo de paciente". (José)

"Muchas veces te tenés que adaptar a las condiciones de trabajo que te impone el servicio, es cuestión de mentalidad del lugar donde se trabaja. Yo no puedo detectar una desnutrición si no tengo media hora, cuarenta y cinco minutos con el paciente. Algunas autoridades tienen la idea de que en los hospitales se debería atender la demanda de patologías complejas y no es así. Es ahí donde pueden captarse, porque los desnutridos no vienen con un cartel". (Juan)

El papel del hospital público es ambiguo, difuso e inespecífico para abordar de manera efectiva a la desnutrición. Esto se refleja en el desfasaje existente entre las necesidades que requiere el diagnóstico y tratamiento del desnutrido y el tipo de servicio que ofrece el hospital:

"En el hospital donde estoy yo no tenemos en el consultorio los gráficos de crecimiento, recién ahora cuando entra un paciente se lo mide, se pesa recién ahora se están haciendo las historias, pero no queda graficado no puedo seguir haciendo la curva de crecimiento, queda un punto en el momento." (María)

"... no hay nadie que haga, o sea, no se hace que, no sé si me entendés, no es que no se les preste atención, cuando se detectan se les presta atención. Pero se pasan muchos". (Ana)

"El tema es la demanda en los hospitales públicos, lo que es la prioridad, lo que es la demanda de la atención pediátrica en los hospitales de La Plata, el Gran La Plata, el primer cordón del conurbano... una locura (...). Se atiende apurado, y la presión de la gente no te permite hacer un trabajo como corresponde y eso tampoco te permite detectar este tipo de trastornos. Habría que hacer una estadística de cuántos pediatras pesan y miden al chico menor de dos años...y cómo lo hacen también (...) Es un problema pero si bien es un problema nuestro, porque no le vamos a escapar a la responsabilidad porque somos nosotros los que lo tenemos que hacer, también muchas veces las condiciones que trabaja uno te van relegando actitudes que son básicas." (Juan) 
Esta situación que se presenta en el control del crecimiento se agudiza en el control de las pautas madurativas y del desarrollo psicomotriz, problemática de creciente preocupación en nuestro país:

"Las normas te sirven para controlar que el chico crezca adecuadamente. Uno así lo controla. Y lo que no se hace es, vos evaluás si el chico aumenta o no aumenta de peso pero en realidad un control del desarrollo tampoco se hace. Por ahí bueno, mientras estás revisándolo ves lo que hace o deja de hacer el chico. Por ahí bueno, dos años y te dice: 'No, no camina', y te llama la atención." (Martín)

Algunos entrevistados plantean que estas deficiencias se vinculan con la desarticulación de los niveles de atención, ya que la demanda al hospital público por problemas banales y controles de salud sobrecarga de trabajo a quienes deben atender problemas de cierta complejidad:

"El hospital es provincial, y a las salitas la gente no quiere ir. No quiere porque o te cambian el médico, o el día que va el médico no fue ...y ese es el único médico que hay. En cambio en el hospital, bueno, si no fue el que la ve habitualmente siempre hay otro y el problema se soluciona. De última llevás el problema solucionado. $Y$ a veces nosotros tenemos el antibiótico o el jarabe o el antitérmico como para darle, entonces.... Y hay gente que bueno, el chico nació ahí, está acostumbrada y no quiere cambiar. Por más que le digas: "tenés la salita a dos cuadras", no la sacás del hospital." (María)

Dicha apreciación contrasta con las carencias de insumos básicos, de bajo costo y simple utilización para los controles de salud.

En general, la relación del hospital con la salita es mínima o nula y plantean la reticencia de las madres a concurrir a la misma: "en general la gente no está muy enganchada con la sala. No sé por qué."

"Tendriamos que recibir pacientes con notas de las unidades sanitarias y no recibimos. No tenemos así un ida y vuelta con los médicos de la salita. Las madres dicen que en la salita dan veinte números y que tienen que ir a las cuatro de la mañana para conseguir número, pero no sé como es realmente. Los médicos de la salita dicen que ellos atienden 25 chicos, que atienden los números que tienen que ver y que no van a ver más de lo que se puede, también tienen razón". (María)

La importancia y necesidad de la relación hospital/salita ni siquiera motiva el esfuerzo del intento. No sólo la relación con la salita es inexistente sino que el paciente mismo, en el contexto de atención hospitalaria, se convierte en un "caso" a raíz de la falta de continuidad de quien lo asiste.

"Lo que pasa es que la mayoría de las madres tienen quejas y no estamos conectados el hospital con las unidades sanitarias. Y acá no podés saber si vuelven o no, no tenemos asistentes sociales para recuperarlos y aparte como no atendemos a los mismos pacientes 
entonces un día lo ve un pediatra, otro día otro y como no tenemos continuidad para ellos es difícil a veces ubicarnos hasta que registran que yo, por ej, estoy los miércoles, otro médico tal día y así." (José)

Un solo caso plantea un buen funcionamiento de los niveles de atención, el que infiere a partir de las características de las enfermedades que atienden:

"Llegan derivados, el resto no llega, entonces eso te hace dar cuenta que resuelven y llegan derivados por algo, para internarse, sino no llegan, eso nos hace pensar que las salitas funcionan bien." (Martín)

Finalmente, llama la atención la estrategia de derivación a las unidades sanitarias instituida en uno de los hospitales, sobre todo por el desaliento que cabría encontrar en los pacientes que en él se asisten:

"Nosotros les damos todas las indicaciones y tienen que ir a la salita a buscar los medicamentos o el suero para la nebulización. Muchos lo consiguen y muchos no. Igual ya saben, no se alarman cuando vos les decís que en el hospital no tiene los remedios, ya saben. Igual eligen el hospital, saben que lo que no les hacen en la unidad sanitaria en el hospital se lo hacen: la radiografía, los análisis...le dan mucha importancia a una placa, entran a la consulta pidiéndote una radiografía y eso en la salita no se lo pueden hacer...., los análisis también se los hacés en el momento. Le descartás una infección en dos horas entonces...por ahí ellos en la salita están una semana." (Martín)

Esta "aceptación" o resignación ante las reglas establecidas ponen de relieve la importancia que las madres atribuyen al diagnóstico precoz y certero, certidumbre que descansa en la confianza depositada en la tecnología médica.

Respecto de las políticas de salud, la superposición de programas dispersos es un problema recurrente en todas las areas de asistencia pública en nuestro país, al que no escapa la desnutrición:

"Lo que sucede es que este tema, de la desnutrición, no está centralizado, de repente hay muchos programas dispersos en los municipios, por provincias y las normas no se respetan en muchos lugares... más que no se respetan no se hacen. Y de repente se utilizan una situación degradente para el ser humano como es ésta con fines políticos y nada más." (Juan)

La responsabilidad de los funcionarios por la inacción o por la desarticulación de programas es puesta de relieve así como el efecto de saturación que esto produce:

\footnotetext{
"¿Por qué no se hace una red si este problema ya sabemos que es un problema demasiado importante en la población infantil?, ¿por qué no se establece una red de atención con un programa de orientación nutricional al menos en la Pcia. de Bs. As.? (...) Lo que pasa es que todos los que tenemos cierta responsabilidad en esto están esperando que lo haga otro y me parece que cada día hay menos gente con ganas de hacer cosas y no es porque no los haya habido lo que pasa es que se han cansado de estas políticas que lo dejan a uno huérfano...fundamentalmente a los hospitales a donde se va a atender este tipo de pacientes." (Juan)
} 
Ni siquiera en los hospitales públicos analizados los recursos del Estado acompañan a las normativas alimentarias:

"pero no sé por qué no se puede implementar en el hospital entregar alimentos o leche, lo mínimo, la leche para el menor de 6 meses, leche maternizada." (Ana)

Tampoco es sencilla -desde la motivación, el interés y el voluntarismo médico- la puesta en marcha de las normativas de control del crecimiento que permitan la implementación de un programa de vigilancia nutricional dentro del ámbito institucional, a veces por la subestimación del problema por parte de los mismos pediatras:

"Me interesaría ver cómo puedo hacer porque no es fácil trabajar como me gustaría. De lo que leés o estudiás se sacan cosas pero en realidad normatizado nosotros, nada, no hay nada. No tenemos una unificación de criterios ni siquiera dentro del mismo hospital. Mucho no interesa." (Ana)

\section{Caracterización y abordaje de la desnutrición}

Todos los entrevistados definen a la desnutrición de manera similar, distinguiéndola según su causa en primaria o secundaria:

"Es el déficit calórico proteico que repercute en el crecimiento y desarrollo físico y psíquico del niño y en su estado inmunológico. Las causas pueden ser primarias por falta de aporte o secundarias a otra patología". (José)

La conceptualización de la misma cubre un amplio espectro que va desde su consideración como enfermedad, problema social, deprivación, trastorno orgánico, alteración del equilibrio, descompensación, ninguno de ellos suficiente ni claramente explicitado:

"Es un trastorno orgánico y como todo trastorno orgánico se le puede llamar patología...lo que pasa que los ingredientes que llevan a un estado de desnutrición son muy diferentes de alguna otra patología orgánica. El chico está enfermo pero por una deprivación socio-psico-nutricional, o por ahí tiene alguna enfermedad desenergizante que lo lleva a desnutrirse......Es difícil definirla como una verdadera enfermedad porque a veces la enfermedad es la que lleva a un estado... a una condición de desnutrición del chico". (Juan)

"Es un déficit... supongo que es social, alimentario (...). Es una enfermedad. Yo supongo que debe haber una predisposición ambiental que lleva a ese déficit y...bueno....todas las patologías que ese chico absorbe y le produce la enfermedad. Está ligado, al menos en mi cabeza a todo lo que es parasitosis, gastroenteritis y los chicos que hacen enfermedades reiteradas." (María) 
Los síntomas de desnutrición no siempre son evidentes, sobre todo la prevalente en nuestro contexto que es de tipo leve:

"Muchas veces son chicos aparentemente normales por eso hay que pesar y medir a todos los chicos, por lo menos a los menores de 6 año. Porque aparentemente pueden ser normales...corren, gritan en el consultorio y cuando uno los empieza a medir bueno ahí descubre la punta del ovillo de una desnutrición." (Juan)

Las cifras se desconocen y la atención y el registro se centran en la patología:

De esto se desprende que no es posible recabar datos para construir una epidemiología al menos institucional:

"Del total de consultas que se hacen, la verdad es que no se sabe cuántos hay desnutridos. No, porque no se hace eso, de desnutrición no hay una estadística. Es más, en la estadística que el jefe de consultorio le pasa al jefe del servicio, mensual, él te pone: infecciosa, respiratoria, etc., pero vos ves los ítems y desnutrición no existe. La patología, sí, infección, te pone el porcentaje o te pone la cantidad total que hubo, pero...en la planilla que manejan para el registro de patología, no está. Lo que pasa es que todos los que vienen al consultorio vienen por una patología...entonces vos, en la planilla qué ponés: si vino con una bronquitis, gastroenteritis....porque no te consultó en realidad por el bajo peso... entonces ese chico pasa como una patología respiratoria. Porque no hay registro...la idea es bueno, hacer algo, ya te digo, para no perderlos." (Ana)

Respecto del tipo de desnutrición que atienden más frecuentemente:

"es de causa primaria, implica mucho la causa social, en la zona son áreas marginales y bueno...no es sólo por el hipoaporte sino por falta de saber utilizar los pocos recursos que a veces brinda el Estado; no saben cómo distribuirlos o hacer bien un aporte para el lactante." (Martín)

En general, la edad de desnutrición se halla comprendida entre "Ya al año y medio, dos años ya...empieza a verse...." tratándose, de acuerdo a la gravedad, de desnutrición leve: "en general primer grado".

El desconocimiento de la situación nutricional de la zona de influencia es marcada recurriendo a suposiciones e impresiones personales para salvar el vacío de información:

"Sí, tenés el hospital y detrás del hospital hasta lo que es el río, que son como treinta cuadras, eso es todo villa, es inmensa. Sí, hay desnutrición. Yo no sé las cifras, no hay porcentajes, pero no lo sé. Sí, supongo que debe haber una estadística..." (Juan)

El conocimiento que poseen acerca del entorno del niño es limitado o nulo: 
"No, se puede hacer un interrogatorio, ahondar más el interrogatorio cuando, este, bueno... si hay algo en el chico que te llama la atención, sí. Pero no, no, habitualmente no se hace así de tomar datos de los padres, del tamaño de las familias...o sea que no se sabe nada de la familia. Claro, por ahí medís un chico, y el chico, bueno, es una talla baja, bueno, entonces ahí entrás a investigar un poco más. O sea, no se hace de rutina digamos porque no se puede en cuanto al tiempo y cantidad de gente." (Juan)

Pese al escaso tiempo dedicado al interrogatorio, los médicos repiten como características de las familias desnutridas una serie de factores de riesgo generales, destacando cualidades maternas negativas:

" $Y$ en general son las madres que tienen más cantidad de chicos. Las familias muy numerosas. Son de nueve chicos, son muy numerosas. Y bueno, y es la falta de atención y aparte la falta de trabajo y... son bastante más descuidadas. Hay algunas que no, ojo..." (José)

"La mayoría son madres que tienen más de cuatro hijos eh... y bueno, no saben, son madres que no tienen la facilidad como para hacer una dieta adecuada (...) capaz que dicen que no tienen pero por ahí tampoco con lo poco que tienen arman un alimento un poco más completo." (Martín)

La consulta espontánea por desnutrición -por demás tardía de acuerdo con el relatoes infrecuente, siendo habitual la detección en la consulta por otras patologías, hecho que correlacionan con características maternas:

"La mayoría va por una patología aguda, pocos son los que van por control. Las madres lo llevan al hospital porque el chico está enfermo y quieren que le resuelvas en ese momento el problema." (María)

"Sí, a veces preguntan. Pero bueno, eh, claro, o que lo ven flaquito o que es más bajito, cuando va al colegio lo ve más chiquitito, sí, sí, sí... y la que viene espontáneamente es porque, bueno, lo compara y ve que es más chico y lo trae. Lo compara con primitos o sino cuando entra al jardín. Que lo ve más delgadito. Pero en general el que viene espontáneamente es el que más rápido sale, porque la mamá es la que está preocupada... esa mamá es la que va a poner las pilas para que aumente el chico." (Ana)

"En general la población no consulta espontáneamente por denutrición sino por parasitosis o infecciones banales reiteradas." (María)

Se desprende la aleatoriedad del diagnóstico dependiendo del tiempo disponible y del "ojo clínico" del médico de turno:

"Sí, sí, cuando viene al consultorio porque tiene mocos o por cualquier otro motivo, bueno, lo mirás y por ahí lo pesás o lo medís...” (José)

"Van más por la patología y se controla al que te llama mucho la atención, que puede estar bajo de peso ...pero el que te llama mucho la atención." (Juan)

Queda en evidencia cómo la práctica profesional cotidiana contrasta con la representación técnica del deber hacer en el diagnóstico: 
"Primero tengo que llegar a un diagnóstico de que el chico está con una detención estatural, con un trastorno del crecimiento y eso lo hago a través de las curvas de distancia y de velocidad del crecimiento, para lo cual necesito varias determinaciones, una vez definido, primero bueno...buscar si no hay una causa que ambientalmente pueda estar haciendo que el chico coma mal o menos, el cuidado de los padres y descartar que no hay patología secundaria como puede ser una infección urinaria, una parasitosis....y bueno, se actuará en función de eso." (María)

Todos destacan la importancia del diálogo con la madre para realizar el diagnóstico e indicar el tratamiento más factible de llevar a cabo:

"Muchas veces sí vienen con síntomas visibles, en los lactantes: la pérdida de panículo adiposo, la emaciación de la la masa glútea, los panzones,... pero esas son ya características demasiado evidentes como para... y otras veces hablando con la mamá, cuando uno interroga y observa, ya en el interrogatorio uno puede sacar un montón de causas de situaciones que pueden estar pasándole a un chico... o una mamá que llega al consultorio y "tira" al chico sobre la camilla te está dando una pauta de cómo está vivendo esa maternidad...son datos." (Ana)

El tratamiento que realizan, limitado por la carencia de recursos que caracteriza al hospital público consiste en:

"Y ahí, bueno, dándole pautas a la mamá de alimentación. Si está anémico se le da... hierro y eso, pero es un problema social... Lo que pasa es que tampoco el hospital tiene alimentos como para darle. Ya te digo, leche hay veces que, bueno, hoy nos quedamos sin leche, pero lo ideal sería, bueno, eh, yo particularmente... En vez de dar una caja a todo el mundo...eh, darle realmente al que..." (José)

"El problema socioeconómico no lo vamos a solucionar desde nuestro consultorio... podemos intentar alguna recuperación porque en los hospitales no hay apoyo alimentario." (Ana)

La representación técnica del deber hacer surge nuevamente, ocultando la respuesta referida al tratamiento concreto del paciente desnutrido:

"El tratamiento de la desnutrición primaria es multifactorial y consiste en la rehabilitación nutricional, la educación a la madres en los cuidados del niño y el apoyo psicológico. Con eso se logra una buena recuperación" (Martín),

dado que todos afirman la escasez de recursos para poder llevar a cabo dichas actividades. Incluso, un caso límite plantea la inexistencia de medicamentos.

Lo que resta hacer, y es a lo que todos los médicos entrevistados apuntan, es:

"Intentar compensar la causa que en ese momento lo está descompensando porque nosotros generalmente lo vemos en agudo. Y bueno...el apoyo orientativo a la mamá con la alimentación. Suplementos alimentarios no tenemos, si damos suplementos vitamínicos y hierro porque generalmente está acompañado de anemia." (José)

Respecto de la prevención reconocen que, en su práctica asistencial: 
"Lo que pasa es que la forma de prevenir este tipo de trastorno no depende de vos como médico ni de la madre como madre... hay todo un entorno de tipo familiar, comunitario, de la provincia, del país. Es difícil, yo a la madre lo único que le puedo decir es la importancia de la comida que coma lo que es más útil. Ahora de ahí a que ella lo haga, dedique tiempo a preparar o que el marido traiga el solvente económico para los recursos que uno le indicó este...eso ya uno no lo puede...."

(Juan)

de todos modos,

"La mayoría de los controles que vemos son menores de un año y se les da leche por el Programa Materno-Infantil cuando hay porque no siempre hay; después del año no lo lleva casi ninguno espontáneamente a control", agregando que "en general esos son los que no vienen con problemas." (Martín)

Las recomendaciones alimentarias y el control del niño consisten en:

"Se le dan ciertas pautas de alimentación, ciertos manejos ambientales y familiares. Pero es difícil. Porque esa gente que llevó a ese chico desnutrido, eh... el chico no se desnutrió porque la madre quiso que se desnutriera (...). Simplemente se le dice qué alimentos puede manejar todos los días, los que pueden serle más económicos y con mayor valor energético y cómo prepararlos, explicarle la importancia de la calidad de la comida y de las veces que tiene que comer...dentro de las posibilidades que tenga la madre." (José)

"En los primeros meses darle pecho, seis meses por lo menos y después si quieren que le sigan dando, y dar semisólidos a partir de los seis meses, antes no por las alergias." (Juan)

Pese a estas pautas generales referidas a duración de la lactancia materna y edad de incorporación de semisólidos que todos comparten y tipo de alimentos prescriptos/proscriptos según la edad, no existen a nivel institucional muchas más especificaciones en torno a las recomendaciones alimentarias:

"No hay nada planificado. En cuanto al tema desnutrición no hay nada implementado, ni de refuerzos nutricionales o dietas para anemia, no hay nadie que se encargue." (Ana)

Si esto sucede en la práctica asistencial, las posibilidades de realizar prevención a nivel poblacional se diluyen cada vez más:

" QQué complicado para resolver eso! Porque tendrías que armar, en la zona en donde estoy yo, primero un consultorio como para por lo menos seguirlos...y detectarlos. $Y$ aparte es un problema social que el médico no lo puede, lamentablemente...por más que les des la caja de leche... ¿viste?, porque le das la caja de leche a ese, pero se tomaron los seis esa leche, obviamente. Es un drama." (Juan) 
La visión de las madres según los médicos y las prácticas médicas alternativas

Según los médicos entrevistados, la respuesta materna frente al diagnóstico imprevisto no evidencia alarma aunque sí preocupación:

"No,...no, hay muchas que no se hacen problema. Hay otra por ejemplo como la que está hoy citada, que viene acá, este, sí, estaba re- preocupada." (María)

"Hay otras como que se sienten heridas digamos. Porque es como que es culpa de ellas. Este... y es medio como que no les gusta." (Ana)

El estigma asociado al término desnutrido es compartido por las madres a quienes les incomoda tal etiquetamiento:

"No les vayas a mencionar distrófico ni desnutrido porque les choca. Si les decís está flaquito ya es distinto y vos en definitiva querés expresar lo mismo. Porque ya viene con la idea de que es maltrato hacia el chico o porque evidencian el trastorno económico. Otros vienen directamente y te dicen: 'me dijeron que está desnutrido' porque ya hicieron una consulta en la salita." (Juan)

Aunque prevalece la actitud de negación de problemáticas económicas o de alimentación familiar, las reacciones maternas frente al diagnóstico dependen de la edad del niño, la gravedad de su estado nutricional, presencia de patologías y motivo de la consulta:

"Los que llegan con patología y con un déficit de primer grado, esos, jamás la madre piensa que está bajo de peso, dice que come bien.... bueno, medio que lo niegan. Pero a veces también se preocupan mucho y ahí empiezan a dar bolilla y responden bien." (Martín)

“Les sorprende el diagnóstico 'porque el nene come bien'. Otras lo aceptan como algo factible: 'me parecía que estaba flaquito', 'me come poco'. En general después de varias charlas entienden el diagnóstico y cumplen las indicaciones en la medida de sus posibilidades económicas." (María)

La mayoría de las veces consideran que la desnutrición no es una enfermedad:

"La gente no considera a la desnutrición como una enfermedad en sí misma. Muchas veces hacen referencia a la desnutrición como una consecuencia de infecciones. Otras veces señalan que todos los hermanos son flaquitos y ese también." (Martín)

Y la percepción médica acerca de lo que la madre supone son causas de desnutrición es que:

"Está enfermo el chico, por enfermedad, claro. Que no es culpa de ellas... y algo que le busque yo...porque el chico tiene algo que por eso no engorda. Entonces, este... tratan de desligar.." (Martín) 
"Que se enferman muchas veces y eso los hace bajar de peso, que le tocan más las diarreas o el mal tratamiento de la enfermedad, ya que se reitera siempre lo mismo." (Juan)

Salvo en casos de suma gravedad "los signos de alarma no los tienen".

Contradiciendo su apreciación acerca de la importancia de la comunicación con la madre, de la explicación de la enfermedad y de los cuidados maternos hacia el niño, a este informante sólo le preocupa que las madres sepan reconocer los signos de la desnutrición, no sus causas y menos aún la forma de resolverla argumentando que "para eso estamos nosotros":

"yo quiero creer que la gente tiene que creer que es una enfermedad más, un trastorno, que debe ser atendida y que no tiene por qué saber por qué su hijo está desnutrido porque para eso estamos nosotros. Yo lo que necesito como médico es que se den cuenta de que algo alrededor de su hijo está pasando, después somos nosotros los que nos tenemos que encargar." (María)

Los médicos entrevistados plantean el uso de medicina popular por parte de las madres y opinan que:

"Yo no tengo experiencia con la medicina folklórica porque estoy formado para usar otro tipo de medicina. Se dicen muchas cosas de un lado, en la parte profesional, y se dicen cosas del lado del paciente. Es cierto que muchas cosas que toman son tóxicas, incluso los chicos corren riesgo de vida en los primeros meses sobre todo. Pero también gente que ha hecho experiencias en comunidades donde ha trabajado y manejado medicaciones a base de hierbas, se sabe que tienen beneficios. Entonces yo lo único que le digo a la gente....cada uno es respetuoso de tener la creencia que tenga. Yo estoy obligado a informarle lo que conozco de cada yuyito, de cada hierba y recomendarle lo que no le conviene hacer. Un paico al mes de vida puede llegar a ser mortal." (Juan)

La utilización de infusiones caseras y de curanderos aparece sobredimensionada y se le atribuye un carácter intrínseco y extensivo a toda la población pobre ya que "Yo te digo, yo pienso que es más cultural que otra cosa, por eso se mantiene, se da más en la gente de más bajo...nivel.....socio-cultural".

"Usan yuyos, té de yuyos en cantidad. De todo, hasta orégano, de todo. Tenemos cualquier cantidad de esa medicina folklórica, cualquier cantidad....de todo, paico... y tenemos un cartelón así en la pared incluso, cada cosa lo que provoca, para qué lo dan habitualmente y qué es lo que hace y este..., no, pero y muchas lo niegan. Pero sí, sí, le dan. Hay muchísimos casos de intoxicación, chiquititos, ¿eh?... paico, poleo son los más comunes. Pero hasta orégano he escuchado. Que según dicen...la que llega al orégano es porque ya le dio todo. Yo ni sabía que le daban té de orégano (...) A veces se lo dan porque tienen cólicos, porque más que nada por eso, por problemas digestivos." (María)

El "respeto" hacia dichas prácticas está condicionado a su uso complementario y subalterno respecto de la medicina científica, tratándose de una declaración ética formal y relativa al tipo de tratamiento ya que lo que recomiendan y advierten es: 
"Que mientras que no les dé de tomar algo, tés o algo que sea ingerir, que sea de palabra o pasarles un talco sí, nada que absorba por piel....que lo lleven pero siempre ahí junto con la consulta del médico ¿eh? (...) Porque tienen muchas creencias, hay muchos que están muy aferrados, por más que en la consulta vos le decís que no, al curandero van a seguir llevándolo. Tienen fe en las palabras y bueno, es su forma de expresar de tratar de ayudar al chico de su parte." (Juan)

De acuerdo con los testimonios de los entrevistados, las creencias populares se mantienen no sólo por hallarse enraizadas en "su" cultura sino también por desconfianza hacia la medicina científica:

"Los tratamientos populares pueden ser aceptados por la medicina mientras no interfieran con ella. Pienso que esos tratamientos se dan cuando la gente no tiene completa confianza en la medicina y también porque están muy arraigados en la población. En la medida en que no retrasen los diagnósticos o interfieran con el tratamiento médico indicado o dañen la salud como la intoxicación folklórica, no se realizan mayores recomendaciones. Los padres en general no hablan espontáneamente del tema sino que surge del interrogatorio: ¿le curó el empacho?, ¿le dio algún té de yuyo?" (Martín)

El médico intenta captar la confianza de la madre a fin de asegurar mayor control del caso:

"Generalmente les digo que no les den nada de tomar y que me cuenten. (...) Yo creo que las mamás con esos tratamientos se deben sentir más contenidas... es como parte de ellas ¿no? Yo les digo que tienen que ir a las dos cosas paralelas." (José)

alarmando acerca de los efectos iatrogénicos que pueden provocar:

"Con los pacientes se habla sobre el tema. Es más y es como que cuando hablamos alarmamos sobre las contraindicaciones, sobre los efectos, digamos, y como que se los hacemos.......peor de lo que son. Que realmente te digo, han llegado algunos y se han muerto." (José)

El efecto negativo atribuido por la mayor parte de los entrevistados a las prácticas de automedicación hace pensar que hay amplios conjuntos sociales totalmente irracionales, que apelan a recursos terapéuticos con el fin de lograr sino la muerte, al menos una internación:

"No sirven para nada. Yo creo que es un problema cultural, por eso siguen. Se lo van diciendo de madre a hija: '...porque yo te daba y si le das un poquito', y... así, se trasmite." (María)

La pregunta pendiente que se impone, dada la habitualidad que según los médicos tiene tal práctica, es: ¿por qué no se mueren más o hay más registros de internación por intoxicación "folklórica"? 
La eficacia que algunos médicos le asignan a los tratamientos populares se funda en la historia natural de la enfermedad y tiene como eje el aspecto biológico del proceso salud/enfermedad/atención

"Lo que pasa que cuando se cura, que piensan que es por el curandero coincide con la evolución de la enfermedad, entonces generalmente coincide con eso: se terminó la virosis." (Ana)

La reproducción de los saberes adquiridos y la falta de actualización de nuevos saberes obligan al médico a refugiarse en el terreno de lo conocido y a condenar aquello que en realidad desconocen o conocen fragmentariamente:

"Generalmente con los pacientes no les pregunto si van al curandero o eso... no porque ya te digo...es una creencia que ellos deben.... si yo veo a un chico con signos de haber ingerido alguno de esos yuyos... ojo hay que informarse hay que leer pero en la medicina que me formé yo no figuraban. Hoy la OMS está saliendo a reconocer como productos útiles a ciertas hierbas. En este momento no recuerdo cuáles son." (María)

Respecto de la "pata de cabra", enfermedad ampliamente conocida en las familias de sectores pobres que cae bajo la órbita de atención de la medicina popular y que se relaciona fecuentemente con un estado de desnutrición (Ortale y Rodrigo, 1997) los médicos plantean:

"Ahí en esa zona (la desnutrición) se relaciona mucho a veces con el bajo peso, con alguna enfermedad que lo tratan que es la pata de cabra y no lo relacionan con que tenga alguna enfermedad sino que tienen algo de esto que para ellos es enfermedad a su manera. Dicen que no aumentó porque tenía la pata de cabra...pero cuando uno les pregunta puntualmente." (Juan)

Esta situación no es ocultada por las madres quienes la comentan al médico siempre y cuando el mismo se interese por el tema:

"Sí, ellos hablan de la pata de cabra. Y es una deshidratación. Ellos no sé qué hacen....pero cuando llegan lo traen porque tiene pata de cabra...y lo comentan...sí, y te dicen que lo llevan al curandero... No sé a la pata de cabra qué le dan pero en general los frotan..." (José)

"Muchos lo curan de palabra o le pasan algo en la espladita. Las madres no lo ocultan que fueron, me lo dicen, siempre asocian al hijo flaquito con la pata de cabra. A veces el mismo curandero también lo manda al médico." (Juan)

El problema de la automedicación y de las medicinas alternativas, restringido por parte de todos los entrevistados al campo de la medicina folklórica en sectores bajos, aparece finalmente como problema y se abre como espacio de reflexión también para el caso de la medicina científica y de sus respectivas eficacias: 
"Ese es un tema grandísimo, el tema de la automedicación...el tema de creer de que a través de esas hierbas hacen milagros...el único que hace milagros es Dios. Para responderte tendríamos que hablar de creencias culturales, de lo que la gente piensa de por qué el sistema permite que la gente vaya y compre medicamentos. (...) Y con la masificación de la medicina como se está produciendo, de la atención médica masificada cada día van a pulular más esos tratamientos alternativos. Antes si vos ibas a ver a un médico clínico se tomaba 45 minutos, en este momento no sé cuantos médicos hacen eso. Y no sé, por la falta de tiempo, cuántos diagnósticos se pueden estar escapando por la forma en que yo puedo atender o en general los médicos pueden estar atendiendo en ese momento. Si van cien personas a un lugar a consultar, de esas cien se curaron cincuenta y quedaron otras cincuenta sin respuesta. $Y$ en los hospitales ni hablemos, la posibilidad de solucionar esos problemas son cada vez menores. $Y$ la gente necesita soluciones y las va a ir... va a recurrir y la gente, la gente en general, el ser humano, por una cuestión de instinto de salvación...va a buscar las soluciones donde sea." (Juan)

Desde sus categorías conceptuales, este médico hace referencia mediante su idea de "instinto de salvación" al proceso de autoatención -desarrollado anteriormente- en tanto modelo médico estructural de los individuos y de los microgrupos.

\title{
15.2. La perspectiva y experiencia de los pediatras de unidades de atención primaria
}

\section{Normativas, condiciones de trabajo y política sanitaria}

Los problemas que surgen en las entrevistas relativos al significado e importancia de las normas destinadas a controlar el crecimiento se relacionan con la división del trabajo entre médicos teóricos y prácticos, la relatividad de las normas y la necesidad de las mismas para homogeneizar criterios de diagnóstico, tratamiento y derivación:

\begin{abstract}
"Mirá, las normas las hacen efectivamente los que más saben, a veces, ¿no?... y se hace un seguimiento y descubren que una forma de proceder es más rápida y obtenés más datos, ¿por qué no hacerla? ¿eh?, si vos, hay una norma de diagnóstico y de tratamiento de determinadas enfermedades, no estamos en una época en que cada uno hace lo que quiere, en teoría...cada vez uno trata de hacer lo que mejor tiene que hacer...y en forma más precisa y concreta. Y la norma un poco te ayuda a que trabajemos de una forma igual ¿no?...no es lo mismo que, eh, un médico de ahora que un médico de veinte años atrás." (Lorenzo)
\end{abstract}

El avance científico conduce inevitablemente al cambio de normativas y a la necesidad de su actualización, no siempre posible, por parte de los médicos asistencialistas:

"Bueno, pero cambió y pienso que va a seguir cambiando porque el descubrimiento va a ser cada vez mayor...de los nutrientes, de los micronutrientes, eh, de las necesidades, de la maduración del chico. A medida que se va descubriendo se va acercando un poco más a lo que sería lo óptimo... ¿viste?, pero en el camino, eh, por ahí a medida que van estudiando, se van priorizando cosas sin conocer que hay otras dando vueltas, entonces...por ahí se mete la pata y uno va afinando la puntería. Y ahí eso depende también de cada chico." (Violeta) 
Los fundamentos científicos de las normas no siempre son conocidos, aceptando como criterio de autoridad el saber de quienes las elaboran:

"Yo creo que los debe haber fundamentos científicos, por supuesto, lo que pasa que, eh,...a veces uno no tiene tiempo de ponerse a leer cada una de las cosas, a mí me pasa...este, siempre decimos que los médicos de las unidades sanitarias nos venimos atrofiando.... Cambian las normativas, es cierto. Y sí, y si no tenés la posibilidad del curso o de ampliar los conocimientos, de viajar a Buenos Aires a los congresos, te vas quedando con las normativas que tenías de antes y viene una mamá que lo llevó al Hospital...a mí me ha pasado, que lo llevó al Hospital y me dice: 'Me dieron esta dieta', y yo la leo y digo: 'Bueno, la mitad de las cosas que te daba... yo, eh...no se las hubiera indicado..." (Susana)

Los pediatras proceden a una adecuación de las normas en función de las normas preexitentes, de la evaluación de su práctica y de las particularidades del caso:

"Entonces bueno, si bien las pautas van modificándose, uno desde este nivel de atención primaria no las va modificando demasiado... a no ser, bueno, sí, que la información ya caiga, eh, y sea muy amplia... que sí o sí la tenés que aceptar, incorporar...

Y bueno, modificar en función de eso. Pero nos pasa, eh, por lo menos a mí me pasa, este, que, eh, trabajo ocho horas acá, que tengo el consultorio tres veces a la semana en mi casa, que tengo una familia, que hace que no tenga a veces el tiempo como para decir bueno, este, me siento a leer, a actualizarme, a buscar bibliografía... a no ser, ¿viste?, que tenga...

Tenemos anualmente 58 horas...de curso, este, si se extiende, eh, más allá de ese tiempo, habría que devolver las horas con trabajo...eh, muchas veces no se hace." (Susana)

Esta flexibilidad se debe además al hecho de reconocer que las normas tienen un carácter provisorio y variable en función del tiempo y de particularidades individuales, regionales, étnicas, etc. ya que:

"La medicina no es una ciencia super-exacta...tiene sus bemoles...y no todos los pacientes responden de igual forma a un tratamiento. También está esa posibilidad.

Eh, es, es medio arte a veces, ¿viste?, a veces es medio suerte; prescribir lo correcto en el momento correcto...en dosis suficientes para salvar o curar una enfermedad. Es un decir, ¿no?, eso se puede extender a todo lo que sea medicina ... la forma preventiva, cuándo conviene hacer la profilaxis, con las vacunas pasa algo similar...¿Qué calendario es el mejor?, ¿el de Estados Unidos?, ¿éste?, ¿el de Europa? Son todos diferentes....¿cuál tiene razón? No sé ¿viste?, ¿quién tiene la razón? Y sin embargo estamos hablando de una cosa tan simple que es: cuándo debés vacunar y con qué vacuna...y cuántas dosis. Imaginate con la comida... Esa variación de criterios tiene que ver con las características de los que hacen la norma... Vos no podés pretender que el que hace la norma acá sea la misma que está en África. Cada uno va conociendo cada vez más su parte regional, su entorno ¿viste?, yo no puedo dar un consejo en un chico que es europeo o africano o asiático...porque es otro entorno que se manejan...y otras comidas, $y$ otras costumbres, $y$ otras, es decir,...

Y por la gente que las hace, a veces hay normas en otros países que son hechas por, son fabricadas por los países del primer mundo, ¿no? Y entonces ahí ¿cómo encajás?

Este, sí, las tablas son medias arbitrarias también porque tienen que ser de esa forma...pero con algo tenés que comparar. Para saber si estás bien, si estás equivocado, el chico lo mismo...

Pero las tablas también son, son también que se pueden modificar, ¿viste?, a medida que va pasando el tiempo...no siempre son estáticas, ¿no?” (Lorenzo) 
Asimismo, el tipo de formación recibida induce a focalizar en la enfermedad y no en la salud, hecho que explica la escasa importancia asignada a las normas de control del crecimiento y alimentarias:

"Mirá, yo te puedo hablar de la formación que tuve. Eh, la salud, eh, generalmente uno veía la medicina por las enfermedades no por la salud... casi todas las patologías..., hospitales, patologías, hospitales...y mirá, cada uno ve lo que quiere ver...¿ ¿viste? Cada uno ve la realidad que quiere ver... Como que lo otro lo ignora, así que, eso depende de cada uno...Pero que te incentiven a hacer algo desde la universidad cuando yo estudiaba, no. En la formación de posgrado depende mucho de quién te toque al lado, ¿viste?, que te enseñe..." (Gabriela)

Algunas de las cuestiones que ponen de relieve todos los pediatras de las unidades sanitarias se vincula con el sub-Programa de Vigilancia y Rehabilitación Nutricional (PRN) -componente del Programa Materno Infantil de la Municipalidad de La Plata (PMI-MLP)- desarrollado entre 1995 y 1998 y con un Censo Nutricional llevado a cabo durante una semana en mayo de 1998 en todas las unidades sanitarias en niños menores de seis años que demandaron asistencia.

Uno de los entrevistados, partícipe de la coordinación del Programa Materno Infantil comenta:

“...le dimos un poco más de importancia a lo que es vigilancia nutricional...por pensar que es una población, eh, siempre pensando en los desnutridos, ¿no?. Es una población, eh, reducida, para decirlo así...en general, en el cual una acción temprana, efectiva, podría tener resultados concretos, satisfactorios...y medibles...en forma también precoz, y bueno, y por la importancia que significa la recuperación de un chico desnutrido." (Responsable del PMI-MLP)

El sub-Programa de Rehabilitación Nutricional dura tres años y se funda en la necesidad y relativa facilidad para centralizar la detección, seguimiento y recuperación de los niños desnutridos y derivarlos, en el caso de ser secundarios, a niveles asistenciales de mayor complejidad. Al niño detectado se le entrega mensualmente una bolsa de alimentos durante tres meses junto con los controles. Los chicos se ingresan a través de unas chequeras que manda el pediatra que lo detecta al nivel central y allí queda asentado en una computadora así como los controles de seguimiento. Si a los tres meses recupera peso, durante uno o dos meses más se le sigue dando la bolsa de alimentos y si no recupera se hace un segundo plan de rehabilitación, derivándolo en última instancia al hospital. De los chicos bajo programa hubo un $70 \%$ de recuperados y el $30 \%$ restante permaneció desnutrido a causa de otras patologías. Como plantea la coordinadora del sub-programa "En general...el chico que era desnutrido puro...se recuperaba." Recortes presupuestarios afectaron al municipio repercutiendo en la continuidad del programa para desnutridos "se siguió 
hasta el año pasado, hasta principio de este año, que no hubo más ingreso para bolsa de alimento y se interrumpió." (Coordinadora del PRN)

Uno de los problemas que se evidencia durante el desarrollo de dicho programa tiene que ver con el sesgo asistencialista de la atención primaria:

"Es decir que por ahí estaban, se detectaban, pero no se denunciaban. Yo pienso que...como demanda tiempo, ¿viste?, registrarlo, anotar, y por ahí el pediatra está en un trabajo, digamos, acelerado, asistencial, que sentarse a pensar, a recopilar los datos y todo eso, lleva otro esfuerzo que por ahí no quieren hacer, ¿viste?. Y como nadie exige ese esfuerzo extra... y entonces por ahí es como que el que lo quiere hacer lo hace, el que no lo quiere hacer no lo hace, total da lo mismo." (Responsable PMI-MLP)

Además, la falta de seguimiento se vincula con la fluctuación laboral de los pediatras:

"Como que es mucha población...muy variable y muy difícil de globalizar, ¿viste?, toda la información y eso porque es muy cambiante, cambiantes los efectores, ¿viste?, los pediatras, y bueno, es muy difícil..." (Responsable del PMI-MLP)

El resultado del censo fue:

"Nos dio que de los chicos menores de un año, encontramos desnutridos el 7,6\%...hay que tener en cuenta que la mayoría eran grado uno y algunos grado dos...grado tres no hubo. Y así que por ahí porque estaban cursando alguna patología, o estaban con algún cuadro, es decir, no de quizás, no separamos acá los que estaban enfermos de los que estaban sanos...

Así que nos dio que un 7,6\% menor de un año era desnutrido... y encontramos un 16,6 de sobrepeso en menores de un año. De uno a dos años: encontramos que había más o menos un $11 \%$ casi de desnutridos, y un 9,2 de sobrepeso. Y mayor de dos años: encontramos un 6,6 de sobrepeso y un 14,3 de desnutrición. Como que después del año, hay veces, la gente, este, los lleva a control pero la mayoría de las veces los lleva por enfermedad. Y después difícilmente vengan a control...los chicos mayores." (Responsable PMI-MLP)

Hay que tener en cuenta que se trata de una muestra sesgada que además no diferencia quienes fueron a control de salud de aquellos que consultaron por patología: El tipo de atención predominante en las unidades sanitarias responde a la demanda de atención por patologías y en promedio cada pediatra atiende 400 prestaciones mensuales.

En cuanto al manejo de normas y a la capacitación de los profesionales para manejar las normas de control del crecimiento se desprende que:

"Eh, las normas...la mayoría sí, son las mismas. Hay muy pocos que no hicieron residencia, que hicieron concurrencia pero igual, manejan los mismos términos y teorías... manejan, sí, las tablas, eh, se trata de manejar la historia clínica pediátrica, que eso lo implementamos hace poco. Es una historia clínica informatizada. Pero algunos centros todavía no la usan, ¿viste? porque son médicos ya viejos, ¿viste?, que están acostumbrados a otro tipo de manejo....

En teoría está todo técnicamente dentro de lo que uno, eh, en normas generales, lo que se tendría que hacer y se hace y en la práctica...lo que sí falla es el registro." (Responsable PMIMLP) 
El problema reside no en la competencia de los profesionales sino en la escasa motivación que sienten para participar de programas y censos que se les proponen:

"Sí, claro, la gente está capacitada....pero está desmotivado, para decirlo así, ¿viste?, como que 'para qué me vienen a joder, a llenar una encuesta, a hacer esto, a hacer lo otro, ¿para qué?', ¿viste?, 'si yo el laburo lo voy a seguir teniendo igual, si mis reclamos no los van a escuchar', ¿viste?, están cansados, ¿viste?, entonces como uno le pide cosas, le pide, le pide y están, así... 'iotra vez me venís a joder con esto!... si no vas a solucionar nada'." (Responsable PMI-MLP)

Los pediatras evalúan su práctica y reflexionan sobre su función y sobre la finalidad de su intervención, sobre todo cuando participan en la recolección de datos:

"Sí, uno, qué sé yo, uno por ahí se embarca cuando hace algo y no, a veces no mide consecuencias o a dónde querés llegar...Te empezás a embalar, a embalar y después llega un momento que, bueno, de reflexión y ¿para qué me sirve?, ¿qué voy a hacer con esto?, ¿qué voy a modificar? $Y$ ahí las pretensiones empiezan a achicarse. $Y$ va a llegar un momento que por ahí ya podés llegar a decir, bueno, son datos, nada más...del momento actual... Cada uno decide, el grado de responsabilidad, eh, por ahí en algunas cosas es limitado, ¿no?

¿Hasta dónde quieren llegar con algo?: hasta donde pueda, hasta donde me dejen, hasta donde...qué sé yo, hasta donde me den las fuerzas o hasta donde, bueno, hasta acá llegué, o me interesan nada más que los datos y lo demás que se encargue otro. ¿Viste?, eso es medir hasta dónde quiere llegar uno con algo." (Raúl)

En ese sentido, un entrevistado enfatiza, en relación a las enfermedades que atiende, la naturaleza política de su trabajo:

"Claro, son las patologías de la pobreza. Una cosa genera la otra. Creo que no hay nada peor para un ser humano que no tener sentido de la dignidad. Más que no tener sentido, no darse cuenta de su propia dignidad como para reclamar lo mínimo de lo que es digno un ser humano. Lo que nos hace dignos: el alimento y la higiene. Y creo que la gente... es como que no hay derecho a reclamar. Uno como pediatra, yo ya me planteé todo, ¿viste?, porque si la globalización produce más pobreza, ¿viste?, cada vez va a ser peor, y yo lo veo que cada vez es peor y no depende de tal o cual gobierno sino que es así. Entonces yo ya me planteé, ¿viste?, o sea, que uno, cuál es mi finalidad, qué objetivo voy a tener como médica pediatra y bueno, qué estoy haciendo en este momento en un centro asistencial, Unidad Sanitaria, qué sé yo, tratar de preservar la dignidad de los chicos. Sí, porque es como que alguien tiene que hablar por ellos. Sí, ellos no pueden levantar la voz." (Eduardo)

El responsable del PMl destaca el papel estratégico de los médicos de atención primaria en tanto articuladores de la población con las decisiones políticas y señala la centralidad de registrar y elevar datos epidemiológicos:

"Pero desde el punto de vista de acá, que está a un paso intermedio entre lo que es el Centro de Salud y los políticos...es como que necesitás generar esta información para demostrar la necesidad real y para exigir...claro, y en base a la necesidad real tratar de modificar un poco, pero es difícil, ¿no?, es difícil." (Responsable PMI-MLP) 
La intensa actividad asistencial no deja tiempo para esa tarea: "me ha absorbido, acá la demanda es un poco desgastante...siempre está lleno" y la falta de información se ha agudizado en el último año por el desvanecimiento del programa de rehabilitación nutricional:

La evaluación que hacen del trabajo en la salita refleja gran satisfacción en lo que hace a la relación con los pacientes, pero cierta frustración por la imposibilidad de capacitación fuera del horario de trabajo:

"cuando vine acá al principio me sentía castigada...porque en la década del setenta y pico, ochenta, que yo terminé, la residencia era muy, eh, como para la gran medicina pero yo a lo que iba es a lo siguiente: que he visto en estos 18 años, estoy criando, ayudando a criar a los nietos sería, entre comillas, eh, de las mamás, o sea...mis nietos postizos, mis pacientes, y no todos los chicos que fueron desnutridos quedaron con lo que yo esperaba que iban a quedar. (...) Atender acá te lleva por lo menos unos cuantos minutos asesorarte de cómo... Cuando uno se liga tanto a la gente, terminás queriéndolos...fue tu vida también...fue parte de tu vida.

Y hablar con las mamás te lleva mucho tiempo, si le das bolilla, ¿no?”(Violeta)

Los magros salarios hacen que el médico tenga que trabajar 40 horas semanales 0 más en la asistencia, con el consecuente desgaste y poco margen para actualizarse que ello implica:

"Tenés que tener mucha energía para luchar contra el sistema. El médico de acá, que es el médico de trinchera...somos como médicos de guardia...

Yo trabajo desde las nueve de la mañana hasta las cuatro de la tarde con una hora de descanso. Pero es la única manera de tener un sueldo que ronde un poquito más de mil...porque sino ganás setecientos...y te morís de hambre. Pero entonces el tiempo para el estudio no te queda.

Tenemos 56 horas curso que yo las tomé siempre, alguna vez hasta me han tenido, tengo que decir porque me han dejado hacer alguno más, pero parece que uno siempre, yo comparo con los médicos, compañeros míos del Hospital y trabajamos el triple. Es un trabajo más desgastante porque tenés poco retorno para cultivarte. Eso es una cosa que el Hospital critica pero hay que estar." (Violeta)

La permanencia en el trabajo y la regularidad horaria del servicio contribuyen a afianzar la relación médico-paciente:

"En el barrio tengo buena relación, hace mucho tiempo que estoy, eso es importante...ya vengo, eh, atendiendo generaciones... Sí, sí. Yo de lunes a viernes acá me encuentran...seguro, seguro. $Y$ creo que no saben ni mi apellido, yo soy Susana...la doctora Susana." (Susana)

Sin embargo, esa continuidad y el conocimiento mutuo conducen a que el médico reconozca su limitada capacidad resolutiva:

"Esa es mi experiencia, de cualquier manera es bastante, eh, no, en algún aspecto es un poquito...desalentadora...ubicate en mi realidad, eh,... que uno cree cuando viene acá cree que con lo que viene a traer le va a ayudar a la gente a resolver sus problemas. Tenés que 
aprender que el problema del chico lo resuelve la familia...y con las potencialidades que tiene. Por ahí el médico puede ayudarles a hacerles ver esas potencialidades..." (Malena)

No obstante, la atención está asegurada:

Quizás acá son hiperdemandantes ...y bueno, pero esa hiperdemanda lleva a que el chico nunca se quedó sin atender, es decir...que tuvo respuesta...porque la mamá que te joroba al final...como dice por ahí la Biblia, si golpeas muchas veces te van a dar...bueno, acá están acostumbrados a eso porque yo tengo un sí demasiado fácil... Ahora lo estoy cerrando al sí porque estoy agotada." (Belén)

La continuidad horaria del servicio y la relación personalizada con el pediatra llevan a la hiperdemanda de atención, transformando a la salita en un lugar de encuentro barrial:

"Y acá en la Sala, bueno, yo eso es mi teoría, por ahí no es verdad, yo tengo la teoría de que mucha gente viene porque sale de su casa como una salida...porque hay una demanda reiterada por patologías mínimas...y a veces están horas acá. Es como un lugar de reunión...donde ellos saben que está la odontóloga, la ginecóloga, suele estar casi siempre la leche, eh, buscan medicamentos para la pediculosis, sería como un shopping, entre comillas, en broma te lo digo...está el médico clínico, está la enfermera, y como se cumple bastante acá...eh, siempre nosotros decíamos, parece que acá también es como un lugar de reunión." (Violeta)

Finalmente la implementación cíclica de viejos programas y la ausencia de respuesta de los niveles de decisión política hacia los eternos problemas de la asistencia conducen a la incredulidad:

\begin{abstract}
"¿Sabés la crítica que yo hago al sistema? Que las politicas no son, no tenemos continuidad nunca. Vos sabés las veces que a mí me vinieron a plantear de vuelta el Plan Materno Infantil...a mí me da una gracia porque el Plan Materno Infantil existe hace muchísimos años...y es más o menos el mismo, no hay grandes variantes. $Y$ cada tanto...ahora vas a ver que van a venir de vuelta...y yo los miraba y les decía: 'Pero eso yo ya lo tengo hace mucho acá. ¿Sabés lo que necesito yo? una asistente social'." (Gabriela)
\end{abstract}

Pese a las políticas del sector salud que pudieran desarrollarse exitosamente, un dato que destacan es que:

"Ahora, para lograr un plan, yo lo que he notado cuando la familia tiene trabajo mejora todo. Yo he tenido la experiencia de familias desocupadas que de golpe adquieren trabajo, desde la ropa, cambian de escuela, los chicos engordan. O sea, vos ves que no es que la gente toda quiere vivir mal...no, ese es un problema..." (Eduardo)

\title{
Caracterización y abordaje de la desnutrición
}

Respecto a las características de la población que asisten, la mayoría de los entrevistados acuerda -con matices- que: 
"Si bien esta zona es carenciada... hay lugares que son peores. Pero el problema más importante es que por ahí tampoco la gente es escuchada. Yo creo que tampoco hay que echarle tanto la culpa a que la gente es ignorante. Un ignorante también tiene el mismo derecho a ser escuchado...al que es culto y por ahí no los escuchan en otros lugares. Y no son dejados, tan dejados como parecen. Yo creo que bueno, hay gente que es muy dejada pero las madres en general tan dejadas no son. Acá vienen, acá cumplen con...los controles y con las indicaciones." (Raúl)

En cuanto a la desnutrición, los datos que manejan remiten al censo, y todos plantean que no es un problema que revista demasiada gravedad:

\begin{abstract}
"Acá se atienden un promedio de 700 consultas mensuales. De los cuales no podría especificar puntualmente el porcentaje. Pero lo que en realidad no es tanto el número de desnutridos como que si vemos cuáles son las causas de los chicos que están en el límite....del peso adecuado y la talla para la edad y un desnutrido (...) No, cuantificado exactamente no sé, pero desnutridos agudos no hay, son todos límites. Lo más frecuente que se ve que son anemias ferropénicas originadas por parásitos, por parasitosis múltiples...el chico entra ya en el percentilo del tópico, pero está siempre en el límite. Son chicos que vuelven a caer, y sí, una infección, las infecciones y todo eso lo desnutren cada vez más..." (Gabriela)
\end{abstract}

"Este... así que bueno, si vos me preguntás si acá hay mucha desnutrición ...yo te digo que no. Que hay mal nutrición, sí. Este...porque la base es el hidrato de carbono, eh, los fideos." (Belén)

Aunque muchos niños no puedan ser catalogados como desnutridos, sí reflejan signos de subnutrición o malnutrición:

"Yo había observado que la contextura de los chicos, eh, de peso aparentemente normal de algunas familias, no de todas...era como más... que la composición era blanda...es decir, lo que se podía llamar el desnutrido farináceo... ¿viste?, que era gordito pero que no era un chico, eh, sólido...como que le faltaba musculatura. Le hacés la curva y está bien, pero vos lo mirás y es como que le falta....le falta, bueno, una que hay mucha parasitosis también, ¿no?...eso ya lo...ha llegado a toda la ciudad. Eh, mi abuela lo llamaba pelo de hambre, que acá mucha gente cree que es pelo sucio y es pelo de hambre...es pelo de ¿viste?, pajizo...opaco, coloradito, y vos le mirás y decís...porque si vas a ver a donde viven..." (Violeta)

El tipo de desnutrición que atienden es en general leve o de primer grado, los que detectan de mayor gravedad son derivados a niveles de atención de mayor complejidad por tener patologías de otro tipo:

"...los pacientes que son, que no hay muchos, desnutridos, digamos, moderados a graves...son pacientes que tienen patología renal importante, o patología cardiovascular...que no los manejo yo, no los, no les hago yo el control, este, porque no tengo los medios ni los, o sea...

Esos pacientes que son desnutridos graves consultan en el Hospital de Niños...obviamente. Se atienden en los servicios de subespecialidad." (Lorenzo)

No obstante reconocen fallas en la detección por no realizar controles antropométricos de manera rutinaria y generalizada: 
"...nosotros en reuniones chiquitas de pediatras nos cuestionábamos si es que nosotros no la veíamos...o es que no había. Con el censo se demostró que había...que a nosotros se nos puede pasar por alto...en función de que si viene por un cuadro, eh, infeccioso, un cuadro catarral o alguna otra patología, no fijamos la atención en el control antropométrico del chico...pero lo que se, acá, yo decía que yo no veía tantas desnutriciones, pero sí había obesos.

Y en el informecito así verbal que nos pasaron era cierto. Había tantos desnutridos como obesos. Eh, difícil de revertirlo... uno como otro." (Susana)

Una de las entrevistadas plantea que el seguimiento y las estadísticas se han desvanecido a partir del recorte presupuestario que afectó la dación de alimentos:

"Yo cuando hacía la estadística mensual, que nos pedían porcentaje, tenía entre un tres y un cinco siempre...de demanda de desnutridos. En general la mayoría de los chicos desnutridos son menores de un año, sí, entre los primeros meses y después queda el crónico...el famoso crónico...que es el petiso y gordito, como dice...

Mirá, tengo, te voy a decir la verdad, los registros que yo tengo no son muy, eh, fidedignos porque la gente con chicos de bajo peso...concurre más cuando hay bolsas...de comida. Y ahora, eh, bueno, hubo como un parate este año...no se compró alimentos." (Coordinadora del PRN)

Si bien el tipo de atención es "fundamentalmente a demanda de lo que pide la gente", los controles de salud

"Sí, se hacen. Sí,...hasta el año ... acá en el Centro nuestro es la actividad prevalente. Y durante el primer año las madres cumplen, el primer año lo cumplen.... A los que necesitan les damos leche de vaca, no maternizada porque...eh, maternizadas la Municipalidad a veces compra, pero tenemos a veces un stock de 12 kilos de leche maternizada por mes y a veces pasan dos, tres meses y no tenemos..." (Lorenzo)

Luego del año los controles se hacen cada vez más espaciados y la demanda se da en caso de patologías:

"Y del año a los dos años el, yo lo que les digo son controles trimestrales...y ya después de los dos años, una vez que cumplimos con todo el esquema de vacunación, les digo por lo menos dos veces al año los tienen que traer a los controles. Lo que pasa que bueno, una vez que empiezan con el jardín, con el colegio, ya es mucho más espaciado, lo traen cuando tiene una patología...y bueno, ya que está con el catarrito, con la bronquitis. Después de los dos años, eh,...bueno, y nos pasa a nosotros con nuestros hijos...y las madres también aprenden

En general charlamos, ¿viste?, bastante sobre las conductas anticipatorias que uno tiene, que las mamás tienen que tener y que conocer con respecto al manejo de los chicos, sobre todo, bueno, en determinadas patologías...y lo saben...qué sé yo, la dieta para una diarrea...preparar el suero de rehidratación...lo saben, lo saben..." (Lorenzo)

Uno de los problemas que preocupan a los pediatras tiene que ver con el desarrollo psicomotriz y psicosocial, sobre todo de aquellos que atienden a población boliviana, con particularidades étnicas-nacionales: 
"Este, y después la falta de estimulación, que es aterradora. Sí, sino, ¿viste?, que lo llevan acá atrás...envuelto, al rayo del sol, ellas están levantando la cosecha y el pibe está en la espalda recibiendo todo el sol, así que por ahí hay algunos deshidratados, ¿viste?, y después la falta de higiene...son todas cosas, bueno, que te llevan mucho trabajo, en el Centro se puede trabajar mucho con eso, si, si les tenés paciencia..."

"Lo que, el problema del boliviano es cuando empieza a caminar porque los hábitos de higiene... ¿viste?, que no son muy......son pobres. Y el estímulo es pobre también. En la feria los ponen en cajoncitos...y son esos chicos con cabecitas braquicéfalas, chatitas...y están mucho tiempo quietos. Porque ellos aparte cultivan la, eh, cultura...de la quietud. O sea, el chico que se mueve molesta." (Violeta)

Si bien los problemas de estimulación se vinculan con la población boliviana, los problemas nutricionales se dan -comparativamente- con mayor frecuencia en los paraguayos:

"Bueno, no, te digo que mi experiencia acá es de diecinueve años...tenemos muchas migrantes, eh, hay desnutridos en todos los grupos de, que atendemos...los migrantes, eh...paraguayo se desnutren más los paraguayos...que los bolivianos... ¿viste que los bolivianos vienen de la cultura aymara y tienen una estructura familiar muy sólida, muy rígida... El boliviano por ahí se puede llegar a desnutrir por la parasitosis cuando empieza a caminar, pero son muy buenos lactantes..." (Violeta)

Además, el proceso de pauperización creciente en nuestro país hace que familias de clase media empobrecida recurran de manera creciente a la asistencia pública, complejizando el perfil de población que tradicionalmente es atendida:

"Mirá...al centro de salud, por ahí van, para decirlo así en forma global...como dos tipos de, es difícil decir categorías de gente...o de clases.....de gente, ¿no?, pero bueno, están los que son pobres y los nuevos pobres, por decirle a la clase media empobrecida.

Por lo tanto las demandas son diferentes, ¿no?, o los niveles de, de exigencia también son diferentes. No es lo mismo el nivel de exigencia que presenta una familia, eh, que entró a la pobreza por estos cambios económicos y una que...ya venía de familia de gente pobre, ¿no? Son muy diferentes... como que unas se sienten preocupadas, ¿viste?, las madres se sienten tocadas cuando se les dice que por ahí el chico está desnutrido, ¿no? ...o está bajo de peso, es decir, como que sí, toman en cuenta que es una responsabilidad de ellas por ahí que su chico esté desnutrido." (Raúl)

Las características de las familias con niños desnutridos tienen que ver con cierta desatención que obedece a limitaciones económicas:

"Un nivel muy bajo... nivel económico muy bajo...hay ...un pseudocuidado, ¿viste?

En general se da en aquellos chicos, en los de bajo peso, en los que las mamás se despreocupaban...Entrecomillalo el despreocupado...porque me los traían acá a los controles: '¿Le hiciste los análisis?: 'Ay, no, no tuve tiempo...este, tuve que salir a trabajar, no tengo con quien dejar al otro chico'...este, ¿viste?...también están limitadas...en eso.” (Malena) 
Algunos plantean que el problema económico no es determinante destacando el peso de la contención e integración familiar:

"Te cuento otro caso, tengo miles de casos. Éste fue uno donde yo vi que la desnutrición no siempre son las calorías, no siempre es todo lo que uno...se preocupa de la bolsa de alimentos, ¿viste?, para mí va por otra parte. Acá la mamá evidentemente no tenía incorporado el reflejo del cuidado, porque ella misma, vos la veías que no tenía la higiene, no le daba...pero sin embargo en el afecto, el abrazo, los besos, eh, los retos quizás...que yo a veces veía (...) o sea, ahí hubo afecto, hubo también una abuela contenedora, o sea, hubo un abuelo que murió que daba un poco de sostén. Hubo como un clan. Yo le doy mucho valor al aspecto, eh, no sé cómo explicarte, al cariño que la gente pone en la crianza. O sea, eso lo veo, lo he visto en el tiempo...

Tengo la otra vertiente, está el otro, la familia disgregada que hay en todos los niveles sociales donde hay droga, donde hay una mamá adolescente, donde el chico sí se desnutre...donde no tienen un nivel de alarma...

Esos no son tantos casos como uno cree porque por ahí yo pienso, y eso vos lo sabés más que yo...el chico que la mamá está muy sumergida, no llega a la consulta, a la Sala ni al Hospital. O llega ya cuando están para internar en terapia." (Violeta)

Las características maternas que relacionan con la desnutrición son la edad y el número de hijos fundamentalmente:

"porque el embarazo adolescente es un factor de riesgo para la desnutrición y tenemos $50 \%$ de embarazadas adolescentes, hizo la doctora un relevamiento y le dio eso así que son madres ..." (Malena)

La historia familiar, la violencia y el alcoholismo dentro del ámbito doméstico son los factores que los médicos entrevistados asocian a la desnutrición infantil:

"Yo te diría que hay sí, las madres son afectuosas, hay mamás, eh, absolutamente, como dicen ahora, maternalizadas...pero depende de cómo fue su historia personal... que también yo la he visto, en el devenir lo hemos visto...si hubo mucha violencia, que hemos tenido, hay mucha violencia familiar...en todos los niveles, pero acá hay más...porque hay un nivel de alcoholismo alto...también hay en las mujeres, no son tantas pero lo tengo, y cómo te podría decir, esas mamás en algunas yo observaba actitudes de gran tensión...de maltrato directo o indirecto con los chicos. $Y$ esos son los chicos que se enferman más, los que por ahí no engordan..." (Belén)

Sin embargo, en la mayoría de los casos existe preocupación de la madre por el estado nutricional del hijo, sobre todo si es menor de un año:

"Sí, les preocupa. Si la madre es normal, sacando las madres que te dije de alto riesgo, todas vienen al control para ver cómo está el peso de su bebé." (Violeta)

La consulta espontánea incluso se da cuando el niño no presenta signos evidentes: 
"Siempre consultan, muchas veces...consultan espontáneamente por desnutrición no estando el chico desnutrido. Yo te diría que de, ponele, cuarenta, de treinticinco consultas diarias, yo te diría que diez son porque la mamá lo trae porque no quiere comer. La mamá se ocupa mucho de eso. Porque eso...la comida, representa para ella un vínculo, una manera de vincularse con el hijo. Es el primer vínculo con la madre...y a través de la comida es el medio.

A mí me pasa eso, a las madres les preocupa el estado nutricional del chico, no sé si a todo el mundo le pasará." (Susana)

Además de las características maternas mencionadas como factores intervinientes, las causas de la desnutrición remiten fundamentalmente a dificultades económicas de la familia, al abandono afectivo y a las parasitosis:

"Eh, en realidad, aparte de lo económico y la carencia y otras cosas, y pautas socioculturales que en este momento cada vez están como afectando más, este, y humanas, eh, una de las causas de la desnutrición son los parásitos. Y yo no diría sólo en, por ahí, en clases más carenciadas sino en todas las clases sociales. Por los parásitos no comen, están más anoréxicos, más anémicos, eso los desnutre más. Entonces, es un círculo en realidad muy simple. Aparte es espectacular la mejoría del chico que es medicado y es tratado, y que la madre cumple el tratamiento antiparasitario. La mayoría son parasitados (...) además... digamos que después de la causa orgánica, como yo digo, parasitosis y a su vez anemia, este... la desnutrición psico-afectiva es una causa también importante, ¿sí?” (Gabriela)

El tratamiento indicado a los desnutridos consiste en la dación de leche, alimentos, hierro y suplemento vitamínico, además de recomendaciones a la madre en cuanto a la preparación de alimentos. Asimismo, el tratamiento antiparasitario contribuye sustancialmente a mejorar el estado nutricional:

"Los chicos que son tratados con el tratamiento antiparasitario es espectacular cómo mejoran en peso...los chicos tienen otra actitud frente a la comida, comen más, ¿eh?, porque tampoco vamos a decir que toda la gente que se atiende, al menos en esta Unidad Sanitaria, son tan carenciados."

(Gabriela)

Respecto de la eficacia del tratamiento, hay quienes reconocen limitaciones y gran frustración:

"A veces, ¿viste?...te das contra la pared diciendo: 'hasta acá llegó mi amor'...porque realmente...se hace difícil. Es limitado, sí, sí." (Raúl)

"Desnutrido es algo más de lo que, sí, se puede llegar a ayudar en forma de, de hacerle más controles seguidos, ¿viste?...tratar de que se enferme menos...tratar de conseguirle medianamente, si se puede, algo de lo que necesita...pero son problemáticas muy duras y muy difíciles de resolver." (Eduardo)

El conocimiento de las condiciones de vida de la población y la experiencia profesional conducen a tomar precauciones acerca de las indicaciones y de los tratamientos, no sólo para lograr su adecuación sino también a fin de evitar efectos iatrogénicos: 
"He visto cómo viven y cambié algunas indicaciones, porque hay cosas que los pediatras decimos que son imposibles de realizar. Por ejemplo, qué sé yo, hacer vapor en una casa donde no hay una ducha. A mí se me quemó y no me olvido nunca más..., no se me quemó a mí...pero yo me sentí responsable de la desfiguración del rostro de una nena. Sabés que la nena se quemó toda la cara!... era una muñeca, después bajé la indicación de vapor, casi la tengo reducida a madres que conozco muy, muy bien. (...) de otro caso similar me acuerdo que al chico le habían quemado no sólo la cara, le habían quemado el árbol respiratorio.... Yo no me olvido más. El médico le había indicado que le hiciera vapor con un cartón y pusiera al bebé ahí. El médico hizo una macana considerable, ¿no? O sea que atender acá te lleva por lo menos unos cuantos minutos asesorarte de cómo... "(Violeta)

Las actividades preventivas se limitan a recomendaciones durante la consulta propiciando conductas anticipatorias y umbrales de demanda oportunos:

"La tarea preventiva, bueno, la hacemos un poco en el consultorio, eh, no tenemos posibilidad de salida al exterior, este...no hay asistente social. Y este, y aparte, bueno, yo aparte de hacer pediatría soy la jefa del centro, así que...termino mi tarea asistencial y me queda un resto de tiempo para hacer las tareas administrativas del centro y nada más". (Susana)

La falta de tiempo para dedicarse a la prevención es crítica pese a la buena disposición de la gente para el diálogo:

"Y que es bueno prevenir. Yo creo y siempre me pregunto, ¿no?, o sea, cuánto tiempo vamos a tardar por ejemplo en, en que alertemos algo más para prevenir otras enfermedades, bueno, hay miles de maneras, ¿no?, de prevenir. Y si bien es cierto que la población merece ser escuchada....la población también escucha." (Raúl)

De aquí la autocrítica que algunos entrevistados realizan a su práctica profesional:

"A veces fallamos nosotros. En, no nosotros...te digo, el...la soberbia médica...este, de creer que el otro que no sabe nada, este, y que no se da cuenta de nada, y resulta que las mamás se dan más cuenta de uno...que en quince minutos o en diez minutos tenés que ver al chico y, este, y vos decís, bueno, yo no le encuentro nada, está bien, y resulta que no está bien.

Porque ellas lo ven las veinticuatro horas del día...y el chico, eh, es activo, es dinámico y bueno, vos lo ves acá que está tranquilo, quietito, lo revisás, no tiene nada...pero la madre sabe que algo tiene.

Este, entonces bueno, aunque yo no le encuentre nada...este, le digo, bueno, yo no le encuentro nada...lo más probable es que tenga algo...entonces le digo: bueno, vamos a esperarlo o consultás en el Hospital o...venís mañana." (Eduardo)

En relación al conocimiento de pautas alimentarias por parte de las madres, destacan que si bien es adecuado, en la práctica hay hábitos difíciles de modificar que tienen consecuencias en la vida adulta:

"Yo creo que las madres saben bastante y que los hábitos alimentarios también han cambiado mucho, sí. Y han mejorado, si bien hay costumbres por ahí que vienen de familia, que... 
Pero el hábito tiende a ser más sano; pero hay cosas que son difíciles de modificar, como por ejemplo que el chico no coma verduras....desde que es un bebé y entonces va a ser un constipado...entonces hay cosas que son difíciles de modificar.

$Y$ vemos las consecuencias en los adultos...que tienen patologías cardiovasculares ...obesos, hipertensos y diabéticos. O sea, eso es el espejo de la cultura y nosotros adultos, somos lo que fueron nuestros padres, y lo que nos, la cultura alimentaria que nos trasmitieron...

Y bueno, yo trato, siempre les hago mucho hincapié en eso por ejemplo, desde pequeño tratar de prevenir la obesidad, la hipertensión con la escasa ingesta de sal, del lactante." (Gabriela)

En lo que hace al cumplimiento de las recomendaciones médicas sucede que:

"La mayoría sí cumple...hay casos, como todo, ¿no?, de excepción, pero generalmente lo que, estos casos de excepción son porque hay una problemática social muy grave de trabajo...que por más que hagas lo que hagas ese chico está, por la problemática social está ya jugado, ¿no?

...y es muy difícil de revertirlo en el centro de salud, cosas muy groseras, muy fuertes y muy...que escapan a uno...eso no podés llegar a resolver nada, es todo el entorno social que vive, ¿no?" (Lorenzo)

Sin embargo, algunos refieren que las madres, pese a saber el momento indicado de alimentación con semisólidos, los han incorporado precozmente:

"Cuando les indicás semisólidos, eh, te encontrás que ya habian, no es que...ya le había dado: 'Sí, sí, porque como se sienta a la mesa con nosotros y nos mira y se babosea y...quiere comer...y desea...'. Generalmente habían empezado antes de la indicación.

O las mamás que ya tienen varios chicos...es como que ya no necesitan de la indicación médica como tal.

Este, pero en general, eh, ¿viste?, el manejo de la alimentación corre mucho más por el bolsillo del grupo familiar que por la indicación que uno pueda llegar a darle." (Malena)

A menudo, sienten que su actividad docente en la consulta con vistas a promover la salud cae en saco roto:

"Un día me sentí defraudada porque atendí el tercer hijo de una paciente mía y yo le digo: '¿Qué le das de comer?', tres meses, 'Come con nosotros', yo ya me empecé a...le daba de todo. Tenía tres meses y le daba de todo...le daba los guisos completos, le daba, faltó que le diera vino...Y ella tenía más chicos y yo se los había atendido yo a todos. O sea dije: estos no entendieron nada, ¿para qué hablé?, hablé de gusto. No hablo más. Sobrevivieron igual todos. También pienso en eso, sobrevivieron. No, pero era mucho, ¿eh? te digo que era mucho." (Violeta)

Los médicos, en función de su apreciación del caso particular, adecuan las prescripciones alimentarias:

"Mirá, en general están bastante informados...aunque a veces te llevás algunas sorpresas tristes. Yo soy bastante elástica con algunas cosas....eh, hay madres que tienen mucha presión familiar para incorporar precozmente. Entonces ahí uno trata de que incorporen cosas de bajo contenido osmótico, algún poquito de zapallo...un poquito de manzanita y medio que se van contentas." (Gabriela) 
Finalmente, un dato que debe destacarse -debido al énfasis puesto en la promoción de la lactancia a fin de prevenir la desnutrición- refiere a su prolongada duración:

"Pero en general las mamás les dan de mamar y a veces en demasía, o sea, habitualmente sucede al revés, yo creo que sucede más que nada por la prolongación... de la lactancia que por el poco tiempo. La lactancia, más allá de los ocho meses, o sea, al prolongarse la lactancia el chico comienza a desnutrirse, porque el chico que toma la teta no toma leche de vaca y no come. Y ya tiene una edad como para, este, necesita más calorías para crecer. Entonces no crece, empieza a anemizarse, la anemia origina menos apetito, es un círculo." (Violeta)

\section{La visión de las madres según los médicos y las prácticas médicas alternativas}

Ante el diagnóstico de desnutrición, la reacción de las madres es de preocupación:

"Cuando les digo a las madres que su hijo está desnutrido ...se preocupan. Solamente una mamá en todos estos años...me hizo cambiar la palabra desnutrido, o sea, a la madre, ¿viste?, que la palabra desnutrido la hace sentir incómoda...Pero eso depende del nivel cultural." (Eduardo)

La estigmatización es mencionada por otros entrevistados quienes adoptan un cambio en la terminología:

"Le dijo que era bajo peso...le cambió el nombre...porque con esa mamá yo la palabra desnutrido no la puedo usar. (...) la pauperización la hace sentir muy mal, por eso, sin embargo ella sí tiene nivel de alarma..." (Raúl)

Según los pediatras, las madres que se preocupan -la mayoría-, son aquellas cuyos hijos no presentan mayores problemas o bien las que responden exitosamente al tratamiento:

"Algunas a las que, las que no se tienen que preocupar...se preocupan porque la abuela les dice que el chico está flaquito...entonces venís, lo traés, lo pesás, lo medís y está dentro del percentilo normal... percentilo 50, bárbaro, le digo: 'no, quedate tranquila', porque la abuela, la suegra le dijo.... no, está bien. Y las que son desnutridos, a ésas no les preocupa." (Malena)

En relación al uso de tratamientos populares, la posición de los entrevistados es de respeto "siempre y cuando no sea nocivo":

"Soy respetuosa porque creo que es toda una manera de expresar la cultura. Por eso dije, que en el caso de los tés, o sea, hay algunas situaciones que no...o sea, siempre y cuando no sea nocivo, no le haga daño, sí." (Belén)

"Sí, ellas me cuentan que lo mandan, pero no son la mayoría,, no, para nada. Y cuando me cuentan no les digo nada. Es respetar al otro. Yo sé cómo ellos piensan y es como ponerse en el lugar del otro....y bueno, entender que ellos, este, tienen ese razonamiento y bueno...y esa es su interpretación. Yo no la voy a cambiar. Lo que sí es que hay que advertirles, claro, en cuanto al uso de tés, ¿no?. O sea, todo lo que es la intoxicación folklórica, para evitarla, el uso 
de los yuyos, que es re-frecuente que cuando está con diarrea todas las mamás le dan algún té: de manzanilla, yerba de pollo, poleo, qué sé yo." (Lorenzo)

Otros destacan la eficacia pragmática de los tratamientos populares, habiendo conocido y experimentado algunas de las prácticas de uso frecuente:

"Sí, el doctor Gianantonio me enseñó a tirar el cuero. Mi mamá me enseñó a mí...y le enseñó, te estoy hablando del doctor Gianantonio...eh, él fue el que le enseñó a tirar el cuero...o sea, existe la explicación fisiológica. No, y los yuyos también, digamos, aparte se confunde, yo a veces digo, bueno...el problema es de osmolaridad. Sí, y por ahí...o se deshidratan.... Por ahí no el yuyo en sí, pero sino la cantidad...

Cuando son chiquitos sí, se mueren, ese tipo de convulsiones...el desequilibrio es muy grande La hidratación en los chicos de menos de un año, el balance del agua...es muy delicado." (Gabriela)

Una de las entrevistadas, a raíz de su experiencia profesional y de una investigación realizada con plantas medicinales comenta que:

"había empezado a hacer un relevamiento porque yo tenía la hipótesis que se confirmó...se confirmó pero no lo pudimos hacer bien...de que no eran tan tóxicas las sustancias...

No son tóxicas. Yo relevé, ya te digo, doscientos casos, me llegaron a traer, tenía lleno de paico, yo no las conocía...de todo. El caso más simpático es una chica que me mencionó diez yuyos. Cuando termino, me habian dado, habíamos confeccionado una planilla donde decía, bueno, formas de administración, dosis, eh, para qué lo daban, o sea, posología, todo...

Yo tenía con nombre y apellido, familias... O sea, eso volcado a datos concretos.

Las familias cómo le daban al adulto, cómo le daban a los chicos, cómo los preparaban...

De todos los casos, si no me mintieron, hubo un solo caso que la mamá reconoció una intoxicación...y el caso más gracioso fue una abuela, la chica esta que le digo: '¿Cómo sabés tanto...eh, de yuyos?' 'Mi abuela me enseñó', '¿Y tu abuela vive?', le digo, 'Sí', me dijo. '¿Y qué edad tiene?' '104 años'. Yo dije: 'Dame los yuyos'.

No, yo creo que con todo hay que hacer, hay que hacer un equilibrio... Yo trato de que si veo, primero trato que no lo tomen los bebés chiquitos, porque acá hay mucha gente que hace cocimiento...no es lo mismo que infusión...y el cocimiento sí intoxica...

Entonces, yo recuerdo acá, van a hacer diecinueve, veinte años que estoy acá...intoxicados por yuyos vi un solo caso. Yo les, les trato de que no lo hagan porque son muchas cosas después para valorar en la evolución del chico...pero el empacho, la cintitas rojas...los collares con dientes de perro...sí." (Violeta)

De allí que la mayoría advierta sobre las consecuencias negativas de los tés de yuyos ya que:

"no tienen la forma de cuantificar cuánta concentración le están dando del yuyo, este, que puede ser tóxico. El tema es la concentración y eso es lo que yo les explico, entonces bueno, te lo entienden..." (Violeta)

La actitud neutral del médico -al menos aparente y provisoria- obedece a la necesidad de conocer qué otro tratamiento está recibiendo el niño y así poder evaluar su estado y evolución: 
"Nunca le contradigo cuando me dicen que van al curandero. La primera reacción que uno toma siempre es de escuchar... ver que termine de decir todo lo que tiene que decir, por ahí larga algo para ver qué reacción tiene uno...y según la reacción esa sigue largando o no, o se calla la boca. Entonces, más vale escucho...aunque me dice que le está dando un yuyito, algo, escucho y espero que siga contando a ver qué más está haciendo, ¿no?

Es una forma de acercarme...pero no, trato de, de por lo menos no contradecir lo que es curar el empacho, curar la pata de cabra, eh, no le aconsejo que vayan pero tampoco le digo que no vayan. Las madres me comentan que van, sí, sí, es muy frecuente. Y por lo menos, con esas creencias no, no podés, es como la religión, ¿no?” (Lorenzo)

No está de más señalar que los tratamientos alternativos se dan simultáneamente con la asistencia a la medicina formal:

“... acá igual vienen solitos, ¿eh?. Yo no sé si el curandero, este, les dice vayan al pediatra, eh, pero vienen. Yo creo que se quedan más conformes... sí, más tranquilos. Le hicieron la terapia alternativa...y por las dudas que no tenga alguna otra cosa vienen el día de la atención, eligen ellas el horario, desde las 8, cada 15 minutos doy un turno...entonces ellas eligen el horario en los que pueden venir y saben que en 20 minutos se fueron y se quedan más tranquilas." (Eduardo)

Respecto de la "pata de cabra" los entrevistados opinan que:

"La pata de cabra es una fábula que todo el mundo la cree. Y que te la cuentan, yo la aprendí acá, nunca la había escuchado, es algo muy mágico, ¿viste?, bueno, vos sabés lo que es...

Yo tenía entendido que le llamaban a la, cuando el chico está flaquito...y se le ven los huesos...pero no es así...acá pata de cabra le dicen a cualquier chico enfermo...que no come bien.... Pero te cuentan, digamos, que van y todo... es como una fantasía...es como que va subiendo, dicen, por el espinazo y que llega a la zona de acá...algo yo escuché del...del bicho, del gusano...ponen mucha magia en eso." (Belén)

\subsection{Resultados de la encuesta provincial sobre recomendaciones alimentarias}

En un estudio reciente realizado por los responsables del Programa Materno Infantil del Ministerio de Salud de la Pcia. de Bs. As. (1998) se afirma que el equipo de salud y en especial los profesionales médicos asignan importancia relativa a la alimentación y promueven pautas alimentarias que no siempre condicen con los nuevos conocimientos científicos en ese campo.

A fin de orientar estrategias de capacitación, se realizó una encuesta dirigida a médicos que se desempeñan en el sector público tendiente a saber cuáles son las prácticas alimentarias por ellos recomendadas durante las consultas pediátricas y evaluar el grado de conocimiento respecto de la alimentación complementaria durante el primer año de vida: inicio, alimentos recomendados, criterios para su recomendación. 
Una de las variables analizadas fue la densidad energética de los alimentos indicados (categorizada en adecuada, baja y muy baja), la combinación de alimentos, la adecuación (combinando densidad energética, textura, consistencia y diversidad de sabor de los alimentos). Del total de 626 encuestas surge que el $77 \%$ responde que el momento recomendado para iniciar la alimentación complementaria es entre los 5 y 6 meses, considerando un $21 \%$ que lo adecuado es entre los 3 y 4 meses de edad. La edad y la maduración neurológica son los criterios mayoritariamente mencionados para realizar tal recomendación. Los alimentos más recomendados fueron el puré de zapallo y zanahoria, las frutas, jugos y derivados lácteos. Las calorías que aportan los alimentos recomendados por cada profesional fueron un $15 \%$ de combinaciones de densidad energética adecuada, el $69 \%$ baja y el $16 \%$ muy baja.

En el análisis de los criterios de textura, consistencia y sabor combinados con la densidad energética se encontró un $4 \%$ de recomendaciones adecuadas, $79 \%$ parcialmente adecuadas y $17 \%$ inadecuadas, respondiendo de manera más satisfactoria aquellos que han realizado su formación de post-grado a través de un programa de residencia médica, así como el grupo de profesionales menores de 40 años.

Otra apreciación importante que plantea el informe surge al comparar los alimentos o combinaciones de los mismos recomendadas por los médicos con los que ellos presuponen que las madres le dan a sus hijos, independientemente de su indicación. Se observa que la supuesta elección materna es más acertada que las indicaciones de los profesionales, tanto en lo referido a la densidad energética como de la adecuación general.

Si bien la encuesta arroja resultados satisfactorios ( $70 \%$ de los casos) en relación a la edad de introducción de alimentos complementarios así como los criterios usados para realizar tal indicación, en relación al tipo de alimentos recomendados se observan deficiencias con respecto de la densidad energética de los mismos así como en la textura y consistencia, debido a la indicación de jugos, sopas y derivados lácteos.

El estudio enfatiza la necesidad de desarrollar estrategias de capacitación dirigidas al equipo de salud a fin de aportar la información científico-técnica más actualizada respecto de las características que deben reunir los alimentos a ser recomendados en esta etapa fundamental de la vida. 


\subsection{Síntesis comparativa de las representaciones y prácticas médicas sobre desnutrición infantil}

Analizando este apartado, de los datos provenientes de las entrevistas realizadas a los médicos pediatras que trabajan en hospitales públicos y en Unidades Sanitarias del Gran La Plata así como de aquella resultante del análisis de fuentes secundarias, se desprende -en relación al saber médico sobre desnutrición- que:

- Los datos sobre la situación nutricional en la Argentina son asistemáticos, fragmentarios y discontinuos.

- Existe escasa información por su no obtención, fallas en el registro, procesamiento y difusión.

- Mayor es el descononcimiento sobre deficiencia de micronutrientes.

- Los problemas nutricionales prevalentes en población pobre son: la desnutrición crónica, la carencia de micronutrientes (hierro) y la obesidad.

- La dieta de las familias con menores recursos se caracteriza por su monotonía .

- La ingesta con escaso valor nutricional constituye un riesgo para el crecimiento en los 2 primeros años de vida.

- La desnutrición se encuentra vinculada con retrasos madurativos y del desarrollo motor.

- La edad de 24-30 meses es un límite para la recuperación nutricional y para el afianzamiento -o no- del riesgo de padecer obesidad ya que no hay crecimiento compensatorio luego de esa etapa.

- La Pcia. de Bs. As. registra un $22 \%$ de desnutrición crónica en niños de 0 a 6 años y en el partido de La Plata un $24 \%$ de niños de la misma edad (captados también en centros asistenciales) tiene algún tipo de desnutrición y un $10 \%$ de sobrepeso.

- Los retrasos del crecimiento coinciden con la edad de incorporación de semisólidos.

- La ausencia de normatización homogénea sobre alimentación infantil determina un vacío acerca de los criterios que los pediatras deberían adquirir en su formación.

- La alimentación constituye un tema banal al que se le brinda poca o nula atención en la formación de pre y post-grado.

- Las recomendaciones alimentarias dadas por los pediatras arrojan, de acuerdo con la encuesta provincial citada, sólo un $15 \%$ de casos que indican una dieta con una adecuada densidad energética. 
- El mismo estudio destaca además, que los conocimientos maternos sobre alimentación son adecuados (y que la dieta por ellas preparada presenta una densidad energética más adecuada que la que indican los especialistas).

- Se impone la capacitación sistemática a los pediatras y equipo de salud sobre la alimentación en el primer año de vida (selección, preparación, refuerzos, equivalencias, reemplazos).

- Los programas de salud materno-infantil son discontinuos por dificultades presupuestarias y organizativas.

- La capacitación de los médicos sobre esta problemática queda relegada a sus intereses y posibilidades.

- Hay carencias de insumos básicos y de bajo costo en los distintos niveles asistenciales.

- Los niveles de atención primaria presentan deficiencias en su capacidad resolutiva a causa de la irregularidad en la provisión de insumos.

- La inadecuada y/o insuficiente articulación entre los niveles asistenciales.

- El modelo de atención se centra en la reparación más que en la prevención, resultando una atención más cara e ineficaz (Ortale y Rodrigo, 1998).

- Las normas oficiales para las actividades de atención infantil, particularmente para el control del crecimiento, existen y son conocidas.

- Dichas normas no son utilizadas rutinariamente en la asistencia pública hospitalaria.

- Las diferencias encontradas entre médicos de hospitales públicos y médicos de atención primaria en relación a las normativas, condiciones de trabajo y evaluación de políticas sanitarias se reflejan, para el caso de los pediatras de hospital, en: el no cumplimiento de normas destinadas al control de salud y del crecimiento, la pérdida de pacientes por imposibilidad de seguimiento vinculada a la atención despersonalizada y cambiante, un mayor peso de las determinaciones institucionales que imponen la atención de patologías, sesgos profesionales más marcados por la subespecialización, inespecificidad para abordar las problemáticas del crecimiento y del desarrollo por falta de insumos básicos, subestimación de la problemática reflejada en la inexistencia de un código específico destinado al registro del estado nutricional de los niños atendidos. Los pediatras de las unidades de atención primaria reflejan mayor interés en la problemática, el que se pone de manifiesto en su activa contribución en el desarrollo de un "Programa de vigilancia y rehabilitación nutricional" y en la realización de un censo nutricional. Demandan en mayor medida la posibilidad de capacitación y actualización y si bien comunican gran satisfacción por su relación 
con los pacientes, reconocen a menudo escasa capacidad resolutiva: su mayor compromiso con los pacientes los lleva a un mayor grado de reflexión acerca de su tarea.

Las similitudes que aparecen en este punto entre ambos grupos tienen que ver con el conocimiento de las normas y el reconocimiento de su utilidad, la percepción de la desarticulación entre los niveles de atención (apreciación más acentuada en los médicos del hospital), la sobrecarga de trabajo, la escasa motivación para participar de programas debido a la discontinuidad de los mismos, la falta de recursos del Estado que permitan el cumplimiento de las normas y un adecuado tratamiento, la falta de datos sistemáticos, la formación recibida que enfatiza el estudio de las patologías y no de la salud, la poca relevancia dada en su formación al control del crecimiento y a la alimentación, el sesgo asistencialista de su práctica.

-En relación a la caracterización y abordaje de la desnutrición, las diferencias entre ambos grupos refieren, para el caso de los pediatras de hospital, a: la ausencia de registros sobre desnutrición, mayor ambigüedad en la conceptualización de la desnutrición y de su cadena causal, escaso o nulo conocimiento del entorno del niño, mayor énfasis en características maternas negativas como factor desencadenante de la desnutrición, la afirmación de que ellas nunca consultan por el estado nutricional del niño -siempre por patologías-, el reconocimiento de errores diagnósticos, mayor contraste entre la representación técnica y las prácticas tanto de diagnóstico como de tratamiento, mayor escasez de recursos para el diagnóstico y tratamiento y carencia de criterios unificados sobre alimentación. Los médicos de las unidades de atención primaria tienen datos estadísticos sobre el estado nutricional de la población que demanda asistencia. Realizan habitualmente los controles de salud -sobre todo en los menores de un año-, las madres cumplen con los controles así como con las recomendaciones médicas. Refieren una mayor preocupación de las madres por el estado nutricional de su hijo, consultando incluso cuando están eutróficos o no tienen signos evidentes de desnutrición. Los pediatras reconocen las categorías de subnutridos o malnutridos y proceden a la derivación al hospital en caso de sospechar alguna patología de base. Presentan un conocimiento bastante exhaustivo de la población que atienden, reconociendo idiosincracias según la nacionalidad, adscripción étnica o clase social. El tiempo dedicado a la atención y a la prevención es mayor y destacan que su lugar de trabajo conforma un espacio familiar para la población con el cual se sienten identificados. Llaman la atención sobre el elevado porcentaje de embarazos adolescentes y acerca de los crecientes problemas de violencia y alcoholismo cuyas consecuencias en la salud infantil deben afrontar. 
Las similitudes aparecen en la definición de la desnutrición, sus síntomas, el tipo de desnutrición prevalente (primaria y leve) que asocian a carencias socioeconómicas y señalan fallas en el registro de datos. Destacan la importancia del conocimiento del entorno del niño, de la relación médico-paciente y del diálogo con las madres para afinar el diagnóstico e indicar el tratamiento.

-En relación a la visión materna y al uso de medicinas alternativas, las apreciaciones de los médicos difieren en que los pediatras del hospital consideran que las madres carecen de signos de alarma, sobredimensionan la utilización de medicinas alternativas, las estigmatizan en mayor medida, y la eficacia que atribuyen a las mismas está basada en principios y entidades reconocidas por la medicina científica (la cura coincide con la evolución natural de las virosis). Los pediatras de las unidades de atención primaria muestran un mayor conocimiento de la medicina popular y reconocen los principios activos de los "yuyos" así como los mecanismos fisiológicos que desencadenan ciertas prácticas curativas. Asimismo señalan no tanto la oposición sino más bien la complementariedad de ambas formas de atención.

Las consideraciones similares en ambos grupos se relacionan con la visión de los médicos acerca de la reacción materna -de preocupación y no de alarma- frente al diagnóstico de desnutrición y sobre la negación, por parte de las madres, de limitaciones económicas familiares que imposibilitan una adecuada alimentación, estando presente en esta negación el estigma con el que la madre debe cargar. Las madres, de acuerdo con la apreciación de los entrevistados, consideran que la desnutrición es resultado de una patología o de la "pata de cabra" y la mayoría de ellas responde de manera satisfactoria a las recomendaciones médicas. Todos los entrevistados conocen y reconocen el uso de la medicina popular por parte de sus pacientes y adoptan una actitud de "respeto" con advertencias referidas a los riesgos de intoxicación con té de "yuyos". Plantean la dificultad de modificar o alterar dichas prácticas y creencias ya que forman parte de "su" cultura y en general, las remiten al campo de lo sobrenatural, de la magia y de la fábula. 


\section{CONCLUSIONES Y COMENTARIOS}

La década de los 90 se inicia para nuestro país, como para gran parte de los países de América Latina, en el marco de una recesión económica persistente y de una creciente pobreza para amplias capas de la población. La crisis económica y el ajuste han significado un alto costo social para las grandes mayorías urbanas y los efectos de este proceso en el consumo de alimentos se reflejan rápidamente afectando sus condiciones de alimentación-nutrición, especialmente visible en población infantil. La inadecuada alimentación en la infancia temprana tiene repercusiones sobre el crecimiento, desarrollo y salud general de los niños y el estado nutricional representa un indicador sensible de las condiciones de vida de las familias.

La desnutrición como manifestación del proceso de salud/enfermedad/atención, representa una expresión particular de la problemática de la reproducción social. Los determinantes de la salud/enfermedad de la población son componentes propios de los procesos de producción y reproducción social en tanto conforman condiciones diferenciales de vida y procesos diferenciales de morbi-mortalidad.

Pese a las limitaciones de la información secundaria disponible, puede afirmarse que los problemas nutricionales prevalentes en nuestro medio dentro de población pobre son: la desnutrición crónica, la carencia de micronutrientes (principalmente el hierro) y la obesidad. La Pcia. de Buenos Aires registra un $22 \%$ de desnutrición crónica en niños de 0 a 6 años y en el partido de La Plata un $24 \%$ de niños de la misma edad presenta algún tipo de desnutrición y un $10 \%$ sobrepeso.

De la información recogida en los dos centros asistenciales en donde fueron identificadas las familias estudiadas con hijos desnutridos (GD) y con hijos eutróficos (GE): la Unidad de Rehabilitación Nutricional del Hospital de Niños de La Plata y la Unidad Sanitaria "El Molino" respectivamente, se desprende que las condiciones de salud de los niños de GD son más desfavorables de las que se presentan en los niños de GE. Asimismo se evidencia la condición agravante de la desnutrición dada su estrecha asociación con patologías banales que requirieron hospitalización.

Los dos grupos de familias estudiados pertenecen a sectores pobres, resaltándose que los comportamientos individuales y familiares, a pesar de la amplia variedad que puedan presentar y la especificidad que adquieren dentro de cada familia, deben ser comprendidos dentro del espacio macrosocial en que su accionar se inscribe. Por cierto, el margen de autonomía es variable y será más o menos amplio o más o menos estrecho según los límites fijados por las condiciones objetivas.

Las estrategias familiares entendidas como "aquellos comportamientos de los agentes sociales de una sociedad dada que -estando condicionados por su posición social- se 
relacionan con la constitución y mantenimiento de las unidades familiares en el seno de las cuales pueden asegurar su reproducción biológica, preservar la vida y desarrollar todas aquellas prácticas, económicas y no económicas, indispensables para la optimización de las condiciones materiales y no materiales de existencia de la unidad y de cada uno de sus miembros" (Torrado, 1981) aluden a las condiciones materiales objetivas de existencia y a su internalización por parte de los agentes sociales.

Las estrategias familiares de reproducción permiten, en este estudio, aprehender la dinámica intra y extrafamiliar y sus efectos en la salud infantil analizando particularmente la incidencia de las condiciones socioeconómicas sobre la alimentación, considerando la organización alimentaria en una economía mercantil, su incidencia en la conformación de prácticas y creencias, en la composición de la dieta, en su distribución diferencial dentro del hogar, y en la evaluación de la misma.

La primera parte del estudio se centró en el análisis de las estrategias implementadas por familias pobres urbanas del Gran La Plata, incluyendo los comportamientos y los significados relacionados a la problemática alimentaria, cuyas modalidades se expresan en la existencia -o no- de desnutrición en sus niños.

El abordaje de las condiciones materiales para la existencia y la satisfacción de las necesidades básicas constituyó el punto de partida.

Se analizaron inicialmente las condiciones materiales de vida de las familias: características sociodemográficas, de vivienda y las restricciones impuestas a los comportamientos alimentarios en los dos grupos de unidades domésticas diferenciadas a partir de la presencia/ausencia de hijos con desnutrición primaria: la situación ocupacional de los integrantes de la familia, el nivel de ingreso familiar, la participación en programas sociales y la implementación de estrategias alimentarias autogeneradas.

a) Del conjunto de características estructurales indagadas mediante la aplicación de encuestas y que caracterizan a ambos grupos de familias, los resultados arrojan que aquellas que diferencian a las familias GE y GD se relacionan con los siguientes aspectos:

- Las características sociodemográficas de la unidad doméstica tienen relevancia en el análisis dado que la apreciación del sistema de salud sobre la relación entre familiasmonoparentaless con madre a cargo y desnutrición se halla bastante difundida. Por otra parte hay autores que consideran a las familias extendidas y fundamentalmente a las numerosas, como una estrategia exitosa para hacer frente a las precarias condiciones de vida. "Los grupos domésticos más resistentes son los que consiguen una composición en la que se maximiza el número de hijos u otros 
parientes en edad de trabajar. Ya sea mediante el aumento de la fertilidad o por la incorporación de parientes productivos al grupo doméstico, la presión adaptativa empuja en dirección de la familia extensa o ampliada." (Ashton, citado por Bartolomé,1983). "Así, se utiliza trabajo intensivo y no remunerado familiar y se depende de las redes sociales para canalizar recursos. Esta estrategia, denominada "sistema de seguridad social informal" (Lomnitz,1975) confiere un valor adaptativo a la familia numerosa, minimizando la vulnerabilidad frente a la incertidumbre y agresión del medio." (Bartolomé,1983).

Contrastando con las formulaciones arriba planteadas, se resalta en primer lugar la diferencia en el tipo de familia en ambos grupos, presentándose en GD un elevado porcentaje de familias extensas.

En GE, las familias de tipo nuclear son mayoritarias, mientras que en GD éstas constituyen la mitad de los casos.

- El promedio de miembros por familia es de 6.8 en GD, levemente superior al de GE, siendo el promedio de hijos de 4, similar en ambos grupos.

Por lo tanto, no puede sostenerse que el tipo de familia extensa juegue un papel positivo en la dinámica familiar -al menos en términos de la salud infantil- atenuante de su situación adversa. Asimismo, considerando la similitud en el número de hijos y dado el desfasaje en el ciclo de vida familiar de ambos grupos, más avanzado en GE, podrían aventurarse hipótesis explicativas de tal situación referidas al menor intervalo intergenésico en GD y a un menor control de la natalidad.

- La estructura de edad de ambas poblaciones muestra la mayor edad relativa de GE, situación que resulta de los criterios de selección muestral y no de un hallazgo del estudio.

Las familias de GD y GE se encuentran en diferentes etapas del ciclo familiar: las primeras se hallan en la etapa de expansión y algunas de las segundas han entrado en la etapa de fisión, con independencia de los hijos mayores del núcleo familiar.

- Respecto a los niveles de escolaridad de los jefes y cónyuges, puede verse que este factor se presenta discriminatorio, habiendo marcadas diferencias entre GD y GE: considerando conjuntamente a jefes y cónyuges, en GD la mitad de ellos son analfabetos o presentan primaria incompleta.

Esta variable tiene relevancia ya que la educación, desigualmente distribuida en nuestra sociedad, tiene una importancia particular -entre otras cosas- como instrumento que posibilita al hombre un mejor aprovechamiento de los recursos disponibles. Pese al acceso creciente y masivo a la educación formal, la estructura y la lógica del mercado de trabajo excluyen a capas relativamente calificadas. La posesión de niveles elevados de educación formal no garantizan la inserción en el 
mercado de trabajo; no obstante su carencia sí asegura la imposibilidad de inserción en trabajos estables y con una remuneración aceptable.

- En cuanto a la vivienda, se registra que el tiempo de residencia en el barrio es mayor en GE que en GD. Tal vez la mayor utilización de programas alimentarios estatales guarde relación con este hecho: la permanencia en el barrio permite un mejor conocimiento de los recursos urbanos disponibles y de los canales que posibilitan su utilización.

Más de las tres cuartas partes de ambos grupos carecen de la titularidad del terreno en el que viven. En GD se destaca el hecho de que casi la mitad de las familias comparten el terreno con otros hogares.

La propiedad de la vivienda, si bien mayoritaria en ambos grupos, se registra con mayor fuerza en GE.

GD muestra valores más desfavorables en la relación personas por cuarto y personas por cama, presentando asimismo en menor medida cuarto de cocina con uso exclusivo. Los materiales de construcción de la vivienda denotan una peor calidad relativa en GD.

El sistema de provisión de agua se da a través de cañería ubicada dentro de la vivienda en la mayoría de los casos de GE. GD, por su parte, presenta en algo más de la mitad de los casos agua corriente, pero la fuente de abastecimiento se ubica mayoritariamente fuera de la vivienda, compartiéndola con vecinos o parientes.

El sistema de eliminación de excretas se realiza a través de pozo ciego en casi todos los casos tanto de GD como de GE. GD muestra un mayor porcentaje de sanitarios compartidos y mayor proporción de letrinas.

La calidad de la vivienda refleja niveles de bienestar relativos que repercuten indudablemente en las condiciones de salud infantil.

Los aspectos descriptos constituyen parte de las condiciones en las que se reproducen las familias de la pobreza urbana.

En esas condiciones, los mecanismos a los que acceden o que implementan las familias tendientes a asegurar la alimentación diaria y la satisfacción de otras necesidades son muy diversos. Algunos intentan aumentar los recursos monetarios y no monetarios, otros apuntan a hacer estirar los recursos disponibles, algunos se apoyan en los beneficios del sector público, otros se sustentan en una red social informal, algunos consisten en una incorporación al mercado de trabajo de una mayoría de miembros, etc. (Raczynski y Serrano, 1985).

El trabajo es clave por el papel que cumple como determinante de los niveles y tipos de consumo. 
- Con relación a la situación ocupacional, en GD el $18 \%$ de los jefes se encuentran desocupados -registrándose un porcentaje levemente inferior en GE-, habiendo un porcentaje marcadamente menor de cónyuges que trabajan y un mayor porcentaje de otros miembros (parientes o allegados e hijos) ocupados.

En GE casi la tercera parte de las cónyuges trabaja, presentando hijos y otros miembros que trabajan en menos de la mitad de casos que GD.

En cuanto al tipo de trabajo que desempeñan los jefes, pueden marcarse diferencias entre GD y GE: los jefes del primer grupo se desempeñan fundamentalmente como autoempleados en comercio, construcción, servicios y en segundo lugar como obreros.

Los jefes de GE trabajan básicamente como empleados en comercio, transporte y servicios, y en segundo término como autoempleados en comercio, construcción y servicios.

Las categorías ocupacionales predominantes son para GD el cuentapropismo y para GE la de empleados. En segundo término, en ambos grupos y en proporciones similares aparece la categoría obrero como trabajo más frecuente.

La rama de actividad que aglutina a los trabajos de los jefes de GD es la de construcción y comercio, siendo para los jefes de GE las de servicios y construcción.

Cabe resaltar la elevada presencia de trabajadores informales en GD: ellos constituyen más del doble de los casos registrados en GE. En este último grupo, más de la mitad de los jefes se desempeñan en el sector formal.

Respecto al trabajo de las cónyuges, predomina el servicio doméstico en GD, trabajando las cónyuges de GE como empleadas en servicios, transporte y comercio o como autoempleadas en comercio y servicios.

La problemática de la subocupación no parece incidir significativamente en el trabajo de los jefes de ambos grupos: las tres cuartas partes de los jefes de GD y GE trabajan más de 35 hs. semanales. La subocupación se da básicamente en las cónyuges, sobre todo de GE. La mayoría de los otros miembros que trabajan -en ambos gruposregistran subocupación.

- La tasa de dependencia, que refiere a la relación entre productores de ingreso y no productores dentro de la familia, se presenta más desfavorable en GD.

- La estimación del ingreso en correspondencia al que define la Fundación de Investigaciones para el Desarrollo Económico (FIDE,1995) para adquirir una canasta básica de alimentos, muestra ser inferior en la mayoría de las familias de GD, mientras que en GE esto sucede en menos de la mitad de los casos.

Asimismo, la distribución de las familias por estratos de ingreso refleja que las de GD presentan distribución sesgada hacia el estrato inferior del ingreso, presentando las 
familias de GE una menor presencia en dicho estrato. El ingreso per cápita familiar es el indicador que refleja mayores diferencias: cada integrante de GE dispone para alimentarse, casi la mitad más de dinero que un integrante de GD.

Las características ocupacionales del jefe y de la familia en su conjunto, así como los niveles de ingreso familiar, imponen fuertes restricciones a las oportunidades y necesidades de los menores que crecen en su seno. La situación ocupacional presente en GD, en el que prevalecen en mayor grado las ocupaciones por cuentapropia, precarias, de baja calificación e ingresos insuficientes para cubrir los costos de la canasta básica de alimentos, se corresponde con las peores condiciones de nutrición y salud infantil que contienen sus familias. Reconociendo la centralidad del trabajo y de la forma de percepción y monto de los ingresos para la adquisición alimentos, se consideraron las estrategias alimentarias utilizadas por las familias a fin de evaluar cómo intervienen los consumos alimentarios no mercantilizados en la satisfacción de las necesidades alimentarias.

Las estrategias alimentarias refieren a los recursos alimentarios utilizados por las familias provistos a través de programas sociales estatales, de organizaciones no gubernamentales o autogenerados por éstas. Las opciones generadas por el Estado, conforman, desde la perspectiva doméstica, alternativas a las que se recurre en la estructuración de las estrategias de reproducción y son, en países como el nuestro de larga trayectoria de intervención estatal, de vital importancia en la reproducción social de los sectores pobres (Hintze, 1989).

- En GD y en GE se registra un porcentaje similar (14\% y $16 \%$ ) de familias que no utilizan ninguna estrategia alimentaria.

- En GE es mayor el porcentaje de usuarios de los programas alimentarios estatales, destacándose el Plan País y el comedor escolar.

La leche provista por el Programa Materno-Infantil es la opción más utilizada en GD, en similares porcentajes que en GE, apareciendo en más de la mitad de las familias. Con motivo de la rehabilitación nutricional, las familias GD reciben quincenal o mensualmente una bolsa de alimentos en la URN, la que, por constituir una ayuda coyuntural, no es considerada por las madres un programa de asistencia alimentaria.

Ellas destacan en cambio, la importancia de las redes informales de intercambio con parientes y de los recursos no gubernamentales provistos por iglesias y partidos políticos.

Los animales de cría para consumo familiar se presentan en la cuarta parte de las familias de ambos grupos. La huerta, si bien con baja presencia, es más frecuente en GD que en GE. 
En las familias de GD cuya tasa de dependencia (c/p) es de 5 a 8 personas, se verifica un uso intensivo de las redes de ayuda informal y el autoabastecimiento. Llama la atención la ausencia de plan País en la mayoría de las familias de GD, sobre todo en aquellas con c/p superior a 8 .

Las familias de GD consideran como prioritarias las opciones provistas por organismos/agentes no gubernamentales, destacando la centralidad de la ayuda de parientes o amigos.

La leche, pese a tener la mayor cobertura -dentro de los programas estatales- no es considerada por las informantes de GD como una opción que aporte significativamente a la alimentación familiar.

En GE, los sistemas priorizados por las mujeres encuestadas son el Plan País y el comedor escolar, no teniendo relevancia otros sistemas de ayuda.

En GE -cuyos componentes estructurales así como las condiciones de nutrición y salud infantil reflejan condiciones más favorables que las familias de GD-, se resalta la utilización más diversificada, intensiva y continua de los programas alimentarios estatales mientras que en GD estos presentan, dentro del conjunto de estrategias alimentarias, escasa relevancia.

En tanto la presencia de los recursos estatales son más frecuentes en las familias GE, puede hipotetizarse, dados los escasos ingresos que perciben, que este complemento del consumo alimentario global de las familias contribuye a la reproducción de manera medianamente satisfactoria.

Esto lleva a sostener la importancia, pero a la vez cuestionar las modalidades de implementación de las políticas públicas en materia alimentaria.

b) La relación entre los aspectos arriba mencionados y las características de la alimentación familiar se observa en:

- El papel desempeñado por el trabajo formal del jefe de familia y la percepción regular del ingreso en la realización de las compras, la fuente de abastecimiento utilizada y periodicidad, posibilitando a GE adquirir en el supermercado una mayor variedad de alimentos y/o marcas y mejores precios, básicamente de alimentos no perecederos.

- El nivel de ingreso -más elevado en GE- se refleja en la estimación del gasto diario per cápita en alimentación: cada miembro de GD gasta diariamente un $25 \%$ menos de dinero que uno de GE para alimentarse.

- El mayor peso de la forma de pago mixta, si bien minoritaria, en GE se relaciona con el tiempo de residencia en el barrio y la consecuente familiaridad y confianza que los comerciantes tienen en la familia, con la certeza de pago en el mediano plazo. En GD, el "vivir al día" y la incertidumbre de los ingresos imponen el pago al contado. 
- Por eso los arreglos domésticos tendientes a obtener comida son más frecuentes y variados en GD que en GE, interviniendo (y afectando a) todos los miembros de la familia quienes apelan a todo tipo de fuentes y de recursos formales o informales. Hay que destacar que en las situaciones de carencia, tanto en GE como en GD, la primer variable de ajuste es la mujer/madre, que disminuye o anula su comida, sosteniendo el "deber ser" materno.

- De acuerdo al tipo de alimentos más utilizados en la dieta habitual, se observan diferencias en el sentido de un mayor aporte de carbohidratos en GD. Ambos grupos elaboran como comidas más frecuentes guisos de fideos o de arroz, puchero o pastas. Sin embargo en GE se aprecia mayor diversidad de comidas preparadas con verduras y carnes. Si bien la preparación de una comida diaria aparece en la mitad de los casos tanto de GD como de GE, debe considerarse la mayor utilización del comedor en este último. Probablemente esto explique la apreciación del almuerzo como la comida más importante -frecuentemente la única- en GD.

Cabe destacar que uno de los supuestos básicos del análisis afirma que la alimentación no sólo está hecha de nutrientes sino también de significaciones, no sólo desempeña una función fisiológica sino también funciones sociales ya que los "organismos" humanos construyen representaciones que orientan sus comportamientos, definen su lugar en el mundo social y modifican su conformación biológica.

Para la visión predominante dentro de la medicina y la nutrición, el hombre se nutre de glúcidos, lípidos y proteínas. Sólo tiene necesidad de vitaminas, minerales, en síntesis, come nutrientes, no alimentos. Se ha olvidado o negado que el hombre piensa su comida de otra manera. Las ciencias sociales, desde hace mucho tiempo, han insistido en el hecho de que la alimentación humana comporta una dimensión imaginaria, simbólica y social.

De allí que en el estudio del conjunto de los condicionantes y de las estrategias desplegadas por las familias para su alimentación, se incorporó el universo de conocimientos, valoraciones y prácticas de las informantes sobre la misma.

El componente simbólico de la acción humana, más que parte integrante, es el elemento constitutivo de la vida social. La dimensión simbólica de la acción humana ya sea verbalizada en el discurso, cristalizada en los objetos, en los gestos, en las acciones, siempre está presente en cualquier práctica social.

El consumo alimentario así concebido se enfoca, para el caso de las familias pobres urbanas, desde el problema central de regular la relación entre necesidad, elección y posibilidad de obtención de aquellos alimentos que consideran importantes en la dieta cotidiana. 
La creciente homología en los discursos de la cocina, de la medicina y de los mercados de la salud, que se manifiestan de manera paradójica en las representaciones y en las prácticas de regulación de la alimentación relacionada a la salud, posibilita comprender que selección y restricción estén en el centro de la preocupación alimentaria actual (Fischler, 1990).

Los problemas relativos a la valoración de los alimentos, radican en gran medida, en su vinculación con la salud. La alimentación y la medicina sostienen una relación muy peculiar e indisociable y las representaciones sociales en torno a lo alimentario expresan tal relación. En tanto la alimentación es un medio de ejercer control sobre el cuerpo, es un instrumento privilegiado de intervención médica; de allí que la medicina reivindique un derecho de control sobre la alimentación, propiciando comportamientos alimentarios y modelos corporales asentados en bases científicas que enfatizan la importancia de la alimentación para el mantenimiento de la salud.

- En la evaluación de la alimentación familiar que realizan las mujeres entrevistadas, se revela una forma de pensar la alimentación dentro de los parámetros de las condiciones de vida y trabajo, del propio consumo, de los atributos alimentarios pero también en marco del proceso de construcción de identidades que contradictoriamente favorecen o niegan la condición de ser pobres.

Las familias con desnutrición representan aquellas que no llegan a sobrepasar una condición general de empobrecimiento y la presencia de una dieta pobre, pese a aspirar y valorar un patrón alimentario cualicuantitativamente más rico. A menudo la sustitución de alimentos obliga a conformarse con otros como mal menor y las comidas que se consumen obedecen a sus ventajas de diversa naturaleza, sean prácticas, gustativas, o económicas.

El problema del hambre, sigue inquietando y siendo un problema central en la vida de muchas de estas familias, en las cuales la carencia alimentaria, resulta de la escasez de dinero. En ellas es evidente que el escaso valor adquisitivo del salario hace que la mayor incidencia de gastos se verifique en bienes y servicios básicos y sean anulados los consumos más prescindibles. $Y$ quienes se acercan a la indigencia enfrentan desfavorablemente lo más elemental de la reproducción cotidiana: la alimentación.

Al hecho de presentarse como un problema vital, se suma la influencia de los discursos médicos y mediáticos generados sobre el valor de los alimentos.

El no reconocimiento o "encubrimiento" de la inadecuada alimentación familiar, tal como se desprende de la evaluación positiva que realizan las mujeres de GD de la dieta familiar, debe vincularse con el estigma con el que debe cargar -y es asumido por- la mujer. Tal interiorización eufemiza la deficiencia alimentaria familiar, 
argumentando en la situación de entrevista que "siempre de algún lado sale" o "dentro de todo nos arreglamos".

- La alimentación valorada por sus propiedades nutritivas es la misma para las mujeres de ambos grupos: consiste en aquella que aporta proteínas y vitaminas y hierro. En segundo lugar y en iguales proporciones, ellas afirman que "todos son importantes", "todos alimentan". De aquí que consideren que la alimentación completa sea aquella que combina carnes, verduras, frutas y preparaciones -guisos, pucheros- que incluyen una variedad de alimentos.

Como representación, las preferencias alimentarias están ligadas generalmente a categorías médicas mostrando la influencia de las prescripciones/proscripciones alimentarias basadas en la relación alimentación/salud. La mención de las proteínas, vitaminas, y determinados micronutrientes minerales pone de manifiesto tal intervención.

Sin embargo, las prácticas alimentarias no se condicen con las representaciones, descartándose así aquellas apreciaciones que consideran a los factores subjetivos como determinantes y que relegan a un segundo término la realidad material objetiva.

En las representaciones es clara la medicalización de la dieta y las prácticas alimentarias se encuentran ligadas a factores que tienen que ver con la economía y el rendimiento de las comidas. La elección de las comidas se debe a que presentan un balance favorable: sus ventajas prácticas y sus costos es al menos más favorable que el de aquellos alimentos no consumidos o comidas no preparadas.

Las prácticas no responden a los criterios explícitos de la medicina, al menos, no se presentan como una mera reproducción de los mismos y este hecho es reconocido por muchas mujeres. La preparación de las comidas intenta regular, particularmente en GD, la mediación entre necesidad y posibilidad y en GE realizar, cuando es posible, la mediación entre la norma, la necesidad y la posibilidad.

La alimentación representa pues, una condición de vida que contrasta con la aspiración a determinado patrón de consumo: los patrones alimentarios responden a una lógica en la cual opera, por un lado, una estrategia de subsistencia mediante la cual tratan de maximizarse los recursos y los factores de los que depende la reproducción de la fuerza de trabajo y la sobrevivencia de la familia y por otro lado, un sistema de principios y conocimientos valorativos por el cual tratan de optimizar la relación alimento/organismo.

Puede desprenderse que lo que valoran no corresponde -en términos cuantitativoscon lo que consumen habitualmente, a partir de lo cual puede cuestionarse la representación especular de las preferencias-gustos/prácticas alimentarias con la que Bourdieu caracteriza a la alimentación de los sectores populares. 
Según Bourdieu (1979) los gustos populares favorecen las comidas más nutritivas y las más económicas como resultado de "la necesidad de reproducir al menor costo la fuerza de trabajo que se impone al proletariado". Por el contrario los "gustos de lujo son propios de los individuos que aparecen como el producto de condiciones materiales de existencia definidas por la distancia de la necesidad, por la posesión de un capital".

La idea de gusto según Bourdieu, es de hecho típicamente burguesa ya que supone una libertad absoluta en la elección y no puede concebir las paradojas del gusto de necesidad. El contenido de las preferencias en el gusto de necesidad se halla determinado por las relaciones de producción: obreros y campesinos siempre prefieren necesariamente los alimentos más económicos y nutritivos, los que presentan las características objetivas de procurar una sensación de repleción máxima a un costo mínimo. En el gusto de libertad, los alimentos considerados más ligeros, más refinados prevalecerán, pero será siempre la arbitrariedad desmedida la que presidirá su elección, ya que los cambios del gusto están inscriptos en la dialéctica incesante de la pretensión de los sectores ascendentes y de la distinción de las clases dominantes.

Al plantear el gusto de las clases populares como "gustos de necesidad" y los de las clases acomodadas como "gustos de lujo" o "gustos de libertad", otorga un virtuosismo al comportamiento alimentario de los sectores populares basado en criterios eficientistas y conservadores. Sin embargo, en este estudio, lejos está la idea de gusto de necesidad según la cual éste es "lo que hace que se tenga lo que se quiere porque se quiere lo que se tiene".

El análisis aquí presentado muestra que la internalización de referentes hegemónicos sectoriales generan necesidades que tienden a modular el consumo y a establecer sistemas complejos y contradictorios de apreciación de la dieta, induciendo a prácticas que no se condicen con las representaciones, ni con las posibilidades determinadas por el salario ni con las exigencias biológicas. Puede observarse así, cómo el ámbito doméstico, en una actividad cotidiana como es la alimentación, sirve de escenario para consolidar los discursos y prescripciones hegemónicas que, constantemente renovados, imprimen y direccionan las representaciones alimentarias de los sectores subalternos.

En tanto la desnutrición pertenece al campo de intervención médica, su conceptualización como "desvío", "anormalidad" o "enfermedad" revela diferencias tanto en la causalidad y desarrollo como en las estrategias de atención, que refieren a la estructura social e ideológica que la produce.

Los problemas de salud, los padecimientos y daños, comprometen el centro de la subjetividad, pero también la reproducción objetiva de cualquier sociedad. La 
desnutrición es en sí misma una condición biológica desfavorable en tanto aumenta la probabilidad de enfermar y morir.

La aproximación al estudio de la desnutrición a través de los conceptos de representaciones y prácticas permitió aprehender, tanto en los legos como en la propia profesión médica, el sistema de valores en la percepción y categorización de la desnutrición; revelar el rol constructor de la enfermedad por parte de la medicina así como el rol normativo en relación a las prácticas sociales (funciones de control y legitimación) y analizar los diferenciales entre ambos grupos de familias respecto a la forma en que la desnutrición es percibida, interpretada, valorada.

c) Habiendo descripto las características y las diferencias entre los dos grupos de familias estudiadas en lo que hace a sus componentes estructurales y a sus representaciones y prácticas sobre la alimentación familiar, se puede observar cierta continuidad en la lógica contradictoria con la que, sobre todo las mujeres de GD, discurren acerca de la desnutrición infantil. Cabe destacar que en las mujeres de GE no se hacen evidentes las contradicciones en sus representaciones. En cambio, las mujeres de GD recurren frecuentemente a eufemismos o a racionalizaciones para sustentar las razones por las cuales lo que opinan, conocen, saben o creen sobre la nutrición, el crecimiento infantil y el cuidado infantil, no se traducen en el estado nutricional de los hijos.

Analizando de manera articulada las dos dimensiones consideradas en este estudio: las representaciones (percepciones, conocimientos, opiniones, valores) y las prácticas de atención materna y de los diversos recursos de atención a la salud empleados para la detección, tratamiento y prevención de la desnutrición infantil, contrastan los siguientes aspectos:

- El estado nutricional del niño se relaciona, para GE con la buena crianza dispensada por las familias, el esfuerzo y sacrificio de los padres y la preocupación materna por los controles de salud admitiendo que si bien el proceso de adelgazamiento refleja una inadecuada alimentación, la gordura no significa buena nutrición. Todas estas consideraciones se hallan respaldadas por el reconocimiento médico del rol de los padres en el adecuado crecimiento de los niños y esto es utilizado para afianzar su distinción respecto de aquellas familias que tienen hijos desnutridos y estigmatizar fundamentalmente a sus madres.

Así para la mayoría de estas mujeres, la mala alimentación obedece a descuido materno.

En GD, no se presenta una abierta negación del problema nutricional de su hijo: la mayoría de las mujeres afirma tener hijos desnutridos y refieren que esto se produjo por un estancamiento o pérdida de peso, en general repentino, apareciendo además 
como muletilla en los discursos la aclaración de "el/ella nomás" o "solamente el/ella". No obstante, cabe recordar que en la casi totalidad de los casos entrevistados se presentan dos hijos desnutridos (el asistido en la URN durante la realización de este estudio y otro anterior). Son pocas las madres que responden de manera ambigua sobre la presencia de desnutrición infantil en el hogar, planteando que "no, desnutrido no está" agregando a continuación que "le falta un poco nomás".

Como causas, es posible observar en los testimonios de este grupo dos niveles: uno más abstracto, en el cual los argumentos explicativos hacen referencia a problemas económicos, a la escasez de comida en la familia, la falta de asistencia alimentaria y la inexistencia de una red de contención parental. Sin embargo, en un nivel concreto, próximo al acontecimiento de desnutrición en su familia, las causas remiten al rechazo de alimento por parte de los hijos o a problemas orgánicos que impiden su asimilación, diferenciándose así de "otras" familias ya que siempre "mal o bien nos la rebuscamos". El descuido materno alude a otras mujeres: aquellas que desatienden las necesidades alimentarias de los hijos y/o que recurren al curandero para atender los problemas de salud infantil. No obstante, algunas madres, minoritarias, asumen la responsabilidad por la desnutrición de sus hijos: la pobre calidad de la comida asociada a la desocupación del jefe de familia, el fracaso en la lactancia materna, el uso tardío de los servicios de salud y el suministro de yuyos que precipitaron la desnutrición, constituyen los argumentos explicativos.

Para el resto, la mayoría, las parasitosis e infecciones están en la base de la misma.

Respecto de la prevención, las mujeres de GE opinan que son fundamentales los hábitos alimentarios maternos, la comida "a horario" y la presencia de determinados alimentos tales como la leche, carne, frutas y huevos. En ese sentido, el asesoramiento médico aparece como intervención favorecedora de la prevención, lo mismo que la existencia de programas alimentarios.

Las informantes de GD abundan en consideraciones sobre la prevención de la desnutrición; para evitarla es importante la calidad de la alimentación (destacando el consumo de alimentos que aportan hierro y vitaminas: leche, verduras, frutas y carnes), aunque reconocen que esto no siempre es posible -a veces se torna inviable$y$, de acuerdo a sus experiencias, los cuidados dispensados -y considerados adecuados- no siempre resultan satisfactorios en términos de la salud infantil. De allí que para algunas, la prevención sea imposible. En este grupo, también se incluye el consejo médico u otras intervenciones en la prevención, haciendo hincapié en el control del peso. 
Puede afirmarse entonces que las prácticas de autoatención preventivas de la desnutrición no siempre pueden ajustarse a los criterios explícitos de la medicina o no se presentan como una mera reproducción de los mismos.

- Los síntomas de la desnutrición que consideran más relevantes para identificarla son, en la mitad de los casos GD, el estado de ánimo, el decaimiento, la pérdida de fuerza, el cansancio, apareciendo en el resto evidencias físicas tales como la delgadez, el color de la cara, los ojos hundidos, la distensión abdominal. Un solo caso refiere que sólo "el médico sabe cuando lo pesa" y en otros casos minoritarios la delgadez, si no está acompañada de otros síntomas, no es motivo de preocupación: "es flaquito pero normal", "es normal, bajó de peso nomás". En GE se mencionan los mismos síntomas aunque hay una mayor proporción de aquellas que por inexperiencia, plantean un total desconocimiento.

Cuando en las mujeres de GD se indagan los síntomas presentes en sus hijos desnutridos, aparecen otros tales como los episodios de vómito, diarrea o parásitos. La demanda de asistencia a la salita muestra que la misma funciona la mayor parte de las veces como lugar de derivación. Son minoritarias las madres que refieren haberse dado cuenta porque "no quería comer, lo veía mal" y haber demandado asistencia oportunamente.

Más de la mitad de niños desnutridos debieron ser internados en la primera consulta, lo que da la pauta de la gravedad del caso y del uso tardío de los servicios de salud en relación a la evolución de la enfermedad. En este sentido se destaca como factor agravante de la desnutrición, la extrema dependencia de las madres respecto de un médico en particular: "mi médico"; la consulta se demora hasta tanto éste no esté presente en el servicio. Asimismo la inflexibilidad de las recomendaciones médicas preventivas basadas en las normativas de salud tienen efectos paradójicos, tal es el caso de la insistencia en la lactancia materna cuando la madre comunica reiteradamente las dificultades o la imposibilidad de brindar tal tipo de alimentación.

- Respecto de la representación del tratamiento, casi la mitad de GE responde "no tengo ni idea"; el resto considera que se debe ir al médico para recibir asesoramiento nutricional ya que pueden contribuir a su cura "enseñando a alimentarse", así como mediante un tratamiento especial "con medicamentos y vitaminas".

La mayoría de GD considera pertinente el control médico y los medicamentos que éste indica; las opiniones restantes consisten en dar la alimentación adecuada, rica en calcio, hierro y vitaminas.

La evaluación del tratamiento médico recibido por los niños desnutridos es positiva en la mayoría de las situaciones: más de la mitad de las madres reconoce la eficacia de la intervención consistente en la entrega de leche, vitaminas, hierro y antiparasitarios, 
mencionando los casos restantes que es "regular" por la reiteración de la desnutrición o por la demora en el aumento de peso.

Algunas madres hacen evidente la disputa -en medio de la cual quedan presas- entre los "médicos del hospital" y "los médicos de la salita", siendo a menudo objeto de retos por parte de los médicos del hospital por la inadecuada atención del niño. En ese sentido lo que las madres valoran son las decisiones rápidas y la capacidad de cura asociadas a los médicos de hospital. Las recomendaciones preventivas de los médicos de la salita y la dilación de los tratamientos no tienen buena recepción por parte de las madres; sí en cambio la tienen para muchas las actitudes paternalistas, autoritarias y de control.

El proceso de atención es una negociación entre ambos espacios culturales que genera procesos transaccionales. Estas transacciones responden a una lógica de utilización de los servicios que supone el ingreso voluntario del paciente. Este queda comprometido con su elección a cierto juego institucional conformado anteriormente y al cual debe integrarse para ser atendido. Pero esta integración se organiza no sólo desde una rutina que impone la institución, sino también desde el espacio cultural del que consiente.

La impugnación o resistencia a la atención médica recibida se hace evidente en situaciones en las que las madres visualizan una práctica médica arbitraria, a veces equivocada o contraria a las normativas de control de salud conocidas por ellas.

Los pacientes, a partir de la apropiación del conocimiento científico participan, promueven, interfieren y modifican sus propios procesos de atención de la enfermedad.

El grupo/paciente se reserva un margen de decisión que parece inalienable, que permite elaborar juicios de pertinencia sobre cuándo recurrir o no a los servicios, cómo acceder a ellos y hasta dónde obedecer las prescripciones recibidas.

El paciente acepta o rechaza, cumple o no, pacta diagnósticos aunque estos procedimientos sean ignorados por el equipo de salud; formula hipótesis, las pone a prueba, coteja resultados y decide. Salva las discrepancias entre diferentes sistemas médicos o las mantiene.

No obstante ello, la casi totalidad de las madres refiere que los médicos curan la desnutrición con vitaminas, hierro, calcio y dieta especial asumiendo la imposibilidad de evaluar por su cuenta el aporte nutricional necesario para los niños y remarcando en ese sentido el papel pedagógico de la actividad profesional. Un solo caso plantea que "es la alimentación la que cura, no los médicos."

- La conceptualización de la desnutrición como descuido por parte de las madres de GE, hace que no se la conciba como enfermedad, excepto cuando deriva de otra 
patología. Para las madres de GD, la consideración de la desnutrición como enfermedad es ambigua: algunas la conciben como secuela de alguna enfermedad o producto de la pata de cabra; otras le niegan el estatuto de enfermedad en la medida que no resulta contagiosa, vinculándose más bien con descuido. Finalmente, el estatuto de enfermedad está ligado a la oportunidad de la atención: la demora en el tratamiento lleva a la internación e incluso muerte del niño; sólo en esos casos merece ser considerada enfermedad.

En el fenómeno enfermedad se entrecruzan por lo menos tres componentes: a) un hecho objetivo corpóreo, es decir, una alteración de algún órgano, aparato, función, más o menos demostrable; b) una mayor o menor conciencia individual del mal; c) una idea derivada de los conocimientos y los prejuicios; en consecuencia, un juicio de valor, una interpretación ética, además de científica, que sirve como guía operativa. Entre los deberes asignados a las medicinas y a los distintos médicos/curadores hay uno específico que encontramos siempre: combatir las enfermedades. Cambian las formas pero no la finalidad. En el caso de la desnutrición se complica cuando hay que definirla como enfermedad: cuál es la naturaleza del fenómeno que se quiere controlar y qué pueden resolver los distintos curadores.

- Así, la capacidad terapéutica de los médicos para resolverla se relativiza. Los médicos, según las madres GE, contribuyen a curarla, ellos pueden hacer un diagnóstico diferencial de sus causas y con base en ello dar indicaciones alimentarias pero la curación depende de los padres. Para las madres de GD, también el diagnóstico diferencial así como el tratamiento de complicaciones que derivan de la desnutrición son los ejes de la actividad médica. Las recomendaciones alimentarias, a veces contradictorias con las que se tenían por ciertas, y el suministro de suplementos tales como las vitaminas, el hierro y el calcio forman parte del tratamiento esperado por haber sido el habitual en la experiencia de atención de su hijo desnutrido. Sin embargo, tal como lo plantean las madres de GE, la función de los médicos es de "empuje" pero las madres son las principales responsables de la rehabilitación nutricional. A ello contribuye de manera significativa, la adquisición de conocimientos sobre alimentación infantil brindados por especialistas a través de programas televisivos. Sus recomendaciones, alerta y orientaciones para la acción son incuestionables.

- La indagación de la presencia de "pata de cabra" en los hijos obedece a su relación con el estado de desnutrición (Ortale, 1996). Esta enfermedad, que incumbe a la medicina popular se manifiesta como "una mancha oscura arriba de la cola" -un hematoma producido por la disminución del panículo adiposo en la zona del sacro y la permanencia del niño en la cuna o cama- que da cuenta de la existencia de un "bicho" 
que, "a medida que va subiendo por el espinazo, lo va secando,", "lo chupa por dentro", pudiendo tener pata de cabra "macho" o "macho y hembra" (menos frecuente pero más grave). La "pata de cabra" se acompaña generalmente ya sea de diarrea, vómitos, llanto continuo, nerviosismo, sueño excesivo, etc.

Con relación a ella, la mayoría de las informantes de GE refieren conocerla pero "de escuchar comentarios", agregando que nunca tuvieron un hijo con ese problema. Pese a haber afirmado que la desnutrición no constituye un problema de salud importante en el barrio, dada la existencia de una salita cercana y accesible a todos los hogares, en donde se realizan controles de salud de manera regular y la continuidad de asistencia alimentaria, plantean que la pata de cabra es frecuente en el barrio. Consideran que se trata de un problema de salud que reviste gravedad si no se lo trata a tiempo ya que provoca un abrupto adelgazamiento en los niños: en ese sentido plantean que la pata de cabra causa desnutrición. Niegan conocer el tratamiento porque "no sé, nunca tuve" o enfatizando su adscripción a la medicina científica y la demanda de atención a los servicios públicos de salud.

Todas plantean que los médicos son impotentes para curarla y unas pocas exponen que mediante palabras o tinta china la cura el curandero. Desconocen asimismo las causas y la forma de prevenirla.

Sin embargo, son bien conocidos los tratamientos correspondientes al mal de ojo y al empacho, problemas de salud frecuentes en sus hijos para los cuales sí demandan atención del curandero, también accesible en el barrio. En general plantean que a él recurren cuando falla el tratamiento médico o se demora más allá de las expectativas maternas. Así, la mayoría admite, con base en la experiencia de los resultados obtenidos con ese tipo de tratamiento, que "hay que creer más allá" de lo que permite la razón. También en el abandono de las prácticas médicas alternativas influyen los medios masivos, particularmente en el abandono del suministro de infusiones con yuyos tales como la yerba de pollo, paico, poleo o anís estrellado.

Asimismo se refleja la activa participación del cónyuge en las decisiones sobre la atención de los hijos y el peso de sus opiniones respecto del servicio o recurso de atención a utilizar.

En GD la pata de cabra se registra en casi todos los casos asociada al hijo desnutrido así como a otros hijos. Algunas madres no logran precisar la naturaleza de la enfermedad, refiriendo otras que se trata de un "bicho, no sé de donde viene. Sé que está atrás. Nunca le pregunté a la curandera, me da no sé qué" o explicitando los síntomas: "es una mancha violeta en la espalda", "una mancha atrás, no sé, pero se hace un palito", "no sé, pero se debilitó enseguida, se echaba para atrás". 
Los tratamientos, llevados a cabo en lapsos que oscilan entre los tres y nueve días dependiendo de la gravedad del caso, son diversos: consisten en la cura por palabra, imposición de manos, frotamiento con velas, con aceites, realización de cruces en la espalda con tinta china, e indicación de ciertas prescripciones/proscripciones alimentarias. La mayoría reconoce la eficacia de los mismos, siempre paralelos a los de la medicina oficial. Las causas mencionadas son heterogéneas, pudiendo derivar de "un empacho mal curado", "envidia", "maldad", "un virus", etc. Las medidas preventivas son desconocidas o imposibles aduciendo por otra parte: "no sé, nunca pregunté".

La identificación de la pata de cabra se da en muchos casos luego de haber resultado ineficaces los tratamientos médicos y en las madres más escépticas la curiosidad lleva a la consulta al curandero. Lo mismo que las madres GE, distinguen claramente la desnutrición de la pata de cabra y afirman que se trata de problemas distintos.

Los conjuntos sociales "legos" participan de la visión hegemónica respecto de la salud/enfermedad/atención sustentándola en tanto "cómplices", pero también como sujetos que resignifican o impugnan el saber hegemónico.

La pata de cabra, autonomizada del saber médico hegemónico, sí es considerada como un peligro: si bien no se trata de una enfermedad contagiosa, el riesgo directo para la salud de los niños y la imposibilidad de controlar sus causas, funciona como chivo expiatorio sobre el cual descargar las responsabilidades sociales, familiares y la ineficacia de la medicina.

La relación queda planteada en términos de causalidad: la pata de cabra produce desnutrición en la medida que "lo bajó mucho de peso". El resto reconoce que la pata de cabra es "otra cosa", respondiendo que "no sé", "no sabría decirte". O, como sentencian otras, "hay que creer o reventar".

"Creer o reventar" resulta el corolario de la experiencia de curación y la relación de estas creencias y prácticas de atención no se presenta, para las madres entrevistadas, contradictoria o conflictiva con la medicina científica, aunque reconocen la tranquilidad que presta el consentimiento del médico sobre la demanda de atención al curandero.

Finalmente, una dimensión no contemplada inicialmente en el estudio que surge de las entrevistas como eje de indagación y potencial variable explicativa de los perfiles de salud/enfermedad diferenciales dentro de condiciones de vida pobres, se vincula con la adscripción religiosa. Muchas de las mujeres de GE entrevistadas manifestaron la importancia de su conversión y de las de otros miembros de la familia al culto evangélico o al de los Testigos de Jehová y su influencia en la modelación de estilos de vida "sanos". Destacan el poder terapéutico de Dios invocado en los rituales colectivos y manifestado en múltiples casos concretos, desechando cualquier 
oposición ciencia/religión en la medida que los hombres (médicos) son herramientas a través de las cuales opera el "poder divino de sanación".

En síntesis, tal como ya se ha planteado parcialmente, las representaciones sobre las causas de la desnutrición presentes en ambos grupos de mujeres recuperan los modelos interpretativos de la desnutrición presentes en el sistema sanitario (Aguirre, 1986): uno teórico y otro instrumental, paradójicamente contrapuestos. Para el modelo teórico, la desnutrición es una patología social que reconoce razones estructurales. En el modelo instrumental, las causas sociales se diluyen en el terreno de lo individual o de lo familiar, de tal modo que las condiciones de vida que están en la base de la desnutrición desaparecen del argumento causal. Varias son las entrevistadas cuyas apreciaciones reflejan la transmisión de la perspectiva instrumental del sistema sanitario, a través de quienes lo personifican y tratan la desnutrición de sus hijos: médicos, enfermeras, asistentes sociales. Lo que se rechaza -si no es la presencia de la desnutrición infantil-, es la causalidad social de la misma.

Los discursos predominantes para caracterizar a la desnutrición ponen el acento en desórdenes biológicos individuales causados por un agente externo: parásitos, infecciones, o en la familia -y básicamente en la madre- ya sea por malos hábitos, descuido, desinterés, etc. Esto último sustenta el carácter privado del consumo alimentario: con la desnutrición, "del consumo privado a la responsabilidad privada hay un solo paso" (Hintze, 1989). Tal como aparece en los discursos de la mayoría de las entrevistadas, particularmente en aquellas sin hijos desnutridos, la maternidad en situaciones de pobreza extrema, se ubica en un lugar próximo al "instinto de supervivencia" de la especie y el consumo de alimentos como una finalidad natural de todo ser vivo: el gobierno de la necesidad orgánica y la naturalidad del impulso materno a satisfacerla cobran fuerza: "una si es madre, siempre consigue algo", "uno siempre se la puede rebuscar para que no falte comida".

La idea de culpa está presente en mayor o menor grado en todas las mujeres. La idea de culpa, del enfermo (su madre, su familia) como sujeto transgresor, se representa siempre de diversas formas diluyendo los condicionamientos y las presiones que determinan los estilos de vida. Las acusaciones dirigidas sólo a los individuos muestran cómo la relación entre enfermedad y culpa reaparece continuamente y está muy enraizada en el ánimo popular. Se acusa a quienes tienen estilos de vida morbígenos asignándosele cierta complicidad a la familia del enfermo en el origen de la enfermedad.

Los mecanismos de reproducción ideológica dominantes y los mecanismos de transacción establecidos por los sectores subalternos con los hegemónicos, conducen a que la estructura dominante de las relaciones sociales se apoye en la subordinación 
asumida por los propios sectores subalternos, que se expresa en la autoestigmatización, autoinferiorización, autolimitación de estos conjuntos sociales (Menéndez, 1990).

En el relevamiento de las prácticas relacionadas a la desnutrición infantil aparece en primer lugar una exhaustiva descripción -por parte de las madres de ambos gruposde sus síntomas, quienes además plantean que "la buena comida" (valorada según su contenido en vitaminas y minerales) y "la comida a horario" son las formas de evitar la desnutrición, subestimando el rol del sistema sanitario en la prevención e incluso en la cura.

El reconocimiento, por parte de las madres de GD, de la desnutrición de su hijo queda relegado en el discurso, mencionándola como un episodio eventual en la historia familiar derivada de un desorden orgánico que "lo/a tiró abajo" y enfatizando además que se trata de "el /ella nomás".

Además, tal como lo señalan otros estudios, los sectores populares presentan una tendencia a negarse como enfermos hasta tanto la señal corporal adquiera cierta intensidad, hecho que se registra con mayor fuerza en los adultos (que puede ser atribuido, dadas las condiciones de vida, al costo en tiempo y recursos que implica la atención).

En la identificación de las enfermedades, aunque a menudo se perciben síntomas singulares, no ocurre la síntesis de diagnóstico que lleva a la búsqueda de una terapia, o de medidas que impidan su agudización.

Este comportamiento, para el caso particular de la desnutrición, se ve acentuado: sus características permiten su encubrimiento hasta que no aparezcan signos agudos (diarrea, fiebre, vómitos). Mientras tanto, suele estar enmascarada bajo un criterio de normalidad que se expresa en respuestas del tipo, "ya es asi", "son menuditos", "le cuesta aumentar", etc..

Son minoritarios los casos en los cuales la demanda se relaciona específicamente con el control de peso. Esta actitud debe comprenderse en función de la apreciación que tienen las madres del sistema de salud y de su incumbencia y/o eficacia en la prevención/tratamiento de la desnutrición. Apreciación que refleja, por otro lado, el modelo instrumental que desarrollan los médicos en su práctica asistencial: el médico centra su atención en la enfermedad infecciosa y/o parasitaria frente a la cual se siente capacitado y hacia la cual la industria farmacéutica y la infraestructura sanitaria brindan soluciones eficaces. Muchas veces, ése es el registro y esa la información diagnóstica y terapéutica que brindan a las madres en la consulta.

La conjunción de los elementos arriba planteados dificultan la visión de la desnutrición como patología social y empujan en dirección de la búsqueda de soluciones 
alternativas; frente a su presencia, la "pata de cabra" aparece como una conceptualización popular referida casi siempre al niño desnutrido que elimina toda impronta de responsabilidad a la madre o a la familia.

La medicina popular representa un elemento de integración y validación de la identidad y es una práctica de atención alternativa presente en mayor o menor medida en todos los sectores sociales. Particularmente dentro de los sectores pobres constituye una fuente de recursos, legitimados dentro del ámbito social en el que se originan, circulan, se aceptan y funcionan los diagnósticos y tratamientos considerados "profanos", los cuales han sido subalternizados mediante la exclusión jurídica e ideológica por parte del discurso y la práctica médica hegemónica.

Las prácticas de atención -científicas y populares- no constituyen dos órdenes opuestos y escindidos. Debe subrayarse la continuidad de las mismas en lo que hace a los signos y síntomas identificados, a la recategorización diagnóstica y a la eficacia o ineficacia real y simbólica del tratamiento seleccionado sobre la que se asientan tales cambios.

La apelación a la medicina popular, usada recurrentemente por las madres para tratar a su niño flaco, débil o desnutrido por "pata de cabra" amplía la cobertura de atención y propende a resolver padecimientos por fuera del sistema oficial. Dichas prácticas de atención no obedecen solamente a la falta de recursos formales de salud, a restricciones económicas o a limitaciones o ineficacia de la medicina científica. Responden también a una decisión tomada por la madre u otro pariente cercano compartida y avalada por el grupo social de pertenencia basada en la convicción de la existencia real de tal entidad. El ida y vuelta con los diagnósticos y tratamientos son, desde la perspectiva de las madres, compatibles; sólo son cuestionables desde la racionalidad médica. Ese campo de autonomía y autodeterminación incuestionable de las prácticas legas que el saber médico no logra cooptar, en tanto representa el reverso de lo oficial, de la legalidad, de la norma, es objeto de ocultamiento, negación, indiferencia, estigmatización o negociación.

Su existencia no debe oscurecer la evidencia de que, pese a su utilización, los problemas de salud se resuelven mayoritariamente dentro del sector médico oficial y que su saber, ya sea simplificado o esquematizado, se halla incorporado en el acervo de conocimiento de sentido común y en las prácticas cotidianas de atención a la salud de todos los sectores sociales: tal es la clave de la medicalización y de la expansión y vigencia del Modelo Médico Hegemónico (MMH). Se ha visto su influencia en la valoración de la alimentación, sobre la cual la práctica médica desempeña un papel decisivo en la definición de sus modalidades y contenidos: en ese sentido la 
autoatención constituye de hecho el primer nivel de atención y el más importante por sus potencialidades preventivas.

En la medida que la alimentación constituye un comportamiento cotidiano fuertemente medicalizado y que la desnutrición infantil se encuentra incluida en el campo de intervención médica, las prácticas, conocimientos y valoraciones sobre alimentación y salud de los conjuntos sociales están permeadas por una construcción hegemónica de la salud/enfermedad/atención.

De aquí la exploración acerca de los saberes que sobre nutrición/desnutrición infantil sostiene el personal médico de los centros asistenciales en donde se atiende esta problemática, así como las prácticas destinadas a la prevención/atención/tratamiento de la misma.

d) Así, la información obtenida de las entrevistas realizadas a médicos pediatras que trabajan en diferentes niveles asistenciales acerca del saber médico sobre desnutrición infantil, articula el análisis de sus prácticas y representaciones en torno a: - El problema de las normas de control y evaluación del estado nutricional y de las condiciones de trabajo que posibilitan su uso así como la evaluación de las políticas sanitarias; -la caracterización de la desnutrición, del desnutrido y su familia y de la asistenciaal desnutrido (causas, síntomas, diagnóstico, tratamiento, recomendaciones, prevención); -su interpretación sobre la percepción materna de la desnutrición, el cumplimiento de las prescripciones médicas y el uso de medicinas alternativas.

Concibiendo al trabajo médico asistencial como una actividad científico/técnica impregnada de procesos sociales, ideológicos, económicos e institucionales, los interrogantes planteados refieren a las características básicas del saber de estos dos conjuntos de profesionales y a sus diferencias respecto a la desnutrición: en qué principios teóricos y técnicos basan su actividad profesional; cómo detectan, diagnostican, explican su causalidad, actúan y evalúan su intervención; qué factores limitan, imposibilitan o favorecen la detección, tratamiento y cura de los niños desnutridos; cuáles son sus conocimientos de las estrategias populares y cuál es su capacitación para intervenir en actividades de atención primaria.

Cabe destacar que el reconocimiento/desconocimiento de la desnutrición como problema socio-sanitario responde y se expresa en las siguientes evidencias recogidas de fuentes secundarias:

- Los datos sobre la situación nutricional en la Argentina son asistemáticos, fragmentarios y discontinuos siendo mayor el desconocimiento sobre las deficiencias de micronutrientes.

- La escasa información se debe a su falta de obtención, fallas en el registro, procesamiento y difusión. 
- Las normas oficiales para las actividades de atención infantil, particularmente para el control del crecimiento, existen y son conocidas.

- Dichas normas no son utilizadas rutinariamente en la asistencia pública hospitalaria.

- La ausencia de normatización homogénea sobre alimentación infantil determina un vacío acerca de los criterios que los pediatras adquieren en su formación.

- La alimentación constituye un tema banal al que se le brinda poca o nula atención en la formación de pre y post-grado.

- Las recomendaciones alimentarias dadas por los pediatras arrojan, de acuerdo con la encuesta provincial citada, sólo un $15 \%$ de casos que indican una dieta con una adecuada densidad energética.

- Muchos trabajos señalan la necesidad imperiosa de capacitación sistemática a los pediatras y equipo de salud sobre la alimentación en el primer año de vida (selección, preparación, refuerzos, equivalencias, reemplazos).

- Pero la capacitación de los médicos sobre esta problemática queda relegada a sus intereses y posibilidades.

- Los programas de salud infantil son discontinuos por dificultades presupuestarias y organizativas.

- Hay carencias de insumos básicos y de bajo costo en los distintos niveles asistenciales.

- Los niveles de atención primaria presentan deficiencias en su capacidad resolutiva a causa de la irregularidad en la provisión de insumos.

- La inadecuada y/o insuficiente articulación entre los niveles asistenciales.

- El modelo de atención se centra en la reparación más que en la prevención, resultando una atención más cara e ineficaz.

Todos estos señalamientos se recuperan en mayor o menor medida, en los discursos de los médicos entrevistados, habiendo diferencias entre los dos grupos considerados: los que trabajan en unidades sanitarias y los que trabajan en hospitales públicos.

La actividad médica refleja la potencialidad de los profesional para intervenir con matices diferenciales que expresan, simultáneamente, al sujeto y a las instituciones donde trabaja. La representación médica tiende a enfatizar las características abstractas del saber médico y a opacar la estructuración institucional de sus prácticas y representaciones.

El incremento de instituciones de atención altamente burocratizadas, organizaciones en las que el quehacer profesional está rutinizado y normatizado en alto grado ha favorecido el proceso de uniformidad del sistema de prácticas y representaciones.

- Las diferencias encontradas entre médicos de hospitales públicos y médicos de atención primaria en relación a las normativas, condiciones de trabajo y evaluación de 
políticas sanitarias se vinculan con las prácticas y se reflejan, para el caso de los pediatras de hospital, en: el no cumplimiento de normas destinadas al control de salud y del crecimiento, la pérdida de pacientes por imposibilidad de seguimiento vinculada a la atención despersonalizada y cambiante, un mayor peso de las determinaciones institucionales que imponen la atención de patologías, sesgos profesionales más marcados por la subespecialización, inespecificidad para abordar las problemáticas del crecimiento y del desarrollo por falta de insumos básicos, subestimación de la problemática reflejada en la inexistencia de un código específico destinado al registro del estado nutricional de los niños atendidos.

Las estadísticas de los servicios de salud registran datos generales de la actividad médica: consultas, internaciones, días/cama, gastos, mientras que el dato sanitario: qué enfermedades, en qué zonas y grupos de población, es a veces completamente ignorado. Debido a ello, la enfermedad como señal permanece oculta y distorsionada: con frecuencia la magnitud de la desnutrición es desconocida o mal interpretada y las señales colectivas de enfermedad permanecen en un cono de sombra.

Los pediatras de las unidades de atención primaria reflejan mayor interés en la problemática evidenciado por la puesta en marcha de un "Programa de vigilancia y rehabilitación nutricional" y por la realización de un censo nutricional. Demandan en mayor medida la posibilidad de capacitación y actualización y si bien comunican gran satisfacción por su relación con los pacientes, reconocen a menudo escasa capacidad resolutiva: su mayor compromiso con los pacientes los lleva a un mayor grado de reflexión acerca de su tarea.

No obstante asumir que la desnutrición constituye un problema de salud prevenible, de diagnóstico técnicamente sencillo y tratamiento eficaz y barato y de hallarse estrechamente asociado con el aumento en las tasas de morbi-mortalidad, existe, a nivel poblacional, un notable vacío de información epidemiológica.

Las similitudes que aparecen en este punto entre ambos grupos tienen que ver con las representaciones: con el conocimiento de las normas y el reconocimiento de su utilidad, el reclamo de una mayor articulación entre los niveles de atención (apreciación más acentuada en los médicos del hospital), la sobrecarga de trabajo, la escasa motivación para participar de programas debido a la discontinuidad de los mismos, la falta de recursos del Estado que permitan el cumplimiento de las normas y un adecuado tratamiento, la falta de datos sistemáticos, la formación recibida que enfatiza el estudio de las patologías y no de la salud, la poca relevancia dada en su formación al control del crecimiento y a la alimentación, el sesgo asistencialista de su práctica. 
Puede observarse que las representaciones constituyen un sistema de expectativas, un marco de referencia para la actividad asistencial y establece una guía para la acción, siendo en la práctica donde la representación se realiza y se modifica. Las representaciones técnicas refieren al esquema dominante en la profesión e institución de la que son parte, ellas favorecen más la homogeneización que la diferencia y hallan su fundamentación en la objetividad científica. Mientras que la representación médica se refiere básicamente a la desnutrición, la práctica se refiere básicamente al manejo del desnutrido y aquí es donde se registran las diferencias entre ambos grupos de médicos.

- En relación a la caracterización y abordaje de la desnutrición, las diferencias entre ambos grupos refieren tanto a prácticas como a representaciones. En el caso de los pediatras de hospital se manifiesta: la ausencia de registros sobre desnutrición, mayor ambigüedad en la conceptualización de la desnutrición y de su cadena causal, escaso o nulo conocimiento del entorno del niño, mayor énfasis en características maternas negativas como factor desencadenante de la desnutrición, la afirmación de que ellas nunca consultan por el estado nutricional del niño -siempre por patologías-, el reconocimiento de errores diagnósticos, mayor contraste entre la representación técnica y las prácticas tanto de diagnóstico como de tratamiento, mayor escasez de recursos para el diagnóstico y tratamiento y carencia de criterios unificados sobre alimentación. En los médicos de las unidades de atención primaria se presenta una mayor correspondencia entre representaciones y prácticas. Tienen datos estadísticos sobre el estado nutricional de la población que demanda asistencia, realizan habitualmente los controles de salud -sobre todo en los menores de un año-, y afirman el cumplimiento de los mismos por parte de las madres así como con las recomendaciones médicas. Refieren una mayor preocupación de las madres por el estado nutricional de su hijo, consultando incluso cuando están eutróficos o no tienen signos evidentes de desnutrición. Los pediatras reconocen las categorías de subnutridos o malnutridos y proceden a la derivación al hospital en caso de sospechar alguna patología de base. Presentan un conocimiento bastante exhaustivo de la población que atienden, reconociendo idiosincracias según la nacionalidad, adscripción étnica o clase social. El tiempo dedicado a la atención y a la prevención es mayor y destacan que su lugar de trabajo conforma un espacio familiar para la población con el cual se siente identificada. Las similitudes aparecen en las representaciones relacionadas con la definición de la desnutrición, sus síntomas, el tipo de desnutrición prevalente (primaria y leve) que asocian a carencias socioeconómicas y señalan fallas en el registro de datos. Destacan la importancia del 
conocimiento del entorno del niño, de la relación médico-paciente y del diálogo con las madres para afinar el diagnóstico e indicar el tratamiento.

La desnutrición es definida habitualmente como anormalidad o desviación, o como inferioridad respecto al promedio de la población. Pero ¿cuál es la norma? La distinción de normal y anormal y luego entre anormal y patológico aparece compleja aun en el campo diagnóstico. Las zonas de frontera son variables y a veces inciertas. Hacer coincidir anormalidad y patología es a menudo arbitrario.

En tanto la desnutrición remite centralmente, en términos tanto de causalidad estructural como de prevención, a procesos económico-políticos y culturales, la capacidad técnica de los médicos para resolver dicho problema se ve restringida porque se circunscribe la acción médica a la relación individual con el enfermo.

Plantean que la incapacidad para dar soluciones a los problemas nutricionales, no anula la orientación biologicista, aun cuando muestra limitaciones evidentes.

Es decir, se refleja cómo el abordaje individual de la desnutrición conduce a que, ya que sus causas no se encuentran en el individuo, la práctica médica se limite a los efectos sin referirse al complejo de causas.

Si bien reconocen permanentemente que existe una continuidad entre individuo y ambiente y una conexión entre la enfermedad del individuo y las enfermedades de la colectividad, su formación y la organización sanitaria están orientadas a la curación individual.

En los médicos entrevistados, también es posible entonces recuperar los dos modelos interpretativos sobre la desnutrición expuestos anteriormente. Las prácticas de atención ponen de relieve, en un nivel de generalidad, algunos rasgos del $\mathrm{MMH}$ : exclusión del saber médico, relación médico/paciente asimétrica, subordinación social y técnica del paciente, el paciente como ignorante, el paciente es responsable de su enfermedad, tendencia al consumismo médico, medicalización creciente, racionalización científica como criterio de exclusión de otras prácticas médicas. Si bien en los discursos médicos, no aparecen como rasgos sobresalientes algunas de las características asignadas al $\mathrm{MMH}$ : biologicismo, ahistoricidad, asocialidad, concepción evolucionista/positivista, eficacia pragmática, función curativa, concepción de la salud/enfermedad como mercancía, lo cultural, en tanto diferencia, se plantea como obstáculo, resistencia o barrera a normas y prácticas sanitarias instituidas y se valora su recuperación para mantener el control.

Los médicos reconocen desempeñar parcialmente funciones curativo/preventivas, las actividades principales se vinculan con las de control, normatización y legitimación que hacen al mantenimiento de normas y valores sociales. 
En ese sentido la intervención médica consiste en enfatizar las ventajas de los comportamientos adecuados y modificar, regular o eliminar comportamientos anormales o desviados. Esto lo hacen a través de las recomendaciones alimentarias, la insistencia en los controles de salud, la promoción de hábitos alimentarios y de higiene, etc.

En las entrevistas realizadas es posible detectar diferencias y discrepancias entre representaciones y prácticas. La influencia de factores institucionales que restringen la posibilidad de actuación individual de la representación técnica, es más marcada en los médicos de hospital.

Asimismo, puede verse cómo el saber médico construye representaciones acerca del enfermo, de la familia o la comunidad siendo a menudo difícil diferenciar los contenidos técnicos y socioideológicos del saber médico.

Así, dentro del término desnutrición se incluye, además de un estatuto biológico de crecimiento inadecuado -e indeseable ya que implica "hambre" de quienes ni siquiera pueden expresarla-, un conjunto de estereotipos de uso frecuente en la vida cotidiana que integra representaciones de la desnutrición como problema social, como enfermedad, como patología de la pobreza, como abandono, descuido, anormalidad, etc. sintetizados a través del uso social y técnico en los diferentes contextos, incluido el de la relación médico-paciente.

Todo proceso de atención médica es además de un hecho técnico, un proceso de construcción social e ideológico que los grupos necesitan generar para manejar la enfermedad.

Es en la relación institución/paciente que se constituye el espacio común en el cual se dará la articulación curador/conjuntos. Dicho espacio supone procesos de esquematización y simplificación a partir, a su vez, de un empobrecimiento y esquematización previos constituidos entre el "saber teórico" y el "saber aplicado" de los médicos. Este primer proceso se da en la actualización teórica de los médicos prácticos.

En todos los casos no sólo existe una relación subordinada y dependiente, sino que el tipo de relaciones supone una necesaria enseñanza (la prescripción médica) y una necesaria apropiación (saber cumplir dicha prescripción).

De acuerdo con la referencia de los médicos, no parecen registrarse brechas comunicacionales entre médicos y pacientes relacionadas con el cumplimiento de los tratamientos alimentarios indicados.

La medicalización se presenta entonces como un fenómeno paradójico pues si bien supone un distanciamiento de los saberes y prácticas no científicas, al mismo tiempo implica y requiere de una articulación inteligible con los conjuntos sociales: deben 
existir mínimas correlaciones entre la teoría médica y los conjuntos sociales a partir de una situación subordinada de los pacientes estructurada en torno a saber/no saber. Cuando estas correlaciones o articulaciones no se dan, o pierden inteligibilidad la relación entre representaciones legas y oficiales sobre el padecimiento del niño, se recurre al curandero.

La profesión médica tiene una representación de sí misma que apela a la ciencia como mecanismo de legitimación y diferenciación respecto de los conjuntos sociales y de los curadores populares.

Así, por ejemplo, el conflicto entre médicos y curanderos es, ante todo, un conflicto de legitimidad que opone el saber elaborado por la cultura erudita a los conocimientos menos formalizados de los curanderos, provenientes del saber popular y de la experiencia particular del practicante.

No se limitan por su saber científico o vulgar, sino que lo poseen diferencialmente. Lo que caracterizaría al primero es lo oficial y lo legal, pero eso no impide que emerja en él lo mágico, lo lego, lo casero. Es el espacio del poder cultural, de la política hegemónica desde donde se imponen las normas, se suscita el consenso y se reproduce la adaptación al orden dominante. El otro espacio sustentado en el sistema de referencia lego no representa un saber vulgar, "inculto", popular o tradicional. Incluye saberes y prácticas vulgares y científicos, en contradicción constante con el otro espacio, generando apropiaciones, reproducciones y transformaciones de las pautas impuestas.

Toda sociedad contiene muchos más sistemas de significados y valores que los incorporados en su sistema central $u$ orden dominante; los conjuntos sociales seleccionan, incorporan y también excluyen elementos de toda esa gama posible existente. Como la hegemonía nunca es total ni definitiva, necesita ser renovada, recreada, defendida y modificada porque se encuentra permanentemente resistida, limitada, alterada o desafiada por fuerzas contrahegemónicas.

El sistema dominante debe hacerse y rehacerse continuamente para contener a los significados, prácticas y valores que le son disfuncionales o se le oponen.

La hegemonía no representa la desaparición total de experiencias de clase subalterna, sino la complementariedad lograda entre clases dominante/subalterna y sus culturas.

- Respecto de la interpretación que realizan sobre la visión materna y el uso de medicinas alternativas, las apreciaciones de los médicos difieren en el sentido que los pediatras del hospital consideran que las madres carecen de signos de alarma, sobredimensionan la utilización de medicinas alternativas, las estigmatizan en mayor medida, y la eficacia que atribuyen a las mismas está basada en principios y entidades 
reconocidas por la medicina científica (la cura coincide con la evolución natural de las virosis).

El problema reside muchas veces en el excesivo peso atribuido a las diferencias semánticas entre médicos y pacientes. A menudo, los médicos hablan de "supersticiones" e ignorancia para referirse a las creencias y representaciones de sus pacientes, entendiéndolas como un conjunto de creencias primitivas que deberían retroceder ante la clarificación creciente de la ciencia.

Los pediatras de las unidades de atención primaria muestran un mayor conocimiento de la medicina popular y reconocen los principios activos de los "yuyos" así como los mecanismos fisiológicos que desencadenan ciertas prácticas curativas legas. Asimismo señalan no tanto la oposición sino más bien la complementariedad de ambas formas de atención.

Ellos evidencian una representación de sus pacientes que refleja (Menéndez, 1985):

g) la importancia y legitimidad de la racionalidad cultural y social de los grupos

h) la importancia de las estrategias populares que implicarían un saber colectivo

i) la importancia del núcleo familiar o comunal como el primer nivel real de atención

j) la importancia de la apropiación pragmática de las clases subalternas y del conjunto de las clases sociales, del saber y práctica médicos

Las similitudes en ambos grupos de médicos se relacionan con su apreciación sobre la reacción materna -de preocupación y no de alarma- frente al diagnóstico de desnutrición y sobre la negación, por parte de las madres, de limitaciones económicas familiares que imposibilitan una adecuada alimentación, estando presente en esta negación el estigma con el que la madre debe cargar. Las madres, de acuerdo con la apreciación de los entrevistados, consideran que la desnutrición es resultado de una patología o de la "pata de cabra" y la mayoría de ellas responde de manera satisfactoria a las recomendaciones médicas. Todos los entrevistados conocen y reconocen el uso de la medicina popular por parte de sus pacientes y adoptan una actitud de "respeto" con advertencias referidas a los riesgos de intoxicación con té de "yuyos". Plantean la dificultad de modificar o alterar dichas prácticas y creencias ya que forman parte de "su" cultura y en general, las remiten al campo de lo sobrenatural, de la magia y de la fábula.

Con relación a ello, cabe cuestionar la visión según la cual la medicina "tradicional" o "popular" sería patrimonio de los grupos subalternos.

La institución médica se ve desbordada internamente, por las exigencias de cambio de muchos médicos, y externamente por la emergencia de nuevos terapeutas que compiten en el mercado de la salud y por la permanencia de las medicinas populares en el contexto urbano. 
Pensar que las hierbas, o las prácticas de la medicina popular son tradicionales y exclusivas de los estratos bajos, es incorrecto en términos de la evidencia disponible. "Generalmente, la focalización en la medicina popular ha excluido o seleccionado determinados grupos, sectores o estratos, así como determinadas prácticas e ideologías. Sin embargo, la legitimidad de esta exclusión es dudosa en términos tanto teóricos como empíricos." (Menéndez, 1997). Sería necesario explorar en detalle la eficacia de las medicinas (así como la de los rituales y la adscripción religiosa) y su mutua articulación, particularmente la de las medicinas alternativas sobre las que pesa mayor exigencia de demostración y sobre las cuales, particularmente para el caso de la medicina "popular" o "tradicional" en sectores pobres urbanos, se registra en la actualidad una notable escasez de estudios. La medicina "tradicional" o "popular": ¿es eficaz?, ¿cura realmente?, ¿cómo lo hace?, ¿por qué se practica?, ¿qué tanto hay de eficacia simbólica?, ¿es conveniente seguir manteniendo la dicotomía eficacia simbólica/eficacia pragmática?. Tal como observa Menéndez (1997), luego de una etapa prolífica de estudios antropológicos descriptivos dedicados a la medicina popular, se asiste desde hace aproximadamente tres décadas, a un notable desinterés y vacío de información sobre esta práctica que la misma antropología pareciera identificar con resabios atávicos de tradiciones exóticas, sin mucha importancia ni implicancias para la salud de la población. Lejos de ello, la realidad, más dinámica e indiferente de las categorías, conceptos y modas académicas, muestra cómo las mismas se actualizan, redefinen, surgen, consolidan y usan en la vida cotidiana. Su exploración podría iluminar, entre otras cuestiones, sobre las condiciones de salud de la población, sobre las limitaciones de la medicina hegemónica y sobre la eficacia de los recursos alternativos. 


\section{BIBLIOGRAFÍA CONSULTADA}

- ACC/SCN (1997): Nutrition and Poverty, Paper N 16, WHO, Génova.

- ACC/SCN (1997): Third report on the World Nutrition Situation, WHO, Génova.

- Adams, R. (1952): La antropología aplicada en los programas de salud pública de la América Latina. Boletín de la Oficina Sanitaria Panamericana, vol. $33 \mathrm{~N}^{\circ} 4$, Washington.

- Adams, R. (1955): A nutritional research program in Guatemala, ISA.

- Ageitos, M.L. (1999): "La lactancia materna". En: Hoy y mañana. Salud y calidad de vida de la niñez argentina, Cesni, Bs. As.

- Aguado, J. C. y Portal, A. M. (1992): Identidad, ideología y ritual, UNAM, México.

- Aguirre, P. (1986): "El encubrimiento en el estudio de la desnutrición o cómo las víctimas se convierten en culpables". En: Revista de Antropología, Nº1, Bs. As.

- Aguirre, P. (1990): "Impacto de la hiperinflación en la alimentación de los sectores populares". En: Fundación para el cambio en democracia (FUCADE), Documento № 2, Bs. As.

- Aguirre, P. y Lesser, R. (1993): "Creer para ver. Perspectivas teóricas y metodológicas sobre las estrategias de consumo de las familias pobres". En: Cuadernos Médico Sociales, №65-66, Rosario.

- Aguirre, P. (1995): "La carne es débil? Patrón alimentario y situación alimentaria en el Area Metropolitana de Buenos Aires, 1975-1992. En Alvarez y Barreda comp.: Cultura, salud y enfermedad, INAPL, Ministerio de Cultura y Educación de la Nación, Bs. As.

- Aguirre, P. (1997): "Incidencia de las estrategias domésticas de consumo en el acceso a los alimentos". En Alvarez, M. comp.: Antropología y práctica médica, INAPL, Ministerio de Cultura y Educación de la Nación, Bs. As.

- Aguirre, P. (2000): Entrevista publicada en el Suplemento Zona, diario Clarín, 2/7/00, Bs. As.

- Altimir, O. (1979): La dimensión de la pobreza en América Latina, CEPAL, Sgo. de Chile.

- Alvarez, M. de la L. et al. (1982): "Medición del nivel socioeconómico bajo urbano en familias con lactante desnutrido". En: Archivos Latinoamericanos de Nutrición, vol 32, № 3, Venezuela.

- Alvarez, M y Pinotti, L. (1998): A la mesa, ed. Grijalbo, Barcelona.

- Arribas, V. y Ayerdi, C. (1998): "La naturaleza y la cultura en el mensaje publicitario". En Boivin, Rosato y Arribas comp.: Constructores de otredad, Eudeba, Bs. As.

- Arribas, V., Cattaneo, A. y Ayerdi, C. (1998): "Canibalismo y pobreza". En Boivin, Rosato y Arribas comp.: Constructores de otredad, Eudeba, Bs. As.

- Balandier, G. (1975): Antropo-lógicas, ed. Península, Madrid.

- Banco Mundial (1994-1995) Informe sobre el desarrollo humano, Washington.

- Bartolomé, L. (1983): "Las estrategias adaptativas de los pobres urbanos: el efecto "entrópico" de la relocalización 'compulsiva'". En: XI Congreso Mundial de Ciencias Antropológicas, Quebec-Vancouver.

- Baudrillard, J. (1976): L'échange symbolique et la mort, Gallimard, París. 
- Beccaria, L. (1993): "Cambios en la estructura distributiva 1975-1990". En Minujin, A. (comp): Cuesta Abajo, Unicef/Losada, Bs. As.

- Beccaria, L. y López, N. (1996): Sin trabajo. Las características del desempleo y sus efectos en la sociedad argentina, Unicef/Losada, Bs. As.

- Berger, P. y Luckmann, T. (1978): La construcción social de la realidad, Amorrortu, Bs. As.

- Berian, J. (1990): Representaciones colectivas y proyecto de modernidad, ed. Anthropos, Barcelona.

- Berlinguer, G. (1994): La enfermedad. Sufrimiento, diferencia, peligro, señal, estímulo, Lugar editorial, Bs. As.

- Bloch, C. y otros (1984): "El proceso de salud-enfermedad en el primer año de vida: estudio de una cohorte". En: Cuadernos Médico Sociales Nº32, CESS, Rosario.

- Boivin, M. y Rosato, A. (1998): "Crisis, reciprocidad y dominación”. En Boivin, Rosato y Arribas comp.: Constructores de otredad, Eudeba, Bs. As.

-Boltanski, L. (1976): Los usos sociales del cuerpo, ed. Laia, Barcelona.

- Boltanski, L. (1978): El descubrimiento de la enfermedad, ed. Laia, Barcelona.

- Bonfil Batalla, G. (1962): Diagnóstico sobre el hambre en Sudzal, Yucatán. (Un ensayo de antropología ap/ciada). Instituto Nacional de Antropología e Historia, Dpto. de Investigaciones Antropológicas, México.

- Borsotti, C. (1981): "La organización social de la reproducción de los agentes sociales, las unidades familiares y sus estrategias". En: Demografía y Economía vol.15- № 46.

- Bourdieu, P. (1979): La distinción. Criterios y bases sociales del gusto, Taurus ed., Madrid.

- Bourdieu, P. et al (1985): El oficio del sociólogo, Siglo XXI, México.

- Bourdieu, P. (1990): Sociología y cultura, Grijalbo, México.

- Breilh, J. (1980): Investigación de la salud en la sociedad, CEAS, Quito.

- Brehil, J. (1989): Epidemiología, economía, medicina y política, ed. Fontamarra, México.

- Britos, S. (1994): "Racionalidad de los programas de asistencia alimentaria". En: Boletín Cesni $N^{\circ} 3$, Bs. As.

- Calvo, E. et al. (1991): "Evaluación del estado nutricional de la población de niños de 9 a 24 meses residentes en los partidos del Gran Buenos Aires". En: Archivos Argentinos de Pediatría, 89: 124-131, Bs. As.

- Cagide, A. y Saslavski, L. (1997): "Trastornos de la conducta alimentaria y diabetes: la combinación mortal”. En Alvarez, M. comp.: Antropología y práctica médica, INAPL, Ministerio de Cultura y Educación de la Nación, Bs. As.

- Campanario, S. (2001): "Las nuevas reglas del consumo masivo". En: Suplemento Económico, Diario Clarín, 29/7/01.

- Canesqui, A.M. (1988): “Antropología e Alimentacao". En: Rev. Saúde Públic. 22 (3), San Pablo.

- Canguilhem, G. (1983): Lo normal y lo patológico, ed. Siglo XXI, México. 
- Carmuega, E. et al. (1989): "Encuesta alimentaria y nutricional del partido de Gral. Rodríguez. Evaluación de comedores escolares". Premio de la Sociedad Argentina de Nutrición.

- Carmuega, E. et. al. (1995): "Estudio de ciertos factores de riesgo de salud y de la situación nutricional de adolescentes urbanos". En: Medicina Infantil, No 2:71-79, Bs. As.

- Carmuega, E. (1999): "La calidad de la dieta de los dos primeros años de vida". En: Hoy y mañana. Salud y calidad de vida de la niñez argentina, Cesni, Bs. As.

- Caudill, W. (1953): "Applied Anthropology in Medicine". En: Anthropology Today, The University of Chicago Press.

- CEB (Centro de Estudios Bonaerenses) (1996): Encuesta realizada para el Ministerio de la Producción y Empleo de la Pcia. de Bs. As. Información extraída del Suplemento Económico/Finanzas del Diario "El Día": 15/12/96, La Plata.

- Cecchi, H. (1988): "Hambre en el granero del mundo". En: El nuevo periodista № 211.

- CEPAL (1994): Panorama Social de América Latina 1994, Naciones Unidas.

- CESNI (1992): "Situación alimentaria y nutricional en la Argentina". En: Boletín Cesni, vol. 5, Bs. As.

- CESNI (1995): Proyecto Tierra del Fuego. Diagnóstico Basal de Salud y Nutrición, edición Fundación Jorge Macri, Bs. As.

- CESNI (1998): "La transición epidemiológica y la situación nutricional de nuestros niños". En: Boletín Cesni, Bs. As.

- Cicourel, A. (1973): El método y la medida en sociología, edit. Nacional, Madrid.

- Claudian (1972): “L’alimentation”. En: La France et les Francais, Gallimard, París.

- Colman, O. y otros (1992): "La problemática agroalimentaria en la Argentina (1970-1988)". En: Serie Estudios-Investigaciones № 8, Facultad de Humanidades y Ciencias de la Educación, UNLP.

- Conrad, P. y Schneider (1982): "Sobre la medicalización de la anormalidad y el control social". En Ingleby, D. comp.: Psiquiatría crítica. La política de la salud mental, Grijalbo, Barcelona.

- Cortés, F.; Menéndez, E. y Rubalcava, R. (1996): "Aproximaciones estadísticas y cualitataivas. Oposiciones, complementariedades e incompatibilidades". En Stern, C. (coord.): El papel del trabajo materno en la salud infantil, El Colegio de México.

- CPFDH (s/f) "Programas. Modelo de gerenciamiento social de la Provincia de Buenos Aires", Consejo Provincial de la Familia y Desarrollo Humano, Pcia. Bs. As.

- Cravioto, J. y Arrieta, R. (1988): "Crecimiento y desarrollo. Investigación y enseñanza en México". En Cusminsky; Moreno; Suárez Ojeda: Crecimiento y Desarrollo. Hechos y Tendencias. Publ. Cfca. $N^{\circ}$ 510, OPS, Washington DC.

- Cueto Rua, E., Feldman, R. et al. (1988): "Modelo de estudio de las enteroparasitosis infantiles. Su relación con factores socioeconómicos y ambientales". En: IV Jornadas Nacionales de Enteroparasitosis, Rosario.

- Cusminsky, M.; Moreno, E.; Suárez Ojeda, E. (1988): Crecimiento y Desarrollo. Hechos y Tendencias. Publ. Cfca. $N^{\circ}$ 510, OPS, Washington DC.

- Chavez, A. et al. (1992): Desarrollos tecnológicos para la solución de problemas de nutrición, Instituto Nacional de la Nutrición "Salvador Zubirán", public. L-89, México. 
- Chavez, A. et al. (1994): "La transición epidemiológica nacional en alimentación y nutrición". En: Sociedad, economía y cultura alimentaria, ed. Cynthia Godoy, México.

- De Castro, J. (1955): Geopolítica del hambre, ed. Raigal, Bs. As.

- Delgado, H.; García, B. y Hurtado, E. (1988): "Crecimiento físico, nutrición e infección en los primeros años de vida". En Cusminsky; Moreno; Suárez Ojeda: Crecimiento y Desarrollo. Hechos y Tendencias. Publ. Cfca. N 510, OPS, Washington DC.

- de Souza Queiroz, M. (1986): "O paradigma mecanicista da medicina occidental moderna". En: Rev. Saúde Púb. de Sao Paulo, vol. 20 N 4.

- Diario Clarín: 2/7/00, “La dieta de los argentinos" (Suplemento Zona), Bs. As.

- Diario Clarín: 29/7/01, "Las nuevas reglas del consumo masivo" (Supl. Económico), Bs. As.

- Diario Clarín: 29/7/01, Encuesta del Indec (artículo de Ismael Bermúdez sobre distribución del ingreso), Bs. As.

- Diario Clarín: 30/3/97, "La pobreza perpetua" (Suplemento Informativo) Entrevista a Susana Torrado y Eduardo Amadeo, Bs. As.

- Diario Clarín:5/12/98, "El reparto del ingreso cada vez más desigual" (Suplemento Económico), Bs. As.

- Diario El Día: 19/7/00, “La desnutrición crónica no cede en las villas de La Plata”, La Plata.

- Dirección General de Escuelas y Cultura Pcia. Bs. As. Series estadísticas 1992/93, Bs. As.

- Douglas, M. (1973): Pureza y peligro. Un análisis de los conceptos de contaminación y tabú, Siglo XXI ed, Madrid.

- Douglas, M. (1979): "Les structures du culinaire". En: Communications (31), École des Hautes Études en Sc. Sociales, Centre d'Etudes Transdisciplinaires, París.

- Douglas, M. y Isherwood, B. (1990): El mundo de los bienes. Hacia una antropología del consumo, Grijalbo ed., México.

- Duque y Pastrana, E. (1973): Las estrategias de supervivencia económica de las unidades familiares del sector popular urbano: una investigación exploratoria. Programa ELAS/CELADE, Sgo. de Chile.

- Durham, E. (1984): “Cultura e Ideologías.” En: Revista de Ciencias Sociales, vol. 27, N¹, Río de Janeiro.

- Eagleton, T. (1997): Ideología. Una introducción. Paidós, España.

- Eguía, A. (1992): Estrategias familiares de reproducción en sectores populares urbanos del Gran La Plata. Tesis doctoral en Antropología Cultural, Facultad de Ciencias Naturales y Museo de la UNLP., La Plata.

- Eguía, A. (1995): "Reproducción social y pobreza urbana". Informe de avance, Proyecto de Incentivos a la Investigación, Area de Sociología, Fac. de Humanidades y Ciencias de la Educación, UNLP, La Plata.

- Eguía, A. (1996): “Trabajo, asistencia alimentaria y situación familiar en sectores pobres urbanos del Gran La Plata desde la visión de las mujeres". En: Segundas Jornadas sobre Mujer, Trabajo y Pobreza. Instituto Interdisciplinario de Estudios de la Mujer, Fac. de Ciencias 
Humanas, Univ. Nac. de La Pampa e Instituto Gino Germani, Fac. de Ciencias Sociales de la UBA, Santa Rosa.

- Eguía, A. (1996): "Estudio comparativo de las estrategias alimentarias de familias pobres urbanas del Gran La Plata (1988-1994)". En: Estudios e Investigaciones, Facultad de Humanidades y Ciencias de la Educación de la UNLP, La Plata.

- Eguía, A. (1997): "Participación económica y situación familiar en sectores pobres urbanos del Gran La Plata (Argentina): la visión de las mujeres". Trabajo presentado en el Encuentro de la Latin American Studies Association, Guadalajara, México.

- Eguía, A. y colab. (2000): "Estudio integral de las condiciones de vida de familias pobres urbanas del Gran La Plata". En: Primeras Jornadas de Sociología, Dpto. de Sociología Fac. de Humanidades y Ciencias de la Educación UNLP, La Plata.

- Eguía, A. y colab. (2000): "Propuesta de un enfoque para el estudio de las condiciones de vida de familias pobres urbanas". En: Pobres, Pobreza y Exclusión Social, CEIL-CONICET, Bs. As.

- Eguía, A.; Ortale, S.; Weingast, D.; Dionisi, K.; Pagnamento, L. (2000): "Estudio integral de las condiciones de vida de familias pobres del Gran La Plata". Informe del Proyecto de Incentivos a la Investigación, Dpto. de Sociología, Fac. de Humanidades y Ciencias de la Educación de la UNLP, La Plata.

- Eguía, A. y Ortale, S. (2000): "Estudio comparativo de los efectos del ajuste económico en familias de sectores pobres y medios. Testimonios de mujeres". En Eguía, A; Ortale, S. y Sautú, R.: Las mujeres hablan: interpretaciones de la crisis y el ajuste económico entre mujeres de clase media y popular, editorial Al Margen/Edit. UNLP, La Plata.

- Eguía, A., Piovani, J., Loustau, C., Chironi, F. y Rusiñol, G. (2001): "Evolución de la situación laboral del Gran La Plata en la última década". En: Vo Congreso Nacional de Estudios del Trabajo, Asociación Argentina de Especialistas del Trabajo, Bs. As., agosto de 2001

- Eguía, A.; Ortale, S.; Piovani, J.I.; Dionisi, K.; Pagnamento, L. y Weingast, D. (2001): "Diagnóstico integral de las condiciones de vida en el barrio La Unión (Partido de La Plata)". Dpto. de Sociología de la Facultad de Humanidades y Ciencias de la Educación de la UNLP/Conicet.

- Eisenberg, L. (1977): "Disease and illness”. En: Culture, Medicine and Psychiatry, vol. 1.

- Escudero, J.C. (1984): "Daños sociales por malnutrición”. En: Cuadernos Médico Sociales, CESS, $\mathrm{N}^{\circ} 25$, Rosario.

- Escudero, J.C., (1985): “Lógica de la naturaleza, lógica del lucro". En: Temas de Medicina Social, Cuaderno $\mathrm{N}^{\circ} 7$, Bs. As.

- Escudero, J.C., (1995): "Consecuencias nutricionales del ajuste en América Latina y el Caribe". En: Cuadernos Médico- Sociales N 70, Rosario.

- Esteva Fabregat, F.(1988): "Cómo detener la ayuda y el hambre“. En: Carencia alimentaria. Una perspectiva antropológica, Serbal/Unesco, Barcelona.

- FIDE (1996): "La estructura social de la Argentina. Capacidad adquisitiva de los hogares del Conurbano bonaerense, mayo 1995", Diario Página 12, 4 de febrero de 1996.

- Fischler, C. (1990): El (h) omnívoro. El gusto, la cocina y el cuerpo, Anagrama, Barcelona.

- Fischler,C. y de Garine, I. (1988): "Ciencias humanas y alimentación". En: Carencia alimentaria. Una perspectiva antropológica, SERBAL/UNESCO, Barcelona. 
- Flier, P., Ghigliani, P., Raimundo, M. (1995): En los márgenes. Estudio de población en riesgo social en el partido de La Plata, Centro de Investigaciones Sociohistóricas, Fac. de Humanidades y Ciencias de la Educación UNLP y Secretaría de Salud y medicina Social de la Municipallidad de La Plata, La Plata.

- Foster, G. (1952): "Papel de la antropología en los programas de salud pública". En: Boletín de la Oficina Sanitaria Panamericana, vol $33 N^{\circ} 4$, Washington.

- Foucault, M. (1977): "Historia de la medicalización”. En: Educación Médica y Salud, vol. 8, OPS, Washington.

- Foucault, M. (1980): El nacimiento de la clínica. Una arqueología de la mirada médica, Siglo XXI, México.

- Foucault, M. (1990): La vida de los hombres infames, ed. Piqueta, Madrid.

- Friedson, E. (1978): La profesión médica. Un estudio de sociología del conocimiento aplicado, ed. Península, Barcelona.

- García Canclini, N. (1984): “Ideología y Cultura”. En: Cursos y Conferencias, Facultad de Filosofía y Letras UBA, Buenos Aires.

- García Canclini, N. (1991): "El consumo sirve para pensar". En: Diálogos de la comunicación $N^{\circ} 30$, Perú.

- García Canclini, N. (1991): "Construcción o simulacro del objeto de estudio? Trabajo de campo y retórica textual”. En: Alteridades vol 1 №1, México.

- García Canclini, N. (1993): El consumo cultural en México. Consejo Nacional para la Cultura y las Artes, México.

- Garrote, N. (1995): "El itinerario social del alimento. Estudio antropológico en un hospital". En Alvarez y Barreda comp.: Cultura, salud y enfermedad, INAPL, Ministerio de Cultura y Educación de la Nación, Bs. As.

- Garrote, N. (1997): "Una propuesta para el estudio de la alimentación: las estrategias alimentarias". En Alvarez, M. comp.: Antropología y práctica médica, INAPL, Ministerio de Cultura y Educación de la Nación, Bs. As.

- Garrote, N.; (1988): Antropología de la nutrición: desempeño de roles en el proceso alimentario. Algunas creencias y valores, Cides/OEA, Bs. As..

- Geertz,C. (1973): "El impacto del concepto de cultura en la idea de hombre". En: La interpretación de las culturas, Ed. Gedisa.

- George, S. (1980): Cómo muere la otra mitad del mundo. Las verdaderas razones del hambre, Siglo XXI ed, México.

- Giménez, G. (1997): "Materiales para una teoría de las identidades sociales" (mimeo) Instituto de Investigaciones Sociales de la UNAM, México.

- Giosa Zuazua, N. (1999): "Desempleo y precariedad laboral en la Argentina de los años 90". En: Epoca, 1, Bs. As.

- Godelier, M. (1984): “Lo ideal y lo material”. En: Revista de Cuicuilco, ENAH № 20, México.

- Golbert, L y Tenti Fanfani, E. (1994): "Nuevas y viejas formas de pobreza en la Argentina". En: Sociedad No 4, Fac. de Ciencias Sociales, UBA, Bs. As. 
- Grassi, E.; Hintze, S. y Neufeld, M. R. (1995): "Políticas sociales y sujetos de derecho". En: Cuadernos Médico-Sociales $N^{\circ} 72$, Rosario.

- Grignon, C. (1986): “Les modes gastronomiques a la francaise”, L'Histoire 85:128-134

- Grignon (1987): L'evolution des habitudes alimentaires des Francais, Fondation Universitaire des Sciences et techniques du Vivant, París.

- Grimberg, M. (1995): “De conceptos y métodos: relaciones entre epidemiología y antropología". En Alvarez, M. comp.: Antropología y Práctica Médica, INAPL, Ministerio de Cultura y Educación de la Nación, Bs. As.

- Grimberg, M. (1997): "Teorías, propuestas y prácticas sociales. Problemas teóricos metodológicos en Antropología y Salud". En Alvarez, M. y Barreda, V. comp.: Cultura, salud y enfermedad, INAPL, Ministerio de Cultura y Educación de la Nación, Bs. As.

- Gutiérrez, A. (1993): La diversificación de estrategias de reproducción social en pobreza urbana. Informe de investigación de circulación restringida. Centro de Investigaciones de la Facultad de Filosofía y Humanidades de la Universidad Nacional de Córdoba.

- Gutiérrez, A. (1994): Pierre Bourdieu: las prácticas sociales, CEDAL, Bs. As.

- Hall, S. (1993): A questao da identidade cultural, Univ. Estaduale de Campinas, Brasil.

- Harris, M. (1991): Bueno para comer, ed. Alianza, México.

- Herrera, M. (1998): "Los estudios de crecimiento infantil en México". En: Revista Salud Problema, año $3 \mathrm{~N}^{\circ}$ 5, Xochimilco (UAM), México.

- Herzlich, J. y Pierret, C. (1989): "De ayer a hoy: construcción social del enfermo". En: Cuadernos Médico Sociales $N^{\circ} 43$, CESS, Rosario.

- Hintze, S.(1987): La reproducción de los sectores populares: estrategias y reivindicaciones. Departamento de Ciencias Antropológicas, Fac. de Filosofía y Letras, UBA, Bs. As.

- Hintze, S. (1989): Estrategias alimentarias de sobrevivencia. Un estudio de caso en el Gran Buenos Aires. Centro Editor de América Latina № 270 y 271, Bs. As.

- Hintze, S.; Grassi, E. y Neufeld, M. R. (1994): Políticas sociales. Crisis y ajuste estructural, ed. Espacio, Bs. As.

- INDEC (1984): La pobreza en la Argentina. Serie de Estudios N 1, Bs. As.

- INDEC (1990): La pobreza urbana en la Argentina, Bs. As.

- INDEC (1992): Encuesta de gastos/ingresos de los hogares. Cantidades consumidas. Estudios $\mathrm{N}^{\circ}$ 20. Estadística mensual. Indice de precios al consumidor. Min. de Economía Bs. As.

- INDEC (1991): Censo Nacional de Población y Vivienda.

- INDEC (1994): EPH Censo Nacional de Población y Vivienda.

- INDEC (1994a): Mapas de la pobreza en la Argentina, Documento № 4, Bs. As.

- INDEC (1995): Módulo de monitoreo de metas sociales. Encuesta Antropométrica de niños menores de 6 años, Encuesta Permanente de Hogares, Bs. As.

- INDEC (1995): Encuesta Permanente de hogares. Indice de precios al consumidor 19801995. 
- INDEC (1996): Infancia y condiciones de vida. Encuesta especial para el diagnóstico y la evaluación de las metas sociales, Bs. As.

- Jelin, E. (1984): Familia y unidad doméstica: mundo público y vida privada, Estudios CEDES, Bs. As.

- Jelin, E. (1994): "Familia: crisis y después...". En Wainerman, C.: Vivir en familia, Unicef/Losada, Bs. As..

- Jodelet, D. (1985): "La representación social: fenómenos, concepto y teoría". En Moscovici, S.: Psicología Social, Paidós, Barcelona.

- Jodelet, D. (1989): "Representations sociales: un domaine en expansion”. En: Jodelet, D.: Les representations sociales, Presses Universitaires de France.

- Jordan, J. (1988): "Algunos aspectos de la investigación en crecimiento y desarrollo". En Cusminsky, M.; Moreno, E.; Suárez Ojeda, E.: Crecimiento y Desarrollo. Hechos y Tendencias. Publ. Cfca. $N^{\circ} 510$, OPS, Washington DC.

- Jordán, J. (1988): "El lactante de 0-2 años: antropometría y crecimiento". En Cusminsky, M.; Moreno, E.; Suárez Ojeda, E.: Crecimiento y Desarrollo. Hechos y Tendencias. Publ. Cfca. $\mathrm{N}^{\circ}$ 510, OPS, Washington DC.

- Khare, R. (1988): "La investigación internacional sobre alimentos y nutrición”. En: Carencia alimentaria. Una perspectiva antropológica, Serbal/Unesco, Barcelona.

- Khare, R. (1976): The hindu hearth and home, Durham, Carolina Academic Press.

- Katz, S. (1982): "Food, behavior and biocultural evolution." En Barker, L.: The Psychobiology of human food selection, Westport, Connecticut, Avi.

- Kleinman, A.(1980): Patients and healers in the context of culture, Berkeley, Univ. of California Press.

- Kleinman, A. (1978): "Concepts and a model for the comparison of medical systems as cultural system". En: Social Science and Medicine, 12: 85-93.

- Kliksberg, B. (1994): "La escalada de la pobreza en América Latina”. En: Pobreza. Un tema impostergable. Nuevas respuestas a nivel mundial, CLAD-PNUD; FCE, México.

- Laplantine, F. (1984): "Antropología de los sistemas de representación de la enfermedad". En: Histoire, Economie et Societé, París.

- Laplantine, F. (1991): Antropología de la enfermedad, Payot, París.

- Laurell, A. (1986): "El estudio social del proceso salud-enfermedad en América Latina". En: Cuadernos Médico-Sociales N 37, CESS, Rosario.

- Le Breton, D. (1995): Antropología del cuerpo y modernidad, Ed. Nueva Visión, Bs. As.

- Le Goff, J. (1974): Pensar la historia, Paidós, Barcelona.

- Lejarraga, H.; Morasso, M. del C. et al. (1985): Guías para la evaluación del crecimiento y nutrición del niño menor de seis años en APS", Dirección Nacional de Maternidad e Infancia, Min. de Salud y Acción Social de la Nación, Bs. As.

- Lejarraga, H. (1988): "La supervisión del crecimiento". En Cusminsky, M.; Moreno, E.; Suárez Ojeda, E.: Crecimiento y Desarrollo. Hechos y Tendencias. Publ. Cfca. N ${ }^{\circ}$ 510, OPS, Washington. 
- Lévi Strauss,C. (1965): Lo crudo y lo cocido, FCE, México.

- Lévi-Strauus,C. (1968): El origen de las maneras de mesa, Siglo XXI, México.

- Lévi-Strauus,C. (1968): Antropología estructural I, Eudeba, Bs. As.

- Levitsky, D.A. (1979): "Malnutrition and the hunger to learn". En: Levitsky comp.: Malnutrition, Learning and Behaviour, Ithaca, New York.

- Lewis, O. (1961): Cinco familias: antropología de la pobreza, FCE, México.

- Lomnitz, L. (1975): Cómo sobreviven los marginados, Siglo XXI, México.

- Lores Arnaiz, M. del R. (1986): El concepto de salud: conceptos y paradigmas, ed. de Belgrano, Bs. As.

- Lowie, A. (1942): "The transitions of civilizations in primitive society". En: American Journal of Sociology, vol 47: 527-543.

- Llovet, J.J. (1985): Sectores populares y servicios sanitarios: los años del proceso, Estudios CEDES, Bs. As.

- Mardones Restat, F. y Jones de Mardones, G. (1988): "Predicciones De fallas del crecimiento en niños menores de un año". En Cusminsky; Moreno; Suárez Ojeda: Crecimiento y Desarrollo. Hechos y Tendencias. Publ. Cfca. N 510, OPS, Washington DC.

- Margulis, M. (1980) "Reproducción social de la vida y reproducción del capital". En: Nueva Antropología, Año IV, № 13-14, México.

- Margulis, M. y otros (1981) "Fuerza de trabajo y estrategias de supervivencia en una población de origen migratorio: colonias populares de Reynosa". En: Demografía y Economía vol. $15 \mathrm{~N}^{\circ} 46$.

- Margulis, M. y Tuirán, R. (1986): "Las unidades domésticas: participación en la actividad económica y estrategias de reproducción". En: Desarrollo y población en la frontera norte, El Colegio de México, México.

- Martínez, M. J. (1993): "Acerca del hambre y las responsabilidades compartidas" (Comentario del trabajo de Hintze, S. "Estrategias alimentarias de sobrevivencia" CEAL, Bs. As., 1989). En Cuadernos de Antropología Social N 7, 1993. Fac. Filosofía y Letras UBA, Bs. As.

- Mata, L. (1988): “Interacciones infección/nutrición”. En Cusminsky, M.; Moreno, E.; Suárez Ojeda, E.: Crecimiento y Desarrollo. Hechos y Tendencias. Publ. Cfca. N ${ }^{\circ}$ 510, OPS, Washington DC.

- Mauss, M. (1971): “Sociología y Antropología”, ed. Tecnos, Madrid.

- Mc Keown, Th. (1979): El papel de la medicina: sueño, espejismo o némesis?, Siglo XXI, México.

- Mead,M. (1943): "The problem of changing food habits". En: National Research Council Bulletin (108).

- Mead, M. (1970): “The changing significance of food”. En: American Scientist 58: 176-181.

- Menéndez, E. (1978): "El modelo médico y la salud de los trabajadores". En Basaglia, F.: La salud de los trabajadores, Nueva Imagen, México. 
- Menéndez, E. (1981): Poder, estratificación y salud, Ed. de la Casa Chata, México.

- Menéndez, E. (1983): "Hacia una práctica médica alternativa. Hegemonía y autoatención en salud". En: Cuadernos de la Casa Chata Nº 86, CIESAS, México.

- Menéndez, E. (1985): "Aproximación crítica al desarrollo de la Antropología Médica en América Latina". En: Nueva Antropología, vol. 29, México.

- Menéndez, E. (1987): "Estratificación social y condiciones de morbimortalidad. Algunas reflexiones sobre la crisis y recuperación teórica de esta relación". En: Desarrollo Económico, vol. $27 \mathrm{~N}^{\circ} 105$.

- Menéndez, E.(1989): "Reproducción social, mortalidad y antropología médica". En: Cuadernos Médico Sociales N 49-50, CESS, Rosario, 1989.

-Menéndez,E.(1990): Antropología médica. Orientaciones, desigualdades y transacciones, CIESAS, Cuadernos de la Casa Chata 179, México.

- Menéndez, E. (1991): "Definiciones, indefiniciones y pequeños saberes". En: Alteridades 1: 21-33.

- Menéndez, E. (1992): "Grupo doméstico y proceso salud/enfermedad/atención. Del teoricismo al movimiento continuo". En: Cuadernos Médico Sociales N 57, CESS, Rosario.

- Menéndez, E. y Di Pardo, R. (1996): De algunos alcoholismos y algunos saberes, Colecc. Miguel Othon de Mendizábal, México.

- Menéndez, E. (1997): "Antropología Médica: espacios propios, campos de nadie". En: Nueva Antropología, vol. XV, № 51, México.

- Menéndez, E. (1997): "El punto de vista del actor. Homogeneidad, diferencia e historicidad". En: Relaciones № 69.

- Ministerio de Salud y Acción Social de la Nación (1996): Propuesta Normativa Perinatal, Tomo II, Bs. As.

- Ministerio de Salud Pcia. de Bs. As. (1997): Encuesta provincial nutricional de niños y embarazadas, Programa Materno-Infantil MSPBA, Bs. As.

- Ministerio de Salud Pcia. de Bs. As. Programa Materno-Infantil (1998): Informe de la Encuesta a Médicos sobre Alimentación durante el primer año de vida, La Plata

- Minujin, A. (1992): "En la rodada. Transformaciones en la estructura social argentina". En: Cuesta Abajo. Los nuevos pobres: efectos de la crisis en la sociedad argentina. Unicef/Losada, Bs. As.

- Minujin, A. ed. (1993): Desigualdad y exclusión. Desafíos para la política social en la Argentina de fin de siglo, Unicef/Losada, Bs. As.

- Minujin, A. y Kessler, G. (1995): La nueva pobreza en la Argentina. Ed. Planeta, Bs. As.

- Módena, M.E. (1990): Madres, médicos y curanderos: diferencia cultural e identidad ideológica. Ediciones de la Casa Chata 37, México.

- Monza, A. (1992): La situación del empleo en la Argentina, mimeo, Bs. As.

- Moore Lappé, F.y Collins, J. (1982): Comer es primero. Más allá del mito de la escasez, Siglo XXI ed., México. 
- Moreno, E. (1999): "Morbimortalidad en la niñez". En: Hoy y mañana. Salud y calidad de vida de la niñez argentina, Cesni, Bs. As.

- Moscovici S. (1978): A representacao social da psicanálise. Zahar, Río de Janeiro

- Moscovici, S. (1989): "Des representations collectives aux representations socials". En Jodelet. D.: Les representations sociales, Presses Universitaires de France, París.

- Municipalidad de La Plata (Concejo Deliberante, Bloque de Concejales de la UCR), (1995): La Plata: propuestas para un futuro de progreso.

- Murmis, M. y Feldman, S. (1993): "La heterogeneidad social de las pobrezas". En: Minujin ed. Cuesta Abajo, Unicef/Losada, Bs. As.

- Myers, R. (1994): Los doce que sobreviven, Public.Científica N 545, OPS-OMS, Washington DC.

- O'Donnell y Carmuega (1999): Hoy y mañana. Salud y calidad de vida de la niñez argentina, Cesni, Bs.As.

- O’Donnell, A. (1999): “Una visión de la problemática nutricional de los niños argentinos”. En: Hoy y mañana. Salud y calidad de vida de la niñez argentina, Cesni, Bs. As.

- Oliveira, O. y Salles, V. (1989): "Acerca del estudio de los grupos domésticos: un enfoque sociodemográfico". En: Grupos domésticos y reproducción cotidiana, México.

- Ortale, S. (1996): "Estudio comparativo del consumo alimentario en familias pobres urbanas del Gran La Plata (1988-1994). Ponencia presentada en las Segundas Jornadas sobre "Mujer, Pobreza y Trabajo", Instituto Interdisciplinario de Estudios de la Mujer, Fac. de Ciencias Humanas, Universidad Nac. de La Pampa, La Pampa.

- Ortale, M.S. y Rodrigo, A. (1996): "Estudio Biocultural de la Desnutrición Infantil de causa primaria en el Gran La Plata, Pcia. de Bs. As, Argentina". En: Archivos Latinoamericanos de Nutrición, vol. 46 (2): 136-142, Venezuela.

- Ortale, M.S. y Rodrigo, M.A. (1998): "Condiciones de vida, nutrición infantil y morbimortalidad en familias pobres urbanas del Gran La Plata". En: Archivos Latinoamericanos de Nutrición, № 2 vol. 48 (2): 146-151, Venezuela.

- Ortale, M.S. (1999): "Medicalización del consumo alimentario en familias del Gran La Plata". En: Actas del V Congreso Argentino de Antropología Social, Editorial de la UNLP, La Plata.

- Ortale, M.S. (1999): "Mujer, alimentación y nutrición infantil. Estudio comparativo en familias pobres urbanas del Gran La Plata". En: di Virgilio, Ojeda y Sautú comp.: Mujer, trabajo y familia, Editorial de la UNLP, La Plata.

- Ostiguy, P. y Armstrong,W. (1987): La evolución del consumo alimentario en la Argentina (1974-1984). Un estudio empírico, Biblioteca Política del CEAL (199), Bs. As.

- Parsons, T. (1951): El sistema social. Ed. Revista de Occidente, Madrid.

- Penchaszadeh, V. (1988): Condicionantes básicos para el crecimiento. Una larga polémica: herencia o ambiente. En: Cusminsky; Moreno; Suárez Ojeda, Crecimiento y Desarrollo. Hechos y Tendencias. Publ. Cfca. $N^{\circ}$ 510, OPS, Washington DC.

- Pelto,G. (1988): "Tendencias de la investigación en antropología nutricional". En: Carencia alimentaria. Una perspectiva antropológica, Barcelona, Serbal/Unesco.

- Piacente, T. y otros (1990): Piden pan ... y algo más: un estudio sobre crecimiento y desarrollo infantil, Unicef/Siglo XXI , Bs. As. 
- PISPAL (1978): Líneas prioritarias para la tercera fase, México.

- Portes, A. (1984): "El sector informal: definición, controversias, relaciones con el desarrollo nacional". En Walton y otros: Ciudades y sistemas urbanos, economía informal y desorden espacial, CLACSO, Bs. As.

- PNUD (1990): "Desarrollo humano. Informe 1990", Conferencia Regional de los países de América Latina sobre pobreza, Quito.

- Programa Materno-Infantil del Ministerio de Salud de la Pcia. de Bs. As. (1997): Encuesta Nutricional Infantil.

- Programa Materno-Infantil del Ministerio de Salud de la Pcia. de Bs. As. (1998): Informe de la Encuesta a Médicos sobre Alimentación durante el primer año de vida, Ministerio de Salud Pcia. de Bs. As.

- Przeworski, A. (1982): "Teoría sociológica y el estudio de la población: reflexiones sobre el trabajo de la Comisión de Población y Desarrollo de CLACSO". En: varios autores. Reflexiones teórico-metodológicas sobre las investigaciones en población, El Colegio de México.

- Puffer, R. y Serrano,C. (1973): "Características de la mortalidad en la niñez". En: Boletín de la Oficina Sanitaria Panamericana. Public. Científica $N^{\circ} 262$, Washington DC.

- Rackzynski, D. y Serrano, C. (1985): Vivir la pobreza. Testimonios de mujeres. Pispal/Ceplan, Sgo. de Chile.

- Radcliffe Brown, (1952): Estructura y función en la sociedad primitiva, Barcelona.

- Ramos Galván, R. (1966): "Desnutrición, un componente del síndrome de privación social". En: Gaceta Médica Mexicana 96:929.

- Rappaport, R.A. (1984): Pigs for the ancestors, New Haven, Yale Univ. Press.

- Rappaport, R.A. (): "Naturaleza, cultura y antropología ecológica". En: Hombre, Cultura y Sociedad, FCE, México.

- Richards, A. (1948): Hunger and Work in a Savage Tribe, Glincoe, The Free Press, Illinois.

- Rivera, J. y Ruiz, L. (1998): "Alimentación, nutrición y calidad de vida en áreas urbanas". En: Revista Salud Problema, año $3 \mathrm{~N}^{\circ}$ 5, Xochimilco (UAM ), México.

- Rodrigo, M. A. (2000): Salud Infantil, Observatorio Calidad de Vida. Informe presentado a la Municipalidad de La Plata (en prensa), Comisión de Investigaciones Científicas PBA, Secretaría de Extensión Universitaria Universidad Nacional de La Plata

- Sabulsky, J. et al. (1997): Alimentación, crecimiento y desarrollo, ed. Eudecor, Córdoba.

- Sahlins, M. (1988): "Tabú alimentario y animales domésticos" (cap. IV de Cultura y razón práctica), Gedisa ed., Barcelona.

- Saslavski, L.; Sinay, I. y Rabey, M. (1995): "Brechas comunicacionales entre médicos y pacientes y el incumplimiento dietario en los tratamientos diabetológicos". En: Alvarez y Barreda comp. Cultura, salud y enfermedad, INAPL, Ministerio de Cultura y Educación de la Nación, Bs. As. 
- Scheper-Hughes, N. (1984): "Infant mortality and infant care: cultural and economic constraints on nurturing in northeastern Brazil". En: Social Science and Medicine, vol. 19.

- Scheper-Hughes, N. (1990): "Three propositions for a critically applied medical anthropology". En: Social Science and Medicine, vol $30 \mathrm{~N}^{\circ} 2$.

- Schutz, A. (1974): Estudio sobre teoría social, Amorrortu, Bs. As.

Sempértegui Salazar (1978): "Epidemiología de la desnutrición". En: Cuadernos MédicoSociales, $\mathrm{N}^{\circ} 15$, Rosario.

- Sevalho, G. (1993): "Uma abordagem histórica das representacoes sociais de saúde e doenca". En: Cadernos de Saúde Púb., Fund. Oswaldo Cruz, Escola Nacional de Saúde Pública, vol. $9 \mathrm{~N}^{\circ} 3$, Río de Janeiro.

- Simmel, G. (1981): “Ensayo sobre sociología del sentido”. En: Sociología y epistemología, ed. PUF, París.

- Singer, M. (1990): "Reinventing Medical Anthropology: Toward a Critical Realignment". En: Social Science and Medicine, vol $30 \mathrm{~N}^{\circ} 2$.

- Sperber, D. (1982): El saber de los antropólogos, Hermann, París.

- Sperber, D. (1989): "El estudio antropológico de las representaciones: problemas y perspectivas". Traducción: Licia Pagnamento. En: Jodelet, D. Les Represéntations Sociales, Presses Universitaire de France, París.

- Spink, M. (1993): "El concepto de representación social en el abordaje psicosocial". Traducción: Diana Weingast. En: Cadernos de Saúde Púb., Fund. Oswaldo Cruz, Escola Nacional de Saúde Pública, vol. $9 \mathrm{~N}^{\circ}$ 3, Río de Janeiro.

- Spink, M. (1995): O conhecimento no cotidiano. As representacoes sociais na perspectiva da psicologia social, Editora Brasiliense, San Pablo.

- Tedesco, J. C. (1995): "La educación tiende a democratizarse y el mercado de trabajo a reducirse". Diario Página 12, domingo 27 de agosto de 1995, Bs. As.

- Teubal, M. (1989): “Hambre y alimentación en Argentina”. En: Realidad Económica, № 89, Bs. As.

- Torrado, S. (1981): "Sobre los conceptos de estrategias familiares de vida y procesos de reproducción de la fuerza de trabajo: notas teórico-metodológicas." En: Demografía y Economía, vol. 15, № 46.

- Torrado, S. (1983): La familia como unidad de análisis en censos y encuestas de hogares: metodología actual y prospectiva en América Latina, CEUR, Bs. As.

- Torrado, S. (1985): El enfoque de las estrategias familiares de vida en América Latina: orientaciones teórico-metodológicas, CEUR, Bs. As.

- Torrado, S. (1995): Declaraciones al diario Página 12, 14/1/95, Bs. As.

- Torrado, S. (1997): Declaraciones al diario Clarín, 30/3/97, Bs. As.

- Torrado, S. (1998): “Curvas peligorsas”, artículo Suplemento Político diario Página 12, Bs. As.

- Unicef/Cenep (1985): Condiciones de vida y situación de la infancia en la Argentina, Bs. As.

- Unicef (1991): La infancia Argentina en cifras, Bs. As. 
- Unicef (1992): La infancia Argentina en cifras. Informe imprescindible para conocer el presente y modificar el futuro, Bs. As.

- van Dijk, T. (1999): Ideología. Una aproximación multidisciplinaria. Gedisa ed., Barcelona.

- Vargas, L. A. (1988): "Contexto socioantropológico del crecimiento infantil". En Cusminsky, M.; Moreno, E.; Suárez Ojeda, E.: Crecimiento y Desarrollo. Hechos y Tendencias. Publ. Cfca. № 510, OPS, Washington DC.

- Viteri, F. (1981): "Primary protein energy malnutrition: clinical, biochemical and metabolic changes". En: Textbook of Pediatric Nutrition. Suskind, Robert M. edit, Raven Press, New York.

- Waitzkin, H. y Waterman, B. (1981): La explotación de la enfermedad en la sociedad capitalista, Nueva Imagen, México.

- Wellin, E. (1977): "Theoretical reorientations in medical anthropology". En: Culture, disease and healing, Landy ed., New York.

-WHO (1997a): Nutrición y pobreza. ACC/SCN, Informe N 16, Geneva.

-WHO (1997b): Reporte de la situación nutricional en el mundo, ACC/SCN, Geneva.

- Williams, R. (1980): Marxismo y literatura, ed. Península, Barcelona.

- Willis, P. (1985): "Notas sobre método". En: Cuadernos de formación, Red Latinoamericana de Investigaciones Cualitativas de la realidad escolar $\mathrm{N}^{\circ} 2$, Santiago de Chile.

- Wilson, E. (1975): Sociobiología, la nueva síntesis, Harvard Univ. Press, Cambridge. 


\title{
18. APÉNDICE
}

\section{Estudios recientes sobre alimentación familiar (1999-2001)}

\section{ESTUDIOS RECIENTES SOBRE ALIMENTACIÓN FAMILIAR EN CUATRO BARRIOS POBRES DEL GRAN LA PLATA}

\begin{abstract}
Algunos de los aspectos considerados anteriormente fueron explorados en dos estudios posteriores llevados a cabo en barrios pobres del Gran La Plata. Habiéndose desarrollado en el marco de proyectos realizados en equipo, con objetivos que apuntan a relevar cómo se articulan diversas dimensiones que hacen a las condiciones de vida familiar (cada una objeto de indagación de los diferentes integrantes), se debió adecuar el enfoque a los objetivos de los dos proyectos y restringir la gama de preguntas sobre alimentación, recorte que además toma en cuenta la pertinencia de las preguntas y la relevancia de la información recabada en los estudios previos. Esta situación limita la posibilidad de establecer comparaciones de todas las variables consideradas en los tres estudios (el correspondiente al trabajo
\end{abstract}


de tesis, el realizado en tres barrios en 1999 y el más actual llevado a cabo a través de un censo en el barrio La Unión en el 2001)

Además, en estos últimos estudios no fue posible, pese a los intentos, establecer como variable de diferenciación de las condiciones de vida, el estado nutricional en población infantil.

1) En el trabajo de campo llevado a cabo durante 1999-2000 en las áreas de influencia de las Unidades Sanitarias (US) "El Molino", N 184 (localidad de Punta Lara, partido de Ensenada) y № 15 (localidad de Tolosa, partido de La Plata), se relevó información, mediante encuestas semiestructuradas, de 272 mujeres que concurrieron a la consulta pediátrica de dichos centros asistenciales ${ }^{80}$. Este criterio de selección muestral obedece a la necesidad -planteada inicialmente en el proyecto- de incluir hogares en etapa de expansión con algún hijo menor de 5 años, a fin de tomar a la desnutrición infantil como eje diferenciador de condiciones de vida de los hogares. Cabe destacar, no obstante, que dicha aproximación se vio seriamente afectada ya que, más allá de una apreciación global de los pediatras que trabajan en dichos centros asistenciales, no fue posible acceder a los datos antropométricos actualizados de la población infantil menor de 5 años de dichas familias, situación que impuso limitaciones al proceso de análisis y recaudos en la interpretación de los resultados por contar sólo con la información suministrada por las madres -y el registro parcial que esta estrategia implica.

Dicha limitación condujo a circunscribir el estudio a los siguientes ejes de análisis:

- la organización del gasto familiar y el presupuesto destinado a la alimentación,

- la participación de las familias en programas alimentarios estatales y la evaluación de los mismos,

- la utilización de otros recursos y estrategias para la obtención de alimentos (redes, huerta, animales, iglesias),

- las características de la comida habitual,

- la evaluación cuali-cuantitativa de la misma.

Los mismos fueron considerados teniendo en cuenta la incidencia que sobre ellos tienen: la composición y organización familiar, la situación laboral y el nivel de ingreso de las familias.

${ }^{80}$ Eguía, A.; Ortale, S.; Weingast, D.; Dionisi, K.; Pagnamento, L. (2000): "Estudio integral de las condiciones de vida de familias pobres urbanas", Informe final del proyecto. Programa de Incentivos a la Investigación, Dpto. de Sociología, Fac. de Humanidades y Ciencias de la Educación UNLP. 
Los resultados presentan la información derivada del análisis conjunto de los tres barrios $^{81}$.

Sólo como referencia -y no como eje analítico central- se incluye la apreciación de las informantes sobre la presencia de niños desnutridos o con pata de cabra en sus familias y en el barrio con relación a otras variables analizadas.

La síntesis de los hallazgos de este primer estudio más reciente muestra que:

\section{Con relación al trabajo, ingreso familiar y gasto en alimentación}

-Sólo una tercera parte de las entrevistadas plantea que nunca les sucede el quedarse sin dinero para comprar comida, siendo situaciones ocasionales o frecuentes en los casos restantes. La proporción en que se registra esta apreciación es la misma que se recupera en las opiniones de las madres de los niños desnutridos estudiadas cuatro años atrás.

-Respecto a la incidencia del tamaño familiar en las situaciones de falta de dinero para comprar alimentos se observa como tendencia que en la familias de menor tamaño (3 a 6 miembros) se presenta un mayor porcentaje de situaciones en las que eso nunca sucede y en las de mayor tamaño (9 a 11 miembros) se concentran mayores proporciones de casos en los que la falta de dinero para comprar comida es frecuente u ocasional. Recordemos que en el estudio realizado entre 1995-1997 el tamaño de la familia de GD es superior en un punto a las familias de GE.

-El sector de ocupación del jefe de hogar es informal en la mayoría de los casos, al igual que lo presentado para el caso de las familias GD. Sin embargo, en este estudio, la habitualidad con que se da la falta de dinero para comprar comida no guarda relación con el carácter formal o informal de su trabajo. En este sentido podrían aventurarse hipótesis referidas a la depreciación del salario en los trabajadores formales.

-La (mayor) frecuencia con que se da la falta de dinero para comprar comida se relaciona con los deciles inferiores de ingreso en los tres barrios analizados. De este modo, y pese a la vigencia del Plan Vida en los tres barrios y su uso generalizado por parte de las familias, se reactualiza información sobre la centralidad de los consumos mercantilizados en la alimentación familiar.

-La situación de falta de dinero para comprar alimentos también se relaciona con la tasa de dependencia, siendo proporcionalmente más frecuente en las familias con un índice superior a cinco consumidores por productor de ingresos.

\footnotetext{
${ }^{81}$ En la Tabla Resumen se presentan los resultados encontrados, pertinentes al tema de estudio, desagregados por barrio y de los tres barrios en conjunto.
} 
-Con relación a los ingresos totales familiares, en los tres barrios se presenta la asociación de mayores gastos del ingreso destinados a la alimentación familiar con los ingresos inferiores o variables.

-Como tendencia, en los tres barrios se registran gastos semanales destinados a la compra de alimentos inferiores a los $\$ 40$ en las familias que perciben menores ingresos o ingresos variables. Los mismos aumentan a medida que se eleva el nivel de ingreso familiar.

-La familia promedio compuesta por 5.4 miembros destina mensualmente \$184 para la compra de comida, arrojando un promedio de gasto diario per cápita de $\$ 1.31$, levemente inferior al encontrado en GD años atrás. En 1999, el valor de la canasta básica de bienes y servicios para una familia tipo integrada por cuatro personas es de $\$ 460$ (INDEC). Si consideramos que el valor de la canasta básica de alimentos corresponde a la mitad de este valor, el valor medio en la población estudiada se ubica muy por debajo de dicho monto.

El peso del gasto en alimentos queda reflejado en su comportamiento en función del tamaño familiar: el mismo desciende a medida que aumenta el número de intergantes: de $\$ 14.5$ semanales per cápita en las familias de 2 miembros a $\$ 4.6$ en las de 13 miembros.

\section{Respecto al uso y evaluación de recursos alimentarios del Estado, de ONG y autogenerados:}

-Dentro de los programas sociales usados por el conjunto de familias analizadas, el Plan Vida es el que muestra mayor presencia apareciendo en las tres cuartas partes de los casos. El comedor escolar es una opción usada por un tercio de las familias y el Programa Materno-Infantil (PMI) por el $15 \%$. Puede verse que estos dos últimos pierden peso respecto de lo que sucede en 1995-1997 hecho que responde a recortes presupuestarios que afectaron a dichos programas. Dentro de los recursos autogenerados se destacan las redes de intercambio y ayuda mutua entre parientes y vecinos, aunque con menor importancia que en el estudio realizado en 1995-97.

El promedio de recursos alimentarios estatales utilizados por familia es de 2,5 en el área de influencia de la US EI Molino ${ }^{82}$, de 1,8 en el área de influencia de la US $N^{\circ} 184$ descendiendo a un valor de 1,3 en el area de influencia de la US $N^{\circ} 15$.

\footnotetext{
${ }^{82}$ En este mismo barrio, y en la misma Unidad Sanitaria fueron identificadas las cincuenta familias con niños eutróficos (G2) en 1995. El promedio de recursos alimentarios estatales (Plan Pais, comedor escolar y Programa Materno-Infantil) utilizados por ese entonces fue de 1.7 (sobre el total) o de 2.0 (si se excluyen las ocho familias que no eran beneficiarias de ningún programa). Así, puede observarse una mayor utilización de recursos alimentarios estatales y en ello debe ponderarse el Plan VIDA.
} 
-Lo mismo que se observa en el estudio realizado entre 1995-1997, en los tres barrios estudiados en 1999-2000 el uso del Comedor, del Programa Vida y las redes de ayuda entre parientes y vecinos registran una mayor concentración en las familias que tienen una antigüedad de residencia en el barrio superior a los 10 años, reafirmando la importancia de esta variable en tanto posibilita un mayor conocimiento de las fuentes de recursos y de los canales que permiten su utilización.

-La mayoría de las opciones, tanto las provistas por el Estado como autogeneradas, son evaluadas positivamente por la casi totalidad de las mujeres encuestadas.

\section{Respecto a las características de la alimentación familiar y su evaluación por parte de las mujeres:}

-La casi totalidad de las mujeres entrevistadas refiere que su familia tiene una buena alimentación. Tal evaluación no parece guardar relación con la proporción del ingreso que destinan a la compra de alimentos.

-La proporción minoritaria de encuestadas que admite tener una inadecuada (regular y mala) alimentación familiar, se eleva en los casos que reconocen tener desnutrición infantil, lo cual pone en tela de juicio aquellos argumentos que atribuyen a las madres una conciencia difusa -o no conciencia- de la relación: inadecuada alimentación familiar/desnutrición infantil.

-En los tres barrios se da una relación directa entre la evaluación de la alimentación familiar y situaciones de carencia de dinero para comprar alimentos. Las situaciones que reconocen restricciones monetarias ya sea frecuentes $u$ ocasionales aglutinan una mayor proporción de evaluaciones "regulares" o "malas" de la alimentación familiar y las evaluaciones positivas se concentran en las situaciones que no presentan restricciones para comprar alimentos.

-Frente a situaciones de carencia de alimentos y de recursos monetarios para su adquisición, la estrategia que principalmente despliegan las familias consiste en pedir dinero prestado a parientes o amigos.

En segundo lugar, el total de familias se arreglan con lo que tienen, disminuyendo o empobreciendo la dieta.

El sacar fiado en comercios del barrio es la tercera estrategia en orden de importancia. Finalmente se registra la ayuda de parientes y vecinos mediante la dación de alimentos o de comida.

De esta jerarquía de estrategias: conseguir dinero prestado/sacar fiado/conseguir dinero para pagar lo fiado/aguantarse con lo que hay, se desprende la centralidad del dinero y de los consumos mercantilizados y la disminución del intercambio de recursos materiales. 
-Las comidas más frecuentes en los tres barrios, mencionadas recurrentemente como primera, segunda y tercera opción, son los guisos, las milanesas y las pastas. La reiteración de las comidas preparadas por la casi totalidad de las informantes responde a los patrones alimentarios -monótonos- señalados en otros estudios dentro de sectores pobres.

-Sin embargo, en más de la mitad de los casos de las familias analizados las informantes no reconocen carencias cualitativas en la alimentación familiar.

No obstante, la evaluación de la alimentación familiar guarda relación con el reconocimiento de carencias alimentarias cualitativas: las evaluaciones negativas o regulares se relacionan con el reconocimiento de carencias.

-Respecto a la carencia cuantitativa de alimentos, en los tres barrios más de la mitad de las mujeres responden que en sus familias no se necesita consumir una mayor cantidad de alimentos.

Igual que en el caso anterior, la evaluación de la alimentación familiar guarda relación con el reconocimiento de carencias alimentarias cuantitativas: las evaluaciones negativas o regulares se relacionan con el reconocimiento de carencias.

-En los tres barrios, más de la mitad de las mujeres entrevistadas afirman que en sus familias hay alimentos (pan) o comidas (guisos) que se comen en exceso y este reconocimiento guarda relación también, con la evaluación de la alimentación familiar: ésta se torna más favorable en las situaciones que no reconocen un consumo excesivo de determinados alimentos.

-La correspondencia encontrada en estos últimos puntos muestran coherencia y racionalidad en las evaluaciones de la alimentación realizadas por las mujeres, basadas en el reconocimiento -o no- de carencias o excesos.

-La organización y la jerarquía de las comidas guardan relación con el uso del comedor escolar, lo mismo que sucede en el estudio realizado en 1995-1997.

-En términos generales, hay un tercio de familias en las que se cocina una vez al día y esa proporción aumenta en las familias que hacen uso del comedor escolar.

La cena es la comida considerada más importante por casi la mitad de las informantes de los tres barrios. El valor del almuerzo es destacado por un tercio de las mujeres y una cuarta parte plantea que ambas comidas son importantes por igual. La importancia dada a la cena guarda relación con el uso del comedor, sobre todo en los barrios de Punta Lara. El valor de la cena no se vincula tan sólo a la presencia del jefe de familia, como señala el sentido común o informan algunos trabajos. El mismo radica en constituir la única comida que se prepara para el grupo familiar.

-De lo arriba expuesto puede afirmarse que, de todos los recursos provistos por el Estado, el comedor escolar es el que presenta mayor incidencia en la organización 
doméstica. Constituye además, un recurso de vital importancia para los hogares pobres, en tanto brinda la mayor parte del año (en algunos casos todo el año) un servicio alimentario diario a los niños y contribuye al presupuesto familiar.

\section{Sobre el reconocimiento de desnutrición infantil en la familia y en el barrio por parte de las informantes:}

-Muy pocas informantes afirman tener hijos con desnutrición y una proporción aun menor, con pata de cabra. El $89 \%$ de las familias no presentan, según la referencia de las madres en el momento de la encuesta, ni desnutrición ni pata de cabra. Sin embargo, cuando hacen referencia a situaciones pasadas, el porcentaje de familias con hijos desnutridos o con pata de cabra asciende al $20 \%$ y $32 \%$ respectivamente, resultando que casi la mitad de las familias presenta casos anteriores de desnutrición y de pata de cabra ${ }^{83}$.

-Algo más de la mitad de las mujeres afirma que en el barrio no hay desnutrición o desconoce si existe tal problemática de salud infantil aunque los casos de mayor antigüedad de residencia aglutinan una mayor proporción de respuestas que afirman la existencia de desnutrición infantil.

También más de la mitad de las entrevistadas plantea que en el barrio no hay pata de cabra o la desconoce y cerca de una tercera parte afirma que hay.

Igual de lo que sucede con el reconocimiento de desnutrición en el barrio, en los barrios de Punta Lara (EI Molino y área de influencia de la US 184) puede observarse relación entre antigüedad de residencia en el barrio y reconocimiento de pata de cabra.

2) En el mes de junio de 2001 se llevó a cabo un censo en el Barrio "La Unión" (partido de La Plata) ${ }^{84}$. Siguiendo con esta línea de estudio, uno de los aspectos incluidos en la encuesta realizada a 127 familias fue el alimentario. Surge allí, también en correspondencia con los hallazgos anteriores que:

\footnotetext{
${ }^{83}$ Esa letanía de argumentos (de amplia difusión en los medios masivos de comunicación), que lejos de mirar hacia las desigualdades buscando el origen del problema, sale a la caza de un culpable: el que lo padece, se halla incorporada también en los propios afectados lo que los lleva a responsabilizar a las propias madres de la desnutrición de sus hijos y a generar en esas mismas madres la negación del problema aunque esté dentro de su núcleo familiar (Martínez, Josefina, 1993).

${ }^{84}$ Eguía, A.; Ortale, S.; Piovani, J.; Dionisi, K.; Pagnamento, L.; Weingast, D. (2001): "Diagnóstico integral de las condiciones de vida del barrio La Unión (La Plata)". Dpto. de Sociología de la Fac. de Humanidades y Ciencias de la Educación UNLP.
} 
- Respecto a los programas alimentarios estatales, casi la mitad de las familias (46.5 $\%)$ es beneficiaria del Plan Vida ${ }^{85}$.

De las que no reciben dicho Plan, la mitad no cumple con los requisitos de selección de beneficiarios; el $18 \%$ no conoce el Plan; el $15 \%$ no lo recibe por otras razones; el $9 \%$ plantea que no lo necesitan y pocos casos, aunque cumplen con los requisitos, no fueron aceptadas como beneficiarias.

La evaluación del Plan Vida es buena en más de la mitad de los casos, regular en una tercera parte y mala en un $7 \%$.

Relacionando el tipo de evaluación realizada con los criterios en los que ella se basa, puede observarse que las evaluaciones positivas toman como base a la calidad de la mercadería y a la regularidad de la entrega en iguales proporciones las que, junto con otras razones aglutinan casi las tres cuartas partes de los casos. Las evaluaciones regulares y malas se basan principalmente en la cantidad de mercadería entregada.

Con base en los resultados anteriores, se estableció la relación entre la evaluación con la cantidad de beneficiarios del Plan. La mayoría de las familias que los evalúan de manera regular o mala cuentan con un beneficiario, mientras que aquellas que realizan una evaluación positiva presentan, en mayor proporción, un mayor número de beneficiarios.

-Casi la mitad de las familias (45 \%) son beneficiarias del comedor escolar o Servicio Alimentario Escolar ${ }^{86}$. La mayoría de las que no son beneficiarias del Servicio Alimentario Escolar no cumplen los requisitos (59\%).

Un $13 \%$ no hace uso del comedor porque no lo necesitan, un $7 \%$ prefieren que coman en la casa y un $3 \%$ de casos no asiste porque a los niños no les gusta la comida del comedor. Un solo caso cumple con los requisitos no los aceptaron.

La evaluación del comedor escolar es buena en la casi totalidad de los casos y se basa fundamentalmente en la calidad de la comida, en la calidad de la atención dada a los niños y en casos minoritarios, en la cantidad de comida.

-Poco más de un tercio de las familias es beneficiaria del Programa Materno-Infantil. ${ }^{87}$

La mayoría de las que no son beneficiarias, no cumplen con los requisitos de focalización del programa (61\%), pocos son las familias que dicen no necesitarlo, no conocer el programa o no ser aceptados pese a cumplir con los requisitos.

\footnotetext{
${ }^{85}$ El Plan Vida es un programa alimentario provincial destinado a niños de 0-5 años, embarazadas y mujeres que amamantan de barrios pobres consistente en la entrega diaria de leche y semanal de huevos, fideos y cereales (CPFDH, s/f).

${ }^{86}$ El SAE o comedor escolar es un programa alimentario nacional que atiende las necesidades nutricionales de la población escolar de 3 a 13 años en situación de vulnerabilidad social consistente en la dación de copa de leche, merienda reforzada o almuerzo durante todo el ciclo lectivo (y en algunos durante todo el año) (CPFDH, s/f).

${ }^{87}$ El Programa Materno-Infantil es un plan nacional de larga data que consiste entre otras acciones sanitarias, en la entrega de $2 \mathrm{~kg}$. de leche en polvo durante los controles de salud de niños de 0-2 años en las Unidades Sanitarias.
} 
La evaluación del PMI es positiva en poco más de las tres cuartas partes debido a la regularidad en la entrega y a la cantidad de leche entregada y regular en los restantes casos por la irregularidad en la entrega.

- En lo que hace a las redes entre parientes, vecinos y amigos, el $65 \%$ reconoce que recibe ayuda. Respecto al tipo de ayuda recibida por las familias, los alimentos se registran en la tercera parte y en vestimenta en una cuarta parte de casos. La ayuda mediante el préstamo de dinero se da en un $16 \%$ al igual que la ayuda para conseguir trabajo.

La mayoría de las ayudas recibidas provienen principalmente de parientes, en segundo lugar de amigos, los vecinos en una cuarta parte de familias y los patrones $u$ otras personas en proporciones minoritarias.

- Además de la ayuda recibida mediante redes informales, poco más de un tercio de las familias recibe ayuda de alguna Iglesia. El contenido de la ayuda recibida consiste mayoritariamente en alimentos y ropa.

La merienda para los chicos o algún otro tipo de ayuda registran porcentajes del $17 \%$.

- Aparte de la ayuda de la Iglesia, una escasa proporción (20 \%) recibe además ayuda de otra institución no gubernamental: agrupaciones políticas y Centros Vecinales o de Fomento. La ayuda consiste en la entrega de alimentos, entrega de ropa, almuerzo/cena en el comedor, desayuno o merienda en el comedor.

- Sólo 4 familias (3 \%) tienen huerta y un $16.5 \%$ tiene animales para el autoconsumo: gallinas, cerdos, pollos y conejos.

La mala calidad de la tierra es la razón por la cual casi la mitad de las familias dice no tener huerta. La falta de espacio, el hecho de no gustarles tal actividad, la existencia de animales sueltos y desconocimiento de cómo hacer una huerta conforman el porcentaje restante.

La falta de espacio y el robo aparecen como razones limitantes para la cría de animales.

- El gasto diario en comida es de $\$ 5$ o menos en el $37 \%$ de las familias, $16 \%$ gasta entre $\$ 6$ y $\$ 9$, una cuarta parte gasta $\$ 10$, y el $22 \%$ restante gasta entre $\$ 12$ y $\$ 20$.

- El promedio de gasto diario familiar en comida es de $\$ 8.6$ arrojando un gasto promedio de $\$ 1.8$ per cápita diarios destinados a la alimentación. Dicho monto representa más de la mitad (el $58 \%$ ) del ingreso familiar diario per cápita ${ }^{88}$.

- Relacionando el número de miembros de la unidad doméstica con el gasto diario destinado a la compra de alimentos puede verse que las de menor tamaño se 
distribuyen en mayor proporción en los intervalos de menores gastos y que si bien más de un tercio de las de 7-9 miembros gastan $\$ 5$ o menos diariamente, más de la mitad destina el doble o más. Esta última distribución también se da en las unidades domésticas de 10 o más miembros.

- En la mayoría de las familias se cocina dos veces por día, casi un tercio cocina una vez y en muy pocos casos ( $4 \%$ ) se cocina tres veces por día.

- La mitad de las encuestadas plantea que ambas comidas -almuerzo y cena- tienen la misma importancia. El almuerzo es señalado como la comida más importante por un tercio y la cena por un $20 \%$.

- El tipo de comida que preparan más frecuentemente es el guiso con carne (53\%), carne de vaca con ensalada/puré o arroz (12\%), pastas (9\%), puchero (9\%) y guisos sin carne $(7 \%)$.

- Las tres cuartas partes de las encuestadas considera que su familia tiene una buena alimentación, un $22 \%$ afirma que es regular y un $2 \%$ mala.

- Las evaluaciones positivas de la alimentación familiar se basan, en más de la mitad de los casos, en la calidad de la comida; las evaluaciones regulares se relacionan predominantemente con la cantidad de comida que consumen y las evaluaciones francamente negativas aglutinan la mayor proporción de respuestas en razones que tienen que ver con la calidad de la comida.

- Tanto en los casos de evaluaciones positivas como regulares se cocina dos veces al día, los pocos casos de evaluaciones negativas de la alimentación familiar corresponden a situaciones en las que se cocina una vez al día.

- Relacionando el gasto diario en comida con la evaluación realizada de la alimentación familiar, puede observarse que dentro e las evaluaciones positivas hay una mayor proporción de casos que destinan una mayor monto a la compra de alimentos. En las evaluaciones regulares más de la mitad gastan \$5 o menos en comida, monto que corresponde a la totalidad de casos que realizan una evaluación negativa de la alimentación familiar.

- De las familias encuestadas, 21 (16.5\%) presentan actualmente, según las informantes, algún hijo con desnutrición descendiendo a 17 casos (13\%) cuando se hace referencia a casos anteriores. Son 14 las familias (11\%) que combinan episodios actuales y anteriores de desnutrición. Siete familias refieren registrar sólo casos actuales y 3 sólo casos anteriores.

\footnotetext{
${ }^{88}$ Cabe aclarar que, en tanto se trata de un censo, los resultados deben interpretarse teniendo en cuenta la incidencia de los hogares compuestos por uno o dos miembros, situación ausente en los estudios anteriores.
} 
-Sobre un total de 286 niños de trece años o menos, 22\% ( $\mathrm{N}=62)$ presentan actualmente desnutrición. Sobre ese mismo total, el porcentaje de episodios pasados de desnutrición desciende al $15 \%(\mathrm{~N}=43)$.

\section{Síntesis comparativa y comentarios de los estudios sobre alimentación en familias pobres urbanas del Gran La Plata}

Con base en las limitaciones metodológicas señaladas, la información sobre alimentación familiar pasible de comparación, analizada en los tres estudios: 1995-96, 1999, 2001, permite plantear algunas generalizaciones.

Los hallazgos de los estudios más recientes, en los que no se distinguen familias con y sin desnutrición infantil, marcan tendencias coincidentes con los encontrados en 19951997, particularmente con las familias con niños desnutridos (GD) y algunos muestran ser más desfavorables para la reproducción alimentaria familiar.

Las coincidencias encontradas en:

- las características estructurales de las familias: trabajo informal del jefe de familia, magros e irregulares ingresos familiares,

- en el tipo de comidas más frecuentes que indican monotonía en la alimentación familiar (guisos),

- en el gasto destinado a la alimentación (todo o casi todo el ingreso),

- en la frecuencia con que se presenta la falta de dinero para comprar comida (la mayoría de las familias),

- en el uso de recursos alimentarios obtenidos a través de redes de intercambio con parientes y vecinos,

no habilitan, no obstante, a postular una mayor incidencia de desnutrición infantil. Cabe destacar que en 1999 se presenta una mayor utilización de programas alimentarios estatales que en 1995-96 debido a la presencia casi generalizada del Plan VIDA, disminuyendo su importancia en el estudio realizado en el 2001 en correspondencia con la etapa de desarticulación del Plan. En este último año, sin embargo, se registra una mayor importancia de los recursos alimentarios provistos por ONG, particularmente iglesias y agrupaciones políticas.

- El gasto diario per cápita destinado a la compra de alimentos oscila en los tres estudios entre $\$ 1.3$ y $\$ 1.8$. Ni siquiera considerando el último valor, llega a cubrirse el costo, estimado por el INDEC, de una canasta básica de alimentos para una familia 
tipo (cuatro integrantes) en ninguno de los de los tres períodos de estudio. Debe destacarse entonces, tal como se desprende del primer estudio -en donde se presenta un uso más intensivo y continuo de las estrategias alimentarias en GE-, la importancia que representan los recursos no mercantilizados para la alimentación familiar, particularmente para la población infantil. Así por ejemplo, un tercio de las familias prepara sólo una comida diaria y esta situación se vincula con la asistencia de los hijos al comedor escolar.

-La apreciación de las madres sobre la presencia de desnutrición actual o pasada en sus hijos, arroja diferencias en el último estudio que ameritan una reflexión metodológica. Los dos primeros estudios tuvieron a las Unidades Sanitarias como base de referencia para seleccionar y conocer a las familias. El último estudio, se basó en un censo de todo el barrio y la población encuestada, más allá de la filiación institucional con la Universidad con la que se presentaban los trabajadores de campo, carecía de referencias suficientes como para otorgarles una identidad vinculada con alguna otra institución conocida por ellos. En este caso, se reconoció en el momento de la encuesta, una mayor proporción de casos con hijos desnutridos que en el pasado, a la inversa de lo que se presentó cuando se trabajó a partir de la identificación del trabajador de campo con la Unidad Sanitaria.

Este hecho, sumado a la imposibilidad de contrastar dichas apreciaciones (excepto en el primer estudio) con datos antropométricos, deja abierto el interrogante (en tanto reconocen en la situación actual una mayor proporción de casos de desnutrición) sobre la manipulación -no consciente- de la respuesta en pos de la obtención de recursos para la familia y/o el barrio. Sin embargo, dada la situación de extrema precariedad del barrio y de las paupérrimas condiciones de vida familiar, es posible que tal apreciación se aproxime a lo que realmente sucede y que la estrategia de trabajo de campo utilizada (diferente a la empleada en los otros dos estudios) permita expresar, sin riesgo de estigmatización, la situación de los niños. 


\section{TABLA RESUMEN DE VARIABLES}

\begin{tabular}{|c|c|c|c|c|}
\hline Flias. del area de influencia de: & $\begin{array}{l}\text { US. EL MOLINO } \\
\text { Punta Lara (Ensenada) }\end{array}$ & $\begin{array}{c}\text { US. } \mathbf{N}^{\circ} \mathbf{1 8 4} \\
\text { Punta Lara (Ensenada) }\end{array}$ & $\begin{array}{c}\text { US N'15 } \\
\text { La Plata }\end{array}$ & $\begin{array}{l}\text { GENERAL } \\
\text { (3 barrios) }\end{array}$ \\
\hline \multicolumn{5}{|c|}{ COMPONENTES ESTRUCTURALES } \\
\hline $\mathrm{N}^{\circ}$ de integrantes del hogar & $\begin{array}{l}3-4: 45 \% \\
5-6: 26 \% \\
7-8: 15 \% \\
\geq 9: 13 \%\end{array}$ & $\begin{array}{l}3-4: 31 \% \\
5-6: 35 \% \\
7-8: 16 \% \\
\geq 9: 18 \%\end{array}$ & $\begin{array}{l}3-4: 37.5 \% \\
5-6: 44 \% \\
7-8: 13.5 \% \\
\geq 9: 5 \%\end{array}$ & $\begin{array}{l}3-4: 40 \% \\
5-6: 34.5 \% \\
7-8: 14 \% \\
\geq 9: 11 \%\end{array}$ \\
\hline Antigüedad de residencia & $\begin{array}{l}<3 \text { años: } 25 \% \\
3-10 \text { años: } 28 \% \\
>10 \text { años: } 47 \%\end{array}$ & $\begin{array}{l}<3 \text { años: } 31.5 \% \\
3-10 \text { años: } 34 \% \\
>10 \text { años: } 29 \%\end{array}$ & $\begin{array}{l}<3 \text { años: } 22 \% \\
\text { 3-10 años: } 20 \% \\
>10 \text { años: } 51 \%\end{array}$ & $\begin{array}{l}<3 \text { años: } 28 \% \\
\text { 3-10 años: } 31 \% \\
>10 \text { años: } 39 \%\end{array}$ \\
\hline Condición ocupacional (jefe) & $\begin{array}{l}\text { Ocupado: } 89 \% \\
\text { Desocupado: } 6 \% \\
\text { Inactivo: } 4 \%\end{array}$ & $\begin{array}{l}\text { Ocupado: } 86 \% \\
\text { Desocupado: } 7 \% \\
\text { Inactivo: } 7 \%\end{array}$ & $\begin{array}{l}\text { Ocupado: } 90 \% \\
\text { Desocupado: } 9 \% \\
\text { Inactivo: } 1 \%\end{array}$ & $\begin{array}{l}\text { Ocupado: } 88.7 \% \\
\text { Desocupado: } 7.5 \% \\
\text { Inactivo: } 3.7 \%\end{array}$ \\
\hline Sector de ocupación del jefe & $\begin{array}{l}\text { Formal: } 33 \% \\
\text { Informal: } 67 \% \\
\end{array}$ & $\begin{array}{l}\text { Formal: } 35.5 \% \\
\text { Informal: } 61 \% \\
\end{array}$ & $\begin{array}{l}\text { Formal: } 25 \% \\
\text { Informal: } 75 \%\end{array}$ & $\begin{array}{l}\text { Formal: } 31 \% \\
\text { Informal: } 69 \%\end{array}$ \\
\hline $\begin{array}{l}\text { Deciles de ingreso } \\
\text { Total familiar }\end{array}$ & $\begin{array}{l}\text { Inf: } 52 \% \\
\text { Medio: } 10 \% \\
\text { Sup.: } 1 \% \\
\text { Variable: } 25 \% \\
\text { Sin ingreso: } 6 \% \\
\text { Ns/nc: } 6 \%\end{array}$ & $\begin{array}{l}\text { Inferior: } 51 \% \\
\text { Medio: } 12.5 \% \\
\text { Superior: } 3 \% \\
\text { Variable: } 8 \% \\
\text { Sin ingreso: } 3 \% \\
\text { ns/nc: } 22 \%\end{array}$ & $\begin{array}{l}\text { Inferior: } 43.5 \% \\
\text { Medio: } 18 \% \\
\text { Superior: } 4 \% \\
\text { Variable: } 21 \% \\
\text { Sin ingreso: } 5 \% \\
\text { Ns/nc: } 8 \%\end{array}$ & $\begin{array}{l}\text { Inferior: } 48.5 \% \\
\text { Medio: } 13.6 \% \\
\text { Superior: } 2.6 \% \\
\text { Variable: } 19 \% \\
\text { Sin ingreso: } 5 \% \\
\text { ns/nc: } 11 \%\end{array}$ \\
\hline Indice $\mathrm{c} / \mathrm{p}$ & $\begin{array}{l}\text { Hasta 3: } 43 \% \\
\text { 3-5: } 29 \% \\
\text { 5-8: } 24 \% \\
\text { Más de } 8: 2 \% \\
\text { Sin prod.: } 2 \% \\
\end{array}$ & $\begin{array}{l}\text { Hasta 3: } 18 \% \\
\text { 3-5: } 48.6 \% \\
\text { 5-8: } 22 \% \\
\text { Más de } 8: 9.7 \% \\
\text { Sin prod.: } 1.4 \% \\
\end{array}$ & $\begin{array}{l}\text { Hasta 3: } 36 \% \\
\text { 3-5: } 41 \% \\
\text { 5-8: } 16 \% \\
\text { Más de } 8: 1 \% \\
\text { Sin prod.: } 5 \% \\
\end{array}$ & $\begin{array}{l}\text { Hasta 3: } 34 \% \\
\text { 3-5: } 39 \% \\
\text { 5-8: } 21 \% \\
\text { Más de } 8: 4 \% \\
\text { Sin prod.: } 3 \% \\
\end{array}$ \\
\hline \multicolumn{5}{|c|}{$\begin{array}{l}\text { RECURSOS ALIMENTARIOS NO MERCANTILIZADOS } \\
\end{array}$} \\
\hline Promedio de recursos/familia & 2.5 & 1.8 & 1.3 & 1.9 \\
\hline Tres recursos más usados & $\begin{array}{l}\text { Vida: } 84 \% \\
\text { Redes: } 65 \% \\
\text { Comedor: } 45 \%\end{array}$ & $\begin{array}{l}\text { Vida: } 83.6 \% \\
\text { Comedor: } 34 \% \\
\text { Redes: } 20 \%\end{array}$ & $\begin{array}{l}\text { Vida: } 43 \% \\
\text { PMI: } 20 \% \\
\text { Comedor/Redes/Igle } \\
\text { sia: } 17 \%\end{array}$ & $\begin{array}{l}\text { Vida: } 69 \% \\
\text { Redes: } 36 \% \\
\text { Comedor: } 32 \%\end{array}$ \\
\hline $\begin{array}{l}\text { Evaluación positiva } \\
\text { De los recursos }\end{array}$ & $\begin{array}{l}91 \% \text { (en general) } \\
\text { Redes: } 97 \% \\
\text { Comedor: } 93 \% \\
\text { Vida: } 83 \%\end{array}$ & $\begin{array}{l}90 \% \text { (en general) } \\
\text { Comedor: } 100 \% \\
\text { Redes: } 100 \% \\
\text { Vida: } 92 \%\end{array}$ & $\begin{array}{l}83 \% \text { (en general) } \\
\text { Comedor: } 100 \% \\
\text { PMI: } 90 \% \\
\text { Vida: } 88 \%\end{array}$ & $\begin{array}{l}92 \%(\mathrm{x} \text { todos los } \\
\text { recursos) } \\
\text { Comedor: } 98 \% \\
\text { Redes: } 95 \% \\
\text { Vida: } 87 \%\end{array}$ \\
\hline \multicolumn{5}{|c|}{ DESNUTRICIÓN EN EL BARRIO. OPINIÓN DE LAS INFORMANTES } \\
\hline Hay desnutrición en el barrio & $\begin{array}{l}\text { Hay mucha: } 21 \% \\
\text { Hay poca: } 17 \% \\
\text { No hay: } 36 \% \\
\text { No sabe: } 25 \%\end{array}$ & $\begin{array}{l}\text { Hay mucha: } 8 \% \\
\text { Hay poca: } 9.5 \% \\
\text { No hay: } 49 \% \\
\text { No sabe: } 29 \%\end{array}$ & $\begin{array}{l}\text { Hay mucha: } 24 \% \\
\text { Hay poca: } 22 \% \\
\text { No hay: } 31 \% \\
\text { No sabe: } 19 \%\end{array}$ & $\begin{array}{l}\text { Hay: } 36 \% \\
\text { No hay: } 38 \% \\
\text { No sabe: } 24 \%\end{array}$ \\
\hline Hay pata de cabra en el barrio & $\begin{array}{l}\text { Hay mucha: } 22 \% \\
\text { Hay poca: } 16 \% \\
\text { No hay: } 23 \% \\
\text { No sabe: } 38 \%\end{array}$ & $\begin{array}{l}\text { Hay mucha: } 12 \% \\
\text { Hay poca: } 16 \% \\
\text { No hay: } 11 \% \\
\text { No sabe: } 49 \%\end{array}$ & $\begin{array}{l}\text { Hay mucha: } 10 \% \\
\text { Hay poca: } 19 \% \\
\text { No hay: } 32 \% \\
\text { No sabe: } 35 \%\end{array}$ & $\begin{array}{l}\text { Hay: } 34 \% \\
\text { No hay: } 23 \% \\
\text { No sabe: } 40 \%\end{array}$ \\
\hline
\end{tabular}


Fuente: Encuestas realizadas en el área de influencia de las Unidades Sanitarias El Molino ( $\mathrm{n}=100)$ y N $184(\mathrm{n}=73)$ de Punta Lara (partido de Ensenada) y la Unidad Sanitaria N¹5 (n=99) del partido de La Plata; 1999-2000. $(\mathrm{N}=272)$.

TABLA RESUMEN DE VARIABLES (cont.)

\begin{tabular}{|c|c|c|c|c|}
\hline Flias. del area de influencia de: & $\begin{array}{l}\text { US. EL MOLINO } \\
\text { Punta Lara (Ensenada) }\end{array}$ & $\begin{array}{c}\text { US. } \mathbf{N}^{\circ} \mathbf{1 8 4} \\
\text { Punta Lara (Ensenada) }\end{array}$ & $\begin{array}{l}\text { US. } \mathbf{N}^{\circ} \mathbf{1 5} \\
\text { La Plata }\end{array}$ & $\begin{array}{l}\text { GENERAL } \\
\text { (3 barrios) }\end{array}$ \\
\hline \multicolumn{5}{|c|}{ GASTOS EN ALIMENTACIÓN Y ESTRATEGIAS } \\
\hline Gasto semanal en comida & $\begin{array}{l}<50 \$: 63 \% \\
>50-70 \$: 21 \% \\
\geq 71 \text { \$: } 11 \%\end{array}$ & $\begin{array}{l}<50 \text { \$: } 53 \% \\
>50-70 \text { \$: } 18 \% \\
\geq 71 \text { \$: } 16 \%\end{array}$ & $\begin{array}{l}<50 \text { \$: } 37 \% \\
>50-70 \text { \$: } 24 \% \\
\geq 71 \text { \$: } 22 \%\end{array}$ & $\begin{array}{l}<50 \$: 51 \% \\
>50-70 \$: 21 \% \\
\geq 71 \text { \$: } 16 \%\end{array}$ \\
\hline $\begin{array}{l}\text { Proporción del ingreso } \\
\text { destinado a la compra } \\
\text { De alimentos }\end{array}$ & $\begin{array}{l}\text {-Todo: } 22 \% \\
\text {-Casi todo: } 41 \% \\
\text {-+ de la mitad: } 10 \% \\
\text {-La mitad: } 22 \% \\
\text {-< de la mitad: } 5 \%\end{array}$ & $\begin{array}{l}\text {-Todo: } 15 \% \\
\text {-Casi todo: } 29 \% \\
\text {-+ de la mitad: } 8 \% \\
\text {-La mitad: } 18 \% \\
\text {-< de la mitad: } 18 \%\end{array}$ & $\begin{array}{l}\text {-Todo: } 11 \% \\
\text {-Casi todo: } 23 \% \\
\text {-+ de la mitad: } 12 \% \\
\text {-La mitad: } 22 \% \\
\text {-< de la mitad: } 16 \%\end{array}$ & $\begin{array}{l}\text {-Todo: } 15 \% \\
\text {-Casi todo: } 31 \% \\
\text {-+ de la mitad: } 11 \% \\
\text {-La mitad: } 21 \% \\
\text {-< de la mitad: } 13 \%\end{array}$ \\
\hline Les falta dinero para comida & $\begin{array}{l}\text { Frecuentem.: } 36 \% \\
\text { Ocasionalm.: } 41 \% \\
\text { Nunca: } 19 \%\end{array}$ & $\begin{array}{l}\text { Frecuentem.: } 25 \% \\
\text { Ocasionalm.: } 50 \% \\
\text { Nunca: } 24 \%\end{array}$ & $\begin{array}{l}\text { Frecuentem.: } 23 \% \\
\text { Ocasionalm.: } 40 \% \\
\text { Nunca: } 36 \% \\
\end{array}$ & \begin{tabular}{|l|} 
Frecuentem.: $29 \%$ \\
Ocasionalm.: $43 \%$ \\
Nunca: $27 \%$ \\
\end{tabular} \\
\hline Estrategias & $\begin{array}{l}\text {-Sacan fiado: } 32.5 \% \\
\text {-Se arreglan con lo } \\
\text { que tienen: } 26 \% \\
\text {-Piden dinero a } \\
\text { par./vec.: } 18 \%\end{array}$ & $\begin{array}{l}\text {-Piden dinero a } \\
\text { par./vec.: } 33 \% \\
\text {-Se arreglan con lo } \\
\text { que tienen: } 18 \% \\
\text {-Sacan fiado: } 11 \% \\
\text { Par./vec. prestan } \\
\text { alimentos: } 11 \%\end{array}$ & $\begin{array}{l}\text {-Piden dinero a } \\
\text { par./vec.: } 32 \% \\
\text {-Par./vec. dan } \\
\text { alim./comida: } 23 \% \\
\text {-Se arreglan con lo } \\
\text { que tienen: } 11 \%\end{array}$ & $\begin{array}{l}\text {-Piden dinero a } \\
\text { par./vec.: } 27 \% \\
\text {-Se arreglan con lo } \\
\text { que tienen: } 19 \% \\
\text {-Sacan fiado: } 18 \%\end{array}$ \\
\hline \multicolumn{5}{|c|}{ EVALUACIÓN DE LA ALIMENTACIÓN FAMLIAR } \\
\hline Evaluación de la alimentación & $\begin{array}{l}\text { Buena: } 87.5 \% \\
\text { Regular: } 11.5 \% \\
\text { Mala: } 1 \%\end{array}$ & $\begin{array}{l}\text { Buena: } 87.5 \% \\
\text { Regular: } 12.5 \% \\
\text { Mala: } 0 \%\end{array}$ & $\begin{array}{l}\text { Buena: } 79 \% \\
\text { Regular: } 20 \% \\
\text { Mala: } 1 \% \\
\end{array}$ & \begin{tabular}{|l|} 
Buena: $84.5 \%$ \\
Regular: $14.7 \%$ \\
Mala: $0.8 \%$ \\
\end{tabular} \\
\hline Carencia cualitativa & $\begin{array}{l}\text { Sí, muchos: } 9 \% \\
\text { Sí, pocos: } 24 \% \\
\text { Ninguno: } 67 \% \\
\end{array}$ & $\begin{array}{l}\text { Sí, muchos: } 7 \% \\
\text { Sí, pocos: } 20.5 \% \\
\text { Ninguno: } 71 \% \\
\end{array}$ & $\begin{array}{l}\text { Sí, muchos: } 17 \% \\
\text { Sí, pocos: } 22 \% \\
\text { Ninguno: } 58 \% \\
\end{array}$ & $\begin{array}{l}\text { Sí, muchos: } 11 \% \\
\text { Sí, pocos: } 23 \% \\
\text { Ninguno: } 65 \% \\
\end{array}$ \\
\hline Carencia cuantitativa & $\begin{array}{l}\text { Sí: } 41 \% \\
\text { No: } 58 \% \\
\end{array}$ & $\begin{array}{l}\text { Sí: } 30 \% \\
\text { No: } 66 \% \\
\end{array}$ & $\begin{array}{l}\text { Sí: } 37 \% \\
\text { No: } 59 \% \\
\end{array}$ & \begin{tabular}{|l|} 
Sí: $37 \%$ \\
No: $61 \%$ \\
\end{tabular} \\
\hline Alimentos en exceso & $\begin{array}{l}\text { Sí: } 61 \% \\
\text { No: } 39 \%\end{array}$ & $\begin{array}{l}\text { Sí: } 46 \% \\
\text { No: } 53 \%\end{array}$ & $\begin{array}{l}\text { Sí: } 62 \% \\
\text { No: } 37 \%\end{array}$ & $\begin{array}{l}\text { Sí: } 37 \% \\
\text { No: } 61 \% \\
\end{array}$ \\
\hline \multicolumn{5}{|c|}{ CARACTERÍSTICAS DE LA COMIDA HABITUAL } \\
\hline Comidas más frecuentes & $\begin{array}{l}\text { Guisos: } 23 \% \\
\text { Milanesas: } 12 \% \\
\text { Pastas: } 9 \%\end{array}$ & \begin{tabular}{|l|} 
Guisos: $21 \%$ \\
Milanesas: $10 \%$ \\
Pastas: $14 \%$ \\
\end{tabular} & \begin{tabular}{|l} 
Guisos: $22 \%$ \\
Milanesas: $12 \%$ \\
Pastas: $11 \%$
\end{tabular} & $\begin{array}{l}\text { Guisos: } 22 \% \\
\text { Milanesas: } 12 \% \\
\text { Pastas: } 11 \%\end{array}$ \\
\hline Veces que cocina por día & $\begin{array}{l}\text { Una vez: } 43 \% \\
\text { Dos veces: } 55 \%\end{array}$ & $\begin{array}{l}\text { Una vez: } 26 \% \\
\text { Dos veces: } 74 \%\end{array}$ & $\begin{array}{l}\text { Una vez: } 20 \% \\
\text { Dos veces: } 77 \%\end{array}$ & $\begin{array}{l}\text { Una vez: } 30 \% \\
\text { Dos veces: } 68 \%\end{array}$ \\
\hline Asistencia a comedor & $\begin{array}{l}\text { Asiste: } 46 \% \\
\text { No asiste: } 32 \% \\
\text { No cumple req.: } 22 \%\end{array}$ & $\begin{array}{l}\text { Asiste: } 39 \% \\
\text { No asiste: } 37 \% \\
\text { No cumple req.: } 23 \%\end{array}$ & $\begin{array}{l}\text { Asiste: } 20 \\
\text { No asiste: } 44 \% \\
\text { No cumple req: } 35 \% \\
\end{array}$ & $\begin{array}{l}\text { Asiste: } 35 \% \\
\text { No asiste: } 38 \% \\
\text { No cumple req: } 27 \%\end{array}$ \\
\hline Comida más importante & $\begin{array}{l}\text { Almuerzo: } 31 \% \\
\text { Cena: } 47 \% \\
\text { Ambas: } 22 \%\end{array}$ & $\begin{array}{l}\text { Almuerzo: } 33 \% \\
\text { Cena: } 38 \% \\
\text { Ambas: } 27 \%\end{array}$ & $\begin{array}{l}\text { Almuerzo: } 35 \% \\
\text { Cena: } 41 \% \\
\text { Ambas: } 23 \%\end{array}$ & $\begin{array}{l}\text { Almuerzo: } 33 \% \\
\text { Cena: } 43 \% \\
\text { Ambas: } 24 \%\end{array}$ \\
\hline
\end{tabular}

Fuente: Encuestas realizadas en el área de influencia de las Unidades Sanitarias El Molino (n=100) y N $184(\mathrm{n}=73)$ de Punta Lara (partido de Ensenada) y la Unidad Sanitaria N¹5 (n=99) del partido de La Plata; 1999-2000. $(\mathrm{N}=272)$. 